Hilligje van't Land

Andreas Corcoran

Diana-Camelia lancu

Editors

The Promise of

Higher Education

Essays in Honour of 70 Years of IAU

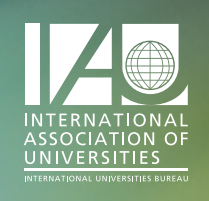

$\vdots \quad \vdots \mid \begin{aligned} & \text { National University of Political } \\ & \text { Studies and Public Administration }\end{aligned}$ 
The Promise of Higher Education 
Hilligje van't Land - Andreas Corcoran . Diana-Camelia Iancu

Editors

\section{The Promise of Higher Education}

Essays in Honour of 70 Years of IAU

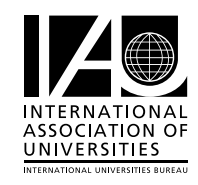




\section{Editors}

Hilligje van't Land

International Association of Universities

Paris, France

Andreas Corcoran

International Association of Universities

Paris, France

\author{
Diana-Camelia Iancu \\ National University of Political Studies \\ and Public Administration \\ Bucharest, Romania
}

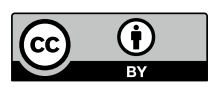

ISBN 978-3-030-67244-7 ISBN 978-3-030-67245-4 (eBook)

https://doi.org/10.1007/978-3-030-67245-4

(C) The Editor(s) (if applicable) and The Author(s) 2021

Open Access This book is licensed under the terms of the Creative Commons Attribution 4.0 International License (http://creativecommons.org/licenses/by/4.0/), which permits use, sharing, adaptation, distribution and reproduction in any medium or format, as long as you give appropriate credit to the original author(s) and the source, provide a link to the Creative Commons license and indicate if changes were made.

The images or other third party material in this book are included in the book's Creative Commons license, unless indicated otherwise in a credit line to the material. If material is not included in the book's Creative Commons license and your intended use is not permitted by statutory regulation or exceeds the permitted use, you will need to obtain permission directly from the copyright holder.

The use of general descriptive names, registered names, trademarks, service marks, etc. in this publication does not imply, even in the absence of a specific statement, that such names are exempt from the relevant protective laws and regulations and therefore free for general use.

The publisher, the authors and the editors are safe to assume that the advice and information in this book are believed to be true and accurate at the date of publication. Neither the publisher nor the authors or the editors give a warranty, express or implied, with respect to the material contained herein or for any errors or omissions that may have been made. The publisher remains neutral with regard to jurisdictional claims in published maps and institutional affiliations.

This Springer imprint is published by the registered company Springer Nature Switzerland AG The registered company address is: Gewerbestrasse 11, 6330 Cham, Switzerland 


\section{Contents}

Introduction

Hilligje van't Land, Andreas Corcoran, and Diana-Camelia Iancu

Part I 70 Years of Higher Education Cooperation and Advocacy

To Cohere and Act as One: IAU-The Global Voice of Higher

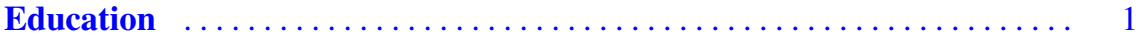

Pam Fredman

Stepping Up Global Collaboration to Protect Higher Education's

Future ......................................... 17

Stefania Giannini

The IAU and Contemporary Global Challenges: A Latin American

Point of View .......................................

Juan Ramón de la Fuente

Drivers of Globalisation of Higher Education over the Last 70 Years $\ldots \quad 25$

Andrew J. Deeks

A Personal View on Two Decades of Recent IAU History

Eva Egron-Polak

IAU President Walter Kamba (1990-1995): A Man of Conscience . .....

Goolam Mohamedbhai

Between Global Inequalities and World Ethics. Personal Reflections on Internationalisation of Higher Education over the Past Seventy Years ..............................

Pavel Zgaga

Creating Democratic Civic Universities in a Post-COVID-19

World: The IAU and Global Collaboration

Ira Harkavy 
Why IAU?

Remus Pricopie

Part II Facilitating International Cooperation

The Role of IAU in Facilitating International Cooperation

Ranbir Singh

Universities, Associations, and Internationalization: Powerful

Forces for Our Time

Laura E. Rumbley

A Global View of Internationalisation: What Next?

Elspeth Jones and Hans de Wit

The Importance of Internationalization Today and the Leadership

Role of IAU

Jocelyne Gacel-Ávila

International Collaboration: Necessary, But Challenging

Jeroen Huisman

Getting Unstuck with Internationalization at Home: Seizing

the Post-pandemic Moment $\ldots \ldots \ldots \ldots \ldots \ldots \ldots \ldots \ldots \ldots$

Madeleine Green

Levelling up International Higher Education: Universities, Nations and Global Goals

Jo Beall

Internationalization of Universities: 70 Years of Experience

Vladimir Filippov

70 Years of Internationalization in Tertiary Education: Changes,

Challenges and Perspectives

Hans de Wit and Philip Altbach

The Evolution of Higher Education Collaboration in the Arctic

Through Networking

Outi Snellman

\section{Part III Coding the Values}

Promoting Values Together: Global Currency with Local Impact

for Universities

Sijbolt Noorda and David-John Lock

"A Question of Integrity": Academic Values Torn Between

Organizational Affiliation, National Competitiveness

and the Global Academic Community

Michael Hölscher 
Valuing the Civic Role of University Education in an Age of Competition and Rapid Change

Pedro Nuno Teixeira and Manja Klemenčič

Mitigating Corruption in Higher Education

Elena Denisova-Schmidt

Higher Education and Public Good in East and West

Simon Marginson and Lili Yang

The Beginning of History and the University

Bryan McAllister-Grande

Higher Education and the Enduring Value of Hospitality:

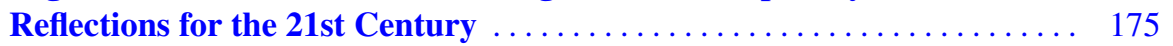

Gerardo L. Blanco

The Role of Quality Assurance and the Values of Higher Education . . . 181 Judith S. Eaton

Recognition of Foreign Qualifications Celebrates Higher

Education Collaboration Too

Jenneke Lokhoff

Part IV The Changing Landscape

Creating Responsible and Engaged Students

Pankaj Mittal

Universities Can Regain the Public's Trust

Frans van Vught

Towards the Other Side of Complexity: Values and Decisions

in a Time of Uncertainty

Marcelo Knobel

Africa's Destiny and Higher Education Transformation

Barnabas Nawangwe

The Constant of Change: Remaining Relevant in 21st Century

Higher Education

Mandla S. Makhanya

The Changing Role of Universities in Lithuanian Society

Saulius Spurga and Inga Žalènienè

Modern Challenges for Universities

Tatiana Klyachko and Vladimir Mau

Universities in an Era of Post-Corona "New Order"

Etsuko Katsu 
Redefining the Role of Universities in a Rapidly Changing

Landscape

Datuk Abdul Rahim Hashim

From Emergency Remote Teaching to Strategically Embracing

Online Learning

Dionisia Tzavara

Overcoming Challenges and Boundaries Through the Innovation

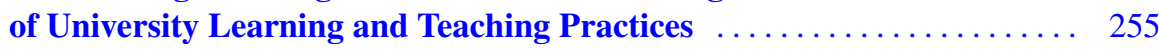

Elena Luppi, Lucia Balduzzi, Nicolò Cavina, and Carla Salvaterra

Is the Pandemic Leading to a Paradigm Shift in Higher Education? . . . 263

Carmen Z. Lamagna and Manzur H. Khan

A Personal Reflection on the Key Challenge for Higher Education:

Improving the Quality of University Instruction

David Dill

University Leadership: Slippage from Abiding to Peremptory

Roles?

Daniel C. Levy

The Dawn for a New Era for Higher Education

Mirta Martin and Jacob Abrams

Are Rankings (Still) Fit for Purpose?

Ellen Hazelkorn

Are Universities Better Off Without Rankings?

Jamil Salmi

\section{Part V The Promise of Education}

Universities as Lifelong Learning Institutions: A New Frontier for Higher Education?

David Atchoarena

The Promise of Education: The Future

Roberto Escalante Semerena

The African Dream for Quality Higher Education

Ahmed Legrouri

Science and Social Responsibility - Heritage and Mission

Godehard Ruppert

Unlocking the Potential of Higher Education by Serving

the Common Good

Patrick Blessinger, Enakshi Sengupta, and Mandla S. Makhanya 
IAU: The Power to Foster Higher Education for Sustainable

Development

Pornchai Mongkhonvanit, Chanita Rukspollmuang, and Yhing Sawheny

Aligning Higher Education's Promise of Well-Being

with Sustainability as a Purpose of Education

Katrin Kohl and Charles Hopkins

Accelerating the Future into the Present: Re-imagining Higher

Education in the Caribbean

Hilary Beckles and Stacy Richards-Kennedy

The Future of Higher Education: A New Paradigm Shift

Addressing Students' Diversity

Khalid Arar and David Chen

Knowledge and Partnerships for Sustainability and Equality

Adam Habib

Post-COVID-19: A Time of Opportunity for Asian Universities

Eden Y. Woon

Part VI Opening up - The Future of Higher Education

Envisioning Higher Education for the Future

Henning Jensen-Pennington

From University to Multiversity to Omniversity: HEIs as Hubs

for Dynamic Development

Roberta Malee Bassett

The Disruptive Futures of Education-Post-COVID-19 Pandemic

407

Dzulkifli Abdul Razak

Universities Beyond 2020

Amr Salama

The Role of Digital Technologies in the New Present and Future of Higher Education

Carles Sigalés

Toward a Different Type of Education

David Fernández Dávalos

Transforming Universities for a Sustainable Future

Dirk van Damme

Education: We Must Keep Our Promise

Sjur Bergan 


\section{Editors and Contributors}

\section{About the Editors}

Hilligje van't Land serves the global higher education community as SecretaryGeneral of the International Association of Universities (IAU). She fosters the key role of higher education in societal transformation, supervises the overall implementation of the Association's strategic plans on internationalisation, value-based leadership, the digital transformation, and sustainable development. She positioned IAU as partner in UNESCO work on Education for sustainable development and in the UNESCO Futures of Education initiative; and higher education as a key stakeholder to reach the UN Agenda 2030-Transforming our world goals. Dr. van't Land strongly believes in the importance of international cooperation and intercultural understanding. She represents IAU in various working groups and expert committees including at the Council of Europe, UNESCO and the UN. Hilligje van't Land holds a $\mathrm{Ph} . \mathrm{D}$. in comparative francophone literature, speaks six languages, and publishes on higher education issues of relevance locally and globally.

Andreas Corcoran is Deputy Secretary-General of the IAU, he leads the leadership programme, the IAU-UNESCO Information Centre, and contributes to the IAU's strategic and institutional development. Prior to joining the IAU, Andreas was Director of Higher Education at SOFIA in Rome and Tanzania, with a special focus on academic and institutional development, strategy, and governance. He has worked for the University of Kent in the UK, the Federal Chancellor Willy Brandt Foundation and the German Historical Museum in Berlin. He holds a Ph.D. in History from the European University Institute in Florence.

Diana-Camelia Iancu is senior fellow of the International Association of Universities since 2019 and Dean of public administration, at the National University of Political Studies and Public Administration (Bucharest), since 2012. For the past decade, she has taught comparative public management in Bucharest and Nijmegen (at Radboud University) and assumed different academic assignments in Greece, France, Slovenia, Spain, and the US. Her research interests include international 
development and administrative capacity building in transitional countries, as well as quality assurance in teaching public administration. Dr. Iancu holds a Ph.D. cum laude in public administration from the National University of Political Studies and Public Administration.

\section{Contributors}

Jacob Abrams Fairmont State University, Fairmont, WV, USA

Philip Altbach Boston College, Chestnut Hill, MA, USA

Khalid Arar Texas State University, San Marcos, USA

David Atchoarena UNESCO Institute for Lifelong Learning, Hamburg, Germany

Lucia Balduzzi University of Bologna, Bologna, Italy

Roberta Malee Bassett The World Bank, Washington, DC, USA

Jo Beall London School of Economics and Political Science, London, UK

Hilary Beckles The University of the West Indies, Kingston, Jamaica

Sjur Bergan Council of Europe, Strasbourg, France

Gerardo L. Blanco Boston College, Chestnut Hill, MA, USA

Patrick Blessinger St. John's University, New York, NY, USA;

International Higher Education Teaching and Learning Association, New York, NY, USA

Nicolò Cavina University of Bologna, Bologna, Italy

David Chen Tel-Aviv University, Tel Aviv-Yafo, Israel

Andreas Corcoran International Association of Universities, Paris, France

Juan Ramón de la Fuente Permanent Representative of Mexico to the United Nations, New York, NY, USA

Hans de Wit Boston College, Chestnut Hill, MA, USA

Andrew J. Deeks University College Dublin, Dublin, Ireland

Elena Denisova-Schmidt University of St. Gallen, St. Gallen, Switzerland

David Dill The University of North Carolina at Chapel Hill, NC, USA

Judith S. Eaton Council for Higher Education Accreditation, Washington, DC, USA

Eva Egron-Polak International Association of Universities, Paris, France 
Roberto Escalante Semerena Association of Universities of Latin America and the Caribbean (UDUAL), Mexico City, Mexico

David Fernández Dávalos Universidad Iberoamericana Mexico City, Mexico City, Mexico

Vladimir Filippov RUDN University, Moscow, Russia

Pam Fredman International Association of Universities, Paris, France

Jocelyne Gacel-Ávila University of Guadalajara, Guadalajara, Mexico

Stefania Giannini UNESCO, Paris, France

Madeleine Green International Association of Universities, Paris, France

Adam Habib School of Oriental and African Studies (SOAS) - University of London, London, UK

Ira Harkavy University of Pennsylvania, Philadelphia, PA, USA

Datuk Abdul Rahim Hashim University of Malaya, Kuala Lumpur, Malaysia

Ellen Hazelkorn Technological University Dublin, Dublin, Ireland

Charles Hopkins York University, Toronto, Canada

Jeroen Huisman Ghent University, Ghent, Belgium

Michael Hölscher German University of Administrative Sciences Speyer, Speyer, Germany

Diana-Camelia Iancu National University of Political Studies and Public Administration, Bucharest, Romania

Henning Jensen-Pennington Universidad de Costa Rica, San José, Costa Rica

Elspeth Jones Leeds Beckett University, Leeds, UK

Etsuko Katsu Meiji University, Tokyo, Japan

Manzur H. Khan American International University-Bangladesh, Dhaka, Bangladesh

Tatiana Klyachko The Russian Presidential Academy of National Economy and Public Administration, Moscow, Russia

Manja Klemenčič Harvard University, Cambridge, MA, USA

Marcelo Knobel University of Campinas (Unicamp), Campinas, Brazil

Katrin Kohl York University, Toronto, Canada

Carmen Z. Lamagna American International University-Bangladesh, Dhaka, Bangladesh 
Ahmed Legrouri International University of Grand-Bassam, Grand-Bassam, Côte d'Ivoire

Daniel C. Levy University at Albany, State University of New York, Albany, NY, USA

David-John Lock Observatory of the Magna Charta, Bologna, Italy

Jenneke Lokhoff Nuffic, The Hague, The Netherlands

Elena Luppi University of Bologna, Bologna, Italy

Mandla S. Makhanya University of South Africa, Pretoria, South Africa

Simon Marginson University of Oxford, Oxford, UK

Mirta Martin Fairmont State University, Fairmont, WV, USA

Vladimir Mau The Russian Presidential Academy of National Economy and Public Administration, Moscow, Russia

Bryan McAllister-Grande Northeastern University, Boston, MA, USA

Pankaj Mittal Association of Indian Universities, New Delhi, India

Goolam Mohamedbhai International Association of Universities, Paris, France

Pornchai Mongkhonvanit Siam University, Bangkok, Thailand

Barnabas Nawangwe Makerere University, Kampala, Uganda

Sijbolt Noorda Observatory of the Magna Charta, Bologna, Italy;

University of Amsterdam, Amsterdam, The Netherlands

Pedro Nuno Teixeira University of Porto, Porto, Portugal

Remus Pricopie National University of Political Studies and Public Administration, Bucharest, Romania

Dzulkifli Abdul Razak International Islamic University Malaysia, Kuala Lumpur, Malaysia

Stacy Richards-Kennedy The University of the West Indies, Kingston, Jamaica

Chanita Rukspollmuang Siam University, Bangkok, Thailand

Laura E. Rumbley European Association for International Education, Amsterdam, The Netherlands

Godehard Ruppert University of Bamberg, Bamberg, Germany

Amr Salama Association of Arab Universities, Amman, Jordan

Jamil Salmi Diego Portales University, Santiago, Chile;

Boston College, Chestnut Hill, MA, USA

Carla Salvaterra University of Bologna, Bologna, Italy 
Yhing Sawheny Siam University, Bangkok, Thailand

Enakshi Sengupta International Higher Education Teaching and Learning Association, New York, NY, USA

Carles Sigalés Universitat Oberta de Catalunya (Open University of Catalonia), UOC, Barcelona, Spain

Ranbir Singh National Law University, Delhi, India

Outi Snellman University of Lapland/UArctic, Rovaniemi, Finland

Saulius Spurga Mykolas Romeris University, Vilnius, Lithuania

Dionisia Tzavara University of Liverpool, Liverpool, UK

Dirk van Damme OECD, Paris, France

Frans van Vught University of Twente, Enschede, The Netherlands

Hilligje van't Land International Association of Universities, Paris, France

Eden Y. Woon Asian Institute of Technology, Khlong Nueng, Thailand

Lili Yang University of Oxford, Oxford, UK

Pavel Zgaga University of Ljubljana, Ljubljana, Slovenia

Inga Žalènienè Mykolas Romeris University, Vilnius, Lithuania 


\section{Introduction}

\section{Hilligje van't Land, Andreas Corcoran, and Diana-Camelia Iancu}

On 9 December 2020, the International Association of Universities (IAU) celebrated the 70th anniversary of the historic signing of the IAU Constitution. The IAU was called into life when UNESCO and its Member States brought together universities of the world to jointly draft the founding text, signed on 9 December 1950, in Conference, in Nice, France. By doing so, they officialised the creation of an Association with a unique global mandate. The text of the Constitution opens with the following words, which still mark the work of IAU:

"Conscious of their high responsibility as guardians of the intellectual life; Conscious of the fundamental principles for which every university should stand, namely: the right to pursue knowledge for its own sake and to follow wherever the search for truth may lead; the tolerance of divergent opinion and freedom from political interference;

Conscious of their obligation as social institutions to promote, through teaching and research, the principles of freedom and justice, of human dignity and solidarity; to develop mutually material and moral aid on an international level;

The universities of the world, through their representatives assembled in conference at Nice, hereby decide to create an international association of universities." (IAU 1950)

H. van't Land $(\varangle) \cdot$ A. Corcoran

International Association of Universities, Paris, France

e-mail: h.vantland@iau-aiu.net
A. Corcoran
e-mail: a.corcoran@iau-aiu.net
D.-C. Iancu

National University of Political Studies and Public Administration, Bucharest, Romania

e-mail: diana.iancu@snspa.ro 
Back then, the IAU was the only association of its kind, scope and mandate and this is still the case today seventy years later, acting as the global voice of higher education around the world.

The world has changed significantly since the creation of the IAU and the higher education landscape has evolved as never before. The idea of a university referred to in the foundational statements cited above is one that has been passed down over centuries; it is an idea that has remained remarkably stable over time. Indeed, the university, in its corporate structure and mission, is one of the very few institutions in global history that has survived the passing of time despite profound political, economic, and cultural transformations - not least during the seventy years of IAU's existence. What the essays in this book show is that the mission of the university, to research, teach and serve society, has proven to be simultaneously resilient and adaptable. Universities are shown to be drivers, mediators, and critical observers of change at the same time. It is this shared understanding of university that all the contributions in this book have in common. But there are social, political, economic and technological challenges on the horizon that question the idea of higher education as we know it. For instance, the onslaught of rapid technological advances in AI and delivery, the pace of which has been hitherto unknown, is having an immense impact on research, teaching and collaboration. Given the growing influence of tech and commodification of higher education, it is being asked whether the university is still the most suitable institution to provide the skills and competences the labour market requires. In epistemic terms, universities are confronted with expanding scepticism, which, in conjunction with increasingly populist and nationalist policies, tries to cast doubt on the validity and relevance of academic values and higher education as trusted places of knowledge and research. In social and moral terms, the university is being challenged along questions of equity, equality and access and urged to more clearly engage in shaping just and sustainable societies. Some wonder if the future university still requires a physical locus given that many of the crucial higher education activities are shifting to a virtual space with global access. These and many more are questions universities will have to find answers to.

While retaining their core institutional form, universities have always been astonishingly agile and receptive to change when it mattered, not least demonstrated by the speed and scale with which universities across all faculties have responded to the current pandemic. This has brought forth a new appreciation of the role of universities in society on which to build.

For seventy years now, the IAU has accompanied processes of change by providing a platform, a meeting point, by acting as an instigator and facilitator of debate; debates that indeed try to address the great issues of our time and define and shape the role of higher education in relation to them.

One of the key tasks of the IAU has been to monitor the gradual expansion of the higher education landscape. In 1950, the IAU published the very first 'Universities of the World' which listed 620 universities and higher education institutions. The list 
later became known as the 'International Handbook of Universities' (1959-2020). ${ }^{1}$ Since 2014, the data of the Handbook has become the basis of the IAU-UNESCO online portal: World Higher Education Database (WHED). ${ }^{2}$ The WHED now contains data on around 20,000 universities and other higher education institutions in 196 countries and territories - and the list is growing — which testifies to the fact that higher education is still a growing field on the global scale.

Over time, the number of IAU Members has remained stable, while the Members listed, and countries represented, have changed. Many who attended the Nice Conference in 1950 and added their signatures to the text of the Constitution are still Member today, and many other universities have joined. The membership has been enriched with new categories of membership since the late 1990s, namely Organisational, Affiliate, and Associate categories, with the latter contributing their expertise to our programme and thematic work. ${ }^{3}$ In creating these categories, IAU wished to become more inclusive and to contribute to the development of quality in higher education globally. ${ }^{4}$

The IAU Members, universities and other higher education institutions, organisations and associates, and the affiliates devote quality time and effort to the life and work of the Association, in line with its mission and vision, ${ }^{5}$ and promote the values we foster and help address its strategic goals. It is thanks to the efforts and commitments of thought leaders from around the world that the Association is able to serve the global higher education community today and to do so in the future.

The IAU is global and reaches out way beyond its membership to stakeholders active in higher education, including governments. Its connection with national representatives and international and multilateral organisations is important and manifests itself through its constructive contributions to various UN organisations, in particular to UNESCO, the World Bank, OECD and the Council of Europe.

Today, the IAU works on issues and topics that were also important seventy years ago: fair and equitable internationalisation of higher education, strong globally engaged leadership, value-based higher education. To these, the IAU has added the priority areas of work on higher education and research for sustainable development, and digital transformation of higher education. ${ }^{6}$ The first one since the early 1990s and the second not much later. All priority areas of work are of key importance today and even more so in the context of the current COVID-19 crisis, bearing so heavily

\footnotetext{
${ }^{1} 2020$ saw the twenty-ninth and last publication of the IHU by Palgrave Macmillan. It is published in a set of 10 volumes and includes 20,000 higher education institutions in 196 countries and territories.

${ }^{2}$ For more information on the World Higher Education Database: www.whed.net.

${ }^{3}$ Finally, and in order to ensure better inclusiveness of voices, IAU also developed an 'Observer status' which can be granted to public or private not-for-profit degree-conferring higher education institutions, which do not yet meet the eligibility criteria for membership of three cohorts of students in the first instance.

${ }^{4}$ For more information on IAU Membership: https://www.iau-aiu.net/Members.

${ }^{5}$ For further information on IAU mission and vision, please see: www.iau-aiu.net/Vision-Mission

${ }^{6}$ For further information on IAU strategic plan and work on the key priority themes please go to the website: www.iau-aiu.net.
} 
on society and education on an unprecedented scale. Within months, COVID-19 has exacerbated existing problems and made even more vivid the fault lines of the higher education landscape. It seems that this crisis is forcing all of us to look even more closely at the issue of Relevance and Value of Higher Education-the very theme selected by the IAU Board for the IAU 16th General Conference. This is not necessarily 'new' as can be seen from the many IAU Conferences and themes that have marked the life of the IAU over the many years of its existence, yet each time these questions are raised within a specific context; it requires particular attention especially today when our societies are being reinvented at such a phenomenal pace: after all, higher education is one of the key stakeholders to building the kind of society we want (Harkavy et al. 2020).

\section{The Idea of the Book}

With the Members and Deputy Board Members of the IAU Board-29 esteemed higher education leaders from 27 countries and all five continents-we chose to celebrate the 70th anniversary of the Association in a special way.

Indeed, what better opportunity to mark this milestone than to publish a collection of essays that point to the various challenges and opportunities, that highlight accomplishments and future potential of higher education and cooperation, essays that revisit the past, analyse the present, and look into the future. We were very pleased to see the enthusiasm with which this Open Call was met. Given the breadth of the themes discussed, it would be impossible to provide a synopsis of the keen observations, analyses, argumentations, reflections and joyful accounts of times gone by gathered in this book. What is noticeable are clusters of arguments that we wish to touch upon without any pretensions of being exhaustive.

This book includes reflections on global cooperation; human rights; academic values including ethics and integrity; globalisation and HE; associations as drivers of change; the opportunities and limits of internationalisation; local and international mission of universities; knowledge governance; HE and sustainable development; the civic role of universities; $\mathrm{HE}$ as a public good in various national and international contexts; international mobility and cooperation: the role of quality assurance and recognition; the internationalised student experience; epistemic scepticism / phobia and public trust; aspects of leadership; de-colonialism and equity; digitalisation and online learning; community engagement; teaching quality; political role of university leadership; the heuristic limits and impact of rankings; lifelong learning and universities; questions of social equality, diversity and inclusion; future models of online institutions; HE forging and ensuring democracy; access, social justice and responsibility. 


\section{Outline of the Book}

Eighty-one authors from thirty-two countries, forty-seven universities, and sixteen organisations have contributed 64 chapters to this book. ${ }^{7}$ They all accepted the challenge to reflect on higher education's past, present and future, to share views on specific topics close to their own work and to think about the roles and contributions an association like the IAU has had over time and will have in the future.

The essays were arranged according to the themes of the following sections:

Part I- "70 years of Higher Education Cooperation and Advocacy" features a set of nine papers providing perspectives on the IAU by past and present IAU Board Members, past and present Presidents of the Association, friends of the Association, and Stefania Giannini, the Assistant Director General for Education to UNESCO. This part looks back on IAU's history, its mission and significant activities over time, as well as the current global context informing its quest to promote academic partnerships and solidarity on a global scale. The contributions reflect on how IAU has critically engaged with themes in higher education over the last seventy years and how they have helped shape the agenda to bring about change.

Part II- "Facilitating International Cooperation" offers a series of ten papers written by university leaders from India, UK, US, Mexico, Russia and Finland, and from Associations like EAIE, NAFSA and UArctic which provide for different perspectives on the transformation of the internationalisation of higher education and the contribution of higher education to international cooperation.

Part III- “Coding the Values" debates the values upon which higher education was, is and will have to be built to provide for a democratic and inclusive society. The nine papers published present the work of the Magna Charta, look at the political and economic aspects of what values are under review in Germany, the US, Switzerland, and what role quality assurance and the recognition mechanism for qualifications play in fostering value-based higher education.

Part IV- "The Changing Landscape" explores various aspects of the transformation of higher education over time. This section received most attention, and 17 papers analyse the changing landscape across the globe from India to The Netherlands, Brazil, Uganda, South Africa, Lithuania, Russia, Japan, Malaysia, UK, Italy, Bangladesh, Ireland and Chile.

Part V-“The Promise of Higher Education” UIL, UDUAL, HETL and colleagues from Côte d'Ivoire, Germany, South Africa, Canada, USA, Israel and Thailand reflect on the role of higher education, its ideals and shortfalls and what it must do to stay true to its promise to help shape our societies.

In the concluding chapter, Part VI- "Opening up_-the Future of Higher Education" authors focus on future scenarios of higher education in Costa Rica, Malaysia, the

\footnotetext{
${ }^{7}$ The views expressed are those of the authors.
} 
Arab World, Spain and Mexico. Finally, the World Bank and OECD call on the reader to envision a different kind of higher education and how it contributes to the transformation of our societies. The closing remarks are given to the Council of Europe who reflects on future roles for the IAU.

\section{To Conclude}

As editors, we enjoyed interacting with the authors and conceptualising this book, and we would like to thank all for their valuable contributions, insights, their patience and commitment on the road to completion. This book would not have been possible if not for the vision and work of the founders of the IAU and builds on those who have worked at the IAU over the last seventy years.

We wish to give special thanks to Trine Jensen, Nicholas Poulton, Amanda Sudic and Samantha Grillo for their valuable assistance in shaping this book. Special thanks also go to the Board Members for their support to this initiative.

The IAU is very grateful to Remus Pricopie, Vice-President of the IAU and Rector of the National University of Political Studies and Public Administration (SNSPA, Romania), for making this publication possible. He seconded Diana Iancu to the IAU for this beautiful initiative and provided generous support towards the publication of the book. It was wonderful to team up with Diana throughout the process.

As much as it needs to be noted that this book is not on COVID-19, the crisis has had a significant impact also on the development and creation of this publication. Indeed, COVID-19 has heavily impacted the life of universities and other higher education institutions as well as all associations and organisations we are working with. ${ }^{8}$ Given the current context, it is not surprising that many papers also take on board the various challenges of COVID-19 for the present and future of higher education. The pandemic also impacted on the book in so far as it has generated delays and made it impossible for some authors to submit. They will have other opportunities to contribute to IAU work in the future.

At the IAU, we will be sure to benefit from the insights and suggestions made in these papers for the future work of the IAU, particularly when planning the future of the Association, when developing future IAU strategic plans and when organising future Conferences and other events.

\footnotetext{
${ }^{8}$ The IAU did much to monitor the impact of COVID-19 on higher education: through a series of global surveys and web-pages, as well as through the IAU webinar series on The Future of Higher Education: past Present and Future. All are available online in 2020-2021: https://iau-aiu. net/COVID-19-Higher-Education-challenges-and-responses.
} 


\section{References}

IAU (1950). The IAU Constitution. Available online: www.iau-aiu.net/IMG/pdf/iau_constitutionen.pdf

Ira Harkavy, Sjur Bergan, Tony Gallagher and Hilligje van't Land, (2020) Universities must help shape the post-COVID-19 world, in University World News (18 April 2020). https://www. universityworldnews.com/post.php?story=20200413152542750

Hilligje van't Land serves the global higher education community as Secretary General of the International Association of Universities (IAU). She fosters the key role of higher education in societal transformation, supervises the overall implementation of the Association's strategic plans on internationalization, value based leadership, the digital transformation and sustainable development. She positioned IAU as partner in UNESCO work on Education for sustainable development and in the UNESCO Futures of Education initiative; and higher education as a key stakeholder to reach the UN Agenda 2030 - Transforming our world goals. Dr. van't Land strongly believes in the importance of international cooperation and intercultural understanding. She represents IAU in various working groups and expert committees including at the Council of Europe, UNESCO and the UN. Hilligje van't Land holds a $\mathrm{PhD}$ in comparative francophone literature, speaks six languages and publishes on higher education issues of relevance locally and globally.

Andreas Corcoran is Deputy Secretary-General of the IAU, he leads the leadership programme, the IAU-UNESCO Information Centre, and contributes to the IAU's strategic and institutional development. Prior to joining the IAU, Andreas was Director of Higher Education at SOFIA in Rome and Tanzania, with a special focus on academic and institutional development, strategy, and governance. He has worked for the University of Kent in the UK, the Federal Chancellor Willy Brandt Foundation and the German Historical Museum in Berlin. He holds a PhD in History from the European University Institute in Florence.

Diana-Camelia Iancu is senior fellow of the International Association of Universities since 2019 and Dean of public administration, at the National University of Political Studies and Public Administration (Bucharest), since 2012. For the past decade, she has taught comparative public management in Bucharest and Nijmegen (at Radboud University) and assumed different academic assignments in Greece, France, Slovenia, Spain and the US. Her research interests include international development and administrative capacity building in transitional countries, as well as quality assurance in teaching public administration. Dr. Iancu holds a PhD cum laude in public administration from the National University of Political Studies and Public Administration.

Open Access This chapter is licensed under the terms of the Creative Commons Attribution 4.0 International License (http://creativecommons.org/licenses/by/4.0/), which permits use, sharing, adaptation, distribution and reproduction in any medium or format, as long as you give appropriate credit to the original author(s) and the source, provide a link to the Creative Commons license and indicate if changes were made.

The images or other third party material in this chapter are included in the chapter's Creative Commons license, unless indicated otherwise in a credit line to the material. If material is not included in the chapter's Creative Commons license and your intended use is not permitted by statutory regulation or exceeds the permitted use, you will need to obtain permission directly from the copyright holder.

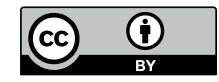




\section{Part I}

70 Years of Higher Education Cooperation and Advocacy 


\title{
To Cohere and Act as One: IAU-The Global Voice of Higher Education
}

\author{
Pam Fredman
}

Knowledge and knowledge development have always been essential for the survival and continuing development of humankind. As part of the human condition, people have always adapted to the particularities of local environments which in turn are influenced by global conditions and changes, such as climate change, disease, and armed conflict, among others. Knowledge has, throughout human history, been shared and transferred, and with time ever more extensively across regions and national borders. The basic idea that knowledge has no borders has always been and needs to continue to be a guiding light for higher education (HE). International mobility is part of this knowledge transfer and exchange as it augments our understanding of cultural, structural, and financial differences in the world, which must be considered collectively as our shared global responsibility for sustainable social development. These, as well as other perspectives, will be addressed in the following lines.

The COVID-19 pandemic, which is ongoing at the time of writing, is a global phenomenon, both in regard to the spread of the virus and the consequences the pandemic has in social and financial terms; consequences which the whole world will have to bear in both the short- and long-term, and for which there is a common responsibility. To contribute to sustainable social development for all and to ensure the survival of the planet for generations to come is what 193 countries' governments promised to do by ratifying the 2030 Agenda (UN 2015). This agenda includes 17 goals (SDGs) to (i) eliminate extreme poverty; (ii) reduce inequalities and injustices; (iii) promote peace and justice; and (iv) solve the climate crisis (UN 2015).

SDG4 is specifically aimed at education_- "Good education for all_Ensuring an inclusive and equal education of good quality and promoting lifelong learning for all". However, extensive involvement of research and teaching is required for

\footnotetext{
P. Fredman (ه)

International Association of Universities, Paris, France

e-mail:pam@gu.se

(C) The Author(s) 2021 
the fulfilment of each and all the SDGs, which is why the United Nations have underlined the key role of universities. In 2017, Peter Thomson, the former President of the United Nations General Assembly, used the contact information collected in the vast IAU World Higher Education Database (whed.net) to reach out to all higher education institutions (HEIs) in the world: "It goes without saying that young people are the most capable of the transformation required, having the most to gain or lose, from the success or failure, of Agenda 2030. I therefore make this sincere request to you to make these goals an integral part of research, teaching and study at your institutions".

The International Association of Universities (IAU) was founded 70 years ago in 1950 as a global network in order to mark and promote the role of HE in society and its significance for building democratic societies and peace. At UNESCO's initiative, HEIs and organisations from around the world convened in Utrecht in 1948 to discuss the future of $\mathrm{HE}$ in a world that was then recovering from the consequences and experiences of the Second World War. They addressed the need to rebuild confidence in the role of $\mathrm{HE}$ to impart knowledge and values and thus contribute to social and democratic development, the building of civil society, and the preservation of peace. Universities were reminded of their most fundamental values and that the university's mission extends beyond teaching and research, and were called upon to take up their social responsibility. Indeed, the vigorous safeguarding and defending of the core values of HE was deemed a prerequisite for HEIs in order to be able to truly assume what later became to be known as corporate social responsibility. These core values include academic freedom (to critically ask questions and carry out unrestricted research) and institutional autonomy free of economic, political or ideological pressures. The result of the meeting resulted in an agreement on the need for more global cohesion among universities, and under the UNESCO mandate, the IAU was formed in 1950 (IAU 1950).

Throughout the 70 years of the Association's existence so far, the demand for $\mathrm{HE}$ and the conditions under which HE operates have changed dramatically in many respects. The massification of HE has virtually exploded. The number of HEIs in the world has grown nearly ten-fold, and universities have spread out across 196 countries. ${ }^{1}$ Never before have the younger generations had as much access to HE and vocational training as today. Accordingly, universities have accompanied and driven the transformations associated with the training of graduates to serve the needs of a knowledge-based society.

However, the increase of the student population in HE and of HEIs has been accompanied by the emergence of new negative aspects. The first is the commodification of HE, which affects accessibility and has resulted in considerable socioeconomic inequality. This is a development that counteracts the goal of the 2030 Agenda to ensure "good education for all" and thereby produces competencies that reflect social, economic and cultural diversity in society. The commodification of HE also

\footnotetext{
${ }^{1}$ For the expansion of the higher education sector see the yearly increased figures in the IAU's International Handbook of Universities and World Higher Education Database (WHED) (www. whed.net/).
} 
means that many HEIs around the world depend on tuition fees as a significant or dominant part of their funding — and thus rendering the uneasy relationship between $\mathrm{HE}$ as a private and/or public good ever more complicated.

COVID-19 has with great force and speed magnified the financial fault lines of the higher education sector: future cutbacks in public spending for HE in many countries; over-reliance on tuition fees from students; dependence on large numbers of international students (IAU 2020). Whether or when student mobility will be back to the volumes seen before the pandemic remains uncertain. It is therefore high time to rethink internationalisation of students and how we can maintain the so important cultural and structural exchange in a meaningful way. Loss of tuition fees from international students and the resulting financial deficit will likely result in increased tuition fees nationally. Unless governments introduce financial support schemes or frameworks, there is a great risk of increased socioeconomic inequality in society.

Another consequence of the massification of HE is the ever-greater decoupling of research and teaching. Today we can note that of the 19,700 HEIs $^{2}$ many do not carry out their own research. Research and teaching should be inseparable as it is one of the fundamental principles of HE (Magna Charta 1988). It is obvious that research funding has not increased in parallel with the expansion of teaching. There has been a redistribution of research funds to medicine, science and technology at the expense of the humanities, social sciences and arts, and the resources allocated fall way short of the needs. The coupling of teaching with research and empirical knowledge is important to provide the students with current subject knowledge but also with analytical and creative skills and critical thinking. Education must have the capacity to impart the relevant knowledge and skills needed to keep up with the increasing pace of change. The skills of the future should be the skills for sustainable social development. Subject knowledge is continuously changing; more important is the ability to be critical and analytical in assessing information and knowledge and use those skills to creatively generate (new) solutions in the different sectors of society.

To ask all HEIs to conduct their own research would be a tall order, but HE must rest on a scientific or empirical framework, and HEIs and organisations must jointly support and ensure that university teachers have a postgraduate education with research experience. Teachers with competencies to impart skills to students so that they can translate new knowledge critically and analytically into their professional life. HEIs and organizations must jointly take responsibility for building capacity worldwide by putting cohesion before competition. Without taking global responsibility, the goals of Agenda 2030 will not be achieved, regardless of the fact that 196 countries have ratified it.

Internationalisation in research equates to strong collaborations between researchactive universities around the world. Knowledge creation and development through research is needed for societal development and crucial for reaching the SDG goals. Research might focus on local challenges but will have to be informed by knowledge which may come from any part of the world. Knowledge in any discipline needs to be

\footnotetext{
${ }^{2}$ Ibidem.
} 
shared through publications; in this, open access is an important development. The COVID-19 pandemic is having a severe effect on young scientists, especially who are prohibited from taking up postdoc or doctoral positions and who are thus having to postpone the start of their career. Their participation in research projects is an important part of capacity building, global exchange and development of knowledge. This also means that a research project will not be completed due to travel restrictions and that there is a much greater risk of less research-active HEIs falling behind.

Physical mobility of researchers and students is an important component of research and teaching especially in regard to knowledge exchange and capacity building around the world. The ongoing pandemic, with its immediate effect on physical mobility, has shown that HE must jointly come up with short- and long-term solutions to the new challenges to internationalisation, even if this means finding new modes with limited physical mobility. Local and regional research and development projects must have a global perspective, and the HE sector needs to, in a cohesive way, promote and advocate for international knowledge exchange.

For many years societies have experienced ever-faster technological development, including digitalisation and its introduction to all sectors of society. This has also been the case for HE. There are high expectations that this will lead to greater accessibility to higher education, to support distance education, especially for lifelong learning. Many stakeholders, including politicians, have complained that such transformation is coming about too slowly. However, the COVID-19 pandemic has shown higher education's ability to swiftly adapt and take responsibility. Almost overnight, the universities started to work remotely, both in teaching and research (IAU 2020).

However, many HEIs do not avail of the necessary resources or infrastructure needed to carry out their activities online. Many students, also in developed regions, do not live in an environment which is conducive to studying. Some of the consequences of the switch to unplanned and unprepared remote teaching has led to students complaining about the deterioration of quality and the loss of the human experience from physical interaction with classmates and teachers.

The expectations from decision- and policymakers to continue digital development in HE will put pressure on HEIs. Any kind of quality assurance in the digital transition of higher education institutions and organisations can only come about through cooperation and shared notions of quality. This includes aspects of equality in HE locally and globally and the promoting and advocating of academic competencies such as creativity, critical and analytical thinking.

When IAU was founded 70 years ago, there was a concern for the fact that fundamental values of higher education were cast into doubt: academic freedom, free choice of research questions and methods, and institutional autonomy, prerequisites for HE to fulfil its unique role in society, not least as an important critical voice. Unfortunately, today we are experiencing a time in which these values and the relevance of $\mathrm{HE}$ are again being increasingly questioned by politicians, decision-makers and other stakeholders. We find ourselves in a post-truth society, characterised by a form of epistemic phobia, showing little confidence in scientific knowledge and questioning the science and relevance of HE. The world is also experiencing a time of increased protectionism and nationalism, and freedom of expression and human rights are 
challenged. However, a positive finding of the IAU survey on the consequences of COVID-19 was that in many countries, not all, HEIs have been experiencing an increased demand for expertise and advice. Thus, the necessity of cohesion and a "global voice" promoting and advocating for the importance of HE is as important as it was 70 years ago. A unified voice that is expressed and heard at national and regional levels by both HEIs and organizations.

Cohesion and collaboration between HE institutions and organisations need to involve the societal stakeholders, politicians, the public and private sector, and civil society. This is probably best developed locally and regionally, where collaboration addressing local challenges and specific needs for skills and personal cohesion comes more naturally. Collaboration must be based on respect and trust and have common goals; it must promote HE as a public good, that knowledge is an investment in society and the labour market and will strengthen civil society. Without competencies, society cannot drive technical development and actively contribute towards the SDGs.

However, collaboration and social responsibility in HE must be part of a quality assessment framework and needs to include not only quantitative but also qualitative benchmarks. In this context, the IAU is committed to the sharing of knowledge from local and regional initiatives while championing the importance of cohesion and collaboration with all sectors of society.

In summary, the unique role of HE for a sustainable society must be understood, advocated, and promoted by all stakeholders in society and across the higher education sector. HE needs a common global voice, a voice that the IAU has had for seventy years now. However, a global voice of higher education will not be heard without a degree of cohesion among HE institutions and organisations around the world. The IAU's credibility and opportunities to promote the role of universities for a sustainable future of our planet and for future generations must be based on trust, respect and cohesion. In all the diversity characterising universities around the world, they are bound by a common denominator: they share a set of academic values and a common ontological narrative. As President of IAU, I see that the university sector is showing a greater willingness than ever before to jointly support and safeguard HE locally, regionally and globally, and this is a fantastic confirmation of our work and motivation to amplify the global voice of IAU in its endeavour to shape the future of higher education and society.

\section{References}

International Association of Universities (IAU). (2020). The Impact of COVID-19 on Higher Education Around the World. IAU Global Survey Report. Retrieved from: www.iau-aiu.net/IMG/ pdf/iau_covid19_and_he_survey_report_final_may_2020.pdf (26.07.2020)

International Association of Universities (IAU). (1950). Constitution of the International Association of Universities. Retrieved from: https://iau-aiu.net/IMG/pdf/iau_constitution-en.pdf (26.07.2020)

Magna Charta. (1988). Magna Charta Universitatum. Retrieved from: www.magna-charta.org/ resources/files/the-magna-charta/english (26.07.2020) 
United Nations. (2015). Resolution adopted by the General Assembly on 25 September 2015. Transforming our world: the 2030 Agenda for Sustainable Development. A/RES/70/1. New York: United Nations. Retrieved from: https://sustainabledevelopment.un.org/post2015/ transformingourworld (26.07.2020)

Pam Fredman served as Rector of the University of Gothenburg from 2006 until 2017. She is a Professor of Neurochemistry and has held several leading positions within the University, for example as Dean of the faculty of medicine at the University of Gothenburg-the Sahlgrenska Academy. Since 2016, Pam Fredmam has been the President of the International Association of Universities.

Open Access This chapter is licensed under the terms of the Creative Commons Attribution 4.0 International License (http://creativecommons.org/licenses/by/4.0/), which permits use, sharing, adaptation, distribution and reproduction in any medium or format, as long as you give appropriate credit to the original author(s) and the source, provide a link to the Creative Commons license and indicate if changes were made.

The images or other third party material in this chapter are included in the chapter's Creative Commons license, unless indicated otherwise in a credit line to the material. If material is not included in the chapter's Creative Commons license and your intended use is not permitted by statutory regulation or exceeds the permitted use, you will need to obtain permission directly from the copyright holder. 


\title{
Stepping Up Global Collaboration to Protect Higher Education's Future
}

\author{
Stefania Giannini
}

Whether a university was founded centuries ago or in recent decades, the past 70 years have seen momentous change in the landscape of higher education and its place in our societies. The year 2020, coinciding with the 70th anniversary of the International Association of Universities (IAU), witnessed change that no forecast had anticipated: the closure or re-alignment to online learning of nearly all higher education institutions in the world, affecting some 220 million students in 175 countries.

Although technology has radically transformed the delivery of higher education in the past decades more than at any other level, systems were not prepared for disruption at such a scale, with many institutions unable to deliver courses online. UNESCO's Institute for Higher Education in Latin America and the Caribbean (IESALC) estimates that in this region alone only $75 \%$ of institutions have the capacity to offer online education, while one-quarter of students are being left out due to lack of access to technologies and platforms. Between the recessionary outlook, uncertainty about when and whether institutions will reopen physically or personal financial struggles, the future for tertiary level students has never been more fragile. According to UNESCO's research, higher education students are in fact at greater risk of not continuing their studies, with an anticipated 3.5\% decline in enrollment, equivalent to 7.5 million students, with the highest numbers in South and West Asia and Sub-Saharan Africa.

More than ever, deeper international cooperation is the only response to this crisis-whether to strengthen inclusion, combat inequality, generate innovation and build the capacity to advance societal well-being and sustainable development. UNESCO and the IAU were born in the same generation, sharing similar faith in the right to education and in the power of intellectual and moral solidarity to build

\footnotetext{
S. Giannini $(\varangle)$

UNESCO, Paris, France

e-mail: adg-ed@unesco.org

(C) The Author(s) 2021 
peace beyond shifting political fault lines. Today, innovative and inclusive tertiary education systems are being turned towards for designing solutions to the crises facing our societies - ones that have never been so interdependent and yet, fragile and unequal. The international community adopted a universal agenda to address these inter-related crises, encompassed in 17 sustainable development goals to benefit people, planet, peace and prosperity. This roadmap, more than ever relevant today in the face of a pandemic that has exposed the life-threatening implications of inequalities, demands a quantum leap in knowledge and can only be achieved if education is at the core. The Agenda includes a specific target on providing equal access for all women and men to affordable and quality tertiary education. This is not negligible as it reflects the strategic role of higher education in generating the knowledge, innovation and professional training that is required to understand the complexity of our times and unlock solutions that make our world more safe, just and fair.

Despite a meteoric rise in tertiary enrollments over the past 70 years, today global coverage stands at only $38 \%$, with wide disparities between regions and countries. Demand will increase, and governments must be braced for this, to nurture the talents that their future depends upon. This starts with equity-centred policies at every educational level, targeted ones where needed, and measures to ensure the equal distribution of opportunities for inclusive access to higher education, without any form of discrimination. Looking to the future, it is incumbent upon the State and higher education institutions to reinforce policies designed to address the multiple structural barriers that prevent students from pursuing their studies, including through financial levers and affirmative action measures. The development of inclusive higher education systems in Africa, where enrolment remains under $10 \%$, should be a priority for international cooperation, together with the establishment of national quality assurance agencies, which do not exist in many countries, leaving students all the more vulnerable to exploitative providers.

Globally the COVID-19 pandemic has laid bare inequalities that are not only social and economic in nature, but also digital. Any inclusive policy must therefore strengthen the digital infrastructure of higher education, encompassing investment in online pedagogical resources, training for faculty and equitable access for all students.

Beyond the inclusion imperative, global cooperation must be strengthened to facilitate mobility, the recognition of qualifications, and the creation and sharing of knowledge. By 2025, it is predicted that over 8 million students will study abroad, nearly double the current figure. The Global Convention on the Recognition of Higher Education Qualifications, adopted in November 2019 by UNESCO's General Conference, represents a multilateral milestone, a collective move towards democratizing knowledge, enabling a more fluid circulation of talent and fostering global trust.

Notwithstanding the critical importance of quality assurance to protect academic standards, excellence in higher education should be measured by the extent to which systems are inclusive and connected to societal and ethical challenges, such as the applications of artificial intelligence that go as far as blurring our core notion of humanity. Because today's defining challenges are global in nature-climate change and the COVID-19 pandemic know no frontiers - they require a response that is 
based on deeper solidarity and collaboration, including how knowledge is produced and shared for societal benefit. Gearing study programmes to the 2030 Agenda for Sustainable Development requires transdisciplinary approaches, action-research and stronger linkages between research, policy design and labour market demands. The IAU's Global Higher Education Cluster on the SDGs is paving the way with sixteen universities around the world championing one of the Global Goals and working with satellite institutions from all continents to advance them.

The Agenda has implications for how higher education and research is organized and funded. The development of open educational resources and open science is the way forward to narrow knowledge gaps, based on a culture of collaboration and citizen participation. This is a movement gaining ground worldwide, one in which UNESCO is leading a global dialogue with a view to develop a Recommendation to our 2021 General Conference.

The future of higher education and global development cannot be delinked. If societies are to become more resilient, equitable and sustainable, then higher education has to provide the intellectual infrastructure for this transition to happen-one that is economic, social, political and environmental. These are after all the institutions responsible for grooming the next generation of leaders, teachers, health and medical personnel, scientists, researchers and other talents to advance the ambitious sustainable development goals in the next decade.

Any reduction in spending on higher education will have irreversible consequences for people and societies. Higher education should be included in stimulus plans for economic and social recovery, with focus on the most vulnerable students, remedial learning and massive digital upgrading. This has to be accompanied by a paradigm shift to make higher education more inclusive, lifelong through more fluid approaches to learning, and catalytic in driving sustainable change.

The Futures of Education initiative, launched in September 2019 to catalyse a global debate on how knowledge, education and learning need to be reimagined in a world of increasing complexity, uncertainty and precarity, has seen its foresight mission collide with the global disruption of the COVID-19 pandemic. Such disruption is the opportunity to accelerate innovation and lead reform. Decisions made today in the context of the pandemic will have long-term consequences for the futures of education. The International Commission on the Futures of Education of which the IAU is an Advisory Board member, has urged that every choice be based on a humanistic vision of education as human right and a common good, one that should be a bulwark against inequalities. As the Commission states in a paper outlining nine ideas for public action, "COVID-19 has shown us the extent to which our societies exploit power imbalances and our global system exploits inequalities." It calls for "renewed commitments to international cooperation and multilateralism, together with a revitalized global solidarity that has empathy and an appreciation of our common humanity at its core." (UNESCO 2020).

As the only UN agency with a mandate in higher education, UNESCO, together with vital partners such as the IAU, is committed to championing global cooperation in this field to fulfil the rights of every student, protect academic freedom and chart the future along more ethical, equitable and sustainable lines. 


\section{Reference}

UNESCO. (2020). Education in a post-COVID world: Nine Ideas for Public Action, (10.08.2020) Retrieved from: https://en.unesco.org/futuresofeducation/news/nine-ideas-for-public-action

Stefania Giannini is Assistant Director-General for Education at UNESCO and former Minister of Education, Universities and Research in Italy (2014-2016). She became Professor of Linguistics in 1992 and served as Rector of the University for Foreigners of Perugia (2004-2012), being one of the first female Rectors and the youngest at that time in Italy. In addition to her current position at UNESCO, Stefania Giannini is Advisor to the European Commissioner for Research and Innovation as well as a member of the Atlantis Group of the Varkey Foundation and of RISE (Research, Innovation and Science Policy Experts).

Open Access This chapter is licensed under the terms of the Creative Commons Attribution 4.0 International License (http://creativecommons.org/licenses/by/4.0/), which permits use, sharing, adaptation, distribution and reproduction in any medium or format, as long as you give appropriate credit to the original author(s) and the source, provide a link to the Creative Commons license and indicate if changes were made.

The images or other third party material in this chapter are included in the chapter's Creative Commons license, unless indicated otherwise in a credit line to the material. If material is not included in the chapter's Creative Commons license and your intended use is not permitted by statutory regulation or exceeds the permitted use, you will need to obtain permission directly from the copyright holder. 


\title{
The IAU and Contemporary Global Challenges: A Latin American Point of View
}

\author{
Juan Ramón de la Fuente
}

In today's world, in which the problems that affect us all are interconnected, global problems and global issues require global solutions. Pandemics, climate change, the growing waves of intolerance, inequality and migration are but some examples of the challenges that require a joint response. In a context where global, multiple stakeholders are needed to formulate efficient solutions to these global problems, universities must play a more active role. To this end, the IAU, the only truly global association of universities, offers a unique and important platform to foster that role.

There is a positive balance on the impact generated by international and multistakeholder cooperation. Multilateralism is a form of international cooperation that led to the formation of the UN. I believe globalism and multilateralism are far better approaches to addressing global problems than nationalism. The current context we live in offers a great opportunity for the International Association of Universities because its mission and scope are suited to this context. There is no equivalence to it in the academic world. But it is precisely in this sense that work must be done to implement innovative approaches, new activities, to think out of the box, to network, to attract and consolidate a diverse community, to allow us to move forward as an academic family in its pluralistic nature.

The idea of an isolated university or a higher education institution or even a national system, devoting its energy, efforts, talent and resources just to satisfy its own interests and curiosity is no longer viable. Universities do have a local mission; however, its regional and international interactions will strengthen it. For this reason, it is essential that universities engage with each other and with diverse, multiple stakeholders in order to overcome the countless local and global challenges. They need to work together, not only across regions but across continents. If not, given the times in which we are living, it will be difficult to maintain a wide perspective,

J. R. de la Fuente $(\bowtie)$

Permanent Representative of Mexico to the United Nations, New York, NY, USA

e-mail: jrfuente1@gmail.com

(C) The Author(s) 2021

H. van't Land et al. (eds.), The Promise of Higher Education,

https://doi.org/10.1007/978-3-030-67245-4_4 
justify its profound reason d'être to foster its leadership role and receive the social recognition needed to effectively play such a role.

The specific socio-economic and cultural context in which universities operate has always been crucial for defining the university role. The context that prevails in society has always been relevant when understanding the role of universities. Currently, we are experiencing low levels of confidence and high levels of anxiety in many regions of the world. Loss of confidence in traditional institutions that have not been up to the expectations of the young produces a feeling of frustration in both students and faculty. While in the past, the mere fact of entering higher education basically ensured that the expectations of the majority were met, students today are not satisfied with being admitted to a university and obtaining a degree. There needs to be something else in the process, an additional social value. A more robust offer is needed. This perception, if correct, bids us to reflect on the role that universities must play today, to become a source of solutions and not of frustration. That is one of the challenges higher education faces.

A stepping-stone in such a direction lies in recognising that universities need to engage in cooperation and partnerships among each other and with other stakeholders. To build their foundations as part of the solution, universities must not only innovate curricula, they must also partner more effectively with the private sector, civil society, government agencies, multilateral institutions, as well as other allies at the local, regional and global levels. They need to succeed to counteract the growing spiral of frustration and to regain and/or strengthen moral authority.

Recognising that partners are needed, and that those partnerships need to be innovative and effective is something that must be fostered. There are examples of institutions that have been able to achieve this, albeit only to some extent. We must look into them in depth and take advantage of their experience. These are the kinds of projects that IAU may emphasise more strongly and share with its membership and beyond.

In addition to multi-stakeholder partnerships, there are also other topics to be considered, which will be relevant for the future of higher education institutions. Particularly important are those relating to innovative cross-sectoral investment. If we consider that quality higher education is both a result as well as a catalyst of economic growth and social progress, then it should be presented as a clear example of sustainable financing. Higher education must become more visible, but its financing must become more transparent as well. Accountability is a theme of general interest and some concern in several countries, not only in Latin America but also in other regions. Universities must be set up to deliver their message with trust and credibility, and I believe that therein lies another challenge.

I will end by mentioning a practical example where universities and university associations are much needed these days: data provision. Universities are usually very good at both data generation and rigorous documentation of facts. This can help overcome many global challenges we face, as a number of decisions made at critical policy levels are unfortunately based on misinformation, as surprising as it sounds. Universities dedicate a lot of effort, resources and time to collecting reliable data, to analysing it and systematising it. As a result, they hold information that no other 
set of institutions or organisations in the world has or can generate. We all must take advantage of this and foster active participation and a true contribution from universities and other higher education institutions to the development of solutions to contemporary problems.

Juan Ramón de la Fuente has been the Permanent Representative of Mexico to the United Nations since February 2019. He has served as Mexico's Minister of Health and as Rector of the National Autonomous University of Mexico (UNAM), also as an Emeritus Professor. Juan Ramón de la Fuente has also worked with UNESCO as a member of the Board for Latin America and the Caribbean on Higher Education, and is a former President of the International Association of Universities (2008-2012).

Open Access This chapter is licensed under the terms of the Creative Commons Attribution 4.0 International License (http://creativecommons.org/licenses/by/4.0/), which permits use, sharing, adaptation, distribution and reproduction in any medium or format, as long as you give appropriate credit to the original author(s) and the source, provide a link to the Creative Commons license and indicate if changes were made.

The images or other third party material in this chapter are included in the chapter's Creative Commons license, unless indicated otherwise in a credit line to the material. If material is not included in the chapter's Creative Commons license and your intended use is not permitted by statutory regulation or exceeds the permitted use, you will need to obtain permission directly from the copyright holder.

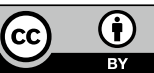




\title{
Drivers of Globalisation of Higher Education over the Last 70 Years
}

\author{
Andrew J. Deeks
}

\section{Introduction}

The 70th anniversary of the International Association of Universities provides an opportunity to look back over the post-World War II era, and to reflect on the drivers that have led to the international higher education environment we experience today. The anniversary also provides an opportunity to look forward and to consider how such a globalised system of universities might contribute to future society.

Since the IAU was set up under the auspices of UNESCO just five years after the end of the Second World War and the establishment of the United Nations, we have seen an explosion in the number of universities, the number of people participating in higher education, and the mobility of faculty and students, all contributing to the development of a truly global university ecosystem.

Many drivers have contributed to this development. This chapter will consider in particular the emergence of English as a lingua franca, the development of cheap and convenient international transport, the globalisation of industry and commerce, the massification of higher education, the development of the internet and social media, and the emergence of international university rankings.

If human society is to have a long-term future, we must work together to address the challenge of creating a sustainable global society. A globalised university ecosystem represents the best opportunity for moving this agenda forward, as universities, ideally, stand outside the political, nationalistic, and religious dogma that influence decision-making and cooperation at state level.

\footnotetext{
A. J. Deeks (凶)

University College Dublin, Dublin, Ireland

e-mail: andrew.deeks@ucd.ie

(C) The Author(s) 2021 


\section{Language}

While scholarship has been associated with civilisations and cultures since the beginning of recorded history, the university tradition and the research culture of free enquiry and open publication of research papers emerged in Europe. Up until the Second World War, scholars typically published in one of the major European languages (here including Russian as a European language). During the war, much of Europe and Russia had suffered great social, economic and infrastructure loss, and in the aftermath went through a decade of rebuilding. The USA, on the other hand, avoided much of this loss and was able to recruit leading European scientists and engineers to exploit the technological advances made by both sides during the war effort. Coupled with a booming economy powered by cheap oil, the USA became the primary driver of the world research effort, and English became the dominant language for publication of research results. By the time European countries were again competitive in the research space, and other regions started paying more attention to research and development, the pre-eminence of English as the language of research and technology had been established. At the same time, the economic strength of the United States, together with economic re-emergence of the UK and the colonial legacy of English use throughout the subcontinent and much of Africa, led to English becoming the lingua franca of global trade and commerce. Consequently, English has also become the dominant language of global education.

Not only are there now more English speakers in the world than there are speakers of any other language, but there are also around twice as many speakers of English as a second language than there are native speakers (Ethnologue 2020). No other language has more second language speakers than first language speakers. There is nothing about English that makes it particularly suitable to be a lingua franca, and that English has emerged to be this lingua franca is an accident of history more than anything else. Nevertheless, the rise of a language which is widely spoken and read by educated people around the world has been a significant driver and enabler of the

globalisation of higher education. Universities around the world who wish to attract students from outside their home country now offer programmes in English and hire faculty who can teach and publish in English.

\section{Transport}

Although intercontinental transport has been with us for centuries, for much of that time, such travel involved significant time and danger. Within the 70 years of the IAU, we have seen a transformation in our ability to travel the world. Over that time, the cost, reach, comfort and safety of air transport have all dramatically improved. From very few commercial flights at the end of the second world war to some 310 million aircraft passengers per year by 1970 , and then to 4.233 billion passengers a year by 2018 (The World Bank 2018), the number of people travelling between 
countries has increased exponentially. Although the COVID-19 pandemic has put a temporary halt to this expansion, the infrastructure and economics of the global aviation system remain intact, and affordable and convenient intercontinental travel is with us to stay.

From a global education perspective, students and their families can easily travel between countries to access higher education, and the cost of travel relative to the overall cost of participating in higher education has become a smaller and smaller consideration.

\section{Globalisation of Industry and Commerce}

The reduction in the cost of transport, not just for passengers, but also for freight, and the increase in convenience and reduction in cost of communication across the world were also enablers of a globalisation of the world economy. Since 1950 the value of exported goods has increased by a factor of more than 30, a compounded annual increase averaging $6 \%$ over the entire period, and the average proportion of country GDP that is exported has moved from under $10 \%$ in 1950 to over $25 \%$ now (OrtizOspina and Beltekian 2018). Even these figures do not fully capture the massive change which has occurred, as the increase in GDP around the world over this time has been increasing, driven by growth in the service sector. In most countries, the manufacturing sector has dramatically decreased as a proportion of GDP since 1950 . Globalisation of manufacturing has dramatically decreased the cost of products to the consumer and reduced the proportion of people employed in the production of goods. However, the global logistics industry associated with moving manufactured and agricultural goods around the world has grown accordingly, while improved communication and decreased cost of travel has meant that the service sector is also increasingly globalised.

Associated with this globalisation has been the rise of major multinational companies, particularly in the resource sector, the technology sector and certain parts of the services sector. Increasingly, these companies recruit employees globally, and they are looking for graduates with a global view and international experience. Students see that taking part of their higher education outside their home country provides an advantage when seeking employment with these multinational companies. For their part, the multinational companies have an interest in engaging with higher education institutions so they can access quality graduates with an understanding of their home market.

These multinational companies are also keen to tap into the research being done at universities around the world and can play the role of a catalyst in bringing together research teams from different universities spread across different countries. In addition, domestic companies looking for opportunities abroad may be keen to engage with universities to identify students from their target markets for potential graduate employment. 


\section{Massification of Higher Education}

In 1950, just $3.4 \%$ of young people in the UK went on to higher education. That number has now increased to around 50\% (Department of Education 2019). This growth in higher education participation is reflected around the world. As mechanisation and the growth of digital technology has reduced the number of jobs available to those with lower levels of education, and improving income levels have allowed families to keep children in education longer, the number of children completing primary school, secondary school, and now higher education has increased dramatically over these seventy years.

Despite this increase in the participation rate, the preparation and ability of the incoming students remain similar, and the level of achievement of graduates has been maintained. However, in a competitive job market, many students look for opportunities to make themselves stand out from the crowd. Undertaking studies abroad is one way students can do this. If they come from a non-English-speaking country, studying abroad in an institution or country where English is spoken provides a way of distinguishing oneself, while also building English skills.

At the same time, the massification of the higher education system has placed increased strain on the government funding of higher education. While governments could generally afford the costs of educating 3.4\% of their population to undergraduate degree level, as participation levels approached (and in some cases exceeded) $50 \%$, many governments found it necessary to cut the support they were giving to universities and to increase the financial burden carried by the students. For political reasons, most governments prescribe or cap the amount paid by domestic students towards their education, while at the same time fixing state funding. However, many governments allow universities to set their own international student fees, so international students are often charged a fee that provides the university with a premium over and above the cost of providing the education.

Consequently, the massification of higher education has generated incentives for students to undertake studies outside of their home country, and for universities to recruit students from outside their home country. The provision of higher education services to students who wish to study abroad has become a significant industry, one which has contributed to the globalisation of higher education.

\section{The Internet and Social Media}

The development of the internet and the worldwide web, together with fixed and mobile data services spanning the world, has greatly raised awareness of opportunities to travel to other places and to undertake studies at universities in other countries. Coupled with the widespread use of English on websites, students can explore the many opportunities available to them with an ease that would have been unthinkable before these developments. 
Social media allows students who are undertaking studies abroad to remain in touch with their friends and families and to share their experiences with other students who might be considering studying abroad. Video conferencing and messaging services mean that students studying abroad can stay in touch with their loved ones and friends in a very intimate way, and so the fear of loneliness and losing the connection that once existed is mitigated.

From a research perspective, the internet allows researchers from around the world to collaborate and share results with an immediacy which was not previously possible and allows widespread and convenient access to research papers, particularly those written in English. Prospective research students can easily identify the leaders in a field they are interested in and contact those people directly to seek opportunities to undertake studies under their supervision, no matter what part of the world they might be resident in. This connectivity also facilitates the mobility of researchers and faculty, and the organisation of international meetings and conferences, which consequently have become much more numerous in recent times.

The internet and widespread availability of connection to it have therefore driven globalisation of higher education over this period, increasing the diversity of faculty at universities around the world and increasing the number of students studying outside their home country. It has also improved the experience of those involved in this mobility, allowing them to stay connected to their home communities.

\section{Rankings}

Although relatively recent in their establishment (the Academic Ranking of World Universities was established in 2003), world rankings of universities have had a dramatic impact on the global higher education environment. Prior to the establishment and popularisation of these rankings, universities generally looked to other universities in their geographic location as comparators, while prospective students selected universities based on their historical reputations. The international student market in some regions allowed some movers to present themselves at a level which their domestic reputation would not have supported.

By purporting to rank universities in an order which represented the 'best', rankings were quickly seized on by prospective students and parents as an easy way of comparing universities. They also became a benchmark for prospective faculty weighing up employment options. Because of the potential impacts of these phenomena, but also because the ranking brought out the competitive spirit in university leadership, alumni and stakeholders, rankings quickly became an obsession, not just for universities, but also for governments.

While there are now a number of rankings that have a global impact, each of these rankings uses basically the same metrics, albeit with differences in weights: measures of research productivity and impact; student: faculty ratio; proportion of international students; proportion of international faculty; engagement with industry/industry funding; and reputation amongst academics and employers globally. 
The nature of the metrics is such that the global visibility and reach of a university is one dominant factor in ranking performance, while another is research performance, where research performance is measured primarily through the number of publications in 'international' English language journals and the number of citations by other authors in the same journal set.

Rankings incentivise universities to benchmark themselves against similar universities around the world, recruit the best faculty from around the world (with research performance being the primary criteria), increase their number of international students, and increase their visibility in all regions of the world. The desire to increase visibility has led many universities to increase their participation in international university networks and to establish more bilateral institutional partnerships.

From a globalisation perspective, the increased engagement of universities globally has led to increased opportunities for student and employee mobility and increased visibility of and support for those opportunities. The rankings' use of citations metrics and reputation surveys weighted in favour of reputation outside a university's home country have increased institution support for collaboration undertaken between research groups based in different countries. Combined with the greater awareness brought about by the internet and the increased ease and reduced expense of travelling between countries, international research collaboration has flourished.

Of course, the rise of rankings has caused problems too. By their nature, the rankings incentivise all universities to pursue the same goals (and in many cases the same professors), driving universities towards the comprehensive research-intensive model. Many argue that national interests are better served with a tiered higher education system, and having universities competing against each other for global rankings that are not linked to national goals, or indeed the personal goals of the students, may be counterproductive.

Nevertheless, the perceived prestige of having universities ranked in the top 100 in the world has incentivised many national governments to invest additional funding into targeted institutions in order to improve their ranking. This is often positive from the perspective of bringing additional money into the institutions, particularly money to support research. However, reporting requirements imposed by these governments may also lead to the university leadership adopting a very narrow focus and losing sight of the broader role a university should play in its community and national contexts.

\section{Recent Setbacks}

From the sixties through to the first decade of this century, there was a continuous increase in the level of globalisation of national economies, leading to increases in average material well-being of people around the world, higher participation rates in higher education and greater mobility of university students and faculty.

The Global Economic Crisis of 2008 and the recession that followed triggered a decade of questioning of the value of globalisation and a resurgence of national- 
ism. When recession hit, people noticed the number of jobs that had disappeared in manufacturing and the number of national industries that had been lost as a result of cheaper imported products, and some blamed globalisation for their economic situation. In doing so, they forgot about the prosperity globalisation had brought, which they had come to take for granted.

National politics in many countries have pandered to this push-back against globalisation, leading to an increased division between those who understand the benefits of globalisation and those who see it as a threat. However, as nationalist forces have come into power in some countries, the futility of trying to reverse globalisation is becoming increasingly clear. Politicians have to change the story-Brexit moved from being an anti-immigration, anti-Europe campaign to stop free movement of people into the country and to invest money 'sent to Europe' back into the national economy (the basis on which the referendum was fought) into a new 'Global UK' story where the UK will be a champion of world free trade.

The 2020 COVID-19 pandemic has illustrated the extent to which we now live in a single global society, as within three months of first being recognised, the novel coronavirus was spread throughout the globe by the global mobility of the world population. The pandemic has also brought challenges to globalisation as this mobility is drastically reduced and as economies have been shut down in a bid to tackle the virus. While temporarily halting the face-to-face interactions on which relationships are based, the loss of mobility has not reduced other aspects of globalisation in any significant way. Digital communications technology allows education and research to continue in partnerships which are now maintained at a distance, while global supply lines continue to function to deliver food, medical supplies and other goods and services to consumers around the world. The long term effect of the pandemic on the cost and convenience of international travel has yet to become clear, but given that the infrastructure remains in place and there are sufficient skilled workers for the industry, it is likely that once international travel can again be undertaken without public health concerns, the industry should bounce back quickly.

\section{The Future-Addressing Global Challenges Together}

The globalisation of industry and commerce has been built on the back of cheaper transport of goods and people, together with ubiquitous communication and information technology systems. Building, operating and maintaining the infrastructure which underpins these enablers currently relies on exploiting the mineral resources of the Earth (primarily metals, oil and gas). Developing technologies that have allowed the extraction of these resources from greater depths and from lower grade deposits than was previously possible, has, to this point in time, avoided a shortage of these resources. However, such technologies require greater amounts of energy to be invested in the extraction, and most of this energy is currently supplied by fossil fuels. Similarly, we can feed the increasing population of the Earth largely because agricultural technologies are allowing us to get greater yield from farmland, and 
to bring into use land which was previously unsuitable for agricultural purposes. Again, the cost of this increased productivity is more energy invested per $\mathrm{kg}$ of food produced, with most of this energy currently coming from fossil fuels.

As mineral resources are unequally distributed between nations, the reliance of our global society on these resources generates fundamental inequities in the distribution of wealth throughout the world, which is reflected in inequality of educational and health outcomes. Coupled with competing political and religious ideologies, this sets the stage for intranational and international conflicts of various types.

It is by nations recognising that we can only achieve a sustainable future through addressing these global challenges together that we can continue to flourish as a society. In a globalised world, universities are ideally positioned to lead this agenda, as, within universities facts, data and ideas are put ahead of political, nationalistic and religious dogma, and colleagues from different cultural backgrounds work together with a common purpose. These universities also educate the leaders of the future, and we have the opportunity to educate these leaders to understand the responsibility they will have to work together with other leaders of their generation to advance the creation of a sustainable, healthy and equitable global society.

Higher education has come a long way in the last 70 years, and we are now part of a truly global higher education ecosystem. We are uniquely positioned to contribute to the building of a global human society which is sustainable and equitable, and which promotes the health and well-being of all members of this society, and the International Association of Universities provides a vehicle through which our contributions can be coordinated.

\section{References}

Department of Education. (2019). Participation rates in higher education. Retrieved from: www.gov.uk/government/statistics/participation-rates-in-higher-education-2006-to-2018 (13.07.2020)

Ethnologue. (2020). What is the most spoken language?. Retrieved from: www.ethnologue.com/ guides/most-spoken-languages. (13.07.2020)

Ortiz-Ospina, E., \& Beltekian, D. (2018).Trade and globalization. Our World in Data. Retrieved from: https://ourworldindata.org/trade-and-globalization (13.07.2020)

The World Bank. (2018). Air transport, passengers carried. Retrieved from: https://data.worldbank. org/indicator/IS.AIR.PSGR (13.07.2020)

Andrew J. Deeks has been the President of University College Dublin since January 2014. He is a member of the Administrative Board of the International Association of Universities, a member of the Executive Committee of Universitas 21, and a Council member of both the European Universities Association and the Irish Universities Association. He is a Fellow of the Irish Academy of Engineering, the Institution of Engineers Ireland and the Institution of Engineers Australia. 
Open Access This chapter is licensed under the terms of the Creative Commons Attribution 4.0 International License (http://creativecommons.org/licenses/by/4.0/), which permits use, sharing, adaptation, distribution and reproduction in any medium or format, as long as you give appropriate credit to the original author(s) and the source, provide a link to the Creative Commons license and indicate if changes were made.

The images or other third party material in this chapter are included in the chapter's Creative Commons license, unless indicated otherwise in a credit line to the material. If material is not included in the chapter's Creative Commons license and your intended use is not permitted by statutory regulation or exceeds the permitted use, you will need to obtain permission directly from the copyright holder. 


\title{
A Personal View on Two Decades of Recent IAU History
}

\author{
Eva Egron-Polak
}

It is customary to share the successes and joys with those who are celebrating an anniversary. Looking back at my own relatively long history with the IAU, I am tempted to do the same. Yet, there were both highs and lows during these nearly two decades, and a sense of satisfaction with achievements was often coupled with frustration as well. Despite these sentiments, I, and nearly all the leaders of the IAU, continue to share an unwavering belief that if the association did not exist, it would be invented. This is so, not only because there is a real need for such an organization, but also because of what IAU has contributed to the world of higher education over the seven decades it has existed. My brief note will highlight some of these sources of satisfaction and share the obstacles and difficulties encountered along the way as well.

\section{Serendipity}

International relations among nations are complex, delicate, and not always logical or easily understood. The fact that Canada is part of the Europe Region within the UN system, a quirk in history and a lucky break for me, as the first among several factors that led me to become involved with the International Association of Universities. Eventually becoming its Secretary-General in 2002. Working for what is now known as Universities Canada, in the mid-1980s I joined a network of higher education representatives from the Europe Region who regularly met within the framework of UNESCO's regional office for higher education in Europe-CEPES. In the context of these meetings, that in large part focused on facilitating collaboration among

E. Egron-Polak $(\varangle)$

International Association of Universities, Paris, France

e-mail: e.egronpolak@gmail.com 
universities in a Europe (defined broadly) still divided by the Cold War, I became familiar with the IAU. It was often the only Non-Governmental Organisation (NGO) that regularly participated in these meetings. During these discussions, I realized that IAU acted as an essential bridge spanning gaps and working to overcome the various barriers that prevented cooperation in higher education between East, West, North, and South-divides that largely characterized the world in the 1980s.

\section{IAU Often Avant-Garde}

During this time, and thus just prior to the full implementation of the ERASMUS program in Europe and its commitment to easing the recognition of credits, as well as the Council of Europe and UNESCO Lisbon Recognition Convention, the IAU was spearheading an international project-TRACE_-designed to make information about higher education institutions and credentials worldwide available to all. The project, in part supported by UNESCO, proposed a technology-based, decentralized data entry system which, by using a standardized and agreed-upon structure, would make the data comparable. The goals of this project were to facilitate information sharing for recognition purposes, to ensure that only bona fide information was included and to promote collaboration on a level playing field among the world's universities. With hindsight, the TRACE project was simply too ahead of its time in terms of technological capacity and too poorly financed to overcome the multitude of obstacles. Predating widespread use of the internet, Google, and other search engines, but led by visionary practitioners from North America and Europe, it never came to fruition. For me, however, as the Canadian member of the initial voluntary team that steered this initiative for more than two years, it was a direct introduction to the ideals for which IAU stands - a global collaborative effort, facilitating and promoting international cooperation and mobility, committed to being inclusive, adhering to the principle that free access to accurate information is an essential basis of inter-institutional cooperation in higher education and a strong conviction that universities need to be in the driving seat of any such initiative.

I became a fan of the IAU and was very grateful to be offered an opportunity to join its Secretariat in Paris from 1996 to 1998 as Director of Cooperation while on a two-year leave of absence from Universities Canada. This experience, a kind of wishful prequel to my eventual appointment as Secretary-General in 2002, confirmed my view that IAU had huge potential to be an even greater positive force within the global higher education landscape.

\section{A Unique Vantage Point}

This direct experience truly opened my eyes to the global and diverse nature of the IAU membership, and the diversity of higher education systems and institutions 
worldwide. It was my role to increase membership by identifying services that the IAU could provide while positioning the Association more firmly as a global platform for networking and collective advocacy in the interests of higher education. This was the run-up to the first UNESCO World Conference on Higher Education (WCHE) held in 1998, and IAU worked hard to play a constructive role in this watershed event on behalf of higher education institutions. In preparation for the WCHE, an IAU working group drafted a policy statement on Institutional Autonomy, Academic Freedom and Social Responsibility. I was invited to join the UNESCO Working Group preparing the program of the WCHE as well, and even more importantly, became one of only two NGO representatives to join the Drafting Group for the final WCHE 1998 Declaration. This WCHE remains, until today, a global milestone in the history of higher education, and its values enshrined in the WCHE Declaration and Action Plan were both ambitious and inspiring.

The IAU input to the WCHE Declaration focused on issues such as higher education as a public good, access based on merit but taking into consideration each learners' circumstances, equity, academic freedom, and autonomy as well as other topics of importance to universities. Together with the representative of Education International (EI), we often faced fierce opposition from representatives of ministries of higher education from around the world who represented the bulk of the Drafting Committee. But having IAU and IE at the table was an important recognition that universities and their staff members were essential partners in the design of the future of higher education. Unfortunately, though many argued for the presence of students, they were absent from the Drafting Group, though present and active in the conference.

In the 1990s, the global governance of higher education was not really on anyone's mind, or indeed in anyone's interest at that time. Yet, given the challenges of the moment - the recent end of the Cold War and rapid privatization of higher education especially in East and Central Europe; concerns over the quality of higher education in an era of rapid massification; more and more preoccupation with the Brain Drain facilitated by the ease of travel and growing competition for the best brains; the creation of new European programs to promote mobility, and many other developments - speaking with one voice, expressing concerns or demands for certain policies, defending key principles that universities around the world cherish was needed. It was the role that IAU, in collaboration with other associations, wanted to play. A role it had been created to play 70 years before.

\section{A Unique Frame of Reference}

Armed with prior experiences both in Canada and the IAU, assuming the position of Secretary General should not have had any secrets for me and, though I knew it would be demanding and challenging, I thought that I was ready for the reality in which IAU operates daily. I had already experienced the complexity of issues that higher education institutions were facing in a rapidly changing world; the diversity of their 
points of view; the vastly different circumstances in which IAU members operate; the personalities and agendas of the actors with whom IAU interacts; the distance, language and cultural barriers as well as the incredible shortage of resources-both human and financial-at the secretariat.

What I had not anticipated and what in my view is most important is the IAU's unique frame of reference-it is global, and to serve its membership and the interests of higher education worldwide, it is not pertinent to use any single anchoring point of view. When working for a single institution of higher education, a national association or system, it is natural to use it as the frame of reference for comparisons, for the identification of strengths and weaknesses. Joining IAU, assuming its global perspective, meant that this safety was pulled away. I became highly sensitive to the continuous need to balance the voices, preferences, and demands of strong universities in powerful nations with the needs, interests, and contributions of newer universities often in developing or emerging systems. In fact, the very notion of what constitutes a university was a frequent and hotly contested debate during numerous IAU Board meetings and conferences, as there was no global consensus around the table, or around the world.

A second challenging aspect for the mission of the IAU, and thus for me as Secretary-General, had to do with identifying what matters most for the Members; what is impacting their institutions, and what unique service IAU could offer that would be useful. This may sound simple, but on the one hand, the list of issues was always very long, and on the other hand, given the point above, the list was also quite diverse. However, as globalization continued its advance and the level of interconnectedness between nations deepened in all domains, it became clear that in different ways, most changes experienced in one higher education system were quickly felt by most others. What differed and continues to differ today, as well, is the capacity to respond and to implement solutions that serve institutional, local, and national needs.

The last couple of decades are full of examples of how institutions and policymakers mimicked what was taking place elsewhere, whether it was suitable or desirable in their context or not. The IAU was expected to address these issues, to adopt a position, though just about every time, the actual response in terms of action could only take place at the local level. To cite merely a few examples, public funding for universities, of course, features near the top of the list. For most of the recent years, public funding for higher education was decreasing in most nations around the world if per student funding is considered, but the capacity and ideological or political acceptance to replace the lost funds by revenue from private sources different greatly from nation to nation and continues to be a source of hot debate. As the IAU does not operate at the national level, the Association could only offer strong, international support for a position that valued public responsibility and support (including financial) for higher education above that of the market.

Another example of trends that swept across the global landscape regardless of the state of higher education was the love affair with 'world classness' for universities and the related 'excellence' initiatives that many countries adopted. This trend also saw its heyday during the last two decades and to a large extent owes its conceptual origin in 
the various international rankings that began to become the barometer for excellence, especially for decision-makers. Again, the relevance of seeking to climb the rankings and to meet the criteria that would enable institutions to be considered 'world class', mattered relatively little in this race, though it had a major impact (often negative) on institutions and systems, and was lived as a burden by many higher education leaders within the IAU family of universities. The IAU continuously argued that rankings were not only an incomplete measure of quality but that furthermore, their impact could harm the quality of higher education systems by concentrating support on only a few universities, leaving others impoverished.

The two first decades of the 21st century, which coincided more or less with my direct experience in leading the IAU, were an era when many other trends were felt in all universities around the world - the pressure to be more international; the potential to expand or improve in various ways by using technology; the growing preoccupation with social responsibility which, in some ways included concern with equity and inclusion; but also the requirement to justify the economic utility of universities to society and individuals in terms of employability; the growing consciousness of the demands of sustainable development and the recognition that higher education was a critical actor for change in this regard, yet a growing disenchantment with universities, with expertise, with scientific knowledge in many quarters.

These were indeed the central themes that IAU addressed with policy statements, conferences, research projects based on data that IAU gathered from its membership and through partnerships and collaborations with other groups.

In all of this, IAU remained and is today still deeply rooted in its initial values. Though at times this has brought criticism of a lack of pragmatism, too much idealism, and even naivete, it is also the reason why IAU inspires loyalty-from Board members, from the staff of the secretariat and from all institutional representatives who get directly involved in the work of the association.

Despite all of this, the value and purpose of the IAU are not obvious to everyone. Those who represent the IAU are often asked why a university should join the IAU. This is not, and never will be, an easy question to answer. We can enumerate and recite the activities and services that the association offers, but these cannot be quantified or justified in Euros or Dollars. The work of the IAU is, in my view, a great example of a Common Good-it serves the collective interests of higher education and all of the members of the global community benefit. Furthermore, the benefits are felt long-term and indirectly, but they are nevertheless real.

If understood in this way, it is not difficult to see why the Association continues to flourish after 70 years and why, if it did not exist, it would be invented today by some visionary and idealistic higher education leaders. I was honoured to have had the opportunity to work with and learn from many such visionary leaders over the years, and to devote almost two decades to successfully bring IAU closer towards its 70 th year. I know it has at least another 70 glorious years ahead of it. 
Eva Egron-Polak was Secretary General of the International Association of Universities from 2002 until 2017. Prior to becoming IAU Secretary General, she worked for nearly two decades at Universities Canada, holding various positions including that of Vice President, International. She is a member of many Boards and international advisory committees of organizations such as the Magna Charta Observatory, the Global Access to Postsecondary Education initiative, the Global Centre for Higher Education, StudyPortal and the University of Granada. She is Senior Fellow of the IAU.

Open Access This chapter is licensed under the terms of the Creative Commons Attribution 4.0 International License (http://creativecommons.org/licenses/by/4.0/), which permits use, sharing, adaptation, distribution and reproduction in any medium or format, as long as you give appropriate credit to the original author(s) and the source, provide a link to the Creative Commons license and indicate if changes were made.

The images or other third party material in this chapter are included in the chapter's Creative Commons license, unless indicated otherwise in a credit line to the material. If material is not included in the chapter's Creative Commons license and your intended use is not permitted by statutory regulation or exceeds the permitted use, you will need to obtain permission directly from the copyright holder. 


\title{
IAU President Walter Kamba (1990-1995): A Man of Conscience
}

\author{
Goolam Mohamedbhai
}

\section{First Encounter}

In June 1983, I participated, as representative of the University of Mauritius, in a training course on improving teaching and learning for academics from different African universities. It took place at the Roma campus of the National University of Lesotho. One afternoon, we were introduced to a distinguished guest speaker, Professor Walter Kamba, Vice-Chancellor of the University of Zimbabwe. He happened then to be visiting the university, and the organisers invited him to talk to us. Professor Kamba spoke, not about teaching and learning, but about the vital role African universities have to play in the continent's development, an issue that was highly topical at that time. His lengthy speech, delivered off-the-cuff, was remarkable and passionate. He was a formidable orator, and we were all enthralled. He left a lasting impression on me. Little did I know then that, seven years later, he would be the President of the International Association of Universities (IAU), and that I would follow in his footsteps some ten years after him.

\section{Early Years and Exile}

Walter Kamba was born in 1931 in the British colony of Southern Rhodesia. He went to study Law at the University of Cape Town in South Africa and then returned to Southern Rhodesia where he was one of the few black legal practitioners to the High Court. However, when a Universal Declaration of Independence was issued in 1965 in Southern Rhodesia, he fled the country with his family and went to the UK. He subsequently joined the Faculty of Law at the University of Dundee, Scotland, as

\footnotetext{
G. Mohamedbhai ( $\square)$

International Association of Universities, Paris, France

e-mail: g_t_mobhai@yahoo.co.uk 
Lecturer and spent over eleven years there as an academic, eventually even serving as Dean of Faculty. It was no doubt at the University of Dundee that he developed an appreciation of institutional autonomy and academic freedom in universities, values which guided him throughout the rest of his academic career. In 1982, in recognition of his outstanding contributions, the University of Dundee awarded him an honorary doctorate.

\section{Return to Zimbabwe}

Although he had a successful academic career at the University of Dundee, his heart was in Southern Rhodesia and, from the UK, he constantly followed the political developments there. Subsequently, he was closely involved as a legal adviser to the black nationalist movements in the preparations of his country's independence and even participated in the Lancaster House Conference in London, following which, in 1980, Southern Rhodesia became independent and was named Zimbabwe, and Robert Mugabe was elected its Prime Minister.

Walter Kamba then returned to Zimbabwe in 1980 and took up the position of Professor of Law at the re-named University of Zimbabwe, formerly University of Rhodesia. The following year, he was appointed Vice-Chancellor of the university, the first black academic to take up such a position at that institution.

\section{Vice-Chancellor}

By all accounts, the first five years of Walter Kamba's tenure as Vice-Chancellor were successful. He managed to significantly expand the university, both in terms of increasing student enrollment, especially black Zimbabweans, and the range of courses offered, and bring about positive transformation. He was fair and consultative, and his leadership was appreciated by staff, students and also the government. He realised that the success of a developmental university in the context of a nascent, independent African country needed understanding and close communication between university and government. In a paper he wrote in 1985 for the National University of Lesotho, he expounded his views on the need for compromise between university and government with regard to institutional autonomy and academic freedom (Kamba 1985). Here are some excerpts:

"The development of the university is dependent on the support of those who work in it and on the availability of resources from the government. If the university accepts that university autonomy and academic freedom can only be perceived in the socio-economic context in which it operates, and that it depends on the goodwill of the nation and the sense of responsibility of the academic staff; if the government accepts that the university needs a certain amount of autonomy to carry out its mission effectively and efficiently, then there need not be a conflict between national 
aspirations and academic integrity. Any unbridled provincialism on the part of the university is as threatening to public and national interest, as is the desire of the state to police the university for the sake of control itself. Put differently, some state control is inescapable just as some substantial degree of institutional autonomy is indispensable. This is a balance which needs to be worked at, all the time. The task is to develop consultative relationships that bring the legitimate concerns of the university and the legitimate concerns of government into shared perspectives." These words of wisdom and guidance are remarkable and relevant to public universities in Africa even today. However, by his reference to 'unbridled provincialism on the part of the university', and the 'desire of the state to police the university', one can sense his uneasiness and his intuition that a storm was gathering on his campus.

\section{University Autonomy Threatened}

Indeed, soon after, the situation at the University of Zimbabwe started to deteriorate, to a large extent resulting from the ethnic strife, economic decline, dividing politics and corruption in the country. Walter Kamba himself openly acknowledged in a speech that there had been serious problems during the last few years of his tenure. In 1988, the students of the University of Zimbabwe decided to hold a demonstration on campus to protest against an alleged corruption scandal involving government officials (Magasia 2015). The government sent in anti-riot police to the campus to block that demonstration. A year later, in 1989, the students planned to hold a public seminar to commemorate the events of 1988. The government issued a ban on the seminar and sent in the police to the campus, which led to the arrest of some student leaders and even those who openly supported the students. The students retaliated and decided to boycott lectures, and this eventually resulted in the closure of the university.

The worst was to come in the following year. In order to have greater control over the university, in 1990 the government legislated to amend the 1982 University of Zimbabwe Act. The main amendments aimed at authorising the President, instead of the University Council, to appoint the Vice-Chancellor; at significantly increasing the number of government-appointed members on the University Council; and at assigning powers to the Vice-Chancellor to expel or suspend students, dissolve or suspend the Students' Union and prohibit or suspend any of the Union's activities. Both students and academics, including Walter Kamba, vehemently protested against the amendments which were clearly meant to undermine the University's autonomy, but their voices went unheeded.

It was in that same year that Walter Kamba was elected President of IAU for the period 1990-1995. He was the first President from an African country since the creation of the association in 1950 . 


\section{Graduation Ceremony Speech}

Walter Kamba now faced a dilemma. He was President of IAU, an international organisation that had a strong commitment to university autonomy and academic freedom, in which he staunchly believed, and yet, the university he headed was taking steps to flout the very same principles. As a lawyer, he knew that he would, sooner or later, be forced to implement the amended legislation of his university. He must have realised that he had no option but to leave.

At the 1991 Graduation Ceremony of the University, in the presence of President Robert Mugabe, the University's Chancellor, Walter Kamba made the following audacious remarks in his welcome address and announced his departure (NORRAG 1991).

"Your Excellency and Chancellor, there are too many fingers in the affairs of the University - non-professional fingers with a wide range of agenda. I accept that we live in times in which the only constant variable is change. But for me, professionalism is at the heart of academia. I was appointed purely and entirely for my professionalism. I am a professional at heart, I am a professional by experience, dedication and commitment. I have never and will never play games... In September this year, I will be submitting my notice of retirement as Vice-Chancellor of the University of Zimbabwe."

Kamba's message to President Mugabe was clear: he was not prepared to accept political interference which would undermine the University's autonomy. Earlier in the same speech, he also hinted at the threat to academic freedom on campus:

"I am convinced that intellectual enquiry and excellence will flourish in an environment that encourages dialogue, tolerance and humility. Fear to criticise is not only inimical to free scientific inquiry but also to creativity. For this reason, it is the obligation of the University to restore faith in rational and informed disputation."

There had been reports that there were political spies lurking on campus and present even during lectures, and they would report to authorities what was being discussed, by whom and what events were being planned. Staff and students were, therefore, afraid to openly discuss issues on campus. No doubt this was the reason why Walter Kamba made reference to 'fear to criticise' in his speech.

One could argue that Walter Kamba should have stayed on and, using his influence in Zimbabwe and elsewhere, especially as he then held the distinguished position of IAU President, try to improve the University's situation. But Kamba must have known that his efforts would be futile. He was undoubtedly aware that Mugabe had become very powerful in Zimbabwe and was utilising his notorious infantry "5th Brigade" to crush any insurgency. As a man of conscience, he could not continue.

At the end of his Graduation Ceremony speech, he made the following iconic statement:

"Whatever I do, my conscience is my master. When my epitaph comes to be written, I will be satisfied if the inscription reads: Here lies a man whose master was his own conscience." 


\section{University of Zimbabwe Post-Kamba}

During most of the 1990s following Walter Kamba's departure, student protests increased at the University of Zimbabwe, resulting in student arrests, campus closures and mass expulsions. The situation became worse after 2000 with the approach of presidential elections in 2002. Perhaps the most extreme example of loss of institutional autonomy at the University of Zimbabwe was the award in 2014 of a doctorate degree in sociology to Grace Mugabe, the President's wife, only two months after she had registered on the programme. Other senior members of Robert Mugabe's regime were also believed to have been awarded doctorate degrees without the submission of any dissertation. This became the rallying cause of campus protests in 2017 when the students refused to sit for their examinations until Grace Mugabe's Ph.D. had been revoked, and Robert Mugabe had resigned as President.

The protests had, for once, a direct impact and soon led to the resignation of Mugabe in November 2017. The students of the University of Zimbabwe have been hailed as being the ones who finally succeeded in pushing Mugabe to resign, thus ending his reign of 37 years. He died two years later at the age of 95 .

\section{Later Years}

After leaving the University of Zimbabwe, Walter Kamba moved to the University of Namibia where he set up the Faculty of Law and was Professor of Human Rights and the founding Dean of the Faculty. But he continued to be of service to his country and the University of Zimbabwe, and he was assigned several important assignments. For example, in 1999 he was appointed Vice-Chairman of the Constitutional Commission, set up with Mugabe's agreement, to advise on a process for Mugabe's retirement; the Commission's proposals, however, were never implemented. And until his death, he was the Herbert Chitepo UNESCO Professor of Human Rights, Democracy, Peace and Governance at the University of Zimbabwe.

Professor Walter Kamba passed away in 2007 at the age of 75 after a long illness. At that time, I was President of IAU, having been elected in 2004, and I became the second IAU President from a university in Africa.

\section{IAU and Academic Freedom/ University Autonomy}

Academic freedom and university autonomy, values that were so dear to Walter Kamba, are principles on which the IAU was founded in 1950. In 1998, on the occasion of the UNESCO World Conference on Higher Education, the IAU published a comprehensive Policy Statement on 'Academic Freedom, University Autonomy and Social Responsibility'. 
Twenty years later, these values remain pertinent to the IAU. In the 'In Focus' section of the January 2018 issue of its magazine 'IAU Horizons', the IAU published the views of seventeen international authors covering higher education systems in countries from almost all regions of the world on whether academic freedom and university autonomy were under threat. Their reflections appear to indicate that while the understanding and prevalence of academic freedom and university autonomy vary from region to region, generally, these principles are currently under threat in most countries.

\section{University Autonomy in Africa}

With regard to Africa, there has hardly been any improvement in university autonomy. In many African countries, the executive head of the public university is still directly appointed by the government; there is heavy representation of government on the university's governing Council, and the responsible minister can give directives to the Council which the latter has to implement. Also, many African universities are experiencing political infiltration of their students' union. One can hardly expect university autonomy to thrive in such conditions.

This situation is, no doubt, a consequence of the state of democracy in Africa. According to the 2019 democratic index of the Economist Intelligence Unit, $50 \%$ of African countries have an authoritarian regime and, generally, democracy has been declining on the African continent.

African universities have a role to play in promoting democracy in Africa and in helping to achieve university autonomy. However, for this to happen, both the countries and the universities need to have committed and honest leaders who have a conscience, men and women of the mettle of Walter Kamba.

\section{References}

Kamba, W. (1985). The Response of Institutions of Higher Learning to Africa's Rapidly Deteriorating Social and Economic Conditions. ISAS Occasional Paper No. 2, Institute of Southern African Studies, National University of Lesotho. Retrieved from: https://core.ac.uk/download/ pdf/29136835.pdf (17.03.2020).

Magasia, A. T. (2015). How Mugabe strangled the students' movement in Zimbabwe (Part 2). Retrieved from: https://nehandaradio.com/2015/10/28/how-mugabe-strangled-the-studentsmovement-in-zimbabwe-part-2/ (17.03.2020)

NORRAG News. (1991). Excerpts from the Address of Welcome, Graduation Day, University of Zimbabwe. 1 July 1991 by Walter Kamba, Vice-Chancellor. Retrieved from: www.norrag.org/ fileadmin/Full\%20Versions/NN11.pdf (17.03.2020) 
Goolam Mohamedbhai is former secretary-general of the Association of African Universities, the former president of the International Association of Universities, the former vice-chancellor of the University of Mauritius and a former member and vice-chair of the governing council of the United Nations University. He is currently a member of the Board of the University World News (Africa). His main interest is African higher education about which he has written and spoken widely.

Open Access This chapter is licensed under the terms of the Creative Commons Attribution 4.0 International License (http://creativecommons.org/licenses/by/4.0/), which permits use, sharing, adaptation, distribution and reproduction in any medium or format, as long as you give appropriate credit to the original author(s) and the source, provide a link to the Creative Commons license and indicate if changes were made.

The images or other third party material in this chapter are included in the chapter's Creative Commons license, unless indicated otherwise in a credit line to the material. If material is not included in the chapter's Creative Commons license and your intended use is not permitted by statutory regulation or exceeds the permitted use, you will need to obtain permission directly from the copyright holder. 


\title{
Between Global Inequalities and World Ethics. Personal Reflections on Internationalisation of Higher Education over the Past Seventy Years
}

\author{
Pavel Zgaga
}

When the IAU was founded on 9 December 1950, I had just been conceived. We "met" each other only in the 1990s, but I think it is fair to say that the IAU's seventy years are, in a sense, also my almost seventy years. We both share one aspect of this historical period: the IAU at the macro-level and I at the micro-level. There is no doubt that we are of the same generation.

Until years and experiences are gathered, people look with hope and great expectations at the many paths that will open up before them. But as the years go by, opportunities for reflection and rethinking gradually open up. This is why, on the occasion of the 70th anniversary of such a prestigious association as the IAU, I cannot help but reflect on the time that lies behind us and focus, at least on some points, on the hopes and perspectives: not those of half a century ago, but those we have to face today.

So how has the stream of internationalisation of higher education progressed over this long period, how have we been rowing in it, have we ever got lost in the side arms of the river, how far have we finally come, and what challenges do we now face in choosing a further path? These many questions, however, must be answered in short.

I look at these questions first from the perspective of the micro-level. The generation born around 1950 was referred to as the "baby boomers". It is the generation that personally did not experience the cruellest period in history; and since experience is always the limiting factor, this generation was free to face the inherited situation without prejudice. It is the generation that enrolled in universities in the second half of the 1960s-and soon wrote the graffiti May 1968 on the walls of university history.

From a macro-level perspective, this period corresponded to the "growing up" of the IAU and similar associations and organisations. The revival of endangered cul-

P. Zgaga ( $ه)$

University of Ljubljana, Ljubljana, Slovenia

e-mail: Pavel.Zgaga@guest.arnes.si

(C) The Author(s) 2021

H. van't Land et al. (eds.), The Promise of Higher Education,

https://doi.org/10.1007/978-3-030-67245-4_8 
tural values and the severe destruction of civilisation in the Second World War also placed new demands on the mission of universities on a global scale. The advancement of knowledge in research and its dissemination through teaching and learning, regardless of linguistic, cultural, geographical and other differences, was a fundamental principle of the Enlightenment of both ancient and modern civilisations. However, in the harsh first half of the twentieth century, national higher education systems moved away from each other rather than converging and cooperating more closely. The end of World War II brought with it the hope that the pursuit of knowledge, its dissemination and application would also confirm its cosmopolitan and humanistic potential.

This vision met with great obstacles. In addition to the traditional ones, these were now mainly the complex processes of the Cold War on the one hand and decolonisation on the other. Under the conditions of changing global relations and new political and military escalations in the world, it was necessary to counter the dominant centres of world powers with a cosmopolitan and humanist vision. In this context, a particularly challenging space has opened up for higher education. It has been a challenge for universities to affirm their role in society based on proven academic values. This challenge led, among other things, to the founding of the IAU. In other ways, the same challenge was also symbolically reflected in the values that May 1968 brought to the clouds of tear gas in many countries around the world. A new - and very numerous - generation entered the universities full of enthusiasm. A new chapter in the development of higher education began.

I enrolled at the University of Ljubljana in 1970. After graduating from high school, I attended a two-week summer school in a Europahuis near Maastricht, where I was first acquainted with the idea of a united Europe and had an exciting time in the international society of peers and lecturers. Afterwards, I spent another two weeks with friends in a student residence in Amsterdam. A whole new window to the world opened up to me that summer. In autumn, with the beginning of lectures at my home university, the student movement in our country reached its peak. On the agenda were both the "social dimension" of higher education, as we call it today, and a broad agenda of tough questions regarding domestic and foreign politics. At the forefront was the American aggression in Vietnam and the Soviet aggression against Czechoslovakia-in connection with various issues of global inequality and world ethics.

We, the students - certainly not only students of social sciences and the humanities - came to understand that real life is the best laboratory and classroom, where it is really possible to test theoretical knowledge and at the same time train for active citizenship. For the first time in my life, I encountered concepts such as academic freedom and university autonomy, and also that the academic space cannot recognise external boundaries that might hinder or prevent it. Il est interdit d'interdire, was written on a wall by Parisian students with whom we had direct contact. I still remember a sharp street protest, organised in their support, during the official visit of the French Prime Minister Chaban-Delmas to our city. We also kept contact with students from other countries and of course from Zagreb and Belgrade, the cities of the then common state. In the summer, we went to the Croatian island 
of Korčula, where we listened to lectures from famous Yugoslav (Praxis group) and international professors (among others, Agnes Heller, Herbert Marcuse, Erich Fromm, Jürgen Habermas, Henri Lefebvre, Lucien Goldmann). Last but not least, there were many foreign students in our dormitory, especially from the then so-called non-aligned countries, who gave us insights not only into the restless processes of decolonisation, but also into other cultures and thus into intercultural understanding. When I graduated, the idea — and the practical necessity — of global inter-university cooperation was no longer unknown to me at all.

This idea accompanied me through all the years of my professional career. In the 1980s, I experienced it primarily as the manifestation of a wide gap between a personal desire for international cooperation and many, mainly financial, obstacles that prevented its realisation. I remember that at the end of the $1980 \mathrm{~s}$, I drove with three other colleagues in a car to a conference in Oxford; in addition to personal luggage, we had an even larger quantity of cheap domestic petrol with us. We were caught red-handed by the police while filling up somewhere in the middle of Germany; the policemen were very kind, but we had to hand over the jerry can and refuel at the official petrol pump. But the conference was brilliant; we refuelled our intellectual batteries and created a new network of international contacts. Shortly afterwards, we met TEMPUS, i.e., the European Union programme to intensify cooperation in higher education with Central European countries undergoing profound social and political transition during that time. TEMPUS, a kind of parallel to ERASMUS, enabled us to fully understand what international academic mobility means and what potential it has.

But we also recognised the importance of organisational frameworks that enable and promote international cooperation. We were proud that in 1988 our university participated in the signing ceremony of the Magna Charta Universitatum in Bologna. For us, however, the transition to the 1990s had to do with the establishment of an independent state and a rather arduous path towards its international recognition. Among other things, this transition gave us the opportunity to join international organisations and associations: first and foremost, the United Nations, UNESCO and the Council of Europe, the pre-accession negotiations with the European Union, etc., and in this context higher education also had its own agenda. Academic networks had multiplied; the institutional and, not least, the much-needed legislative and policy framework for higher education had been strengthened. I had the privilege of participating, on behalf of my new-born country, the Republic of Slovenia, in the adoption of two documents which have had a profound impact on European and international cooperation in higher education: the 1997 Lisbon Recognition Convention and the 1999 Bologna Declaration.

Since then, a lot of water has flowed down the river, and many ground-breaking events have taken place in international higher education. During this period, the importance of international cooperation - either when I look at it personally, or when it concerns my university or my country, or Europe and the whole world-has grown enormously, while at the same time its characteristics have changed radically. In the 1950s, it was crucial to establish strong and lasting links between universities around the world. This was a fragmented and conflict-ridden post-war world in 
which it was not only necessary to advance and disseminate knowledge, but also to strengthen mutual understanding and global cooperation in the world. The turn from the 1960s to the 1970s heralded the era of mass higher education, which included a fundamental transformation of higher education, in particular the shift from access to higher education as a privilege to access to higher education as a right ("equally accessible to all on the basis of merit", if we use the language of the Universal Declaration of Human Rights). The 1990s shifted internationalisation into a higher gear; higher education systems worldwide expanded at an incredible rate, and the number of mobile students - and staff - increased exponentially. We believed that we were entering a knowledge society that would lead us, in perspective, to even closer global cooperation. But they were also years marked by a progressive, yet deeply contradictory, globalisation, with neoliberal pressures driving the commodification of higher education.

Thirty years have passed, and in analogy to earlier epochs in history, the idea has arisen that we may be experiencing a new era of transformation, in which a hitherto familiar Zeitgeist is on track to crash into something completely different and unknown. The process of globalisation, which seemed to be unstoppable at the time, has been confronted in recent years with (confronted with? really? maybe it has just turned into) deglobalisation, renationalisation. The political, economic and social processes of gradual international distancing (more on this concept later) which is accompanied by the promotion of "national pride" today, have also had a strong impact on the field of science and higher education, directly or indirectly.

Now, at the end of May 2020, there is no longer any doubt: this year will certainly be marked as another decisive turning point, both in general and with regard to higher education and its internationalisation in particular. It is still too early to make definitive statements, but it is the right time to ask questions and formulate hypotheses. It seems that all it took was an external, completely unexpected and initially quite amazing lever, called COVID-19, to see the problems that have been slowly accumulating for some time in a new light.

In many countries, schools and universities were closed practically overnight. Mobility was stopped. The reassuring statements that we are now living in the digital age and that we can replace the "old" physical world with a "new" virtual world have proven to be a great illusion. The problems we know from the physical world have only multiplied in the virtual world. People remain physical beings and still need the physical world, but they also need a safe and free world, both physical and virtual. However, security and freedom cannot really be guaranteed unless at least the basic principles of equality are enforced in the world. Expanding access to education was seen as a prospect for better times. But the more education has become a mass education, the more clearly educational inequalities have become detectable. We all know that, on a global scale, an immeasurably small percentage of people control an immeasurably large part of wealth. (I recently read in the media that this gap has even widened during the pandemic). This process also has consequences for education. The quantity and quality of knowledge is growing exponentially, yet while for some people the opportunities for (private) top-level education are growing, for many people the (public) educational opportunities are in fact deteriorating. The 
current pandemic, as we read in the media, has launched millions of children and young people - especially in the developing countries—back into a world without schools. It is often believed that learning failures, absenteeism, dropouts, etc. are phenomena that originate on the individual level. No, this is a systemic problem and also a problem of civilisation. Similar to a pandemic.

One would expect higher education at a local and global level to be more sensitive to these and similar issues. But we are dealing with a strange paradox: The more ethical principles are emphasised in academic life, the more fraud is reported. There is an urgent need to broaden the scope of the objectives of higher education beyond purely instrumental goals and to rethink its humanistic potential. How can today's higher education contribute to its community and to society as a whole? The current pandemic poses a major challenge in this direction: the search for resources to help people in need-be it in medicine, communications, economics, social work or education-requires the most advanced knowledge. But this knowledge must not be deemed a means of profit; its value resides in the notion that it is needed to care for people. What are the means and what are the ends? This is a big question, also today.

The time of the pandemic spares neither language nor meaning. In recent months there has been a constant and very loud call for social distancing. This term sends out a false, thoughtless message. What must be respected and practised in a health crisis is physical distancing, because we must stop the physical transmission of the virus from one person to another. We must, therefore, make a loud appeal for physical distancing, while at the same time strengthen social proximity, social cohesion and cooperation. We must not risk weakening or even losing them in this crisis. At a local, national and global level. We can only resolve this crisis and defeat the virus as closely linked social beings. And we must deal with other "viruses" in the same way.

In the late 1980s, there was a heated debate in the wake of the British Prime Minister Margaret Thatcher's statement that "there is no such thing as a society". But global shocks, like a pandemic, prove that there definitely is a society. If we were just isolated, distanced individuals, there would be no danger. In a time of a pandemic, we need physical distance to protect ourselves as a society, as a civilisation; but we can only be truly protected if the close social bond is strengthened, not weakened. All this also applies to international cooperation in higher education. In the coming period, universities and their international associations will have to rise to the challenge as they have an important role to play.

Pavel Zgaga is Professor of Philosophy of Education at the Faculty of Education, University of Ljubljana, Slovenia. He co-founded the Centre for Educational Policy Studies (CEPS, 2001) at the University of Ljubljana and has been its director until today. He was the founder and the first President of the Slovenian Educational Research Association (SLODRE) and took part as a member (2011-2017) in the Council of the European Educational Research Association (EERA). He is a member of the Consortium for Higher Education Research (CHER). 
Open Access This chapter is licensed under the terms of the Creative Commons Attribution 4.0 International License (http://creativecommons.org/licenses/by/4.0/), which permits use, sharing, adaptation, distribution and reproduction in any medium or format, as long as you give appropriate credit to the original author(s) and the source, provide a link to the Creative Commons license and indicate if changes were made.

The images or other third party material in this chapter are included in the chapter's Creative Commons license, unless indicated otherwise in a credit line to the material. If material is not included in the chapter's Creative Commons license and your intended use is not permitted by statutory regulation or exceeds the permitted use, you will need to obtain permission directly from the copyright holder. 


\title{
Creating Democratic Civic Universities in a Post-COVID-19 World: The IAU and Global Collaboration
}

\author{
Ira Harkavy
}

This essay is organized around four questions, the answers to which should, in my judgment, be helpful in thinking about universities now and in a post-pandemic world. My goal is to contribute to discussions and actions that result in the creation of democratic civic universities.

\section{What Are the Purposes of the University?}

The Council of Europe identified four purposes for higher education: preparation for sustainable employment, preparing students for active citizenship, personal development, and creating a broad advanced knowledge base through stimulating research and innovation. The COVID-19 pandemic and its impacts have led me to see these purposes as part of a larger purpose of developing and maintaining good democratic communities and societies, characterised by participation, cooperation and a commitment to the public good. Specifically, this involves the education of students for democratic citizenship and the creation of knowledge to advance the human condition.

Education for citizenship is, for me, the most significant purpose of the university. Specifically, higher education must educate not only able, but also ethical, empathetic, engaged, effective democratic citizens of a democratic society. In 1947, as a 19-yearold freshman at Morehouse College, Martin Luther King, Jr. wrote an article for the campus newspaper on the "Purpose of Education" that powerfully captures this idea. "We must remember," he wrote, "that intelligence is not enough. Intelligence plus

\footnotetext{
I. Harkavy $(\bowtie)$

University of Pennsylvania, Philadelphia, PA, USA

e-mail: harkavy@upenn.edu 
character-that is the goal of true education. The complete education gives one not only power of concentration, but worthy objectives upon which to concentrate."

The other central purpose of universities is to develop the knowledge needed to change the world for the better. In 1899, while an instructor at the University of Pennsylvania's Wharton School, W.E.B. DuBois wrote The Philadelphia Negro about conditions in the Seventh Ward, the city's oldest African American community. At the conclusion of chapter one, he described the purposes of his ground-breaking research as "serv[ing] as the scientific basis of further study, and of practical reform." That same year, in a paper delivered to the American Academy of Political and Social Science, Jane Addams, the activist, feminist founder of Hull House settlement in Chicago's poverty-stricken immigrant 19th ward neighbourhood, claimed that it was essential to "attempt to test the value of human knowledge by action" and "to apply knowledge to life."

My claim about the democratic purpose of higher education is derived in part from the history of colleges and universities in the United States. Every colonial college, except for the University of Pennsylvania, was founded largely to educate ministers and religiously orthodox men capable of creating good communities built on religious denominational principles. Benjamin Franklin, on the other hand, founded Penn (my home institution) as a secular college to educate students in a variety of fields. In 1749, envisioning the institution that would become the University of Pennsylvania, he wrote of developing in students "an Inclination join'd with an Ability to serve Mankind, one's Country, Friends and Family; which Ability . . . should indeed be the great Aim and End of all Learning."

Franklin's call to service echoed in the founding documents of hundreds of private colleges established after the American Revolution, as well as in the speeches of many college presidents. As the American research university evolved in the late 19th century, strengthening democracy at the expense of old social hierarchies served as increasingly the core mission of higher education in general.

Given the development of "illiberal democracy," claims of "fake news" and "alternative facts," and attacks on science and knowledge itself, universities have an increased and pressing responsibility to contribute to both the education of informed democratic citizens and the advancement of knowledge for the continuous betterment of the human condition. That pressing responsibility has become even more pressing with COVID-19, and claims that authoritarian systems are better able to deal with emergencies, along with a failure to acknowledge that authoritarian leaders have denied inconvenient truths that helped COVID-19 become a pandemic, producing a horrific toll in human life. 


\section{Are Universities in a Position to Make Sustained, Significant Contributions to Democracy?}

Higher education institutions, particularly research universities, are among the preeminent institutions in societies throughout the world, functioning as the primary engine of growth for knowledge-based global economies. Universities are sources of new ideas and discoveries, including technological advances; cultural and artistic centres; and anchor institutions that serve as catalysts and hubs for local and regional development. Most importantly, they teach the teachers, and the teachers' teachers, across all subjects, thereby helping to shape the entire schooling and educational systems at all levels, which shape the nature of society itself. As the great philosopher and educator John Dewey powerfully argued, a democratic society requires democratic education and schooling.

Certainly, higher education institutions are and will be negatively impacted by COVID-19. Many will struggle to survive, and many others could well close. Higher education as a sector, however, is and will remain influential in the years ahead. Among other things, colleges and universities possess significant resources, particularly the human resource of bright, able, idealistic students, faculty, and non-academic staff.

During the COVID crisis, higher education institutions, particularly academic medical centres, have in many ways performed admirably providing desperately needed health care and research; helping assure the safety of their students, faculty, and staff; supporting local businesses; donating medical equipment; teaching their students; and engaging with their communities remotely. There has been extraordinary, perhaps unprecedented, levels of collaboration and sharing of intelligence in a globally connected race to develop vaccines.

But this civic spiritedness, this social solidarity, is not a defining characteristic of higher education. The democratic civic university actively engaged with the life and problems of its community, and society has not been the primary model of higher education.

The International Association of Universities (IAU) has been a global leader supporting and advocating for academic engagement and genuinely engaged colleges and universities. Positive steps have been taken over the past decades in this direction. Service-learning, engaged scholarship, community-based participatory research, volunteer projects, and community economic development initiatives are some of the approaches that have been developed to create mutually beneficial partnerships designed to make a positive difference in the community and on the campus. 


\section{What Are the Obstacles to Creating Democratic Civic Universities?}

Significant obstacles have impeded the development of truly engaged, democratic civic universities, however. These impediments include commercialism and commodification, misplaced nostalgia for traditional, elitist, 'ivory tower' liberal arts education, and intellectual and institutional fragmentation.

The neoliberal entrepreneurial university is a model that has gained increasing currency and power throughout the world, contributing to increasingly savage inequalities and a diminished sense of public purpose. Education for profit, not virtue, students as consumers, not producers of knowledge, academics as individual superstars, not members of a community of scholars - all of these developments reflect the commercialization of higher education, which contributes to an overemphasis on institutional competition for wealth and status and has a devastating impact on the values and ambitions of students. When institutions openly pursue commercialization, their behaviour legitimizes and reinforces the pursuit of economic self-interest by students and amplifies the widespread sense that they are in college or university exclusively to gain career-related skills and credentials. Student idealism and civic engagement are strongly diminished when students see their universities abandon academic values and scholarly pursuits to function as competitive, profit-making corporations. Commercialism and the development of the neoliberal university foster an environment in which higher education is seen as a private benefit, not a public good.

Partly in response to galloping commercialism, some make a case for a return to traditional liberal arts education - an essentialist approach with roots in Plato's anti-democratic, elitist theory of education. What is needed instead is, to quote Carol Geary Schneider, "a new liberal art" involving "integrative learning - focused around big problems and new connections between the academy and society." The concept of a new liberal art resonates with John Dewey's rejection of abstract contemplation and his call for an engaged, problem-solving approach to scholarship and learning. In Reconstruction in Philosophy, he wrote: "The social philosopher, dwelling in the region of his concepts, 'solves' problems by showing the relationship of ideas, instead of helping men solve problems in the concrete by supplying them hypotheses to be used and tested in projects of reform."

"Communities have problems, universities have departments," stated a report published by the Organization for Economic Cooperation and Development titled The University and the Community. Beyond being a criticism of universities, that statement neatly indicates another major reason why universities have not contributed to communities as they should. Quite simply, their unintegrated, fragmented, internally conflictual structure and organization impede understanding and developing solutions to highly complex human and societal problems.

Colleges and universities need to significantly decrease the fragmentation of disciplines, overspecialization, and division between and among the arts and sciences and the professions since these departmental and disciplinary divisions have increased 
the isolation of higher education from society itself. Compounding this problem is what might be called the 'disciplinary fallacy' afflicting US universities - namely, the misconception that faculty members are duty-bound to serve only the scholastic interests and preoccupations of their disciplines and have neither the responsibility nor the capacity to help their universities keep their longstanding promise to prepare undergraduates for lives of moral and civic responsibility.

\section{What Is the Role of Global Collaboration in Reducing Obstacles to Creating Democratic Civic Universities?}

Many things need to be done, and done with urgency, to reduce the negative effects of commercialism and commodification, ivory tower nostalgia, and intellectual and institutional fragmentation. Space considerations would make it impossible to enumerate them here. Among the actions needed, however, is to create a global movement of individuals and organizations, including colleges and universities, for change. Simply put, promoting increased cooperation among higher education institutions all over the world to learn from and work with each other is a necessity. That is precisely what the IAU does, serving as a truly global association of higher education institutions and organizations from around the world advocating for social responsibility and higher education and research in the public interest.

Importantly, the IAU is also a core member (along with the Council of Europe, Organization of American States, and the International Consortium for Higher Education, Civic Responsibility and Democracy) of a global cooperation to advance the democratic role of higher education. Let me provide a bit of background.

The International Consortium for Higher Education, Civic Responsibility and Democracy (IC) was formed in 1999 to work in cooperation with the Council of Europe (CoE). The purpose of the IC (which I chair) is to advance the contributions of institutions of higher education to democratic development on campus, as well as in local communities and the wider society. The IC comprises the United States (represented by a Steering Committee from the American Association of State Colleges and Universities, American Council on Education, Anchor Institutions Task Force, Association of American Colleges and Universities, Campus Compact, Democracy Commitment, and NASPA-Student Affairs Professionals in Higher Education); Australia (represented by Engagement Australia); the United Kingdom (represented by the National Co-ordinating Centre for Public Engagement); Ireland (represented by Campus Engage Ireland); South Africa (represented by Universities South Africa); and the Magna Charta Observatory based in Italy.

The CoE, established in 1949, defends human rights, democracy and the rule of law, develops continent-wide agreements to standardize member countries' social and legal practices, and promotes awareness of a European identity across cultures based on shared values. The IC, for example, works in collaboration with the CoE, comprising 47 member countries, and its Steering Committee for Educational Policy 
and Practice. The Steering Committee includes an additional three countries that are also signatories of the European Cultural Convention. This treaty provides the framework for the CoE's work in education policy and practice.

In Spring 2018, the Organization of American States (OAS) joined the cooperation between the IC and CoE. The OAS was established in 1948 "in order to achieve among its member states - as stipulated in Article 1 of the Charter -'an order of peace and justice, to promote their solidarity, to strengthen their collaboration, and to defend their sovereignty, their territorial integrity, and their independence.' Today, the OAS brings together all 35 independent states of the Americas and constitutes the main political, juridical, and social governmental forum in the Hemisphere." The organization uses a four-pronged approach based on its main pillars of democracy, human rights, security and development.

In Autumn 2019, the International Association of Universities (IAU) joined the $\mathrm{CoE} / \mathrm{IC} / \mathrm{OAS}$ cooperation. Created under the auspices of UNESCO in 1950, the IAU, as readers know, is a membership-based organization serving the global higher education community and currently represents more than 640 institutions, organizations and affiliates across 120 countries. The IAU "acts as the global voice of higher education to UNESCO and other international higher education organizations, and provides a global forum for leaders of institutions and associations... The Association advocates for policies and practices that respect diverse perspectives and promote social responsibility."

The IC/CoE/OAS/IAU cooperation undertakes cross-national research projects, joint meetings and the sharing of best practices as part of its efforts to advance higher education's contribution to building democratic societies. The cooperation has hosted six global forums, and the CoE has published monographs on the conference themes, including Higher Education and Democratic Culture: Citizenship, Human Rights, and Civic Responsibility (2008), Higher Education for Modern Societies: Competencies and Values (2010), Reimagining Democratic Societies: A New Era of Personal and Social Responsibility (2013), Higher Education for Democratic Innovation (2016), Higher Education for Diversity, Social Inclusion, and Community: A Democratic Imperative (2018), and Academic Freedom, Institutional Autonomy, and the Future of Democracy (2020). Additional partners were involved in planning the conferences, among them being the International Association of Universities (well before it became a formal member), the European Wergeland Centre, the European Students' Union, the University of Oslo, Queen's University-Belfast, the Australia Catholic University and LUMSA University.

The IAU and the global cooperation of which it is a part have, in my opinion, their roots in the Enlightenment idea powerfully expressed by Francis Bacon at the turn of the 17th century that "knowledge is power" for "the relief of man's estate." To realize his goal of advancing knowledge "for the relief of man's estate," Bacon also called for a "closer connection and relationship between all the different universities of Europe."

Now, of course, connections and relationships must extend well beyond Europe. Collaboration for research, learning, and engagement is necessary to increasingly realize the progressive, continuous betterment of the human condition and create 
democratic civic universities dedicated to producing knowledge and educating ethical, empathetic students for just and sustainable democratic societies. IAU has been, and will surely continue to be, a catalyst and leader of that collaboration.

Ira Harkavy is Associate Vice President and Founding Director of the Barbara and Edward Netter Center for Community Partnerships, University of Pennsylvania. He also chairs the International Consortium for Higher Education, Civic Responsibility and Democracy and the Anchor Institutions Task Force. His recent books include Knowledge for Social Change: Bacon, Dewey, and the Revolutionary Transformation of Research Universities in the Twenty-First Century (2017) and The Local Mission of Higher Education: Principles and Practice (2019, co-edited with Sjur Bergan and Ronaldo Munck).

Open Access This chapter is licensed under the terms of the Creative Commons Attribution 4.0 International License (http://creativecommons.org/licenses/by/4.0/), which permits use, sharing, adaptation, distribution and reproduction in any medium or format, as long as you give appropriate credit to the original author(s) and the source, provide a link to the Creative Commons license and indicate if changes were made.

The images or other third party material in this chapter are included in the chapter's Creative Commons license, unless indicated otherwise in a credit line to the material. If material is not included in the chapter's Creative Commons license and your intended use is not permitted by statutory regulation or exceeds the permitted use, you will need to obtain permission directly from the copyright holder. 


\title{
Why IAU?
}

\author{
Remus Pricopie
}

\section{How Can We Assess the Value of 70 Years of Work?}

We all know that evaluation is a sophisticated science. However, when we talk about celebrating 70 years of the International Association of Universities (IAU), the word "sophisticated" gets an even deeper meaning. How do we evaluate the activity of a global organization, founded in 1950 by UNESCO (IAU, 1950), whose mission it is to be the voice of universities worldwide and the main defender of the two fundamental academic values: (i) academic freedom and (ii) university autonomy? Naturally, an anniversary is always an occasion to look back, just as it is natural to look ahead. But what do we look for when we scan the seven decades of IAU activity? Where do we start? What do we quantify? What lessons do we learn from our experiences so far and what do we decide to adjust for the years to come?

Precisely because the questions are not simple at all and the answers can have several "correct" versions at the same time, the IAU Board, chaired by Professor Pam Fredman, encouraged and fully supported the efforts of the IAU Secretariat, led by Dr. Hilligje van't Land, to build a multi-level framework in which each member of the global academic community, anyone who has known, interacted, worked for or benefited from this organization, can express themselves in a specific way. One of these 'levels' is this book, to which, to a small extent, the university I represent, the National University of Political Studies and Public Administration (SNSPA), has also contributed.

Since we are talking about specific answers, I will try to give some as well. Obviously, they have to do with my educational profile, my professional experiences and my interactions with IAU. At the same time, I am convinced that these can be similarly found in other parts of the world, or at different moments in the existence of IAU. The matrix that I will use in "my evaluation" is a very simple one. I will initially

\footnotetext{
R. Pricopie $(\bowtie)$

National University of Political Studies and Public Administration, Bucharest, Romania

e-mail: remus.pricopie@snspa.ro 
refer to three distinct layers: individual, institutional, system-wide. The individual can be anyone who, during the 70 years, benefited, was assisted or guided by the IAU, directly or indirectly, through the results of its work. The institution, in this case, is the university, even though other types of higher education institutions also come into play. At the systems' level, although we can look at many things, it is the global conceptual system relating to the "idea of the university". If we wanted, we could also consider the university system in a certain region or country. Each of these levels will be analyzed not in a holistic way - here is not the place or time - but from a personal perspective. However, I do believe that this kind of approach will reveal and emphasize the need for IAU and its value. To this I will add a disruptive factor: stress or crisis. In the opinion of many specialists, an organization cannot be classified as "solid" unless it can prove that it can survive difficult times, without altering its mission.

\section{From the Golden Book to the Golden Portal}

I am twenty years younger than IAU. I was born in 1970 and grew up in a relatively isolated village, somewhere in rural Romania. Although the rural area has always been a place where education found itself in a precarious state, I was somewhat privileged by the fact that I was under the intellectual influence of several teachers, priests and engineers in my extended family. Also, I had the advantage that I was close to the largest university center, Bucharest. I therefore always had the option of pursuing a degree in higher education, which is what happened. The revolution of 1989, which led to the abolition of the communist regime in Romania, found me a student at the University of Bucharest, in the teacher training program.

The new democratic society to emerge did not settle down easily and the word "confusion" was best characterizing these times. In this general state of confusion and hesitation, education guided me quite easily to what I was going to achieve in my career. While attending postgraduate courses at my current university (SNSPA) and researching for a paper, I discovered in the library of the Ministry of Education the "Golden Book": International Handbook of Universities (IHU). No, the IHU wasn't actually clad in gold, but for me it was like a treasure. In this pre-Internet world, that huge book (over 1.000 pages), quite old, served as a window to the fascinating world of universities around the globe (IAU, 2020). I leafed through all of them, page by page, country by country, university by university and it instilled in me the idea to study in a foreign country. Since then, I have studied in nine universities, in five countries and I have collaborated on an institutional level with more than 2.000 universities from around the world, all of which are obviously listed on those IHU pages.

"The Golden Book", which I discovered at the age of 26, had a major impact on me. Since encountering that "map of academic maps", my life and that of my family has changed. It is difficult for us to know just how many other young people in the world were similarly touched by "The Golden Book" during their educational journey. But what we do know for sure is that what the IAU has managed to do in all 
these years: to build the most sophisticated register of higher education institutions in the world, while being in permanent dialogue with the governments of 196 countries and territories. It is not only young people like me searching for an academic path who have benefitted from these huge efforts. All those who have studied abroad in these 70 years (UNESCO and World Bank statistics will indicate tens of millions of international students in this time interval), relied on this global catalog of academic programs to get their credentials accredited and officially recognized by the national authorities.

Today, as mentioned by the editors Hilligje van't Land, Andreas Corcoran and Diana Iancu in the Introduction, "The Golden Book" has become "The Golden Portal", as in that the information has shifted to a global portal, known as the World Higher Education Database (WHED). This means that through a simple click, anyone can explore the vast global academic world, including 20,000 higher education institutions and listing probably well over 1.000.000 undergraduate, graduate and Ph.D. programs. Imagine how many academic paths this "Golden Portal" has shaped and continues to shape, year after year, for millions of young people around the world. Young people, who are driven by a thirst for knowledge. Just imagine how many lives and destinies have been shaped by this huge academic map of the world.

This alone - the creating and updating of the "The Golden Book" - would have been enough to justify its 70 years of existence. But the work of IAU has been far more than that.

\section{A Global Community of Universities}

IAU is a global community of universities, one that seeks to ensure and support "the engines" of the intellectual life in the world. And the logic of all actions carried out under the auspices of the IAU is that every university in this world should have the opportunity to dialogue with other universities, similar or different, to find solutions to the challenges they face. The circumstances and problems universities face are in many respects different, especially when we cross continents and cultural borders. It would be difficult, for example, for a Romanian university to implement American higher educational financial policies, just as, in the same way, a US university would not be in a position to understand how someone in Romania could study medicine in a high-quality program for only $10.000 \$$ a year. But dialogue and the patience to understand other paradigms is the path to progress.

As a young rector of SNSPA, I immediately ventured to engage in IAU events and meetings. True, I had known IAU long before I became rector. I knew what it offered from my previous experiences working on governmental public policy. In my new capacity however, I believed it fundamental to build opportunities for my university, for my colleagues and students for a global dialogue. Since 2012, many of the members of the SNSPA academic community (academics, technical staff, and students) have participated in events, conferences, training programs, site visits on all continents and within different frameworks built under the umbrella of IAU. 
All this, in connection with other European or global projects, has given SNSPA today one of the strongest international profiles among Romanian universities. This "profile" can be depicted as: programs in foreign languages, partnership with foreign universities, the highest rate of research projects per professor in Romania, the first Romanian university participating in the consortium - CIVICA - that won a grant within the new European Universities Initiative (CIVICA, 2021), one of the highest rates of academic mobility within Eastern Europe, a leader in digital education, a strong voice for academic freedom and a fighter against any political and ideological interference in academic life, one of the very active universities heavily involved in research for policy design etc.

Obviously, these are the words of a rector who, after eight years in office, can look back and evaluate what his university has achieved with the support of his university colleagues and colleagues from the IAU. But these are the kind of achievements that not just SNSPA, as a member of IAU, has benefited from over the years. All Members can engage in the opportunities IAU offers and do so according to their needs and academic goals. Therefore, in addition to the short story of SNSPA, we could undoubtedly mention thousands of other success stories as well, stories that show how perhaps millions of students and the communities and countries in which they live have benefited from being Members of IAU.

\section{The Shape of the Future}

There is an area in which IAU has worked from the beginning but that specific area is one that is not always easily grasped: the shaping of the future of universities and, in a way, that of our societies.

The university is often said to be one of the few organizations that have survived a millennium. It is true, in a way. But it is also true that the university, as a millennial institution, has shown that it is sensitive to the new, that it has the ability to understand social, political, economic trends, that it has the courage to question the rules of the present in order to make room for new rules and that, not least, it has the ability to modernize, to change from within, and not under the pressure from external factors. If we follow the history of universities and try to understand how these sanctuaries of knowledge survived, the answer is probably simple: because the university has always worked with the future, and sometimes even built and shaped this future.

IAU has worked and continues to work with the future, too.

At its inception, IAU worked within a framework that knew hardly any university cooperation outside national borders at all. It was a matter of vision to encourage universities to be free, independent, not to scare under the power of national governments and to do what they know best - education and research - in a collaborative way. Its inception in 1950 laid the foundations, on the one hand, for what we now call international higher education and, on the other hand, empowered universities to conceptually confront their own governments, when the case. 
In the early years of its establishment, IAU has repeatedly addressed the issue of the relationship between universities and authorities, how universities and their academic programs can be recognized across national borders, the issue of academic status and its freedoms. Massification, quality, mobility and internationalization were other topics discussed by IAU and its Member universities long before these phenomena took shape. The world had been warned in advance: the need for higher education is going to increase significantly, therefore, one better be prepared.

And this is how academic issues, once considered as $100 \%$ strictly national topics, have reached the agenda of international discussions, in various forms. UNESCO established a higher education division in the 70s, and two important institutes specialized in higher education - Romania - CEPES, 1972, and Venezuela-CRESALC, 1974 - were called into life. In addition, UN and UNESCO, inspired by the work of IAU, established a unique kind of institution (the United Nation University,1975) in Tokyo; the World Bank started to approach higher education as one of the important development actors; Europe launched the Erasmus mobility program and later, during the 90s, the Bologna Process, which became one of the most dynamic regional higher education movements in the world.

So, less than 25 years after the founding of the IAU, higher education officially became an "international theme", and the university the main actor in this theme. In the 90s, with the fall of the Iron Curtain, UNESCO, under Federico Mayor as Director-General, surrounded by one of the best teams of experts globally, enhanced the higher education agenda by organizing the first ever global higher education conference (UNESCO, 1998).

Eva Egron-Polak, in her contribution to this book, recounts how IAU was invited to contribute to the organization of the first UNESCO World Conference on Higher Education (WCHE), held in 1998. I cannot report on this "first hand" as I was not involved in this first edition, but I can comment it, however, on the second UNESCO WHEC, which took place in 2009. As I was personally involved in the organization of this event on behalf of the Romanian Government, I can say that IAU continued to be one of the most active actors, especially during the drafting of the final documents (UNESCO, 2009). As mentioned in this book by Stefania Giannini, Assistant Director-General on Education, UNESCO considers IAU to be one of the most important, if not the first collaborator on higher education when it comes to shedding light on the perspective of universities, including the organization of the third UNESCO WHEC, which will take place in 2022, in Spain.

But the IAU was not only present at the debates under the UNESCO umbrella. The Bologna Process, the collaboration of EU - Asia or EU - Latin America, the Francophonie, and many other projects, initiatives, and movements have had IAU as one of the key partners. IAU has participated in all major discussions that have taken place globally and that have led to the shaping of both the future of universities and of the societies in which we live.

Sometimes, a "world conference" is an event too far from the needs of many universities and communities, small and also large. Or, simply saying, some educational institutions prefer a local/regional perspective to a global one. That is why the IAU has not limited itself to the big global picture of social transformations and the role of 
the university as a globally recognized institution. In many cases, based on different governmental invitations, IAU assisted in defining and implementing various public policies. I repeat, there are many examples of such contributions. But, as I underlined in the first section of this paper, it is normal to mention the one I know best. In 2014, at the invitation of UEFIS-CDI, the Romanian institution specialized on research in public policy, worked with IAU on the internationalization of higher education, on two different levels: (1) to help the Romanian Ministry of Education to design the first ever Higher Education internationalization strategy; (2) to guide 20 universities in the shaping of their own vision and to prepare the appropriate university strategies on internationalization (UEFIS-CDI, 2014).

All these examples are, again, indisputable attributes of IAU's role and capacity. They show us not only the strength to understand the most important lines of force, globally, with regard to the need for knowledge and change; it also shows the dedication of the IAU team to work with almost every member, in a customized way, depending on the specificities of each.

\section{Celebrating ... in Pandemic Times}

It is clear that COVID 19 has become a black page in human history, with millions of lives lost and tens of millions more suffering as a result of this global crisis, including job losses, deteriorating living conditions, alarming increase in the level of insecurity, etc.

However, this moment of major crisis must also be seen as a test - harsh and unfortunate. It has shown us that IAU can act and serve the global academic community even during what by some has been described as "a time of war".

Perhaps our assessment of the IAU, whether holistic or a more personal, could not be complete without showing that the IAU is indeed an organization capable of dealing with complex situations and uncertainty. And how can an organization be better tested than in times of crisis.

We all, as member universities of a global community, have seen how the IAU has reacted immediately, transferring its entire activity online and continuing to provide strong support to its Members. Obviously, this would not have been possible without a motivated community and strong leadership (both at the Board and at the Secretariat level). The crisis has somehow given value not only to the work of 70 years of strong higher education cooperation, it also gives us the certainty that this organization, considered and recognized as "the global voice of higher education", is ready for the decades to come.

I do hope that we will meet to celebrate IAU's achievements while also planning ahead during the 16th IAU General Conference, October 25-28 2022, at UCD, in Dublin, Ireland. 


\section{References}

CIVICA - The European University of Social Sciences (2021). About CIVICA. Retrieved from: www.civica.eu/who-we-are/about-civica/

International Association of Universities (IAU) (1950). Constitution of the International Association of Universities. Retrieved from: https://iau-aiu.net/IMG/pdf/iau_constitution-en.pdf

International Association of Universities (IAU) (2020). International Handbook of Universities (IHU). Retrieved from: www.whed.net/Headline1.html

UEFIS-CDI (2014). Internationalizare, echitate şi management universitar pentru un învăţământ superior de calitate. Politici bazate pe evidente şi impactul asupra pieţei forţei de muncă. Retrieved from: iem http://iemu.forhe.ro/u(forhe.ro)

UNESCO (1998). World Declaration on Higher Education for the Twenty-First Century: Vision and Action. World Conference on Higher Education. Retrieved from: http://unesco_ world_declaration_on_higher_education_for_the_twenty_first_century_vision_and_action.pdf (bice.org)

UNESCO (2009). 2009 World Conference on Higher Education: The New Dynamics of Higher Education and Research For Societal Change and Development. Retrieved from: www.inqaahe. org/sites/default/files/UNESCO\%20communique.pdf

Remus Pricopie has been Professor and Rector of the National University of Political Studies and Public Administration (SNSPA) in Bucharest since March 2012. He served in the Romanian Government as Minister of National Education and Research, from 2012 to 2014. He is President of the Board of the Romanian-US Fulbright Commission, Vice-President of the International Association of Universities (IAU) and President of the EU-Latin America and Caribbean Permanent Academic Forum.

Open Access This chapter is licensed under the terms of the Creative Commons Attribution 4.0 International License (http://creativecommons.org/licenses/by/4.0/), which permits use, sharing, adaptation, distribution and reproduction in any medium or format, as long as you give appropriate credit to the original author(s) and the source, provide a link to the Creative Commons license and indicate if changes were made.

The images or other third party material in this chapter are included in the chapter's Creative Commons license, unless indicated otherwise in a credit line to the material. If material is not included in the chapter's Creative Commons license and your intended use is not permitted by statutory regulation or exceeds the permitted use, you will need to obtain permission directly from the copyright holder.

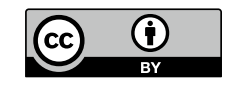




\section{Part II}

Facilitating International Cooperation 


\title{
The Role of IAU in Facilitating International Cooperation
}

\author{
Ranbir Singh
}

The International Association of Universities (IAU), founded in 1950 under the auspices of UNESCO, is a prominent global association of higher education institutions as well as organisations across the world.

With over 600 members from around the world IAU provides a bridge amongst various member institutions for reflection and sharing of best practices on similar lines. IAU acts as the unique global mouthpiece of higher education to UNESCO and national policy makers, as it also provides an international platform for the leaders of its member institutions and associations. IAU promotes academic linkages among its members by enunciating the fundamental values and principles that support the quest, propagation and purpose of knowledge. The IAU brings out new higher education policy statement, perspectives and practices with special emphasis on values and leadership, encouraging new and innovative methods for association among its institutions.

International organizations, of which IAU has been a very significant partner, have continuously highlighted the importance of higher education institutions (HEIs), especially in the domain of highlighting their global visibility. Apart from other aspects of global relevance, internationalization of higher education at the global level has been of much significance because it helps to narrow down the digital and knowledge divide by reducing the differences between developing and developed countries.

This has been made possible because of a very concerted effort by the IAU through technological knowledge exchanges between different countries of the global north and global south. The IAU has for long realized the important role HEIs can play for promoting development and has been instrumental in impacting social change. Many of the institutional associations world-wide have greatly benefitted through

R. Singh $(\varangle)$

National Law University, Delhi, India

e-mail: vc@nludelhi.ac.in 
the hand-holding support of IAU for promoting and strengthening their international cooperation and academic exchange mechanisms.

The inherent quality of internationalization being networking, sharing, equality among partners etc. has ushered in a new area of promoting excellence through regional and international cooperation in various fields of study and research. Internationalization to a great extent has been able to promote global citizenship in education by the exchange of faculty, students and collaborative research.

IAU's continuous effort has been to bridge the demographic, digital and knowledge divide between countries, and it has played a very significant role through internationalization of HEIs through its various programs and missions.

Internationalization is a very familiar phenomenon in higher education, not just in India but in many other countries. For decades, students have been travelling to other countries for higher education. Similarly, faculty members and research scholars have been going to foreign institutions to teach or undertake research initiatives. In fact, many foreign faculties also spearhead the leadership role along with the responsibility of teaching and research. Therefore, in one form or the other, internationalization has had a direct influence on the way teaching and learning has been carried out, and so has research and institution building.

While to a certain extent universities and other institutions of education have always been influenced by the broader global trends, however, in today's globalized and interconnected world, the importance of collaboration and cooperation cannot be left in a vacuum, and that is where the IAU has been playing a lead role.

ICTs have played a large role in further strengthening international cooperation. However, this has not had the desired impact in bridging the gap between academic institutions in the developed world and those in the developing world. A lot more needs to be done for bridging this divide, and for bringing the higher education institutions in the global south to the level of the institutions in the global north.

Similarly, even in the local context, inequality among national higher education systems has increased in the past decades. The academic world has always been characterized by centres and peripheries. The strongest universities, usually because of their research prowess and reputation for excellence, are seen as centres of excellence (Altbach 2011) and attract the brightest students and faculty, as well as endowments and research funding. There is also an urgent need to promote interdisciplinary education all over but especially in developing countries, where they are lacking. Some of these countries have started encouraging this, and there is a need for further development. Similarly, interdisciplinary and transdisciplinary research also needs to be a priority for all academic institutions.

A number of factors have led to the current revolution in the higher education space. As discussed above, the most important is globalization and the role played by ICTs. We should also not discount massive expansion of higher education and the role played by universities in undertaking significant academic research.

However, we should be mindful of certain challenges, including the rapid privatization of education. The increasingly unaffordable fee charged by some universities and decreasing state support for education in a large part of the world is also a major cause of concern. In current times, a number of institutions are more focused on 
maintaining their legacy and securing a high place in a number of influential world rankings and, in a lot of cases, resemble private corporations with the focus on maximizing revenue and profits. Many universities are losing focus on their foundational vision and the core academic values and are not focusing on the greater welfare of society or the democratization of education.

We must also need to rethink our models of education, since industry 4.0 and today's careers require continuous, lifelong learning. While the idea of lifelong learning is not new, the conditions for lifelong learning have changed significantly, and this need has never been more significant (Østergaard and Nordlund 2019). The new education models must incorporate this change and build a culture that promotes it (Østergaard and Nordlund 2019).

All this requires much greater cooperation between educational institutions, and other relevant stakeholders, including the students, faculty, states and industry. IAU has over the years facilitated international cooperation in the higher education ecosystem in a number of ways, including promoting international student and faculty mobility; promoting cultural and intercultural understanding; establishing academic partnerships with foreign institutions relating to teaching; promoting research collaboration at individual and institutional levels.

The IAU also provides dedicated services to its member institutions by way of its expertise and trends analysis, publications and portals, advisory services, peer-topeer learning and training, conducting events on knowledge sharing, representation and global advocacy in promoting international cooperation and leadership.

The IAU has given special attention to the challenges posed by COVID-19 around the world, providing information on online education and the steps required for keeping our campuses safe. Going forward, there may be a greater reliance on ICTs and online education as a way to make quality higher education accessible and affordable.

The initiatives provided by the IAU have gone a long way in building up confidence between HEIs as well as faculty by convincing everybody that together we can boldly face the situation created by COVID-19, in the interest of everybody affected by the pandemic.

There will be numerous challenges faced by universities and other institutions in the immediate aftermath of COVID-19 and after that with the growth of the digital economy and industry 4.0. Closer collaboration and linkages between these institutions provides a better path forward to deal with these challenges, and IAU will have a much greater role and responsibility to make this happen, as well as to meet the emerging challenges brought about by artificial intelligence and other technologies which may be seen as disruptive.

\section{References}

Altbach, P. G. (2011). Global academic revolution: Implications for India. Journal of Educational Planning and Administration, 25(4), 301-313. 
Østergaard, S. F., \& Nordlund, A. G. (2019. December 19). The 4 biggest challenges to our higher education model - and what to do about them. World Economic Forum. Retrieved from: https://www.weforum.org/agenda/2019/12/fourth-industrial-revolution-highereducation-challenges/ (26.07.2020)

Ranbir Singh is the founder Vice-Chancellor of "National Law University, Delhi" established by the Delhi Government in 2008. He is also member of the Administrative Board of the International Association of Universities (IAU) and a member of the council of the Association of Commonwealth Universities (ACU), London. Randbir Singh has been the founder Vice-Chancellor of NALSAR, University of Law, Hyderabad (1998 to 2008) and he has been a Vice-Chancellor continuously for over 22 years now.

Open Access This chapter is licensed under the terms of the Creative Commons Attribution 4.0 International License (http://creativecommons.org/licenses/by/4.0/), which permits use, sharing, adaptation, distribution and reproduction in any medium or format, as long as you give appropriate credit to the original author(s) and the source, provide a link to the Creative Commons license and indicate if changes were made.

The images or other third party material in this chapter are included in the chapter's Creative Commons license, unless indicated otherwise in a credit line to the material. If material is not included in the chapter's Creative Commons license and your intended use is not permitted by statutory regulation or exceeds the permitted use, you will need to obtain permission directly from the copyright holder.

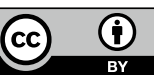




\title{
Universities, Associations, and Internationalization: Powerful Forces for Our Time
}

\author{
Laura E. Rumbley
}

International. Association. Universities. It is hard for me to imagine three words that more meaningfully capture the forces that have animated my professional life over the last quarter century. As an international education specialist, a researcher focused on higher education institutions and systems around the world, and as someone who has worked for two European-level higher education associations, the power and potential of universities, working in tandem through the mechanisms of associations, and engaging internationally to advance their collective interests and agendas, resonates with me very clearly and very personally.

Beyond my own personal connection with these dynamics, however, I also perceive these synergies having a great deal of potential to effect positive change in the world over the next twenty-five years and more, as we look toward a future of immense complexity and challenge. Indeed, the international higher education community and its core organizations, such as the International Association of Universities (IAU), are well-positioned to play a vital role in our collective future, but they must be effectively supported to do so. If this happens, the association sector can continue, and expand upon, its crucial work to help frame the issues - social, economic, environmental - that will demand our attention around the world in the coming years. Universities can further develop their capacity to act as incubators for the kind of creative and courageous thinking that will be necessary to address the massive challenges we face locally and globally. And high-quality, critically assessed educational experiences that are imbued purposefully with international and intercultural dimensions, as well as social justice sensitivities can inspire and empower a new generation of creative, committed, and principled individuals who will carry forward our aspirations for the future.

\footnotetext{
L. E. Rumbley (凶)

European Association for International Education, Amsterdam, The Netherlands e-mail: rumbley@eaie.org 
Of course, all of these mechanisms must act in tandem to deliver their full potential, which requires sustained commitment as well as awareness of both the pitfalls and possibilities embedded in our circumstances. The key is to imagine the future we desire, sketch out a roadmap that can lead us forward, and then act boldly on those objectives.

\section{The Promise of the University}

As with all institutions, universities are imperfect in many ways. However, I am drawn to the notion that the university is uniquely designed to fulfil a particular calling which, in its most elevated form, positions the institution to exercise a considerable act of bravery and humility: "to constantly test rather than impose the values it cherishes" (Giamatti 1990).

As I reflect on current-day examples of terrible abuses of public trust (first and foremost in my home country, the United States), the perversion of news sources, and the large-scale rejection of scientific evidence, let alone common sense, I am reminded of the wondrous potential that exists for universities to explore the limits of our knowledge and understanding in service to society - if given the appropriate freedom and relevant incentives to do so. I am convinced that the perpetuation and empowerment of universities are crucial for our collective well-being. Preserving and deepening our understanding of the past, enhancing our awareness of dynamics in the natural world, cultivating intellectual and technical talent across scores of fields and disciplines, critically questioning "the way things are," supporting the economic and social development of local communities, and helping us build a responsible future for the planet through technological and social innovation are among the key activities universities undertake around the world. We need these institutions, and we need organizations that support them, such as the IAU, to ensure our best chances for a better future.

\section{The Power of Associations}

There is no question that committed individuals can accomplish a great deal. However, collective action brings with it the possibility of greater resources, increased visibility, wider impact, and longer-term sustainability. Associations have long existed to align and elevate the interests and aspirations of individual actors in order to add value on a variety of levels. The pooling of resources, information, ideas, and good practices are known to offer important benefits to those who draw on these collective assets.

In today's 'networked world,' the value of shared resources is difficult to overestimate. This is clearly evident in the higher education sector, where all manner of networks, consortia, strategic partnerships and associations populate the landscape 
and provide immensely useful avenues for the advancement of both core business and special initiatives. Given the profoundly important role that universities can and should play in the world today, collective expressions of the needs and interests of the university community, and the stakeholders who may rely on or support the sector, must be carefully considered, artfully shaped, and intelligently amplified. Associations bring these collective expressions to life.

It is fascinating to consider that decades-old higher education associations - ranging from the 30+-year old European Association for International Education (EAIE), to the 100-year-old Institute of International Education (IIE) in the United States, to the 70-year-old IAU - are all entering new phases of intense and renewed relevance in socially and politically turbulent times. From my perspective, this aligns with the very clear watershed moments that surrounded the birth of these associations: IIE in the post-World War I era, IAU in the post-World War II years, and the EAIE during a period in the late 1980s of dynamic European integration, particularly in the higher education sector. These moments of intense change and new possibilities highlight the importance and utility of pooling insights and leveraging collective wisdom.

Indeed, associations give much-needed coherence and synergy among those who share a direction of travel but who are moving along somewhat erratically, or with limited coordination. We 'associate' with others to find fellowship, gain new insight, solve problems, and enjoy a shared sense of purpose. In a period of deep fragmentation within and across societies, associations offer a special kind of hope for collective action that serves a greater purpose. We need to draw on the strengths of our networks in the global higher education sector, embodied brilliantly by such associations as IAU and EAIE. We also need to ensure that these kinds of reinforcing and value-added avenues for collaboration and connection remain strong and viable at a time when both higher education and international engagement face enormous challenges.

\section{The Urgency of Internationalization}

The COVID-19 pandemic has illustrated two remarkable aspects of the current global reality. On the one hand, after decades of globalization - featuring the lowering of tariffs, the softening of borders, and the increasing international mobility of goods, services and people (notable among these, postsecondary students and faculty!) national borders around the world closed tight in a matter of days. It seems that the internationalization of our lives is, in reality, tenuous at best - at least when it comes to border controls. Meanwhile, the need to think internationally, and ideally globally, about the nature of this crisis and its eventual resolution, came quickly to the fore. Rapid development and deployment of a vaccine may be most achievable if researchers around the world pool their data and insights, and the spread of the disease - which recognizes no official borders - may be slowed if governments bring a coordinated approach to public health protocols. While the drastic reduction in international travel undoubtedly slowed the spread of the virus, the closing of avenues of collaboration will undermine our common objectives. 
International cooperation has been a hallmark of the IAU's work for seven decades and must continue to sit centre-stage as we aim to find our way out of this terrible international public health crisis and consider the future of our world beyond this moment. The work involved in advancing internationalization in higher education must be imbued with ever greater degrees of agility to adapt to changing circumstances, and, in all instances, with unwavering commitments to addressing inequity, serving the common good, and sustaining the natural environment. Focusing ever more intently on what international cooperation ultimately aims to achieve - in the context of life on an increasingly crowded, interconnected, fragile, and unequally resourced planet - sits at the heart of the matter. The International Association of Universities (IAU), its member institutions, many of its sister organizations, and the global higher education community at large - as values-driven organizations - are all on the right side of this argument. How best to enact these values fearlessly, effectively, and consistently remains the central issue moving forward.

Universities, associations, and internationalization: these actors and dynamics can make a measurable difference in a world facing enormous challenges on many fronts. Our collective future will be richer if we are able to offer the right kind of challenge and support to bring out the best that these actors and endeavours have to offer our societies: knowledge to guide us, fellowship to sustain us, and perspectives that value all humanity.

\section{Reference}

Giamatti, A.B. (1990). A Free and Ordered Space: The Real World of the University. New York: W. W. Norton \& Company.

Laura E. Rumbley $\mathrm{PhD}$, is Associate Director, Knowledge Development and Research at the European Association for International Education (EAIE), the Netherlands. Before joining the EAIE, she was Associate Director of the Boston College Center for International Higher Education (CIHE), and she previously served as deputy director of the Academic Cooperation Association (ACA) in Brussels. Laura is a co-editor of the Journal of Studies in International Education and serves on various international higher education publication and project boards. 
Open Access This chapter is licensed under the terms of the Creative Commons Attribution 4.0 International License (http://creativecommons.org/licenses/by/4.0/), which permits use, sharing, adaptation, distribution and reproduction in any medium or format, as long as you give appropriate credit to the original author(s) and the source, provide a link to the Creative Commons license and indicate if changes were made.

The images or other third party material in this chapter are included in the chapter's Creative Commons license, unless indicated otherwise in a credit line to the material. If material is not included in the chapter's Creative Commons license and your intended use is not permitted by statutory regulation or exceeds the permitted use, you will need to obtain permission directly from the copyright holder. 


\title{
A Global View of Internationalisation: What Next?
}

\author{
Elspeth Jones and Hans de Wit
}

The International Association of Universities has long espoused a values-driven approach to internationalisation "to ensure that the outcomes of internationalisation are positive and of reciprocal benefit to the higher education institutions and the countries concerned" (IAU 2012). In line with this, there is increasing discussion about whether the concept of internationalisation has yet been adopted in more distinctive forms in different parts of the world to better reflect local needs and priorities. This debate seeks to consider the impact on policy and practice through new perspectives from those whose voices do not normally have a strong presence in the discourse. In this contribution, we will reflect further on these key points, and consider what might be involved in taking the internationalisation agenda forward in more sustainable, equitable and inclusive ways.

Rather than simply mimicking Anglo-Western, and predominantly Englishspeaking, approaches, the need for higher education to address global societal challenges, summarised in the Sustainable Development Goals of the United Nations (SDGs), implies a global response. Balancing and integrating local needs with global demands and cross-border working is a major challenge for higher education institutions in the context of ongoing massification, on the one hand, and the demand for a global knowledge economy, on the other.

The rapid changes in international higher education have only increased in range and complexity over the past decade, and not least in response to the global pandemic of 2020. Certainly, the world is facing strong threats to the underlying values of cooperative internationalisation and to achieving the SDGs. Populism, nationalism, xenophobia, and parochial politics are on the increase around the world, presenting

\footnotetext{
E. Jones (ه)

Leeds Beckett University, Leeds, UK

e-mail: e.jones@leedsbeckett.ac.uk

H. de Wit

Boston College, Chestnut Hill, MA, USA

e-mail: dewitj@bc.edu
} 
challenges for those who view internationalisation as more than simply a neoliberal or market-driven concern, and who call for a more inclusive, nuanced, values-driven and comprehensive approach.

A range of countries is emerging as important challengers to the dominance of western internationalisation discourse. But at the same time, there is still a trend towards homogenisation of activities, approaches, policies and strategies. Internationalisation strategies of low- and middle-income countries largely copy the western paradigm in focusing strongly on mobility, reputation and branding, and on SouthNorth relations. This is, to a great extent, driven by economic rationales, increased competitiveness, and dominance of the western university model. Rankings exacerbate this, along with the numerical indicators used to measure internationalisation: numbers of international students, international scholars, mobile students and staff, number of internationally co-authored publications. These indicators tend to drive governments and institutional leaders in higher education to focus (a) on increasing these quantitative targets, and (b) on policies for realising them, such as teaching in English, tuition-fee policies, exclusive focus on research, and so on. Little space is left for innovative ideas around internationalisation, embedded in the local and institutional context.

A strategic approach to International Higher Education (IHE) is of critical importance in advancing knowledge-based societies and for sustainable national development. However, despite this awareness, very few countries in the Global South have such policies in place, approaching IHE in more piecemeal and uncoordinated ways. Reasons include issues around colonial histories, economies, political turmoil, civil conflict and so on, resulting in the perpetuation of tensions between indigenisation and globalisation, with resistance towards imported international perspectives.

\section{A More Nuanced Approach to Internationalisation}

In the past, we have argued for a more nuanced approach to the interpretation and delivery of internationalisation in a globalised context than has hitherto been the case and suggested a range of factors that should be taken into account. Differentiated local and regional responses are required according to geographical variation in social and economic needs. It is also crucial to take into account ethical issues in global engagement and sustainability of practice, including careful consideration of the local context and culture when engaging in cross-border activity.

We have also argued that a globalised view of internationalisation demands political and economic rationales are put into context by (a) measuring the things which are important, not simply those which can be measured, (b) learning from partners and diversity of policy, practice and research around the world, (c) understanding the transformational potential of internationalisation for all - students, faculty and support staff - and its link with employability and citizenship. This means prioritising the intercultural as well as the international through curriculum, teaching and learning at home, not only through mobility. 
Yet, internationalisation continues to both reflect and exacerbate the inequalities in global societies. Access to higher education is still only available to a small proportion of the global population, and travelling to study in another country for short or longer periods will always be the preserve of a relatively wealthy, middle-class elite.

The prevailing result of institutional internationalisation strategies which predominantly focus on mobility will be inequality of access, opportunity and outcomes. Sadly, this focus continues to be the dominant paradigm as far as many institutional leaders are concerned. With such limited numbers taking part, mobility can neither solve the growing demands by employers for graduates able to work across countries and cultures nor will it enable local knowledge and contexts to contribute to solving major global issues, such as those highlighted in the SDGs.

\section{Aligning Internationalisation with Human Values and the Common Global Good}

The importance of internationalising the curriculum 'at home' has never been more vital than in the current cultural, economic, social, and political climate, not least because cultural diversity in local populations is increasingly prevalent, with intercultural engagement as part of personal and professional life becoming progressively the norm. However, institutions in the Global North and South are failing to take curriculum internationalisation forward in a way which will embed it more deeply in strategic plans.

Institutional and academic silos work against the need to be more comprehensive and integrated in our approach to internationalisation. Too often it is seen as the role of the international office to deliver an internationalisation agenda principally focused on mobility and income generation, rather than shared human values and the common global good. Moving from the 'success box' of internationalisation requires us to address assumptions and perceptions of what it means to be international, for our institutions and for ourselves. This can mean uncomfortable and challenging debates and may require fundamentally re-thinking our approach to international engagement, bringing it more in line with the institution's broader societal role.

The SDGs may offer a new framework within which the social role and responsibility of higher education internationalisation could evolve. Institutional internationalisation strategies focus overwhelmingly on recruiting international students, on building partnerships according to self-interest for impact at home or abroad through an enhanced international reputation, and on research with the greatest potential to raise both individual and institutional status. Egron-Polak and Marmolejo (2017) point out that this marginalises institutions' existing good work in international capacity building, curriculum internationalisation, global citizenship development, sustainability of lifestyles and the economy, development of health policies and practice, teacher training and so on, which offer more significant contributions to society and achievement of the SDGs. 
Indeed, these reflections are also behind the concept of Internationalisation of Higher Education for Society (IHES), which seeks to align the international and social responsibility dimensions of institutional strategy.

\section{Internationalisation for Society}

In addition to the capacity-building aspects of an institution's international engagement, other thematic examples of the role of higher education internationalisation in wider society include its contribution in relation to refugees and migration and the enhancement of social inclusion. It also needs to be seen in the context of all levels of education in order to be inclusive of as wide a population as possible.

With regard to what has been termed the 'forced internationalisation' of migrants and refugees (Streitwieser et al. 2017) view reception and support of these populations as being an important part of HE internationalisation frameworks and global engagement. Such an understanding, they argue, will not only solve the immediate problems of the individuals concerned but will also help to ensure those individuals have the skills and knowledge needed to facilitate reconstruction when political security has returned. This role can be connected to broader issues of global stability in the short and longer-term, enabling higher education to make a valuable contribution to post-conflict recovery.

Internationalisation as a means of enhancing social inclusion, as a contribution to social responsibility and the development of global citizenship is an increasingly present interest in many parts of the world. This is particularly true in developing countries, where higher education appears to show a more focused acknowledgement of the social mission of universities than elsewhere. In the developed world, the notion of 'society' has become more market-focused, and terms such as 'workforce development' and 'employability' dominate the agenda of higher education and its internationalisation.

To realise key societal objectives, it would seem obvious to suggest that internationalisation should be fundamental to education at all levels. Yet, until fairly recently, internationalisation in primary and vocational education has been largely ignored in spite of having evolved substantially. Internationalisation is not the exclusive domain of higher education and can only reach full potential if it is aligned with and built on other levels of education, emphasising social and individual inclusion in the process.

\section{What Next?}

Far from becoming globalised in the sense of homogenisation, our view is that internationalisation strategy across geographical contexts continues to develop beyond traditional understandings. Engaging with the different political, economic, social, and historical factors in regional settings can offer new insights for those who choose 
not to imitate Anglo-western models. In other words, how can institutions operate successfully in their local, national, and regional environments, making a meaningful and responsible contribution to the society they are part of, while also meeting internationalisation objectives? Will they take a competitive direction or the route towards a more socially-responsible approach?

As the COVID-19 pandemic has made obvious, the competitive route is difficult, requires substantial public and private investment, and can increase the social divide, especially where student mobility retains its primary focus. For some countries in the Global South, the interplay between globalisation, regionalisation and nationalisation may be complex, with the potential to highlight harmful effects of internationalisation resulting in its possible rejection. Delicate discussions around de-colonisation, de-racialisation and de-imperialisation may be more important in these contexts than internationalisation itself. However, nationalisation (or regionalisation) and internationalisation are two sides of the same coin. A total focus on nationalisation or regionalisation would mean isolation while exclusively concentrating on internationalisation would imply ongoing dependency and copying of Western approaches to internationalisation, not embedded in the local context.

A more socially-responsible route is not easy either, and also requires substantial public and private resources, but it is more socially inclusive and, in the long run, will result in a tertiary education sector with higher quality. This approach implies paying greater attention to internationalisation of the curriculum at home. It should align with other levels of education and better address the international dimensions of social responsibility.

So, to return to our question, what next for internationalisation as a global phenomenon? This question is even more fundamental in the current context, with the challenges of a pandemic, Black Lives Matter, nationalism and populism, along with a severe global economic crisis and climate emergency. In our view, internationalisation cannot continue to be driven primarily by competitive economic rationales. It has to find the right balance between local, national, regional and global needs and objectives. It has to work towards achieving the Sustainable Development Goals of the United Nations. It must respect local identities, cultures and languages. Mobility, for qualifications or credit, has to be downgraded as the focus of internationalisation strategies, in the interest of sustainability and inclusivity as well as environmental concerns. Global and intercultural learning for all has to be at the centre of strategies and policies, facilitated in part through the opportunities presented by technological innovation, and replacing the emphasis on mobility for the elite minority.

It is crucial that we take account of different contexts in our understanding and approach, considering internationalisation in a more nuanced fashion than before. We have attempted here to further such examination in order to stimulate reflection, understanding, and actions towards innovative, sustainable, ethical, and socially inclusive conceptualisations of internationalisation. 


\section{References}

Egron-Polak, E., \& Marmolejo, F. (2017). Higher Education Internationalization: Adjusting to new landscapes. In H. De Wit., J. Gacel-Ávila., E. Jones., \& N. Jooste. (Eds.), The Globalisation of Internationalisation: Emerging voices and perspectives. London: Routledge.

International Association of Universities. (2012). Affirming Academic Values in Internationalization of Higher Education: A Call for Action. Paris: IAU.

Streitwieser, B., Miller-Idriss, C., \& De Wit, H. (2017). Higher Education's Response to the European Refugee Crisis: Challenges, Strategies, and Opportunities. In H. De Wit, et al. (Eds.), The globalization of internationalization: Emerging voices and perspectives. (pp. 29-39). Taylor \& Francis.

Elspeth Jones is Emerita Professor of the Internationalisation of Higher Education, Leeds Beckett University, UK, and Honorary Visiting Fellow at the Centre for Higher Education Internationalisation, Università Cattolica del Sacro Cuore, Milan. She is founding editor of the book series Internationalization in Higher Education (Routledge) and curator of a YouTube channel, International Educator Conversations. Elspeth has researched and published extensively in the field and has undertaken work for governments, national and international organisations, and universities across five continents.

Hans de Wit is Professor and Former Director of the 'Center for International Higher Education' (CIHE) at Boston College, USA. He is Senior Fellow of IAU. He is a founding member and past president of the European Association for International Education (EAIE). He is Founding Editor of the 'Journal of Studies in International Education' (SAGE), and Consulting Editor of the journal Policy Reviews in Higher Education. He is a leading expert on internationalization of higher education and has written several books and articles on this topic as well as given advice to organizations like OECD, UNESCO, World Bank and European Commission.

Open Access This chapter is licensed under the terms of the Creative Commons Attribution 4.0 International License (http://creativecommons.org/licenses/by/4.0/), which permits use, sharing, adaptation, distribution and reproduction in any medium or format, as long as you give appropriate credit to the original author(s) and the source, provide a link to the Creative Commons license and indicate if changes were made.

The images or other third party material in this chapter are included in the chapter's Creative Commons license, unless indicated otherwise in a credit line to the material. If material is not included in the chapter's Creative Commons license and your intended use is not permitted by statutory regulation or exceeds the permitted use, you will need to obtain permission directly from the copyright holder. 


\title{
The Importance of Internationalization Today and the Leadership Role of IAU
}

\author{
Jocelyne Gacel-Ávila
}

Since its creation back in the fifties, the International Association of Universities (IAU) has been consistently fostering a set of academic values and principles to frame higher education institutions' mission and institutional practices, such as academic freedom, institutional autonomy, social responsibility, cooperation, solidarity, tolerance, equity in access, open access to knowledge, scientific integrity, ethical behaviour, and quality in learning, research and outreach. These principles are most valuable in a world where globalization and the global economy paradigm have triggered fierce competition among universities for prestige, talent and financial resources at the global level. This is encouraged by global rankings, provoking tensions with universities' national missions and putting at risk the values of inclusion, solidarity and local social commitments. Besides causing increased inequality and tensions in social cohesion, as well as the rise of new trends of nationalism and populism within countries, globalization has provoked geopolitical tensions and boosted a wider division between the Global North and the Global South.

To face this global context and a rising discontentment towards the Western model of internationalization, the IAU has been a pioneer in putting forward and endorsing a set of values in the declaration "Affirming Academic Values in Internationalization of Higher Education: A Call for Action" (International Association of Universities 2012). Besides proclaiming the substantial benefits of the internationalization of higher education, the declaration's main proposal has been to confront internationalization's potentially adverse unintended consequences, in order to ensure that its outcomes are positive and of reciprocal benefit to the institutions and countries involved. In the referred declaration, the IAU stressed internationalization as an evolving and dynamic concept, continuously shaped and reshaped by the international context in

\footnotetext{
J. Gacel-Ávila ( $\varangle$ )

University of Guadalajara, Guadalajara, Mexico

e-mail: jgacelav@gmail.com

(C) The Author(s) 2021 
which it occurs. The present pandemic has definitively raised the importance of the terms of this declaration.

Indeed, the pandemic has provoked a large and ensuing debate concerning the future of internationalization, prompting us to re-examine the validity of the IAU's principles and values in the light of the present context. Is the pandemic a turning point for internationalization? To what extent is the pandemic creating conditions for a long-lasting effect on internationalization? And, last but not least, will the pandemic's impact be the same in the Global North as in the Global South, as far as internationalization is concerned?

In search of a response to these questions, some experts argue that the impact will be transitory, affecting mostly physical mobility and its business-like approach, but without changing its main strategies in the long term; while some others claim that the pandemic is posing a serious threat to internationalization and could even provoke its end, at least as we presently know it; and finally there is another position stating that the pandemic's consequences offer a valuable opportunity to re-examine internationalization's objectives, strategies, values and intended impact. This latter argument is not new, since there was already an ongoing process before the pandemic occurred, to redefine internationalization in the face of globalization's negative economic and social consequences, in the search of addressing rising criticisms towards some aspects of internationalization.

The main criticism of internationalization is that it has mainly been synonymous with international mobility, considered elitist because only accessible to a minority of few economically advantaged students or to the ones who can secure funding or fellowships. In other words, mobility has been too often seen as an end, rather than a means of connectivity through research, teaching and learning.

Internationalization and international mobility are seen as a phenomenon overly dominated by the Global North and the Western model, increasing asymmetry in favour of developed countries and promoting inequality at two levels: inside each country and among nations and regions, thus widening the gap between the Global North and the Global South; as well as provoking a standardisation of ideas.

Furthermore, if it is true that international mobility develops in students intercultural competence, professional and personal skills, which increase their employability and potential for success; its social impact is nevertheless claimed to be quite limited, as its benefits only attain a very small number of students (between 1 and $5 \%$, depending on the region of the world); and furthermore, these benefits are effective at an individual level, but do not help students to be better global citizen, more aware of their responsibilities in civic and environmental matters; since there is a large-scale failure to integrate post-mobile students' intercultural experiences and global citizenship skills within the curriculum at home in benefit to the rest. In other words, mobility sustains an exclusive and selective model of education (Leask and Gree 2020; Hugonnier 2020).

Consequently, in the post-pandemic and its foreseeable long-term effects on the world economy, it is high time to rethink and redesign internationalization in a non-mobile world. In order to do so, countries and higher education institutions internationalization strategies have to change priorities. If internationalisation is to 
remain a defining feature of university life, it has to be re-imagined, and measures must be taken to make internationalization accessible to a much larger number of students in the world (Leask and Gree 2020).

Most likely, the pandemic will also have a strong impact on another key aspect of internationalization, which is international cooperation in capacity building in higher education in the Global South. As Aarts (2020) points out, many universities in the Global North support partner institutions in poorer countries and regions in Global South with the objective of strengthening their capacity to improve institutional practices in order to offer higher education of better quality, to underscore local development agendas and contribute to their research capacity as well as to their global sustainable development agenda. Unfortunately, funding for such efforts will be significantly reduced because of the upcoming economic crisis. Hence, international cooperation, a most pivotal value of internationalization, will be significantly affected.

To substitute international mobility, higher education institutions (HEIs) should then focus their internationalization process on strategies of internationalization at home (IaH) and internationalization of the curriculum (IoC). These strategies could reach similar results in students without mobility by internationalizing programmes, curricula and pedagogies.

According to Leask and Gree (2020):

\begin{abstract}
This new reality represents a rich opportunity for global learning at home, as online learning can open up the possibility of 'border crossing' for all students. Programmes such as Collaborative Online International Learning and virtual internships, combined with meaningful intercultural learning encounters on campus and in local communities, offer exciting potential to engage all students in meaningful intercultural learning on a global scale. The post-mobility world will allow for international partnerships to change from exporting education to collaborative models that use multinational expertise and situate education locally, while still building meaningful connections across borders and cultures. Moreover, a collaborative online model in which local university faculty co-teach with international faculty to deliver online courses could bend the cost curve, allowing high-touch online learning at the cost of a local degree - while encouraging knowledge transfer and building capacity in the process.
\end{abstract}

Nevertheless, the authors conclude that more research should be carried out to better understand the effects of this alternative internationalization and to identify the measures to be taken to make it more effective.

All this sounds fine and promising, but our concern is whether this transformation will be possible for the majority of universities. Will this transformation be within reach of the majority of HEIs in the Global South, namely for the Latin America and the Caribbean (LAC) region? or will the post-pandemic consequences deepen even further the inequality between the Global North and the Global South, as far as higher education internationalization is concerned? If the response is negative, the future of internationalization might well be quite uncertain for LAC and could even diminish to insignificant levels, making LAC graduates even less competitive and potentially less successful than the students of the rest of the world; and LAC higher education systems less pertinent to their society. 
In our opinion, the above-mentioned transformation of internationalization strategies will definitely not be so easy to implement for most universities in the Global South, or least for Latin America and the Caribbean, due to several factors inherent to the weaknesses of its higher education systems.

As reflected in different evaluations, namely the IAU's Internationalization Surveys (Egron-Polak and Hudson 2010; Marioni 2019), the British Council Reports (Ilieva and Peak 2016; Ilieva et al. 2017; Usher et al. 2019) and the OBIRET Survey (Gacel-Ávila and Rodríguez-Rodríguez 2019), LAC's internationalization process is mainly and sometimes exclusively focused on mobility, with IaH strategies quite absent among the large majority of HEIs. Our concern is that $\mathrm{IaH}$ and $\mathrm{IoC}$ are by far the most complex strategies to design and implement, in particular, because they require some basic conditions to be present in the higher education systems; conditions which do not prevail in LAC. First of all, the region is characterised by a lack of public policies to support internationalization and is reported to have the least supportive governments of the world in that respect. In the forthcoming future and deep economic crisis, this situation is not likely to change; on the contrary, the light support achieved in the last decade could well disappear in favour of more urgent matters. Furthermore, as far as institutional policy is concerned, internationalization activities are still largely marginal to policymaking in teaching and research; and consequently, there is an overall lack of institutional planning, budgeting and evaluation of internationalization activities. Moreover, international activities are mainly based on individual initiatives and therefore fail, for the most part, to respond to institutional priorities. In other words, the large majority of HEIs has not yet developed an institutional culture for internationalization and its inclusion within policy, priority setting and budget processes. Additionally, the great majority of faculty is part-time and has no international profile; and the region has no strategy to recruit international scholars. In terms of curriculum, it is well-known that it lacks flexibility and innovation, is mainly traditional, profession-oriented and more than often obsolete. Additionally, the region's higher education systems suffer from a chronic lack of financial resources, infrastructure and professionalised human resources both for academic and administrative work. Furthermore, if international mobility mainly depends on the family's resources, IaH relies on institutional resources, which were extremely scarce before the pandemic and certainly will be even more so after it. The investment in international research is among the least of the world and mostly depend on foreign initiatives and subsidies, which will probably decrease in the post-pandemic period. Last but not least, as Unkule (2020) mentioned, international offices will be key for the transformation and should be:

on the frontline of advising students and faculty members, inventing catch-up strategies and looking for solutions that accommodate the new normal.

Unfortunately, this is another point of concern for LAC's internationalization processes, as the majority of international offices have little sway over policymaking, institutionalization and professional staff, with heads of office most of the time devoid of the expertise and experience required to deal with such a challenging task, due to 
a constant turnover in staff and recruitment based more on affinity with the rectors than on professional standards.

In other words, LAC's internationalization processes are far from being comprehensive, which is a real handicap to overcoming the present situation, as Hudzik (2020) points out:

"A failure to integrate international activity into core teaching, research and scholarship, and community engagement missions is a fundamental error which seriously weakens internationalization's future position within institutions". "Resource sufficiency is at best extremely difficult in the absence of an institution-wide supportive culture and the participation of international leadership (senior international officer and programme directors) in strategic planning and budgeting processes".

In conclusion, the future of the internationalization in the Global South might be greatly affected due to an unprecedented economic crisis, forthcoming budget cuts in higher education, research, innovation and development, as well as a substantial reduction in mobility and international cooperation. Internationalization in LAC will most likely be reduced to insignificant levels, which will eventually deepen inequalities of opportunities among higher education students, faculty and institutions and will reinforce the elitist model of internationalization in society and with the developed regions of the world. More than ever, internationalization will be for a social elite and for institutions in the Global North. Within this context, the universities of the most developed countries should recall the IAU's principles and values of inclusion, fairness, solidarity and global commitment. More than ever, in post-Covid-19, the prevailing context for higher education internationalization will require all institutions to revisit and affirm internationalization values, principles and goals such as intercultural learning, inter-institutional cooperation, mutual benefit, solidarity, mutual respect, and fair partnership. The future of internationalization will require institutions committed to help shape a global system of higher education that values academic integrity, quality, equitable access, reciprocity and placement of academic goals such as global citizenship skills, the advancement of research, and addressing global problems at the centre of internationalization efforts. Within the context of forthcoming internationalization, IAU's principles expressed in the 2012 Declaration will be more than ever relevant and reflect IAU's pioneer vision and ability to position key ideas and values for the higher education sector. Additionally, the IAU Internationalization Surveys will continue to be the most valuable tool for feedback on institutional practices to help make the necessary transformations in internationalization strategies as described above.

\section{References}

Aarts, H. (2020, June). Covid-19 hits higher education capacity building ties with the Global South. University World News.

Egron-Polak, E., \& Hudson, R. (2010). Internationalization of Higher Education: Global trends, reginal perspectives. (IAU 3rd Global Survey Report). Paris: International Association of Universities. 
Gacel-Ávila, J., \& Rodríguez-Rodríguez, S. (2019). The Internationalization of Higher Education in Latin America and the Caribbean. First edition in English. Guadalajara: Universidad de Guadalajara, UNESCO-IESALC.

Hudzik, J. (2020, June). How to strenghten internationalization post-covid 19. University World News.

Hugonnier, B. (2020, April). Internationalizating higher education for a better world. University World News.

Ilieva, J., \& Peak, M. (2016). The Shape of of Global Higher Education: National Policies Framework for International Engagement. London: British Council.

Ilieva, J., Killingley, P., Tsiligiris,V., \& Peak, M. (2017). The Shape of Global Higher Education: International Mobility of Students, Researach and Educational Provision. London: Bristish Council.

International Association of Universities (IAU). (2012). Affirming Academic Values in Internationalization of Higher Education: A Call for Action. Paris: IAU.

Leask, B., \& Gree,W. (2020, May). Is the pandemic a watershed for internationalization. University World News.

Marioni, G. (2019). Internationalization of Higher Education: An Evolving Landscape, Locally and Globally. IAU 5th Global Survey. Paris: International Association of Universities.

Unkule, K. (2020, March). An opportunity to change international higher education. University World News.

Usher, A., Ilieva, J., Killingley ,P., \& Tsiligris, V. (2019). The shape of global higher education: The Americas. London: The Bristish Council.

Jocelyne Gacel-Ávila is Associate Dean in Social Science and Humanities and tenured Professor at the University of Guadalajara; coordinator of RIESAL (Network for the Internationalization of Higher Education in Latin America) and of the UNESCO Observatory for the Internationalization of Higher Education and Networks in Latin America and the Caribbean. She was NAFSA Senior Fellow for Internationalization; Vice-President of the OECD Institute for the Management of Higher Education, Vice-President of the Consortium for Higher Education in North America; President of the Mexican Association for International Education; collaborator of the World Bank and the IAU.

Open Access This chapter is licensed under the terms of the Creative Commons Attribution 4.0 International License (http://creativecommons.org/licenses/by/4.0/), which permits use, sharing, adaptation, distribution and reproduction in any medium or format, as long as you give appropriate credit to the original author(s) and the source, provide a link to the Creative Commons license and indicate if changes were made.

The images or other third party material in this chapter are included in the chapter's Creative Commons license, unless indicated otherwise in a credit line to the material. If material is not included in the chapter's Creative Commons license and your intended use is not permitted by statutory regulation or exceeds the permitted use, you will need to obtain permission directly from the copyright holder.

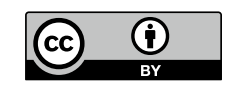




\title{
International Collaboration: Necessary, But Challenging
}

\author{
Jeroen Huisman
}

The claim that international collaboration is important is a truism. A myriad of reasons for cooperation is evident if one looks at existing cooperative arrangements. These may be motivated by an economic perspective (an efficient and synergetic use of human and technological resources, think for example, of large telescopes, particle accelerators, labs, but also of large international datasets), by a cultural perspective (learning from each other) or by a political perspective (development and diplomacy).

In the past two decades or so, the theme of international collaboration has witnessed increased attention. First and foremost, higher education institutions themselves have been eagerly exploring partnerships. Globalisation and technological progress have broadened the institutional horizon and hence offer new - and plenty opportunities. Second, governments - national and supranational - have been increasingly seeking and actually trying to stimulate cross-border institutional cooperation. Especially the fairly recent European Universities initiative springs to mind, but we should not underestimate national governments' initiatives to stimulate international collaboration. Comparing these developments with early-day collaboration in higher education, we see a gradual change in efforts of scholars to work together on an individual basis towards more structured arrangements involving the leadership and administration of higher education institutions.

Increased interest in the theme has also sparked scholarly attention to the phenomenon. A quick search in the archives of Higher Education Policy leads to numerous papers that address collaboration, competition, partnerships, etc. Actually, the history can be traced back to the first volume of the journal, with former IAU president Justin Thorens' 1988 reflection on problems of culture and international cooperation. The continued attention to the theme is witnessed by the (so far) latest paper on the theme, by Marianne Larsen and Clara Tascón on cooperation between Cuban

J. Huisman ( $\varangle)$

Ghent University, Ghent, Belgium

e-mail: jeroen.huisman@ugent.be

(C) The Author(s) 2021 
and Canadian higher education institutions. The variety of specific themes addressed in the 33 volumes of the journal is overwhelming. Publications address micro-level motivations of individual researchers and lecturers, meso-level motivations for strategic partnerships, the experiences of staff, students and leadership and the impacts of collaboration. Not surprisingly, the attention to cooperation echoes the long-standing and laudable commitment of the IAU to university collaboration and partnerships across the globe. It does a wonderful job, speaking with one voice while respecting the diversity of its membership.

What most of the studies on collaboration in higher education have in common is that they continue to stress the challenges, barriers and problems in cooperation. We should not dismiss great achievements, but it is interesting to see that even after decades of experience, challenges still appear to dominate. Much of the strains are undeniably connected to the fact that partners differ. In fact, this is the premise for cooperation. Whatever motivates institutions and individual academics, it boils down to the idea that we seek collaboration when we cannot do things on our own or can do things better if we cooperate. This presupposes that partners have different qualities that transpire in different specific rationales for cooperation, different cultures and different structures. Although Joe Jackson - in the song We Can't Live Together did not refer to cooperation in higher education, his lyrics go straight to the heart of the matter:

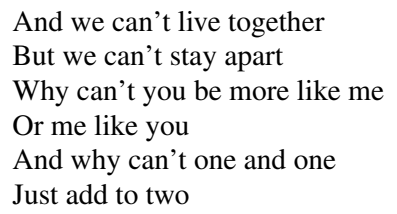

We should, however, not give up. The challenges are definitely there, but they are not insurmountable. We have to realise that success in structural partnerships is not a given and that investments (personal, administrative and financial) are needed to make it all work.

This leads me - in closing - to a couple of personal reflections. My experiences have taught me that international cooperation in research or teaching can be challenging. The hardest bit - in my view - is to make a start with new partners. Courting, getting to know each other are exciting phases of the collaboration process, but go along with anxieties related to the short- and longer-term sustainability of the partners. Once having successfully worked with international partners, it appears to be relatively easy to continue the collaboration, either firmly through a formal contract or more organically when opportunities arise. Risk-avoiding behaviour, however, may also imply that potentially promising new partnerships are not explored or are too easily discarded.

A second reflection pertains to the challenges of synchronising the institutional objectives with personal academic ambitions within a particular higher education institution. As mentioned earlier, more and more higher education institutions are developing plans for strategic international cooperation and are setting priorities in this area. This makes sense from a rationalistic efficiency perspective: why not focus 
on a limited set of sustainable partnerships that are successful or are very likely successful in the near future? The challenge here is two-fold. First, it is difficult to unambiguously prove or predict success in international collaboration. Success is dependent on so many different factors, and even if all preconditions seem to be met, effects may not easily be measurable or not even be visible in the short-term. Therefore, what criteria should a higher education institution use to make strategic decisions? Second, despite all the gloss that higher education institutions themselves put on strategic collaboration, ultimately institutions actually do not collaborate. Representatives of the institutions may sign contracts or memoranda, but the actual collaboration relies heavily on the motivation and interests of academics, administrators and students. And these may not correspond seamlessly with those of the institutions. The institution may look to the east, the academic to the west and the student to the south. Anyway, maybe we should not unnecessarily problematise this: as long as different parties are willing to look in different directions, there will be sufficient scope for interesting and beneficial cooperation.

Jeroen Huisman is Professor of Higher Education and Director of the Centre for Higher Education Governance Ghent (CHEGG), Ghent University since 2013. He holds a PhD from the University of Twente, the Netherlands, where he also worked as a post-doctoral researcher and research coordinator (1991-2005). He was a Professor of Higher Education Management at the University of Bath, UK (2005-2013). He is editor of IAU's journal Higher Education Policy and his main research interests are organizational diversity and change in higher education and policy and governance in higher education.

Open Access This chapter is licensed under the terms of the Creative Commons Attribution 4.0 International License (http://creativecommons.org/licenses/by/4.0/), which permits use, sharing, adaptation, distribution and reproduction in any medium or format, as long as you give appropriate credit to the original author(s) and the source, provide a link to the Creative Commons license and indicate if changes were made.

The images or other third party material in this chapter are included in the chapter's Creative Commons license, unless indicated otherwise in a credit line to the material. If material is not included in the chapter's Creative Commons license and your intended use is not permitted by statutory regulation or exceeds the permitted use, you will need to obtain permission directly from the copyright holder.

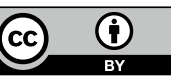




\title{
Getting Unstuck with \\ Internationalization at Home: Seizing the Post-pandemic Moment
}

\author{
Madeleine Green
}

\section{An Uncertain Future for Higher Education and Internationalization}

As I write this essay in late May 2020, the higher education press is blanketed by debate about the enduring changes brought on by COVID-19. Some maintain that the pandemic has already triggered disruptive changes, such as the quick move to online learning and variations in the academic calendar. They speculate that these shifts will endure after the crisis passes. Others predict a shift in the landscape of higher education. In countries with a private higher education sector that is highly dependent on tuition revenue, a substantial number may close, and the resulting landscape will be dominated by stronger, richer institutions. One estimate is that $20 \%$ of private institutions in the United States will close (Wescott 2020).

Although changes precipitated by the pandemic have been largely reactive, many higher education observers see the crisis as presenting a window of opportunity for making lasting and fundamental changes long overdue in the academy. A minority view less visible in the press and undoubtedly less exciting and encouraging, highlights the inevitable pull of business as usual, that, over time, higher education will revert to old practices. Since it is not possible to predict the future, it is too early to know which scenario will dominate or if there will be some combination of the two.

The future of internationalization is equally contested. Some, such as Philip Altbach and Hans De Wit (2020), see the inevitable pull of returning to the status quo ante and are sceptical that the move to online learning will endure, that mobility will cease to be an important option over the long-term, or that institutions will easily give up the revenue provided by international students. Indeed, they speculate that institutions may double down on the recruitment of international students,

\footnotetext{
M. Green ( ()

International Association of Universities, Paris, France

e-mail: madeleinefgreen@gmail.com 
so important is the revenue they bring to the financial health (or viability) of the enterprise.

A major question is whether the pandemic will provide a moment for Internationalization at Home to flourish given that mobility, which already involves only the privileged few, will be curtailed for the foreseeable future. Will this disruption of the status quo push institutions to redirect their attention to the academic and socio-cultural benefits of internationalization, rather than the economic benefits, and pay serious attention to Internationalization at Home?

Although the past does not predict the future, it is useful to consider where internationalization was headed before the pandemic and the three important trends affecting the future of Internationalization at Home.

\section{Three Important Trends in Internationalization Pre-COVID}

Changing patterns of mobility: The last 20 years have seen tremendous growth in the numbers of international students, from 2.1 million in 2001 to 5.3 million in 2019 (IIE, Project Atlas), with China and India sending the lion's share of students. We have also seen a shift in the receiving nations, with the United States receiving a diminishing share of these students, from $28 \%$ in 2001 to $21 \%$ in 2019 (IIE, Project Atlas). Short-term credit mobility has grown, especially in the United States, where $64 \%$ of all students are engaged in education abroad programs of eight weeks or less (IIE, 2019, Open Doors.) But it is important to consider that patterns shift over time. Korea, Iran, and Saudi Arabia are no longer as significant senders as they were in the past. Government support for mobile students ebbs and flows. Intra-regional mobility has grown, and the attractiveness of the United States has waned while Canada and Australia have gained international enrolments. The result will certainly be less international mobility in the short-term, and perhaps long-term, as well as further shifts in the relative positions of sending and receiving countries.

The drive for revenue from international students: International students are a vital source of income for various nations and their institutions: Australia had 440,000 international students in higher education in 2018-19 (Australian Government Department of Education 2020). International education was Australia's fourth-largest export in 2019, worth nearly AU\$38 billion; about half of that total comes from higher education. (Australian Government Department of Education 2019). According to NAFSA estimates, international students bring US $\$ 41$ billion and 458,000 jobs to the U.S. economy (NAFSA n.d.). U.S. institutions compensated for the decrease in state appropriations after the 2008 recession by stepping up their recruitment of international students; international enrolments grew by 30 percent from 2007 to 2012. More than 36 percent of US campuses derive more than 10 percent of their income from international students (Fischer 2019). Many speculate that this financial dependency on international students in the high-receiving nations 
such as the U.S., Australia, and the U.K. is unsustainable and that the effect of the pandemic will cause a shift from seeing international students largely as a major revenue source to an earlier conception stressing the academic and socio-cultural benefits of their presence and a revival of "ethical internationalization" (De Wit 2020). A shift towards the original goals of internationalization would bode well for greater attention to Internationalization at Home.

The push for Internationalization at Home: International educators enthusiastically endorsed Internationalization at Home at the same time that mobility gained visibility and importance. If learning and the quality improvement of all aspects of higher education are key goals of internationalization, it stands to reason that nonmobile students and faculty need to participate as well. Internationalization at Home democratizes internationalization, broadening access to all students rather than the select few who have the financial means to be mobile. It represents an opportunity to incorporate global learning in the mainstream of curriculum, moving internationalization from the margins of an institution (where it generally resides) to the center. But Internationalization at Home has been an uphill battle, explained in part by the fact that mobility has been synonymous with internationalization and economic benefits have taken precedence over internationalization's academic and socio-cultural value. Although limited progress has been made to date, might a conscious move away from the "mobility equals internationalization" model, with the advantages of increased access, lower carbon footprint, and combatting brain drain, give new energy to Internationalization at Home? (White and Lee 2020).

\section{Moving Ahead with Internationalization at Home}

What will it take for Internationalization at Home to gain real traction in higher education? The jury is out on this question, as Leask and Green (2020) note, but doing more of the same is unlikely to yield anything but continued slow progress. As the following section of this essay outlines, several conditions will have to be present for this to happen.

\section{A Sense of Urgency}

Often, a sense of urgency is required to generate energy for important changes. Such pressure is usually a result of an external force or set of circumstances-budget crises, changes in government policy, and now COVID-19. The urgent issues resulting from the pandemic are practical and operational, such as coping with enrollment and revenue shortfalls and safely reopening campuses. Not surprisingly, curriculum (as opposed to pedagogy related to online instruction) is likely to take a back seat until the most pressing problems are tackled. Although the issues addressed by 
internationalization are of supreme urgency to humanity-climate change, poverty, health - to date, there has not been a sufficient sense of urgency on most campuses to warrant a sustained campaign for internationalization. This is not to say that some faculty members, often depending on their discipline, do not feel a sense of urgency about the global issues with which they are engaged. But given the competition for attention on any campus, the lack of success to date in truly embedding Internationalization at Home, and the overwhelming institutional preoccupation with coping with the immediate fallout of the pandemic, it is unlikely that Internationalization at Home will rise to the top of the priority list soon.

Is it possible to generate a sense of urgency without severe external pressure? It is not easy. An internally generated change such as Internationalization at Home usually starts with the perception that something is not working (a problem) or that it could be working a lot better (an opportunity). The more severe the perceived problem, the greater the likelihood of it generating a sense of urgency around its solution. Shared recognition of the existence of a problem and agreement on its nature constitutes a crucial first step, generally accomplished through abundant conversations among faculty, usually at the department level, or in the case of general education in the United States, with a larger group of faculties from many disciplines who teach in the general education program.

\section{Reframing the Discussion}

Another emerging theme in the internationalization discourse is that internationalization is not an end in itself. Rather, it is a means of furthering institutional and societal goals - enhancing the quality of teaching and research, fostering an educated citizenry, and solving local and world problems. Seen this way, internationalization is not just one more thing that faculty members are asked to do on top of everything else - and someone else's idea - but integral to their teaching and research. If internationalization is a means to an end, then the goals become more important than the means to accomplish it. Reframing the discussion in terms of goals should change the language of the discussion (allowing for a largely disciplinary lens and language), It should also diminish the dichotomy between Internationalization at Home and mobility; both can be seen as valid means to the achieve the same objectives, allowing for a "both and" rather than an "either or" approach. Any such mental shift is never easy, and making this happen will require subtle leadership by international officers and more visible leadership by faculty members.

\section{Leadership at Many Levels}

Enduring academic change requires strong faculty leadership as well as visible support and championing from the top. Putting greater emphasis on Internationalization 
at Home requires new thinking about what students need to learn and what goes on in the classroom. Administrative fiats may result in some level of compliance, but they rarely produce shifts in thinking or the belief that the new approach is anything but a fad. By the same token, changes supported by a few faculties rarely get enough traction to spread. They need to be encouraged by the support, resources, policy changes that administrators can provide. In short, an accelerated course for Internationalization at Home will require an articulate group of faculty leaders that is encouraged by vigorous institutional support.

\section{Collective and Individual Action}

The infamous silos of academe and the lack of collective ownership of the curriculum, sometimes even within academic departments, have resulted in a curriculum in many institutions that is not greater than the sum of its parts. Professors own their courses, and departments may or may not choose to provide a coherent study program to progress in such a way that students connect concepts from one course to another. Just as the fragmented curriculum is largely due to the lack of collective ownership, the inability to systematically integrate Internationalization at Home into the curriculum and campus life can be largely attributed to a lack of collective action. Internationalizing specific courses is certainly a good idea, but it will not ensure that students will gain global knowledge or intercultural skills throughout their studies. Similarly, a smattering of international research projects will enhance the quality of those particular efforts, but will likely not affect others.

The curricular and extra-curricular changes required by Internationalization at Home will require collective examination of current curriculum and campus life, developing a shared sense of goals and direction, and agreement on a shared course of action that provides broad commonalities and at the same time allows each faculty member and administrator to autonomously achieve those goals.

\section{A Positive Agenda}

The loftier goals of internationalization should resonate, especially today. Institutions need to be - and be seen as - beacons of progress and hope in a world roiled by COVID19, perilous inequality, and growing nationalism and xenophobia. The pandemic represents an opportunity for institutions and their faculty and administrators to make a strong statement to students and the public about their values and their contributions to society. This is an agenda that has the potential of rallying wide support within the academy and providing a foundation for concerted action. 


\section{Conclusion}

While COVID-19 may present a window of opportunity for Internationalization at Home, without a new sense of urgency, a new language, sense of purpose, and commitment and leadership at many institutional levels, it is likely to progress at a very slow pace and remain a low priority for HEIs. Internationalization at Home is an ambitious change. One requiring many faculty members to think differently about their disciplines and courses, and for administrators to develop a different frame of reference for the workings of the institutions. The challenge is great, but the opportunity is there to seize.

\section{References}

Altbach, P., \& De Wit, H. ( 2020, March 14). COVID-19: The Internationalisation Revolution that Isn't. University World News. Retrieved from: https://www.universityworldnews.com/post.php? story $=20200312143728370(26.07 .2020)$

Australian Government Department of Education (2019, December). Research Snapshot. Retrived from: https://internationaleducation.gov.au/research/Research-Snapshots/Documents/ Education\%20infographic\%20Australia\%202018--19.pdf (26.07.2020)

Australian Government Department of Education. (2020, January). Research Snapshot. Retrieved from: https://internationaleducation.gov.au/research/Research-Snapshots/Documents/ RS_AusUKComparison.pdf (26.07.2020)

De Wit, H. ( 2020, May 23). Business Model of Internationalisation is Falling Apart. University World News. Retrieved from: https://www.universityworldnews.com/post.php? story $=20200519133420380(26.07 .2020)$

Fischer, K. ( 2019, September 13). International students bailed out colleges in the last recession. They won't this time. Chronicle of Higher Education. Retrieved from: https://www.chronicle. com/article/International-Students-Bailed/2471 30 (26.07.2020)

Institute for International Education (IIE). (2019). Project Atlas. Retrieved from: https://www.iie. org/en/Research-and-Insights/Project-Atlas/Explore-Data/Infographics/2019-Project-AtlasInfographics (26.07.2020)

Institute for International Education (IIE). (2019). Open Doors Fast Facts. Retrieved from: https://www.iie.org/Research-and-Insights/Open-Doors/Fact-Sheets-and-Infographics/FastFacts (26.07.2020)

Leask, B., \& Green, W. (2020, May 02). Is the Pandemic a Watershed for Internationalisation? University World News. Retrieved from: https://www.universityworldnews.com/post.php? story $=20200501141641136(26.07 .2020)$

NAFSA (n.d.). NAFSA International Student Economic Value Tool. Retrieved from: https://www. nafsa.org/policy-and-advocacy/policy-resources/nafsa-international-student-economic-valuetool-v2 (26.07.2020)

Wescott, D. ( 2020, March 25). Will the Corona Virus Close Your College for Good? Chronicle of Higher Education. Retrieved from: https://www.chronicle.com/article/Will-Coronavirus-CloseYour/248331 (26.07.2020)

White, B., \& Lee, J. ( 2020, April 18). The Future of international HE in a post-mobility world. University World News. Retrieved from: https://www.universityworldnews.com/post.php? story $=20200417105255362(26.07 .2020)$ 
Madeleine Green served as Vice President for International Initiatives at the American Council on Education until 2010. Since then, she has served as a Senior Fellow at NAFSA: the Association of International Educators and as an independent consultant. Her principal areas of expertise are policy and practice in internationalization and institutional leadership, management and governance. She is widely published in these areas. She has served as a member of the IAU administrative board and on the boards of several U.S. higher education institutions and organizations. She is Senior Fellow of the IAU.

Open Access This chapter is licensed under the terms of the Creative Commons Attribution 4.0 International License (http://creativecommons.org/licenses/by/4.0/), which permits use, sharing, adaptation, distribution and reproduction in any medium or format, as long as you give appropriate credit to the original author(s) and the source, provide a link to the Creative Commons license and indicate if changes were made.

The images or other third party material in this chapter are included in the chapter's Creative Commons license, unless indicated otherwise in a credit line to the material. If material is not included in the chapter's Creative Commons license and your intended use is not permitted by statutory regulation or exceeds the permitted use, you will need to obtain permission directly from the copyright holder. 


\title{
Levelling up International Higher \\ Education: Universities, Nations and \\ Global Goals
}

\author{
Jo Beall
}

\section{Introduction}

Universities are not only the anchors, shapers and innovators of nations but they galvanise the building and rebuilding of nations. They are a source of knowledge, an arena to develop understanding and provide the vehicles for interpreting and addressing the key challenges of our time. Nations need universities to develop home-grown solutions for the problems and opportunities with which they are presented, and so they can participate with value and confidence in international scientific eco-systems. Yet, national universities do not and should not act alone. Agenda 2030 and the Sustainable Development Goals constitute the principal international convention of our time and offer a positive step in recognising the importance of tertiary education to individual and social advancement. However, they do not go far enough, particularly from the vantage point of nations with ambitions to grow prosperous economies and engaged societies. This chapter explores the national and international role of universities and the benefits or otherwise of the internationalisation of higher education and global conventions such as Agenda 2030.

\section{Setting the Scene}

From time immemorial scholars have sought to exchange ideas and to collaborate across international boundaries. National science, understood in its broadest sense to include the humanities and social sciences, cannot and should not remain isolated from global scholarly debates and research endeavours. However, higher education is no longer simply the purview of curiosity-driven scholars engaging across borders.

\footnotetext{
J. Beall (凶)

London School of Economics and Political Science, London, UK

e-mail: j.beall@1se.ac.uk 
Over recent decades, higher education systems have become increasingly internationalised, and along with this trend, they often become more and more commercialised. For some time, this dramatically skewed the international higher education landscape. It did so in favour of universities that were part of established systems, largely in the advanced economies, which were able to dramatically expand their international teaching activities by literally trading on their histories and well-honed expertise.

Universities did this in two ways: by attracting international students to their doors and by delivering degrees abroad. Transnational education (TNE) has taken different forms from joint degrees and Ph.D. programmes offered in whole or in partnership with domestic institutions, through to the full-blown creating and running of branch campuses in new countries. In its best guise, it emphasises partnership and, in its worst, it is most usually associated only with profit. In assessing the impact of TNE, for European and North American institutions it helped them expand their reputation as well as their coffers at a time when they were experiencing declining domestic demand, due to a slow-down in population growth and demand for tertiary education. This suited many countries with smaller higher education systems that were nevertheless experiencing a growing demand for tertiary education due to population growth and greater prosperity.

The internationalisation of higher education is accompanied by both opportunities and challenges. Commercial drivers underpinning TNE demand constant vigilance on the part of host nations and potential students with regard to ensuring standards match those of home campuses and that the education they receive represents value for money. Difficult dynamics can also arise when domestic and international universities compete to secure for themselves the brightest and best academics and students in a country. Further, there are modus operandi that offer examples of better or worse practice. For instance, some universities work on the principle of equitable partnership in their teaching and research collaboration, while others focus primarily on their profit margins. For better or worse, national governments have been known to deliberately cultivate TNE in order to help improve their own standards or research reputations. Countries such as China and Singapore that have gone this route have fared very well, without sacrificing their autonomy and often periodically renegotiating the nature of their international agreements. In the process, their universities have steadily risen up the international league tables.

Universities have also contributed to local and regional development. Today, city and sub-national governments increasingly see universities as pivotal to local economic innovation systems, labour markets and social engagement with local communities and citizens. Universities, industry and local governments working together to create innovative partnerships can become international hubs and players on their own account. This is perhaps best exemplified by the role played by the Government of California and Stanford University in the development of Silicon Valley, but another perhaps less well-known example is Kuala Lumpur, which through national policy support has become an internationally recognised higher education hub that serves not only the country but the Association of South-East Asian Nations (ASEAN) region and beyond. As cities, nations and regions grow their own tal- 
ented knowledge-economy graduates, and as they participate as equals and leaders in international research eco-systems, we see the playing field of international higher education being levelled.

\section{Universities and Nation-Building}

It is against a background of these challenges and opportunities that today's national leaders seek to maintain a critical balance between keeping universities at the heart of their nation-building processes, while at the same time retaining with and for them, their international reputation and relevance. During the independence period in Africa, leaders such as Julius Nyerere and Kwame Nkrumah believed that higher education would be critical to the self-determination and economic development of post-independence countries. In this vein, in 1961 during his speech to the Council of the University of Ghana, Nkrumah said that the University of Ghana, newly independent from the University of London, had to contribute to national and regional development. He added an important caveat: in order to do that effectively and to retain respect, the University also had to remain internationally recognised and connected. Many universities globally have been fellow travellers in the wake of these wise words, to the benefit not only of their own countries but the wider world as well (Enders 2004: 367).

Historically, there has been strong acknowledgement that universities can and do play an important part in the process of nation-building, as custodians and generators of national culture. They do this particularly through the humanities, for example languages, history and the arts, but also through the sciences and the social sciences. In this way, they engage communities and promote political stability by actively contributing to the establishment of national cultures that underpin the formation and strengthening of nation-states. Importantly, it is international recognition from other nations that cements and strengthens national identities. Nkrumah recognised this, and leaders like himself ensured that universities would play a critical role, as newly independent countries sought to establish national systems and institutions in the post-colonial era.

Today, the expansion of international higher education and research partnerships are seen by many national governments as a means to deliver on national growth priorities. Universities are interactive institutions that work together with industry, commerce, government and communities and as such, became increasingly seen as integral to national innovation systems (Mowery and Sampat 2005). In many emerging markets, national and local governments explicitly link the internationalisation of higher education and research to economic development in their national planning processes (Altbach et al. 2009; Beall 2016). As such, state intervention in the field of international higher education and research is unlikely to disappear any time soon. The questions, therefore, are how internationalisation is conducted, who is involved and through what modalities? 


\section{International Conventions and Practices}

At the turn of the millennium, 189 nations made a promise to eradicate poverty across the world by 2015, a pledge that turned into the Millennium Development Goals (MDGs). While good progress was made for many of the MDGs, they were generally seen as unfinished business. The second goal was to 'achieve universal primary education', which was an important and worthy target, although one of the goals not met. Trying to meet the target led to reach being prioritised over quality of provision, but of greater relevance for present purposes was the fact that secondary and tertiary education were ignored. This was reflective of the global educational debates and development priorities in which the MDGs were located, but it also set the terrain for priorities going forward (Beall 2015). As a result, it was a real struggle to achieve a specific focus on higher education under the successor convention, Agenda 2030 and the Sustainable Development Goals (SDGs). Ultimately, however, a holistic and systemic approach to education was endorsed, rather than picking off primary schooling.

In addition to international policy conventions, there are membership bodies in international higher education that have flown the flag and, by definition, exhibit a commitment to principles of parity. Examples here would include the International Association of Universities (IAU), the Association of Commonwealth Universities (ACU) and the African Research Universities Alliance (ARUA). Yet, in looking at the ways in which institutions and system engage internationally, it is important to recognise that relationships are not built on a tabula rasa. Some institutions have been at it for centuries, while others are new to the table. Some faculty are more au fait with international and cross-cultural communication than others. And some countries are better resourced or choose to spend greater proportions of domestic income and savings on internationalising their higher education sectors.

In addressing inequities and imbalances, there are lessons to be learned. I will share just one here. INASP began as an Oxford-based charity that engaged scientific journals and prevailed upon them to offer journals at a highly subsidised rate to less privileged universities in low-income countries. Its brief grew to include programmes such as Author Aid, which helps academics and researchers from these same institutions and settings to get published, including a strong focus on gender disparities within them. Today, INASP is spearheading an international network committed to locally generated knowledge and solutions that are key to solving local and global challenges. As part of this, it supports government institutions in improving the use of research and evidence to inform policy so recourse does not always and only have to be made to bilateral and multinational organisations (INASP 2020). It is examples such as these that offer hope to nations struggling to establish viable and confident higher education systems for themselves, let alone trying to compete internationally, although we should also be clear that they too have much of value to share. All too often, the researchers from institutions with extensive libraries and equipment dominate in research projects and publications over local partners who have access to 'the field' and an understanding thereof. 


\section{Conclusion}

As we enter this unprecedented period in which our global present and future are being shaped by unknown viruses and burgeoning global discontent, learning from local knowledge and solutions drawn from all over the world has never been so important. The treatment and management of HIV/AIDS and Ebola in Africa can tell us much about how to handle global pandemics such as COVID-19. Rebelling against the legacy of colonialism and apartheid rule, South African students challenged those with enquiring minds everywhere to question the nature, source and purpose of knowledge. Calls for decolonising the curriculum are now heard on the streets of Britain as statues of slave traders tumble and fall. Never before has it been so important to answer the question, who owns the canon? The critical thinking and spirit of curious enquiry engendered by universities need to be front and centre not only of the building but also of the re-building of national identities. They are desperately needed to provide the intellectual spaces to forge the canon for the next seventy years of the IAU.

\section{References}

Altbach, P.G., Reisberg, L., \& Rumbley, L.E. (2009). Trends in global higher education: Tracking an academic revolution. Report prepared for the UNESCO World Conference on Higher Education. Beall, J. (2016). Universities and their importance to nations and cities. In M. Stiasny \& T. Gore (Eds.), Going Global: Connecting Cultures, Forging Futures (Vol. 5, pp. 219-231). London: Institute of Education Press.

Beall, J. (2015). Tertiary education: The unfinished business of the Millennium Development Goals. In M. Stiasny \& T. Gore (Eds.), Going Global: Inclusion, Innovation, Impact (Vol. 4,pp. 217-228). London: Institute of Education Press.

Enders, J. (2004). Higher education, internationalisation, and the nation-state: Recent developments and challenges to governance theory. Higher Education 47, 367.

INASP. (2020). INASP Strategic Plan, Oxford. Retrieved from: https://www.inasp.info (26.07.2020)

Mowery, D.C. \& Sampat, B.N. (2005). Universities in national innovation systems. In J. Fagerberg., D.C. Mowery \& R. Nelson (Eds.), The Oxford Handbook of Innovation (pp. 209-239). Oxford: Oxford University Press.

Jo Beall is Emeritus Professor and Distinguished Policy Fellow at the London School of Economics and Political Science (LSE). Formerly Director of Education and Society and on the Executive Board at the British Council, she was also Deputy Vice-Chancellor of the University of Cape Town (UCT) and before that a Professor of International Development at the LSE. She is currently involved in conducting research on urban services in Ethiopia and Pakistan. 
Open Access This chapter is licensed under the terms of the Creative Commons Attribution 4.0 International License (http://creativecommons.org/licenses/by/4.0/), which permits use, sharing, adaptation, distribution and reproduction in any medium or format, as long as you give appropriate credit to the original author(s) and the source, provide a link to the Creative Commons license and indicate if changes were made.

The images or other third party material in this chapter are included in the chapter's Creative Commons license, unless indicated otherwise in a credit line to the material. If material is not included in the chapter's Creative Commons license and your intended use is not permitted by statutory regulation or exceeds the permitted use, you will need to obtain permission directly from the copyright holder. 


\title{
Internationalization of Universities: 70 Years of Experience
}

\author{
Vladimir Filippov
}

The creation of the IAU 70 years ago was one of the consequences of evolving international life following the Second World War. This featured the evolution of organizations such as the United Nations, UNESCO, the Council of Europe and the European Union. In higher education, new international policies led to the internationalization of universities (Altbach 2010). From the beginning, the IAU became one of the international platforms where universities exchanged experiences and built relations. In the acting strategy of IAU adopted in 2016, internationalization is one of the four priorities.

RUDN University, where about ten thousand (about 40\%) international students from more than 150 countries have been studying for decades, has extensive experience in internationalizing various aspects of life now relevant for many universities in the world.

If we do not consider ad hoc programs and training elite international students in universities, massive internationalization of universities went through the following stages.

\section{Stage $1(1950-1970)$}

As a result of the democratization of international life after the Second World War and the emergence of newly independent states, developed countries began a massive admission of international students to universities to train specialists for newly developing countries. While aiding developing countries, donor countries also solved their geopolitical tasks, since at that time, the world was divided into countries with

\footnotetext{
V. Filippov $(\bowtie)$

RUDN University, Moscow, Russia

e-mail: v.filippov@rudn.ru

(C) The Author(s) 2021 
a capitalist and socialist orientation. A key indicator since that period has been the percentage of international students in a university. Currently, in the majority of countries, 5-10\% of international students in a university is considered satisfactory internationalization; 10-15\%—good; 15-20\%—excellent; over 20\%—outstanding.

\section{Stage 2 (1970-1990)}

Starting from the 1970s, confrontation between two ideologies transferred a new scientific and technological revolution to the field; meanwhile various new forms of educational services appeared alongside the tasks of the first stage of university internationalization: international branches of universities, educational programs franchising, joint universities, etc. A significant new element in the internationalization of universities during this period was (Altbach and De Wit 2015) the development of international cooperation and competition in the scientific field: exchange of researchers, including young ones, became systemic; developed countries shifted to keeping the most talented young international students. As a result, by the beginning of the 1990s, international scientific cooperation had become one of the most important factors in the development of universities. Currently, based on an analysis of university monitoring systems in different countries of the world, the presence of more than $5 \%$ of international research and teaching staff in universities is considered a satisfactory indicator, more than $10 \%$ is a good indicator; more than $15 \%$-excellent, and more than $20 \%$ - outstanding.

\section{Stage 3 (1990-2010)}

The processes of internationalization in Higher Education during this period became more dependent on globalization: the previously prevailing bilateral relations and cooperation programs were replaced by various international regional and global networks and unions. As a result, large regional conventions on the recognition of documents in the field of Higher Education began to appear instead of bilateral agreements on the equivalence of documents on education in various countries. For example; the Lisbon Convention of UNESCO/Council of Europe of 1997; agreements on the creation of common spaces of Higher Education (Bologna process in Europe, etc.); harmonization of regional Higher Education Systems (in Latin America, Africa, Asia) with the Bologna process Higher Education structure.

Stage 4 (since 2010) University Internationalization at Home (Domestic Internationalization) this stage tasks the processes of globalization faced by the world community.

In the context of creating modern knowledge-based economies and societies, a new task for modern universities is Universities Internationalization at Home - the massive training of graduates who can work in conditions of global competition, in 
international teams, live and feel tolerant in multinational and multi-faith communities, as well as work in conditions of professional mobility and migration labour resources. These are already tasks aimed not so much at just training foreign students and attracting foreign professors to universities as was important at the previous stages of internationalization - although until now these very indicators have been the main criteria for Internationalization in various World Universities Ranking Systems.

University Internationalization at Home aims (Brandenburg et al. 2019; De Wit et al. 2019) at creating such a sociocultural environment within the university that promotes the development of international and intercultural understanding, provides an international dimension to all educational, research and cultural programs and projects, and includes in all management structures of a Higher Educational Institution the best international practices to improve the quality of teaching and research. Therefore, achieving the necessary competencies and strengthening university management.

To meet the modern challenges that societies and economies pose to universities, namely to prepare graduates to live and work in a globalizing world, the most important task of universities is Altbach and De Wit (2018) to internationalize the vast majority of their domestic students, teachers, and staff. This sets forth serious new requirements on the Internationalization of almost all aspects of university life.

By the year 2010, the new dimension of Internationalization of Higher Education had been sufficiently developed in some countries-the pioneers were universities and the Australian government, which implemented Universities Internationalization at Home as a state policy of an integrated system of measures. As far as European countries are concerned, universities and the Higher Education System of the Netherlands as a whole have advanced most on this path.

The experience of RUDN University as one of the most internationalized universities in the world determines several main activities of Universities Internationalization at Home.

In the field of Education, this includes considering global trends in the implementation of a common framework of qualifications and specialties; exploring and implementing the experience of creating the best examples of educational programs of Higher Education; focusing on the international accreditation of Higher Education programs; and networking between universities, creating joint educational programs, double diploma programs - at least one joint program with a foreign university in each field of study. It also implies shaping international student groups, striving for graduates' fluency in a foreign language (in the field of professional activities), Master students should know at least two foreign languages, one of which is English; massive advanced training of the teaching staff in foreign languages and modern teaching technologies; and ensuring (mandatory) academic mobility of the largest possible share of university students. Finally, Universities Internationalization at Home is introducing interactive methods in the educational process by using global information networks, databases, and MOOCs. 
In the field of Research, Universities Internationalization at Home entails comparative studies; determining priorities and bringing basic research of the university to a level that meets modern requirements in the scientific world; support for international academic mobility of research and teaching staff, especially graduate students and young researchers; active targeted support for the participation of the university and individual researchers in international scientific competitions, projects, and programs; support for publications of researchers in leading foreign journals; and the international cooperation of scientists in the publishing field through international collaborations, where the co-author (co-authors) of the scientific work is a foreign scientist, while co-authorship can be considered not only as a form of scientific collaboration but also an increase in the level of trust in the academic community, a kind of "scientific diplomacy." Also, creating international research laboratories and centres; creating international Advisory and Expert bodies on research and educational policy issues; - hiring talented foreign graduates for scientific work at university; conducting mainly international scientific conferences at the university, with targeted involvement of representatives of the most respected foreign research teams; and actively using information and communication networks for the international activities of university research teams, are all relevant activities for the internationalization of research.

In the field of Attitude Development of Students, Teachers, and Employees RUDN University aims to provide a purposeful attitude among students, teachers, and employees to recognize the values of world cultures and respect the traditions and customs of other peoples and faiths. Taking into account national specifics (primarily in the field of nutrition and healthy lifestyle) concerning the university infrastructure by involving students in various multinational groups in the extracurricular activities of the university (cultural, sports, etc.), develop students' tolerance and ability to work in multinational groups, and provide conditions for tolerance on student campuses, mainly on the principle of placing students of different nationalities in a shared dorm room and creating a student code of conduct. International standards considering the tasks of international teams and the need for active international activities of the university are also considered relevant to the Universities Internationalization at Home policy.

Finally, in the field of Management and Finance, internationalization implies involving qualified foreign representatives in managerial and research structures of the university; conducting regular international audits of various areas of the university; and creating open (in accordance with international criteria) university websites in foreign languages. It also entails promoting the presence of the university and its scientists on the internet, including profiles in foreign languages; diversifying university activities to attract extra-budgetary funds through various forms of international activity of the university and its researchers; and, eventually, introducing progressive forms of university autonomy, defined in accordance with international criteria conditions for the sustainable development status of the university. 
The ongoing advisory visits by IAU experts to various universities around the world allow for the exchange of the practical experience of universities and increasing appropriate level of competencies of universities interested in promoting internationalization. Even RUDN University, having 60 years of experience of internationalization, significantly modernized its policies and technologies for the University's internal internationalization following a visit by IAU experts.

At the same time, comparing the experiences of university internationalization in the world requires serious analytical and comparative research to determine the most effective methods of internationalization, taking into account the specific missions and challenges faced by the university. In this regard, in 2020-2022, RUDN University is implementing a project to create a portal to summarize the experience of internationalizing leading universities of the world-a project that can provide invaluable support to all IAU member universities in accordance with the strategic objectives and the above-mentioned IAU activities.

\section{References}

Altbach, P.G. (2010). The Realities of Mass Higher Education in a Globalized World. In D. B. Johnstone., M. B. d'Ambrosio \& P. J. Yakoboski (Eds.), Higher Education in a Global Society (pp. 25-41), Edward Elgar Publishing.

Altbach P.G., \& De Wit, H. (2015). Internationalization and Global Tension: Lessons from History. Journal of Studies in International Education 19(1), 4-10.

Altbach P.G. \& De Wit, H. (2018. February 23). The Challenge to Higher Education Internationalisation. University World News. Retrieved from: https://www.universityworldnews.com/post. php?story $=20180220091648602(26.07 .2020)$

Brandenburg, U., De Wit, H., Jones, E., \& Leask, B. (2019. June 26). Defining Internationalisation in Higher Education for Society. University World News. Retrieved from: https://www. universityworldnews.com/post.php?story=20190626135618704 (26.07.2020)

De Wit, H., Rumbley, L.R., Craciun, D., Mihut, G., \& Woldegiyorgis, A. (2019. May 1). International Mapping of National Tertiary Education Internationalization Strategies and Plans (NTEISPs). Center for International Higher Education (CIHE), 12. Retrieved from: https://www.bc.edu/ content/dam/bc1/schools/lsoe/sites/cihe/publication/pdf/Perspectives\%2012.pdf (26.07.2020)

Vladimir Filippov is President of RUDN University and professor of Mathematics. He has served as Minister of Education in Russia (1998-2004), Chairman of Organizing Committee (20072009) and President of World Higher Education Conference (UNESCO, 2009). Since 2010, he was Chairman and up to now Member of Steering Committee of UNESCO World Programs "Education for All" and "Education - 2030". 
Open Access This chapter is licensed under the terms of the Creative Commons Attribution 4.0 International License (http://creativecommons.org/licenses/by/4.0/), which permits use, sharing, adaptation, distribution and reproduction in any medium or format, as long as you give appropriate credit to the original author(s) and the source, provide a link to the Creative Commons license and indicate if changes were made.

The images or other third party material in this chapter are included in the chapter's Creative Commons license, unless indicated otherwise in a credit line to the material. If material is not included in the chapter's Creative Commons license and your intended use is not permitted by statutory regulation or exceeds the permitted use, you will need to obtain permission directly from the copyright holder. 


\title{
70 Years of Internationalization in Tertiary Education: Changes, Challenges and Perspectives
}

\author{
Hans de Wit and Philip Altbach
}

Internationalization as a concept and strategic agenda is a relatively new, broad, and varied phenomenon in tertiary education, driven by a dynamic combination of political, economic, sociocultural, and academic rationales and stakeholders. Its impact on regions, countries, and institutions varies according to their particular contexts. Mobility, also known as "internationalization abroad," is the most referred to activity in internationalization and takes in itself a great variety of forms. Curriculum and global professional and citizenship development, also referred to as "internationalization at home," is the other key component of internationalization. It receives increased attention, but still less than mobility.

Over the past seventy years, internationalization in tertiary education has evolved from being a marginal activity to becoming a key aspect of the reform agenda. In the last decade of the last century, the increasing globalization and regionalization of economies and societies, combined with the requirements of the knowledge economy and the end of the Cold War, created a context that enabled a more strategic approach to internationalization in higher education. The International Association of Universities (IAU) is playing an active role in this process.

Internationalization has evolved, and during that process, past priorities have been replaced, or surpassed in importance, by others. Economic rationales have become more dominant, but given the extreme challenges faced by global societysummarized in the Sustainable Development Goals (SDGs) of the United Nationsinternationalization has also recently been called upon to help contribute to meeting these societal challenges and goals.

\footnotetext{
H. de Wit $(\varangle) \cdot$ P. Altbach

Boston College, Chestnut Hill, MA, USA

e-mail: dewitj@bc.edu

P. Altbach

e-mail: altbach@bc.edu 


\section{The Historical Context}

One can argue that tertiary education, by nature, has always been international. Kerr (1994) states that universities have always been essentially international, but at the same time acknowledges that "they have been living, increasingly, in a world of nation states that have designs on them" (p. 6). This tension between universal nature and embeddedness in the national and local contexts is a dominant feature of tertiary education. References to the global nature of universities ignore the fact that many universities were established or transformed in the eighteenth and nineteenth centuries with a clearly national orientation.

Political events, most notably two world wars in the first half of the twentieth century led to a focus on promoting peace and mutual understanding through international cooperation and exchange. The creation of the Institute of International Education (IIE) in the United States in 1919, the Deutscher Akademischer Austauschdienst (DAAD) in Germany in 1925, and of the British Council in the United Kingdom in 1934 are illustrations of this development. This trend continued with the establishment of the Fulbright Program of 1946. The creation of the International Association of Universities in 1950 can also be placed in that context.

In the following years, in addition to peace and mutual understanding, Cold War rationales of national security and foreign policy increasingly took over. Similar trends could be seen in the Soviet Union. The Cold War became the principal rationale to foster an international dimension of higher education. What had started as incidental and individual activities evolved into organized international education programs, driven more by national governments than by universities.

\section{Cooperation or Competition?}

The traditional emphasis in internationalization has been on exchanges and cooperation to contribute to a better understanding of different cultures and languages, as well as for research collaboration. But since the mid-1990s, a gradual but increasingly visible shift has been taking place toward more competition. Van der Wende (2001) calls this a shift in paradigm from cooperation to competition. The optimism at the end of the 1980s that internationalization would move from an ad hoc, marginalized and fragmented activity to a central point on the agenda of higher education had resulted indeed in a broad acceptance of internationalization as one of the core drivers of innovation and change in higher education. But the direction it took was one of copying the already prevalent competitive approach in the United Kingdom and Australia: recruitment of international students and development of cross-border education for revenue, competition for talent (skilled immigration) and reputation (rankings).

This focus on internationalization as a tradeable commodity resulted at the turn of the century in appeals for a return to ethics and values of cooperation by the Inter- 
nationalization at Home movement in Europe in reaction to the focus on Erasmus exchanges (what about the 95\% non-mobile students?), and a call for Internationalization of the Curriculum in the United Kingdom and Australia in reaction to the exclusive focus on international student recruitment and off-shore delivery. But the focus on mobility and revenue generation increased even more in the following decade, in part because governments increasingly looked to international student tuition payments as a key source of revenue for higher education.

In 2011, Brandenburg and de Wit (2011) stated that although internationalization "is claimed to be the last stand for humanistic ideas against the world of pure economic benefits," the reality is that "this ignores the fact that activities more related to the concept of globalization (higher education as a tradeable commodity) are increasingly executed under the flag of Internationalization." They expressed concern about the devaluation of internationalization as it was meant to be and called for a critical reflection on its concept. This 2011 critical reflection on the reality and direction of internationalization as a tradeable commodity, was not unique. The International Association of Universities (IAU 2012) started ten years ago an action to rethink the concept of internationalization outcomes and the work of national and discipline-specific accreditation agencies.

At the same time, there emerged a move away from internationalization as a purely Western concept: "In the current global knowledge society, the concept of internationalization of higher education has itself become globalized, demanding further consideration of its impact on policy and practice as more countries and types of institution around the world engage in the process. Internationalization should no longer be considered in terms of a westernized, largely Anglo-Saxon, and predominantly English-speaking paradigm.” (Jones and De Wit 2014)

The 2015 study for the European Parliament on the state of internationalization in higher education, in which IAU was actively involved, reflects this new line of thinking. It promoted a new agenda for the future, with the following definition for internationalization:

The intentional process of integrating an international, intercultural or global dimension into the purpose, functions and delivery of post-secondary education, in order to enhance the quality of education and research for all students and staff and to make a meaningful contribution to society (De Wit et al. 2015).

This definition gives a normative direction to the process by emphasizing that such a process does not happen automatically, but needs to be intentional; that it is not a goal in itself, but must contribute to quality improvement; that it should not be an advantage reserved for a small elite of mobile students and scholars, but benefit all; and finally, that it should also benefit society.

At the beginning of 2020, although the critique on the notion of internationalization as a competitive and exclusive tradeable commodity became widely acknowledged and notions like 'internationalization at home', 'internationalization of the curriculum', 'internationalization for society', 'humanistic internationalization', 'global learning for all' have found ample support in reports, documents, statements and even 
policies, the reality of internationalization as a tradeable commodity is still strongly prevalent.

The rise of nationalist-populist movements, bans on immigration, attacks on academic freedom, anti globalist protests and, in Europe, anti-integration trends (Brexit), might all have negative implications for internationalization. It is too early to tell what the exact and direct consequences of these developments will be, but most likely they will change and/or accelerate patterns of mobility, autonomy and academic freedom, privatization and commercialization, as well as other key dimensions of global tertiary education. Similarly, through the interconnection of our societies and economies, natural disasters and health hazards have increasingly a global scope, impacting higher education and internationalization endeavours. The current COVID-19 epidemic is a clear illustration.

In general terms, the key characteristics of internationalization these past decades are:

- Greater focus on internationalization abroad than on internationalization at home.

- More ad hoc, fragmented, and marginal than strategic, comprehensive, and central in the policies of universities and governments.

- Benefiting a small, elite subset of students, faculty, and institutions rather than aiming for global and intercultural outcomes for all.

- Directed by a constantly shifting range of political, economic, sociocultural, and educational rationales, with an increasing focus on economic motivations.

- Increasingly driven by national, regional, and global rankings.

- Poor alignment between the international dimensions of the three core functions of higher education: education, research, and service to society.

- Primarily a strategic choice and focus of institutions of higher education, but increasingly also a priority of national governments (for reasons of soft power, reputation and/or revenue) and of regions (European Union, Bologna signatories, the Association of Southeast Asian Nations [ASEAN], etc.)

- Increasing commercialization and involvement of for-profit companies in all aspects of the international higher education agenda.

Although still present in the rhetoric of international education, traditional values such as cooperation, peace and mutual understanding, human capital development, and solidarity, have been moved to the sidelines as universities strive for competition, revenue, and reputation/branding.

\section{Institutional Strategies}

Overall, institutions are still the main agents that drive internationalization. According to the 5th Global Survey of Internationalization of Higher Education by the International Association of Universities (IAU), based on data from 2018, more than $90 \%$ of institutions mention internationalization in their mission/strategic plan, with the exception of North America, where only one-third do so. "Enhanced international 
cooperation and capacity building," and "improved quality of teaching and learning," are mentioned as the most important benefits. "International opportunities accessible only to students with financial resources," followed by "difficulty to assess/recognize the quality of courses/programs offered by foreign institutions," as well as "excessive competition with other higher education institutions," are mentioned as the highest risks. The main obstacles mentioned include "insufficient financial resources," "administrative/bureaucratic difficulties," and "lack of foreign languages" (Marinoni 2019). Further, the survey states that two-thirds of university leaders around the world consider internationalization to be an important agenda issue, although Marinoni and de Wit (2019) observe that there is an increasing divide between institutions that consider internationalization as highly important, and those that do not. They observe that

The reasons for such a divide between HEIs ... is worth a reflection and deserves to be studied more in depth, especially if one considers internationalization to be an essential part of all HEIs' mission and a sign of quality.

Institutions developing internationalization strategies face significant challenges and pressures: revenue generation; competition for talent; branding and reputation; a need to focus on international research and publications; on recruiting international students and scholars; and on using English as a language for research and instruction. These challenges and pressures conflict with a more inclusive, less elitist approach, catering to the needs of local students and staff and creating opportunities for these groups. In other words, there is a tension between a short-term, neoliberal approach to internationalization, focusing primarily on mobility and research, and a long-term, comprehensive approach, focusing on global learning for all.

\section{National Policies}

For a long time, international academic activities in the Global North were primarily the domain of national governments as part of their foreign policy, now mostly referred to as "soft power" or "public diplomacy." Cultural and scientific agreements between nations included references to the exchange of scholars and students and the provision of scholarships, in general in small numbers. Capacity building programs intended for mid- and low-income countries included scholarships, faculty mobility to assist tertiary education and support in terms of infrastructure. Institutions were participating in these activities but did not initiate them proactively. The scope and impact of these measures varied by country.

This changed after the end of the Cold War, when economic rationales became more dominant, and institutions started taking a more proactive role. Over the past decade, however, international higher education has been increasingly recognized by governments as an important factor in national economic development, trade, and reputation. Considering the magnitude of current global student and staff mobility, the increased presence of branch campuses and international providers, and the boom- 
ing competition for international talent, tertiary education institutions and national governments in the Global North are mobilizing to both leverage and steer internationalization. National strategies and plans represent the most tangible and direct attempts by governments to play an active and decisive role, but there are substantial differences in their approaches, rationales, and priorities. A study by De Wit et al. (2019) for the World Bank showed that low- and middle-income countries are becoming also more active in defining internationalization policies and fostering South-South cooperation, but also revealed a degree of policy mimicry in adapting western modes of internationalization and focusing heavily on mobility. And they appear to sustain the dominance of high-income countries through their scholarship schemes, their geographic priorities and their choice of partnerships.

\section{Challenges and Opportunities for the Future}

Internationalization in higher education is entering a new phase. A shift from internationalization abroad with its strong focus on a small elite of mobile students, faculty, administrators, and programs toward internationalization at home for all members of the academic community has become more urgent than ever, certainly after the Covid-19 pandemic. Making internationalization more carbon-neutral (De Wit and Altbach 2020), increasing the contribution of internationalization to society (Brandenburg et al. 2020) and linking the global to the local, are imperative.

Internationalization is a process in constant evolution, which changes in response to the local, national, regional, and global environments. Current global trends appear to be more radical than in the past and require stronger attention and international cooperation than ever.

\section{References}

Brandenburg, U., \& de Wit, H. (2011). The end of internationalization. International Higher Education, (62), 15-16. Boston, Boston College Center for International Higher Education. https:// doi.org/10.6017/ihe.2011.62.8533

Brandenburg, U., de Wit, H., Jones, E., Leask, B., \& Drobner, A. (2020). Internationalization in Higher Education for Society (IHES), concept, current research and examples of good practice (DAAD Studies). Bonn: DAAD.

De Wit, H., Hunter, F., Howard L., \& Egron Polak, E. (Eds). (2015) Internationalisation of Higher Education. European Parliament, Directorate-General for Internal Policies, Brussels.

De Wit, H., Rumbley, L.E., Craciun, D., Mihut, G. \& Woldegiyorgis, A. (2019). International Mapping of National Tertiary Education Internationalization Strategies and Plans (NTEISPs). CIHE Perspectives 12. Boston College Center for International Higher Education, and World Bank.

De Wit, H., \& Altbach, P. G. (2020. January 11).Time to cut international education's carbon footprint. University World News. (580). 
IAU. (2012). Rethinking Internationalization, theme IAU Horizons 17(3) \& 18(1), 17-18. International Association of Universities (IAU). www.iau-aiu.net

Jones, E., \& De Wit, H. (2014, Spring). Globalized Internationalization: Implications for Policy and Practice. IIEnetworker, pp. 28-29. IIE, New York.

Kerr, C. (1994). Higher Education Cannot Escape History: Issues for the Twenty-first Century. SUNY Series Frontiers in Education. Albany: State University of New York Press.

Marinoni, G. (2019). IAU The $5^{\text {th }}$ Global Survey, Internationalization of Higher Education: An Evolving Landscape, Globally and Locally. Berlin: International Association of Universities/DUZ Medienhause,

Marinoni, G., \& de Wit, H. (2019. January). Internationalization and inequality, first results from the 5th Global Survey of IAU. University World News. (A20534).

Van der Wende, M. (2001). Internationalization Policies: About new trends and contrasting paradigms. Higher Education Policy 14, 249-259.

Hans de Wit is Professor and Former Director of the 'Center for International Higher Education' (CIHE) at Boston College, USA. He is Senior Fellow of IAU. He is a founding member and past president of the European Association for International Education (EAIE). He is Founding Editor of the 'Journal of Studies in International Education' (SAGE), and Consulting Editor of the journal Policy Reviews in Higher Education. He is a leading expert on internationalization of higher education and has written several books and articles on this topic as well as given advice to organizations like OECD, UNESCO, World Bank and European Commission.

Philip G. Altbach is Research Professor and Founding Director of the Centre for International Higher Education at Boston College, where from 1994 to 2015 he was the Monan University Professor. In 2010, he was Erudite Scholar of the Government of Kerala. He has taught at Harvard University, the University of Wisconsin, and the State University of New York at Buffalo.

Open Access This chapter is licensed under the terms of the Creative Commons Attribution 4.0 International License (http://creativecommons.org/licenses/by/4.0/), which permits use, sharing, adaptation, distribution and reproduction in any medium or format, as long as you give appropriate credit to the original author(s) and the source, provide a link to the Creative Commons license and indicate if changes were made.

The images or other third party material in this chapter are included in the chapter's Creative Commons license, unless indicated otherwise in a credit line to the material. If material is not included in the chapter's Creative Commons license and your intended use is not permitted by statutory regulation or exceeds the permitted use, you will need to obtain permission directly from the copyright holder.

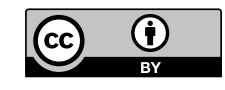




\title{
The Evolution of Higher Education Collaboration in the Arctic Through Networking
}

\author{
Outi Snellman
}

Academic collaboration across the Arctic region-the eight nations bordering the Arctic Circle (United States, Russia, Canada, Denmark/Greenland, Finland, Norway, Sweden and Iceland)_was extremely difficult and restricted during the Cold War years, despite efforts like the establishment of UNESCO and, indeed, the International Association of Universities. Issues and problems, however, do not respect national boundaries: for example, the emergence of massive environmental problems across borders in the region became quite clear during the 1980s. The iron curtain was successful in restricting the movement of people and ideas, but not pollutants.

The University of Lapland, still the northernmost university in the European Union today, was established in 1979 as the last university in the wave of new regional universities in Finland. Other universities in what was then called the North Calotte region had been established earlier: Umeå University, Sweden (1965), Oulu University, Finland (1958), Tromsö University, Norway (1968) and Luleå University of Technology, Sweden (1971). From its creation, these northern neighbours also became the closest academic collaborators for the University of Lapland-they were, after all, founded on the same type of Nordic values. However, internationalisation was not at the core of the university's mission from the beginning. The foundations for a more focused strategy on internationalisation were laid a decade later in a broader global political process.

During the political turmoil of the 1980s, one key speech changed the history of the Arctic and laid the foundation for long-lasting environmental, political and academic cooperation in the region. This speech, held in Murmansk in 1987 by the Soviet President Mikhail Gorbachev, called for the Arctic to become an international 'zone of peace' and called on all the Arctic states and other regional actors to cooperate on issues of scientific research and environmental protection. This speech led to many things, for example, the creation of the International Arctic Science Committee

\footnotetext{
O. Snellman $(\varangle)$

University of Lapland/UArctic, Rovaniemi, Finland

e-mail: outi.snellman@ulapland.fi 
in 1990 and the foundation of the Arctic Council in 1996. The higher education community, quite independently of any national governments, also immediately reacted to the speech, forming the Circumpolar Universities Association, CUA, in 1988 for enhancing international cross-border collaboration between the universities in the region. The University of the Arctic (UArctic) was established in 1998 on the initiative of the Arctic Council to complement its functions. CUA and UArctic joined forces in 1999 and became one organisation: UArctic.

The University of Lapland was one of the founding universities of the Circumpolar Universities Association in 1998 and soon took on a coordinating role for the organisation. Through this, the university also chose arctic and northern research as the core of its strategic profile and adopted the first internationalisation strategy. International mobility, international education programmes as well as research were tied to a strong focus on working in and on the Arctic. The University of Lapland also established the Arctic Centre, which remains Finland's Arctic research hub today.

In 1998, when UArctic was established, the University of Lapland merged CUA's and UArctic's International Secretariats. Through this, the University of Lapland assumed a coordinating role for the largest Arctic higher education collaboration network and also continued to keep arctic research and collaboration at the centre of its own international strategy.

From the start, UArctic was very strongly based on the values of circumpolarity, diversity and interdisciplinarity. There are four million people in the Arctic across the eight Arctic states, and numerous indigenous peoples and languages. The initial promise to the indigenous peoples was recorded into the Shared Voices Statement by the Arctic Permanent Participant organisations Inuit Circumpolar Conference, Sami Council and RAIPON, the Russian indigenous people's organisation. "With Shared Voices", symbolising collaboration and diversity, also became the vision of UArctic in its first strategic plan; this vision has survived as one of the core principles of UArctic until today.

These values are also strongly reflected in UArctic's activities from student mobility in UArctic's own north2north mobility program to the now 54 thematic networks that are engaged both in collaborative research and education.

Initially, UArctic's goal was to "empower the north", to ensure that northerners have the tools to take charge of their own destinies. This type of broad capacitybuilding goals is challenging when one attempts to show real impact on society. UArctic seeks to improve the lives of all northerners by increasing human competence and capacity, creating a healthy environment and bringing northern voices and knowledge to the global stage.

Just as the Arctic states and their challenges are interconnected, the Arctic is connected to the rest of the globe. The world is heavily dependent on the resources of the North: oil, gas, minerals, fish, freshwater. At the same time, although the Arctic is not the source of one of the biggest environmental challenges the globe is facing in the history of mankind, climate change, it is impacted by it in the most severe way. This is why the Arctic itself is a grand challenge: no one state, no one discipline, no one economic system or scientific paradigm can tackle the challenge alone. We need to work together, "with shared voices", in the arctic and all around the world. 
Naturally, UArctic, just as the Arctic Council and other research and environmental organisations that were created in the Arctic, has a very clear additional purpose as well: ensuring peace and stability in the Arctic. Indeed, even as geopolitical insecurity elsewhere in the world creates tensions that influence the Arctic, we have continued with 'business as usual' - not because we are ignorant of threats to cooperation, but precisely because of them. Our best way to ensure mutual understanding and focus on common interests is to maintain cooperation and keep an open dialogue through active support of the UN Sustainable Development Goals.

Through UArctic we have strived to create a common Arctic region and circumpolar identity among researchers, students and leaders. We will work with our membership, well over 200 organisations in 2020, as well as regional and national governments to ensure that the generation leading the Arctic in 2030 does not have to start over, but can continue on a platform of mutual understanding and partnership.

The Arctic states have both the resources and instruments for cooperation, and their peoples have the will. The leadership of the North will benefit not just the Arctic but the whole world, and we can also be an important inspiration to others globally. This is particularly the case now, at a time when humankind needs to find a new way forward for future generations and the healthy stewardship of this unique planet.

UArctic was built on the same kind of ideal for collaboration, albeit more regionally, as IAU was 40 years earlier. 2021 marks the 30th anniversary since UArctic's Launch in 2001. In those 30 years, it has grown from a small and loose collaboration of about 30 institutions to one of the world's largest higher education networks, organised as UArctic Association, where the power to decide on the organisation's future direction rests with its members through the UArctic Assembly.

The next UArctic Assembly will approve UArctic's Strategic Plan 2030 in their meeting in May 2021 - the current draft is strongly based, again, on the same values of circumpolarity, diversity, respect, collaboration and openness, and the UN 2030 Sustainable Development Goals. The University of Lapland, as a member of IAU and UArctic, continues to take forward the IAU ideals of international collaboration, respect for diversity and promotion of peace through its coordination role and engagement in UArctic.

With organisations like IAU, the Arctic Council and UArctic aligning their goals, we may indeed be one step closer to making the prospect of healthy futures for the North and the globe a reality.

Outi Snellman is Vice-president at the University of the Arctic and Director of International Relations, University of Lapland, Rovaniemi, Finland. She has been working on International Education and the development of circumpolar academic cooperation for the past 30 years first in her capacity as Educational Adviser in the Finnish Fulbright office in Helsinki (1987-1990), the Director of International Relations at the University of Lapland (1990-) and Secretary General for the Circumpolar Universities Association (1992-1998) as well as Vice-President Organization of the University of the Arctic. She is the Editor-in-Chief of the UArctic Shared Voices Magazine, published annually. 
Open Access This chapter is licensed under the terms of the Creative Commons Attribution 4.0 International License (http://creativecommons.org/licenses/by/4.0/), which permits use, sharing, adaptation, distribution and reproduction in any medium or format, as long as you give appropriate credit to the original author(s) and the source, provide a link to the Creative Commons license and indicate if changes were made.

The images or other third party material in this chapter are included in the chapter's Creative Commons license, unless indicated otherwise in a credit line to the material. If material is not included in the chapter's Creative Commons license and your intended use is not permitted by statutory regulation or exceeds the permitted use, you will need to obtain permission directly from the copyright holder. 
Part III

Coding the Values 


\title{
Promoting Values Together: Global Currency with Local Impact for Universities
}

\author{
Sijbolt Noorda and David-John Lock
}

The missions of the Magna Charta Observatory (MCO) and the International Association of Universities (IAU) have much in common. They both serve universities, are global in their reach but sensitive to local situations, and, fundamentally, they are based on values, values which have both global currency and local impact.

It is perhaps worth reflecting on why values are becoming ever more important. Universities today face greater complexity and uncertainty and have to respond more quickly. This is further complicated by the increasingly varied expectations of internal and more numerous and more diverse external stakeholders, the changing dynamics of national and international politics, increased competition for students and funding, challenges arising from internationalisation, the rapid evolution of technology and communication and occasional local and global emergencies, the current Coronavirus pandemic being a recent example. These challenges affect universities across the globe, regardless of their traditions, cultures, styles of operating, and missions. Decisions are required for which there is no recent precedent.

Values have, of course, been at the heart of universities since their formation and remain an essential tool in dealing with these challenges, offering universities guidance for their conduct and decision-making. Whether it is the traditional and more fundamental values of autonomy and academic freedom, social responsibility toward their community, or other values specific to institutional missions, values are crucial in helping universities understand and identify themselves and communicate that identity and mission to stakeholders.

\author{
S. Noorda $(\bowtie) \cdot$ D.-J. Lock \\ Observatory of the Magna Charta, Bologna, Italy \\ e-mail: s.j.noorda@uva.nl \\ D.-J. Lock \\ e-mail: davidjohn.lock@unibo.it \\ S. Noorda \\ University of Amsterdam, Amsterdam, The Netherlands \\ (C) The Author(s) 2021


To create and maintain public trust in universities amid today's complexity and uncertainty, universities need to define their values carefully and explicitly, clearly communicate them to staff, students, and stakeholders, and demonstrate that their values inform practice and decision-making.

The principles and values at the heart of the MCO are those set out in the Magna Charta Universitatum (MCU) which was first signed in 1988 by 388 rectors on the 900th anniversary of the founding of the University of Bologna. The first principle declared was independence: research and teaching must be intellectually and morally independent of all political influence and economic interests. The second was that teaching and research should be inseparable, with students engaged in the search for knowledge and greater understanding. The third principle identified the university as a site of free enquiry and debate, distinguished by its openness to dialogue and rejection of intolerance.

The original 1988 MCU outlined the values, scope and means of a common intellectual venture, based in Europe which was put together by many of its universities. According to the history, 'The Charter was to sum up in a few articles the main principles and values the universities can recognise as their common European inheritance. .... The power of intelligence, i.e., the capacity to link elements of knowledge in innovative ways for social and scientific development, was recalling its partners in society - the government, the church, the city fathers, representatives of trade and industry-'....' that its means and ends are at the centre of the European mind and behaviour, because they represent a shared way of life and thought' (Observatory Magna Charta Universitatum (n.d.) 2020).

Signing the Magna Charta committed universities to valuing autonomy and academic freedom and operating accordingly, as well as making public statements to this effect. Over 900 universities from 87 countries have now signed it.

Much has changed over that 30-year period, both in the contexts in which universities operate and within universities themselves. Enrolment in universities increased from $99.9 \mathrm{~m}$ in 2000 to $215.9 \mathrm{~m}$ in 2016 (UNESCO). It is projected to rise to $594 \mathrm{~m}$ by 2040. Estimates of the number of universities vary but have increased from around 10,000 in 2000 to over 25,000 by 2020 . With this growth come high expectations and also a growing appetite for control by governments, businesses and other stakeholders. This poses quite a challenge to autonomous universities.

Universities now operate more internationally, have to respond more quickly to larger numbers and more diverse learners and research requirements, use advanced technology, different modes of delivery and are challenged to be more sustainable and more equitable as well as serving the diverse needs of a wider range of local, national and international stakeholders. The recent pandemic requires a re-think of pedagogy and assessment procedures to ensure the safety of students and staff while enabling them to continue to study and derive the full range of benefits of traditional programmes - and to do so in a way that maintains public confidence in the process and outcomes.

Universities are seen as critical players in the achievement of the UN's Sustainable Development Goals (SDGs). Although education is only mentioned in the title of 
SDG 4, research and other university involvement are also required for successful achievement of each of the other 16 goals.

Furthermore, the growth in the number and variety of league tables for different purposes and the range of indicators to provide supporting evidence makes the performance of universities more transparent and more open to scrutiny.

Universities are consequently having to review their values; how they are given effect and how they contribute to the maintenance and development of their mission and reputation, as well as specific responses.

Over the past 20 years, the MCO, which is an association of signatories, was formed to assist with monitoring, enhancing and advising on the status of academic freedom and institutional autonomy. It organised annually an anniversary conference, commissioned reports, produced publications and engaged in other activities including lobbying, advocacy, publications to support universities worldwide as well as developing thinking on and practising of values in university life with a view to helping universities to reinforce trust in their relationship with their communities.

Often working with IAU, for instance on the joint IAU-MCO Guidelines for an Institutional Code of Ethics in Higher Education (2012), the MCO has, in addition to the activities above, increased significantly the number of regional workshops which it has convened to address the ways in which changes in society are impacting on universities.

In response to the findings from these workshops in 2016, the MCO embarked on two major projects. The first was the development of the Living Values project. This was designed to help universities identify, adopt and live by values that enable them to fulfil their mission and engage with their community successfully. The thinking behind the project is that reviewing and articulating values with the input of stakeholders will increase community engagement and create more trust between the institution and its staff, students, and stakeholders. Guidelines help universities to ensure that the values they espouse reflect the institution's mission and community; staff, students, and stakeholders have been effectively engaged in defining those values; and all members of the institution are able to articulate and effectively live by these defined values.

The second major project was to develop a new MCU to take account of the societal changes which have affected universities since 1988. Determining the process of doing this and how the vast amount of evidence was to be analysed so as to produce a document of less than two pages which would have global applicability and also be locally sensitive was critical for its success.

The task of preparing the draft 'MCU 2020' was given to an internationally diverse group of experienced higher education professionals, including a student leader. Members of the group reviewed the current and emerging situations in their part of the world, examined declarations from different countries which were written in different circumstances for different purposes and identified priorities for the new Magna Charta Universitatum.

The new Magna Charta Universitatum retains all the principles and values set out in the 1988 edition to which universities signed up. It strives to be responsive to and resonate with contemporary challenges and concerns. Its tone recognises that 
the pursuit of the fundamental values has worth along with their actual attainment, which, in practice, is a constant quest. It recognises the more global nature of what universities do and the wider range of local responsibilities which they have. It sets out principles, values and responsibilities which universities are invited to sign up to. It makes more explicit the importance of sustainability, civic responsibility, respect for diversity, equity, fairness and access to higher education. If they put them into practice, the contract between universities and society should become stronger, despite that fact that ever more dynamic changes are likely to come into play over the next 30 years.

The MCO's collaboration with IAU has played an important part in informing and launching the Living Values Project (n.d.) (2020) and developing MCU 2020. That collaboration will continue to further understand where and how values have impact, to share this learning and together enabling universities to best serve society.

The MCO 2020 will be formally launched in June 2021 in Bologna. We hope it will stimulate as well as support and protect a keen engagement with values in universities worldwide. At the end of the day, one should realise that-although declarations like MCO 2020 are valuable vehicles of principle and purpose-it is only through joint action and courageous advocacy that the global community of universities can protect and practice its ideals.

\section{References}

Living Values project. (n.d.). Retrieved from: http://www.magna-charta.org/activities-and-projects/ living-values-project (19.07.2020)

Magna Charta Universitatum. (2020). Retrieved from: http://www.magna-charta.org/magnacharta-universitatum/read-the-magna-charta/the-magna-charta (19.07.2020)

Observatory Magna Charta Universitatum. (n.d.). History, Retrieved from: http://www.magnacharta.org/magna-charta-universitatum/history (19.07.2020)

Sijbolt Noorda is Former President of the Governing Council of the Magna Charta Observatory. $\mathrm{He}$ is President Emeritus of the University of Amsterdam, past president of the Association of Dutch Research Universities and a former board member of the European University Association. His academic field is cultural history of religions in Europe. He holds degrees from Free University Amsterdam, Utrecht University and Union Seminary/Columbia University, NYC.

David-John Lock is Secretary General of the Magna Charta Observatory. He was International Director of the UK's Leadership Foundation, the founding Chief Executive and Registrar of the British University in Dubai and the administrative head of two UK universities. He holds degrees from the University of Bath. 
Open Access This chapter is licensed under the terms of the Creative Commons Attribution 4.0 International License (http://creativecommons.org/licenses/by/4.0/), which permits use, sharing, adaptation, distribution and reproduction in any medium or format, as long as you give appropriate credit to the original author(s) and the source, provide a link to the Creative Commons license and indicate if changes were made.

The images or other third party material in this chapter are included in the chapter's Creative Commons license, unless indicated otherwise in a credit line to the material. If material is not included in the chapter's Creative Commons license and your intended use is not permitted by statutory regulation or exceeds the permitted use, you will need to obtain permission directly from the copyright holder. 


\title{
"A Question of Integrity": Academic Values Torn Between Organizational Affiliation, National Competitiveness and the Global Academic Community
}

\author{
Michael Hölscher
}

Values of higher education, as supported by the IAU, ${ }^{1}$ are grounded in the beliefsystems and behaviour of the individual researchers/teachers and the academic community more generally. Although these values are influenced from the outside by educational policies and economic considerations, and although they also encompass societal views on science (e.g. trust in science), it is academia itself that has to uphold, and sometimes defend, the inner principles of higher education.

Individual academic freedom and values, however, are under pressure from different quarters. On the meso-level, higher education institutions, due to increased competition and accountability, have moved over the last 70 years from being "organized anarchies" to organizations that are fully administered, demanding loyalty from their members. On the macro level, especially in the context of the knowledge society or knowledge economy, higher education (HE) is now regarded as a significant part of a nation's innovative competitiveness, with important impacts on internationalization strategies, for example. In this essay, I would like to develop some ideas on the interplay of these three levels, and how academic values can be maintained in this field of tension.

Although even older than the IAU, Merton's ethos of science from 1942 is still a good starting point for looking at academic values ${ }^{2}$ :

- Communality (originally called “communism”): common ownership of scientific results

\footnotetext{
${ }^{1}$ Please see the official webpage of IAU: https://www.iau-aiu.net/Vision-Mission.

${ }^{2}$ Describing the principles in just one sentence does not give justice to Merton's ideas, so I recommend reading the original text in "A Note on Science and Technology in a Democratic Order".
}

M. Hölscher $(\varangle)$

German University of Administrative Sciences Speyer, Speyer, Germany

e-mail: hoelscher@uni-speyer.de 
- Universalism: evaluation of scientific truth has to follow impersonal criteria, independent of personal attributes of the researcher

- Disinterestedness: science should be pursued for the common good, not for personal gain

- Organized scepticism: scientific findings need to be thoroughly scrutinized.

Merton does not claim that these principles are always in force or adopted, and he already mentions that competition could put pressure on them. Nevertheless, these four principles can work as a guiding line for our behaviour as academics and help guarantee the functioning of science along its own logic. The combination of his global ethos of the scientific community and individual academic freedom is the basis for unbiased and joint truth-seeking as the main spirit of science.

Developments, especially during the last two or three decades, undermine this ethos as well as academic freedom. There are many direct pressures from populist and authoritarian governments on higher education institutions, and we see an overall decrease in funding in many countries (see OECD's "Education at a Glance" for figures). I would like, however, to concentrate here on two related trends connected to the growing importance of higher education for society and the economy in the context of a knowledge society. These trends, at first sight, are often seen as beneficial, but they increase non-scientific claims on academia with important repercussions for academic values.

On the macro-level, higher education is increasingly seen as (one of) the most important input(s) for a nation's economic competitiveness. Tertiary education and innovation from research are the drivers of growth in the knowledge economies of industrialized countries. Governments often deliberately force their HE institutions to contribute to this competitiveness, and as the state is still the main funding body of $\mathrm{HE}$ in most world regions, they also have the means of doing so. International organizations such as the World Bank act in the same vain, as they see HE often from an economic perspective and focus on its contribution to development. While pushing universities to excel in teaching and research would not be a problem per se (on the contrary!), many current initiatives focus on benefits for their own nations only. For example, many countries have developed so-called excellence initiatives during the last few years (e.g. Germany's "Excellence Initiative/Strategy", China's "Projects 211 and 985" or Russia's "Project 5-100"), virtually always with the aim of improving their nations' competitive position in the international market.

This trend undermines the scientific ethos in at least two ways. First, on the international level, it contributes to a predominantly strategic approach to international scientific collaboration. As countries strive to improve their universities' positions in international rankings in conjunction with their business competitiveness, principles such as communality (sharing research results instead of patenting them or hiding them behind pay-walls) or disinterestedness (the common good is often much broader than regional or national interests) are counterproductive for these goals.

Second, instead of using resources to improve the scientific system overall, such initiatives often make universities within a country compete with each other, leading to a stratified system of some winners and many losers (often following the Matthew 
effect: "For whosoever hath, to him shall be given, and he shall have more abundance: but whosoever hath not, from him shall be taken away even that he hath."). Again, competition as such may not be bad, as long as it works along scientific rationales and is characterized, first and foremost, by a competition for prestige as the currency of science. However, in reality, these initiatives redistribute financial resources introducing non-scientific incentives for organizations and individual researchers.

This leads us to the second, the meso-level of the organization. Universities have long been described as "specific organizations" (Musselin 2007) or even "organized anarchies" (Cohen et al. 1972). One of the reasons is that in science as a "profession" academics accept only their peers' judgement as a legitimate evaluation of the quality of their work. Therefore, academics' identities are often shaped far more by their scientific discipline than by their university (for different reasons this is probably much more so in Germany than, for example, in the US, but probably holds true for many regions of the world). As a result, universities are a rather loosely coupled system (Weick) of faculties with a relatively weak centre.

In the wake of the utilization of higher education by nation-states as described above, universities as organizations are being held responsible to "deliver". New Public Management reforms have increased organizational autonomy and competition between universities, raising the need for central steering and strategic decisions at the leadership level of the whole organization. International university-rankings (not of individual researchers!) additionally contribute to the focus on higher education organizations. Universities, therefore, need to become "entrepreneurial" (Clark 1998) actors in their own right. Again, there is nothing negative about usefully pooling resources to increase research capacities and effectiveness, or in improving central administrative tasks. However, too often university organizations-following external incentives such as third-party funding or increasing student figures to increase income, etc. - alter their strategies not necessarily for the good of science or society, but for the good of the specific organization. In Germany, for example, as in many other countries, universities are allowed to withhold research findings if they see a chance of gaining income from patents stemming from that research. Such organizations are tempted to reduce academic freedom and communality using researchers and teachers to reach non-science-inherent goals such as growth or legitimacy (e.g. as proposed by neo-institutionalist theory).

To summarize my argument here: The in principal welcome growing importance of higher education for society and the economy may, in fact, contribute to the corruption of academic values by (a) rewarding social and economic benefits for nation-states or the organization more than contributions to global science and (b) increase the relevance of non-scientific incentives, mainly economic ones, within academia. One reason for this is the at times excessive use of science to serve a wider political agenda of enhanced national and international competitiveness, another the resulting increased focus on HEIs as actors in toto instead of the work of individual researchers/teacher or research/teaching groups. With regard to accountability and impact, governments tend to deal with organizations rather than individuals. Both, nation-states and HEIs, follow other rationales than science. While academic values and the scientific ethos, as outlined above, foster universalism, communality and 
openness for the common good, states as well as HEIs have to delimit knowledgeexchange to be able to exploit added value of science to their own advantage.

It is, of course, rational for states, organizations and individuals to strive for their own advantage. The task of academic values and the ethos of science, supported by the high intrinsic motivation of academics, is to transform this self-interest into scientific progress and benefits for the common good. To foster academic values in this endeavour, it is important to recognize and confer status especially to those academics who appreciate this scientific ethos and who transform their intrinsic interests into hard scientific work. It is our duty as peers to make sure that we do not base our recognition mainly on the number of publications and impact factors, or on the acquisition of third-party funding. Instead, we should appreciate academics that truly contribute to global knowledge and formative education (in German you could add "Erkenntnis" and "Bildung" in a broader sense) as the main goals of higher education.

A good example is the sequencing of the human genome. While Craig Venter, researcher-turned-entrepreneur with his company Celera Genomics and extensive financial backing, sought to decipher the human genome purely for the end of acquiring a patent, researchers from all over the world pooled their resources in the "Human Genome Project" to make the results freely available. Today, during the Covid-19 pandemic, the international scientific community is working together in all parts of the globe in order to make quick progress into finding a treatment for the virus and a vaccine which will benefit everyone ("the common good"), instead of competing for quick wins to increase a specific university's/company's/nation's income. Additionally, we can also identify how important an "organized scepticism"-dimension is, as the publication of premature research findings in the race for the first place may not only discredit the actual researcher but science and higher education overall.

In times of big science and global grand societal challenges on the one hand, and increasing pressure from organizational and national agendas on the other, it is of utmost importance that we defend our academic integrity against mainly economically-driven interests, and promote science's ability to contribute to truth and human wellbeing. Therefore, it is increasingly important to foster international cooperation in the spirit of the above-outlined ethos of science instead of trying to maximize national benefits. In this, organizations such as UNESCO and the IAU have an important role to play: to help overcome national and organizational selfishness.

\section{References}

Clark, B. R. (1998). Creating entrepreneurial universities. Organisational pathways of transformation. Oxford/New York: Pergamon Press.

Cohen, M. D., March, J. G., \& Olsen, J. P. (1972). A Garbage Can Model of Organizational Choice. Administrative Science Quarterly 17(??), 1-25.

Merton, R. K. (1973) [1942]. The Normative Structure of Science. In R.K. Merton (Ed.), The Sociology of Science: Theoretical and Empirical Investigations (pp. 267-278). Chicago: University of Chicago Press. 
Musselin, C. (2007). Are Universities specific organisations? In G. Krücken, A. Kosmützky \& M. Torka (Eds.), Towards a Multiversity? Universities between Global Trends and national Traditions (pp. 63-84). Bielefeld: Transcript.

Michael Hölscher is Professor of Higher Education and Research Management at University of Speyer. His fields of interest are international comparisons of higher education systems; cultural sociology; innovation and creativity.

Open Access This chapter is licensed under the terms of the Creative Commons Attribution 4.0 International License (http://creativecommons.org/licenses/by/4.0/), which permits use, sharing, adaptation, distribution and reproduction in any medium or format, as long as you give appropriate credit to the original author(s) and the source, provide a link to the Creative Commons license and indicate if changes were made.

The images or other third party material in this chapter are included in the chapter's Creative Commons license, unless indicated otherwise in a credit line to the material. If material is not included in the chapter's Creative Commons license and your intended use is not permitted by statutory regulation or exceeds the permitted use, you will need to obtain permission directly from the copyright holder. 


\title{
Valuing the Civic Role of University \\ Education in an Age of Competition and Rapid Change
}

\author{
Pedro Nuno Teixeira and Manja Klemenčič
}

\section{Introduction}

In recent decades the discourse about higher education (HE) has been dominated by an instrumentalist view that emphasized the labour market benefits for graduates and the net (social) returns to tax payers for the public funding of $\mathrm{HE}$ (Psacharopoulos and Patrinos 2010). Nonetheless, HE's contribution to students' development and life is much broader than that through several non-market benefits to graduates, including improved health, improved education prospects for children, and greater longevity (see McMahon 2009). Furthermore, the effects of HE are visible in many civic dimensions, such as strengthened citizenship and civic mindedness and participation in democratic institutions. Thus, in this chapter, we discuss the significance of the civic contribution of HE beyond a narrow version of economic effects and on education practices that foster students' civic mindedness and civic engagement.

\section{Beyond a Narrow Understanding of the Economic Benefits of Higher Education}

The development of human capital theory in the mid-twentieth century anchored education as a central tenet of individual and social wealth and contributed to a massive increase in HE worldwide. Though the average private return to HE continued to be very attractive, there is significant evidence of a growing differen-

P. Nuno Teixeira $(\bowtie)$

University of Porto, Porto, Portugal

e-mail: pedrotx@fep.up.pt

M. Klemenčič

Harvard University, Cambridge, MA, USA

e-mail: manjaklemencic@g.harvard.edu 
tiation among groups of graduates and of the unequal benefits to each of them (Oreopoulos and Petronijevic 2013). The acceleration of technological change is also having an impact on the relevance of existing stocks and profiles of human capital (Aoun 2017), which will also affect qualified workers and selective occupations (and not only low-skilled workers). This has stimulated increasing debate about the skills and competencies that HE should develop in students. If we add to these trends the impact of the great recession and the challenging political and social context that has been emerging in many countries over recent years, the need to rethink the benefits of HE more broadly through the so-called nonmonetary benefits becomes more apparent (McMahon 2009).

Both the developments in the labour market and the aforementioned challenges of social cohesion and political fragmentation emphasise the importance of the role of HE shaping civic beliefs and attitudes. The relationship between education and civic behaviour is not straightforward. Education increases income and therefore raises the opportunity cost of civic activities vis-à-vis productive ones. Thus, greater investments in education increase the returns in the labour market and create a lower incentive for civic activity. However, there is also an educational impact on developing cultural attitudes and the link between the educational system and values. Each of these forces will differ according to the institution attended, the field of study or type of degree, since each of these dimensions will entail different educational experiences and different opportunities for graduates in the labour market.

Generally speaking, education's impact on citizenship has quantitative and qualitative aspects. On the one hand, education encourages broader participation by increasing interest and knowledge of civic issues. On the other hand, education enhances the quality of civic participation by equipping people with cognitive skills that enable their capacity to play a more critical and effective role. There is strong empirical evidence between education and a variety of social outcomes associated with civic values, including a greater likelihood to join organizations and participate in community activities (Glaeser et al. 2007). Although the effects may correlate with other factors, such as family and social background, they are sufficiently strong even when controlling for that.

One of the areas being studied in social and civic benefits of education refers to political participation and engagement. The impact of education on voting behaviour is one of the best documented aspects in political behaviour, with various recent studies showing that more educated individuals are more likely to vote (Dee 2004; Milligan et al. 2004). Education reduces the costs of certain forms of civic engagement and increases the perceived benefits of civic engagement. More educated individuals are more likely to register to vote, to follow political campaigns and political affairs, to attend political meetings, to volunteer for community issues or to attend community meetings. Moreover, they also tend to have a more favourable judgement about politics, its relevance, and the value of involvement in the political process, that may contribute to a better polity. HE contributes to promoting engaged and alert citizenship. This is referred to as critical citizens (Norris 2010), i.e., individuals who support and value democratic ideals but present at the same time significant levels of dissatisfaction with the performance of the political system. 
Civic virtues may transcend political participation and refer to greater trust in institutions or others or the willingness to accept and tolerate diversity (Borgonovi 2012). Trust and tolerance are attitudes or ways of being that have consequences on social cohesion (Glaeser et al. 2007). More open, diverse, and tolerant societies have a greater capacity for innovation and entrepreneurship as tolerance can manifest itself in the creation of bonds of trust, either interpersonal or in the institutions themselves.

Although the accumulation of evidence about a strong and positive relationship between $\mathrm{HE}$ and civic behaviour is important, it is even more relevant to understand the mechanisms by which that link operates. That is getting inside the so-called black-box of HE. There is some exploratory evidence that certain types of skills and disciplines seem to strongly correlate with political participation more than others (Hillygus 2005). However, we do not know how comparable those individuals were regarding their characteristics and preferences and to what extent individuals that chose certain fields are different in their social and political attitudes and values. Moreover, it is relevant to discuss how much those individuals had comparable experiences in $\mathrm{HE}$ (the type of education, content, learning methods) and the extent to which differences in those experiences could be relevant in shaping their political values and engagement.

\section{Revaluing the Civic Role of University Education}

We can explore the civic role of HE through two main approaches. The capabilities approach (Sen 1999) submits that freedom to achieve wellbeing, which is of primary moral importance, is to be understood in terms of people's capabilities which are real opportunities to do and to be what they reason to value. Nussbaum (2010) suggests that the capabilities that are crucial for the internal health of democracies are critical thinking, global citizenship dispositions, and empathetic understanding of human experiences, and it is education's task to equip students with these capabilities. We can also consider the civic effects of HE through the lens of normative democratic theory, especially regarding what is reasonable to expect from universities in guiding the design or development of democratic institutions. As well as the democratic practices within different social institutions, including universities (Biesta 2010). At the same time, educating future legislators, since a college degree is one advantage of getting elected to a legislative body (Hillygus 2005). The question here is how universities can help develop or foster democratic practices in their societies or help combat illiberal democratic practices. Both the capabilities approach and normative democratic theory are closely related in the context of education of students for civic mindedness and participation in democratic institutions. While the civic role of universities should, in principle, encompass all areas of operations, we are particularly interested in how that role can be better fulfilled through the function of education. That is, by strengthening student civic engagement and civic-mindedness.

Elite HE with small class cohorts undoubtedly provides better conditions for impairing civic values while nurturing students' individuality and autonomy in civic 
expression. In mass HE, the tendency is towards the standardization of education provision which lends itself better to indoctrination rather than individuality in civic mindedness (McFarlane 2017). Yet, standardized practices towards educating civically minded students, such as variations of mandatory civic courses, seem to be counterproductive to those objectives. Nonetheless, there are several examples of good practices in several networks and university initiatives that constitute the "global engaged higher education" movement (Watson et al. 2011). Major examples include the Talloires Network, an international association of over 400 universities committed to strengthening the civic roles and social responsibilities of higher education (Watson et al. 2011); and the Campus Compact, an organization based in the U.S. dedicated to promoting civic purposes of higher education (Battistoni 2017). The most vocal proponent of education for democracy and diversity in Europe has been the Council of Europe. Other national or regional networks have emerged over the past two decades in the United Kingdom, Ireland, Australia, South Africa, and the Arab world.

The enactment of civic mission through education is by no means uncontested. It is intertwined with the persistent debate about what should be taught and to what purpose. Looking at the aim of education serving democracy by strengthening civic mindedness in students, there are notable differences between the classical and progressive traditions (for an excellent review see Sant 2019). The classical tradition, i.e., the tradition of liberal learning, is in favour of education serving democracy but in a way that is disengaged from current life (Oakenshott 1989). Students are asked to delve deep into classical works of world civilizations and explore the ways of knowing, critically examine, and deliberate about democratic traditions and its core themes. Including conceptions of liberty, theories of democracy, and principles of distributive justice. In contrast, progressive educational tradition argues in favour of appraising the knowledge of the past for its relevance to solving the social problems of present times. The progressive educationalists advocate for the revision of curricula in line with critical, deliberative, and action-centred pedagogies. In a milder variation of progressive education, teachers are asked to help students develop civic mindedness and civic agency in any course, regardless of discipline, by introducing meaningful topics and activities that make connections to the real world (Boyte 2008).

The globally engaged university movement follows both educational traditions. The trend has not been to offer specific civic education courses in HE, but instead to offer courses that purposefully include civic competence-building to balance the disciplinary courses (Zgaga 2016). Moreover, students are involved in political and civic deliberations, contestations, and actions on campus (Biesta 2010). Students are also guided into co-curricular and extracurricular activities, such as community volunteering, paid internships, student leadership, and other types of volunteer or paid activities in the domain of public service or community engagement (Cress et al. 2013). These public service activities can be directed to communities outside the campus, as well as directly serve university communities. Student service to their university community is considered highly impactful for overall positive student experience and wellbeing (Kuh 2008). Furthermore, by providing opportunities for 
civic engagement on campus, universities can significantly enhance students' civic agency (Boyte 2008). Regardless of the students' motivations to engage in public service roles - be that altruistic or CV-building — students inevitably gain some civic mindedness through exposure to issues and other civic minded individuals.

Finally, the informal (or incidental) learning for civic mindedness is associated with the notion of universities as 'sites of citizenship' (Bergan 2004). Universities transmit values and attitudes through the ways of doing and through issues to which they give more or less attention (Klemenčič 2010). One such value is enabling student governments as a distinct form of political institutions within universities that organize, aggregate, and represent student interests (Klemenčič 2020). Another, more contested, is acceptance of (non-violent) student activism as a form of political expression. Yet, the education practices at universities have shifted from democratic principles of governance into more corporate models that undermine the civic roles of students through representation, and pay more attention to individual student rights. Such changes undermine the notions of universities as sites of citizenship and civic engagement and deprive students of civic opportunities that would strengthen their civic mindedness, and dispositions for (university) citizenship and civic engagement.

\section{Concluding Remarks}

Higher education is facing important challenges regarding its societal role. For many decades, the sector's relentless expansion was largely supported by the belief in the income and employment benefits of a degree. Universities were assessed regarding their contribution to that goal. Nonetheless, rapid and substantial changes in the labour market, and important crises and tensions in many countries (amplified by the current pandemic), have underlined the need to consider the contribution of $\mathrm{HE}$ to individuals and society more broadly. Particularly in times of increasing social change and tensions, it has become even more important to reflect on the role of $\mathrm{HE}$ in forging civic-mindedness among its students, as well as the type of education and skills that should be more relevant for the development of HE.

Practices to foster civic mindedness in HE students are diverse and demonstrate a commitment to experiential learning that is not confined to classrooms but can take place anywhere on campus and in engagement with community partners. These practices also express the conception of students as partners in knowledge generation and as full members, indeed university citizens, contributing to university communities. As we have tried to argue, promoting civic mindedness should be regarded less as an additional element in education that can be promoted in a standard way, but rather as something that pervades the missions and governance of the institution, which, therefore, needs to be integrated and adapted to the individual profile and circumstances of the institution. This is especially relevant given the growing stratification/differentiation in many HE systems. Meaning that the type of education that students receive can be very different. 
With the growing erosion of trust and social bonds (Pharr and Putnam 2000), and with growing political polarization, there are very few social institutions left with the capacity and vitality of HE to nurture civic values and promote critical citizenry. This needs to be addressed in the framework of HE's specificity and mission and the diversity of students they serve, namely the type of degree, the field, or other major characteristics of the student body. Universities should also strive to understand their impact effects through students' civic engagement and the extent to which innovative approaches can strengthen the nexus between HE and civic virtues. This will require universities to articulate a long-term strategy that places multidimensional social development at the core of its mission.

\section{References}

Aoun, Joseph (2017). Robot-Proof: Higher Education in the Age of Artificial Intelligence. MIT Press.

Battistoni, R. M. (2017). Civic Engagement Across the Curriculum: A Resource Book for Service Learning Faculty in All Disciplines. Boston, Massachusetts: Campus Compact.

Bergan, S. (2004). The University as Res Publica: Higher education governance, student participation and the university as a site of citizenship. Strasbourg: Council of Europe Publishing.

Borgonovi, F. (2012). The relationship between education and levels of trust and tolerance in Europe. The British Journal of Sociology, 63(1), 146-167.

Biesta, G.J.J. (2010). How to Exist Politically and Learn from It: Hannah Arendt and the Problem of Democratic Education. Teachers College Record, 112 (2), 558-577.

Boyte, H. C. (2008). Against the current: Developing the civic agency of students. Change: The Magazine of Higher Learning, 40(3), 8-15.

Cress, C.M., Collier,P.J., Reitenauer, V.L., \& Associates. (2013). Learning through serving: A student guidebook for service-learning and civic engagement across academic disciplines and cultural communities. (2nd ed.), Expanded. Sterling: Stylus.

Dee, T.S. (2004). Are There Civic Returns to Education? Journal of Public Economics, 88, $1697-$ 1720.

Glaeser, E.L., Ponzetto, G.A.M., \& Shleifer, A. (2007). Why does democracy need education?. J Econ Growth, 12, 77-99.

Hillygus, D. (2005). The Missing Link: Exploring the Relationship Between Higher Education and Political Engagement. Political Behavior, 27(1), 25-47.

Klemenčič, M. (2010). Higher education for democratic citizenship. In E.Fromet, (Ed.), EUA Bologna Handbook: Making Bologna work, B 1.3-1. Berlin: Raabe.

Klemenčič M. (2020). Student Governments. In Teixeira P., Shin J. (Eds). Encyclopedia of International Higher Education Systems and Institutions. Springer, Dordrecht.

Kuh, G.D. (2008). High-impact educational practices: What they are, who has access to them, and why they matter. Washington, DC: Association of American Colleges \& Universities.

McFarlane, B. (2017) Freedom to learn: The threat to student academic freedom and why it needs to be reclaimed. London: Routledge.

McMahon, W. (2009). Higher Learning Greater Good: The Private and Social Benefits of Higher Education. Baltimore: Johns Hopkins University Press.

Milligan, K., Moretti, E., \& Oreopoulos. P. (2004). Does education improve citizenship? Evidence from the United States and the United Kingdom. Journal of Public Economics, 88 (9-10), 16671695.

Norris, P. (2010). Democratic Deficit: Critical Citizens Revisited. Cambridge University Press, Cambridge. 
Nussbaum, M. C. (2010). Not for Profit: Why Democracy Needs the Humanities. Princeton, N.J: Princeton University Press.

Oakenshott, M. (1989). The Voice of Liberal Learning. New Haven: Yale University Press.

Oreopoulos, P. \& Petronijevic, U. (2013). Making college worth it: A review of the returns to higher education. The Future of Children, 23(1):41-65.

Pharr, S., \& Putnam, R. D. (2000). Disaffected Democracies. Princeton University Press, Princeton, NJ.

Psacharopoulos, G., \& Patrinos, H. A. (2010). Human Capital and Rates of Returns, In Johnes \&Johnes (Eds.) International Handbook on the Economics of Education, pp. 1-57.

Sant, E. (2019). Democratic Education: A Theoretical Review (2006-2017). Review of Educational Research 89(5), 655-696.

Sen, A. (1999).Development as Freedom. Oxford University Press.

Watson, D., Hollister. R., Stroud.S.E., \& Babcock.E., (2011). The engaged university: International perspectives on civic engagement. London: Routledge.

Zgaga. P. (2016). Higher Education and Democratic Citizenship. In: Shin J., Teixeira. P. (Eds) Encyclopedia of International Higher Education Systems and Institutions. Springer, Dordrecht.

Pedro Nuno Teixeira is the Director of CIPES - the Center for Research in Higher Education Policies and Associate Professor of the Faculty of Economics at the University of Porto. He has served as an adviser on Higher Education and Science to the President of Portugal since April 2016. He was Vice-Rector for Academic Affairs at the University of Porto (2014-2018) and was also a member of Portugal's National Council of Education (2014-2018). He is also a member of the Board of Governors and Secretary General of the Consortium of Higher Education Researchers (CHER).

Manja Klemenčič is Lecturer in Sociology and in General Education at Faculty of Arts and Sciences, Harvard University, and Associate Researcher at the Centre for Educational Policy Studies, University of Ljubljana. Manja serves as Editor-in-Chief of European Journal of Higher Education and co-editor of Bloomsbury book series Understanding Student Experiences of Higher Education. She co-edited Springer International Encyclopedia of Higher Education Systems and Institutions (2020) and Routledge International Handbook of Student-Centered Learning and Teaching in Higher Education (2020).

Open Access This chapter is licensed under the terms of the Creative Commons Attribution 4.0 International License (http://creativecommons.org/licenses/by/4.0/), which permits use, sharing, adaptation, distribution and reproduction in any medium or format, as long as you give appropriate credit to the original author(s) and the source, provide a link to the Creative Commons license and indicate if changes were made.

The images or other third party material in this chapter are included in the chapter's Creative Commons license, unless indicated otherwise in a credit line to the material. If material is not included in the chapter's Creative Commons license and your intended use is not permitted by statutory regulation or exceeds the permitted use, you will need to obtain permission directly from the copyright holder.

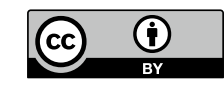




\title{
Mitigating Corruption in Higher Education
}

\author{
Elena Denisova-Schmidt
}

The lack of academic integrity, fraud, and other forms of unethical behaviour are problems that higher education faces in both developing and developed countries, at mass and elite universities, and public and private institutions. While academic misconduct is not new, massification, internationalization, privatization, digitalization, and commercialization have placed ethics higher on the agenda for many universities (Denisova-Schmidt and De Wit 2017; Denisova-Schmidt 2018, 2019; Bretag 2020).

Corruption in academia is particularly unfortunate, not only because of the high social regard that universities have traditionally enjoyed but also because studentsyoung people in critical formative years - spend a significant amount of time within these educational institutions. How they experience corruption while enrolled might influence their personal and professional future, the future of their country, and much more.

An experiment conducted among bank employees in Switzerland suggests that the business culture of banks supports, and even promotes, dishonest behaviour. Such study outcomes strengthen the assumption that recent financial scandals were caused by a questionable business culture. The authors (Cohn et al. 2014) recruited 128 employees from a large international bank, representing both core business and support units, to participate in an online survey. The subjects were randomly divided into two groups: one where their professional identity was stressed or another where professional identity was ignored. After the priming questions, all of the subjects anonymously performed a coin-tossing task: they were asked to take a coin, toss it ten times and report the outcomes. For each toss, they were able to win up to 20 USD, for a maximum payoff of 200 USD. All subjects were informed before each toss if "heads" or "tails" would win the cash prize, then asked to report their results. The study outcomes reinforce the assertion that this dubious business culture may have

E. Denisova-Schmidt $(\varangle)$

University of St. Gallen, St. Gallen, Switzerland

e-mail: elena.denisova-schmidt@unisg.ch 
contributed to the financial scandals of the late 2000s: bank employees were shown to be substantially more dishonest in the professional identity group, which reported on average $58.2 \%$ winning coin tosses - significantly higher than both random chance $(50 \%)$ and the success rate reported by the control group $(51.6 \%)$. For the higher education sector, these results suggest that a similarly dubious academic culture might also be transferred into the students' future professions. Less qualified people might be responsible for making serious decisions for which they are not properly trained, decisions that might directly or indirectly involve human lives. Indeed, one study found that students attending US medical universities with a strong gift restriction policy are more resistant to the marketing campaigns of pharmaceutical companies that they encounter later in their professional careers (King et al. 2013).

Ethical behaviour in higher education is a very complex issue that may be perceived differently by insiders and outsiders; it is also deeply embedded into larger institutional and cultural contexts that make the problem challenging for comparative analysis.

Cheating and other aspects of misconduct and academic fraud are manifold and widespread. Why do students cheat? Is it because their secondary school preparation was insufficient? Or are they pursuing a university degree as a credential without regard for how they obtain it? Why do faculty members and administrators ignore student misbehaviour? Are they overloaded with other duties and obligations or is teaching no longer important to academic career advancement? What are faculty members doing when they hold a part-time job outside of academia? Are they gaining current, practical experience to share with students to better orient them to the job market? In some fields, such as medicine or music, such employment might not be only an expectation, but a requirement. In other fields, such as management studies and political science, it can raise questions - are these faculty members leveraging their affiliation with a prestigious university to be considered for influential and lucrative positions in politics or industry? How will they manage the research, teaching, and service obligations they have in combination with private employment? Why do some faculty members publish in predatory journals, falsify data, employ professional ghost-writers, or steal papers submitted to them for review and publish them as their own? Plagiarism is widespread in academe at all levels. Were professors actively cheating as students and were they perhaps inadequately oriented to issues of academic integrity? Or are they just under too much pressure to publish to renew their contract or be considered for promotion?

\section{Current Trends in Research on Corruption}

Corruption is not a new phenomenon; the Bible, the works of Dante, and the plays of Shakespeare all discuss it. Intensive academic studies on corruption are relatively new, however and can be traced back to the early 1990s. This trend is often explained by the end of the Cold War, the rise of democracy, a free press in many countries, the influential role of international organizations like the World Bank and 
the International Monetary Fund, and the Organization for Economic Co-operation and Development. Corruption in centrally planned economies has been exposed, and international organizations have put integrity at the top of their agendas. Transparency International (TI), an international NGO headquartered in Berlin with chapters in more than 100 countries, along with other NGOs has led the fight against corruption globally (Tanzi 1998).

The main issue being raised in corruption studies is the question of why anticorruption reforms do not work. The answer to this question is associated with three factors - the definition of corruption; the measurement of corruption; and the design and implementation of anti-corruption policies (Ledeneva et al. 2017).

\section{Definition of Corruption}

One of the first academic definitions of corruption was suggested by Brooks (1970, pp. 56-64), "The intentional misperformance or neglect of a recognized duty, or the unwarranted exercise of power, with the motive of gaining some advantage more or less personal." One of the first definitions of corruption in higher education was offered by Heyneman, "The abuse of authority for personal as well as material gain" (2004, p. 637). He suggested considering professional misconduct as education corruption.

Today, scholars and practitioners working on corruption in general, and academic corruption in particular, often apply the definition suggested by Transparency International, "Corruption is the abuse of entrusted power for private gain". It should be noted, however, that corruption is an umbrella term covering multiple activities such as bribery, collusion, conflict of interest, embezzlement, fraud, lobbing, nepotism, patronage, revolving door affiliations, and other activities. The broader research on corruption suggests more than fifty manifestations. Some of these are illegal, while others are not, but all of them are unethical and questionable to some extent.

Defining something seemingly as simple as "bribery" is complicated, as it is not just cash, but rather "the offering, promising, giving, accepting, or soliciting of an advantage as an inducement for an action which is illegal, unethical, or a breach of trust. Inducements can take the form of gifts, loans, fees, rewards, or other advantages such as taxes, services, donations, favours, etc." (Global AntiBribery Guidance 2020). Not all scholars and practitioners working in this field would dare to call plagiarism or student cheating, corruption, nor would they consider universities that add a high "overhead" percentage to third-party grants or students preparing the first draft of their recommendation letter for their professors to sign to be corruption. Nevertheless, whether or not these practices represent corruption, the lack of academic integrity, academic dishonesty, cheating, professional misconduct, or other unethical behaviour, can lead to a decrease in the quality of higher education and increase public distrust in one of the most important societal institutions. 


\section{Measurement of Corruption}

Despite the numerous barriers to researching corruption in higher education, many studies in this field have been carried out. In 2013, Gareth Sweeney, Krina Despota, and Samira Lindner edited TI's Global Corruption Report: Education. In the nearly 500 pages of text, scholars and practitioners showed that corruption exists in academia all over the world and at all levels of education, from primary schools to universities (Sweeney et al. 2013). In addition to media reports, citizen reports, and studies of court records, the data sources for corruption in education include various types of surveys and experiments related to corruption and the perception of corruption. Lab, field, and natural experiments are new trends in the study of corruption in higher education. One of the advantages of these tools is that they address causality. Therefore, their outcomes might be helpful for educators, policymakers, and other practitioners.

Most scholars argue that measuring the true volume of academic corruption is impossible and impractical. Researchers working on corruption in higher education might face additional challenges, especially if they are themselves affiliated with an educational institution. How can they separate their job as faculty members from their study outcomes? What is their motivation? Are they whistle-blowers? Are they the offenders themselves, reflecting on their own experiences? In any case, researchers often have to explain their position in terms of corruption.

\section{Design and Implementation of Anti-corruption Policies}

There are two main models for analyzing corruption and, therefore, two main approaches to designing and implementing anti-corruption policies- the principalagent model and the collective action model (Ledeneva et al. 2017).

The first approach considers the principal, who represents the public interest and controls corruption, and the agent, who might be open to corrupt transactions. For example, if a faculty member (the agent) was to demand a bribe from a student (the client), the role of a dean (the principal) would be to intervene and prevent such a transaction. This model assumes that there are any no conflicts of interest between the principal and the agent. In reality, the principal might also be corrupt or have other reasons to allow, ignore, or even support corrupt transactions between the agent and the client. Nevertheless, scholars working with this model suggest tackling the incentives along the chain and changing the organizational structure to eliminate corruption.

The second approach considers all corrupt actions in context. For example, several high-profile politicians have been accused of plagiarism in their Ph.D. dissertations or during their university years. While some politicians "only" lost their academic titles, others also lost their jobs (such as Hungarian President Pál Schmitt in 2012). Some even saw the end of their public careers (e.g. German Defense Minister, Karl-Theodor 
zu Guttenberg, in 2011 and German Education Minister, Annette Schavan, in 2013), while other politicians were caught but completely unaffected (Russian President Vladimir Putin in 2006) or only slightly tainted (Former US Vice President Joe Biden in 1987). In societies where some forms of corrupt behaviour are considered the norm, many anti-corruption policies will be not effective.

Contributions to the scholarship of both approaches are crucial, but the models above do not address the scope of corrupt activity, such as problem-solving, especially in the context of weak and ineffective institutions. Looking for a third approach-what problems are solved by corrupt practices-might mitigate corruption more efficiently. The label "fake university," for example, can be applied to very different situations. U.S. Immigration \& Customs Enforcement (ICE) established the University of Farmington in Michigan as a trap for international students whom authorities believed were intending to enter the country as students only to remain in the country illegally. Another example, Central European University (CEU), a private university founded in Hungary in 1991 to support social and economic transitions in Eastern European countries and the former Soviet Union, is considered a fake university by the Viktor Orbán administration. While they are both "fake universities" in the classical meaning, the 'remedies', if any, to deal with the University of Farmington and the CEU might be completely different.

\section{Conclusion}

Many educators tend to focus on large-scale corruption. Indeed, the consequences for financial fraud during a building renovation or the purchase of new furniture are more visible and measurable than those for a plagiarized term paper. But the person in charge of procurement was once a student. He or she might be less inclined towards corruption if compromises for personal benefit had been addressed at that earlier stage and a more ethical attitude instilled. By acknowledging this problem-the lack of academic integrity among students - and allocating the necessary resources to mitigate academic misconduct involving students, universities might prevent corruption not only within their institutions but also far beyond.

Misguided silence and ignorance of the problems to maintain the reputation of the academic field, the university, or the entire country can lead to disasters such as Chernobyl (1986) or the COVID-19 pandemic (2020). Remedies for mitigating corruption should not focus on the general lack of academic integrity, but rather target specific practices to both prevent and control. Corruption in higher education might not only be the problem; it could also be the solution, and the reasons behind this should be tackled more precisely.

Corruption in higher education is a global problem. Some academic cultures are simply more researched and more open to those controversial topics than others. Some forms of corruption are more obvious and visible, even to outsiders, but others remain subtle and less visible. This, to some extent, mirrors the discussions between Donald Trump and Kim Jong-un on the size of their respective nuclear buttons- the 
size does not matter if either of them was to use it, as world order would be destroyed. The same is true about corruption in academia - the acts might differ in size, but with equally serious consequences in all parts of the world.

IAU plays an important role in mitigating corruption: it sets the standards (cf. IAUMCO Guidelines for an Institutional Code of Ethics in Higher Education), provides a platform for expert discussions (cf. IAU HORIZONS, 22(1), 2017), and maintains the IAU World Higher Education Database (WHED) with comprehensive and reliable information about higher education systems and institutions worldwide-a crucial service in this era of "fake news".

Acknowledgements This essay is a revised version of Denisova-Schmidt (2020). Introduction in 'Corruption in higher education: global challenges and responses. Leiden: Brill/Sense. Revised with permission from the copyright holder.

\section{References}

Bretag, T. (Ed.) (2020). A Research Agenda for Academic Integrity, Cheltenham: Edward Elgar Publishing.

Brooks, R. C. (1970). The nature of political corruption. In A. J. Heidenheimer (Ed.) Political corruption: Readings in comparative analysis (pp. 56-64). London: Holt, Rinehart and Winston.

Cohn, A., Fehr, E., \& Maréchal, A. M. (2014). Business culture and dishonesty in the banking Industry. Nature, 516, 86-89.

Denisova-Schmidt, E. (Ed.). (2020).Corruption in higher education: global challenges and responses. Leiden: Brill/Sense.

Denisova-Schmidt, E. (2019). Corruption in higher education. In Teixeira, P. N., \& Shin, J.-C. (Eds.). Encyclopedia of international higher education systems and institutions. Dordrecht: Springer Netherlands.

Denisova-Schmidt, E. (2018). Corruption, the lack of academic integrity and other ethical issues in higher education: What can be done within the Bologna process? In A. Curaj, L. Deca, \& R. Pricopie. (Eds.). European higher education area: the impact of past and future policies (pp. 61-75). Chem: Springer.

Denisova-Schmidt, E., \& De Wit, H. (2017). The global challenge of corruption in higher education. IAU Horizons, 22(1), 28-29.

Global Anti-Bribery Guidance (2020). What is bribery? Transparency International. Retrieved from: https://www.antibriberyguidance.org/guidance/5-what-bribery/guidance (27.08.2020).

Heyneman, S. (2004). Education and corruption. International Journal of Educational Development, 24, 637-648.

King, M., Essick, C., Bearman, P., \& Ross, J. S. (2013). Medical school gift restriction policies and physician prescribing of newly marketed psychotropic medications: Difference-in-differences analysis. BMJ, 346, 1-9.

Ledeneva, A., Bratu, R., \& Köker, P. (2017). Corruption studies for the twenty-first century: Paradigm shifts and innovative approaches. Slavonic and East European Review, 95(1), 1-20.

Sweeney, G., Despota, K., \& Lindner, S. (Eds.) (2013). Global corruption report: Education. Transparency International. London and New York: Routledge.

Tanzi, V. (1998, December 4). Corruption around the world. IMF Staff Papers, 45. 
Elena Denisova-Schmidt is a Research Associate at the University of St. Gallen (HSG), Switzerland, and a Research Fellow at the Center for International Higher Education, Boston College, USA. Previously, she has held appointments at the Humboldt University of Berlin, the Kennan Institute of the Woodrow Wilson International Center for Scholars, the German Institute for International and Security Affairs, the UCL School of Slavonic and East European Studies, the Edmond J. Safra Center for Ethics at Harvard University, and the Aleksanteri Institute of the University of Helsinki.

Open Access This chapter is licensed under the terms of the Creative Commons Attribution 4.0 International License (http://creativecommons.org/licenses/by/4.0/), which permits use, sharing, adaptation, distribution and reproduction in any medium or format, as long as you give appropriate credit to the original author(s) and the source, provide a link to the Creative Commons license and indicate if changes were made.

The images or other third party material in this chapter are included in the chapter's Creative Commons license, unless indicated otherwise in a credit line to the material. If material is not included in the chapter's Creative Commons license and your intended use is not permitted by statutory regulation or exceeds the permitted use, you will need to obtain permission directly from the copyright holder. 


\title{
Higher Education and Public Good in East and West
}

\author{
Simon Marginson and Lili Yang
}

The 70th year of the IAU has been marked not only by the Covid-19 pandemic but by the geopolitical tension between the United States and China. After almost four decades of cooperation, which began in shared opposition to Soviet Russia and a shared interest in China's modernisation, the leaders of each country have become strident critics of the other. The escalating war of words has led to disruptions in trade, communications and visas and now threatens the vast and fruitful cooperation between universities and researchers.

Much is at stake. Many US universities are in China, such as Stanford with its state-of-the-art centre at Peking University and NYU with a branch campus in Shanghai. Chinese universities benefit from visits in both directions, from bench-marking using American partner templates and from the return of US-trained doctoral graduates. US-China links in science are focused on crucial areas like biomedicine and epidemiology, planetary science and ecology, engineering, materials, energy, cybernetics. In 2018, there were 55,382 science papers co-authored between the US and China, the largest country-to-country collaboration in world science, compared with 23,616 US-Germany papers and 10,664 Germany-France papers. Yet, researchers with Chinese names holding dual appointments are being prosecuted for revealing their US grant applications to colleagues in China. Some US politicians typecast all Chinese students and researchers as spies for the Communist Party of China (CPC). For many, academic freedom is simply incompatible with China's system. Meanwhile, there is pushback in China. Future openness in both directions is in doubt.

Across the US-China divide, universities have much in common. At the same time, they are nested in cultural traditions and political systems that are very different,

\footnotetext{
S. Marginson $(\varangle) \cdot$ L. Yang

University of Oxford, Oxford, UK

e-mail: simon.marginson@education.ox.ac.uk

L. Yang

e-mail: lili.yang@education.ox.ac.uk

(C) The Author(s) 2021 
including relations between universities and government or state. There are divergent ideas about the public responsibility of higher education institutions, the nature of academic duties and freedoms, and student learning and self-development. These differences are much older than the CPC's assumption of power in 1949.

Can East-West trust and cooperation be sustained and where necessary restored? Can universities maintain fulsome connections despite government sabre-rattling? This will depend on the extent to which the similarities and differences between East's and West's social, political and university systems are understood. Moreover, cooperation depends on a readiness in the US and elsewhere to acquire a better understanding of Chinese civilisation - and thus also of higher education in China. Chinese language, ideas and institutions are less well known in the US and Europe, than vice versa.

This article examines similarities and the differences between China and the US/UK through the lens of ideas about the public role of higher education - the contributions of universities beyond the economic benefits for graduates. This lens readily brings the national comparison into view. We consider not just current policies but key ideas in each tradition. The task is challenging because there are only a few concepts which are common to the two traditions.

\section{Anglo-American Tradition}

There are two fundamental differences between Chinese and English-speaking political systems. One concerns state power. The other is about the individual.

The western political system is rooted in the idea of division of powers. This has been the combined legacy of the post-Roman division between church and state, the autonomy of Italian medieval cities and the merchants in many countries, and the evolution of the law and later of electoral systems as being both outside direct executive authority and in a continuing relation with it. The medieval university also emerged as a semi-independent institution, incorporated in its own right and partly separated from the church that nurtured it and the states that tried to control it. Between the two larger powers of state and church, the university built a space for scholars and in later years for science. In modern times, national government has reasserted itself in higher education, but the partial autonomy of the university, famously codified in the Humboldt tradition in Germany, has survived.

Despite periodic attempts to establish absolute rule, from feudal monarchs to twentieth-century dictators, the western state is essentially a limited state and reverts to that default position. Arguably, the Anglo-American political systems, in which the state is habitually distrusted, liberty is defined as freedom from state coercion, and the market is primary in relation to equality and solidarity, are one extreme of the western tradition. In some European countries, the state is seen as synonymous with civil society whereas, in the English-speaking polities, civil society is positioned outside the state. In the US even the public university is understood to be primarily part of civil society and the market. 
The second difference between China and the West, especially the Englishspeaking West, is the normative primacy of the individual. Medieval culture imagined the self in a unique relation with God, and this morphed into the rights-bearing property-owning individual who stood alone, like John Proctor in Arthur Miller's The Crucible. Later, democratic reformers defined the right-bearing person as all adult men, then all adults. The western reading of individual and society has many variants but central to Anglo-American culture are the beliefs that the individual is separable from the society that provides her/him with conditions of existence, and self-realisation of the individual is the purpose of life. Individual liberty, within the 'private' sphere, takes priority over other social goods. Hence the essential role of higher education is to provide opportunities for individual fulfilment.

In mainstream economics, the atomised individual is associated with methodological individualism, 'a doctrine about explanation which asserts that all attempts to explain social (or individual) phenomena are to be rejected ... unless they are couched wholly in terms of facts about individuals' (Lukes 1973, 110). In higher education policy, the most influential manifestation of methodological individualism in economics is human capital theory (Becker 1964). In the framework, higher education produces portable qualities in individuals, occupational knowledge and skills, which in turn generate higher earnings and other economically defined benefits for those individuals. The larger contributions of universities to scientific knowledge, culture, health, civic education or better international relations are seen as 'externalities', marginal to the core purpose of individual benefits.

However, the outcome of the doctrines of the limited state and the absolute primacy of the individual is that important elements are not explained. What is the basis of human society? How do the atomised individuals cooperate outside of economic markets? For example, what is higher education's contribution to the public or common good? Economic theory's ideas of externalities and market 'spill-overs' are not sufficient to explain this.

Arguably, the insufficiency of Anglo-American ideas about the collective dimension of social life has fed into the ambiguity, if not confusion, associated with the term 'public' and the public/private distinction. The term 'public' takes at least three differing meanings.

The first meaning is the public/private dualism. 'Public' and 'private' are seen as two halves of a whole, mutually exclusive and opposed to each other so that the ratio between them is seen as determining. Using this idea, in the first instance, higher education is seen as either a public good or a private good. Here, two kinds of public/private dualisms are in use. One is the distinction between state or government ('public') and market, household or individual ('private'). The other is the distinction in economic theory between private goods produced in a market, and public goods that cannot be profitably produced in a market because their benefits are not confined to individuals and are financed by governments or philanthropy (Samuelson 1954).

In Anglo-American higher education, basic research is seen as an economic public good and so needs government funding. There is no consensus about teaching, which is variously understood as a private or public good. However, it is widely agreed that equal opportunity of individuals in higher education is a public good. Here, the 
public/private dual intersects with the second meaning of 'public', meaning inclusive social relations, access, open communications or democracy, as in terms 'the public', or 'public opinion'. This understanding of 'public' has its origins not in England but in eighteenth-century France and America. It is not opposed to 'private' or exclusive to the individual. Here, the broader public role of universities moves from margins to the mainstream. Universities are expected to prepare graduates as citizens for all social roles and not just for the economy.

This broader open public realm shades into the third meaning of 'public good' as the shared and universal welfare. However, in the Anglo-American world, a problem with the larger ideas of 'public' is that the term retains connotations of limited government. The term 'common good', which includes non-government community building activities as well as the legal public sector, has been suggested in place of 'public good' (Locatelli 2018).

\section{Chinese Tradition}

The norms of Chinese governance have older roots, dating back to the Western Zhou dynasty (1046-772 BCE). The largest influence is the Confucian social system. There the spheres of the individual, family, state and tianxia (all under heaven) are not seen as being arranged on the basis of a separation of powers and the partial autonomy of each sphere. Rather, each smaller sphere ( $\mathrm{si}$ ) is nested in the larger sphere (gong). Hence the person is seen as nested in the extended family or kin group, and the family in the state. The state is not a limited western state. It has a comprehensive mandate for order and prosperity and intervenes freely anywhere at will to further the collective good, tianxia weigong, a concept that is close to the 'public good' in the West.

In Imperial China, unlike in the West, the state was always supreme in relation to the military, merchants, towns or religion, though local villages mostly ran themselves. Higher education was established not as autonomous from church and state but as a branch of statecraft, training officials for government service. Under the Song and Ming dynasties (960-1644 AD,) it expanded to provide partly meritocratic opportunities to enter the gentry on a large scale.

The Confucian individual is not separate from society. She/he is a relational and role bearing individual. Compliance is achieved not primarily by state coercion but through shared values about right conduct established by education. Habits of selfcultivation and lifelong learning, the will to continually improve oneself, are installed early in the family. Confucianism values free will but distinguishes between the inner self-centred on moral autonomy and social action by the outer self. Persons are obliged to restrain from enacting their will if there are negative social consequences. Self-determination is absolute, but self-realisation is not.

There is no translation of the English terms public/private in Chinese, but the priority given to the larger unit ( $g$ ong) over the smaller unit ( $\mathrm{si}$ ) ensures the primacy of the collective and public over the individual and private. Where there was fundamental 
tension between public and private interests in Imperial China, the larger collective was supreme. This led to recurring arguments from scholars that the individual was insufficiently protected.

Confucian self-cultivation remains the cornerstone of personal development, but much has changed, especially since 1949. The authority of the family has declined though it is still important. The party-state continues the comprehensive state but reaches more effectively into village, workplace and household. Geographical and social mobility, entrepreneurship, consumption and mass higher education have all enhanced the agency of the individual.

Modern higher education combines western and Chinese features. Like the Imperial academies, it serves national development but its academic forms and disciplines have been closely influenced by Western and especially American examples. On the other hand, state-nested governance, with dual leadership by the university president and the party secretary, and the potent spirit of continuous self-improvement that animates both persons and institutions, are more traditional. Compared to many western universities, China's institutions are closely regulated in leader selection, curricula and student numbers. Yet, like western universities, they have corporate autonomy and a large measure of academic freedom in the sciences. Faculty shape their research and freely conduct foreign relations. China could not have become a global science powerhouse without disciplinary autonomy. On the other hand, the social sciences and the humanities are more politically constrained, and faculty in China do not engage in American-style freewheeling public commentary.

Although modern China has a history of courageous intellectuals, when central political control is tightened there is limited scope for the American idea of the university as a centre of public discussion in civil society. Faculty value the social responsibility and status entailed in their role. They understand academic freedom as positive, in terms of their potential to contribute, rather than as negative, freedom from the state. Chinese universities are expected to contribute to local economies and communities. Faculty provide expertise to government at all levels, perhaps even more than in the West. Professors are expected to be critical of government policy when this is merited. The difference is that such exchanges take place behind closed doors, inside the party-state rather than open public settings.

Other notions of 'public' have more resonance in China. In interviews reported by Tian and Liu (2019) some faculty draw on the western economic dualism of public/private to describe Chinese higher education as a 'quasi-public' good. Fees are charged, and corporate universities compete for students, resources and status. Though this might suggest a US-China convergence, important differences remain. The same research shows that all of faculty, university leaders and government officials identify universities with the state, seeing them as unequivocally 'public' in the sense of ownership, governance and mission. The regulated private sector is included within the ambit of this comprehensive 'public' domain.

Further, while in both the US and China higher education is valued to the extent it helps individuals to advance in social and economic terms, research on family and student attitudes in China (e.g. Chen 2020) finds that achieving good Confucian personhood is as important as maximising human capital. The two are not seen 
as necessarily in conflict. The stronger individualism that has developed in China passes through a social system in which self-improvement, family and contributing to society remain strong motivators. In American terms, people in China want higher education that is both more 'private' and just as 'public' as before, a double ambition sustained by both state policy and popular culture.

\section{Summary}

How then do the higher education systems compare? In both the individual is important. An attractive feature of China's system is that the student is nested in social context. What matters is not just private enrichment but also personal and social ethics. There is also a stronger sense of governmental responsibility, placing China closer to, say, the Nordic systems than to the US. But it is too easy for the state to dominate. The independent civil order is relatively weak, reducing the scope of the university as constructive critic. The US offers a richer potential for university engagement in civil society. However, the American state, potentially the corrective to inequality, is on the back foot, and methodological individualism in policy narrows university contributions to both individuals and society.

These similarities and differences colour the way each system sees the other. They are longstanding and will not disappear. The key is to understand them and work with them.

\section{References}

Becker, G. (1964). Human capital: A theoretical and empirical analysis with special reference to education. Chicago, IL: University of Chicago Press.

Chen, J. (2020). Values reconciliation: Politics and ethics of Confucian piety and overseas education. ( $\mathrm{PhD}$ dissertation). University of Cambridge Faculty of Education.

Locatelli, R. (2018). Education as a public and common good: Reframing the governance of education in a changing context. UNECSO Education Research and Foresight Working Papers, 22. Retrieved from: http://unesdoc.unesco.org/images/0026/002616/261614E.pdf (1.06.2020)

Lukes, S. (1973). Individualism. Oxford: Blackwell.

Samuelson, P. (1954). The pure theory of public expenditure. Review of Economics and Statistics, 36(4), 387-9.

Tian, L., \& Liu, N. (2019). Rethinking higher education in China as a common good. Higher Education, 77(4), 623-40.

Simon Marginson is Professor of Higher Education at the University of Oxford, Director of the ESRC/OFSRE Centre for Global Higher Education (CGHE), Joint Editor-in-Chief of the journal Higher Education, Professorial Associate of the Melbourne Centre for Study of Higher Education at the University of Melbourne, and Lead Researcher with the Higher School of Economics in Moscow.

Lili Yang is a doctoral researcher at Centre for Global Higher education, University of Oxford. In Lili's doctoral thesis, she explores the similarities and differences between notions of "pub- 
lic (good)" in Sinic and Anglo-American traditions, and the implications for higher education. Broadly, her research interests include higher education policy, higher education in East Asia, and international higher education.

Open Access This chapter is licensed under the terms of the Creative Commons Attribution 4.0 International License (http://creativecommons.org/licenses/by/4.0/), which permits use, sharing, adaptation, distribution and reproduction in any medium or format, as long as you give appropriate credit to the original author(s) and the source, provide a link to the Creative Commons license and indicate if changes were made.

The images or other third party material in this chapter are included in the chapter's Creative Commons license, unless indicated otherwise in a credit line to the material. If material is not included in the chapter's Creative Commons license and your intended use is not permitted by statutory regulation or exceeds the permitted use, you will need to obtain permission directly from the copyright holder. 


\title{
The Beginning of History and the University
}

\author{
Bryan McAllister-Grande
}

The word "truth" features prominently in the mission statements of the International Association of Universities, the United Nations, and other post-World War II organizations. "Truth" also appears in the official mottoes of many universities: Harvard's simple Veritus ("Truth"), National University of the South's elegant Ardua Veritatem ("Through the difficulties to the truth"), Pontifícia Universidade Católica de Campinas' celebratory Fide Splendet et Scientia ("May it shine with truth and knowledge"), Tianjin University's practical 实事求是 (“seeking truth from facts"). Yet, “truth” is an elusive concept. This essay argues that a new history of the university and truth is required. A new history of truth will explore the idea from pluralistic perspectives, not the monolithic and all-powerful "Truth" of the twentieth century and those centuries before it.

A new history of truth would also wrestle honestly with the ways in which universities have sacrificed truth-seeking to ideology. Previous histories of universities have too often lauded their autonomy and freedom from the world and society. A mystique and aura dominate these gilded narratives. Adopting a more radically empirical lens, university leaders and scholars should investigate the ways in which truth has been corrupted by powerful forces of religion, nationalism, and colonial forces disguised as "internationalism."

This essay explores three distinct eras and contexts; each example demonstrates new thinking on the relationship between truth and ideology. In the first example, recent histories have unearthed an old claim that the ancient academies (of Plato, Aristotle, and other giants of philosophy) were rife with early racism and classism. In the second, the so-called "golden age" of university Scholasticism and the subsequent transition to Renaissance Humanism is explored; in the third, I draw a line

\footnotetext{
B. McAllister-Grande ( $\square)$

Northeastern University, Boston, MA, USA

e-mail: b.mcallister-grande@northeastern.edu 
between Puritan dreams in the American colonies and Anglo-American commitments to Christian Humanism. Finally, I outline three steps toward achieving a new set of histories of universities and truth.

\section{The Ancient Academies and the "Unity of Truth" Ideal}

Scholars and experts have often lauded the ancient academies of Plato, Aristotle, and other great figures as innocent and pure. The "canon" discussions often begin with the "Ancients." On the other hand, "moderns" (like Karl Popper) have often painted ancients as dusty relics or, worse, as fascist dictators. This extreme stance against ancients (either celebratory or derogatory) has shrouded us from achieving a more balanced, empirical examination of the classical centres of learning. These early institutions were the forebears of colleges and universities today - so it is doubly important that we understand their origins, their purposes, and, yes, relevant ideologies that guided or influenced their lauded attempt to "search for truth."

While little empirical evidence survives the rages of cultural and physical destruction, scholars still must explore the ideals and realities that drove these academies. For instance, historians, philosophers, and archaeologists could collaborate to better synthesize the schools of thought that intersected with political economies in the ancient world. Plato's Academy was a haven of both philosophical Scepticism and Idealism. Both philosophies attacked the Stoic "dogma" that sense impressions (what we now call science) could give accurate knowledge of the universe. Philosophers have well documented these competing philosophical schools of thought, but they have not always connected them with political ideals or ideologies.

This situation, too, is partly a product of the "search for truth." Modern giants such as Marx and John Dewey - caught in their own intellectual cold wars - were eager to pin "ideology" to the nineteenth and twentieth centuries. Yet, ideology - a system of ideals and ideas that informs policy - has existed since the birth of humanity and society. Scholars can connect the history of knowledge to ideological aims and draw lines to the modern era. Indeed, Ibram X. Kendi, in his celebrated Stamped from the Beginning: A Definitive History of Racist Ideas in America (2016: 17), ties American and global slavery directly back to the Greek idea of power and control. Casting Aristotle in racial terms, Kendi writes that Aristotle "situated the Greeks... as the most beautifully endowed superior rulers and enslavers of the world," and that Greek ideas of Idealism and knowledge pointed at a teleological goal: domination over the what Aristotle himself called the "burnt faces" of Africa. Scholars can follow lines of thought as they intersected with political and humanistic goals and formed policy in both the ancient and modern worlds.

Chief among these ideals was the one of the "Unity of Truth." This Idealistic ideal, promoted by Plato and his followers (especially the followers known as NeoPlatonists), argued that all truth and facts (including what we now call spiritual or divine truths) are united into a single system. Such a belief had multiple goals, including disciplinary (all disciplines are united in a single system of knowledge), 
religious (all beings are united by a prime mover or god), and political (all subjects are united under a philosopher-king or set of philosopher-kings, a popular Platonic idea). Yet, histories of the Unity of Truth ideal are few and far between. A new history of truth will also be a history of knowledge, a history of learning, and those crucial intersections between knowledge, faith, race/empire, and politics - especially the Unity of Truth ideal.

In addition, the Platonic and Aristotelian academies were obviously not the only ancient academies. Similar and diverse examples existed in China's Tang Dynasty, Korea's Joseon Dynasty, Rome (the Imperial University of Constantinople), India (for example, Nalanda University), and ancient Iran/Persia (such as Gondishapur University). Ideals of the "Unity of Truth" animated these academies and spiritual centres, especially the idea that faith and knowledge (science) were two sides of the same coin. Similarly, these universities were part of religious and ideological structures associated with centres of power and politics. Again, while physical and archaeological evidence is slight, efforts to excavate and study these institutions in an interdisciplinary fashion - are too few and hampered by lack of funding and political interference.

\section{Truth in the Age of Scholasticism and the Role of Catholicism}

Similarly, scholars must produce updated understandings of the Middle Ages and the Age of Scholasticism, when Europeans created the famous universities of Paris, Bologna, Oxford, and others. In our histories of higher education, scholars write as if these early universities were truly "international" because those Scholastic scholars spoke a "universal" language (Latin), featured regular exchange of scholars and students, and had similar methodologies - namely, the Scholastic dialectic that helped lay the foundations for modern natural science as well as the humanities (then unified under a single study, called "philology"). Indeed, much of romantic idealism associated with the word "Truth" and the association of truth with universities derives from this Scholastic era. In this era, historians often claimed, benevolent and humble scholars searched for truth without much influence from the outside world. Their method - the detached, "objective," methodology of the dialectic - still holds some sway in our conceptions of research as being unbiased or pure. The image of universities as "ivory towers" derives, in part, from this era. Much of the work on these universities was due to the Neo-Thomistic (Thomism refers to the thought of St. Thomas Aquinas, a key Scholastic thinker) revival in the 1930s and 1940s. At that time, world-renowned Catholic scholars such Jacques Maritain and Étienne Henri Gilson helped popularize the image of a dusty Scholasticism as a modern symbol of the "pure" and "international" university scholar that still persists today. Not only does this intense focus on Scholasticism overshadow non-Western and non-European institutions, it also presents an image of the pure "ivory tower" that is misleading. 
As the historian of science Steve Shapin (2012: 1) observes, "There never was an Ivory Tower. It was always a figure of speech. There are towers and there is ivory, both quite real; it is their combination in the idea of an Ivory Tower which is both imaginary and consequential." Our ideas of the Scholastic era are outdated; and, similar to the ancient era, filled with either lofty praise or blanket criticism.

We can better understand the commitments and ideas during this crucial time period of Scholasticism, when many of the familiar structures of modern universities - such as disciplines, research methodologies, terminologies, traditions, and approaches to knowledge - were conceived of and formulated. Scholars can better search for the origins of their disciplines by grasping the complex differences in methodologies between various forms of Scholasticism. We must also seek to trouble the notion that these universities were inherently international/universal and better connect them to the burgeoning empires of Europe. Finally, scholars can overcome what was once imagined as a large break between Scholasticism and its successor philosophy in Europe, Renaissance Humanism. At one time, intellectuals perceived a fairly wide chasm between the Middle Ages and the Renaissance; now, these premodern eras are better seen as ideologically, politically, and intellectually connected.

The term "Scholasticism" itself should be studied intensely. The word formally means the organization of knowledge in a systematic and unified fashion; our modern notion of the "scholar" who studies a subject intensely derives from this usage. In addition, what Americans know as "majors" and others know as "course" or "specialism" derives largely from this era. Ideologically, we might better understandwithout bias or undue criticism - the linkages between this organization of knowledge and the various branches of Catholicism that animated those desires to organize thought.

\section{Christian Humanism - The Anglo-American Unity of Truth}

As Renaissance Humanism transitioned to new realities created by empire, war, and the modern advent of democracy, a utilitarian-inspired Christian Humanism - and its associated religion called "Protestantism" - took shape in Britain and the American colonies. Intersecting with the dawn of modern Capitalism, this utilitarian Christian Humanism favoured the natural sciences for predicting accurate and universal renderings of truth. It also allowed more "particularistic" viewpoints ascendant in Protestantism and Renaissance Humanism to flourish. Thus, we get the modern balance in many Western universities between a product-oriented science and literary studies, which, in contrast, favours deeply contextual studies of the human condition.

Christian Humanism should be studied as the major philosophy/ideology of American higher education. It coincided with the growth of both Capitalism as a political economy and the birth of Utilitarianism as an Anglo-American political philosophy. Early ideas about Christian Humanism philosophy/ideology emerged with the 
English Restoration; one major figure was Robert Boyle, the Anglo-Irish natural philosopher and founder of the modern experimental method in science. Not only did Boyle establish the foundations of modern chemistry, but he also helped promote Christian Humanist philosophies throughout the English colonies. Boyle sat on the original Council for Foreign Plantations in 1660, which was commissioned concurrently with the Royal Society to centralize and advise the vast empire that Charles II inherited (Kendi 2016: 46). As Kendi notes, Boyle believed that the "physics of light" showed the "whiteness" was the "chiefest color"; much of his work was deployed to advance both scientific production and the notion that certain biological and physical characteristics were "preferred" rather than natural or heredity (this was deemed "progressive" at the time, but was clearly racist). A scientist who was heavily influenced by Boyle, Isaac Newton, carried forward Boyle's experiments in "Optiks" to conclude that "white" was at the very centre of all colours and all things - a kind of "ether" ordering the universe and the qualities of light, from which all other things could be judged.

Another key figure of Anglo-American Christian Humanism was the English Puritan theologian William Ames, whose works helped form the early curriculum of Harvard and Yale universities. Ames was one of the leaders of an effort to make morality or "the unity of truth" itself scientific - in the sense that it could be studied by observing particular cases in "natural" habitats. Ames was also a racial ideologue who claimed that "blood kin" was superior to all others and that "free men" (meaning white men) should have superiority over those who were inferior. Much of his and later utilitarian writings were designed to show the superiority of Protestant, white ways of life, science, literature, and habits.

In the nineteenth century, most educated Americans read another Utilitarian and Christian Humanist writer, the scientist William Paley. His books The Principles of Moral and Political Philosophy (1785) and Natural Theology, or Evidences of the Existence and Attributes of the Diety (1809) both promoted Utilitarianism as a political and moral philosophy, and attempted to prove the existence of an active, intervening, and highly practical Christian God. Paley's works made the claim that the Christian God and natural science were aligned; he thus gave a new definition of the "unity of truth" as the (maybe imperfect) union of Protestant Christianity and experimental science. Paley used the now-famous analogy of the "watchmaker" to explain this union; he explained that like a watchmaker, who must make all the pieces fit and work together, God acted like a primer move or Newton's "ether" to stitch together the diverse particularities of nature and humanity.

\section{The Present Day}

Lest we think that these are historical examples, more present-day issues can be examined. The efforts of nationalists/populists governments to undermine universities and science is not a random occurrence, but, rather, a coordinated ideological 
strategy. It is a productive strategy, too - productive in the sense that it has worked in prior eras.

\section{New Histories}

New histories of universities could be both "bigger" in scope and far more particularistic and balanced in historical method. Instead of lauding universities as bastions of purity or condemning them as evil, scholars can join together to understand universities as flawed institutions. Scholars can connect the dots between Unity of Truth ideas throughout spaces and places, understanding how those ideals led to both research breakthroughs and as covers for ideological and racial control. More so, new histories of truth and universities could and should unlock new potentiality for what our institutions can achieve when collaboration, not competition, is the goal. Nothing less than the fate of the world is at stake.

\section{References}

Kendi, I. (2016). Stamped from the beginning: The definitive history of racist ideas in America. New York: Nation Books.

Shapin, S. (2012). The Ivory Tower: The history of a figure of speech and its cultural uses. British Journal of the History of Science, 45(1), 1-27.

Bryan McAllister-Grande is the assistant director for curriculum integration at Northeastern University. He is the co-founder of NAFSA's Global Studies Literature Review and a member of NAFSA's Teaching, Learning, and Scholarship Leadership Team. His work has appeared in The Future Agenda for Internationalization in Higher Education and will appear in upcoming volumes and special issues of Perspectives on the History of Higher Education, Teacher's College Record, and the SAGE Handbook of International Higher Education.

Open Access This chapter is licensed under the terms of the Creative Commons Attribution 4.0 International License (http://creativecommons.org/licenses/by/4.0/), which permits use, sharing, adaptation, distribution and reproduction in any medium or format, as long as you give appropriate credit to the original author(s) and the source, provide a link to the Creative Commons license and indicate if changes were made.

The images or other third party material in this chapter are included in the chapter's Creative Commons license, unless indicated otherwise in a credit line to the material. If material is not included in the chapter's Creative Commons license and your intended use is not permitted by statutory regulation or exceeds the permitted use, you will need to obtain permission directly from the copyright holder. 


\title{
Higher Education and the Enduring Value of Hospitality: Reflections for the 21st Century
}

\author{
Gerardo L. Blanco
}

\section{Introduction}

The 21st century is a perilous time for international collaboration among university actors. Mobility and international exchange have come to a total standstill as the world shelters in place, trying to slow down the course of a pandemic. However, the crisis of hospitality in higher education has been long in the making. Within universities, internationalization has been driven by profits and revenues for decades, while discussions of core values have been cast aside as utopian or idealistic. There are thousands of displaced, imprisoned and exiled academics, and there are millions of university-aged refugees in the world, with only a tiny fraction of them entering universities. Beyond university walls, scepticism toward the other has been brewing, popularizing xenophobic nationalism and construing mobility as a threat that must be curtailed or regulated to new extremes. As some governments have turned to authoritarianism, universities have become targets, and government actions have resulted in significant numbers of displaced and unemployed academics, many of whom look beyond national borders to find spaces where the pursuit of their ideas is less threatening and where they can exercise their intellectual calling. Responding to these needs requires hospitality, which is not unprecedented, but that has become a lower priority among many others such as the constant pressure to move up the rankings or league tables.

It can also be observed that, judging by policies and the attitudes of local students and the general populace, some of the most sought-after countries for international mobility are also among the least hospitable. In the United States, which is the largest recipient of international students, xenophobic incidents against international students have been recorded, and policymakers have singled out international students and visiting scholars from China, the largest sender of students and scholars,

G. L. Blanco $(\varangle)$

Boston College, Chestnut Hill, MA, USA

e-mail: blancoge@bc.edu

(C) The Author(s) 2021 
as potential spies or thieves of intellectual property. These examples illustrate an ongoing crisis of hospitality. This chapter explores the contours of hospitality in the context of higher education and imagines the possibility of universities radically and unconditionally open to hospitality. As the International Association of Universities (IAU) celebrates its seventieth anniversary, revisiting hospitality as an enduring value that guides the work of universities constitutes a timely and necessary task.

\section{Hospitality, Hostility and the Other}

Like UNESCO and the UN, it is possible to situate the origins of the IAU in the historical context of building global institutions after the Second World War. With this background in mind, reminded of the post-war ravages and displacement, it is easy to argue that hospitality is an enduring value of universities and worth of analysis as IAU begins its eight-decade of existence. This is also a momentous task, given that the first two decades of the 21 st century have been marked by climate change, refugee crises and large political shifts in the direction of xenophobic nationalism. As vast portions of the world continue to shelter in place, and as an unprecedented number of borders remain closed in an attempt to slow down the pace of a pandemic, the idea of unconditional hospitality as an enduring university, and therefore universal, value is not only timely but urgent.

In a surprising twist, the word hospitality is etymologically connected not only to host, but also to hostage and hostility (Dufourmantelle and Derrida 2000). This connection may account for the fact that it is not possible to be open to others and other's ideas without incurring in risk or the possibility of conflict. Whether we dub it global, universal or cosmopolitan, the university — as ideal—involves both convergence and conflict of ideas and both are enshrined in the IAU Constitution. However, it appears that universities have moved away from their embrace of vigorous argumentation as societies find solace in the echo chambers of like-minded social media contacts and followers. Heated debate and the frustrating task of welcoming someone else's ideas that one might find wrongheaded or even offensive pales in comparison with the appeal of surrounding oneself, albeit only electronically, by those who are already in agreement, blocking those who might think differently. Perhaps to the same extent that open intellectual antagonism has given way to ideologically segregated spaces on campus, hospitality, too, has receded.

Taking the next step in this chain of words-from hospitality to hostility-we arrive at an unsettling term: hostage. There is no hospitality without the other, and Levinas (1989) goes as far as stating: "I am hostage to the Other" (160). The other, who receives our hospitality, is always foreign - a stranger in Romance languagesand therefore strange (Bauman 2016) to us. This is a central role of universities, which for centuries have promoted cosmopolitan values: to make the others familiar, embracing their foreignness without erasing differences. This is the balancing act of universities: to promote peaceful co-existence without committing the violence of cultural cloning. Even as we commit to specific values, and while all societies 
include a principle of hospitality (Derrida 2005b), this universality does not mean sameness in how the value is manifested across cultural contexts. While welcoming ideas is widely recognized as an academic and intellectual value, we might also remember that ideas are always, at some point, embodied — even written words have authors - and as a result, welcoming new ideas always involves welcoming the other.

\section{Radical or Not at All}

Universities in the 21 st century cannot relinquish their calling to universality, but their global connections must not be subordinated to economic interests, but rather emerge from a deep commitment to enduring values. Just as universities continue to defend their obligation to interrogate and deconstruct (Derrida 2005a), they must remain unconditionally hospitable to ideas, and to those generating them, regardless of how foreign they may appear. Universities also need to remain fundamentally open to those who have been systematically excluded from the benefits afforded by these most enduring and resilient institutions and to those who have been displaced or endangered for exercising their right to think and express their ideas. Just like the slightest interference with academic freedom threatens to invalidate the entire intellectual enterprise of universities, it is necessary to be vigilant that the smallest violation to the principle of hospitality in universities - which can be extended to ideas, individuals and groups_-runs the risk to overturn the role of universities as sanctuaries of knowledge.

It is the duty of those of us, fortunate enough to inhabit within universities, to extend this principle of hospitality to the future. This involves future generations, of course, and as such it is necessary to be committed to sustainability and serving as good stewards of these great institutions, mobilizing them to solve the great challenges that humanity faces. As well, we have an obligation to extend this principle of hospitality to new forms of instruction that may appear foreign-even from a different dimension or from an alternate reality as we have been forced to reimagine our teaching altogether as a result of COVID-19. We can reframe our current embrace of remote learning and the learning of neologisms like "asynchronous" in response to the pandemic less as an imposition and, increasingly, as an expansion and new expression of hospitality. This is not only an opportunity; but also, our duty. Just like it is our duty to critique and deconstruct these new modalities in order to improve them once we have properly welcomed them to our midst. 


\section{Parting Thoughts}

A conversation about radical hospitality in universities for the 21 st century is necessary because, judging by the first two decades, we are off to a rough start. The practice of radical hospitality requires us to take a long and hard look at the most vulnerable aspects of the experience of international students and to turn that gaze toward the most vulnerable groups in higher education mobility, which, despite their vast numbers, are often invisible. The conversation about hospitality is needed because we recognize that the other's presence is indeed a disruption to our everyday life, but not nearly as significant as the disruption to theirs, especially when we talk about the growing number of displaced academics, students of refugee backgrounds, or stranded international students.

The first two decades of this century and the first seven decades of IAU's existence serve as reminders that we need universities to serve as sanctuaries and beacons and work according to principles of hospitality and solidarity because we are all one epidemic away, or one government flirting with totalitarianism away, or one economic crisis away from closures, disbandment and mass dismissals. We exercise hospitality today, not only inspired by deep empathy for the other and responding as their hostage but rather because we all are hostages to a future that is cruelly uncertain.

\section{References}

Bauman, Z. (2016). Strangers at our door. Wiley.

Derrida, J. (2005a). The future of the profession or the unconditional university (thanks to the "humanities," what could take place tomorrow). Deconstructing Derrida ,pp. 11-24. Palgrave Macmillan, New York.

Derrida, J. (2005b). The principle of hospitality. Parallax, 11(1), 6-9.

Dufourmantelle, A., \& Derrida, J. (2000). Of hospitality. Stanford University Press.

Lévinas, E. (1989). The other in Proust. In S. Hand (Ed.), The Levinas reader, pp. 160-165. Oxford: Blackwell.

Gerardo L. Blanco is Associate Professor of Higher Education and Director of the Center for International Higher Education at Boston College. His research explores the intersections of quality and internationalisation of higher education. A Fulbright Specialist, and a past Erasmus+ Teaching Fellow, his professional activities have taken place in 14 countries and 5 continents. He has taught at the University of Massachusetts Boston, the University of Connecticut, Shaanxi Normal University, and the John Paul II University of Lublin. 
Open Access This chapter is licensed under the terms of the Creative Commons Attribution 4.0 International License (http://creativecommons.org/licenses/by/4.0/), which permits use, sharing, adaptation, distribution and reproduction in any medium or format, as long as you give appropriate credit to the original author(s) and the source, provide a link to the Creative Commons license and indicate if changes were made.

The images or other third party material in this chapter are included in the chapter's Creative Commons license, unless indicated otherwise in a credit line to the material. If material is not included in the chapter's Creative Commons license and your intended use is not permitted by statutory regulation or exceeds the permitted use, you will need to obtain permission directly from the copyright holder. 


\title{
The Role of Quality Assurance and the Values of Higher Education
}

\author{
Judith S. Eaton
}

Quality assurance, the internal and external examination of the effectiveness and performance of colleges and universities, has always played a crucial role in sustaining and improving the best of what higher education has done in the past in order to build the future. The "best" includes the core values of academic freedom, institutional autonomy and social responsibility. ${ }^{1}$

Quality assurance has a history of buttressing and, at times, leading our commitment to these fundamental values. In these early decades of the 21 st century, quality assurance has been playing an especially vital role in sustaining core values as higher education takes on the challenges of change and innovation. Quality assurance plays this key role even as we adopt new teaching and learning practices, develop new types of institutions, engage new types of education providers and continue our commitment to expand access and equity in higher education. Add to this the current environment of both the Covid-19 pandemic and the major and painful focus on social change around issues of race and equality, and it is clear that quality assurance efforts are more important than ever.

Quality assurance is essential to sustaining these values in three ways. First, the vision that drives this review of higher education is premised on the worth of these values. Second, quality assurance is a key source of reinforcement and support for

\footnotetext{
${ }^{1}$ For purposes of this article, "academic freedom" refers to the conduct of higher education teaching and learning, research and service without inappropriate influence from external centres of power, whether public or private. "Institutional autonomy" refers to the independence essential to institutions to make academic judgments and to set academic direction, as reflected in institutional policies and priorities in teaching and learning, research and service. "Social responsibility" refers to viewing higher education as including all major organisations and bodies in society and society in general as stakeholders, as well as students and the academic community.
}

\section{J. S. Eaton (ه)}

Council for Higher Education Accreditation, Washington, DC, USA

e-mail: eaton@chea.org 
these values in thousands of colleges and universities around the world as well as emerging new providers. Third, quality assurance can and should be a voice to students and society about these values and how the values are essential to quality higher education.

\section{A Vision of Quality Based on These Values}

Academic freedom, institutional autonomy and social responsibility are built into the fabric of what quality assurance does and its vision of quality. Leaders in quality assurance are clear and emphatic. We cannot have quality education without academic freedom. We cannot have quality universities without institutional autonomy. We cannot sustain the quality of our value to students and society without full awareness and commitment to social responsibility. We have built both internal and external quality review on this edifice of values.

Academic freedom, especially in the current environment of trending populism and authoritarianism as well as the pressures of the Covid-19 pandemic, is particularly threatened as a core value of both higher education and quality assurance. Yet, quality assurance bodies around the world have stood firm in their contention that it is not feasible to sustain a quality higher education institution in which academic freedom is absent. Quality assurance, in its role as a validator of the importance of higher education institutions, is central to affirming the urgency of assuring a university environment that is grounded in freedom of inquiry and freedom of intellectual engagement, the hallmarks of academic freedom. Quality assurance is there to affirm that universities sustain an environment of free expression, have the resources needed to bring together academics to exercise this freedom and to assure a campus climate that encourages this freedom.

Similarly, to speak of a "quality higher education institution" without autonomy is a contradiction. Quality assurance itself provides both an incentive and leadership for maintaining and assuring this autonomy. It is there to affirm that the conditions for such autonomy prevail, both that governance arrangements are grounded in autonomy and that universities fully exercise the needed academic leadership that is the central justification for this autonomy.

Quality assurance also provides evidence that universities can responsibly sustain this autonomy over time. Sustained autonomy is indispensable in assuring that commitment to this academic leadership and direction is embedded in the life of an institution. As the current pandemic has clearly demonstrated, institutional autonomy, combined with academic freedom, created the environment in which higher education sustained much-needed leadership in thought and action, as researchers, scientists and other intellectuals responded quickly and effectively to provide direction, essential data and information as well as the creative thinking fundamental to addressing the current crisis.

Social responsibility as a value has been identified as particularly important for universities during the last several years, in many ways a restatement and expansion of 
the "community service" mission of higher education which is common throughout the world. It accompanies teaching and learning as well as research. Quality assurance is grounding more and more of its work in consideration of social responsibility by focusing attention especially on issues of access, equity, diversity, inclusion and inequality. Universities are increasingly examined for the extent of this commitment and success in carrying out this vital work.

\section{Quality Assurance Is a Key Source of Reinforcement and Support for These Values}

Those institutions that are able to sustain robust commitment to these values benefit from the additional impetus provided by quality assurance. Universities that are perhaps struggling to fully realise these values gain from the very public support and encouragement that emerges from quality review. Faculty, academic administrators, students and employers are all engaged in quality assurance and its key processes of self-study, peer review and institutional evaluation. Quality assurance standards, policies and practices provide a framework and direction for these values. This framework and these various actors help institutions to build investment in these values and view them as part of what is considered quality throughout higher education.

Quality assurance has expanded quietly but dramatically during the past 25 years, moving from a presence in perhaps an initial third of the countries in the world to the current environment in which quality assurance bodies operate in almost every country. A key characteristic in the expansion of quality assurance has been the concomitant expansion of these values. Country after country has been forceful and vocal in its commitment to academic freedom, institutional autonomy and social responsibility. Key multi-national organisations such a UNESCO, OECD and the World Bank that play leadership roles in higher education worldwide have been invaluable here in their clear emphasis on these values as indispensable for higher education. It is hard to conceive, in today's world, that any major effort to establish or reimagine higher quality assurance would exclude these values.

As higher education is undergoing the challenge of significant change and major innovation, quality assurance is challenged as well. Given the range of changes to what higher education is, how it operates and the students it serves, how is quality maintained and, with it, the core values? We are witnessing a major expansion of higher education providers, going beyond traditional institutions and degrees to online education offered not only by higher education but also civil society and the business world. We are starting to talk less about "institutions" or "universities" and more about "providers." The providers are typically online rather than campus-based and certificate- or badge-based rather than primarily focused on degrees. They are open access - challenging the selectivity model that has long accompanied what is considered to be elite education. 
For example, Class Central reported that, in 2019, more than 13 million massive open online courses were available from online providers such as Coursera, FutureLearn and EdX and others, serving more than 100 million students (Shah 2019). These numbers predate the Covid-19 pandemic and the enormous expansion of remote learning. And, increasingly, these providers are offering micro-credentials and even degrees and are establishing partnerships with traditional institutions.

We have witnessed the emergence of new types of institutions such as Minerva Schools (n.d.) with interdisciplinary programmes, interactive learning platforms and a powerful set of international experiences. New networks are emerging as well, such as the European Universities Initiative (n.d.), a conglomerate of European universities enabling students to combine studies from a number of participating institutions across borders to obtain a degree. Multiple teaching and learning platforms are now available, changing the nature of the engagement of students and faculty through establishing effective means of electronic communication for the classroom and, increasingly, for counselling and advising and for extracurricular activities.

All of this means that, first, quality review needs to change to examine quality in these new settings and, second, that creative thought needs to be given to sustaining academic freedom, autonomy and social responsibility in providers offering education in these newer and innovative ways. We need the core values to assure the effectiveness and value of innovative higher education just as we need these values in the traditional realm.

\section{Quality Assurance Can and Should Be a Voice to Students and Society About These Values and How They Are Essential to Quality Higher Education}

Quality assurance, working with higher education, also has responsibility for framing and articulating the core values to students, government, to employers and the public. This is part of its social responsibility dimension. This can be done through using quality review to articulate and examine the social responsibility efforts of higher education, calling on colleges, universities and the emerging providers to, for example, take meaningful action in such areas as access, equity, diversity and inequality. It can be done by demonstrating that academic freedom and autonomy are part of the foundation on which social responsibility is based. In many ways, "social responsibility" is about the role of both quality assurance and higher education in achieving social justice, whether in a country, region or internationally.

As described in the 2017 publication UNIBILITY: University Meets Social Responsibility - 2015-2017 (Wallace and Resch 2017), social responsibility is about institutions embracing a range of stakeholders, taking responsibility for the multiple ways that institutions affect society as well as considering the wider society itself to be a stakeholder. It is about universities moving beyond campuses. This can mean, for example, work with public bodies, university engagement in public policy and 
policymaking and work with business and industry as well as engagement and impact on cultural, civic and social life. Especially as universities and emerging providers frame and carry out their commitment to social responsibility, the activities serve to inform those outside higher education. Higher education can also model some of these activities.

We are living with a combination of the Covid-19 pandemic, concerns with the growth of populism and authoritarianism and social justice needs that are crying out for attention. Higher education can and needs to play a vital role in addressing the range of issues before our societies and strengthen its social responsibility commitment. Nowhere is this more essential now than in issues of race and inequity.

Academic freedom, institutional autonomy and social responsibility are all values essential to higher education, students and society. Quality assurance is keenly aware of its ongoing responsibility to sustain and strengthen these values, not only to protect quality but also to play a central role in building the future of colleges, universities and, going forward, many other providers.

\section{References}

European University Initiative (n.d.), Retrieved from: https://ec.europa.eu/education/events/ european-universities-initiative_en (8.6.2020)

Minerva Schools (n.d.), Retrieved from: https://www.minerva.kgi.edu/about/ (8.6.2020)

Shah, D. (2019, December 2). By the Numbers: MOOCs in 2019. Class Central. Retrieved from: https://www.classcentral.com/report/mooc-stats-2019/ (8.6.2020).

Wallace, M. \& Resch, K. (Eds.) (2017). UNIBILITY: University Meets Social Responsibility-20152017. UNIBILITY Project. Retrieved from: https://www.fpce.up.pt/ciie/?q=en/content/unibility$\%$ E2\%80\%93-university-meets-social-responsibility-0 (8.6.2020)

Judith S. Eaton is President emeritus of the Council for Higher Education Accreditation (CHEA), the national coordinating body for accreditation and quality assurance in the United States. Prior to her work at CHEA, she served as Chancellor of the Minnesota State Colleges and Universities, as President of the Council for Aid to Education, the Community College of Philadelphia and the Community College of Southern Nevada and as vice president of the American Council on Education. She has held teaching positions at Columbia University, the University of Michigan and Wayne State University. 
Open Access This chapter is licensed under the terms of the Creative Commons Attribution 4.0 International License (http://creativecommons.org/licenses/by/4.0/), which permits use, sharing, adaptation, distribution and reproduction in any medium or format, as long as you give appropriate credit to the original author(s) and the source, provide a link to the Creative Commons license and indicate if changes were made.

The images or other third party material in this chapter are included in the chapter's Creative Commons license, unless indicated otherwise in a credit line to the material. If material is not included in the chapter's Creative Commons license and your intended use is not permitted by statutory regulation or exceeds the permitted use, you will need to obtain permission directly from the copyright holder. 


\title{
Recognition of Foreign Qualifications \\ Celebrates Higher Education \\ Collaboration Too
}

\author{
Jenneke Lokhoff
}

International higher education collaboration and recognition of foreign qualifications have been inseparable from the very start. The institutionalization of higher education collaboration after the Second World War, when international organizations such as IAU were founded, also marked the start of the institutionalization of recognition of foreign qualifications.

This piece celebrates seventy years of IAU by reflecting on the past, present and future of academic recognition of foreign qualifications, as one of the elements of internationalization that facilitate and validate international student mobility. It will do so by providing snapshots from some milestones in the field. The perspective taken is based on the experiences of Nuffic, which was founded only two years after IAU, in the same spirit of international cooperation in education. Nuffic was tasked with the recognition of foreign qualifications in 1958.

\section{The History of Recognition, a History of Student Mobility}

How did the field develop in those early decades? From the end of the Second World War to the mid-1970s, student mobility between countries was limited to those that qualified for one of the few scholarships available or were able to finance the experience themselves. The low mobility rate resulted in few evaluations, but this would gradually change, as would the attitude towards recognition. The 1980s and especially the 1990s would see developments that would lay the foundation of current recognition practices.

\footnotetext{
J. Lokhoff $(\bowtie)$

Nuffic, The Hague, The Netherlands

e-mail: jlokhoff@nuffic.nl

(C) The Author(s) 2021 


\section{The First Decades: Evolving Attitudes}

After the Second World War, attitudes towards recognition favoured "equivalence". This aimed to match components of one foreign programme with every component in a receiving country's programme. In other words, a foreign degree had to be identical or almost identical to be recognised.

This attitude shifted towards "recognition" out of necessity from increased student mobility in the 1980s. A degree no longer had to be identical but could be recognised according to the purpose for which recognition was sought. The foreign degree sufficed if assessed at a comparable level with comparable functions, even though it may differ in detail.

When internationalization really took off in the 1990s, a new approach gained ground that is still used today: "acceptance". Under this precept, a foreign qualification deemed slightly inferior to the nearest comparable degree in the receiving country, would be accepted at that level. Small differences could be softened and degrees still accepted because of the enrichment that a different educational approach can bring to the host society. Denial of recognition occurred only when differences were too substantial.

This principle of 'acceptance while respecting the differences' prevails today - reflected in the General Directives for professional recognition of the European Union and the Lisbon Recognition Convention of the Council of Europe/UNESCO. Mutual trust in each other's education system, as a result of growing mobility and the increase of information on the different systems, made this change of attitude possible.

During this time, attitudes also changed in the workplace. After a "royal" start in an actual palace (and the current work palace of the King of The Netherlands), Nuffic moved to the former hotel "Wittebrug" in 1978. Into the 1990s, Nuffic's credential evaluation team made their home in a spacious attic - stuffed with reference books and university catalogues from across the globe. The space was filled with cigarette smoke and a team whose members subtly rivaled to show their erudition. Pride and effort went into the style and language used to write the statement. Recognition was considered a serious intellectual exercise, and the ambiance described by some as rebellious, yet still cozy or "gezellig": every day featured a collective tea break at 16:00.

Nuffic's "epic stories from the attic" capture a scene in stark contrast with today's workplace. Though still amiable and intellectual, Nuffic now has flexible workspaces, clean desk policies and efficiently processes a high number of evaluations. Evaluation time dropped from three days to $30 \mathrm{~min}$ on average - a high(er) level of efficiency aided not only by modern communication and digitalization, but also new developments that refined modern recognition practices in the 1980s and 1990s.

\section{Towards a Legal Framework Based on Burden of Proof}

In the early days, the international community worked towards creating a legal framework for the recognition of foreign qualifications. The first conventions emerged in 
the 1950s. Later in the 1970s, UNESCO launched regional conventions including Latin America and the Caribbean (Mexico City, 1974), Arab States (Paris, 1978), European region (Paris, 1979), the African region (Arusha, 1981), and Asia and the Pacific (Bangkok, 1983).

At the time of these conventions, educational systems of signatory countries in Europe were still quite comparable. But over time, the diversification in higher education systems and expanding signatories showed the limits of these conventions. These developments led to a new UNESCO/CEPES and Council of Europe treaty: The Lisbon Recognition Convention (LRC) of 1997.

The LRC adopted a new positive attitude of acceptance, as mentioned above. The core was to emphasize the principle of fair and transparent recognition procedures, and the acknowledgement that differences should be accepted unless substantial differences were detected. The Convention also created the LRC Committee Bureau to oversee operations and tasked the European National Information Centres (ENICs) with the implementation of the Conventions' principles.

\section{Networks and Peer Collaboration}

In the 1980s/1990s, a second fundamental element for recognition emerged: the institutionalization of collaboration between national information centres. In 1984, the predecessor of the European Union created the National Academic Recognition and Information Centres (NARIC network), while in 1994 the NEIC (the National Education Information Centres) network transformed into the afore-mentioned European National Information Centre (ENIC) Network from UNESCO and the Council of Europe.

The importance of the Networks is their provision of an operational structure for recognition. The LRC tasks ENICs with providing information about their countries education system as well as treaty implementation in the national context. The two Networks work closely together to solve recognition issues, and in practice, they overlap; each NARIC Centre is also the ENIC Centre.

In the early days, discussions on "methods and techniques" contributed to the text of the LRC. Good practice was also developed in working groups from the Council of Europe/UNESCO and through structural project funding from the European Commission. Centres collaborated with other stakeholders in higher education - institutions, students, quality assurance and communities such as the European Association for International Education.

Peer collaboration also resulted in capacity building, such as the establishment of NARICs in the future members of the European Union through the PHARE programme. Nuffic offered support and, small in terms of number of staff but large in terms of means - the experts always travelled with two extra suitcases filled with reference books, including the voluminous IAU International Handbook of Universities. These were truly pre-digital times.

The Network's joint annual meeting is the highlight for networking, debate, and sharing expertise, giving members a robust and effective operational structure to further develop recognition. For a full understanding, it is important to note that 
recognition is organized differently in each LRC Treaty country, and each ENICNARIC has a different remit and size.

\section{Political Collaboration}

The third and final pillar for recognition was developed in the 1990s and culminated in the launch of the Bologna Process to create the European Higher Education Area in 1999. The Bologna Process placed recognition of foreign qualifications at the heart of its agenda and supported recognition through comparability and compatibility of higher education systems.

The harmonization efforts towards a three-cycle structure across the EHEA facilitated the recognition of qualifications on the system level. The political commitment to the process pushed the development of various instruments and tools serving recognition, such as the Diploma Supplement, the European Credit Transfer Accumulation System and qualification frameworks. The shortness of this paragraph is evidently inversely proportional to the significance of "Bologna" for recognition within Europe!

\section{Recognition at Present}

What is the present state of play for recognition? There is an ongoing increase in student mobility and digital solutions, and both are shaping recognition along the lines of the framework established in the 1980s/1990s; the international legal framework has been further strengthened and innovated. While major steps were taken in the previous decade, there are still challenges in regards to the implementation of fair recognition, notably on the practical and institutional level, where further collaboration would be desirable.

\section{Student Mobility, Digitization and Efficiency}

Since the millennium, global student mobility has tripled and directly impacted credential evaluation as a process and profession. The higher volume of international students has driven demand for more evaluations and has accelerated efforts to innovate and optimize the process, especially in high volume countries.

The late 1990s saw the introduction of computers and the internet, and this enabled unprecedented access to evaluation information. The first databases reduced processing times and increased the consistency of decisions. Statements could be made in digital layout with block texts focused on key information. This was a world apart from the eloquently written epistles of the 1980s. Another aspect was the possibility for national information centres to provide information to its stakeholders.

The new modes of communication also drove international collaboration. Email became the standard, allowing for a fast and easy exchange of information. 


\section{International Framework}

Globally, different regions have been pushing fair "recognition" forward. The creation and adoption of the "Global Convention on the Recognition of Qualifications concerning Higher Education" in November 2019, formulated a number of general criteria to promote the fair and smooth recognition of diplomas worldwide. This Convention's novelty was a clear definition of substantial differences.

In recent years, several UNESCO regions have introduced a new generation of regional conventions that describe the principles of fair recognition, and these currently experience a momentum. Recently, the Asia and Pacific (Tokyo 2011) and African region (Addis Ababa 2014) entered into force with Latin America and the Caribbean (Buenos Aires 2019) expected to follow in the near future.

Following ratification of the Tokyo Convention, the Asian Pacific region has moved towards operationalizing recognition through the establishment of the "AsiaPacific Network of National Information Centres" (APNNIC). The Association of Southeast Asian Nations (ASEAN) has initiated several initiatives to support the recognition of foreign qualifications in their region, including qualification frameworks and a credit transfer system. We also see advances towards inter-regional collaboration between the ENIC-NARIC and APNNIC Networks, which is a welcome development in information provision due to the ever-increasing number of global students. This also signals the importance of (operationalizing) the regional conventions in offering support for a successful implementation of the Global Recognition Convention.

In the European Higher Education Area, there is a focus on automatic recognition at the system level and further implementation of the LRC, supported by the European Commission that made automatic recognition a priority within their ambition to create a European Education Area by 2025 .

One of the LRC's challenges -and possibly other regional conventions' tooremains a shared understanding of the principles by all competent authorities. Inclusion in law does not mean that legal principles are implemented at the practical level. Here there is still enormous work to be done. Collaboration between national information centres and the higher education institution community will be essential for building a shared understanding of implementation on a practical level.

\section{3 "We Can Only See a Short Distance Ahead, But We Can See Plenty There That Needs to Be Done." - Allan Turing}

What does the future hold for foreign qualifications recognition of? While this may be unknown, it merits highlighting student mobility trends, the expansion of the legal framework, flexibilization of education and digitalization of student data. 


\section{Asia-Pacific in the Lead?}

Student mobility trends predict a continued increase in international students in the coming decades. Whereas the majority of international students currently study in North America and Europe, some predict other regions such as Asia will assume a larger, perhaps even the largest share of international students in the future. This underscores the need for smooth and fair recognition, both regionally and globally.

\section{International Legal Framework}

The UNESCO conventions provide a robust legal framework for recognition. However, judging from current experience, their implementation - especially on a practical level - depends on how the Global Convention and regional conventions are translated into action and rendered operational; their success also depends on the extent of political support available for facilitating fair recognition.

At the time of writing, the COVID-19 crisis had only just begun to impact education, international student mobility and, consequently, recognition of foreign qualifications. Even when student mobility numbers rise again, the aspect of fair recognition during this period may continue to be a daunting process. International collaboration will be the key for fair recognition of learning experiences, and could also serve future global student mobility.

\section{Flexibilization of Education}

Another trend impacting the future is the changing education landscape itself with an increase in standalone learning units. While this phenomenon existed previously, institutions are adopting and creating flexible learning paths at a hitherto unseen pace. Before the COVID-19 pandemic, digital solutions were a catalyst for the delivery of education "units" online (e.g. MOOC type solutions), that resulted in microcredentials.

The flexibilization and stacking of credits create opportunities - and along with these, fundamental questions for recognition. Opportunities exist for applicants using these standalone credits to fill gaps in their experience. But, using the current methodology, a stack of credits that match the workload may not necessarily lead to recognition when a coherent profile is missing. A profile is part of any degree and describes the purpose and content of a programme. If stacking takes off, how are these experiences validated within the current methodology? This will need to be further explored so that we can ensure fair recognition of these experiences.

\section{Digitalization of Student Data and Recognition}

Recognition may be on the eve of another major development with the promulgation of digital solutions for the field. The transformative impact of digital communication and infrastructure on recognition, begun in the 1990s, continues to drive innovation in areas of digitalization of student data, such as diplomas, transcripts and personal 
information. This takes place against the backdrop of digitalization of other relevant information, such as the unique identifiers of HEIs in the IAU World Higher Education Database, the Global WHED ID.

The digital exchange of student data offers potential opportunities for recognition, for example, in terms of efficiency, consistency, verification and reliability. Yet, some effort will have to be made to reap the benefits. Within ENIC-NARIC Networks, collaboration between the Groningen Declaration Network and EMREX takes digitalization further, and ASEAN are exploring possibilities for its own region as well. Points of attention include standardization, both at the level of data format and content. Solutions will ideally involve both recognition practitioners, technicians and other end users (qualification holders, institutions and credential evaluators) to achieve innovative solutions.

The expectation is that we will see the transformation of credential evaluation as a profession in the near future, through digitalization and automating steps of the evaluation process. This will be even more so the case when higher levels of data maturity - such as machine-readable data - will become operational, and a higher level of standardization of the data content has been reached. This, obviously, requires international collaboration.

\section{CONGRATULATIONS IAU!}

If anything, this piece wishes to contribute to the celebration of 70 years of IAU from the perspective of recognition. Both IAU and Nuffic embarked on their respective journeys together and, looking ahead, we will have plenty - if not more - to work on as we work supporting higher education around the globe. But for now, congratulations!

Jenneke Lokhoff is senior policy officer at Nuffic, the Netherlands organization for internationalization in education, home to the Dutch ENIC-NARIC. She has been project lead for numerous international recognition projects. She currently serves as President of the ENIC-NARIC networks.

Open Access This chapter is licensed under the terms of the Creative Commons Attribution 4.0 International License (http://creativecommons.org/licenses/by/4.0/), which permits use, sharing, adaptation, distribution and reproduction in any medium or format, as long as you give appropriate credit to the original author(s) and the source, provide a link to the Creative Commons license and indicate if changes were made.

The images or other third party material in this chapter are included in the chapter's Creative Commons license, unless indicated otherwise in a credit line to the material. If material is not included in the chapter's Creative Commons license and your intended use is not permitted by statutory regulation or exceeds the permitted use, you will need to obtain permission directly from the copyright holder.

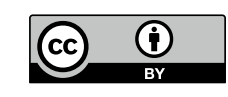




\section{Part IV \\ The Changing Landscape}




\title{
Creating Responsible and Engaged Students
}

\author{
Pankaj Mittal
}

Since 6 BC, when the first university of the world was established in Takshila in India, higher education in India has been integrating advanced knowledge and skills with larger social concerns. Apart from teaching and research, a prime concern of universities is to engage with the community and to contribute towards the development of society. Much emphasis is placed on the values of education by complementing curricular instruction for shaping future generations and enabling active engagement with society. The emphasis has been on holistic development of the student leading to complete realization and liberalization of oneself. To quote Swami Vivekananda, a well-known Indian scholar, "Education is not the amount of information that we put into your brain and runs riot there, undigested, all your life. We must have lifebuilding, man-making, character-making assimilation of ideas. If you have assimilated five ideas and made them your life and character, you have more education than any man who has got by heart a whole library. If education is identical with information, the libraries are the greatest sages of the world and encyclopaedia are the greatest Rishis".

\section{Genesis}

The idea of involving students in the task of national service in India dates back to the times of Mahatma Gandhi, the father of the nation. The central theme which he tried to impress upon his student audience time and again was that they should always keep social responsibility at the forefront. The first duty of the students should be not to treat their period of study as one of the opportunities for indulgence in intellectual

\footnotetext{
P. Mittal (凶)

Association of Indian Universities, New Delhi, India

e-mail: pankajugc@gmail.com

(C) The Author(s) 2021 
luxury, but to prepare themselves to offer dedicated services to those who provided the sinews of the nation with the national goods and services, so essential to society. Advising them to form a living contact with the community in whose midst their institution is located, he suggested that instead of undertaking academic research on economic and social disability, the students should do "something positive so that the life of the villagers might be raised to a higher material and moral level".

The setting up of the National Service Scheme (NSS) by India in 1969, the centenary year of Gandhiji, was a concrete manifestation of this emphasis with the motto, 'not me but you'. This was in the form of 'adding on' community engagement to teaching and learning. The NSS, which exists in every university in the country and in some of the undergraduate colleges, has about 3.86 million students enrolled as volunteers. Many worthwhile projects are undertaken by the NSS such as Adoption of Villages, Cleanliness Drive, Afforestation, Health Camps, Blood Donation, Sustainable Development, Mass Literacy, National Integration and Social Harmony.

\section{Education as a Tool for Social Transformation and Sustainable Development}

Today in the 21 st century, the whole world has realized that apart from individual prosperity, education must also lead to the attainment of social transformation and sustainable development. The seventeen Sustainable Development Goals designed by the United Nations are a blueprint to achieving a better and more sustainable future for all. The goals of ensuring inclusive development, democratic governance and sustainable growth can be meaningfully achieved through a process of broadening and deepening the involvement of institutions of higher education; in societal development, and in the process, the idealism and dynamism of youth can also be harnessed in a more meaningful manner. Community engagement helps to bridge the gap between theory and practice, in order to make theory more relevant and practice more informed, where community knowledge systems are seen as legitimate partners in the process of development of innovation and trained human resources. It also promotes deeper interactions between higher education institutions and local communities for identification and solution of real-life problems faced by the communities in a spirit of mutually agreed interest and interaction and facilitates partnerships between local communities and institutions of higher education so that students and teachers can learn from local knowledge and wisdom, thereby democratizing knowledge production. There is a need to engage higher institutions with local communities and make curriculum, courses and pedagogies more appropriate to achieving the goals of national development; catalyse acquisition of values of public service and active citizenship amongst students and undertake research projects which are need-based and community-oriented, including community as research partners, leading to policy formulation for societal development. 


\section{Forms of Community Engagement}

To achieve the objective of societal development through community engagement, it is important that an institutional mechanism is developed to adopt a holistic and functional approach to community engagement based on core principles such as; articulating and respecting mutually agreed interests and needs of both communities and institutions; encompassing all the three functions of institutions of higher education - teaching, research and outreach/practice/extension; creating institutional engagements cutting across disciplines; giving credits to students for participation in community engagement projects while integrating it into their evaluation systems; and by making it a part of the performance assessments of teachers, researchers and administrators in institutions.

The need of the hour is integration of knowledge - bringing together education and work, theory and practice, university and society. To be an integral part of the objectives of higher education, university-community linkages have to be integrated into the processes of making and sharing knowledge, into teaching-learning, research and practice. Strengthening higher education-community linkages means that we place the connection between community and the university at the heart of the educational process in order to ensure the continuing relevance of higher education. There can be multiple ways of institutionalizing such engagements. Firstly, learning can be linked with community service; in which students and teachers apply their knowledge and skills in a chosen community to improve the lives of people in that community. This can be achieved through 'adoption' of a specific village or slum and then providing engagement opportunities to students from various disciplines and courses to apply their knowledge to address the challenges of that specific community. Secondly, we can link research with community knowledge in which joint research projects can be devised in partnerships with the communities. Through this, the community's own knowledge is integrated, systematised and integrated into the design and conduct of the research. Thirdly, the knowledge available with students and teachers in various disciplines can be shared with the local community to realize its developmental aspirations, secure its entitlements and rights from various public and private agencies. These can take the forms of surveys, camps, training, study reports, public hearings, policy briefs, engagement with urban homeless shelters, teaching and health services in poor communities, to give but few. Fourthly, in consultation with local communitybased organisations, institutions of higher education can develop new courses or modify existing ones by enriching the curriculum through locally-appropriate subject matter; and create new, locally-appropriate educational programmes of interest to a new generation of students. Fifthly, local community elders, women leaders, tribal and civil society practitioners having enormous practical knowledge of a wide variety of issues - from agriculture and forestry to child-rearing, micro-planning, water management and project management—can be invited to co-teach courses both in the classroom and in the field and lastly, in consultation with student unions, associations and clubs, student-initiated learning projects which have a social impact can be supported. Such social innovation projects by students can also have meaningful 
links to curriculum and courses. In practice, these different forms can be integrated together in an organic and dynamic manner for each institution and its surrounding communities.

\section{Paradigms of Community Engagement}

Community engagement should not be seen as an 'addition' to learning and teaching, but intrinsic to it. This is essential if education is to be a vehicle for social transformation and attainment of social justice, rather than as the means to individual prosperity alone. For this, institutions of higher education need to place their learning and teaching in the communities in which they are located and to harness the idealism and dynamism of the youth.

We can explore the possibility of creating an Alliance for Community Engagement (ACE), a membership-based network primarily engaged in promoting ideas and practices of community engagement throughout the country. This mechanism has to be an independent ACE that comprises champions of such engagement from the sectors of higher education (including students) and civil society. It can serve as a platform for community engagement by institutions of higher education and also act as a vehicle for sharing knowledge and good practices. The Alliance can encourage and be a catalyst for new initiatives in community engagement for a wide variety of post-secondary institutions in the country by regular sharing of information; disseminating existing and emerging models, approaches, best practices and lessons of change and transformation through various media; create a webbased platform for the dissemination and communication of practices and models, as well innovations and challenges; create mechanisms for sharing such experiences and knowledge through national and regional conferences, workshops, field exposures and newsletters and web-based platforms; evolve benchmarks and standards of quality, monitoring mechanisms and recognition/awards of effective and sustainable community engagements in the country; disseminate knowledge internationally in a proactive and mutually responsive manner; invite, scrutinize and fund innovative proposals from institutions of higher education in respect of fulfilling the above goals; generate new schemes of funding as per requirements, including student and researcher fellowships, engaged scholars' fellowships, etc.; create funding schemes for community-university research projects, and guidelines for promoting the same through various existing research funding councils; and define policy elaborations and criteria for effective integration of such goals in the national, provincial and local systems of higher education in the country. The Alliance can act as a motivator, facilitator, encourager and recognizer of new initiatives in this field in a spirit of partnership; it can generate demands for engagement; and it can act as a funding mechanism pressure group for implementation of policy in this regard.

Flexibility in terms of devising new systems of curriculum design, review and pedagogy that incorporate elements of community engagement should be encouraged. Universities and other higher education institutions should be provided with 
the autonomy to make their programmes, courses and initiatives more relevant to the needs of society. Such curricula flexibility would enable enhancement of the quality of knowledge produced by the university about communities and also help create new programmes. Student-initiated community engagement work (including internships, fellowships, and course-work) should be particularly encouraged to leverage the dynamism and idealism of youth. It is also necessary to establish a few institutions which will primarily engage in community-based and common knowledge traditions. These institutions can be linked to vital aspects of community health, community cultures (arts, crafts, music etc.), community practices in sustainable development/ natural resources, and other aspects of community knowledge production, application and dissemination.

\section{Initiatives at BPS Women's University: A Case Study}

The BPS Women's University, a rural women university in Haryana, realized its vision of socially relevant education by empowering women through education. The university is reinforcing its strong nexus with the wider society by setting up activities, programmes and centres that liberate rural women from their physical drudgery and empower them; by enabling them to use their inherent strength and inherited skills for their own and the rural community's welfare, and by preparing them for self-employment through training in all aspects of entrepreneurship. The author, as Vice-Chancellor of the university from 2008 to 2014 undertook several such initiatives.

One of the initiatives was to re-link the university with its social and natural environment by involving women outside the university and their knowledge in diverse fields, and women students of the university with their academic knowledge acquired at the university and their knowledge of life and activities of the local community. It took the university out of the confines of four walls to the larger community outside, particularly the women, and involved them in the knowledge creation and dissemination process by establishing a number of innovative areas of study. Among others, the 'Centre for University Society Interface and Research' was established to bridge the gap between the university and its local rural community. The disconnect between society and the university was removed by way of carefully designed courses for students in areas like micro-financing, integrated energy resource management and folk medicine which were held on a 50:50 basis, whereby 50 percent of the course was taught in the classrooms and 50 percent in the villages. It was thus a two-way process by which the university was able to both learn from and teach the community at the same time. The curricula of the academic programmes were also tweaked to align them with community engagement. The centre, in collaboration with neighbouring universities, developed small-time technologies for direct use by the rural community such as a machine for making cow dung cakes (cow dung cakes are used as fuel in rural household) and a 'fitness-cum-washing machine' which doesn't need electricity but someone cycling. The centre also adopted some villages from 
nearby areas to take care of their overall development in terms of awareness, medical facilities, infrastructure, sanitation, education etc. A state government-funded demonstration centre, based on the Indo-Israel project was set up to demonstrate to the rural community various means of enhancing agricultural production by adopting modern farming techniques of vertical farming in the poly-houses rather than traditional horizontal farming to improve their earnings manifold, thereby, increasing the relevance of education for the rural masses.

\section{Involving HEIs in Rural Upliftment}

The government of India has also launched 'Unnat Bharat Abhiyan (UBA)', to involve the higher education institutions of the country in the process of indigenous development for self-sufficient and sustainable village clusters. The mission of the UBA is to develop the necessary mechanisms and proper coordination among education institutions, implementation agencies and the grass root level stakeholders to enable effective interventions at field level, holistic development of rural clusters and reorienting academic curricula and research programmes in higher education institutions to align them with development of the local community. The UBA engages the faculty and students of higher education institutions in understanding rural realties, to devise implementation methods for innovative solutions and to leverage the knowledge base of the institutions to devise processes for effective implementation of various government programmes.

\section{Conclusion}

University Social Responsibility (USR) needs to be created as a formal structure within the higher education system in the pattern of Corporate Social Responsibility (CSR) with mandatory participation by every institution of higher education. The Indian higher education system, with about 37 million students and 15 million teachers, can make a major impact on programmes of societal development through active and positive engagement with the community.

Pankaj Mittal is Secretary General of the Association of Indian Universities (AIU). She has been serving the higher education sector for over three decades at senior positions at the University Grants Commission of India. She is a Fulbright Scholar and has a PhD in Agricultural Statistics. Dr Mittal has also served as the first regular Vice-Chancellor of Bhagat Phool Singh Mahila Vishwavidyalaya, Haryana, the first rural women university of North India for two terms. 
Open Access This chapter is licensed under the terms of the Creative Commons Attribution 4.0 International License (http://creativecommons.org/licenses/by/4.0/), which permits use, sharing, adaptation, distribution and reproduction in any medium or format, as long as you give appropriate credit to the original author(s) and the source, provide a link to the Creative Commons license and indicate if changes were made.

The images or other third party material in this chapter are included in the chapter's Creative Commons license, unless indicated otherwise in a credit line to the material. If material is not included in the chapter's Creative Commons license and your intended use is not permitted by statutory regulation or exceeds the permitted use, you will need to obtain permission directly from the copyright holder. 


\title{
Universities Can Regain the Public's Trust
}

\author{
Frans van Vught
}

\section{Introduction}

Public trust in universities appears to be decreasing. In this age of "fake news" and even "fake science", the esteem of academic institutions is diminishing. In the eyes of the general public, universities may still be respectable institutions, but they are also seen to be relatively self-centred and to have an insatiable hunger for (public) resources. Furthermore, doubts are being raised about the self-organising capacities of autonomous academic institutions to assure and protect the quality, relevance and efficiency of their activities. Stakeholders ask for more information about costs and benefits. And for greater accountability.

There are several reasons underlying this growing demand for information and accountability. First, the financial contributions made by students, taxpayers and others to higher education are rising. Second, the increasing number and variety of providers of higher education and the (degree and non-degree) programmes they offer makes it increasingly difficult for (prospective) students to decide where and what to study. Similarly, employers and governments wish to be assured that higher education providers deliver the quality education and research services that are needed for their labour markets, their businesses, and their communities. Third, our society is increasingly characterised by mass individualisation, where the different clients of universities (in particular, their students) demand services that are customised to their needs, plans and abilities.

The result is an increasing demand for transparency tools: instruments that aim to provide information to stakeholders about the profiles and performances of universities. From the perspective of students, employers, public authorities and the general public, the need for tools that provide better and broader use of information regarding the services and performances of universities is growing.

\footnotetext{
F. van Vught $(\varangle)$

University of Twente, Enschede, The Netherlands

e-mail: f.a.vanvught@utwente.nl 
For more than three decades, several tools have been (re-)designed to increase the transparency of the activities and performances of universities across their different missions: education, research, knowledge transfer and community engagement. In this chapter, I will address two higher education transparency tools: accreditation and rankings. I will present these tools in a brief theoretical context and will argue that the need for transparency can be seen as a new challenge for universities and the IAU, but also as an opportunity to regain the public's trust.

\section{Information Asymmetry}

The basic theoretical notion underlying the increasing interest in transparency in higher education stems from an (economic) understanding of higher education as an experience good. An experience good is a good or service whose quality can only be judged after consuming it. This contrasts with the textbook case of "search goods", whose quality can be judged by consumers in advance. Experience goods are typically purchased based upon reputation and recommendation since physical examination of the good is of little use in evaluating its quality. It might even be argued that higher education is a credence good: a product whose utility consumers do not know even after consumption. Higher education being an experience or credence good emphasises the importance of trust.

From the perspective of the provider, academics may argue that they know better than any other stakeholder what it takes to deliver high-quality higher education; and surely, they have a case. At the same time, this view implicitly perpetuatesand justifies - information asymmetry between client and provider. According to the principal-agent theory, information asymmetry might tempt academics and universities not to maximise the quality of their educational services. For instance, universities might — and do- - exploit information asymmetries to cross-subsidise research activity using resources intended for teaching.

In principal-agent theory, several policy tools are suggested to protect clients and society against the possible abuse of information asymmetries. All of these tools are designed to affect the behaviour of the providers of higher education and research. Influencing the behaviour of universities-by governments, independent agencies or by the providers themselves - may take different forms. It may involve regulation: rules on service quality, standards for teaching, qualifications frameworks, quality assurance requirements, or conditions imposed on providers. Secondly, (financial) incentives may be developed to reward desirable behaviour and sanction undesirable behaviour. Thirdly, influencing the behaviour of universities may aim to alleviate information asymmetry by focusing on the provision of information; this is the intention behind the use of transparency tools. 


\section{Accreditation}

Accreditation is the most common form of external quality assurance in higher education. The distinguishing characteristic of accreditation is that external quality assessment leads to a summary judgment (pass/fail, or graded) that has consequences for the official status of the institution or programme. Often, accreditation is a condition for the recognition of degrees and their public funding. Accreditation is the simplest form that quality assurance can take. However, the transparency function of quality assurance appears to be only an additional aim-its primary aim is to assure that quality standards are met.

When accreditation and other forms of external quality assurance were introduced, their focus was on what higher education institutions were offering, measured by input indicators such as the numbers and qualifications of teaching staff, the size of libraries, or staff-student ratios. However, the relevance of input indicators for making the quality of the teaching and learning experience more transparent, or for demonstrating the quality of outputs (e.g. degree completions) and outcomes (e.g. graduate employment) was questioned.

Increasingly, therefore, accreditation standards first began to include measures of institutional educational performance, such as drop-out or time-to-degree indicators. More recently, the focus of accreditation has also emphasised achieved learning outcomes. The degree to which study programmes succeed in enabling students to learn what the programme curriculum intends is argued to present a more transparent, more pertinent, and more locally-differentiated picture of quality.

The emphasis on achieved learning outcomes redirects accreditation more towards the diversified information needs of stakeholders, i.e. more on higher education's public value; in this way, it aims to enhance transparency. However, this is only the case if the assessment of learning outcomes is comparative in nature, preferably on an international scale, and the results are made public.

Admittedly, whether stakeholders are interested in measures of achieved learning outcomes is another matter. For instance, even if students behave as rationally as policy would have it, they would not only be interested in outcomes in the distant (uncertain) future but also in characteristics of the educational process and its context. Potential students (and others) are likely also to be interested in current students' satisfaction with such factors, allowing them to benchmark satisfaction scores across different institutions and thus to make proxy assessments of programme quality. However, in accreditation systems, such information is often hard to find. Unlocking this information is one of the challenges in further redesigning accreditation mechanisms as stronger transparency tools. 


\section{Rankings}

Whereas quality assurance and accreditation were introduced mainly on the initiative of governments, university rankings have appeared mostly through private (media) initiatives. Rankings emerged in reaction to the binary (pass/fail recognition) information resulting from accreditation. They intend to address a need for more fine-grained distinctions in a context where many institutions and programmes pass the basic accreditation threshold.

It is widely recognised that, although current global rankings are controversial, they are here to stay and that especially global university league tables have a considerable impact on decision-makers worldwide, including those in universities. Yet, major concerns persist about the rankings' methodological underpinnings and their drive towards stratification rather than diversification.

The following sets of problems surrounding the familiar global rankings can be distinguished. First, traditional university rankings do not distinguish their various users' different information needs but provide a single, fixed ranking for all. Second, they ignore intra-institutional diversity, presenting universities as a whole, while research and education are "produced" in faculties, hospitals, laboratories, etc., which each may exhibit quite different qualities. Third, rankings tend to use available information on a narrow set of dimensions only, overemphasising research. This suggests to lay users that more and more frequently cited research publications are an indication of high-quality educational programmes. Fourth, the bibliometric databases used for the underlying information on research output and impact on peer researchers mostly contain journal articles, while journal articles are a type of scientific communication that is relevant for many natural science and medical disciplines, but this is less so for fields such as engineering, humanities, law and social sciences. In addition, the journals included in these databases are mostly English-language journals, largely disregarding publications in other languages. Fifth, the diverse types of information and indicators that underlie the rankings are weighted by the ranking producers and consolidated into a single composite value for each university, usually presented in a league table with a ratio scale. This is done without any explicit-let alone empirically corroborated-theory on the relative importance and priorities of the indicators or with a sound methodological base for the league table scale.

Given these criticisms, some analysts (including this chapter's author) have endeavoured to construct alternative rankings, and in recent years-partly due to these efforts—not only have innovative rankings appeared but also the methodology of traditional global rankings has improved: information on individual areas (fields, disciplines) have been added to the global rankings, and the dimensions of the data included have been broadened.

In particular, U-Multirank has addressed the shortcomings of the traditional global rankings. As a transparency tool, this ranking is very different from its competitors. Firstly, because U-Multirank has adopted a multi-dimensional view on university performance; when comparing universities, it provides information about the different activities the institution engages in: teaching and learning, research, knowledge 
transfer, international orientation and regional engagement. Secondly, U-Multirank invites its users to compare institutions with similar profiles, thus enabling comparisons of "like with like", rather than "comparing apples with oranges". Thirdly, U-Multirank is interactive and stakeholder-focused; it allows users to choose from a menu of performance indicators and to select indicators according to their own preferences. Fourthly, U-Multirank does not create league tables; it does not force its users to combine indicators into a weighted score or a numbered league table position. Fifth, U-Multirank allows universities to analyse and communicate their own specific "profiles" and hence to emphasise their individual strengths. Sixth, U-Multirank assigns scores on individual indicators using five broad performance groups ("very good" to "weak") to compensate for the imperfect comparability of information. Finally, U-Multirank complements institutional information pertinent to the whole institution with a large set of disciplinary (field-based) performance profiles, focusing on particular academic disciplines or groups of programmes, using indicators specifically relevant to the different subjects.

In general, rankings provide information to the different stakeholders of universities. From this perspective, they can be seen as transparency tools. However, not all rankings are methodologically sufficiently developed to offer relevant and custommade information and to assist clients and other stakeholders in making choices. As such, many global rankings are still relatively weak in their transparency function.

\section{Conclusion}

From the perspective of the need to increase the transparency of the performance of universities, the conclusions regarding the two transparency tools discussed are as follows.

Accreditation remains a crude transparency instrument, providing little information of value to clients beyond the basic though crucial protection against substandard provision. The refinement that stresses public value-oriented ideas, namely focusing accreditation on achieved learning outcomes, which would make accreditation more directly relevant to (prospective) students, cannot overcome this basic crudeness. Moreover, designing such apparently more relevant accreditation schemes remains a challenge, also given academics' resistance to their intrusiveness and the effort needed to design and incorporate sensible indicators of learning outcomes.

Regarding rankings, some recent initiatives - in particular U-Multirank-appear to have been designed to overcome the drawbacks of traditional global rankings. The basic characteristics of U-Multirank empower stakeholders to compensate for their asymmetrical information position vis-à-vis higher education providers, while at the same time assisting these higher education providers in communicating their specific profiles. Multi-dimensional, user-driven rankings have the potential to function as rich transparency tools, as client-driven and diversity-oriented instruments. However, such a transparency tool is only as useful as the information it offers to users. Specifically, the underlying data on the higher education institutions' value added 
in terms of education performance (e.g. learning outcomes, societal engagement of higher education institutions) needs further elaboration.

For the improvement of both accreditation and rankings, universities can play a major role. Both sets of transparency tools will profit from stronger commitment by universities, in making them better tools for stakeholders' information needs. For the universities, these tools offer the possibility for stronger accountability and better public visibility.

This is where the IAU can play a major role. As a well-respected global association of universities, the IAU can take a leading role in assisting its members to show their profiles and communicate their specific strengths, while at the same time creating a more open and transparent attitude about their performances. Building such an open attitude may well be the best way to regain the public's trust.

Frans van Vught was Rector and President of the University of Twente, the Netherlands. He currently acts as an international 'higher education consultant' and is the co-project leader of UMultirank, the only user-driven multi-dimensional global ranking system. Internationally he was a member of the board of the European University Association (EUA), president of the European Centre for Strategic Management of Universities, a member of the Universities Grants Committee of Hong Kong, and a member of the board of the European Institute of Technology Foundation. He published widely on higher education and holds several honorary doctorates.

Open Access This chapter is licensed under the terms of the Creative Commons Attribution 4.0 International License (http://creativecommons.org/licenses/by/4.0/), which permits use, sharing, adaptation, distribution and reproduction in any medium or format, as long as you give appropriate credit to the original author(s) and the source, provide a link to the Creative Commons license and indicate if changes were made.

The images or other third party material in this chapter are included in the chapter's Creative Commons license, unless indicated otherwise in a credit line to the material. If material is not included in the chapter's Creative Commons license and your intended use is not permitted by statutory regulation or exceeds the permitted use, you will need to obtain permission directly from the copyright holder.

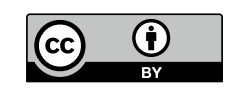




\title{
Towards the Other Side of Complexity: Values and Decisions in a Time of Uncertainty
}

\author{
Marcelo Knobel
}

Humanity is experiencing a moment of great uncertainty. This is not the first time a pandemic threatens the lives of millions of people. However, the speed with which governments and scientists are reacting to events is unprecedented. In an incredibly short time after the discovery of the virus, public health measures were implemented, and the development of defences in the form of public policies, medical therapies, and vaccines began. At this precarious moment, when the proliferation of information (and misinformation) from a variety of sources contribute to the spread of panic, universities and the scientific community emerge as the best and most reliable sources of information. It is only highly qualified specialists who can truly address the pandemic and its terrible economic, political, and public health consequences.

Paradoxically, this pandemic has been a game changer in terms of the public perception of higher education institutions (HEI), which have lately been under constant attack in many countries. In Brazil, for example, there is an agenda to discredit public universities and the sciences through fake news and undermine them through budget cuts. The current crisis now underscores the importance of research universities and institutes for the future of the country and the world to face this and future threats.

While the importance of higher education is starting to be appreciated again, HEIs still face major internal challenges and new problems every day. Even without clear answers, decisions must be made, and one will only know in the future how to assess these decisions.

In fact, as I am writing this text, the future is very uncertain. During this world crisis caused by the coronavirus pandemic, the outlook has become even more nebulous. Today, we simply do not know how or when the Covid19 pandemic will end or how it will change the way we live on our planet. Even with so many uncertainties,

\footnotetext{
M. Knobel ( $\varangle)$

University of Campinas (Unicamp), Campinas, Brazil

e-mail: knobel@unicamp.br 
universities must respond and keep moving. Leadership in HEI must still make complex decisions and provide answers on a daily basis. The best way to proceed is by allowing the mission of the institution to serve as the main compass while considering the needs of all of the people it serves.

As we are now in the middle of the pandemic and full of uncertainties, each decision taken by the leadership can have important consequences, ranging from the livelihood and well-being of the community to the long-term survival of the institution. These decisions are more and more complex because there are so many sources of information with equally conflicting conclusions as James O'Toole has pointed out:

Today's problems are also complexly interrelated and, thus, build demonically on each other. The challenge of coping with these problems is compounded by two paradoxical trends: an implosion of the speed of global communication and a simultaneous centrifugal explosion of information. These trends conspire to make managers increasingly interdependent while affording them the data to make more independent decisions. As if that weren't enough recipe for conflict and confusion, today we all feel entitled to a say in dealing with the problems that affect us all. (O'Toole 1995: 4).

When dealing with such complex issues, it is important to be pragmatic and look for straightforward solutions that rely on basic, fundamental concepts:

The simplicity on the other side of complexity offers a different prospect: that incompatible values might be made mutually achievable and reinforcing. The leadership challenge, then, is to get to the other side of complexity. But how does one get there? Only one sure route has been identified: the enhancement of understanding. To move beyond the confusion of complexity, executives must abandon their constant search for the immediately practical, and, paradoxically, seek to understand the underlying ideas and values that have shaped the world they work in. (O'Toole 1995:7).

This is why it is so important to focus on the mission of the institution, especially when the future is undetermined. The mission, on the other hand, must be rooted in values, which are essential for any institution. The values are fundamental to deal with any sort of challenge, as they offer HEIs guidance for their behaviour and decision-making process. Some values define the core of the idea of a university, such as autonomy and academic freedom (and in recent times underlined by the Magna Charta Universitatum $^{1}$ ). There are many other values as well that are critical to helping HEIs understand and define themselves, such as social responsibility, diversity, excellence, and other principles specific to institutional missions. To expand public trust in universities amid today's complexity and uncertainty, HEIs need to explicitly define and communicate their values while demonstrating that their values inform practice and decision-making processes. In fact, a well-established mission, based on consolidated values, is the only safe guide for these unclear times.

The challenges ahead are not new to universities. They come in different forms and velocity, and they come as part of political, sanitary, and economic crises. As mentioned, in order for universities to tackle the question of how to face the challenges at hand, we must return to the basic problems that lie behind the current pandemic. In

\footnotetext{
${ }^{1}$ See http://www.magna-charta.org/.
} 
a wonderful speech given by Julián Marías, on the occasion of the 4th centenary of San Marcos University (Lima, Peru), titled "The University, Problematic Reality", Marías claims (Marías 1953, p. 61):

I know of no other way to solve problems than to use them as a starting point: the only way to overcome difficulties is to rest on them to jump upwards. For this reason, what most urges the university on is to penetrate its inner problematic condition. To be a university student today is only possible with a dose of uneasiness, I would even say a certain state of mind... But this uneasiness can also be a form of salvation; its prime consequence is to avoid inertia, to avoid carrying on with the usual, as if it were justified and obvious; the second is to eliminate petulance and easy satisfaction, to replace them with the most fruitful characteristic available to man: discontent. The current university student must understand that his studies are not the only or most important thing, that he must not be certain of exactly what to do, that his mission is more than doubtful, and that he must carry it out with proud modesty."

The idea here, as antiquated as it may sound, is that difficult times can indeed serve as an opportunity for positive and needed transformation. To do so, we need to step forward, and demand of society to help with this huge challenge. Again Marías (Marías 1953, p. 63):

Faced with all difficulties, this state of mind can be comforting: this is why I spoke [...] of proud modesty. Isn't this an undertaking worthy of the University, with its glorious history of seven centuries, to recreate itself within these narrow delimitations? The University has its back against the wall: the best situation to fight. It is the right moment to assert the university scholars' claim and status, in all its aspects. We all have been informed and formed by the University, we will always be universitas magistrorum et scholarium, in whatever locus the authentic form of that belonging may be."4

HEIs have a commitment to students and their families and to the larger society that finances them. Perhaps most importantly, they must provide basic and applied research as well as direct medical assistance. Universities cannot fail to disseminate scientifically correct content and participate in campaigns to ensure that the population has timely, accurate information. As harsh as the forecasts are for the immediate

\footnotetext{
${ }^{2}$ La Universidad, Realidad Problemática, in Spanish.

3 "No conozco otro modo de resolver los problemas que partir de ellos: la única manera de superar las dificultades es apoyarse precisamente en ellas para brincar hacia lo alto. Por esto, lo que más urge a la Universidad es penetrarse de su condición problemática. Sólo es posible hoy ser universitario con cierta intranquilidad, yo diría hasta de conciencia. Esa inquietud puede ser salvadora; su primera consecuencia es evitar la inercia, el hacer lo de siempre, como si estuviese justificado y fuese obvio; la segunda, eliminar la petulancia y la fácil satisfacción, para sustituirlas por lo más fecundo de que dispone el hombre: el descontento. El universitario actual debe pensar que no es lo único ni lo más importante, que no sabe bien qué tiene que hacer, que su misión es más que dudosa, y realizarla con una orgullosa modéstia.

4 "Frente a todas las dificultades, esta conciencia puede ser confortadora: por eso hablaba unas líneas más arriba de orgullosa modestia. No es una empresa digna de la Universidad, de su gloriosa historia de siete siglos, recrearse de nuevo en estas estrechas circunstancias? La Universidad está entre la espada y la pared: la mejor situación para luchar. Y entonces conviene reivindicar, en todas sus formas, la condición de universitarios. Lo somos todos los que hemos sido informados y conformados por la Universidad, los que pertenecemos para siempre a aquellas universitas magistrorum et scholarium, sea cualquiera el lugar donde nos sitúe la forma auténtica de esa pertenencia.
} 
future, universities will be up to the challenge. In such a complex atmosphere, their focus must continue to be their mission, and they must make every effort to demonstrate to the society that sustains them that their primary role is the well-being of that very society.

Higher education institutions have a duty to continue their activities, despite the restrictions that the current situation imposes. They represent a huge social investment that cannot be overlooked or minimized. Now, more than ever, they must make it clear that this long-term investment is fundamental to a better future for all.

\section{References}

Marías, J. (1953). La Universidad, Realidad Problemática. Cruz del Sur (Santiago de Chile). Retreived from: http://www.educacionyfp.gob.es/dctm/revista-de-educacion/1952/ 195205/1952re05universidad.pdf?documentId=0901e72b81ee08a7 (28.08.2020).

O'Toole, J. (1995). The Executive's Compass: Business and the Good Society. Oxford University Press.

Marcelo Knobel is rector of the University of Campinas (Unicamp) and a member of the Board of Directors of the Brazilian Center for Research in Energy and Materials (CNPEM). A full professor of Physics, Knobel held several leadership roles at Unicamp, including vice-rector for Undergraduate Programs. He also served as executive director of the Brazilian Nanotechnology National Laboratory (LNNano) at CNPEM. Knobel received both his bachelor's and his doctoral degrees in Physics from Unicamp, and was a post-doctoral researcher in Italy and Spain. He has published more than 250 scientific papers and numerous opinion pieces in newspapers and magazines.

Open Access This chapter is licensed under the terms of the Creative Commons Attribution 4.0 International License (http://creativecommons.org/licenses/by/4.0/), which permits use, sharing, adaptation, distribution and reproduction in any medium or format, as long as you give appropriate credit to the original author(s) and the source, provide a link to the Creative Commons license and indicate if changes were made.

The images or other third party material in this chapter are included in the chapter's Creative Commons license, unless indicated otherwise in a credit line to the material. If material is not included in the chapter's Creative Commons license and your intended use is not permitted by statutory regulation or exceeds the permitted use, you will need to obtain permission directly from the copyright holder.

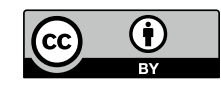




\title{
Africa's Destiny and Higher Education Transformation
}

\author{
Barnabas Nawangwe
}

\section{Introduction}

Africa, the cradle of mankind and civilization, presents the best example of a people falling from the most culturally and technologically advanced society to the most backward and marginalized. While other ancient civilizations like China, Babylon, and India either transformed and survived or persisted in the case of China, the Egyptian civilization was destroyed and was never to recover. The University of Sankore at Timbuktu, established in the 13th century and recognized by many scholars as one of the oldest universities on earth, is testimony to the advancement in scholarship that Africa had attained before any other civilization. But that is all history. Instead, Africa remains the most marginalized continent, viewed by many as a hopeless sleeping giant without any hope for awakening and moving forward as part of a modern global society.

Different parts of Africa were conquered by different civilizations, and their influence implanted to varying degrees. Little is known about scholarship between the time of the fall of the Egyptian Empire and the era of colonialism. However, Africa still boasts of some of the oldest existing universities, including the University of Karueein, founded in 859 AD in Fez, Morocco. Outside the Maghreb, all universities are modern-day creations of the colonial powers which subdued Africa as early as the 15 th century.

\footnotetext{
B. Nawangwe ( $\varangle)$

Makerere University, Kampala, Uganda

e-mail:vc@admin.mak.ac.ug 


\section{The Colonial African University}

No other place on earth has been raped and humiliated like Black Africa. All precious resources have over the centuries been shipped out of the Continent for close to no compensation. Even the people themselves were herded into slavery with the connivance of Africa's greedy rulers of the time. With all these injustices perpetrated on the Continent, it is surprising that some people wonder why Africa is such a huge landmass with inherent inertia. But not all is lost.

The colonists established training institutions at the very basic level, which were eventually to grow into universities. Makerere University in Uganda is a good example of such a colonial university. Founded as a small vocational school in 1922 by the British colonial government in Uganda, Makerere would eventually become the country's lone institution of higher education. The aim was to build a technical school for the indigenous Africans, obviously to serve the needs of the growing European population. The first class of fourteen students, seven enrolled in carpentry and seven enrolled in auto mechanics, began their training towards the end of 1922. All the fourteen students were men, and the school's motto was 'Let Us Be Men'.

British governor Philip Mitchell (1935-1940) proposed moving Makerere beyond vocational training and expanding it to become the centre for higher education in British East Africa (Kenya, Tanganyika, and Uganda), and in 1937 Makerere began to offer post-high school certificates. Other certificate courses were introduced to satisfy the demands of the migrant European community, including nursing and agriculture. It is clear that the intention of the colonists was to provide semi-skilled labour for the consolidation of their power. In 1949, the University of London affiliated with Makerere, just as it did with similar schools in sub-Saharan Africa, including Ibadan, Accra and Lagos. As the colonies became more advanced, the colonial governments needed more advanced skills to serve their interests, and in 1963 courses taken at Makerere could count toward a degree at the University of London, and its students were listed as graduates of the British institution. But while these developments helped the colonists exploit the colonies better, they also created a critical mass of enlightened Africans who would start agitating for the independence of their countries.

\section{The Emergence of National Universities}

After attaining independence, African countries desired to reduce dependence on their colonial masters for the production of much needed human resources. The colonial university was designed to produce middle carder technical personnel and officers to help the colonial government in administration. Very little attention had been given to producing human resources to manage industrialization processes, which the young independent countries felt was crucial to the consolidation of their independence. By 1970, Makerere became the independent university of the Republic 
of Uganda, offering both undergraduate and postgraduate courses toward its degree programs. Similar universities were established at Nairobi, Dar es Salaam and other African capitals. The University was seen by the young independent African countries as an essential ingredient of national pride and independence. Indeed, professors at Makerere University, for example, were paid higher than Ministers of Government, causing unease among some of the ministers.

In Ronald Bisaso's article in the book 'Flagship Universities of Africa', Bisaso (2017) states that '[s]uch universities were established as both national and regional symbols with the main objective of human resource capacity development. Makerere University transformed from a colonial university to a nationalist university'. The new national universities were gems in their countries, and they enjoyed enormous influence, and resources were unlimited. The students were practically paid to study, and because of their small numbers, all of them left university to find well-paying jobs waiting for them. It was time for the independent countries to demonstrate full independence. Even in the area of scholarship, new programs were introduced to train critical human resources for the countries' development. The new programs included engineering, human and veterinary medicine, agriculture, law, and business studies. However, the university was still viewed mainly as a place for human resource training.

In many African countries, the two decades which followed independence were characterized by strife and very little development. This pushed Africa further down the drain of marginalization. When the guns finally went silent, the African countries were heavily indebted, and the World Bank practically ran their economies and dictated their development agendas. I will not tire in decrying the disastrous structural adjustment programs of the World Bank, which brought African universities to their knees. It took almost two decades for the World Bank to realize that their assertion that higher education was a private good was causing untold damage to universities in Africa. By this time, African universities had entered the era of so-called neo-liberalism. According to Bisaso (2017): 'The era of the neoliberal university triggered considerable expansion of higher education institutions differentiated by type and ownership'. Governments created new public universities to try and address the high demand, and the higher education sector was liberalized, leading to the mushrooming of private institutions. New academic programs were introduced as a way of increasing revenue and responding to market demands, with little regard for quality.

\section{Becoming Research-Intensive Universities}

The tremendous success of the so-called Asian Tigers, which were at the same level of development as most sub-Saharan countries at the time of independence, sent a strong message to African universities. African universities could no longer thrive on the production of large numbers of graduates. They had to re-invent themselves. The society in which they are located started questioning their relevance. A few of 
the universities including Makerere, Nairobi and Dar es Salaam, Ghana and Ibadan embraced a culture of research with the support of international development agencies. It became increasingly clear that African universities had to undergo a paradigm shift.

Many scholars argue that Africa cannot continue hiding under the excuse of colonialism as the reason for lack of development. Universities are called upon to champion a new era in Africa's development agenda. Agenda 2063 and national development agendas require that African universities will lead the struggle to achieve the SDGs and position Africa on a clear path of development. And the universities are responding positively. Through regional organisations including the African Research Universities Alliance (ARUA), the Regional Universities Forum for Capacity Development in Agriculture (RUFORUM), the Consortium for Advanced Research Training in Africa (CARTA) and others, African research universities are beginning to address the insignificant contribution to global research, currently standing at 2\%. Former South African President Thabo Mbeki declared that Africa was undergoing a renaissance. That renaissance will not succeed without the critical involvement of Africa's universities, and finally African governments are coming along to appreciate this reality. Many of them have started funding universities to do research critical for national development. The recent COVID-19 pandemic has clearly demonstrated that Africa has to wake up or perish. The innovations that have come out of African universities are a clear sign that African universities have the capacity to turn around the Continent's fortunes.

\section{Conclusion}

For more than 1500 years, Africa has suffered humiliation and marginalization. Africa's weakness is mainly attributed to lack of knowledge and knowledge institutions, but a new era is dawning on Africa. Are African universities the engine that will propel this great continent ahead? The answer is certainly YES.

\section{Reference}

Bisaso, R. (2017). Makerere University as a Flagship Institution: Sustaining the Quest for Relevance. In D. Teferra (Ed.), Flagship Universities of Africa (pp. 425-466). Palgrave Macmillan.

Barnabas Nawangwe has been the Vice-Chancellor of Makerere University, one of the oldest and premier universities in Africa, since August 2017. Prior to that, he was Deputy Vice-Chancellor, Dean and Principal of the College of Engineering, Head of the Department of Architecture, all at Makerere. He is a member of several international professional organisations and has overseen the academic and administrative transformation of Makerere University, including her transformation from a faculty-based to a collegiate University. 
Open Access This chapter is licensed under the terms of the Creative Commons Attribution 4.0 International License (http://creativecommons.org/licenses/by/4.0/), which permits use, sharing, adaptation, distribution and reproduction in any medium or format, as long as you give appropriate credit to the original author(s) and the source, provide a link to the Creative Commons license and indicate if changes were made.

The images or other third party material in this chapter are included in the chapter's Creative Commons license, unless indicated otherwise in a credit line to the material. If material is not included in the chapter's Creative Commons license and your intended use is not permitted by statutory regulation or exceeds the permitted use, you will need to obtain permission directly from the copyright holder. 


\title{
The Constant of Change: Remaining Relevant in 21st Century Higher Education
}

\author{
Mandla S. Makhanya
}

\section{Illuminating Change and Transformation in Higher Education}

While the old Heraclitan adage: "The only constant in life is change" remains true, it is the scale and impact of that change that distinguishes the routine from the radical, and the evolution from the revolution. This difference is captured succinctly by Palinkas who asserts:"Change uses external influences to modify actions, but transformation modifies beliefs so actions become natural and thereby achieve the desired result" (Palinkas 2013). Higher education, in its current state of disruption, is forcing us to revisit everything that we know and believe about education, in pursuit of its continued relevance and sustainability as a "new normal".

Key contributors to the state of disruption are fundamental and influential shifts in geo-socio-economic and political practices, rampant technological and scientific innovation, a multiplicity of role players, many of whom reside outside of the traditional higher education sphere, changing views on the nature and value of knowledge and the role of the university, and compelling contextual realities such as the need (and demands) for equity, social justice and redress. If we were ever in any kind of doubt as to the urgency of the transformation, then the current COVID-19 pandemic has brought into sharp focus the current precariousness of global higher education, revealing our weaknesses and shortcomings and galvanising a collective rethinking of virtually everything that we know and do and which we regard as "education".

This essay will briefly examine four key drivers of the current transformation in higher education which will need to be addressed to ensure relevance and sustainability. These are elucidated below.

\footnotetext{
M. S. Makhanya ( $\square)$

University of South Africa, Pretoria, South Africa

e-mail: makhams@unisa.ac.za 


\section{Co-dependent, Borderless, Yet Profoundly Unequal and Conflicted Global Societies}

Gross socio-economic disparities and increasing political polarisation, even within affluent societies, are increasingly prevalent and deleterious (OECD 2015). Poverty often scaffolds on pre-existing socio-economic inequality, and the affordances of the digitisation, when it comes to access to a quality and affordable education, more especially for women, have not been significantly reflected in the lives and development of those who need it most (Bennett and Kent 2017). This picture of exclusion is growing quite rapidly to also include disadvantaged people within more affluent societies. Diarra observes appositely [that]: "Globalization does not render the world a space with clearly delineated borders, but rather a mosaic of zones of prosperity and zones of poverty which fragment and intermingle in perpetuity...." (Diarra 2004: 122).

The nexus of these forces and trends has contributed materially to the disintegration or "unbundling" (Czerniewicz 2018); of global higher education into contextual enclaves, weakening the status of universities and shifting higher education worldwide from once a public good to a benefit for those who can afford it. Technological innovation and digitisation, firmly ensconced and facilitated by a neoliberal ideology which ostensibly encourages capitalism in the form of marketized education, even where this excludes the so-called "have nots", continues to play a fundamental role in this trajectory of disintegration.

\section{The Changing Nature, Relevance and Value of Knowledge}

As growing numbers of articles attest to massive job losses and redundancies, it is unsurprising that questions are being asked about the purpose and relevance of education. Schwab and Samans predict [that] "On average, by 2020, more than a third of the desired core skill sets of most occupations will be comprised of skills that are not yet considered crucial to the job today...." (Schwab and Samans 2016). Primary drivers of this growing irrelevance include the transience of knowledge, skills and expertise in the era of the Fourth Industrial Revolution (4IR), the unpreparedness and inability of graduates to "hit the ground running" when they enter the workforce, the changing locus of knowledge production (it is estimated that $65 \%$ of knowledge is now generated externally), and a (still) growing number of learning organisations external to the formal university sector (Veldtsman 2019). At a time when 21 st Century graduates need to be contextually relevant, socially mobile, ethical, critical, responsible, adaptable and appropriately equipped to navigate an opaque future, it would seem that the current understanding of knowledge, its creation and dissemination are increasingly out of touch with the lived realities of our societies and our students. 


\section{The Growing Redundancy and Harsh Reality of the Current Business and Delivery Models}

Universities have been impacted by the pandemic in a fundamental manner, challenging notions of their role and function at the most basic levels and laying bare shortcomings which for generations have been ignored, glossed over or remained undetected. The impact of the pandemic on higher education has been quite catastrophic, with many countries reporting the possible loss of the academic year as both staff and students have been sent home, and academic activities moved "online" for continuity. Success has been varied, and responses have been contextually circumscribed. Academics, students and parents have been brought down to earth with a jolt as the realisation of what it means to study "online" hits home. At this unpredictable stage, four realities have emerged and are growing, as the pandemic unfolds:

1. The shocking entrenched and systemic inequalities in education across the world. Even in first world countries, there are glaring inequalities between those who have, and those who don't; in the same communities and in the same institutions. Assumptions made about the capacity and capabilities of students (and staff) to move seamlessly into remote learning environments, and even what it takes to do so, are proving to be woefully out of touch with reality. Many students, even those at ivy league institutions, just don't have the capacity, ability or desire to engage in self-directed learning. Many are electing to take a gap year or to "lose" a year of study, rather than struggle online with what is perceived to be inferior teaching, learning and assessment. The same inadequacies are noted among academic staff, who are genuinely struggling to adapt and cope with the avalanche of work that the remote teaching context encompasses. The issue of access, social justice and equity has thus become an immediate reality for many higher education institutions.

2. The entire world has had to revisit their understanding of "online education", and in that process, their assumptions and shortcomings in their understanding of what this entails, and its complexity, have been revealed. Clearly, online learning means something different to just about everyone who has never practised it before. Many prefer to dub it "remote learning" while still others are now calling it "emergency teaching by remote means," because they have realised that the more traditional Open, Distance and eLearning (ODeL) such as that practised by the University of South Africa (UNISA) and other open universities simply cannot happen overnight. ODeL is a model that takes decades to set up efficiently, and that requires a sophisticated quality assurance model and regime. ODeL has pedagogical and didactical models that differ fundamentally from those in faceto-face universities. With that understanding has come the revelation that many face-to-face teachers and students actively dislike online learning and are simply unable (or they don't want to) cope with it. However, there is consensus that some forms of "online learning" will definitely continue in most universities post COVID-19 (also as a means of ensuring risk mitigation and business continuity), and this may possibly result in exciting new business models emerging in line 
with new realities. The almost mythical belief of online learning, promoted in no small measure by the corporate world, as simply "going online" that is, simply transposing face-to-face learning online, has been shattered.

3. The pandemic has accelerated the process of redefining the university for sustainability. Most would agree that education as we know it is changing fundamentally, and that in order to survive, we will simply have to change our way of doing business. The pandemic has resulted in massive sums of money being lost, for example, in terms of revenue from foreign students and from domestic students who cannot/will not travel, or who can no longer afford education because of changed home circumstances, or because of leadership who have neither the capacity nor the wherewithal to change direction. Reduced income from subsidies and the corporate world (donors) who are now struggling with their own sustainability issues must also be factored into universities' sustainability risks and strategies. Economically, there is little certainty of what will happen, but we are sure that recession is upon us, globally and nationally. We have yet to decipher the impact on finances for our institutions as they are obliged to transform, over the longer term. No doubt some of the benefits of technology, revealed by "remote teaching" will be retained post covid-19, but the predominant sites for creating, producing and disseminating new knowledge have yet to be revealed.

4. The pandemic has brought to the fore many of the issues that ODeL institutions have been working through for years, such as knowledge hegemony and power when it comes to courseware utilisation and development, and the appropriate use of context and language for nation-building and responsible, critical graduates. For many "going online" and making use of online resources, including OERs has brought home the fact that many of these resources are not of local origin and are therefore often contextually inappropriate, even to the extent that they may perpetuate existing stereotypes and prejudices while being out of date and inapplicable in specific work environments. This is an issue of epistemic justice and nation-building which is gaining ground in developing nations and must be addressed.

5. That said, the need for collaborations and agreements has never been greater, but this must be done in a sensitive manner ensuring win-win outcomes. Moving into the future, very few universities will have the means to flourish on their own, with their own resources and capacities. Collaborations and sharing and leveraging of one another's resources and capacities may well become the "new normal," especially where institutions decide to take part of their offerings more fully online.

\section{New Models of Organisational Design and Leadership}

Clearly, most universities must revisit their purpose and their business and leadership models to ensure their relevance and sustainability. The current context demands flexible, integrated and holistic solutions which, for example, may include a greater focus 
on multi-inter and trans-disciplinarity (MIT) and collaboration with other entities such as professional bodies, business and industry in the development of courseware and teaching practice, as well as different modes of student support, assessment and credentialing to meet different societal requirements and student expectations. There is a growing emphasis on the Recognition of Prior Learning (RPL) and the upskilling of mature learners to broaden access and employability. Furthermore, higher education institutions should be open to very fundamental restructuring (operations and administration) to build in the agility needed to adapt quickly to changing contexts.

A different kind of leadership will be needed that truly understands and is able to navigate the complexity and pressures of the prevailing and emerging global and national contexts. Such contexts may extend beyond that for which they have traditionally been responsible (or trained), to include managing the responses and expectations (on the part of staff, students and stakeholders) to socio-economic and political forces globally, continentally and nationally in the best interest of the university; an ever-increasing community of role players and stakeholders all of whom will have their own agendas; and crucially, delivering relevant pedagogy and quality graduates suited to the environment of 4IR.

Leadership will need to be comfortable with pushing the boundaries of transformation and driving the mindset change that is required for a productive workforce and an agile, efficient and effective institution. This presumes an invested academe, that is likely to require reskilling and successful immersion in a new, transformed institutional culture. Academics sometimes oppose change under the guise of sacrosanct academic freedoms, but in truth concerns around marketisation/commercialisation and excessive workloads and administrative demands that come with it are wellfounded and will require innovative, yet sensitive and productive solutions if the sustainability of the institution is taken seriously.

\section{Conclusion}

Higher education is on the cusp of profound transformation, driven by a host of unstoppable socio-economic and political forces. This provides a unique opportunity for universities to pause, reflect and reorient to a "new normal" that will secure their relevance, value and sustainability.

\section{References}

Bennett, R., \& Kent, M. (2017). Massive Open Online Courses and Higher Education: What Went Right, What Went Wrong and Where to Next. New York: Routledge.

Czerniewicz, L. (2018). Unbundling and Rebundling Higher Education in an Age of Inequality. Educause Review, November-D, 10-24. 
Diarra, F. (2004). Diarra, F.D. 2004. IV. Towards New and Re-Emerging Forms of Discrimination? Human Rights Literacy for the Twenty-First Century (Translated from Paul Robert, L'Atlas géopolitique et culturel du Petit Robert des noms propres (Paris, 2000:108)

Nybom, T. (2012). The Disintegration of Higher Education in Europe, 1970-2010: A PostHumboldtian Essay. In S. Rothblatt (Ed.), Clark Kerr's World of Higher Education Reaches the 21st Century: Chapters in a Special History. (pp. 163-181). Springer Netherlands Retrieved from: https://doi.org/10.1007/978-94-007-4258-1_7 (26.07.2020)

OECD (2015). Why Less Inequality Benefits All, OECD Publishing, Paris. The New Zealand nursing journal, Kai tiaki. 84, (1). OECD. Retrieved from: https://doi.org/10.1787/9789264235120-en (26.07.2020)

Palinkas, J. (2013). The Difference Between Change and Transformation. CIO Insight. Retrieved from: https://www.cioinsight.com/it-management/expert-voices/the-difference-betweenchange-and-transformation (26.07.2020)

Schwab, K., \& Samans, R. (2016, January). Global Challenge Insight Report?: The Future of Jobs. World Economic Forum, 1-167. Retrieved from: https://doi.org/10.1177/1946756712473437 (26.07.2020)

Veldtsman, T. H. (2019). Higher education institutions need to face up to the future. Mail and Guardian. Retrieved from: https://mg.co.za/article/2019-06-28-00-higher-educationinstitutions-need-to-face-up-to-the-future/ (26.07.2020)

Mandla S. Makhanya is Principal and Vice-Chancellor of the University of South Africa and President of the Higher Education Teaching and Learning Association (HETL) - International Body. He is past President of the International Council for Distance Education (ICDE) and is also Treasurer of the African Council for Distance Education (ACDE). He is a Deputy Chairperson of the South African National Commission for UNESCO and Chairperson of the Culture Sector of the South African National Commission for UNESCO.

Open Access This chapter is licensed under the terms of the Creative Commons Attribution 4.0 International License (http://creativecommons.org/licenses/by/4.0/), which permits use, sharing, adaptation, distribution and reproduction in any medium or format, as long as you give appropriate credit to the original author(s) and the source, provide a link to the Creative Commons license and indicate if changes were made.

The images or other third party material in this chapter are included in the chapter's Creative Commons license, unless indicated otherwise in a credit line to the material. If material is not included in the chapter's Creative Commons license and your intended use is not permitted by statutory regulation or exceeds the permitted use, you will need to obtain permission directly from the copyright holder. 


\title{
The Changing Role of Universities in Lithuanian Society
}

\author{
Saulius Spurga and Inga Žalènienè
}

The Lithuanian Republic was re-established on 11 March 1990 after the fall of the USSR, marking the beginning of a wave of reforms in the country's higher education (HE) sector. The prevailing assumption had been that, as a Soviet society, Lithuania enjoyed a high level of education at the tertiary level. Yet, the facts of the matter speak differently; during the Soviet period, only about $10 \%$ of the general population went on to obtain HE qualifications. Moreover, throughout the country, HE's development remained patchy. While it is fair to say that technical-related fields such as medicine and mathematics were sufficiently developed, the same could not be said for the social and humanitarian sciences, which had been under constant surveillance throughout the occupation. During the Cold War, the Communist authorities required these educational fields to serve the purposes of Soviet ideology and reinforce the merits of the regime, all of which had little or nothing to do with education.

In taking its first steps as an independent country, Lithuania faced many serious challenges. According to Claus Offe (Offe 1996: 34), the German political sociologist, the newly-independent states of Eastern Europe that emerged following the collapse of the USSR experienced transformation on three levels: nation-building; constitution-making; and the politics of allocation and distribution. Significantly, this needed to be achieved in a considerably short time frame and with limited experience. The field of education presented one of the greatest challenges. Insofar as high school education was concerned - formulated in the concept of a new Lithuanian education system drafted in 1992 - the task of middle schools was to cultivate independent and creative personalities. As for the universities, they were expected to play the vitally

S. Spurga $(\bowtie) \cdot$ I. Žalènienė

Mykolas Romeris University, Vilnius, Lithuania

e-mail: saspur@mruni.eu

I. Žalènienè

e-mail: izaleniene@mruni.eu

(C) The Author(s) 2021

H. van't Land et al. (eds.), The Promise of Higher Education,

https://doi.org/10.1007/978-3-030-67245-4_35 
important role of preparing specialists for a completely new economic system and a changing society.

In the first instance, newly trained specialists were needed in fields related to the social sciences, and to this end, several new universities with a primary focus on the social sciences were established soon after the formation of the Lithuanian state. The year 1990 saw the opening of the Police Academy of Lithuania (PAL), which in 1997 was renamed the Law Academy of Lithuania. In 2000, it became the Lithuanian University of Law, and in 2004 it received the name that it holds to this day - Mykolas Romeris University (MRU). The aforementioned university continues to educate and train specialists in fields that are crucial to the development of Lithuania's democracy, most notably, among others, matters of public security, public administration, law, and management.

In 2004, MRU became a member of IAU, which marked the start of an important journey towards intensive internationalisation of the university's studies and research. In 2008, the Rector of Mykolas Romeris University became one of the six European full Board Members of IAU. In 2010, Lithuania and MRU was chosen as a host country for an IAU International Conference "Ethics and Values in Higher Education in the Era of Globalisation: What Role for the Disciplines?", which was the unique opportunity to present Lithuania's Higher Education system to the world. It opened the doors for MRU to become part of global university networks and expand its international cooperation. In 2011, MRU carried out the comprehensive review of its internationalisation strategy ISAS coordinated by IAU. Following the recommendations of reputable international experts, MRU is continuing its vision to become a leading specialised social sciences university in Lithuania and in the region.

The early years following the reestablishment of the Republic of Lithuania has been referred to as the so-called "wild economy" stage, which was characterised by weak institutions, poor legal regulation and law enforcement that lacked the means to enforce. Yet, the country managed to get back on its feet, with young people acknowledging the value of higher education and even considering a university education. This coincided with a global trend of 'massification' in higher education which received a boost, particularly in Central and Eastern Europe, especially when compared to previous years when the level of education was considerably lower. The majority of the students were keen to choose social sciences.

Most of the country's universities were established by the Seimas - parliamentof the Republic of Lithuania, and are partially funded under the national budget. A few small universities function as for profit, limited liability companies.

In 2000, special secondary education institutions ("technical schools") were reorganised into colleges and granted the status of higher education institutions, providing ISCED Level 6 education. With colleges included in the system of higher education, the number of higher education institutions increased from 15 to 48 in a country with a population of just 3.5 million at that time. This also meant a sharp rise in the number of students at tertiary level. However, this reform is still considered to be controversial because it helped to promote the view that the oversupply of tertiary education resulted in a lower quality of education. 
In short, the state lacked the means to provide adequate funding for higher education, especially with the constant increase in student numbers. This problem was addressed in 2009 by the higher education reform introduced by a conservative, right-wing liberal government. It introduced a new funding model based on a 'student voucher', whereby the funding follows the student (European Commission 2011:48). The intention was to extend the student's choice of study programme, as well as to provide adequate funding. At the time, the mantra was that competition between universities would result in a greatly improved quality in HE.

Soon it became apparent that 'free choice' was failing to attract candidates to the study programmes and professions prioritised by the government. In modifying policy, the government dedicated a set number of vouchers for each of the academic fields. With the application of this model, competition between universities now takes place only in individual fields of study. Thus, a university funding system of this type prevails in Lithuania to this day. Whilst a great portion of students choose HE in the social sciences, the state prioritises the technological fields and other professions by granting more vouchers. For almost a decade, HE policy assumed that there was a surplus of social science professionals, but without any objective data being provided to justify this assertion.

During the global financial crisis (GFC) which seriously impacted the Baltic states from about the end of 2008 to 2010, many young people who had lost their jobs used this enforced free time to enrol at university. In 2010, more than 21,000 students were enrolled in Mykolas Romeris University. Meanwhile, politicians and even some education experts were quick to point out that in their view, HE massification resulted in the overall decline in quality and graduates struggling to find employment in their chosen field. There was, however, a more objective view underpinned by data which showed that most Lithuanians wanted to secure a tertiary qualification; indeed, such was the demand for skilled workers that wages were twice those of unskilled workers (European Commission 2011:10, 14). The importance of a higher education was further supported by observable trends during the crisis: unemployment rose sharply among low-skilled occupations, while skilled professionals more often managed to retain their jobs. Lithuania was and still remains a country where skilled professionals who obtain higher education have a significant advantage in comparison to less qualified workers (Oecd 2019:10,14).

Soon after the GFC crisis had passed, Lithuania's HE sector was faced with a decline in the number of students entering higher education, a trend common in many other EU countries. In the case of Lithuania, certain factors were also at work: the country was facing a serious demographic crisis due to declining birth rates and emigration. This was compounded by the government's declared goal of raising the quality of HE, which in practice meant restricting student access. Lithuania has a centralised system of final examinations of secondary education that ensures all school-leavers sit their examinations at the same time and are assessed according to the same criteria. The government has set a minimum score that must be reached during these exams in order to be eligible to enter higher education. A minimum score was also set for admission to state-funded places and is recommended for students who pay for their own studies. 
The decline in the number of HE students has been alarming. During the academic year 2008-2009, 210,400 students were enrolled in the country's HE institutions (Lietuvos 2016:11), with just 111,300 in the academic year 2018-2019 (Osp 2019). By this time, only 39\% of young people in the 20-24 age group were seeking higher education, compared to 2017 when $58 \%$ in the 30-34 age group had a tertiary qualification (Osp 2019). The outlook for the future looks bleak; as skilled workers retire, Lithuania will no longer be able to meet the demand for skilled labour in the near future.

It should also be noted that many graduates from schools with a lower quality of education have more difficulty in accessing higher education on account of changes to the national scoring system; such schools are generally attended by children from less affluent families.

At the dawn of independence in 1992, Lithuania's universities began their journey on the basis of academic freedom, yet over time they have been subject to the increasing pressure of state regulation, which has gone as far as violating the autonomy of universities. For example, a study on university autonomy conducted by the European University Association revealed that academic freedom in Lithuania's universities has been severely restricted. The 2016 academic autonomy ranking ranked the country $26^{\text {th }}$ among the EU's 28 analysed national higher education systems, although the organisational, financial and staffing autonomy of Lithuanian higher education was rated better (Eua 2020). Some decisions restricting the autonomy of universities were declared unconstitutional by the Lithuanian Constitutional Court. Worse still, the means of control seem to have no clear strategic objective(s) or framework, with measures and policies being frequently changed.

The position of the authorities would appear to be somewhat contradictory. While espousing "quality of education", they do not define the concept of quality which results in confused and conflicting policies. One case in point was the $2009 \mathrm{HE}$ reforms when the government proclaimed that competition would improve quality, although today they insist that competition is an example of inappropriate academic practice. On the one hand, massification is seen as a negative thing, but on the other hand, universities are constantly being redirected towards meeting the market demand. As in other countries, universities are constantly urged to justify the economic benefits of their research (which ignores the fact that the significance of research is often much broader and deeper) (Collini 2012) or to simply compete to achieve academic rankings, whose reliability is open to question. At the same time, state funding is very limited; Lithuania has one of the lowest levels of government spending per student at the tertiary level, which is twice as low as the OECD average (Oecd 2019). Such policies oblige universities to abandon their traditional mission, which only encourages influential (and poorly informed) political groups, who advocate for elite higher education, yet who refuse to take responsibility for the predicament in which universities find themselves.

Nevertheless, despite such problems and issues, Lithuanian universities are some of the most advanced institutions in the country, and continue to consolidate their reputations on the international stage, maintain high standards of transparency, continuously change and improve, as well as contribute significantly to the country's 
development. In 2018, the employment rate for tertiary-educated young adults in Lithuania was 93\%, which is higher than the OECD average (84\%) and the highest across OECD countries. The same can be said of wages, the pay gap between skilled and unskilled workers in Lithuania being the largest in the EU (Oecd 2019). Lithuania's growth in innovation is the highest in the European region and has reached about $20 \%$ over the last decade (Setkus 2020).

It is heartening to note that the attitude of the Lithuanian Government is starting to be more supportive, which may presage a shift in policy direction. State funding increased for undergraduate studies, especially by increasing the number of vouchers awarded in the field of social sciences and humanities, all of which is consistent with the needs of entrants. Furthermore, during the COVID-19 crisis, it became clear that Lithuanian universities were quickly adapting to the new conditions and moving smoothly to the remote mode.

\section{Conclusions}

In view of the aforementioned discussion, and the lessons learned from the recent COVID-19 crisis, a number of important issues need to be addressed if higher education is to continue to grow and contribute to the country's development. These include the need to:

- understand and evaluate the significance of HE in a broader sense: its impact reaches beyond a country's economic development and affects the society, national culture, quality of life in a broader sense;

- state focus on innovation and exchange of expertise, knowledge and research findings between HE institutions, businesses and other market participants;

- extend access to HE in particular, and recognise its substantial role in promoting wider inclusion by all groups in the community;

- increase investment by the state and HE institutions in creating virtual environments, platforms and open resources for studies and research. For this to happen, IT systems in HE institutions must be upgraded to apply to distance learning and blended studies, as well as the creation of effective IT support systems for students and lecturers;

- boost the digital competencies of lecturing staff, as well as empower them to organise a high-quality study process using modern advanced educational technologies;

- revise and quickly eliminate bureaucratic and legal obstacles that are holding back the further application of technology to study models in HE institutions;

- meet the challenge of decreasing the international mobility of students, which means ensuring "internationalisation at home" through the integration of virtual sessions of foreign teachers into national programmes, and distance learning facilities and opportunities for students living outside of Lithuania. 


\section{References}

Collini, S. (2012). What are universities for?. Penguin Books.

EUA. (n.d.). University Autonomy in Europe. Retrieved from: www.university-autonomy.eu/ (20.05.2020)

European Commission. (2011). Supporting growth and jobs - an agenda for the modernisation of Europe's higher education systems. Brussels: COM(2011) 567 final, 20. 9.2011.

Lietuvos Respublikos švietimo ir mokslo ministerija. Mokslo ir studiju stebėsenos ir analizès centras(2016) Lietuvos švietimas skaičiais 2016. Studjos. Vilnius.

OECD. (2019). Education At a Glance. Country Note. Lithuania. (pp.2). Retrieved from: www. oecd.org/education/education-at-a-glance/EAG2019_CN_LTU.pdf (20.05.2020)

Offe. C. (1996). Varieties of Transition: The East European and East German Experience. Cambridge: Polity Press.

Oficialiosios statistikos portalas (2019) Lietuvos švietimas, kultūra ir sportas. Aukštasis mokslas. Retrieved from: https://osp.stat.gov.lt/lietuvos-svietimas-kultura-ir-sportas/lietuvossvietimas-kultura-ir-sportas-2019/aukstasis-mokslas.\%20Accessed\%2020\%20May\%202020 (20.05.2020)

Šetkus, K. (2020). Kaip kuriame inovatyvia Lietuva ir kokie iššukiai laukia ateityje. Verslo žinios, March 19, Retrieved from: www.vz.lt (20.05.2020)

Saulius Spurga is the Deputy Rector of Mykolas Romeris University. He also lectures at the University and undertakes the duties of an Associate Professor. He has been elected to Mykolas Romeris University's Senate and is now the Senate Secretary. He regularly publishes articles, reviews and analysis of Lithuanian society and political life in various types of mass media.

Inga Žalėnienė was appointed as Vice-Rector for Research and International Relations in 2012, then in 2017 as Vice-Rector for Education and Research and since March 2019, she holds the position of Rector of Mykolas Romeris University. Inga Žalènienè is an IAU Board member since 2017.

Open Access This chapter is licensed under the terms of the Creative Commons Attribution 4.0 International License (http://creativecommons.org/licenses/by/4.0/), which permits use, sharing, adaptation, distribution and reproduction in any medium or format, as long as you give appropriate credit to the original author(s) and the source, provide a link to the Creative Commons license and indicate if changes were made.

The images or other third party material in this chapter are included in the chapter's Creative Commons license, unless indicated otherwise in a credit line to the material. If material is not included in the chapter's Creative Commons license and your intended use is not permitted by statutory regulation or exceeds the permitted use, you will need to obtain permission directly from the copyright holder. 


\title{
Modern Challenges for Universities
}

\author{
Tatiana Klyachko and Vladimir Mau
}

During the COVID-19 crisis, which has turned out to be an unprecedented challenge for higher education all over the world, IAU has become a platform that unites the efforts of universities and other educational institutions and also encourages the collaborative search for solutions to the problems they face. The communication mechanisms developed during this period, the global research conducted, and various web resources have significantly enriched the discourse in higher education. But most importantly, a solid foundation for the future strategic rethinking of the management of universities has been laid.

We have realised that in the post-COVID world universities will be changing dynamically, and they will need new values to operate. For instance, IAU was one of the first organisations to draw attention to universities' contribution to the SDGs and, undoubtedly, will continue to develop this topic. IAU's role as an expert and consultant has been constantly praised during the crisis. The series of online webinars with leading experts in higher education from different countries and regions have shown both general and individual challenges that universities have faced. As a result of IAU research activities, a broad vision of the situation in global higher education has been presented, and recommendations have been developed that will help universities survive in the post-pandemic period. In the future, we can expect an avid interest in IAU's reports on topical issues and transformations in higher education all over the world. All the more so because universities will have to once again position themselves in the rapidly changing world.

T. Klyachko $(\varangle) \cdot$ V. Mau

The Russian Presidential Academy of National Economy and Public Administration,

Moscow, Russia

e-mail: tlk@ranepa.ru

V. Mau

e-mail: rector@ranepa.ru 
Universities always face both external and internal challenges. These challenges can be narrowed down to the following ones:

1. Exceptional labour market dynamism including the emergence of new professions;

2. Transformation of education into one of the key drivers of economic growth and increase in demand for quality education;

3. Rapid emergence and development of new educational technologies that must be quickly adopted in professional education;

4. Stiffer competition for the best academic staff that can also be faced from foreign universities;

5. Technological base and educational environment quality are the main factors of universities' competitiveness;

6. Scientific development through global network cooperation;

7. Organisations, companies and countries are competing with each other in terms of the quality of both management models and management teams. The importance and development of universities' management;

8. Student and staff mobility is becoming a factor in the effective development of education;

9. Maintenance of universities' dynamic development and their financial stability.

The COVID-19 pandemic and enforced shift to distance learning have revealed a host of issues and risks to higher education development. Firstly, it is the awareness of vulnerability of mass systems like health service or education in the face of such shocks. Secondly, it is the understanding of the necessity of having capacity both in higher education and education at other levels in order to protect the systems from stress overload. The development of distance learning technologies and universities' digital environment has become a mechanism for creating spare capacity that can be quickly deployed to undertake a significant proportion of the overload. At the same time, the pandemic has shown that this capacity is not enough, and its deficit leads to differences in accessibility to quality education, not only between different universities but within universities.

While recovering from the pandemic, universities will have to become aware of their capacity deficit and build a brand-new configuration of educational activities which will successfully combine face-to-face teaching, distance learning technologies and free online courses. Whether the importance of face-to-face learning decreases is a vital question. On the one hand, the reaction to the stressful shift to distance learning can be the wish to get back to normal, which will lead to overvaluing face-to-face teacher-student interaction for some time. On the other hand, there can be overall awareness of the undervaluation of distance learning technologies and their usefulness for global network cooperation between universities and for student and staff academic mobility intensification. Naturally, it will require brand new managerial and economic decisions which will gradually make the system of higher education increasingly global.

There is a more difficult question, though: how technological shifts and new opportunities influence the relevance of specific professions? Surveys among 15-year-old 
schoolchildren, carried out by OECD, show that modern teenagers paradoxically tend to choose rather traditional professions like doctors, teachers, military personnel and police officers.

What does it all mean for universities? First of all, they must be ready to deal with the fact that young people's job preferences will change over time. This is why it is vital that universities provide a wide range of non-specific disciplines to let their students form their preferences more clearly. For this reason, programmes in the liberal arts will be developed and attract more and more students.

The development of practice-oriented education is also a widely discussed topic because it allows recent graduates to become immediately engaged in work. However, this rapid change of technologies makes this strategy risky, to say the least. On the contrary, the fundamentality of university education should be the underlying principle because only this strategy will help students become successful. Fundamental knowledge can be used as a basis on which we can, so to say, 'put' practiceoriented, momentary knowledge. In fact, we must prepare students for the long run, not for a short run in life. It is also vital that universities develop ranges of additional courses to make education truly continuing. Most of these courses will be developed as online-courses, i.e. MOOCs. In addition to that, MOOCs allow students to acquire the necessary knowledge, but only if (1) students understand what courses they need, and (2) all necessary courses can be found among MOOCs. This is why distance learning courses are also necessary, when students contact universities and get the knowledge they need, combining the use of MOOCs with distance learning which can be more personalised than MOOCs. Distance classes and consultations can be conducted both for individuals and small groups when a teacher can take the interests and needs of their students into consideration.

We can, therefore, say that a university is (1) a wide range of courses, especially in the first two years of undergraduate studies; (2) fundamental and thus complex education; (3) continuing education, i.e. the ability to offer and deliver programmes for specialists at various stages of their career.

At the same time, university is a full-time education, connected with MOOCs and distance learning. However, the ratio between the components can vary with years of study, levels of higher education and, later, of postgraduate education.

It should be stressed that full-time face-to-face education will be preserved even though the system of higher education has learned the lesson of the mass and rapid launch of distance learning courses in 2020. This is due to the fact that the university is not only a place of knowledge acquisition but also a place for socialisation, human interaction and common values and trust development.

In short, in order to incorporate all the above-mentioned components, a modern university should develop network cooperation: the stronger the network, the bigger a course range is, as well as the capability of MOOCs development and distance education. It is safe to say that a university of the future is a networked university or, to be more exact, a network of universities united by a common mission and providing their students and trainees with a huge range of educational, cultural and social practices. 
However, the development of strong networks does not mean that universities will not compete for students or professors, eminent scientists, who create and strengthen universities' reputations. In the post-pandemic world, this competition will get more intense because now it has become clear that a teacher or professor who can attract lots of students conducting the classes online allows the university to develop both extensively and intensively. Moreover, in addition to the competition for students, best professors and renowned researchers, one should add the competition for universities integrated into specific university networks. It is currently hard to assess how this institutional competition will influence the world's system of higher education.

There is one more factor that should be taken into consideration when it comes to universities' future. These are opportunities that bring new technologies into universities to advance science. These days it is vital to form university networks for research/projects implementation. Then the following question arises: will this network coincide with the educational one or can a university be included in different networks regarding education and science? At the moment, inclusion of the university into one university network for education, and into another one for science seems rather exotic, but nevertheless, this can turn out to be quite effective. Subsequently, the competition for including a certain university into a certain scientific university network may intensify as well. It is only natural to ask, then, why the competition will take place in this field and why it is not allowed to include everyone into the network. In fact, this option is also possible. However, extremely rapid growth of the network is dangerous from the point of view of its sustainability and effectiveness. If a certain regionalisation of global economy takes place, it is possible to suppose that regional university networks will appear first-both educational and scientific (educational-scientific), which will try to strengthen themselves drawing universities from one regional network to another. That is why it seems that at the beginning of the process there will be tough competition in the development of university networks.

The entry of non-university elements into the above-mentioned networks will become an important factor in universities' development. It can be Internet companies that develop online education, various platforms with educational courses, marketplaces of expert and consulting services. The good thing about the digital world is that it brings different activities together, shortening space and expanding the opportunities of communication both between individual universities and within university networks.

It is also necessary to take into account that resources, including modern educational technologies, available to some universities may be unavailable or not easily available to other ones. As a result, within national borders and in the world in general, differentiation between universities will take place based on their level of digitalisation. This will strongly influence the quality of higher education that will be available in different countries to different social groups. Currently, we are already witnessing this differentiation, but the existing division between universities will gain one more essential dimension. For this reason, we are facing the problem of reducing this differentiation and the mechanisms that will allow us to overcome it so that an increasing number of students gain access to quality higher education. Distance education technologies can play a positive role, giving access to their digital resources to 
other universities, expanding programmes of academic and staff mobility. However, whereas within university networks academic mobility is predominantly horizontal, in this case, it is vertical: when students from weaker universities get an opportunity to attend - face-to-face or remotely—some courses provided by stronger, especially in terms of digitalisation, universities.

The development of university networks and horizontal and vertical academic mobility will demand further training for universities' management teams because they will have to solve ever-complicating problems amidst quickening technological and social changes. It is the quality of management that will become a decisive factor in the development of universities. Therefore, one can expect an increase of another type of competition: in terms of the quality of university management, financial health, and financial stability of the university.

Universities' transition to a new level of development will demand new resources. For a long time, there was an idea that the development of online education would reduce the costs of universities. The year 2020 has shown that distance learning involving online courses is still much more expensive than its traditional form. Currently, universities around the world are in a rather difficult financial situation. Therefore, increasing their financial stability in the new conditions is becoming an extremely urgent problem that will have to be addressed amidst the growing uncertainty of the future.

Tatiana Klyachko is Director of the Center for the Economics of Continuing Education, RANEPA, Russia. She specialises in education economics, as well as in managing and reforming this area. She is the author of more than 200 papers devoted to various issues of education system development, which have been published both in Russian and in English.

Vladimir Mau is the Rector of The Russian Presidential Academy of National Economy and Public Administration (RANEPA). He is a specialist in political economy, economic history and economics in transition. He is the author of numerous articles, books and textbooks. His studies have been published in Russian, English, French, German and Italian.

Open Access This chapter is licensed under the terms of the Creative Commons Attribution 4.0 International License (http://creativecommons.org/licenses/by/4.0/), which permits use, sharing, adaptation, distribution and reproduction in any medium or format, as long as you give appropriate credit to the original author(s) and the source, provide a link to the Creative Commons license and indicate if changes were made.

The images or other third party material in this chapter are included in the chapter's Creative Commons license, unless indicated otherwise in a credit line to the material. If material is not included in the chapter's Creative Commons license and your intended use is not permitted by statutory regulation or exceeds the permitted use, you will need to obtain permission directly from the copyright holder.

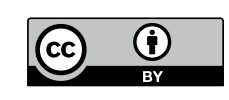




\title{
Universities in an Era of Post-Corona "New Order"
}

\author{
Etsuko Katsu
}

Since the beginning of 2020, the global spread of the coronavirus has caused a sudden disappearance in both supply and demand of goods. This had a major impact on the macroeconomy and corporate management. Our lifestyle is about to change drastically, and companies and universities have changed their work styles by moving to remote work and online meetings. In this memorable year, which also marks the 70th anniversary of IAU, I focus on how universities should be in an era of postCorona "new order" from a Japanese perspective.

Restrictions on entering campus have been in place since the beginning of the academic year at my institution, Meiji University. All ceremonies and physical activities, including the admission ceremony, were suspended, and all classes were moved online. Besides, the virus has had a great impact on the number of international students, which had increased sharply at Japanese universities in recent years and reached some 230,000 in May last year according to JASSO statistics (JASSO 2020). Due to cross-border travel restrictions, the exchange programs have been suspended, and the economic problems of privately funded international students and Japanese students have become apparent.

Teachers were suddenly forced to give online lectures since the beginning of this academic year. We have three types of online lectures: (1) document/assignment presentation, (2) on-demand (recorded video distribution of lectures), and (3) realtime delivery (simultaneous interactive). According to a survey of students at our university conducted in May 2020, on-demand and real-time delivery lectures were highly evaluated, while the lectures consisting in document/assignment scored low in student preference. In particular, on-demand lectures received an outstandingly high rate of satisfaction (by $85 \%$ of students).

\footnotetext{
E. Katsu (ه)

Meiji University, Tokyo, Japan

e-mail: etsuko@meiji.ac.jp

(C) The Author(s) 2021 
The reason for the latter is that students can repeatedly listen to lectures anytime and anywhere and that the communication between teachers and students is easily secured (on-demand lectures use a university system platform, real-time lecture delivery uses chat functions to communicate), and the teachers use student input to improve their class and lecture style. Online classes make the "quality" of lectures visible. Indeed, one can see immediately whether the lecture on a certain subject is well organized, whether it is based on previous research, and whether it captures the essence. On the other hand, there are many complaints from students due to the number of assignments they have to comply with, which means that the students spend much more time studying each subject.

I participated in various discussions regarding the quality assurance of university education at the Ministry of Education. One thing that has always been pointed out is that "Japanese university students do not study". There are reasons for this, such as the fact that university grades are not as relevant for finding a job or students' economic issues, that students spend a lot of their time in part-time employment, but it is still a fact that Japanese university students have extremely little weekly study time compared, for instance, to American university students. The significant advantage of online education was, I think, that the students could devote much more time to the lessons and had to treat them more seriously. Many students avail of the university online system and actively ask their teachers questions, and online lessons had a certain effect on "independent studying".

In addition, it confirmed that communication between teachers and students is of crucial importance in education. In online classes, as mentioned above, there is a chat function for real-time interaction and even for presenting teaching material, a means for communication between faculty and students through the university web system. By using them, many questions could be asked in one lesson, which would further improve the quality of the lectures and the learning experience. In other words, it was reconfirmed that the lectures are made up jointly by lecturers and students, which in turn improves the quality of lectures.

Furthermore, although exchange programs were suspended from the fall semester, it was decided that student and faculty exchanges would be conducted online. It is expected that the exchange of high-quality classes and the development of more debate among students will have an incredibly positive effect on students and staff. During the recent closure of Japanese universities, a transition to fall enrolment, which had been considered already in the past, was considered once more. This is because classes starting from April were initially suspended at all educational institutions. However, considering that the Japanese system would have to change also for spring admission, it appeared exceedingly difficult to change the academic calendar, even during this emergency period.

Regarding the impact on academic research, a number of issues were raised as a result of a survey shared among the researchers and conducted by the Ministry of Education, Culture, Sports, Science, and Technology in May this year. These included, for example, restrictions on access to research facilities, library closures, delays in ordering and delivery due to shrinking administrative systems, restrictions on researcher communication including those overseas, pressure on research time 
through online classes, problems with securing graduate students due to the difficulties encountered in finding jobs and decreasing international students. Regarding the research community, however, webinars are becoming popular, and research communication at international online meetings and academic societies have become easier than before. Research gates $($ ) and other means of scholarly communication with foreign researchers are also showing significant progress.

Looking at Japan's science and technology strength in terms of papers published, Japan was in the top three until 2013 (World Bank 2020). Now, China is growing steadily, and the number of papers published by Japanese researchers is far behind China. Especially in Japan, the number of internationally co-authored papers has not grown as significantly as in China. These are currently being discussed by various parties, and activating the flow of researchers at research universities, the expansion of regular faculty positions, promoting joint appointments at universities and private companies, and cooperation with international top schools and Japanese universities are specially required and should be promoted.

Regarding science and technology policy in the post-Corona era, the government is currently formulating the 6th Science and Technology Basic Plan (2021-2026). We are discussing the structural reform of the social system infrastructure to realize Society 5.0, Japan's model leading contribution in the post-Corona "new order" (MEXT 2016). For example, the following is being developed: intense investment of public funds in science and technology, the creation of a resilient society and informed response to pandemics, the construction of data-oriented social structures, and expanding investment in humans as a source of value creation from knowledge and data. Universities have a large role to play in contributing to such science and technology policies.

Finally, universities are asked to focus more on social responsibility and on the sustainable development goals (SDGs). According to one US newspaper article (Wirz 2020) in recent years, top schools in the United States have "divested" in the fossil fuel industry, partly driven by students and alumni associations. Universities are very influential, and although there are similar movements in areas such as pension funds, universities are being criticized for being overly involved in political issues or that such engagement would reduce the actual returns on investment. Albeit, the role of universities in promoting the SDGs is now extremely large in the world.

There are more than 70 Japanese universities that are members of the Academic Impact initiative of the United Nations ${ }^{1}$ ). Many of those are also members of IAU, and have declared their commitment to research, education, and social contribution in conformity with the ten principles of the United Nations (United Nations 2020). These are also connected to the 17 SDGs and help universities make a great contribution to solving social issues.

For example, Meiji University has been focusing on internationalization as an "open university", and at the same time has actively engaged in global issues such as environment, sustainability, poverty, and human rights protection while promoting

\footnotetext{
${ }^{1}$ For further reference, please see: United National Academic Impact, Japan: https://en. academicimpact.jp (26.08.2020).
} 
further sophistication of education and research. The university has a responsibility to contribute to problem solving also for these kinds of global issues and has been making various efforts so far. For example, it is working on human rights issues in collaboration with Human Rights Watch, has held a symposium with UNHCR (United Nations High Commissioner for Refugees), opened a museum for peace education named the Noborito Research Institute, ${ }^{2}$ and is holding a symposium on tackling environmental issues. In this way, it is even more important in the postcorona era that each university builds its own model, like the Japanese model, and cooperates with companies to promote social contributions.

IAU also regularly exchanges views and information through its extensive work on Sustainable Development, and, in cooperation with UNESCO, it offers essential support to their member universities. IAU is committed to strengthening cooperation with these universities in the future and to promoting such efforts at universities worldwide. I think it is one of the most important and distinguished efforts of the Association.

Congratulations on the 70th anniversary. I wish IAU a bright future and I am convinced it will continue to play an active role in promoting strong and quality university education and research, in strengthening its role in the international community and having an active role in accompanying the development of the Members' university systems.

\section{References}

JASSO (Japan Student Services Organization). (2020). International Students in Japan 2019.www.jasso.go.jp/en/about/statistics/intl_student/_icsFiles/afieldfile/2020/05/08/data19_ brief_e_1.pdf accessed 26/07/2020.

MEXT (Ministry of Education, Culture, Sports, Science and Technology - Japan). (2016). The Science and Technology Basic Plan. Retrieved from: www.mext.go.jp/en/policy/science_ technology/lawandplan/title01/detai101/1375311.htm (26.08.2020).

United Nations. (n.d.). Academic Impact - Principles, Retrieved from: https://academicimpact.un. org/content/principles (26.08.2020).

Wirz, M. (2020). Universities cut oil investments as student activism builds. Wall Street Journal. Retrieved from : www.wsj.com/articles/universities-cut-oil-investments-as-student-activismbuilds-11594719181 (26.08.2020).

World Bank. (n.d.). Scientific and technical journal articles number Retrieved from:https://data. worldbank.org/indicator/IP.JRN.ARTC.SC?year_low_desc=true (26.08.2020).

Etsuko Katsu is a professor at the School of Political Science and Economics, Meiji University. In 2008 she took up the position as Vice President for International affairs of Meiji University for 8 years. She was external director of Mitsui O.S.K Lines, and director of Dentsu corporation. She acts as a consultant for government policy in national commissions belonging to the Japanese Ministry of Education, Ministry of Labor, and Ministry of Finance.

\footnotetext{
${ }^{2}$ For more details, please see: Noborito Research Institute: www.meiji.ac.jp/cip/english/institute/ noborito.html (26.08.2020).
} 
Open Access This chapter is licensed under the terms of the Creative Commons Attribution 4.0 International License (http://creativecommons.org/licenses/by/4.0/), which permits use, sharing, adaptation, distribution and reproduction in any medium or format, as long as you give appropriate credit to the original author(s) and the source, provide a link to the Creative Commons license and indicate if changes were made.

The images or other third party material in this chapter are included in the chapter's Creative Commons license, unless indicated otherwise in a credit line to the material. If material is not included in the chapter's Creative Commons license and your intended use is not permitted by statutory regulation or exceeds the permitted use, you will need to obtain permission directly from the copyright holder. 


\title{
Redefining the Role of Universities in a Rapidly Changing Landscape
}

\author{
Datuk Abdul Rahim Hashim
}

Over the past few decades, the Malaysian higher education sector has experienced important reform, particularly guided by the Malaysia Education Blueprint for Higher Education 2015-2025 to stimulate continued excellence in the system. However, the dawn of 2020 has unfolded many challenges as COVID-19 rages across the globe bringing sudden paralysis to the whole world. Indeed, the pandemic has affected the world and greatly impacted our lives not only from a health perspective, but also from the political, economic, and social aspects. To date, universities in Malaysia have been closed for more than four months, although the Ministry of Higher Education has recently permitted postgraduate students undertaking full-time research programmes to return to the university should their research necessitate their physical presence in laboratories, workshops, design studios or to use specific equipment available only on campus. For other university students, online or virtual teaching and learning is set to continue until the end of this year, although identified groups of students will be allowed to return to the campus in stages.

Traditionally, universities are institutions of higher learning and research, with the general mission of disseminating and discovering new knowledge, as well as moulding holistic graduates. For the past millennium, the concept of teaching and learning (T\&L) and its delivery has not evolved much from the typical lecture-centric approach, even with the advent of technology. Although universities attempted to introduce blended learning in efforts to keep up with the times and stay up-to-date with the new (digital) generation of students, the uptake was slow as many lecturers still preferred to deliver their lectures in the traditional face-to-face manner. However, the COVID-19 pandemic has caused a sudden tectonic shift in the higher education paradigm, forcing rapid changes that we have never witnessed before within such a short time.

\section{A. R. Hashim ( $\varangle)$}

University of Malaya, Kuala Lumpur, Malaysia

e-mail: rahimhs@um.edu.my 
As we endeavour to seek a new normal amidst this chaos while remaining compliant with social distancing efforts, universities have implemented many innovative and creative initiatives to ensure minimal disruption to teaching and learning. Notably, one of the aspects which universities had to urgently resolve at the beginning of the crisis was how to go on with "business as usual", especially with one of its core activities - teaching and learning (T\&L). Amongst the immediate changes we have seen was the accelerated shift from classroom-based lectures to a variety of online platforms, the heightened pace of innovation in virtual learning, as well as adjustments to the delivery and assessment of T\&L. There was also an evident shift in linear and fixed outcome-driven T\&L to a more flexible, responsive, and agile one within a short period of time. The adoption of online learning by lecturers that had seen some resistance prior to this has now been fast-tracked in a massive way.

As educators begin to embrace online learning, though it may not have been by choice, they are now challenged with devising ways and means to address the pressing need to make T\&L not only suitable for remote learning but also to ensure that students are engaged with their lectures, albeit through a computer screen. To ensure that their teaching remains effective and accessible on a remote basis, they need to adapt to a new practice of teaching, upskill and equip themselves with digital skills for online learning, and adjust to the new, remote learning environment without the physical interactions on campus they are familiar with. At the same time, students now have to take more responsibility for their learning progress and be self-motivated to pursue knowledge. This requires a great amount of dedication and self-discipline from both lecturers and students.

With an avalanche of online learning and applications, universities are also able to widen their scope and open up their doors to those who previously did not have the chance to enrol in tertiary education due to personal limitations, be it to commit the time to attend lectures, or the financial means to relocate to a different state or country in pursuit of education. Microcredentialling, the latest buzzword in higher education that has gained more traction amidst the current crisis, will also unfold another vista to boost continuous learning, encouraging adults to reskill and upskill to enhance their career prospects, thus promoting life-long learning. Massive Open Online Courses (MOOCs) will, perhaps, also regain popularity in the education sphere as learning becomes more accessible to those whom it had not reached before. Universities will not be regarded as just tertiary institutions but life-long learning institutions.

There is also potential for greater collaboration between universities and industries, as well as amongst universities themselves to work together while opening up new avenues and modalities to provide a fresh take on delivering shared content and improving curricula. With an increasing number of courses being available online, lecturers can be encouraged to open up their classes to participation by students from partner universities for selected topics that are not available in the students' own university or in cases when there is no such expertise at their university. Students will also benefit from interactions with diverse peers from different institutions as well as gain more exposure through opportunities to learn from experts outside their university. At the same time, industries could play a larger role in academia by firstly, collaborating with universities to provide digital and infrastructural support to facil- 
itate the transition to online learning, followed by sharing valuable input based on practical experience in the field to help universities train a future-ready workforce. As more $T \& L$ and research activities transition into the virtual setting, there will also be more possibilities for collaboration between institutions in terms of sharing physical facilities to optimise operations and maximise the use of existing resources and infrastructure.

Advanced technology has played a vital role in easing the sudden shift to online teaching and has made it possible for lecturers to now replicate smaller classes and personalise learning through both synchronous and asynchronous lectures. This, in turn, encourages more interaction between the lecturer and student, which is a crucial element for learning to be effective. With knowledge readily available at their fingertips, students can now study at their own time, pace, and convenience, having ample time to reflect on lectures, as well as being able to communicate with lecturers directly to pose questions and discuss ideas. It comes as no surprise that since we began implementing remote-learning on a full-time scale, students are reportedly more participative in their virtual classes, and attendance rates have also increased. While active participation in face-to-face classes may have been daunting for some students who shy away from actively participating in discussions due to personal barriers or peer pressure, they are now more comfortable and confident within the online learning setting. However, it also cannot be denied that accessibility to online content is still a major obstacle for students living in remote areas or unconducive environments for studying. Much work still needs to be done to improve infrastructures to facilitate and provide support for these groups of students.

As we move into online and remote learning as the new convention for higher education, at lFieast for the foreseeable future, one might also ask whether universities and university campuses are still relevant. It must be recognised that with the many positive changes and experiences in terms of the shift to online and remote learning, universities still play an important role in developing and moulding graduates to be well-rounded. Along the lines of the Malaysia Education Blueprint, there needs to be a balance between both knowledge and skills (ilmu), as well as ethics and morality (akhlak). One cannot expect students to leave the university with a degree in hand, while deprived of the opportunity to experience the richness of face-to-face interactions with their lecturers and peers. Interpersonal skills and attributes such as being able to communicate effectively, teamwork, emotional intelligence (EQ), leadership, volunteerism, and other soft skills would be difficult and almost impossible to teach and experience in a purely online learning environment. It is on the campus grounds that they learn life lessons, interact with their professors and fellow students, participate in student activities, build relationships and network with others, all of which adds great value to their life during, and after university.

As we begin to envision and create a new normal for higher education, universities will face the challenge of finding the right balance in terms of how to blend online learning without forgetting the value of on-campus education. Online learning, with all its merits, is not the 'silver bullet' or a panacea to the crisis we are facing. Nevertheless, as the saying goes - in the midst of every crisis lies great opportunity. Life must, and should, go on. Although under difficult circumstances, this is the 
time for the higher education sector to revolutionise, particularly with the various technologies available to us today. Moving forward, what will the future be for universities, and where are we headed? Will universities still be relevant? It is safe to say that T\&L will undergo a revolutionary path with the current situation providing the impetus. What is certain is that universities have to work together as a global community to prepare students for an uncertain future while making every effort to ensure that the quality of their programmes remain of high standard and remain accessible to all those who seek knowledge and wisdom.

Datuk Abdul Rahim Hashim is currently the Vice-Chancellor of Universiti Malaya (UM). Prior to this appointment, he was the Vice-Chancellor of Universiti Teknologi PETRONAS. In October 2016, he was admitted as a William Pitt Fellow by the Pembroke College of Cambridge. He is the Past President of the International Gas Union (2009-2012), the Past President of the Malaysian Gas Association (2003-2015) and Past President of the Asia Pacific Natural Gas Vehicle Association (2003-2009).

Open Access This chapter is licensed under the terms of the Creative Commons Attribution 4.0 International License (http://creativecommons.org/licenses/by/4.0/), which permits use, sharing, adaptation, distribution and reproduction in any medium or format, as long as you give appropriate credit to the original author(s) and the source, provide a link to the Creative Commons license and indicate if changes were made.

The images or other third party material in this chapter are included in the chapter's Creative Commons license, unless indicated otherwise in a credit line to the material. If material is not included in the chapter's Creative Commons license and your intended use is not permitted by statutory regulation or exceeds the permitted use, you will need to obtain permission directly from the copyright holder. 


\title{
From Emergency Remote Teaching to Strategically Embracing Online Learning
}

\author{
Dionisia Tzavara
}

As a response to the Covid-19 pandemic, universities across the globe closed campuses, cancelled face-to-face classes, and resorted to digital instruction in an attempt to continue offering instruction, providing continuity to their students, and keeping the academic year going. This movement away from face-to-face instruction happened on a large scale (according to a World Economic Forum article "Some 1.5 billion students-close to $90 \%$ of all primary, secondary and tertiary learners in the world-are no longer able to physically go to school" (Kandri 2020), across various institutions and departments, and large numbers of students and academics were impacted by this shift to online instruction. Many termed this shift to digital instruction, "online learning", and questions were asked as to whether this was going to transform education forever in what was characterized as an unprecedented movement to online education.

Universities adapted quickly and creatively. We should commend all parties involved who, under the circumstances, did the best they could. Academics had to learn how to use various technologies, put their lectures online, create content for their students, and keep their students engaged. Students had to adapt to this new way of instructional delivery, and universities quickly came up with resources to support both students and academics. However, we need to accept that universities, students, and academics were not planning for this move from face-to-face to digital instruction. They were certainly not prepared for it. Many students are dissatisfied with this emergency unplanned shift to digital instruction. Often noting that the quality of the learning experience was not what they had signed up for and that the learning experience was inferior to what they were getting on campus, with some asking for refunds or not planning to start university next year (Moules 2020; Batty and Hall 2020). Also, many academics had no experience in digital or online teaching. Without time

D. Tzavara $(\varangle)$

University of Liverpool, Liverpool, UK

e-mail: dtzavara@gmail.com 
for training, many felt overwhelmed by the effort required and the adjustment they had to make.

Online education is not a new idea; it has been around for about three decades. There is ample research on online learning pedagogies and models, as well as the factors that determine the effectiveness of online learning. An increasing number of universities worldwide offer online education, ranging from open courses (MOOCS) and microcredentials to full degree programmes, both undergraduate and postgraduate. However, what happened this spring was not online learning, despite many referring to this shift to digital instruction as such. What happened can best be described by the term 'emergency remote teaching' which, according to Hodges et al. 2020, is "a temporary shift of instructional delivery to an alternate delivery model due to crisis circumstances. It involves the use of fully remote teaching solutions for instruction or education that would otherwise be delivered face-to-face or as blended or hybrid courses and that will return to that format once the crisis is or emergency has abated".

Online learning is not about replicating the campus learning experience or about 'translating' it to a digitally mediated format. What defines online learning is not the technology, but the pedagogy and the learning design behind it. Pedagogy must be a priority when designing online learning (Ferrel et al. 2018). Online learning, just like campus learning, requires the development of an engaged learning community. Students and educators are actively engaged to create a meaningful learning experience. Meaning that online learning is not about delivering a lecture in a digitally mediated format or about putting together lists of resources that students can access online, but rather about making sense of learning by being integrated into a community with learning as a shared goal. The role of the educator is to design the learning experience and to act as the facilitator of learning, and there is integration between the educator and the learning resources rather than the educator delivering content to students (Bower 2019).

Those of us who have been involved in online learning for years know that online learning requires careful planning and considerable expertise and that it takes months of careful planning to design and develop an online course. Learning design is very important. There are various models and theories that may be appropriate to meet the needs of different learning environments. Similarly, different technologies and learning activities will support different pedagogic approaches and objectives (Ferrel et al. 2016). Several practices that may work on campus, like delivering 2-hour lectures, will not work online. Successful online learning needs to be supported by content, resources, activities, teacher engagement and facilitation, and assessments appropriate for an online learning environment (Bower 2019). Online learning uses combinations of resources and activities to engage learners such as text-based resources, video and audio material, podcasts, blogs, learning journals, quizzes and self-assessment exercises, asynchronous discussion forums, webinars, question and answer sessions, group work, etc.

Many universities offering online learning before Covid-19 were looking to expand their online learning portfolio, either through offering more online programmes and/or credentials (e.g. microcredentials, certificates, diplomas, profes- 
sional development programmes, etc.) or by boosting enrolments through new markets. Several universities were also looking to embrace online learning by launching their first online programmes pre-Covid-19. The anticipated drop in enrolmentsmainly international enrolments - and major loss in revenues that universities face, as well as the uncertainty surrounding campus reopening, has made the need for strategic planning even more pressing. In addition to embracing online education faster and to a larger extent than planned, universities may need to continue remote instruction for longer - at least for the next academic year-due to the changing conditions that Covid-19 is creating, like social distancing.

If universities are going to accelerate their efforts to conquer online education, then a strategic approach informed by the principles of online learning design will have to be adopted. Also, if campuses are going to remain closed in the autumn, then it will not be sufficient to replicate the spring emergency remote teaching experience. Universities will have to come up with a better plan to keep students and academics satisfied and engaged. This shift to emergency remote teaching could lead not just to a boost of online learning, but also to more integration of digital technologies and technology-enabled learning in traditional campus delivery. Universities can create digital content and resources that can be used to supplement classroom instruction and make more effective use of technologies to transform the learning experience for campus students.

Now that the emergency phase of this massive digitalization has passed and stakeholders have started evaluating the experience and discussing lessons learned, universities need to come up with an online learning plan that integrates the overall strategy of the institution and is aligned with its mission. Universities will have to base their plans on the desired outcomes, the purpose of online education, and pedagogies rather than an urgent response to a crisis. Technology mediated learning can take various forms, from fully online learning to various models of blended learning, to campus face-to-face learning supported by digital technologies. Therefore, universities must understand where they want to position themselves on this spectrum. It is very easy to call all forms of technology-mediated learning online learning, but the only thing that can be achieved this way is confusion, misunderstanding, and scepticism toward online learning. At the heart of any online learning plan, we must see online learning pedagogies and theories of instructional design, as well as learning models aligned with learning objectives and learners' needs.

Academics struggled through this urgent digitalization of teaching. Several universities across the globe offer programmes which are fully online and have many faculty members with extensive experience as online academics. But the truth is that the majority of the academic community worldwide had no prior experience with technology-mediated learning, and they had no training in using digital technologies for teaching. More importantly, they lacked experience in the pedagogies of online learning and the principles of online learning design. During this period, some academics pleasantly discovered the potential that digital technology offers to educators and learners, but many were sceptical, overwhelmed, and even questioned the effectiveness of online learning and its potential to offer a fulfilling and worthwhile learning experience. Universities need to establish training programmes to support 
academic faculty in a technology-mediated learning environment, that engages them in this new learning experience while inviting them to rethink and re-evaluate their teaching practices and the ways that they interact with and support their students.

Enabling digitalization was on the agenda of higher education institutions before Covid-19, as demonstrated in the IAU Global Report on Higher Education in the Digital Era (Jensen 2019). But the experience with emergency remote teaching this spring will probably bring about a shift to the agenda for digitalization and in many cases an acceleration of plans. Given the urgency of the situation, video conferencing was probably the best that could happen in many cases. But video conferencing is not online learning, and it is not the only means to enable digitally-mediated learning. There is a richness of tools and mediums that can be used, and universities need to invest in learning technologies and management systems that will enable students with an integrated learning experience. Campus learning is not just about delivering a lecture but rather about creating an environment that integrates various elements. Including, for example, office hours, peer interaction in the department common room, seminar series, access to study skills resources, etc. Those of us who are familiar with online learning know that online learning is the same. Creating a virtual campus for learners and educators is very important, as are supporting resources for students as well as faculty. Resources will have to cover things like instructional design support, media production, technical support, student services, study skills support, library support, etc. An online learning experience must incorporate all of this, in addition to content and instructional delivery.

Many predict that this will be a turning point for higher education and that universities not embracing change will be left behind (El-Azar and Nelson 2020). Whether this is a turning point or not, it is certainly an opportunity for online learning to increase its reach in higher education, as well as an opportunity for campus education to become innovative, flexible, and adaptable. There is ample evidence to suggest that despite the criticism toward online education and the concerns that some raised about the quality and effectiveness of online education, online learning is at least as effective as traditional campus learning and can act as a facilitator of learning (Means et al. 2009; Nguyen 2015; Wilcox et al. 2016). We used to consider students of online learning programmes as non-traditional students (part-time students, with full or part-time employment and considerable professional experience in their field, mature), but given the situation with Covid-19, online learning will be the most preferred option for many traditional university students who might otherwise choose to go to campus. This is a great opportunity for online and campus education to work together with the potential to create synergies to provide innovative, current, and relevant high-quality education. 


\section{References}

Batty, D., \& Hall, R. (2020). No campus lectures and shut students bars: UK universities’ £1bn struggle to move online. The Guardian. Retrieved from: www.theguardian.com/education/ 2020/apr/25/degrees-of-separation-can-universities-adapt-in-the-rush-to-online-learning? CMP=Share_iOSApp_Other (29.04.2020).

Bower, M. (2019). Technology-mediated learning theory. British Journal of Educational Technology, 50(3), 1035-1048.

El-Azar, D., \& Nelson, B. (2020). How will higher education be different in 2030? British Council. Retrieved from: www.britishcouncil.org/voices-magazine/future-higher-education (30.05.2020).

Ferrel, G. Smith, R. \& Archer, W. (2016). Curriculum design and support for online learning. London: JISC. Retrieved from: www.jisc.ac.uk/full-guide/curriculum-design-and-support-foronline-learning (15.05.2020).

Ferrel, G., Smith, R., \& Knight, S. (2018). Designing learning and assessment in a digital age. London: JISC. Retrieved from: www.jisc.ac.uk/full-guide/designing-learning-and-assessmentin-a-digital-age. (15.05.2020).

Hodges, C., Moore, S., Lockee, B., Trust, T. \& Bond, A. (2020). The difference between emergency remote teaching and online learning. Educase Review. Retrieved from: https://er.educause. edu/articles/2020/3/the-difference-between-emergency-remote-teaching-and-online-learning. (5.04.2020).

Jensen, T. (2019). Higher Education in the digital era. The current state of transformation around the world. International Association of Universities. Retrieved from: www.iau-aiu.net/IMG/pdf/ technology_report_2019.pdf. (8.05.2020).

Kandri S.E. (2020). How Covid-19 is driving a long-overdue revolution in education. World Economic Forum. Retrieved from: www.weforum.org/agenda/2020/05/how-covid-19-is-sparkinga-revolution-in-higher-education/. (16.05.2020).

Means, B., Toyama, Y., Murphy, R., Bakia, M. \& Jones, K. (2009). Evaluation of evidence-based practices in online learning: A meta-analysis and review of online learning studies. US Department of Education. Retrieved from: https://files.eric.ed.gov/fulltext/ED505824.pdf. (28.04.2020).

Moules, J. (2020). Coronavirus pandemic accelerates shift in MBA market. Financial Times. Retrieved from: www.ft.com/content/f2d91aca-8933-11ea-9dcb-fe6871f4145a. (26.05.2020).

Nguyen, T. (2015). The effectiveness of online learning: Beyond no significant difference and future horizons. MERLOT Journal of Online Learning and Teaching, 11(2), 309-319.

Wilcox, K.E., Sarma, S. \& Lippel, P.H. (2016) Online education: A catalyst for higher education reforms. Massachusetts Institute of Technology. Retrieved from: https://oepi.mit.edu/files/2016/ 09/MIT-Online-Education-Policy-Initiative-April-2016.pdf (26.05.2020).

Dionisia Tzavara is currently the Director of Online Studies for Laureate Online Education of the University of Liverpool Online Professional Doctorates (DBA \& EdD). She has a long career in higher education, more than 14 years of experience with online learning, and she has served in various academic and managerial roles. She has been involved in the design and development of online programmes and modules. She is an active researcher with publications in academic journals and presentations at academic conferences. 
Open Access This chapter is licensed under the terms of the Creative Commons Attribution 4.0 International License (http://creativecommons.org/licenses/by/4.0/), which permits use, sharing, adaptation, distribution and reproduction in any medium or format, as long as you give appropriate credit to the original author(s) and the source, provide a link to the Creative Commons license and indicate if changes were made.

The images or other third party material in this chapter are included in the chapter's Creative Commons license, unless indicated otherwise in a credit line to the material. If material is not included in the chapter's Creative Commons license and your intended use is not permitted by statutory regulation or exceeds the permitted use, you will need to obtain permission directly from the copyright holder. 


\title{
Overcoming Challenges and Boundaries Through the Innovation of University Learning and Teaching Practices
}

\author{
Elena Luppi, Lucia Balduzzi, Nicolò Cavina, and Carla Salvaterra
}

\section{Premises}

Our universities today embody the outcome of a long transition of higher education institutions from environments for intellectual selection to engines of democratization, social promotion and widespread innovation (Biggs and Tang 2011; Trow 2007). Universities are tasked nowadays with increasing the knowledge and skills of a population whose schooling rates are growing progressively and whose training needs are becoming more and more complex. They are called upon to respond to current cultural, social and economic challenges and, above all, to the challenges of tomorrow, in a constantly changing scenario. For the above-mentioned reasons, university curricula are increasingly incorporating issues related to citizenship education or citizenship, since the great challenge of the transition from local to global, understood as plural, is a priority (Owens et al. 2018; Aydin 2014). Moreover, work environments require professionals who have deep disciplinary knowledge but, at the same time, high transversal skills needed for adaptation and innovation (Wheat et al. 2018).

This perspective requires strong academic coordination between the different actors involved in learning processes: university management-for the definition of policies, strategies and organizational models; teaching staff_called to self-reflect and innovate their practices-and students, who play the leading role in learning.

\footnotetext{
E. Luppi $(\varangle) \cdot$ L. Balduzzi $\cdot$ N. Cavina $\cdot$ C. Salvaterra

University of Bologna, Bologna, Italy

e-mail: elena.luppi@unibo.it 


\section{Innovation in Teaching and Learning as a Dynamic Strategy}

Innovation in teaching and learning within our institutions will require a plan of strategic actions for innovation: our view is, and taking inspiration from the formative educational evaluation research (Scriven 2003), that these could be based on three levels of intervention:

- Level A actions: Action Research Activities: A strategic view on teaching innovation will profit from a sound scientific base, systematic data collection and research activities, aimed at engaging the teaching and administrative support staff in participatory activities of analysis and collective reflection, identification of the training needs and implementation of the consequent training actions useful for future redesign, also experimenting techniques of video analysis to support teachers in the reflection and redesign of the didactics.

- Level B actions: Specific training paths through innovative methodologies: Transversal actions, connected to the qualifications of university teaching and learning, may be aimed at raising awareness of the whole teaching staff to the quality of teaching through a series of transversal actions, addressing the development of competencies related to the "Organizational Citizenship Behaviours" (Organ 1988) and aimed at introducing training on transversal competencies for students.

- Level C actions: Design of an organizational model to support innovation and for the quality of teaching: The quality of teaching and learning should be supported by a dedicated organizational structure making the implementation possible of the system for innovation described above. Quality management is understood as a managerial approach to the intentional development of the conditions and skills that are necessary for constant improvement. The synergy between all these levels and processes is guaranteed through quality assessment actions, accompanied by training interventions, in the logic of "formative assessment".

\section{Innovation in the National Context: Teacher Training}

Teacher training, in Italy as in many countries, represents a typical field of strong national regulations and frequent regulatory interventions that make it difficult to create stable training paths over time and therefore long-term experimentation.

Today's scenarios require universities to provide training courses for initial and in-service teachers who must cope not only with the acquisition of disciplinary and teaching skills that comply with national school regulations and systems. They must also acquire new skills to face new global challenges. We are referring not only to soft skills, on which all curricula at universities and schools are progressively concentrating efforts but also to competencies that are fundamental today such as education 
for active citizenship, education for social and environmental sustainability, requiring multi and interdisciplinary approaches and training. In regard to these fields, the most promising scenarios will be shaped by the construction of national and international networks. These networks will also, thanks to the many important strategic partnerships and alliances funded by international programmes like the Erasmus+ and H2020 programme in Europe, to design participatory action and advocacy processes. This type of intervention is particularly important in countries like Italy today, not only for the qualification of educational and instructional paths, but also to support the visibility and social prestige of the work of teachers and, more generally, of humanistic and scientific culture, which do not enjoy great social recognition in all countries. Among the societal challenges faced by education, we now have to cope with the issue of training new citizenship skills for sustainable development in a society increasingly influenced by scientific and technological development. Public engagement, as well as science education, together with ethics, gender and governance, also require transversal attention and new research efforts. Those topics are objects of interdisciplinary research and need further investment in order to become an object of not only cultural but also didactic methodological approach within teacher training programmes, planned through strong collaboration between education sciences and other disciplines, for the implementation of innovative actions and the dissemination of good practices in the school sector.

\section{Impacting in the Local Context: Innovating Lifelong Learning and Continuing Education}

Promoting, supporting, and effectively making lifelong learning opportunities available is crucial for further establishing and consolidating the university mission in a rapidly evolving technological scenario and in a world increasingly characterized by cultural diversity, migrations, centralization of wealth, with access to higher education becoming more and more based on the economic situation of the individual and his or her social status (Crossan et al. 2004).

Lifelong learning is one of the central elements of the educational and training mission of most universities that are investing to make the lifelong learning and continuing education offer structural and diversified. This approach is analyzed below in two specific areas, apparently very different but which respond in a complementary way to the needs of inclusion, increased job opportunities and active participation in civil society: corporate education, or technical and vocational training, and prison university programmes. 


\subsection{Corporate Education}

The process of redefining the methodology with which to design, organize and deliver training to company employees starts with the definition of the main objectives to be achieved:

- Answering requests and anticipating needs of higher professional education from companies, stakeholders, institutions;

- Strengthening relations with industrial partners;

- Ensuring uniformity of design, support services, and delivery of corporate education (including standard costs);

- Establishing a data collection system that allows for the monitoring of training needs of companies and the universities in terms of offer.

As regards in particular the first element, it has been found that one of the main needs of companies today is to invest in training for their employees by implementing solutions aimed at increasing internal skills, speeding up professional growth and expanding knowledge in new sectors and technological fields, involving staff on several levels (e.g. basic courses for a wide audience, advanced courses for specific profiles, alignment for new hirees).

Two procedural models, which, according to our experience, are most effective, can be identified and put in place. The first one is characterized by a medium- to long-term scope, which provides for the setting-up of a series of courses, possibly repeatable, co-designed with company management. Such a model is implemented through a multi-year renewable agreement with the industrial partner and the creation of a coordination committee, responsible for co-designing the educational offer. Specific contracts are then signed to put in place the individual training courses, awarding credits to the students-employees through a system of continuing education units. The second model is instead designed to provide timely and typically shortterm training, commissioned by the industrial partner with the university, which goes the way of bridging specific skill-gaps of its employees.

The benefits that derive from this structured and systematic approach are manifold:

- Consolidation of the university's vocation to interact with the local community, through the transfer of innovative knowledge to companies, fostering growth and producing positive effects on the economic-social system;

- Development of innovative teaching methods and strengthening the ability to respond to varying training needs;

- Integration of the university's educational offer, both generalized and "tailormade";

- Strengthening of university-industry interaction impacting on multiple areas. 


\subsection{Prison University Programmes}

Penitentiary university centres and prison colleges are for some universities a long tradition, for others a recent development, but in both cases reaffirming an HEI's aspiration to fully guarantee access to study as an inalienable right of the human being by providing higher education to prisoners. Since public universities have the duty to provide ways and means for this right to be potentially realized, a network of university penitentiary programmes has gradually developed throughout Italy over the last 20 years. The main objective is to expand quality higher education opportunities for incarcerated people and to foster the values of equity, civic engagement, independence of thought, and freedom of expression.

The University of Bologna Penitentiary Programme was one of the first to be established in Italy, and now there are 33 structures nationwide based on the same model, serving 74 penitentiaries. Based on our experience in this field, we think this will be an area of promising exchange for innovative practices to improve educational experiences within universities. A peculiar innovation concerns the involvement of students in cooperative work with their colleagues who attend courses from inside the prison. Innovative forms of "service learning", that is, a learning-by-doing experience with a social purpose can be an area for improving meaningful experiences and sharing within the university community and among universities. Another aspect that is worth noting in this context, in terms of "lessons learned" and innovative teaching, is certainly the need for teachers to develop new educational methods that, while being compatible with logistical constraints, are effective in adult training and oriented first of all towards individual empowerment, thanks not only to fostering creative learning, but also to improving employment opportunities once the learner has completed his or her prison sentence, and engaging in the intellectual challenge towards knowledge and culture, especially for those who are serving lengthy or life sentences.

\section{Concluding Remarks}

Innovation does not happen by simply applying innovative methods or tools, but requires high skills for investigating learning environments, assessing students' needs, fostering motivation and innovating daily in order to choose the methods that can provide the best answers to the current learning challenges in the most diverse contexts.

This article has presented, very briefly, some reflections arising from the system of innovation of university teaching and learning processes that the University of Bologna is experiencing. The model is based on research and, in particular, on assessment and evaluation in its formative sense, where data collection allows for a continuous monitoring of the teaching actions and the consequent redesign, according to the learning needs. The model is designed to promote interventions that have an impact on all actors and the actions that can improve teaching and learning processes, with the ultimate aim of increasing student skills and participation. 
Moreover, we have put forward views in three areas of typical national and local contexts (developments in school education, corporate education and penitentiary programmes) in which universities can play a fundamental role.

As we hope to have shown in all these very localized contexts the global commitment of HEIs towards educational values and improved access to tertiary education, the exchange of innovative practices and networking of universities within international projects, can significantly improve impact in local societies and create positive change at a global level. Universities are increasingly at the heart of innovation, not only in research and knowledge but also in education, training, teaching and learning for citizenship.

\section{References}

Aydin, O. T. (2014). Current developments and trends in higher education. Journal of Business Economics and Finance, 3(4).

Biggs. J., \& Tang. C. (2011). Teaching for quality learning at university. Maindenhead, UK: SRHE and Open University Press.

Crossan, B., Gallacher, J., Osborne, M. (2004). Researching Widening Access to Lifelong Learning: Issues and Approaches in International Research, Routledge, ISBN 978-0415322362

Organ, D. W. (1988). Organizational citizenship behavior: The good soldier syndrome. Lexington Books/DC Heath and Com.

Owens, M. T., Trujillo, G., Seidel, S. B., Harrison, C. D., Farrar, K. M., Benton, H. P. \& Byrd, D. T. (2018). Collectively improving our teaching: attempting biology department-wide professional development in scientific teaching. CBE—Life Sciences Education, 17(1), ar2.

Scriven, M. (2003). Evaluation theory and metatheory. In International handbook of educational evaluation (pp. 15-30). Springer, Dordrecht.

Trow, M. (2007). Reflections on the transition from elite to mass to universal access: Forms and phases of higher education in modern societies since WWII. In International handbook of higher education (pp. 243-280). Springer, Dordrecht.

Wheat, C. A., Sun, Y., Wedgworth, J. C., \& Hocutt, M. M. (2018). Active University Teaching and Engaged Student Learning: A Mixed Methods Approach. Journal of the Scholarship of Teaching and Learning, 18(4), 28-50.

Elena Luppi is Rector's Delegate for Innovation in Teaching and Learning at the University of Bologna and has been Rector's Delegate for Gender Equality in the same university. She is Associate Professor in Educational Research at the University of Bologna at the Department of Education Studies.

Lucia Balduzzi is professor at the Department of Education Studies "Giovanni Maria Bertin", and Director of First Cycle Degree of Educator in childhood Social Services at the University of Bologna.

Nicolò Cavina is Full Professor of Internal Combustion Engines and Hybrid Powertrains at the University of Bologna. In 2002 he founded, with three colleagues, Alma Automotive srl, a spinoff company of the University of Bologna. Since then, he has served as member of the board and vice-president. 
Carla Salvaterra is assistant professor at the Department of History and Cultures at the University of Bologna. She was Vice-Rector for International Relations at the University of Bologna from 2009 to 2015.

Open Access This chapter is licensed under the terms of the Creative Commons Attribution 4.0 International License (http://creativecommons.org/licenses/by/4.0/), which permits use, sharing, adaptation, distribution and reproduction in any medium or format, as long as you give appropriate credit to the original author(s) and the source, provide a link to the Creative Commons license and indicate if changes were made.

The images or other third party material in this chapter are included in the chapter's Creative Commons license, unless indicated otherwise in a credit line to the material. If material is not included in the chapter's Creative Commons license and your intended use is not permitted by statutory regulation or exceeds the permitted use, you will need to obtain permission directly from the copyright holder. 


\title{
Is the Pandemic Leading to a Paradigm Shift in Higher Education?
}

\author{
Carmen Z. Lamagna and Manzur H. Khan
}

\section{Introduction}

Indoor gatherings of many people are high-risk sites for the spread of COVID-19; this includes schools, colleges and university campuses. This evolving situation will not only be vastly disruptive but will also lead to a paradigm shift in higher education institutions (HEI).

It is not only a daunting challenge for institutions and students alike but even more so for those who are yet to be able to adapt to the change and adopt the 'new normal'. That in itself is an incredibly difficult task for those in developing countries, given their pre-existing conditions of socio-economic constraints, slow advancement of IT infrastructure, and the poor literacy and the general apathy towards technology. Amidst this global crisis, HEIs have been stripped to their fundamental functionalities and put to an eccentric acid test.

The pandemic is an unpredictable and unforeseen event with extreme consequences that is prompting us to rethink how we operate HEIs at every level. No doubt, this disruption has caused a major and likely unequal interruption in student learning and assessment in all educational institutions.

Students live in close community proximity, they take classes in enclosed classrooms, eat and spend time for classwork and activities in communal settings, and cheer on their teams and engage socially with the usual physical contact like shaking hands, high fives and hugs. With the shutdown, some HEIs have moved quickly to create a remote-teaching alternative.

The pandemic could be a catalyst for online education and other ed-tech tools, with physical distancing being the most effective tool for flattening the infection curve in

C. Z. Lamagna $(\bowtie) \cdot$ M. H. Khan

American International University-Bangladesh, Dhaka, Bangladesh

e-mail: clamagna@aiub.edu

M. H. Khan

e-mail:manzur@aiub.edu

(C) The Author(s) 2021 
the absence of test capacity, and of a vaccine. In this context, sending students home and finishing the academic year/semester online is an appropriate solution. Physical distancing is a temporary new norm, prompting HEIs to develop pedagogical and administrative practices to enable operations from a distance.

Unfortunately, in Bangladesh, most HEIs struggle to pursue activities from a distance as they are not built for remote work and may have little experience in carrying it out or managing it, unlike the tech sector.

There is also a financial backlash as the shift to online delivery and adding the requisite support proves to be costly. Students may not be in the classroom, but they are getting the same curriculum and courses by distance-a shift that requires tremendous efforts from teachers and administrative staff and supported by digital means.

Amidst all these factors, Bangladesh has been brought to a standstill by the pandemic. All the hustle-bustle of a densely populated country has come to a quiescent halt; the only sound to be heard is the whisper of anxiety. The struggle of HEIs to react to this sudden catastrophe has been magnified by uncertainties. According to a survey, out of 151 universities (public and private), 63 universities (2 public and 61 private) reportedly started online classes during this pandemic (Mohiuddin 2020). Despite this report, there are doubts about the success of remote teaching carried out by these universities, with the exception of a successful few, which are mostly private universities.

Classes have been shifted online, enabling students and teachers to conduct and undertake their teaching within the safety of their homes with a unified communication and collaboration platform that combines persistent workplace chat, video meetings, file storage, and application integration. With a dynamic interface and diverse features, students and faculties can now participate in a unique teachinglearning experience, that not only ensures the health and welfare of both, but also encourages the continuity of academic activities in these difficult times. Teachers are delivering lectures through video conferencing while students can communicate with them through video, audio or message boards for queries, and class participation.

Online platforms enable an interactive and versatile set-up as an alternate medium to conventional in-class teaching and learning environments, augmenting another layer of advanced digitized education in the modern world today. The initiative has safeguarded students from incurring the loss of the semester.

\section{Will Students Have Discovered Online Education as a Viable and More Affordable Alternative?}

The question is whether this temporary experience of distance learning represents a more affordable and viable alternative for students? Online education alleviates housing costs by letting students take advantage of their current living situation, thereby saving expenses each semester. Textbooks are another expensive reality of tradi- 
tional HE that online education alleviates. Thanks to the digital nature of eLearning, many of the course materials are included in the curriculum. The underlying technology that makes all this possible, the internet, laptops and smartphones is something which students can actually afford. Transportation costs can also be considerably reduced. Parking fees, tolls, fuel, and the wear-and-tear of everyday driving can add up significantly. When it comes to HE, not everything should be analyzed in terms of financial value and cost-saving; there is the more important aspect of whether students can receive a truly valuable education. The internet currently holds the most extensive collection of academic material; it has essentially become what Ptolemy envisioned when he founded the Ancient Library of Alexandria thousands of years ago. The most prestigious lecturers in the world have agreed to be digitally filmed and recorded for the benefit of the entire world; when students go online, it does not necessarily mean they are receiving less of an education with fewer costs.

\section{Unified Theory of Acceptance and Use of Technology (UTAUT2)}

Based on the Unified Theory of Acceptance and Use of Technology (UTAUT2) model (Venkatesh et al. 2012), a questionnaire was developed to determine student acceptance of online classes, and Entrepreneurial Potential Model (Moghavvemi et al. 2012) was integrated to study how the COVID-19 pandemic situation moderated their ultimate use behaviour.

This integrated model focused on the challenges of this paradigm shift-in terms of stakeholders' behavioural intention, availability of the online platform, prior experience, attitude towards usage (ease of use and usefulness) and most importantly the effect of coronavirus on the behavioural intention to ultimately adopting online classes. Additionally, the issues of social and cultural impact were also taken into consideration.

An online survey was conducted at the end of the spring 2019-20 semester. The survey population consisted of randomly chosen students from private universities which represents the major HEI student share.

\section{Results and Discussions}

The study hypotheses based on the research integrated framework (UTAUT2 and Entrepreneurial Potential Model) were analyzed and tested using Statistical Package for the Social Sciences (SPSS). The prime objective of the study was whether the constructs of the research framework influence the behavioural intention (Islam et al. 2013) of the students to adopt online classes and whether this pandemic ultimately 
moderated their decision. The following results were observed (organized as per the constructs used in the study):

- Performance Expectancy (PE): The extent of a student's belief that online classes will be advantageous. (Venkatesh et al. 2012). Performance expectancy has a significant effect on the behavioural intention of students to attend online classes.

- Effort Expectancy (EE): The ease of using technology during online classes (Jambulingam 2013). Effort expectancy has a significant effect on the behavioural intention of students to attend online classes.

- Social Influence (SI): The extent of influence of those people who are important to the students in accepting the online classes (Venkatesh et al. 2012). Social influence has a significant effect on the behavioural intention of students to attend online classes.

- Facilitating Conditions (FC): The assessment of organizational and technical infrastructure to support the online classes (Venkatesh et al. 2003). Facilitating conditions have a significant effect on the behavioural intention of students to attend online classes.

- Hedonic Motivation (HM): The enjoyable and fulfilling experience of using the technology of online classes (Brown and Venkatesh 2003). Hedonic motivation has a significant effect on the behavioural intention of students to attend online classes.

- Value (V): The assessment of the resources spent on, and perceived value gained from attending online classes (Venkatesh et al. 2003). Value has a significant effect on the behavioural intention of students to attend online classes.

- Precipitating Events (PEV): Effect of sudden change in environment caused by COVID-19 pandemic on the perception of student's decision to accept this radical change in their everyday campus life and completely shift to online classes. It captures the effect of external factors on student's intention to act and is considered as a moderator on the connection between their intention and behaviour to adopt online classes (Krueger et al. 2000). Schindehutte et al. (2000) categorized such moderating triggers into five key dimensions: opportunity- driven vs. threat-driven, market pull vs. technology push, internal vs. external (to organization), top-down vs. bottom-up, systematic or deliberate search vs. chance or opportunism (Schindehutte et al. 2000; Moghavvemi and Mohd Salleh 2011). In this study, the authors posit how environmental, external factors and unforeseen events can change the student's intention. Precipitating Event moderated the behavioural intention of students to attend online classes.

The data further suggested that hedonic motivation has the highest effect whereas facilitating condition has the lowest effect on the students' behavioural intention to adopt online learning. It was also found that precipitating events (sudden crisis caused by COVID-19) affected and moderated their behavioural intention to adopt online learning.

Some of the important and interesting demographic observations are-the highest percentage of the students $(37 \%)$ who responded to the survey came from families 
with a monthly income range of 400-600 USD; the highest percentage of respondents (40\%) uses the internet for 3-5 h daily. Even though the majority of students indicated their first preference of using the internet is for education, but most of them $(37 \%)$ spend $3-5 \mathrm{~h}$ on social media, very interestingly $48 \%$ (highest) female students are in this same bracket. In metropolitan cities, the majority of their internet connectivity is via broadband; but in rural areas, most of them depend on mobile data.

\section{Conclusion}

Agility, flexibility, and resiliency are not just fundamental skills for the 21st century students. They are imperative for the 21 st century educational institutionsespecially in an era when disruptive pathogens and natural calamities are predicted to become all the more common.

Whether or not COVID 19 quickly subsides, the life as we knew it had been permanently altered. Tumultuous times have a way of reordering reality and, in the process, opening doors to new opportunities and mindsets (Lamagna 2020).

In alignment with UTAUT2's postulates, it was found that student acceptance of online classes was influenced by its advantages, its user-friendly technologically, social influence on students, support from university and technology providers, its enjoyable experience, cost-benefit assessment. Most importantly, the sudden change in their lifestyle caused by COVID-19 pandemic significantly affected their decision to engage into online classes and hence, is one of the prominent attributes of this paradigm shift in the higher education institutions.

This study was based on students who successfully participated in an online class in a homogenous environment. Unfortunately, that might not have been the case for many universities of the country, even the ones who managed to take classes online during this coronavirus pandemic. Hence, it may not be possible to generalize the findings for the HEIs of Bangladesh. Even though the most widely popular research framework was used to assess the adoption of technology, the nature of the situation was also undoubtedly unprecedented. This fact also establishes the novelty of this article.

It certainly opens a whole new frontier for the nation's higher education policymakers, educators and administrators. Along with motivated HEI leaders, technology can transform the curriculum and better prepare students for the new world of work, helping students to unleash their potential and harness their talents. Digital transformation of institutions will provide equality, accessibility, and empowerment for all to what they can make and do. 


\section{References}

Brown, S. A., \& Venkatesh, V. (2003). Bringing Non-Adopters Along: The Challenge Facing the PC Industry. Communications of the ACM (46:4), 76-80.

Islam, M. Z., Kim, P. C. L., \& Hassan, I. (2013). Intention to use advanced mobile phone services (AMPS). Management Decision, 51(4), 824-838.

Jambulingam, M. (2013). Behavioral intention to adopt mobile technology among tertiary students. World Applied Sciences Journal, 22(9), 1262- 1271.

Krueger, N., Reilly, M.D. \& Carsurud, A.L. (2000). Competing models of entrepreneurial intention. Journal of Business Venturing, Vol. 15 Nos. 5/6, pp. 411-432.

Lamagna, C. Z. (2020). A PARADIGM SHIFT: The Case of AIUB. The Daily Star. Retrieved from: www.thedailystar.net/shout/news/paradigm-shift-the-case-aiub-1891033 (16.06.2020)

Moghavvemi, S. \& Mohd Salleh, N. A. (2011). Entrepreneurs Intention toward IT-Innovation Adoption in Malaysia. Journal of Communications of Global Information Technology (COGIT). (3) $78-86$.

Moghavvemi, S.; Mohd Salleh, N.A.; Zhao, W. \& Mattila, M.M. (2012). The Entrepreneur's Perception of Information Technology Adoption: An Empirical Analysis of the Role of Precipitating Events on Usage Behavior. Innovation: Management, Policy \& Practice. 14(3)' 220-235.

Mohiuddin Alamgir (2020). Online Classes Amid Shutdown: A distant reality, still for many, The Daily Star, Retrieved from: www.thedailystar.net/frontpage/news/online-classes-amidshutdown-distant-reality-still-many-1900918 (16.06.2020)

Schindehutte, M.; Morris, M.H. \& Kuratko, D.F. (2000). Triggering Events, Corporate Entrepreneurship and the Marketing Function. Journal of Marketing Theory and Practice. 8(2), 18-30.

Venkatesh, V., Thong, J.Y.L. \& Xu, X. (2012). Consumer acceptance and use of information technology: extending the unified theory of acceptance and use of technology. MIS Quarterly, 36(1), 157-178.

Venkatesh, V.; Morris, M.G.; Davis, G.B. \& Davis, F.D. (2003). User Acceptance of Information Technology: Toward a Unified View. MIS Quarterly. 27(3), 425-478.

Carmen Z. Lamagna is the Vice-Chancellor of the American International University-Bangladesh (AIUB). Under her guidance from its inception in 1995, the university has earned distinction as a source of quality education. The university grew from 70 to more than 11,000 students across the Faculties of Science and Technology, Engineering, Business Administration and Arts \& Social Sciences.

Manzur H. Khan is currently working as the Director of Student Affairs and also as the Associate Professor of Computer Science in the American International University-Bangladesh (AIUB). He has closely observed the growth of AIUB as an administrator and a faculty member over the last 17 years from around 3000 to 10000 students currently enrolled in AIUB. He is also a member of the Academic Council and the Syndicate of AIUB.

Open Access This chapter is licensed under the terms of the Creative Commons Attribution 4.0 International License (http://creativecommons.org/licenses/by/4.0/), which permits use, sharing, adaptation, distribution and reproduction in any medium or format, as long as you give appropriate credit to the original author(s) and the source, provide a link to the Creative Commons license and indicate if changes were made.

The images or other third party material in this chapter are included in the chapter's Creative Commons license, unless indicated otherwise in a credit line to the material. If material is not included in the chapter's Creative Commons license and your intended use is not permitted by statutory regulation or exceeds the permitted use, you will need to obtain permission directly from the copyright holder.

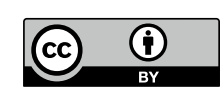




\title{
A Personal Reflection on the Key Challenge for Higher Education: Improving the Quality of University Instruction
}

\author{
David Dill
}

\section{Introduction}

Since the founding of the University of Bologna in 1088, the quality and societal impact of university-based research has steadily risen and is widely expected to continually improve in the future. But, while the effectiveness of university teaching over this same period has improved through the adoption of laboratory instruction, the seminar method, tutorials, and more valid and reliable means of assessing students, the qualitative enhancement and continuous development of instruction compared to research appears less certain. Why does this difference exist? I will argue the cause is to be found in the limitations of universities' traditional collegial culture and in the failure of recent national efforts to improve academic quality to effectively address academic norms and values.

Detailed sociological studies of leading universities (Paradeise and Thoenig 2015) have confirmed the influential role professional norms and a shared academic culture play in motivating and assuring the continual improvement of academic research. In these elite universities, communal norms generated and communicated through the social interactions occurring within and between academic subunits and among academic staff are the primary means of collegial control over the quality of university research. These interactions include many formal and informal internal conversations among academic staff as well as repeated self- and cross- evaluations, which strongly regulate the research behaviour of faculty members in differentiated academic units. But, while this academic culture is influential on the research behaviour of academic staff, the university context for instruction and student learning is more frequently reflective of "hollowed collegiality" (Massy et al. 1994). That is, while faculties meet collectively to discuss what particular courses should be offered and who should teach them, active collegial efforts to improve curricular structure, pedagogical alternatives,

D. Dill ( $\varangle)$

The University of North Carolina at Chapel Hill, NC, USA

e-mail: david_dill@unc.edu 
and student assessment are often avoided because of the commitment of individual staff members to the values of individual autonomy and academic freedom.

How do we create incentives for cooperative behaviour to improve student learning in an institution that is organised to encourage individual discretion in teaching and research? What is most needed, in my view, is the effective implementation within universities of a collegial process of science-based peer review of instruction and student assessment.

\section{A Framework for Effective Collegial Control}

Lazega (2005) has developed and empirically tested a sociological model of the social processes indispensable for effective professional behaviour in knowledge-based, collegial organisations. Lazega focuses on the mechanisms which make it possible for interconnected professionals to cooperate and engage in collective actions for the efficient production of complex work. These include "essential values and norms," "authority to know," "lateral control mechanisms," "graduated sanctions," and "precarious professional values". His model offers potentially valuable concepts for the design of effective means of continually improving and assuring instructional quality in collegially governed universities.

A first issue is whether university policies effectively define and communicate "essential values and norms," the professional values and ethical obligations indispensable to effective instruction and student assessment. Some national quality assurance agencies have attempted to address professional values and norms regarding teaching and student learning (Daniel 2016). At the institutional level, a leading example is the Principles of Teaching and Learning (Eberly center 2017) developed and communicated to its faculty by Carnegie Mellon University (CMU) in the US. These principles were derived from the rigorous and respected research on effective university course design conducted by the Open Learning Institute at CMU.

The second issue is whether a university possesses an effective "lateral control mechanism," a horizontal process for monitoring and enforcing the professional norms essential to achieving effective instruction and student learning. Because teaching and student assessment practices often vary across departments and degree programs within the same university, peer review of a programme's methods is more beneficial if it is truly cross-disciplinary, or as Lazega has suggested, horizontal. This is the most effective means for assuring academic standards within a university as well as for promoting the transfer of effective tools for improving instructional quality and student learning among academic programmes. A comparable collegial control mechanism, termed "academic quality work," has been designed and implemented in Hong Kong universities as well as in the US public university systems of Missouri and Tennessee (Massy et al. 2007).

A third issue is "who should be awarded the authority to know" in evaluating university instruction and student assessment? Many universities now rely on standardised student surveys of university teaching, but studies in both the US and France 
(Stark and Freishtat 2014; Boring et al. 2016) have discovered these surveys to be biased by discriminatory evaluations of women and minorities, positively associated with the award of inflated student grades, and negatively related to direct evidence of student learning. To better monitor and improve instruction, direct assessments of teaching behaviour appear more valid, such as systematic appraisals of instructional materials and classroom observations by academic peers, evaluation methods much less commonly employed within universities.

In addition, accumulating research in the field of "learning science" (Massy 2016) is now making significant contributions to our understanding of how effective learning at university level takes place and the means by which instruction and student assessment can be improved for maximum effectiveness. Potentially effective assessment of instructional quality and student assessment should therefore include rigorous evaluation of whether an entity - a university, an academic programme, or a course module within a university - reflects the principles and values emerging from research on learning science. But, unlike peer reviews in research, there appears to be no similar expectation in the US or other nations that external review teams assessing universities or internal university committees evaluating instructional quality are staffed by researchers with the scientific expertise to thoroughly evaluate the validity, reliability, and efficiency of methods of instruction, student marking and assessment.

A fourth issue is the use of "graduated sanctions" for controlling unprofessional or opportunistic academic behaviour. Direct command or the use of administrative hierarchy are inappropriate means for exercising control in universities because of the complexity of academic tasks and the need for individual autonomy. Consequently, effective collegial organisations apply personalised means of professional monitoring and sanctioning by individuals respected by their colleagues in order to maintain future relationships. Therefore, graduated sanctions for university teaching would start as already noted with a clear communication of normative expectations for instruction and student assessment, followed by discussion and counsel with relevant programmes on means of improving discovered flawed practices. Only after thoughtful and systematic efforts at personal guidance and education have been conducted might a negative action on an instructional quality decision be rendered.

The most effective example of this process I have observed was at a world class university in Hong Kong where an elected Faculty Senate Committee on Teaching and Learning Quality reviewed annual reports from each academic programme on its processes for assuring effective teaching, student learning, and marking standards. The committee included a number of the university's most distinguished professors. When the committee had questions about the rigour or effectiveness of a programme's processes, they met in person with the programme's collective faculty to discuss needed changes and improvements and then followed up systematically on proposed reforms. One may question the influence of such cross-disciplinary discussions of teaching and student learning, but research on collegial organisations (Ostrom and Walker 1997) emphasises that face to face communication is the most effective means of producing substantial increases in needed cooperation and coordination over time. Furthermore, field studies (Hage 1974) have confirmed that communication influential on individual professional behaviour is not vertical as from administrators, 
nor primarily written as in reports or procedural documents, nor episodic. Rather, communication helpful to professional practice is horizontal, with respected peers, largely verbal and face-to-face, continuous, and focused on the exchange of information about the means of improving core professional tasks.

Finally, contemporary collegial organisations grappling with changing technology also need collective means for renegotiating "precarious professional values" such as the concept of academic freedom. The implementation in universities of a "lateral control mechanism" such as a multi-disciplinary academic quality assurance committee has often been resisted by academics advocating individual autonomy regarding means of instruction and student marking. But, as contemporary universities have grappled with ethical lapses of academic staff in both research and instruction, it is increasingly apparent the independence of thought necessary to advance knowledge and properly educate students is linked to professional responsibilities, "which include the obligation to adhere to professional norms and to discipline those who fail to do so" (Bowen and Tobin 2015, 201).

How feasible would it be to induce university faculties to adopt the needed core values and supporting collegial mechanisms to effectively evaluate and continually improve instruction and student assessment in universities? Ironically, over the last several decades, as a number of countries have implemented academic quality assurance policies with mixed success, a parallel effort to assure ethical practices in university research on human subjects in the US and a number of developed countries has proved much more influential. What distinguishes the US approach to university quality assurance from its approach to university research on human subjects is the latter policy has adopted a design more reflective of Lazega's principles for effective collegial governance (Dill 2020). For example, the US policy began by articulating the essential professional values for relevant research conduct and required that each university develop means for effectively communicating these ethical obligations to all relevant staff. The policy also required each university to implement a peer-based mechanism for the review of all relevant proposals for human subjects research and designated the type of scientific expertise each review team would need to include in its review. Finally, applications for federally-funded proposals for academic research were contingent on effective university implementation and continuous improvement of these professional values and controls.

\section{Conclusion}

A major challenge for higher education will be identifying how the academic community itself can act to restore and develop the internal web of collegial accountability whereby the quality of instruction, student learning, and assessment can be continually assured and improved. Responsibility for the effectiveness of teaching and learning must remain where the power exists to control or change academic practices-with the faculty of an institution. Seeking means to better understand 
and to strengthen the processes within universities whilst ensuring that the faculty collectively and within academic units can successfully exercise its responsibility for instructional quality assurance and improvement appears to be a critical goal.

\section{References}

Boring, A., Ottoboni, K., \& Stark, P. B. (2016). Teaching evaluations (mostly) do not measure teaching effectiveness. Science Open. https://doi.org/10.14293/S2199-1006.1.SOR-EDU.AETBZC. v1.

Bowen, W. G., \& Tobin, E. M. (2015). Locus of authority: The evolution of faculty roles in the governance of higher education. Princeton: Princeton University Press.

Eberly Center for Teaching Excellence and Educational Innovation (2017). Principles of teaching and learning. Retrieved from: www.cmu.edu/teaching/principles/ (9.07.2020)

Daniel, J. (2016). Advisory statement for effective international practice: Combatting corruption and enhancing integrity: A contemporary challenge for the quality and credibility of higher education. Council for Higher Education Accreditation, Retrieved from: https://files.eric.ed.gov/ fulltext/ED603202.pdf. (9.07.2020)

Dill, D. D. (2020). Enhancing academic quality and collegial control: Insights from US policy on the ethical conduct of human subjects' research. Higher Education Policy, 33(1), 45-64.

Hage, J. (1974). Communication and organizational control: Cybernetics in health and welfare settings. New York: John Wiley.

Lazega E. (2005). The theory of collegiality and its relevance for understanding professions and knowledge intensive organizations. In T. Klatetzki \& V. Tacke (Eds.), Organisation und Profession (pp. 221-251). Wiesbaden: Verlag für Sozialwissenschaften. pp. 221-251.

Massy, W. F. (2016). Reengineering the university. Baltimore: Johns Hopkins University Press.

Massy, W. F., Graham, S. W., \& Short, P. M. (2007). Academic quality work: A handbook for improvement. San Francisco: Jossey-Bass.

Massy, W. F., Wilger, A. K., \& Colbeck, C. (1994). Overcoming hollowed collegiality. Change, 26(4): 10-20.

Ostrom, E. \& Walker, J. (1997). Neither markets nor states: Linking transformation processes in collective action arenas. In D. C. Mueller (Ed.), Perspectives on public choice: A handbook. Cambridge: Cambridge University Press.

Paradeise, C. \& Thoenig, J.-C. (2015) In search of academic quality. New York: Palgrave Macmillan. Stark, P. B. \& Freishtat, R. (2014). An evaluation of course valuations. Science Open.; 1.SOREDU.AOFRQA.v1, https://doi.org/10.14293/S2199-1006.

David Dill is professor emeritus of Public Policy at The University of North Carolina-Chapel Hill. He has published extensively on higher education policy, research policy, and the governance and management of higher education. His work was recognized with election as a Life Fellow of the Society for Research into Higher Education (SRHE) in the UK. With the support of the Ford Foundation, David Dill created the Research Program on Public Policy for Academic Quality, a cross-national study of quality assurance policies in higher education. 
Open Access This chapter is licensed under the terms of the Creative Commons Attribution 4.0 International License (http://creativecommons.org/licenses/by/4.0/), which permits use, sharing, adaptation, distribution and reproduction in any medium or format, as long as you give appropriate credit to the original author(s) and the source, provide a link to the Creative Commons license and indicate if changes were made.

The images or other third party material in this chapter are included in the chapter's Creative Commons license, unless indicated otherwise in a credit line to the material. If material is not included in the chapter's Creative Commons license and your intended use is not permitted by statutory regulation or exceeds the permitted use, you will need to obtain permission directly from the copyright holder. 


\title{
University Leadership: Slippage from Abiding to Peremptory Roles?
}

\author{
Daniel C. Levy
}

\section{The Issue}

"Our university leadership strongly encourages you to attend today's session on . This topic is of the utmost importance to us all." Such urging populates the Inboxes of faculty, workers, and students at U.S. universities. They come from presidents, vice-presidents, deans, directors of diversity and inclusion offices, coordinators of training and development, and subordinates in the enlarging bureaucracy mobilized to support this leadership. Seminars train employees with "best practices" to improve their "cultural competencies" and correct their deficiencies. Meanwhile, senior administration's moral purview extends to pronouncements on the political controversies of the day. Taken together, these internal and external roles mark huge scope for university leadership. Since when? Who signed such a contract when hired as faculty or paying tuition?

Deep breath and question: What does University Leadership mean? The matterof-fact invocation of "leadership" in U.S. universities, often self-referentially, belies a murky reality: there is no simple, clear, credible answer, let alone consensus, on who leads a university, who should lead it, in what ways, with what prerogatives, and by what right. No international consensus on university leadership, none even in the U.S. alone.

At their best, universities have historically instructed students and sought and codified knowledge through free inquiry. The addition of "service to society" fundamentally contemplated faculty and student activity, leaving knowledge development and dissemination at the core. Today, the massive growth of U.S. university bureau-

D. C. Levy (ه)

University at Albany, State University of New York, Albany, NY, USA

e-mail: dlevy@albany.edu 
cracy has overreached into venerable faculty affairs (Ginsberg 2011) and added for itself roles, new and inappropriate to the university, even indoctrinating on hot button issues.

It helps to distinguish internal university leadership from university attempts to lead society. On each front, there are abiding leadership roles. Internally, a university with any autonomy needs some structured leadership authority. Beyond the university, any university leadership should be through persuasion that is knowledgebased. What then is problematic? Internally, it is licentious efforts to elevate the moral rectitude of the university's citizens, habitually leverage control over internal communications, or allocate resources to promote positions on issues of ongoing social controversy. Beyond the university, it is senior administrators' presumptuous speech in the name of the institution.

The essay develops in three parts. The first explores university leadership's legitimate range. It considers abiding (venerable, enduring, even sanctified) notions of administrative internal leadership institution and similarly long-established space for university actors, especially faculty and students, attempting to lead on matters beyond the institution. The essay's second part turns to peremptory (overreaching, presumptuous, even hectoring) senior administration leadership on both fronts and, as that substantive focus yields a U.S. focus, the essay's third part explores internationally for parallel overreach.

Notwithstanding our international interest, several considerations warrant special attention to the U.S.: its universities' overall pre-eminence, unmatched influence on other nations' universities, consequently unmatched international interest in the U.S. university, and the long-distinctive tradition of strong university administration making institutional policy. A prosaic additional reason is the author's own university work-life experience. More enticing is a sense that the U.S. may be rather exceptional for its peremptory university leadership. If so, perhaps that lends indirect hope for some relief.

Finally, the essay lacks space for three important related matters. One is why we exclude private universities except in the U.S. (Levy 2019). Second, our focus on problem identification and analysis extends only limitedly to alleviation (which, realistically, is itself limited). Third, ample space would have allowed elaboration of how (a) criticism of administration's means says nothing about their goals; (b) ambiguity surrounds when to cede principled ground for pragmatic or compassionate reasons, (c) institutional declarations on controversial policy have precedent. Were senior administration mostly about replacing abiding with peremptory roles, U.S. universities could not remain their society's and the world's leaders in free inquiry.

\section{Abiding University Leadership Roles}

Abiding university leadership roles inside the university have been fundamentally different historically between the U.S. and most of the world. Abiding university leadership beyond the university has been much more similar. 
Classically contrasted to a European or Continental model, the U.S. model entrusts much greater authority and power to autonomous universities, creating a "thick middle" that requires centralized administration capable of decision-making rather than just complying with State rules from "above" or wishes of component units and faculty from "below" (Clark 1983). The thick middle is meant to allow for efficient autonomy and competition with other institutions largely through accountability to their own nourishers (students, governments, alumni, employers, etc.). Yet, the U.S. model emphatically does not contemplate university administration as supreme leader on the most vital university work. With trustee boards above, CEOs (presidents) and their cabinets and staffs exist within a pluralist structure ideally distributing power according to expertise and rights; thus, faculty make most curriculum and research decisions, students choose much for themselves (institutions, majors, courses), governments pursue their own or the public interest, etc. (Epstein 1974). Superior administrative expertise and authority is centred on managerial and financial matters, not conveying like authority over other university actors on academics-or morals.

In Europe and elsewhere, lack of a strong public university middle means much less university administration authority and power to run the university. With so much policy made by the State and faculty units, it is difficult to contemplate counterparts to legendary U.S. university presidents making distinctive internal reforms that then led by example and competition to reform at other universities. Correspondingly, we see differences between the U.S. and much of the world in how universities have lost power. Loss of power to the market is worldwide, though the market has always been important in the U.S., whereas net loss of power to the government is clearer and much greater in the U.S. than elsewhere, given the U.S. weak State history. Regardless of who the rising power has been, a key difference is that in the U.S. lost university power has meant diminished autonomy and institutional power (even as administration takes new powers).

As we turn to abiding university authority externally, however, historical leadership has been much more similar between the U.S. and Europe and most of the world that allows academic freedom - whether with strong university autonomy and internal administration or without them. The IAU some 70 years ago enshrined the "pursuit of knowledge for its own sake" as the university's prime purpose internationally. It then proceeded to sanctify service to society as well. Nearly a century ago, the Spanish philosopher Ortega y Gasset's (1930) classic mission of transmission of culture, science, research, and training also envisioned societal relevance. No stereotypical Ivory Tower.

But, crucially, such university leadership in society has generally been the faculty's domain, notably "through teaching and research," in the IAU's words. There is no legitimate corollary in administrative authority. And globally, far more than in the U.S., a university pretence to leadership on national political, social, and moral dimensions has also involved students. If Latin America is most illustrative, Africa, Asia, and Europe also provide powerful examples, apart from Communist, military, or other stifling regimes. National political parties have had prominent student wings, and where national universities were expected to help lead in consolidating and 
advancing new nations, it was through their students and faculty. Granted, this elitist conceit generally lost steam as higher education grew and diversified while other parts of civil society blossomed. Regardless, and worldwide, whatever was considered legitimate university leadership in guiding society was not the province of university administration.

\section{Peremptory University Leadership}

Some conservative critics argue that, if the university has any leadership role in society, that role rightfully belongs to faculty. Faculty members, however, have no right to speak in their university's name. Could the university then be the exceptional institution in a free society with no capacity to speak for its institutional interests? It seems especially implausible to reconcile that view with the venerable role of U.S. administration in internal leadership.

This, however, leads to a slippery slope. One reasonable but vague guideline is that senior leadership can (even should) speak out on matters central to the institution's functioning. But what is central or so clearly central that it confers a right to propound? $A n$ institutional interest should be insufficient justification. Yet, it too often becomes de facto sufficient where moral conviction or felt pressure from internal and external groups is strong. Administrative imperialism can be bold and imaginative. An issue of guns on campus, for instance, becomes license to address gun-control policy generally.

If administration feels compelled to speak on controversial societal issues, it should limit itself to whatever aspect most affects the university and where it can demonstrate special expertise. That generally leaves inadequate justification for an institutional position on environmental or foreign policy. Crucially, senior administration should make clear that it does not speak for the whole university community even where it speaks for the institution. The university's true voice is not a unitary "all" but rather the range of expressed individual opinions, expert and non-expertand surely the most hallowed right to speak freely on external issues belongs to students and, above all, faculty. Senior administration has no legitimate authority to sum up or override those views. In the same vein, and just as senior administration must beware the slippery slope of what social issues to speak on, so it must resist the profoundly anti-university tendency to declare debatable questions resolved. Free inquiry, not sanctification of any "right" idea or solution to problems, is a university's consecrated leadership calling (Cabranes 2019).

The threat to free inquiry is even greater inside the university, where it combines with institutional authority and resources, than it is beyond the university. Cultural training sessions for incoming and current students, staff, and professors exceed legitimate bounds when they identify the right way to think and act on controversial matters. Increased mandatory training (sometimes stemming from government coercion) is often stuffed with infantilizing questions whose true rather than "correct" answers are debatable, whereas questionnaires leave no room for No Opinion, Other, 
or completing surveys if left blank. Less blatantly intrusive, the "we hope to see you at the seminar" is inappropriately menacing. One wonders how many senior administrators appreciate the anxiety felt by many students and their own staff subordinates who resent the coercion, elite conceit, or both. Can objective participant observers be blind to political litmus tests in some faculty hiring and even student admissions, and more baldly in invitations and awards for external individuals? And for internal appointments to . . . senior administration? Imagine a presidential candidate's response of no, I don't believe the president should have a public position on national environmental policy. Meanwhile, infatuation with "engagement" provides new justification to proselytize and materially incentivize, although engagement administrators seem unable to identify what engagement adds to the abiding service role. Of course, like equity, inclusion, and diversity, engagement commonly translates to subjective notions of social justice, perilously promoted as objective notions and fed with material incentives (and disincentives) furthering an ostensible virtuous cycle between internal and external.

\section{And Internationally?}

The peremptory administration this essay bemoans appears unprecedented in U.S. history (Geiger 2019). We need research to determine how exceptional it is internationally. Fortunately, the identified overreach appears limited internationallyfortunately for the world, if all the more damningly for the U.S. Yet, our international sense is only tentative, from background knowledge and numerous discussions with leading scholars of higher education in societies with ample freedom. It is a terrible irony that the U.S. leaps to the forefront on political abuse of university leadership, blatantly contradicting the U.S. model. How often leading U.S. universities advised aspiring emulator professors and administrators worldwide to keep administration "above" the political fray (Levy 2005) and pointed to U.S. university leadership's comparative protection of their institutions from external and internal coercion. And how often U.S. universities hailed the virtues of professional administration, not only apolitical but also managerially skilled, responsible, and accountable to society, market, and government. This rosy view probably made, and makes sense generally ... as long as the administration acts as advertised_even if that sometimes requires board intervention. But when administration turns to peremptory political leadership while trustees remain irresponsibly idle, all bets are off.

Additionally, while praising their own model, U.S. experts bewailed other countries" "co-governed" supreme councils of faculty, students, and even workers, for surely these administrative amateurs are prone to non-pragmatic, inward-looking, and irresponsible policy. Yet, however large the continuing problems resulting from cogovernment or weak institutional administration are, they apparently do not include the abuses rampant today in the U.S. While students and faculty from India to Chile sustain abiding activism to lead society, more than their U.S. counterparts (unless 2020 is the U.S. new normal), even co-governing councils generally exercise restraint 
in issuing declarations in the university's name on external political matters. When European universities issue statements on the environment, they are generally bland, and on an issue less contentious than in the U.S.; recently increased statements on immigration and race likewise tend to be bland. Significantly, even where council control in Argentina, Brazil, and elsewhere is markedly leftist, efforts to make less progressive members think and act correctly appear rare, albeit more frequent in "soft" fields of study.

We have only informed speculation to explain such restraint. There are hard-nosed power realities. University central administration remains far from strong or "thick." This is true in Europe despite decades of some shift from State standardization to university autonomy. Decades into worldwide government-forced partial privatization, most public universities depend heavily on government budgets, even where there is public tuition, as in Japan and South Korea. Dependence suggests prudence in criticism, including of parties that might ascend to power. South Korea further illustrates how national universities largely execute government directives. In Australia and New Zealand, few look to university administration to be public leaders; senior administration accepts that public policy authority lies beyond and sticks to council-backed sporadic virtue-signalling. Ethical training is on matters like business ethics, mandated seminars on matters like safety rules. Generally, no thick middle, no great potential for strong peremptory university leadership. And if co-government develops urges to progressive activity and training, it has limited resources to fund such.

But apparently, more than raw power and money restrain peremptory action. One sees in Brazil, for instance, that co-government composed mostly of individuals primarily engaged in teaching and learning comes with an academic ethos generally alien to a university presuming to speak with one voice, let alone for university officialdom to indoctrinate. In much of Europe, the academic ethos likely combines with a political culture of coalition, at least compared to contemporary U.S. hyperpolarization.

How ironic if the U.S. model of powerful professional management is what allows leadership to run wildly into peremptory leadership. How ironic if the U.S.'s robust institutional autonomy and resources help victimize academic freedom. Ironic too that for all the university's autonomy, the vast majority of its putative leadership says mostly the same things!

One can debate university leadership's responsibility for ground ceded to government, markets, or social demands, but it is always inappropriate when the reach to serve society undermines the primary mission and obligation of free inquiry. It is dubious that anyone in the name of the institution characterize policy beyond as "irrational," "unjust" or "counter to our core values." It is likewise dubious when leadership unequivocally voices "their university's strong support for x," x not being free inquiry, and leadership should never be party to, let alone supervise, internal indoctrination. The question-mark in this essay's title is warranted by international reality, for the sad answer in the U.S. must be that indeed there is ample slippage from abiding to peremptory university leadership. 
The author gratefully acknowledges comments especially from Malcolm Abbott, Philip Altbach, Tara Cope, Roger Geiger, Morris Levy, David Post, Pedro Teixeira, Sandra Vergari, and Ben Wildavsky.

\section{References}

Cabranes, J. (2019). The present danger at our leading universities: what is to be done? Remarks accepting The Philip Merrill Award for Outstanding Contributions to Liberal Arts Education. The American Council of Trustees and Alumni (ACTA).

Clark, B. (1983). The higher education system: academic organization in cross-national perspective. Berkeley, CA: University of California Press.

Epstein, L. D. (1974). Governing the university: the campus and the public interest. San Francisco, California: Jossey-Bass.

Geiger, R. L. (2019). American higher education since World War II: a history. Princeton: Princeton University Press.

Ginsberg, B. (2011). Fall of the faculty: the rise of the all-administrative university and why it matters. Oxford University Press.

Levy, D. (2005). To export progress: the golden age of university assistance in the Americas. Bloomington, IN: Indiana University Press.

Levy, D. (2019). Juxtaposing global and U.S. private higher education: what is to be learned? In International perspectives in higher education, (pp. 49-66). Cambridge MA: Harvard Education Press.

Ortega y Gasset, J. (1930). Misión de la universidad. Madrid: Revista de Occidente.

Daniel C. Levy, University at Albany, is Distinguished Professor, the State University of New York's highest rank. He directs the internationally renowned PROPHE (Program for Research on Private Higher Education). Levy has authored ten books, edited six, and published abundant scholarly articles on state-societal issues, emphases including higher education and Latin America. He has lectured at most leading U.S. universities, lectured and researched in six continents, and been grantee and/or consultant with international foundations, development banks, and academic agencies.

Open Access This chapter is licensed under the terms of the Creative Commons Attribution 4.0 International License (http://creativecommons.org/licenses/by/4.0/), which permits use, sharing, adaptation, distribution and reproduction in any medium or format, as long as you give appropriate credit to the original author(s) and the source, provide a link to the Creative Commons license and indicate if changes were made.

The images or other third party material in this chapter are included in the chapter's Creative Commons license, unless indicated otherwise in a credit line to the material. If material is not included in the chapter's Creative Commons license and your intended use is not permitted by statutory regulation or exceeds the permitted use, you will need to obtain permission directly from the copyright holder.

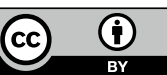




\title{
The Dawn for a New Era for Higher Education
}

\author{
Mirta Martin and Jacob Abrams
}

Colleges and universities cannot immunize themselves against COVID-19 by simply shutting their gates and throwing away the key, nor can they claim ignorance of the broader social and economic storms impacting their students. Rather, institutions of higher education must embrace their core mission to educate and improve the lives of their students. In a Fall 1821 letter from the Rector of the University of Virginia, Thomas Jefferson, wrote, "we fondly hope that the instruction which may flow from this institution...by advancing the minds of our youth with the growing science... and elevating the views of our citizens generally to the practice of the social duties, and the functions of self-government, may ensure to our country the reputation, the safety and prosperity, and all the other blessings which...result from the cultivation and improvement of the general mind." At the turn of the twentieth century, education reformer John Dewey (Dewey 1900) similarly contends that "All that society has accomplished for itself is put, through the agency of the school, at the disposal of its future members. All its better thoughts of itself it hopes to realize through the new possibilities thus opened to its future self'. The precedents of history thus demand that higher education not shrink from the needs of the times, but rise to meet them.

The times at present are indeed unprecedented. The current pandemic has claimed over half a million lives and infected over 24 million people around the world (Hopkins 2020). In the United States alone, the Centers for Disease Control now estimates that between 196,000 and 207,000 people will be lost to the virus by September 19th, 2020 (CDC 2020). A Harvard study suggested that waves of social

M. Martin ( $\varangle)$. J. Abrams

Fairmont State University, Fairmont, WV, USA

e-mail: Mirta.Martin@fairmontstate.edu

J. Abrams

e-mail: Jacob.Abrams@ fairmontstate.edu 
distancing may be necessary through at least 2022 in order to combat the virus's spread and lessen its toll on the human population (HSPH 2020). At the same time, economies worldwide have been ravaged. A Reuters poll found that by March 27, 2020, one in four adults had been laid off or furloughed in the United States, and the World Bank more recently concluded that the globe will plunge into a Recession not seen since World War II (Kahn 2020; Worldbank 2020). In other words, lives and livelihoods will continue to be lost as a result of the pandemic for the foreseeable future.

Similar patterns are emerging at the local level. The University of Texas COVID19 Modeling Consortium (2020) projects that West Virginia will experience anywhere from 5 to 20 deaths per day by mid-August. As of this writing, West Virginia has one of the highest rates of transmission of COVID-19 in the country (Silverman 2020; Krieger 2020). Though there are signs of improvement in economic conditions, the June unemployment rate in West Virginia was double (10\%) than it was in January of 2020 (5\%); from March to April, over half of all leisure and hospitality sector jobs were lost, and less than half of those jobs have returned to the State thus far (US Bureau of Labor Statistics 2020).

Additional complications present themselves: West Virginia's population, including its younger citizens, are particularly vulnerable to experiencing severe, even fatal, outcomes from the virus. This is particularly notable, as the United States consistently ranks among the wealthiest countries with highest rates of obesity, diabetes, heart disease, chronic lung disease, and disability in general (Woolf and Aron 2013). A study reported by US News and World Report in May ranked West Virginia as the state with a population most vulnerable to COVID-19, with two out of five people in 52 of West Virginia's 55 counties having one or more risk factors (Davis 2020). West Virginia has the highest prevalence of obesity, cardiovascular disease, chronic obstructive pulmonary disease (COPD), and arthritis in the country, the second highest rate of diabetes, and the second highest percent of adults who smoke cigarettes or use smokeless tobacco frequently (WV DHHR 2020). In 2017 alone, West Virginia ranked 8th in the United States for deaths from influenza and pneumonia, with mortalities almost $4 \%$ points above the national influenza and pneumonia fatality rate that year (WV DHHR 2021). Among high school students, the national High School Youth Risk Behavior Survey reveals that almost 1 out of 4 adolescents report having asthma, 1 out of 5 students indicate they are obese, and more than 1 out of 3 students note having three or more health conditions OPA 2019). As concerning, one fifth of adults and one fourth of children live in poverty throughout West Virginia (Talk Poverty 2018) In fact, in 2018, the State again ranked first in the United States for the number of people age 18-24 who are neither employed nor are pursuing an educational credential, and last in the country for the percent of its population ( $a$ little over 33\%) who have a college degree (Talk Poverty 2018).

What does this mean for higher education in West Virginia and beyond? It means that universities nationwide must endeavour to address the barriers to their students' safety and wellbeing, and in doing so, they may paradoxically ameliorate the enrolment trends already negatively impacting the outlook of higher education for decades. According to surveys from Student Experience at a Research University Consortium, 
only $1 \%$ of respondents throughout the United States indicated that they planned not to return to a research university to continue their education as a result of COVID-19, suggesting that enrolment declines for returning students at larger institutions may not be severe (Jaschik 2020). Indeed, an analysis from the National Student Clearinghouse of actual nationwide enrolment data from Spring 2020 semester found that enrolment patterns at institutions across the United States were consistent with those seen prior to the pandemic, and universities in States hardest hit by the pandemic over the Summer, such as Georgia and Texas, actually reported record-high summer course enrolments (NSC Blog 2020; Zalaznick 2020; Johnson 2020). With respect to the current Fall semester, another nationwide survey conducted by McKinsey and Co. found that total full-time enrolment for baccalaureate degree-seeking students entering higher education straight out of high school will probably remain relatively unchanged from previous years during the Fall, but would likely experience overall enrolment shifts to the benefit of many public institutions; within the group of students surveyed, 1 out of 5 had changed their first choice school to an institution closer to their home with cheaper tuition (Hayoung et al. 2020).

The increased sensitivity to cost, and the comfort-indeed the mandate in some areas - of staying close to home will affect enrolment patterns nationwide. Already, students appear to be resisting high or downright exorbitant tuition prices at private institutions, regardless of the prestige or brand-name recognition of the institution. Many students at institutions such as Rutgers, Harvard, the University of Chicago, Chapman University, etc. have already expressed concerns, even to the point of filing lawsuits, at paying large non-refundable tuition prices for a college education delivered through a "glorified Skype" session (Hubler 2020; Hendrickson 2020). In fact, Harvard's yield rate declined $3 \%$ by late June of 2020, and over one out of five freshmen, rather than experience Harvard virtually, requested a deferral of the Fall admission until the Spring or Fall 2021 (Theharvardgazette 2020; Bikales and Chen 2020). Indeed, some private colleges are reporting up to $20 \%$ declines in enrolment as of the beginning of the Fall 2020 semester, while many public institutions in June of 2020 were reporting relatively stable, if not augmented, anticipated enrolment for Fall 2020 (Jaschik 2020).

Prior to the pandemic, enrolment trends in West Virginia were already an evergrowing concern for many, as the college-going rate stagnated, the number of adults returning to seek a college-degree profoundly weakened. The number of high school seniors subsequently enrolling at a college or university immediately following graduation was $10 \%$ points less in 2018 than in 2009, while students older than 25 left higher education by almost a third over the past 4 years (Treadway 2019). Further, 200,000 people are expected to move out of the State by 2040, and NCES anticipates the number of 2027 high school graduates from West Virginia, Ohio, and Pennsylvania to decline by at least 5\% relative to 2013 (Hussar and Bailey 2019). ${ }^{1}$

\footnotetext{
${ }^{1}$ For an interactive map provided by the Demographics Research Group, Weldon Cooper Center for Public Service, University of Virginia, please see: https://demographics.coopercenter.org/unitedstates-interactive-map (27.08.2020).
} 
However, at least some of this decline may be attributable to the improvement in economic conditions experienced across and around the State prior to COVID19. A paper from the National Bureau of Economic Research (NBER) suggests that as much as $30 \%$ of nationwide college enrolment declines experienced prior to the Great Recession are attributable to the growth in wealth experienced during the housing boom, as many potential students concluded that the opportunity costs of not engaging in an expanding job market at the time were too great (Charles et al. 2015). Similarly, a study from the Dean of the Harvard Graduate School of Education suggests that college enrolment grew greatly, particularly among twoyear degree programs, during periods of high unemployment at the height of the Great Recession (Long 2014).

As such, the current economic conditions in the State and across the country may actually induce enrolment from students who would have otherwise not done so, particularly given the necessary expansion of distance learning options as a result of COVID-19. The number of students taking at least 1 online class in the United States increased from 1 in 10 in 1999 to almost 1 in 3 by 2015, to the detriment of many public institutions which did not adapt this option into their educational delivery methods (Hobson and Puruhito 2018). While public in-state student enrolment declined 5\% from 2010 to 2018 , enrolment in online-only degree programs at private for-profit universities - institutions that charged almost three times as much in 2019-2020 tuition as their public in-state counterparts-increased by $7 \%$ for undergraduates and a whopping $28 \%$ for graduate students from 2012 to 2016 (College Board 2019; NCES 2020; Howarth and Stifler 2018). COVID-19 therefore offers public institutions a reprieve to enrol both students from regions outside of the State and those within West Virginia who would have otherwise pursued online learning in the for-profit sector, thus expanding the types of students institutions can reach, such as those with young children or those older adults who left higher education previously to engage in occupations that precluded enrolment on a full-time schedule. Moreover, online, virtual, hybrid, and distance forms of learning have the advantage of limiting the density and physical contact of students on-campus, thereby reducing the risk of viral spread, while allowing the institution to service students who may rely on housing and dining on-campus to compensate for food and housing insecurity at their homes (Hamidi et al. 2020).

However, there is a price to pay for such educational delivery. A late March of 2020 poll of students conducted by EDUCAUSE revealed that students' strong, negative experiences related primarily to the accessibility of the physical tools required in order for distance learning to take place, such as wi-fi, and the availability of resources and services that were previously more easily accessible to them outside of the physical classroom, such as mental health counselling, career services, health clinics, etc. Indeed, a report from New America in April of 2020 found that West Virginians on average pay higher costs for slower connectivity than most other areas of the country, and a US News and World Report metric similarly concluded in 2017 that West Virginia had the second-worst infrastructure for internet availability in the country (Park 2020). While many institutions may be able to successfully address the availability of services like counselling in online mediums throughout the coming 
semesters, the precarious socioeconomic status of many students makes it difficult for institutions already struggling to keep costs contained to provide quality services to those students absent outside financial support.

As such, though a possibility for improvements in enrolment through the type of educational delivery methods offered to students is heightened, higher education in West Virginia faces a cost calamity as a result of COVID-19. Moody's already projects the State to experience anywhere from the 13th-5th worst budget shortfall in the country due to COVID-19 (Kablerstaff 2020). Even prior to the pandemic, a report from the National Conference of State Legislatures showed that though state appropriations to higher education improved by $1.6 \%$ across all 50 States from 2014 to 2018, West Virginia experienced a massive decline-20.6\% - the largest experienced in the country during the same time period (Seltzer 2018). Moreover, in 2019, West Virginia had a 3-year average student loan default rate of 17\%, meaning that even if augmented costs are absorbed by students via increases in tuition and fees, there is a likelihood that those expenses would be passed to loans that many students (possibly 1 of 5) would not repay, and that such action would hinder enrolment, as studies have shown that up to 2 out of every 5 high school students are loanaverse (Federal Student Aid 2020; Boatman et al. 2017). Without infusion of revenue from other sources, it is possible that West Virginia's institutions will face financial consequences up to and including closure in the future.

Nationally, things are not much better. By late July, over 15,000 employees at universities and colleges across the country were no longer employed by those institutions, with over 220 schools laying off staff and faculty as a result of profoundly severe budget shortfalls (Sultan 2020). Indeed, a preliminary analysis from the Brookings Institute found that financial risks posed by the pandemic were practically universal, with Baccalaureate and Master's degree-granting institutions facing more risks than those faced by doctoral and Historically Black Colleges and Universities (HBCUs) for the upcoming academic year (Startz 2020). Moreover, colleges and universities have also begun to cut degree programs, with one university removing 39 programs from their rosters (Dickler 2020). Indeed, the 2020 Inside Higher Ed's Survey of College and University Business Officers (CBOs) found that over half of all respondents indicated that they were not confident in their institution's financial stability over the next five years, with CBOs at private institutions expressing less confidence that those over public colleges and universities (Lederman 2020). In the face of COVID19 , it is not necessarily declining enrolment which threatens survival through the pandemic, but the financial costs of adapting to it.

West Virginia's trends can be generalized to the trends currently at play, not only in the United States, but worldwide. We have seen institutions close their doors due to declining enrolments and poor financial conditions. We find ourselves in the darkest, longest night for higher education. It is anticipated that smaller colleges will continue to fail—accelerated by the pandemic (McLaughlin 2020). But, higher education will awaken and survive. The opportunities presented by this pandemic, to reinvigorate the local and community-based missions of higher education and to transform the educational experience to meet students' needs regardless of where they are, are 
paramount. As such, from the scourge of this pandemic will arise new methods of content delivery and new disciplines which will guide the next generation of leaders to ushering forth a dawn for a new era in higher education.

\section{References}

Bikales, J., \& Chen, K. (2020). Over 20 Percent of Harvard Undergrads Do not Intend to Enroll in Fall 2020 (07.08.2020), Retrieved from: www.thecrimson.com/article/2020/8/7/harvardcoronavirus-fall-enrollment-numbers (28.08.2020)

Boatman, A., Evans, B., Soliz, A. (2017). Understanding Loan Aversion in Education: Evidence from High Schools Seniors, Community College Students and Adults, AERA Open vol.3 (1), 1-16, https://doi.org/10.1177/2332858416683649

CDC (Centers for Disease Control and Prevention) (2020). Coronavirus Disease 2019 (COVID-19), Retrieved from: www.cdc.gov/coronavirus/2019-ncov/covid-data/forecasting-us. html (28.08.2020)

Charles, K.K.; Hurst, E. Notowidigdo, M. (2015). Housing Booms and Busts, Labor Market Opportunities, and College Attendance, NBER Working Paper Series, Working Paper 21587, National Bureau of Economic Research, Retrieved from: www.nber.org/papers/w21587.pdf (28.08.2020)

College Board (2019). Trends in College Pricing 2019, Trends in Higher Education Series, Retrieved from: https://research.collegeboard.org/pdf/trends-college-pricing-2019-full-report. pdf (28.08.2020).

Davis, E. (2020). The States Most Vulnerable to COVID-19, U.S. News \& World Reports (12.05.2020), Retrieved from: www.usnews.com/news/best-states/articles/2020-05-12/a-newstudy-unveils-the-states-most-vulnerable-to-the-coronavirus (28.08.2020)

Dewey, J. (1900). The School and Society. Being three lectures, Retrieved from: www.gutenberg. org/files/53910/53910-h/53910-h.htm\#Page_19 (28.08.2020)

Dickler, J. (2020). Colleges cut academic programs in the face of budget shortfalls due to Covid-19, CNBC (23.06.2020), Retrieved: www.cnbc.com/2020/06/23/colleges-cut-programs-in-face-ofbudget-shortfalls-due-to-covid-19.html (28.08.2020)

Federal Student Aid (2020). Official Cohort Default Rates for Schools, Retrieved from: www2.ed. gov/offices/OSFAP/defaultmanagement/cdr.html (28.08.2020)

Hamidi, S.; Sabouri, S., \& Ewing, R. (2020). Does Density Aggravate the Covid-19 Pandemic, Early Findings and Lessons for Planners, Journal of the American Planning Association, https:// doi.org/10.1080/01944363.2020.1777891

Hayoung, K; Krishnan, C., \& Law, J. (2020). COVID-19 and US higher education enrolment: Preparing leaders for fall, McKinsey \& Company (21.05.2020), Retrieved from: www.mckinsey.com/industries/public-and-social-sector/our-insights/covid-19-and-us-highereducation-enrollment-preparing-leaders-for-fall (28.08.2020)

Hendrickson, M. (2020). US Chicago announces tuition freeze, but students still threaten payment strike, Chicago Sun Times (16.04.2020), Retrieved from: https://chicago.suntimes. com/education/2020/4/16/21222787/university-of-chicago-tuition-freeze-strike-studentscoronavirus-covid-19 (28.08.2020)

Hobson, T.D., \& Puruhito, K.K. (2018). Going the distance: Online course performance and motivation of distance-learning students. Online Learning, 22(4), 129-140.

Howarth, R., \& Stifler, L. (2019). The Failings of Online For-Profit Colleges: Findings from Student Borrower Focus Groups, The Brookings Economic Studies, Retrieved from: www.brookings.edu/ wp-content/uploads/2019/03/The-Failings-of-Online-For-profit-Colleges.pdf (28.08.2020)

HSPH (Harvard School of Public Health) (2020). Intermittent social distancing may be needed through 2020 to manage COVID-19, Retrieved from: www.hsph.harvard.edu/news/hsph-inthe-news/intermittent-social-distancing-may-be-needed-through-2022-to-manage-covid-19/ $(28.08 .2020)$ 
Hubler, S. (2020). As Colleges Move Classes online, Family rebels against the Coast, textitNew York Times, (15.08.2020), Retrieved from: www.nytimes.com/2020/08/15/us/covid-college-tuition. html (28.08.2020)

Hussar, W., \& Bailey, T. (2019). Projections of Education Statistics to 2027, Retrieved from: https:// nces.ed.gov/pubs2019/2019001.pdf (28.08.2020)

Jaschik, S. (2020). Survey: 90\% of Students Will Return to Research Universities, Inside Higher Ed (18.06.2020), Retrieved from: www.insidehighered.com/quicktakes/2020/06/18/survey-90students-will-return-research-universities (28.08.2020)

Jaschik, S. (2020). Swill Students Show up at Private Colleges?, Inside Higher Ed (24.08.2020), Retrieved from: www.insidehighered.com/admissions/article/2020/08/24/will-students-showprivate-colleges (28.08.20 20)

Jefferson, T. (1821). From the University of Virginia Board of Visitors to Literary Fund Bord, 29 November 1821, Retrieved from: https://founders.archives.gov/documents/Jefferson/98-01-02$2460(28.08 .2020)$

John Hopkins (Coronavirus Resource Center) (2020). COVID-19 Dashboard by CSSE, Retrieved from: https://coronavirus.jhu.edu/map.html (28.08.2020)

Johnson, J. (2020). Texas A\&M Summer Enrollment Increases 18 Percent, Texas A\&M Today (03.08.2020), Retrieved from: https://today.tamu.edu/2020/08/03/texas-am-summerenrollment-increases-18-percent/ (28.08.2020)

Kabler Staff, P. (2020). Moody: Coronavirus Impact will send WV revenue collection plunging, Charleston Gazette-Mail (28.04.2020), Retrieved from: www.wvgazettemail.com/coronavirus/ moody-coronavirus-impact-will-send-wv-revenue-collection-plunging/article_5d464b0f6c9a-5845-96a0-a00ca0d944a5.html (28.08.2020)

Kahn, C. (2020). Almost one in four Americans lost job or furloughed because of coronavirus, poll finds, Reuters (27.03.2020), Retrieved from: www.msn.com/en-us/money/markets/ almost-one-in-four-americans-lost-job-or-furloughed-because-of-coronavirus-poll-finds/arBB11OwCc?\&ocid=spartanntp (28.08.2020)

Krieger, M. (2020). $\mathrm{R}_{t}$ (effective reproduction rate) COVID-19, Retrieved from: https://rt.live/ (28.08.2020)

Lederman, D. (2020). Covid-19's Forceful Financial Hit: A Survey of Business Offices, Inside Higher Ed (10.07.2020), Retrieved from: www.insidehighered.com/news/survey/covid-19sforceful-financial-hit-survey-business-officers (28.08.2020)

Long, B. T. (2014). The Financial Crisis and College Enrollment: How Have Students and Their Family Responded? In: J. Brown and C. Hoxby (eds.), How The Financial Crisis and Great Recession Affected Higher Education, University of Chicago Press (pp. 209-233), Retrieved from: www.nber.org/chapters/c12862.pdf (28.08.2020).

McLaughlin, K. (2020). The coronavirus could force smaller liberal arts and state colleges to close forever, Insider (26.04.2020), Retrieved from: www.insider.com/smaller-colleges-may-neverreopen-because-of-the-coronavirus-2020-4 (28.08.2020)

NCES (National Center for Education Statistics), Undergraduate Enrollment, Retrieved from: https://nces.ed.gov/programs/coe/indicator_cha.asp (28.08.2020)

NSC Blog (2020), New Research Center Report Shows COVID-19 Effects on Post-Secondary Enrolment (30.06.2020), Retrieved from: www.studentclearinghouse.org/nscblog/new-researchcenter-report-shows-covid-19-effects-on-postsecondary-enrollment/ (28.08.2020)

OPA (US Department of Health and Human Services, Office of Population Affairs) (2019), Adolescent Health, Retrieved from: www.hhs.gov/ash/oah/facts-and-stats/national-and-state-datasheets/adolescent-physical-health-and-nutrition/west-virginia/index.html (28.08.2020)

Park, C (2020). The Cost of Connectivity in West Virginia, New America (1.04.2020), Retrieved from: www.newamerica.org/oti/reports/cost-connectivity-west-virginia/ (28.08.2020)

Seltzer, R. (2020). 'Anemic' State Funding Growth, Inside Higher Ed (22.01.2018), Retrieved from: www.insidehighered.com/news/2018/01/22/state-support-higher-ed-grows-16-percent$2018(28.08 .2020)$ 
Silverman, H. (2020). West Virginia has highest rate of transmission of Covid-19 in the country, state official says (10.07.2020), Retrieved from: https://edition.cnn.com/world/live-news/coronaviruspandemic-07-10-20-intl/h_2e9566af310be24a81505350dd785f0c (28.08.2020)

Startz, D. (2020). University finances and COVID-19: Different Schools, Different Risks, Brookings (18.06.2020), Retrieved from: www.brookings.edu/blog/brown-center-chalkboard/2020/06/18/ university-finances-and-covid-19-different-schools-different-risks/ (28.08.2020)

Sultan, Z. (2020). Colleges Consider Layoffs as COVID-19 Wreaks Financial Havoc, U.S. News and World Report (27.07.2020), Retrieved from: www.usnews.com/news/education-news/articles/ 2020-07-27/colleges-move-to-lay-off-faculty-as-covid-19-decimates-budgets (28.08.2020)

Talk Poverty (2018). West Virginia, Retrieved from: https://talkpoverty.org/state-year-report/westvirginia-2018-report/ (28.08.2020)

The Harvard Gazette (2020). Class of 2024 yield drops marginally (26.06.2020), Retrieved from: https://news.harvard.edu/gazette/story/2020/06/covid-19-concerns-drop-class-of-2024yield-by-3-percent/ (28.08.2020)

The University of Texas COVID-19 Modeling Consortium (2020). COVID-19 Mortality Projections for US States, Retrieved from: https://covid-19.tacc.utexas.edu/projections/ (28.08.2020)

The World Bank (2020). COVID-19 to Plunge Global Economy into Worst Recession since World War II, press release (08.06.2020), Retrieved from: www.worldbank.org/en/news/pressrelease/2020/06/08/covid-19-to-plunge-global-economy-into-worst-recession-since-worldwar-ii (28.08.2020)

Treadway, C. (2019). Enrollment Report 2019, West Virginia Higher Education Policy Commission (5.12.2019), Retrieved from: www.wvhepc.edu/wp-content/uploads/2019/12/HEPC_ EnrollmentReport_FINAL_5DEC2019_pdf (28.08.2020).

US Bureau of Labor Statistics (2020). Economy at a Glance - West Virginia, Retrieved from: www. bls.gov/eag/eag.wv.htm (28.08.2020)

Woolf, S.H., \& Aron, L, (eds). (2013). U.S. Health in International Perspective: Shorter Lives, Poorer Health. Washington (DC): National Academies Press (US); 2013. Summary. Retrieved from: www.ncbi.nlm.nih.gov/books/NBK154469/ (28.08.2020)

WV DHHR (West Virginia Department of Health and Human Resources) (2020), Fast Facts / Data reports, Retrieved from: https://dhhr.wv.gov/hpcd/data_reports/pages/fast-facts.aspx (28.08.2020)

WV DHHR (West Virginia Department of Health and Human Resources. Influenza and Pneumonia Fact Sheet, Retrieved from: www.wvdhhr.org/bph/hsc/pubs/other/Influenza_and_Pneumonia_ Fact_Sheet/2017_Influenza_and_Pneumonia_Fact_Sheet_DHHR.pdf (28.08.2020)

Zalaznick, M. (2020). More colleges breaking summer enrolment records, University Business (29.06.2020), Retrieved from: https://universitybusiness.com/summer-enrollment-recordscollege-admissions-online-learning-covid/ (28.08.2020)

Mirta Martin is the President of Fairmont State University in West Virginia. Dr. Martin's career involves extensive work in both the public and private sectors where she served in various academic and industry executive roles. She has received numerous awards, among which are: 2020 West Virginia Inspiring Women; 2019 West Virginia Educator of the Year; The Humanitarian Award for Academic Excellence; and The Presidential Volunteer Service Award awarded by the President of the United States.

Jacob Abrams is the Director of Institutional Research and Effectiveness at Fairmont State University. Mr. Abrams previously served as a Research Associate for the Harvard-Smithsonian Center for Astrophysics. He is a summa cum laude, Phi Beta Kappa graduate of the College of William and Mary, where he also completed a Visiting Studentship at Oxford University. He holds an EdM in Higher Education from the Harvard Graduate School of Education. 
Open Access This chapter is licensed under the terms of the Creative Commons Attribution 4.0 International License (http://creativecommons.org/licenses/by/4.0/), which permits use, sharing, adaptation, distribution and reproduction in any medium or format, as long as you give appropriate credit to the original author(s) and the source, provide a link to the Creative Commons license and indicate if changes were made.

The images or other third party material in this chapter are included in the chapter's Creative Commons license, unless indicated otherwise in a credit line to the material. If material is not included in the chapter's Creative Commons license and your intended use is not permitted by statutory regulation or exceeds the permitted use, you will need to obtain permission directly from the copyright holder. 


\title{
Are Rankings (Still) Fit for Purpose?
}

\author{
Ellen Hazelkorn
}

\section{Rankings, Influence and Relevance}

Global rankings emerged in the early years of the millennium at a time of increasing globalisation of higher education. Initially touted as a transparency instrument, a source of information about higher education for students, parents and the public, rankings have succeeded by comparing quality and performance internationally. They soon became an indicator of university reputation and status and national competitiveness in a world in which knowledge and talent reign supreme. Over the past decades, there has been a close correspondence between their growing influence and the expansion of their product range in terms of rankings by world region, subject and discipline, reputation and impact.

Despite criticism of their methodologies, choice of indicators and reliability of the data, there has been strong interest from governments and universities who use rankings to inform policy decisions and resource allocation, reinforce strategic ambition and identify priorities and KPIs, and as an aid to re-organisation and benchmarking. Students, especially international students, use rankings to help inform their university choice (Hazelkorn 2015). Today, there are around 20 global rankings, and, at a rough guestimate, upwards of several hundred other primarily nationally-based rankings (IREG Observatory 2018).

But, can rankings keep pace with or respond to the many challenges we face or the changes we see around us? As the world emerges from the tremendous and sharp social, economic and personal shock due to the Covid-19 Pandemic, the challenges affecting higher education and research are more significant now than ever. The crisis has affected both public and private institutions in different ways including a significant loss of income from public sources and tuition, a transformation in the teaching and learning environment and restrictions on academic and researcher

\footnotetext{
E. Hazelkorn ( $₫)$

Technological University Dublin, Dublin, Ireland

e-mail: ellen.hazelkorn@TUDublin.ie

(C) The Author(s) 2021 
recruitment and salaries. All this is affecting the student experience and graduate opportunities. Mass higher education is undergoing an existential crisis.

In recognition of the pressures currently being experienced, the Times Higher Education World University Rankings (WUR) announced it would postpone changes to its methodology until 2023 (Ross 2020). However, rather than simply making amendments, isn't it time to ask: Are rankings (still) fit for purpose?

\section{Promoting Elitism in the Era of Mass Higher Education}

Demographic, economic, labour market and technological developments underpin a growing demand for higher education everywhere. The bulk of new employment opportunities into the future will require higher-order cognitive, communication and interpersonal skills, complex problem solving, creativity, fluency of ideas and active learning requiring people to have broad-based skills alongside specialist knowledge. As economic growth advances, countries have no option but to invest in their education and training systems. Worldwide participation in tertiary education has been increasing at a rate of approximately $4 \%$ a year since 1995 . This growth is reflected in the growing number of accredited universities, rising from around 12,000 in 1997 to 19,700 in 2020 according to IAU's World Higher Education Database (www.whed. net).

As Piketty has written, "it is access to skills and diffusion of knowledge that allow inequality to be reduced both within countries and at the international level" (Piketty 2020, p. 534). Thus, widening access to higher education to under-served groups and to those who have been inactive is essential to meet societal and labour needs as well as stem social inequalities. As people live longer, there is a necessity to expand life-long learning opportunities to cater for re-skilling and up-skilling for those in the labour force or wishing to re-join, this includes women after child-birth or rearing. Significant investment in digital skills is essential to avoid risks of worsening the digital divide. The Covid-19 pandemic is accelerating these inequalities and disadvantages as the crisis deepens (ILO 2020).

Approximately $220 \mathrm{~m}$ students are currently enrolled in higher education; this number is estimated to reach $660 \mathrm{~m}$ by 2040 (Calderon et al. 2018, p. 187). However, rankings consider only $5 \%$ of the world's universities. The top 100 universities listed by the Academic Ranking of World Universities (2019) represent only $1.4 \%$ of total students worldwide. What is particularly striking is that the top 20 is dominated by US universities, eleven of which are private. The five institutions with the largest endowments in 2016 were Harvard University ( $\$ 36$ billion), Yale University ( $\$ 25$ billion), the University of Texas System ( $\$ 24$ billion), Stanford University ( $\$ 22$ billion), and Princeton University (\$22 billion) (Institute of Education Sciences 2019)_amounts which surpass the (higher education) budgets of many countries (CIA, n.d.).

At a time of growing demand for and from higher education, rankings measure the outcomes of historical advantage. Elite universities and nations benefit from accumulated public and/or private wealth and investment over decades if not centuries. 
They also benefit from attracting high achieving/socio-economic students who graduate on-time and go-on to have successful careers (Perna et al., (forthcoming 2022). All these factors are reproduced in the indicators which rankings use and popularise. Taking all resources into account, including endowments, the resources available to the best universities and the rest highlights and perpetuates the inequality gap (Piketty 2020: 537-538). As Cantwell (2017) argues, rankings are a "report card" on disparities in resources and the unevenness in the global production of knowledge, the effect of which is to legitimise such inequities.

\section{Measuring Excellence?}

Rankings purport to measure excellence. They use a range of indicators, but they predominantly measure research and reputation. This bias is best demonstrated when research and research-dependent indicators are combined: e.g. academic reputation, Ph.D. awards, research income, citation, academic papers, faculty and alumni medals and awards, and internationalisation. There is a close correlation between research performance and reputation. Accordingly, $100 \%$ of the total scores for $A R W U$ and THE are based on research, and $70 \%$ for $Q S$.

Research is primarily measured by way of citation and publication counts using bibliometric databases: 21,294 journals, books and conference proceedings in Web of Science (n.d.) and 25,100 in SCOPUS (2020). Citation counts rely on the journal impact factor (JIF) developed by Garfield in 1955.

There has been growing concern that exceptional attention to high-impact journals and impact factors is distorting research practice, with accusations of over/misinterpretation, misconduct and manipulation (Biagioli and Lippman 2020). Research may be frequently cited because of topicality or to dispute an argument. There are differences according to disciplinary practice: the physical, life and medical sciences publish frequently with multiple authors whereas the social sciences, humanities and arts tend to have single authors and publish in a range of formats or produce artefacts, and engineering focuses on conference proceedings and prototypes. JIF can mean other important publications are ignored while new research fields or ideas which challenge orthodoxy can find it difficult to get published.

These concerns have been highlighted in the San Francisco Declaration on Research Assessment (DORA 2012) and the Leiden Manifesto (Hicks et al. 2015) attracting many thousands of individual and institutional supporters. Dutch universities and funding agencies and the Chinese government have renounced usage of citation counts for academic assessment, appointment and promotion (Creus 2020; VSNU et al. 2019; te Roller 2020). To evaluate research performance, best practice suggests always using quantitative indicators and data in conjunction with qualitative methods, such as peer review (Expert Group on Assessment of University-Based Research 2010; Wilsdon et al. 2015).

Recent years has seen a big move to embrace open science. Open science is the movement to ensure research and its dissemination is accessible to everyone in 
society, amateur or professional, rather than blocked by subscription journals and behind paywalls. Open Science presents a challenge to JIF.

The debate around what constitutes "excellence" has broadened to include emphasis on societal impact and engagement. To paraphrase John F Kennedy, it's not only what universities do for themselves that counts but the overall benefits they bring to their communities and citizens. But measuring impact is very complex; too often there is a tendency to focus only on commercialisation of research through patents and licensing and to ignore wider societal impact and civic engagement, the contribution to public discourse or public behaviour, helping build sustainable communities, etc.

Jumping on this bandwagon, Times Higher Education (Times Higher Education 2019) launched an impact ranking to measure activity aligned with the seventeen UN Sustainability Development Goals (SDG). However, research activity accounts for $27 \%$ of each SDG against which data is submitted. In addition, each university is required to submit evidence. Not only is gathering this material a lot of work, but it is unlikely THE can control or validate the accuracy and comparability of the information provided. Anyone with experience of evaluating large scale projects will understand the magnitude of the work involved and the necessary integrity and transparency of the process.

In addition, the evaluation is carried out behind closed-doors. Submissions provide a lucrative treasure trove of institutional data which remains behind a paywall. This exposes one of the biggest developments of recent years - the monetisation of university data by commercial rankings and publishing organisations (Hazelkorn 2020).

Finally, global rankings, such as THE and QS, measure the proportion of international students as a proxy for quality. However, international mobility is heavily influenced by factors attributed to reputation and status. There is a "correlation between the position of universities in international university rankings and their attractiveness to international students" (OECD 2015: 357). Over the years, universities have significantly expanded their percentage of international students and accordingly, the income earned. The pandemic exposes profound difficulties associated with overdependence on international students.

\section{Are Rankings Still Fit for Purpose?}

The world around us is changing, and the issues impacting on and expected of higher education are changing also. Are rankings still relevant?

Rankings suffer from a fundamental problem. They use indicators based on their own value-judgement. There is no such thing as an objective ranking. Measurements are also indirect and consist primarily of proxies.

Teaching is the essential mission of most universities, but rankings focus overwhelmingly on research and research-related activities. This is because there is considerable difficulty measuring and comparing results across diverse countries, insti- 
tutions, and students. It is also misplaced to think we can measure teaching, at scale, distinct from the outcomes of learning (Altbach and Hazelkorn 2018).

In contrast, bibliometric data is relatively easy to capture. JIF data is readily available. This explains the over-emphasis on research. Reliance on such data helps us understand the increasingly close corporate integration between rankings, the publishing industry and big data (Fyfe et al. 2017; Posada 2018). It also helps us understand levels of publisher resistance around open science protocols currently being discussed and promoted by many countries and organisations. Ultimately, open science challenges a primary data source used by rankings.

The overemphasis on performance of a small number of elite universities is based on the misperception that national performance is an outcome of individual institutional performance. Yet, there is little evidence that the high achievement of a few elite universities trickle down to the overwhelming majority of the population who attend the majority of institutions. Is the policy objective to have a higher education system which serves elites (where progress depends on the cutting-edge knowledge of the chosen few) or to empower a mass knowledge society (where progress depends on the "wisdom of the many")?

The big assumption underpinning rankings is that the indicators are meaningful measures for quality. But, the questions being asked about rankings are similar to, for example, those being asked about the meaningfulness of GDP or the stock-market with regard to the quality of life or economic sustainability for society as a whole (Coclanis 2019). Rather than student learning outcomes, equity and diversity or the contribution to society/the economy or civic engagement, prestige and reputation have become the dominant drivers of policy and decision-making. There is little evidence that rankings have any meaningful impact on improving quality. And, there is no correlation between rising in the rankings and making a significant contribution to society or the public good.

These shortcomings are magnified by current events and the severity of the challenges now facing almost every country. Amendment is not possible because the methodology and underpinning assumptions are flawed. Indeed, what meaningful information can come from ranking the top universities at time of a global pandemic and world recession?

Whatever arguments were used initially to say rankings were improving public information for students and others, no such argument can be made now. Are ranking (still) fit for purpose- the answer is No.

\section{References}

Academic Ranking of World Universities (2019). Retrieved from: http://www.shanghairanking. com/ARWU2019.html (26.07.2020).

Altbach, P. G., \& Hazelkorn, E. (2018). Measuring Education Quality in Global Rankings: What's the Likelihood? International Higher Education, 95(Fall), 12-14. Retrieved from: https:// ejournals.bc.edu/ojs/index.php/ihe/article/view/10721/9194 (26.07.2020) 
Biagioli, M., \& Lippman, A. (Eds.). (2020). Gaming the Metrics. Misconduct and Manipulation in Academic Research. https://doi.org/10.1017/CBO9781107415324.004

Calderon, A. (2018). The geopolitics of higher education: pursuing success in an uncertain global environment. In B. Cantwell, H. Coates, \& R. King (Eds.), Handbook on the Politics of Higher Education (pp. 187-208). Cheltenham: Edward Elgar Publishing

Cantwell, B. (2017). The geopolitics of the education market. In E. Hazelkorn (Ed.), Global Rankings and the Geopolitics of Higher Education. Understanding the influence and impact of rankings on higher education, policy and society (pp. 309-323). London: Routledge

Coclanis, P. A. (2019, June). Why we urgently need a real alternative to GDP as an economic measure. New Statesman. Retrieved from: https://www.newstatesman.com/politics/economy/2019/ 06/why-we-urgently-need-real-alternative-gdp-economic-measure (26.07.2020)

CIA (n.d.) The World Factbook, Retrieved from: https://www.cia.gov/library/publications/theworld-factbook/fields/224.html (26.07.2020)

Creus, G. J. (2020). Will others follow China's switch on academic publishing?? Univeristy World News. Retrieved from: https://www.universityworldnews.com/post.php? story $=2020031810362222$

DORA. (2012). San Francisco Declaration on Research Assessment (pp. 1-10). https://doi.org/10. 1242/bio.20135330

Expert Group on Assessment of University-Based Research. (2010). Assessing Europe's UniversityBased Research. https://doi.org/10.2777/80193

Fyfe, A., Coate, K., Curry, S., Lawson, S., Moxham, N., \& Røstvik, C. M. (2017). Untangling Academic Publishing. A history of the relationship between commercial interests, academic prestige and the circulation of research. https://doi.org/10.5281/zenodo.546100

Hazelkorn, E. (2015). Rankings and the Reshaping of Higher Education: The Battle for world-class Excellence (2nd ed.). https://doi.org/10.1057/9781137446671

Hazelkorn, E. (2020, March 21). Should universities be ranked for their SDG performance? University World News. Retrieved from: https://www.universityworldnews.com/post. php?story $=20200317145134326$

Hicks, D., Wouters, P., Waltman, L., De Rijcke, S., \& Rafols, I. (2015). Bibliometrics: The Leiden Manifesto for research metrics. Nature, 520(7548), 429-431. https://doi.org/10.1038/520429a

IAU (n.d.) IAU Whed: https://www.whed.net/home.php (26.07.2020)

ILO. (2020). COVID-19 and the world of work. Retrieved from: https://www.ilo.org/ wcmsp5/groups/public/@dgreports/@dcomm/documents/briefingnote/wcms\$_\$740877.pdf (26.07.2020)

Institute of Education Sciences. (2019). Endowments. In National Center for Education Statistics. Retrieved from: https://nces.ed.gov/COLLEGENAVIGATOR/?s=MD\&sp=4 (26.07.2020)

IREG Observatory. (2018). IREG Inventory of International University Rankings, 2014-2017. Retrieved from: http://ireg-observatory.org/en/pdfy/IREG-Inventory-ofInternationalUniversityRankings.pdf (26.07.2020)

OECD. (2015). Education at a Glance. OECD Indicators. Paris: OECD Publishing.

Perna, L. W., Wright-kim, J., \& Brickfield, J. (2022). The Implications of Rankings for Equity in Higher Education Attainment. In E. Hazelkorn (Ed.), Research Handbook on University Rankings: History, Methodology, Influence and Impact (Forthcoming). Cheltenham, UK: Edward Elgar Publishing.

Piketty, T. (2020). Capital and Ideology. Cambridge, Massachusetts: Belkap Press of Harvard University Press.

Posada, A., \& Chen, G. (2018). Inequality in Knowledge Production: The Integration of Academic Infrastructure by Big Publishers. 0-21. https://doi.org/10.4000/proceedings.elpub.2018.30

Ross, D. (2020, April 30). What might Covid-19 mean for the World University Rankings?? Times Higher Education. Retrieved from https://www.timeshighereducation.com/world-universityrankings/what-might-covid-19-mean-world-university-rankings 
te Roller, E. (2020, March 27). Dutch funders move away from journal impact factor. Research Professional. Retrieved from: https://www.researchprofessionalnews.com/rr-news-europenetherlands-2020-3-dutch-funders-move-away-from-journal-impact-factor/(26.07.2020)

SCOPUS (2020). Content Coverage, Retrieved from: https://www.elsevie.com/\$_\$\$_\$data/assets/ pdf\$_\$file/0007/69451/Scopus\$_\$ContentCoverage\$_\$Guide\$_\$WEB.pdf (26.07.2020)

Times Higher Education (2019). Impact Rankings 2019, Retrieved from: https://www. timeshighereducation.com/rankings/impact/2019/overall\#!/page/0/length/25/sort\$_\$by/rank/ sort\$_\$order/asc/cols/undefined (26.07.2020)

VSNU, NFU, KNAW, N. and Z. (2019). Room for everyone's everyone's talent. Retrieved from: http://www.vsnu.nl/files/documenten/Domeinen/Onderzoek/PositionpaperRoomforeveryone? stalent.pdf (26.07.2020)

Web of Science (n.d.) Web of Science platform: Web Science: Summary of coverage, Retrieved from: https://clarivate.libguides.com/webofscienceplatform/coverage (26.07.2020)

Wilsdon, J., Allen, L., Belfiore, E., Campbell, P., Curry, S., Hill, S., ... Johnson, B. (2015). The Metric Tide: Report of the Independent Review of the Role of Metrics in Research Assessment and Management. https://doi.org/10.13140/RG.2.1.4929.1363

Ellen Hazelkorn is Joint Managing Partner, BH Associates education consultants, and Professor emerita, Technological University Dublin (Ireland). She is Joint Editor, Policy Reviews in Higher Education, International Co-Investigator, Centre for Global Higher Education, London, and Research Fellow, Centre for International Higher Education, Boston College, USA. Ellen is a member of the Commission of the College of the Future (UK), and the Quality Board for Icelandic Higher Education. She was policy advisor to the Higher Education Authority (Ireland), and President of the European Society for Higher Education. She was Vice President, Dublin Institute of Technology (now TU Dublin) (1995-2014).

Open Access This chapter is licensed under the terms of the Creative Commons Attribution 4.0 International License (http://creativecommons.org/licenses/by/4.0/), which permits use, sharing, adaptation, distribution and reproduction in any medium or format, as long as you give appropriate credit to the original author(s) and the source, provide a link to the Creative Commons license and indicate if changes were made.

The images or other third party material in this chapter are included in the chapter's Creative Commons license, unless indicated otherwise in a credit line to the material. If material is not included in the chapter's Creative Commons license and your intended use is not permitted by statutory regulation or exceeds the permitted use, you will need to obtain permission directly from the copyright holder. 


\title{
Are Universities Better Off Without Rankings?
}

\author{
Jamil Salmi
}

\section{Introduction}

The advent of international rankings almost twenty years ago-pioneered by the first Academic Ranking of World Universities by Shanghai Jiao Tong University in 2003 - changed the university landscape in an irreversible way. Today, the creation of world-class universities has become part of the political agenda in many countries.

Much progress has been achieved in the past twenty years. It would appear that the global rankings have indeed played a positive role in boosting academic excellence. But, is it progress in the right direction? How can we reconcile advances in research power with lack of progress in tackling mankind's major challenges, such as hunger, poverty, disease, and environmental decay? Have the top-ranked universities become more inclusive or elitist? Are societies using the vast knowledge generated by worldclass universities to make choices based on scientific evidence and rational political debate? Are the leading universities contributing to the construction of ethical and democratic societies?

\section{Impact of Rankings on Policies and Behaviours}

\subsection{National Level}

When Vladimir Putin was re-elected as president of Russia in 2012, one of his first declarations was a call to transform the country's universities into world-class institutions, with the specific goal of having five Russian universities in the top 100 .

\footnotetext{
J. Salmi (凶)

Diego Portales University, Santiago, Chile

e-mail: jsalmi@ @ertiaryeducation.org

Boston College, Chestnut Hill, MA, USA

(C) The Author(s) 2021 
These kinds of initiatives are characteristic of the influence that the global rankings have had on the political scene of many countries in the past two decades, especially in East Asia and Europe.

Perhaps less beneficial have been policy decisions narrowly focused on the rankings. In Brazil, for instance, the Science without Borders program to send thousands of students to the best universities in the world was restricted to the top 100 universities globally. The global rankings have also influenced national decisions about university partnerships and immigration visas.

\subsection{Institutional Level}

The sway of international rankings has perhaps been even stronger at the institutional level. A major positive development has been widespread reliance on the rankings for strategic planning and quality improvement purposes.

Less helpful are the shortcuts that universities have sometimes elected to take in their quest to rise quickly in the rankings without necessarily building capacity in a genuine manner. Some universities approach academics in other institutions to encourage them to provide positive feedback through the reputation surveys conducted by some of the global rankings such as THE and QS. Others have entered into contractual relationships with commercial rankers with the expectation of boosting their standing in the respective rankings.

\section{Performance of World-Class Universities After Twenty Years of Shanghai Ranking}

Analysing the evolution of the WCU concentration index over the years gives a precise picture of progress and decline. Figures 1 and 2 calculate the WCU concentration index as the number of universities each country places among the top 100 globally relative to its population (using the Logarithmic value of the population).

The most significant change is the progress made by small countries. While five out of the seven leading countries in 2004 were large countries (US, UK, Japan, Germany and France), the picture had changed substantially by 2019, with four small population countries among the top six (Australia, Switzerland, Netherlands and Canada). Despite two rounds of excellence initiatives, Germany moved down from third to seventh position, and France came down from seventh to tenth. By contrast, Australia climbed in an impressive manner from tenth to third. The USA and the UK lost eight universities altogether. Japan moved down from fifth to eleventh.

Finally, it is instructive to look at which universities have most improved and most regressed in the ranking over the 16-year span. While there has hardly been any change among the top 20 universities in the world, the highest jumps were 


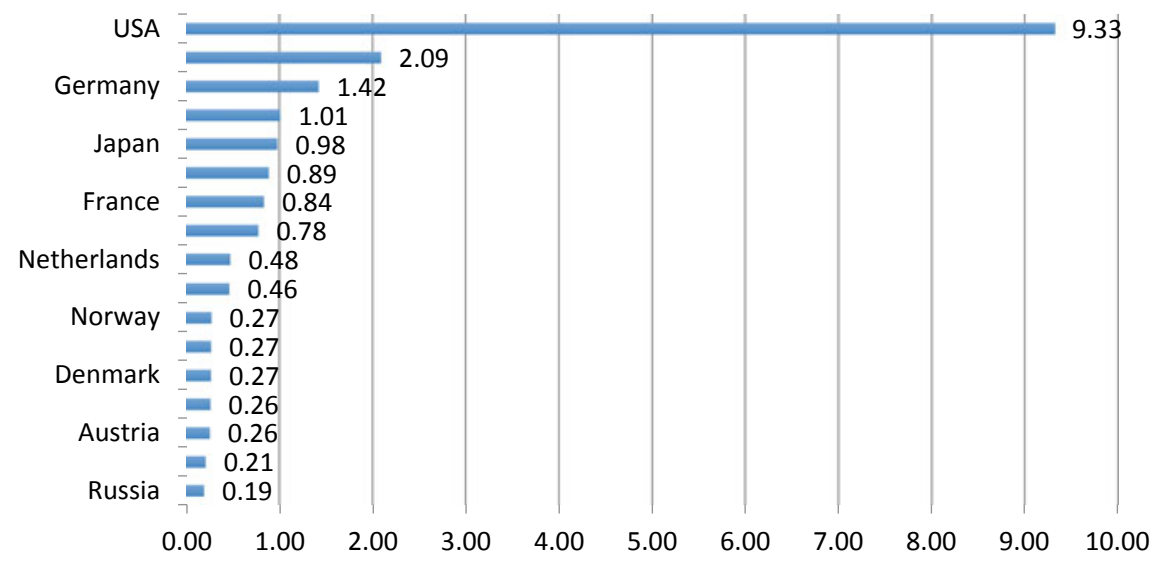

Fig. 1 WCU Concentration Index (2004). Source ARWU and World Population Data

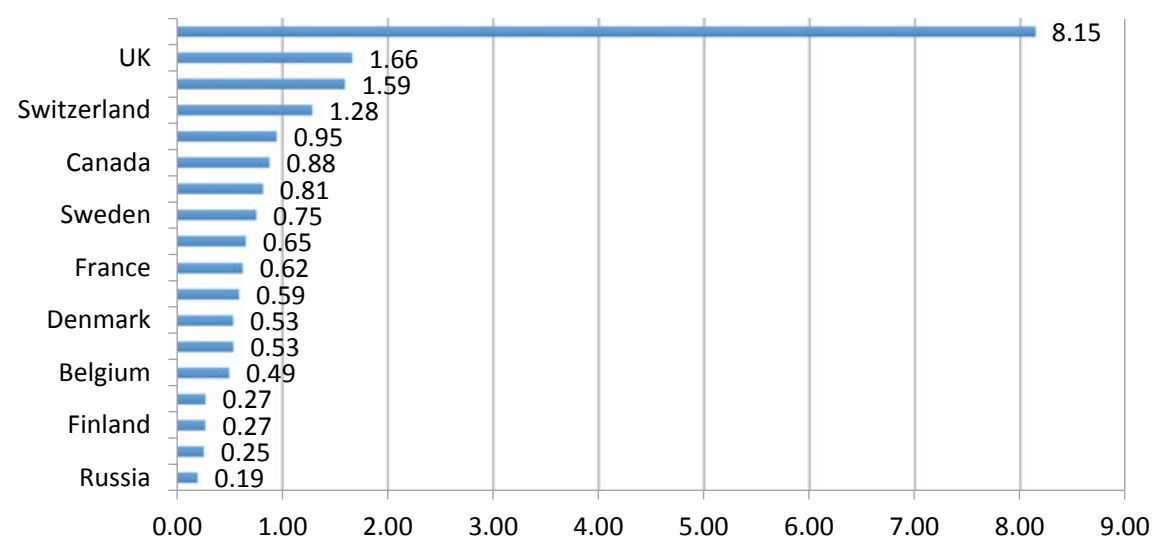

Fig. 2 WCU Concentration Index (2019). Source ARWU and World Population Data

achieved by four top Chinese universities, Singapore's Nanyang Polytechnic, and several Australian universities. Substantial progress was also achieved by two Swiss universities, two Danish universities, two US institutions, two Belgian universities, and one university each from Israel and The Netherlands. The great majority of universities that have lost significant numbers of places are from the United States.

It is difficult to assess in a conclusive way the extent to which past and present excellence initiatives explain the success or demise of individual universities. The availability of additional resources is certainly a positive factor. Perhaps more important is the crucial role of governance in explaining the success of world-class universities.

Among the various governance dimensions, leadership and the mode of selection of university heads are crucial. Denmark and Finland, for instance, have moved from 
a popular election process to a professional selection led by independent university boards. Analysing the leadership selection modalities for the top 100 universities in the Shanghai ARWU ranking over time shows that the number of top 100 universities whose leader is selected through a professional search increased from 71 to 77 between 2004 and 2019, while the number of ranked universities with some form of popular election went down from 28 to 18 .

By contrast, the number of top-ranked universities from France and Germany, two countries where the Excellence Initiative did not include significant changes in the governance arrangements went down from seven to four, and four to three, respectively, over the last sixteen years.

\section{Missing Dimensions of Academic Excellence}

Many ${ }^{1}$ researchers have documented how, under the guise of measuring research output in various forms, the rankings are mainly selling international visibility, losing key facets of a university's mission in the process.

\subsection{Equity}

In the search for academic excellence, many top universities have become more selective, which bears the risk of keeping talented students from low-income / low cultural capital families away. The Ivy League universities are the most selective universities in the United States, admitting one out of every 10-15 candidates. Table 1 , which contrasts the proportion of Pell Grants beneficiaries enrolled in selective and less selective top US universities, offers concrete evidence of the lack of inclusion of many world-class universities. ${ }^{2}$

The socio-economic distribution of students at leading public universities in California shows clearly that achieving world-class status is not incompatible with being more inclusive. UCLA and UC-Berkeley are ranked eleventh and fifth in the world in the 2019 Shanghai ranking while having one of the highest proportions of lowincome students among US research-intensive universities.

Similarly, in the United Kingdom, policymakers and researchers have observed for many years the non-abating elitist nature of the top universities. Among the 132 universities operating in the United Kingdom, the bottom ten in terms of social equality at admissions were Cambridge (worst case), St Andrews, Bristol, Oxford, Aberdeen, Edinburgh, University College London, Durham, Robert Gordon, and the

\footnotetext{
${ }^{1}$ This section builds on earlier work by Pierre de Maret (Emeritus Rector of the Free University of Brussels) and the author. See (de Maret et al. 2018).

${ }^{2}$ Pell Grants are the main federal financial-assistance program for low-income students in the United States.
} 
Table 1 Proportion of low-income students at top US universities

\begin{tabular}{l|l|l|l}
\hline $\begin{array}{l}\text { More Inclusive } \\
\text { Universities }\end{array}$ & $\begin{array}{l}\text { Proportion of Pell } \\
\text { Grant recipients (\%) }\end{array}$ & $\begin{array}{l}\text { Less inclusive } \\
\text { universities }\end{array}$ & $\begin{array}{l}\text { Proportion of Pell } \\
\text { Grant recipients (\%) }\end{array}$ \\
\hline $\begin{array}{l}\text { University of } \\
\text { California-Los } \\
\text { Angeles }\end{array}$ & 35.9 & Stanford University & 15.6 \\
\hline $\begin{array}{l}\text { University of } \\
\text { California-Berkeley }\end{array}$ & 31.4 & $\begin{array}{l}\text { University of } \\
\text { Pennsylvania }\end{array}$ & 14.4 \\
\hline $\begin{array}{l}\text { University of Southern } \\
\text { California }\end{array}$ & 23.4 & Duke University & 14.0 \\
\hline $\begin{array}{l}\text { Ohio State } \\
\text { University-Columbus }\end{array}$ & 22.4 & $\begin{array}{l}\text { Northwestern } \\
\text { University }\end{array}$ & 14.0 \\
\hline New York University & 21.5 & Harvard University & 13.0 \\
\hline Columbia University & 21.4 & Yale University & 11.9 \\
\hline $\begin{array}{l}\text { University of } \\
\text { Missouri-Columbia }\end{array}$ & 21.4 & $\begin{array}{l}\text { California Institute of } \\
\text { Technology }\end{array}$ & 11.3 \\
\hline $\begin{array}{l}\text { University of North } \\
\text { Carolina-Chapel Hill }\end{array}$ & 21.3 & $\begin{array}{l}\text { University of Notre } \\
\text { Dame }\end{array}$ & 11.2 \\
\hline
\end{tabular}

Source Carnevale and Van Der Werf (2017)

London School of Economics (Study International 2018). Five of these are among the top 100 universities in the Shanghai ranking.

By contrast, the Nordic countries are able to place universities in the top 100 with admission systems that are much more open than those of US and UK universities.

\subsection{Truth}

The Covid-19 pandemic has revealed the importance of relying on scientific evidence to drive public policy and save human lives. In the post-truth world, building up and spreading critical thinking are absolutely essential. Universities have the responsibility to teach how to distinguish real evidence from fabricated information. The former British Minister for Higher Education David Lammy observed that in "the age of populism" academics have a duty to "stand brave and tall and communicate quite strongly the dangers that could lie ahead for the global world" (Times Higher Education 2019).

Truth-seeking skills, the foundation of a genuine liberal arts education, should be at the core of every curriculum. World-class universities should lead in upholding the academic tradition of free and fair debate that has been undermined by relativism and political correctness. A good example of such practice is the yearly LorneTrottier Public Science Symposium Series, launched by McGill University in 2016, to communicate science responsibly to the public in these troubled times. 
An important challenge in that respect is the growing tension between the search for excellence and constraints to full academic freedom, which has traditionally been regarded as a fundamental characteristic of universities. Several excellence initiatives have been launched in countries with limited democracy-China, Hungary, Iran, Russia, Saudi Arabia, Turkey and Vietnam to name a few-and it remains to be seen whether top universities can operate with sustained outstanding results where academic freedom is restricted.

\subsection{Ethics}

Another central question is the extent to which world-class universities promote ethical behaviours in the way they operate as institutions and in their relationship with the outside world. This starts with upholding high principles within the university community itself to prevent and punish academic dishonesty with respect to fraud in examinations and research, as well as any form of sexual violence, discrimination, harassment and bullying. A second aspect that the rankings are not well-designed to assess is whether the graduates are well prepared ethically, besides their general education and professional training. For instance, after the 2007-2008 financial crisis triggered by the subprime mortgage crisis, itself caused by the unregulated use of derivatives, many voices challenged the lack of emphasis on corporate responsibility in the programs of business schools.

Third, world-class universities must avoid conflicts of interest in their dealings with the political and business world to preserve their intellectual independence. This requires transparency in setting and applying strict rules regarding which donors they are willing to accept fundraising contributions. The University of Hong Kong, for example, has traditionally shied away from receiving any donations from companies manufacturing arms and tobacco products. By contrast, both Harvard and MIT have been criticised in recent years for their financial ties with the Government of Saudi Arabia.

Lastly, in recent years, universities in Australia, South Africa, the UK and the USA have re-examined their past with a critical eye and acknowledged their close association with ugly moments in their country's history, such as slavery, apartheid or discrimination towards native population groups.

\subsection{Commitment}

The main aspect that the global rankings identify well is the ability of world-class universities to conduct excellent 'blue sky' research. But, the high publication count does not measure whether universities engage actively with society and the economy to help solve real problems. The search for global visibility often pushes world-class 
universities to collaborate with other highly-ranked institutions in other corners of the world instead of engaging closely with their local community (Hazelkorn 2020).

While the rankings are not constructed to take this relevance dimension into consideration, an exception is the new THE impact ranking, which is based on submissions made by interested universities about their contribution to the Sustainable Development Goals. Comparing the list of top 100 universities in this new ranking and with those in the Shanghai ranking shows that none of the top 20 world-class universities appear in the impact ranking, most likely because they did not show any inclination to participate. In total only 12 among the Shanghai top 100 are in the top 100 THE impact ranking.

\subsection{Sustainability}

The last important dimension to consider is the extent to which world-class universities operate in an environmentally-responsible manner. The University of Indonesia produces a sustainability ranking (Greenmetric ranking) based on a number of factors including the carbon footprint of each institution linked to its electricity consumption, water usage, waste management, and education and research activities in the field of climate change (UI Greenmetric n.d.). Only five universities appearing in the Shanghai top 100 ranking are also included in the Greenmetric ranking.

Finally, a growing number of universities have divested their endowment funds from investment in fossil fuel firms after sustained student campaigns. Half the UK universities have moved in that direction in the past six years. The movement has been slower in the United States.

\section{Conclusion}

The 2003 irruption of the Shanghai ranking has had a profound and long-lasting impact on governments and universities. Many countries have financed ambitious investment programs to upgrade their universities, in some cases even creating new institutions with the explicit aim of achieving world-class status.

Universities, in turn, have eagerly joined this new form of "brain race". Too often, the rankings have become the new milestones guiding institutional strategic plans. While many universities all over the world have indeed improved their research performance over the past decade, there are signs that the kind of academic excellence promoted by the rankings is often side-tracking universities from contributing to progress in several crucial dimensions of human life.

The pandemic, the resulting economic crisis and the explosions of social frustration at the deeply ingrained structural racism in the United States make it all the more urgent and imperative to look at the missing dimensions in the definition of academic excellence fuelled by the global rankings. The Shanghai principles launched 
in 2017 were an attempt in this direction, as a reminder to world-class university leaders of the social responsibility of their institutions (De Maret and Salmi 2018). Echoing the key principles promoted by IAU (ethics, social responsibility, academic freedom, autonomy), these Shanghai principles focus on social inclusion, scientific truth, ethical values, responsible research, and global solidarity as moral pillars for world-class universities.

\section{References}

Carnevale, A. P., \& Van Der Werf, M. (2017). The 20\% Solution: Selective Colleges Can Afford to Admit More Pell Grant Recipients. Washington DC: Georgetown University Center on Education and the Work Force.

De Maret, P., \& J. Salmi (2018). "World-Class Universities in a Post-Truth World". In Wu, Y., Wang, Q, and N. Cai Liu (Eds). World-Class Universities: Towards a Global Common Good and Seeking National and Institutional Contributions. Leiden and Boston: Brill Sense (pp. 70-87).

Hazelkorn, E. (2020). Higher Education in the Age of Populism: Public Good and Civic Engagement". International Higher Education. Number 100 Winter 2020. Retrieved from: https://www. internationalhighereducation.net/en/handbuch/gliederung/\#/Gliederungsebene/789/Winter-

Issue-No.-100-(2020) (26.07.2020)

Study International - SI (2018). 9 April 2018. “The most \& least equal universities in the UK”. SI News. Retrieved from: https://www.studyinternational.com/news/most-least-equal-universities$\mathrm{uk} /(26.07 .2020)$

Times Higher Education (2019). "In conversation with David Lammy MP”. 10 June 2019. Retrieved from: https://www.timeshighereducation.com/news/conversation-david-lammy-mp (26.07.2020)

UI Greenmetric (n.d.). Webpage: http://greenmetric.ui.ac.id/ (26.07.2020).

Jamil Salmi is Emeritus Professor of higher education policy at Diego Portales University in Chile and Research Fellow at Boston College's Center for Higher Education. Until January 2012, he was the World Bank's tertiary education coordinator. In his capacity as a global tertiary education expert, he provides policy advice to governments, universities, professional associations, multilateral development banks and bilateral cooperation agencies.

Open Access This chapter is licensed under the terms of the Creative Commons Attribution 4.0 International License (http://creativecommons.org/licenses/by/4.0/), which permits use, sharing, adaptation, distribution and reproduction in any medium or format, as long as you give appropriate credit to the original author(s) and the source, provide a link to the Creative Commons license and indicate if changes were made.

The images or other third party material in this chapter are included in the chapter's Creative Commons license, unless indicated otherwise in a credit line to the material. If material is not included in the chapter's Creative Commons license and your intended use is not permitted by statutory regulation or exceeds the permitted use, you will need to obtain permission directly from the copyright holder.

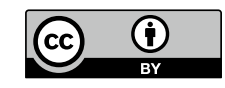


Part V

The Promise of Education 


\title{
Universities as Lifelong Learning Institutions: A New Frontier for Higher Education?
}

\author{
David Atchoarena
}

For half a century now, lifelong learning has provided — with more or less intensitythe philosophical and conceptual background in which education policies have been framed (Kejawa, 2017). When Paul Lengrand defined l'éducation permanente (1970), learning was conceived as part of a humanistic vision of the world, intrinsically characterized by fundamental values like human dignity, equal rights and social justice and respect for cultural diversity, as well as a sense of shared responsibility and a commitment to international solidarity. Today, these principles remain fundamental aspects of our common humanity and the enduring ideals of what learning can achieve.

While at international level, the Council of Europe, the European Commission and the OECD have played an active role in promoting lifelong learning, UNESCO shaped the vision and concept of 'lifelong learning for all', notably through the seminal works of two International Commissions led by Edgard Faure (1972) and Jacques Delors (1996). In the ensuing decades, the terminology of lifelong learning and its oft-used 'cradle to grave' metaphor remained, yet economic motives of competitiveness and labour market adaptation displaced attention from a humanistic vision to a materialist, market-driven perspective, the paradigm of a learning society giving way to the notion of a learning economy (Biesta 2006; Field 2000). Similarly, focus gradually shifted from the collective dimension of learning to an individual scale. Initially defined as a right to learning (United Nations 2016), lifelong learning often appeared as a duty which also had deep implications for the distribution of responsibilities between the state, social partners and individuals, and for designing funding schemes (Šimenc and Kodelja 2016). In these ways, the ambitious, inclusive conceptualizations expressed by Faure and Delors were compromised.

\footnotetext{
D. Atchoarena $(\bowtie)$

UNESCO Institute for Lifelong Learning, Hamburg, Germany

e-mail: d.atchoarena@unesco.org 
Adopted in 2015, the 2030 Agenda for Sustainable Development has reinvigorated the concept of lifelong learning and reconnected it with its humanistic origins, in particular with one stand-alone goal - SDG 4 - which calls on countries to "ensure inclusive and equitable quality education and promote lifelong learning opportunities for all'. Framing lifelong learning in relation to sustainable development repositioned the concept in a collective, long-term and holistic perspective, beyond the much narrower discourse that, for several decades, tended to dominate interpretation of the concept through specific policies and measures. Now, while working towards the 2030 Agenda for Sustainable Development, UNESCO is establishing a long-term vision for lifelong learning through its International Commission on the Futures of Education. Established in 2019 and chaired by Ethiopian President Ms Sahle-Work Zewde, the Commission is mandated to reimagine how knowledge and learning can shape the futures of humanity and will report its findings in 2021.

Over five decades, the concept of lifelong learning has been at various times articulated, repurposed, reduced, reframed and reinvigorated - the ideals at the heart of Lengrand's l'éducation permanente have been difficult to realize. Slow progress in changing education pathways and the actual experiences of learners can be explained in large part by the inertia of institutions. This is particularly true for universities, which have been historically slow in responding to the call to democratize access to higher learning. In line with this conservative behaviour, the general public have often regarded universities as elitist, particularly among disadvantaged groups who, for generations, have been deprived of learning opportunities.

Yet, increasingly, universities are redefining themselves as centres of lifelong learning by diversifying their provision, tailoring it to the knowledge and skills needed for the economy and those requested by non-traditional students (Milic 2013; Yang et al. 2015). They are thus gradually becoming key institutions for learning throughout life, opening their doors to adults who wish either to resume their studies or to acquire new knowledge and skills, whether to satisfy their taste for learning, enter or re-enter the labour market, or serve their community through voluntary work (Bernado et al. 2017). This trend mostly follows four interrelated dimensions: wider participation and flexibility; digitalization of learning; community engagement and global citizenship. Through those five dimensions, universities are revitalizing democratic participation in learning and beyond (Flemming 2006).

\section{Widening Participation, Promoting Inclusion and Building Flexible Learning Pathways}

Democratizing higher education and, eventually, society as a whole involves widening access to university studies. Widening access refers not only to an increase in the number of learners, but also to enhancing the chances of students with lower socioeconomic status to gain access to and complete quality education (European University Association 2008). Alternative pathways and financial support mecha- 
nisms are essential for widening access to those learners. Universities that promote inclusion refer to "widening", which refers to more diversity in the student population, and not just increasing the numbers of students (Smidt and Sursock 2011).

In aging societies, universities have to cater to the needs of a fast-growing population of older adults, with very different aspirations and learning needs. In some countries, low fertility rates have already led to a shrinking recruitment base for universities. This demographic decline constitutes a motivation for universities to find new "clients" and fields of action, such as targeting workers or senior citizens (Findsen and Formosa 2011). Furthermore, the COVID-19 pandemic has posed an existential challenge to some universities and, in the process, compelled them to quickly and dramatically widen access (Marinoni et al. 2020). Finding themselves unable to rely on the predictable traditional enrolments and additional income brought by international student mobility, universities have been looking to broaden their appeal to more diverse groups of learners who may remotely access their programmes.

The call for lifelong learning means a transition from the traditional role of educating young students coming directly from school to accommodating a diversity of learners entering, re-entering or late-entering higher education at different ages and at various phases of their personal and professional life (Stromquist and da Costa 2017). The concept of lifelong learning reflects a shift from delivery to demand, meaning that provision should be learner-centred (Cendon 2018). In that context, universities need to respond more flexibly to the needs of the individual learner.

Flexibility in learning pathways aims at offering learners different ways, such as accelerated programmes, apprenticeship schemes, open and distance learning, or blended programmes, to pursue their studies according to their needs. Hence, many universities have established preparatory programmes for candidates who did not complete higher secondary education or who graduated from vocational streams that do not normally grant access to university education. Successful completion of those preparatory programmes, usually one academic year, leads to a certification opening the door to higher education. In Europe, several countries, for example, France, Iceland, Ireland and the United Kingdom, have established such schemes.

The provision of flexible pathways also includes the availability of multiple entry and re-entry points, establishing links between formal and non-formal education programmes and institutions. Offering the possibility to study part-time together with the modularization of programmes are frequent strategies to diversify and widen access (Johannesen 2018).

While the dominant model in higher education remains the traditional full degree, universities offer more opportunities for non-traditional students, allowing diverse shorter, more flexible provision of learning, not necessarily leading to degrees (Jogi et al. 2015). In this context, there is need to introduce quality assurance of microcredentials as this is still rough territory. Hence, quality assurance agencies have an important role to play for promoting flexible pathways through developing standard recognition procedures. In addition, National Qualifications Frameworks and credit transfer systems form an important basis for flexible learning pathways and for the recognition, validation and accreditation of learning outcomes. 


\section{Leading and Adapting to the Digitalization of Learning}

The rapid development of online provision and blended courses offers a host of opportunities for lifelong learning (Carlsen et al., 2016, Cendon, 2018). Universities fully dedicated to open and distance learning, Massive Open Online Courses (MOOCs), mobile learning and open universities have transformed delivery patterns and contributed to widening access, despite their well-documented limitations (Knapper, 1983, Knapper 2009; Moreira et al. 2017).

The global COVID-19 crisis has provided further evidence of how technology can offer an alternative to conventional delivery models, as well as strengthening the diversification of courses to better address community needs. The pandemic has affected all universities around the world, with many of them being forced to close their premises and suspend on-campus teaching. Substituting on-campus teaching for online learning has sometimes been accompanied by measures to prevent dropout, notably by making laptops and $4 \mathrm{G}$ internet devices available to economically disadvantaged students (UNESCO 2020).

In addition to shifting to exclusively online learning activities, many universities have developed their open educational resources policy by enlarging open access to their digital resources, developing new contents, and making many resources available free-of-charge to the general public. In this context, traditional universities have often been forced to design more flexible formats, such as short-term courses and modular learning, and encouraged to reach out to new target groups, for example by catering to intergenerational groups of learners (Times Higher Education 2020). Hence, the pandemic is likely to contribute to the current growth in online provision, resulting in a diversification of content, including more open educational resources. While remotely reaching learners through online learning provision, the university sector seems to have simultaneously moved closer to its immediate environment in responding to the pandemic. There is evidence of universities responding more directly to the needs of the community. If sustained, such engagement could break down the stigma associated with online higher education, which is often deemed inferior to conventional studies by employers, and sometimes by quality assurance agencies. Establishing a parity of esteem between higher education qualifications obtained on campus and those achieved through digital learning continues to constitute a challenge.

\section{Universities as Drivers of Local Development}

Community engagement constitutes a significant part of universities' contribution to lifelong learning ( $\mathrm{Su}$ and Feng 1994). Engaged universities are connected to their ecosystem to work together on socially relevant issues. Responding to the sustainable development agenda ${ }^{1}$ universities are key institutions for promoting social

${ }^{1}$ Please see, for instance the work of the IAU at https://iau-aiu.net/HESD. 
innovations and the co-creation of solutions to major challenges, such as climate change, environmental degradation, rising inequalities, migration and global pandemics, among others (International Association of Universities 2019). Community engagement places particular attention to the needs of socially disadvantaged groups, which are often neglected (Preece 2017). This role is commonly conceptualized as the 'third mission' of universities, alongside education and research (Field et al. 2016).

An illustration of such partnerships is found in the emerging movement of learning cities and, specifically, the role that universities play in learning cities' strategies (Brennan and Cochrane 2019). Measures detailed in such documents include systems to support and incentivize academic staff and students to become more involved in the community and voluntary sector, as well as measures to enhance the local relevance of teaching and research (UNESCO 2015, 2017). This vision is consistent with the conceptualization of new knowledge production models based on networks and collaboration (Piazza 2018). Through community engagement, universities work with their immediate environment to respond to those challenges, linking local, often citizen-led initiatives to global challenges.

Driven by the principle of inclusion, learning cities advance policies and practices that foster sustainable development, social justice and active citizenship through lifelong learning. As such, they emerge as complex objects at the junction of education, economics, geography and political sciences (Facer and Magdalena Buchczyk 2019). Within the learning city, universities are often seen as key agents for the transfer of knowledge and the development of innovation networks. In particular, they are key to fostering processes of collective learning and innovation (Upton 2018). Furthermore, universities are often major economic powers at the local level-both as employers and investors - and are thus legitimate voices in the policy debate on skills needs, in attracting new industries, and more broadly, in urban regeneration and sustainable development at the local level.

\section{Engaging Universities for Global Citizenship}

The migration crisis has modified and introduced a human right dimension to the discussion on the internationalization of universities. Previously dominated by the "dictatorship of international ranking" and the global competition for attracting feepaying students, the debate has recently shifted in response to the deep international migration that currently affects humanity and one of its most tragic expression: the refugee crisis. This new concern has been amplified by media attention and the feeling that universities are failing refugees. While there are at least 79.5 million people displaced globally, including nearly 26 million refugees-around half of whom are under the age of 18 - only $3 \%$ of refugees have access to higher education (UNHCR 2020). This is a humanitarian catastrophe as well as a loss development potential for the planet. In recent years, the international community and an increasing number of universities in the world have been reflecting on ways to open the doors of higher 
education to refugees. Besides financial, physical and psycho-social barriers, the greatest obstacle is the lack of recognition, validation and accreditation of learning outcomes. Refugees are often unable to provide proof of their educational achievements and, even when they are able to do so, their previous studies are often not recognized in the host country.

At the global level, UNESCO has been engaged for a number of years in facilitating a consensus among member states to include specific provisions for refugees in the new regional conventions on the recognition of higher education qualifications. In 2019, the adoption of the UNESCO Global Convention on the Recognition of Higher Education Qualifications marked a pivotal moment. The new convention provides a global standardized process for improving mutual information on higher education systems and qualifications and a methodology for comparing university qualifications across countries. UNESCO has also contributed to the standardization of processes for assessing the qualifications of refugees. The so-called 'Qualifications Passport' is meant to guide the recognition, validation and accreditation of learning outcomes of refugees or vulnerable migrants who have completed or partially completed studies, in the absence of official educational documentation. This will provide credible and reliable information for accessing the job market or further studies.

At the institutional level, a number of universities have taken advantage of their autonomy by already introducing more flexible approaches to admission, using different ways to assess academic achievements in the absence of complete qualification documents. In addition, innovative approaches have been devised to deliver higher education to those who cannot reach university campuses, notably students in refugee camps. For instance, digital learning in higher education is being placed at the service of refugees in Jordan and Lebanon through online programmes. In partnership with UNHCR, universities are now promoting the concept of "university corridors" to give refugee students from war-torn countries the opportunity of continuing to pursue their studies abroad or online. As such, they are contributing to reinvent humanitarian responses and recognize the essential role that higher education plays for addressing the refugee crisis and for protecting the human rights of refugees, including their right to education.

While, for several decades, the discourse on skills has dominated the field of lifelong learning, attempts and progress are being made to broaden its focus to return to a holistic concept of lifelong learning. This changing perspective involves recognizing the role of decentralized learning networks. Within that context, the diversification of access modes and learning pathways, the rise of digital provision and open educational resources, the engagement of universities at the local level-including within learning cities-and their global social responsibility in responding to the refugee crisis are signs of a renewed mandate for the university sector. Through their contribution to lifelong learning, universities ${ }^{2}$ are responding to very deep changes and

\footnotetext{
${ }^{2}$ UIL and IAU launched in 2020 an international university survey on the contribution of universities to lifelong learning, the outcome of this work is meant to be presented at the 2022 UNESCO World Conference on Higher Education.
} 
transformation in our societies, including ageing, social inequalities, environmental sustainability, digitalization, migration and global pandemics. Such transformations pose huge challenges that need to be addressed through collective, participatory and decentralized processes which require and support active and global citizenship. Fostering these dynamics through lifelong learning may be a new frontier for universities.

\section{References}

Bernado, B. S., Audet, X. L. L., \& Isus, S. (2017). Determinants of user demand for lifelong learning in institutions of higher education. International Journal of Training and Development, 21(1), 145-166. https://doi.org/10.1111/ijtd.12101

Biesta, G. (2006). What's the Point of Lifelong Learning if Lifelong Learning Has No Point? On the Democratic Deficit of Policies for Lifelong Learning, European Educational Research Journal, Volume 5, Numbers 3 \& 4

Brennan, J. \& Cochrane, A. (2019). Universities: in, of, and beyond their cities, Oxford Review of Education, 45:2, 188-203, https://doi.org/10.1080/03054985.2018.1551198

Carlsen, A., Holmberg, C., Neghina, C., Owusu-Boampong, A. (2016) Closing the Gap: Opportunities for distance education to benefit adult learners in higher education. Germany: UNESCO Institute for Lifelong Learning.

Cendon, E. (2018). Lifelong Learning at Universities: Future Perspectives for Teaching and Learning. Journal of New Approaches in Educational Research, 7(2), 81-87. https://doi.org/10.7821/ naer.2018.7.320

European University Association. (2008). European Universities' Charter on Lifelong Learning. Retrieved from: https://eua.eu/downloads/publications/european\%20universities $\% 20$ charter\%20on\%20lifelong\%20learning\%202008.pdf (26.08.2020)

Facer, K. \& Magdalena Buchczyk, M. (2019) Towards a research agenda for the 'actually existing' Learning City, Oxford Review of Education, 45:2, 151-167, https://doi.org/10.1080/03054985. 2018.1551990

Field, J. (2000). Lifelong Learning and the New Educational Order. UK: Trentham Books, Ltd.

Field, J., Schmidt-Hertha, B., Wadenegger, A. (2016). Universities and Engagement, Routledge, New York.

Findsen, B., \& Formosa, M. (2011). Lifelong Learning in Later Life: A Handbook on Older Adult Learning. AW Rotterdam: Sense Publishers.

Flemming,T. (2006). The University and Democracy: Habermas, Adult Learning and Learning Society, Maynooth Philosophical Papers. January 2006

International Association of Universities (2019). Higher Education \& SDG 13 : Climate Action Through University Teaching, Research and Community Engagement, IAU.

Jogi, L., Karu, K., \& Krabi, K. (2015). Rethinking teaching and teaching practice at university in a lifelong learning context. International Review of Education, 61, 61-77. https://doi.org/10.1007/ s11159-015-9467-z

Johannesen, H. S. (2018). 'Back into your arms' - Exploring models for integrated university professional learning in a lifelong perspective. Widening Participation and Lifelong Learning, 20(2), pp. 96-121. https://doi.org/10.5456/WPLL.20.2.96

Kejawa, I.D. (2017). Life Long Learning: A Strategic Analysis of Education. International Journal of Current Research, 9(4), 1-19.

Knapper, K. (1983, 2009 online). Media and adult learning: A Forum: Lifelong learning and distance education. American Journal of Distance Education, 2(1), 63-72.

Lengrand, Paul (1970), Introduction á l'éducation permanente, UNESCO: Paris. 
Marinoni, G., van't Land, H. and Jensen, T. (2020). IAU Global Survey on the Impact of COVID-19 on Higher Education around the World, IAU.

Milic, S. (2013). The twenty-first Century University and the Concept of Lifelong learning. Australian Journal of Adult Learning, 53(1), 159-178.

Moreira, J.-A., Reis-Monteiro, A. and Machado, A. (2017), Higher education distance learning and e-learning in prisons in Portugal. Comunicar, 25(51), 39-49.

Piazza, R. (2018). Creating learning opportunities for the cities : community engagement and third mission in the university of Catania, in James, J., Preece, J., Valdés-Cotera, R. (2018). Entrepreneurial learning city regions, Springer.

Preece, J. (2017). University Community Engagement and Lifelong Learning. Palgrave Macmillan. https://doi.org/10.1007/978-3-319-56163-9

Šimenc, M., Kodelja, Z. (2016) Lifelong Learning_From Freedom to Necessity, Creative Education, 7, 1714-1721, https://doi.org/10.4236/ce.2016.712174

Smidt, H. and Sursock A. (2011) Engaging Lifelong Learning: Shaping Inclusive and Responsive Universities (SIRUS). Belgium: European University Association.

Stromquist, N. P., \& da Costa, R. B. (2017). Popular Universities: An Alternative Vision for Lifelong Learning in Europe. International Review of Education, 63, 725-744. https://doi.org/10.1007/ s11159-017-9662-1

Su, Y., \& Feng, L. (1994). Community Service as a Lifelong Learning Practice: Themes and Hypothesis. International Journal of Humanities and Social Science, 4(4), 219-226.

Times Higher Education (2020), When will lifelong learning come of age, Retrieved from: https://www.timeshighereducation.com/features/when-will-lifelong-learning-come-ofage (24.07.2020)

United Nations (2016), Report of the Special Rapporteur on the right to Education, A/71/358 General Assembly, New York

UNESCO (2020), Higher education institutions' engagement with the community, UNESCO COVID-19 Education Response, Education Sector issue notes Issue note $n^{\circ}$ 5.3, Retrieved from: https://data2.unhcr.org/en/documents/details/75890 (26.08.2020).

UNESCO Institute for Lifelong Learning (2015), Guidelines for Building Learning Cities, UIL, Hamburg, Germany.

UNESCO Institute for Lifelong Learning (2017), Learning Cities and the SDGs: A Guide to Action, UIL, Hamburg, Germany

UNHCR (2020). Figures at a Glance, Retrieved from: https://www.unhcr.org/figures-at-a-glance. html (26.08.2020)

Upton, S. (2018). Overcoming cultural resistance to city-regionalism: what role for universities, in James, J., Preece, J., Valdés-Cotera, R. (eds.), Entrepreneurial Learning City Regions, Springer.

Yang, J., Schneller, C. and Roche, S. (2015) The Role of Higher Education in Promoting Lifelong Learning. UIL, Hamburg, Germany.

David Atchoarena has been Director of the UNESCO Institute for Lifelong Learning since April 2018. He was previously Director of the Division for Policies and Lifelong Learning Systems at UNESCO, including higher education. Prior to working for UNESCO, including many years at the International Institute for Educational Planning as programme specialist and later on Team leader, Mr Atchoarena served as Chargé de Mission at the National Agency for Lifelong Education of the French Ministry of Education and as a project coordinator in the Ministry of Finance and Planning in Saint Lucia. 
Open Access This chapter is licensed under the terms of the Creative Commons Attribution 4.0 International License (http://creativecommons.org/licenses/by/4.0/), which permits use, sharing, adaptation, distribution and reproduction in any medium or format, as long as you give appropriate credit to the original author(s) and the source, provide a link to the Creative Commons license and indicate if changes were made.

The images or other third party material in this chapter are included in the chapter's Creative Commons license, unless indicated otherwise in a credit line to the material. If material is not included in the chapter's Creative Commons license and your intended use is not permitted by statutory regulation or exceeds the permitted use, you will need to obtain permission directly from the copyright holder. 


\title{
The Promise of Education: The Future
}

\author{
Roberto Escalante Semerena
}

Universities and higher education institutions (HEIs) have always been key actors in society. Their capacity for knowledge production, their constant enquiry into new possibilities of approaching reality and its problems, and their critical thinking have always been highly valued by society. Universities have always accompanied society in its development and will continue doing so. They are a public good and a social right. Society requires a safe space where the freedom to think and freedom of speech exist to reflect on and serve society's needs. This is why society has granted universities the autonomy to organize and govern themselves, with the sole condition being that universities commit to giving back to society the results of the knowledge they generate.

Society is changing rapidly; never before has it experienced such huge technological changes. Within only a few decades, citizens can draw upon technology to enhance their productive capacity, to facilitate communication, to have unprecedented levels of welfare at their disposal, i.e. health care, education, nutrition. Education has not shied away from innovation, and it has embraced these technological benefits. Remote teaching, online education, virtual education and many other possibilities are today a reality allowing millions of people of all ages to have access to knowledge, not only to train themselves for the future but also to continuously enhance current competences through life-long learning. Knowledge has thus become a lifelong companion. The university has always accompanied society, but today it does so more rapidly and efficiently.

Despite all these admirable developments, universities are facing several hurdles. Addressing and discussing them might help us to overcome some of them.

The first one, and one that is extremely important, is pertinence. It is not true that knowledge per se positively affects society and/or nature. In the social and economic

R. Escalante Semerena $(\varangle)$

Association of Universities of Latin America and the Caribbean (UDUAL), Mexico City, Mexico e-mail: roberto.escalante@udual.org 
arena, the current practice known as neoliberalism has produced immense disparities amongst and within societies. More than ever, societies are unequal, and the world is clearly divided between national economies that can amply satisfy the needs of their inhabitants and others whose citizens suffer from a lack of basic health care or who do not receive even the minimum nutritional levels needed. Latin America and the Caribbean, despite their large endowment of resources (see the case of Venezuela), is the most unequal region of the world.

Neoliberalism is a university product, so to speak, as its theoretical aspects were developed within most prestigious academic institutions. It is safe to say that neoliberalism is, and unfortunately will continue to be for some time, extremely pernicious to society.

It is true that it would be hard to imagine any kind of development without the knowledge produced at higher education institutions. At the same time, it is also true that any such knowledge has to benefit the largest sections of society. Today, according to Oxfam, the richest 800 families of the world earn more than the rest of the world combined.

Universities have to be socially oriented, encompassing every sector of society, and setting their priorities clearly. Science has to set itself the task of fighting and overcoming poverty - especially in those communities in which the overwhelming majority are poor.

Science is not, and cannot remain, neutral; it has to be reoriented now. The outputs of scientific production still favour by far the richest sections of society.

Another fundamental challenge higher education institutions have to face is their failure to establish a mutually enriching process of dialogue within societies. It has been said above that development cannot occur without science. However, at the same time, we must recognize that education cannot per se do the whole job. There are many other factors at play and which determine whether development can become a reality - or not. These factors are linked to politics, and that is why HEIs have to learn how to better interact with society. One of the most effective ways of achieving that is to politicize them. And to do that does not mean linking an institution to a particular political party or association; nor does it mean making universities partisan of a particular ideological persuasion. Quite the opposite. What politicizing universities means is to introduce the public concerns into their structural modus operandi. Students, lecturers, researchers must incorporate into their daily tasks such as teaching and research, the urgent needs and pressuring worries of society. Climate change, malnutrition, sanitation, health, education are but a few subjects that have to be present in the daily agenda of those working with knowledge; this will enhance their capacity to put forward feasible solutions.

Relevance and social engagement are primordial. But equally important is having a modern outlook and looking to the future. In the last forty years or so, the world has changed. The use of the Internet has transformed almost every aspect of our life, including education. Many countries are increasingly using digital tools to educate people at all levels. Its impact is so powerful that some scholars have argued that universities could be replaced by digital education; that universities are not as effective as virtual education and are expensive organizations. 
Undoubtedly, the digitalization of life and education are powerful instruments that can help expand the frontiers of knowledge. However, at the same time, we have to be aware that machines are at the service of humans. Thus, what really matters is how we want to use digital tools and which of those instruments are pertinent in the current context.

One example that comes to hand is the present crisis resulting from Covid-19. Remote teaching has allowed the continuation of education provision to millions of students. However, this is true mainly in developed countries where students have access to computers and the Internet. In the low- and middle-income countries, the situation is quite different. Students from poorer parts of society have been excluded because either they do not have computers, or access to the Internet, or both.

Special effort has to be made to incorporate technology into education, including, of course, higher education. However, technology should be at the service of education, of improving university performance in both the social and economic spheres. Let us be modern in order to be more socially oriented.

The 70th anniversary of the International Association of Universities (IAU) represents the propitious occasion to remind ourselves of the need that universities have to be socially oriented in producing knowledge; socially linked to address the real needs of society and also learn from them and to be modern without losing touch with reality. Such a troika must mean maintaining the real sense of education. And that has to be the promise of education. Education, and higher education in particular, is available and is organized to help society and its members and in a more equitable fashion. If higher education does not fulfil that need, it will inevitably lose its raison d'être.

Roberto Escalante Semerena is Secretary-General of the Association of Universities of Latin America and the Caribbean (UDUAL) and Member of the IAU Executive Board. He is a fulltime Professor in the Faculty of Economics at the National Autonomous University of Mexico (UNAM); he received his Bachelor from UNAM and a Master and PhD in Rural Development from the University of London.

Open Access This chapter is licensed under the terms of the Creative Commons Attribution 4.0 International License (http://creativecommons.org/licenses/by/4.0/), which permits use, sharing, adaptation, distribution and reproduction in any medium or format, as long as you give appropriate credit to the original author(s) and the source, provide a link to the Creative Commons license and indicate if changes were made.

The images or other third party material in this chapter are included in the chapter's Creative Commons license, unless indicated otherwise in a credit line to the material. If material is not included in the chapter's Creative Commons license and your intended use is not permitted by statutory regulation or exceeds the permitted use, you will need to obtain permission directly from the copyright holder.

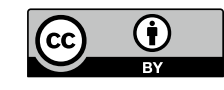




\title{
The African Dream for Quality Higher Education
}

\author{
Ahmed Legrouri
}

\section{Introduction}

Education is well established as a leading means for building broad-based social welfare, promoting economic development and eradicating poverty. Most governments and international development agencies have, for many years, argued for a sequential development of schooling, giving priority to primary and then to secondary education before moving on to higher education. The World Education Forum: Education for All (Dakar, Senegal in 2000) advocated for primary education as a lone driver for development. In 2015, the United Nations recognised the role of HE in advancing the 2030 sustainable development agenda. HE is mentioned among the 17 Sustainable Development Goals (SDGs) in target 4.3 and forms an important part of other goals (See Higher Education and Research for Sustainable Development (HESD) global portal, International Association of Universities).

The relevance and the contribution of $\mathrm{HE}$ and scientific research to economic, social and political development is well recognised in today's world. The increase in the relevance and the quality of these two sectors has become a priority in the strategic agendas of most nations, and especially in developing countries. In this knowledge economy and society, HE is entrusted with the practical mission of creating knowledge that offers solutions to the critical problems facing society. In 2009, the World Bank (2009) argued for the need of higher-order skills and expertise in Sub-Saharan Africa in order to achieve sustainable growth and to be successful in global knowledge-driven markets.

In contrast to traditional education, 21st century HE institutions (HEIs) are required to provide new skills and abilities in this fast-advancing digital era. Several studies have reported that, because of technological advances in all fields, some jobs will disappear, and others will emerge in the near future, and employment

\footnotetext{
A. Legrouri $(\bowtie)$

International University of Grand-Bassam, Grand-Bassam, Côte d'Ivoire e-mail: legrouri@gmail.com 
would therefore require new professional skills and competencies (OECD 2019). Therefore, HEIs should offer practical and dynamic classes and put the emphasis on long-lasting soft skills (critical thinking, leadership, entrepreneurship, communication, languages, innovation, agility, etc.), in addition to the competencies of specific disciplines (computer science, mathematics, finance, economics, political science, sociology, etc.). Ehlers and Kellermann (2019) categorised future skills into 16 skill profiles subdivided into three dimensions, namely (1) individual development skills, (2) individual object-related skills and (3) individual organisation-related skills. Lifelong learning and permanent refreshment are necessary to protect HE graduates from unemployment in this rapidly changing era (Hodgson 2013).

It is within this African and international context that several initiatives have been launched in the continent to experiment new HE models and paradigms. In this paper, the dynamics of HE in Africa are discussed. Given the difference in this area between North and Sub-Saharan Africa, two countries are chosen as examples: Côte d'Ivoire and Morocco. Success stories and challenges facing these two countries are reviewed.

\section{The African Context}

Africa is a huge continent. With over 30 million $\mathrm{km}^{2}$, it could house within its contours China, USA, India, Japan and a very large part of Europe. It is endowed with rich and diverse natural resources. In addition, the continent has by far the world's youngest population, with a median age of 18 years, compared to 42 for Europe, 35 for North America and 31 for Asia and Latin America. Almost $41 \%$ of its population is under 15 -years-old, while only $3 \%$ is more than 65 years old (World Economic Forum 2020).

Africa has the highest rate of population growth. The population of sub-Saharan Africa, estimated to be a billion, is expected to double by 2050. At the same time, the working-age population is expected to increase from 705 million in 2018 to almost 1 billion by 2030 (African Development Bank 2019). This rapid growth would represent enormous opportunities for Africa and make it an important continent in the world economy if the youth is equipped with the right skills and given the right prospects. Otherwise, this will be a major threat as unemployment and underemployment of youth is a major challenge, which is enhanced by urban expansion in most African countries.

It is worth noting that African countries differ significantly, and it is difficult to generalise characteristics and trends in such a large and diverse continent. However, there are some common features and challenges, particularly in different regions. Regarding the HE sector, three countries or groups of countries appear to relate to each other: South Africa, Sub-Saharan Africa and North Africa.

Today, with all its assets, Africa is facing a variety of complex challenges as it attempts to eradicate poverty and build broad-based, social and economic development. One way to mitigate these challenges is to deploy relevant and dynamic 
strategies to create a critical mass of highly educated and skilled people. Therefore, there is a pressing need to improve the educational systems in most African countries, which are lagging behind all the other world regions. A successful transition from educational institutions to the labour market is a key factor to mitigate some of the challenges. Unfortunately, African tertiary education is under-developed, with only $16 \%$ of the relevant age group having access to this sector when the global average stands at about $48 \%$. Additionally, women are underrepresented in higher education, particularly in science and technology (S\&T).

As home to the world's oldest universities, Al Karawiyin in Morocco (859 AD) and Al-Azhar in Egypt (970 AD), Africa is aware of the benefits of HE, and for some time now, HE is recognised as a key sector in African development (Teferra and Altbach 2004). However, HEIs in many African countries are relatively few in number, but projects are underway to change that and also open HE to more females and to students from low-income areas.

In regard to quality, not a single African university features in the rankings of the world's best 100 academic institutions (Shanghai, Times Higher Education, QS, Webometrics). Only six universities appear among the top 500 in the Shanghai ranking (South Africa: 5, Egypt: 1). The number of all African countries listed in this ranking is equal to that of the Netherlands. In addition to South Africa and Egypt, Nigeria appears among the top 500 in the Times Higher Education ranking with two institutions.

In terms of research, Africa produced 58,824 (2.3\%) science and engineering articles in peer-reviewed journals out of the world's production of 2,555,959 in 2018 (National Science Foundation 2020). This is a little higher than the production of Spain. South Africa and Egypt share $43 \%$ of the African output, while the five North African countries produced $50 \%$. This is due to lack of funding for research, facilities and research-experienced faculty in most African HEIs. Another issue is that subSaharan Africa depends greatly on international collaboration for its research output. In 2015, South Africa produced $52 \%$ of its research papers with foreign co-authors (Ekrem 2020).

In the current era of knowledge and intelligence, developments in all areas are intertwined and growing fast, through innovation. Therefore, HE needs to adapt and adopt more entrepreneurial and innovative pedagogical approaches, research and development programmes as well as engage more with socio-professional actors. The governance model should incorporate strategic planning approaches, with SMART key performance indicators, leadership in the culture of change, continuous improvement through quality assurance and accreditation, and social responsibility. Such an innovative and creative model will also ensure the necessary academic integrity.

Apart from South Africa, most of the countries in Sub-Saharan Africa and North Africa regions present several common features. Therefore, two representative countries were chosen as examples: Côte d'Ivoire and Morocco. The HE systems in these two countries, which are based on the French model, have undergone several reforms since independence. The public HEIs may be subdivided into three main components: (1) open-access HEIs that give access to any student with a high school diploma, leading to massification of these institutions, (2) regulated-access HEIs (engineering, 
business, medical, architecture, ...) that are very selective and offer better employment conditions and job prospects to their students, (3) vocational training schools. Some of the regulated-access HEIs are under the supervision of ministries other than the ministry of Higher Education and Scientific Research.

In an attempt to increase the competitiveness of their HE systems, Côte d'Ivoire (in 2009) and Morocco (in 2003) adopted the three-cycle system (3-year Licence/ Bachelor, 2-year Master, 3-year Doctorate) of the Bologna process, created by the European Higher Education Area in 1999. In an attempt to meet society's expectations and labour market needs as well as to enhance the skills set of students, the Moroccan government decided to move away from the 3-year Licence/Bachelor. Starting 2020-2021, the 4-year Bachelor will include, in addition to the speciality courses, modules of foreign languages and four sets of soft skills (study, life, civic, professional skills).

In this globalised world, many non-English-speaking countries are increasing the number of English-taught degree programmes, either partially or entirely. This type of programmes has grown notably during the 21 st century worldwide, including in francophone Africa. Côte d'Ivoire and Morocco have established two independent, US-style and English language-medium universities; namely, the International University of Grand-Bassam (IUGB 2005) and Al Akhawayn University in Ifrane (AUI 1995), respectively. AUI and IUGB, as liberal-arts institutions, have adopted the use of technology and innovative approaches in their teaching and learning systems as well as in their other activities. In order to ensure quality, both institutions are adopting best practices in HE and working with accreditation institutions in the USA. AUI received programme accreditations and institutional accreditation in 2018 from the New England Commission of Higher Education.

In 2017-2018, Côte d'Ivoire counted 219,368 students (41\% female) in 36 universities and 240 specialty schools. Aware of the role of the development of human capital as a major key for national development, the government initiated a ten-year education and training development plan (2016-2025), which includes HE\&SR. Several actions were undertaken to improve the HE system, including the creation of a Joint Commission (private sector/HE), the extension and rehabilitation of existing universities and the construction of six new institutions in different regions, the promotion of quality assurance and accreditation as well as the culture of evaluation. However, despite all these efforts, the sector still faces several challenges, including mobilisation of financial resources, management of human resources, massification of public universities, internal performance (student failure and drop-out) and external performance (level of graduates' professional integration).

In 2019-2020, Morocco counted 1,009,678 students (49\% female) in 23 universities. The marked disinterest of students for science and the unemployment rate of graduates in open-access HEIs, among other reasons, led to the reform of the 3-year Licence/Bachelor. The 01-00 law (2000) brought some strengths to the HE system, such as institutional autonomy. HEIs establish their internal quality assurance system based on on-going self-assessment. Two national evaluation and quality assurance agencies are in charge of evaluating HEIs, training programmes, scientific research, ... Several challenges are still to be addressed in the near future, with the two major 
ones being linguistic inconsistency and the inadequacy of training adapted to labour market needs, mainly from open-access HEIs.

It is worth noting that, in both Côte d'Ivoire and Morocco, the employability of the graduates of some specialty schools, like engineering, medical, business, etc., is good. Unfortunately, a good number of these graduates opt to serve the developedcountries' job markets.

\section{Conclusion}

Although Africa has demonstrated significant efforts to improve its HE systems, most of its diverse societies have not yet reached the desired level to compete within knowledge economies. HE in the continent is seriously affected by the low level of countries' economies. Students from low-income families are generally tempted to enter informal job markets instead of seeking more knowledge, competencies and skills needed for high-level positions. In Africa, unemployment rates tend to be higher among university graduates than the uneducated or less educated youth.

There are several success stories to learn from within the continent. The last decade witnessed the emergence of certain HEIs that adopted active, entrepreneurial and interdisciplinary approaches and offered more meaningful and articulated learning environments. These institutions also understood the role of internationalisation and joined networking initiatives, such as the International Association of Universities, for collaboration, knowledge exchange and advocacy of best practices in HE.

However, most of the public HEIs in Africa are finding it difficult to embrace innovative educational approaches, mainly because of lack of resources and overwhelming student enrolment. Governments and all stakeholders are aware of the challenges and are working on improving their education and training offers.

21 st century students are digital and need dynamic and practical classes and opportunities to develop both their technical skills, through regular interaction with socio-professional environments, and their interpersonal skills, through co-curricular activities and international experience.

\section{References}

African Development Bank (2019). African Economic Outlook 2019, Retrieved from: https:// www.afdb.org/fileadmin/uploads/afdb/Documents/Publications/2019AEO/AEO\$_\$2019-EN. pdf (1.06.2020)

Ehlers, U.-D., \& Kellermann, S.A. (2019). Future Skills: The Future of Learning and Higher education. Karlsruhe, Germany: Results of the International Future Skills Delphi Survey.

Ekrem J. (2020). South Africa by the numbers: An overview of its $S \& T$ performance, Brussels, Belgium: Science Business Publishing International, Retrieved from: https://sciencebusiness. net/international-news/south-africa-numbers-overview-its-st-performance. (1.06.2020) 
Hodgson A., Editor (2013). Policies, Politics and the Future of Lifelong Learning. Abingdon-onThames, UK: Routledge.

National Science Foundation (2020). National Center for Science and Engineering Statistics, National Science Foundation, Retrieved from: https://ncses.nsf.gov/pubs/nsb20206/publicationoutput-by-region-country-or-economy (1.06.2020)

OECD (2019), The Future of Work. OECD Employment Outlook 2019, Retrieved from: https:// www.oecd.org/employment/Employment-Outlook-2019-Highlight-EN.pdf (26.07.2020)

Teferra D., \& Altbach P.G. (2004). African higher education: Challenges for the 21 st century, Higher Education, 47: 21-50.

World Bank (2009). Accelerating Catch-up: Tertiary Education for Growth in Sub-Saharan Africa. Directions in Development, Retrieved from: https://openknowledge.worldbank.org/ handle/10986/2589 (26.07.2020)

World Economic Forum (2020). Mapped: The median age of the population on every continent, Retrieved from: https://www.weforum.org (26.05.2020)

Ahmed Legrouri is Provost \& VPAA, International University of Grand-Bassam, Côte d'Ivoire. He holds a BS, Rabat University, Morocco, a Doctorate, INP Toulouse, France, and a Ph.D., Glasgow University, UK. He was Professor at Marrakech University and Professor, Dean \& VPAA at Al Akhawayn University in Ifrane, Morocco. He supervised several doctoral theses and published more than eighty peer-reviewed articles. He is a member of several advisory committees and received several merit-based fellowships. He speaks Arabic, English, French and German.

Open Access This chapter is licensed under the terms of the Creative Commons Attribution 4.0 International License (http://creativecommons.org/licenses/by/4.0/), which permits use, sharing, adaptation, distribution and reproduction in any medium or format, as long as you give appropriate credit to the original author(s) and the source, provide a link to the Creative Commons license and indicate if changes were made.

The images or other third party material in this chapter are included in the chapter's Creative Commons license, unless indicated otherwise in a credit line to the material. If material is not included in the chapter's Creative Commons license and your intended use is not permitted by statutory regulation or exceeds the permitted use, you will need to obtain permission directly from the copyright holder.

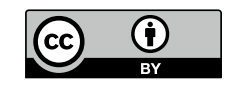




\title{
Science and Social Responsibility - Heritage and Mission
}

\author{
Godehard Ruppert
}

In his poem "The Garden of Theophrastus" of 1962, dedicated to his son, Peter Huchel writes "remember those who once planted their conversations like trees." This is a nice bit of advice from father to son, but it holds an even greater meaning.

Theophrastus, the great logician and botanist, was Aristotle's student and successor, and thereby heir to a kind of intellectual tradition that more than any other cultivated the art of conversation as a means of seeking the truth. It also marks the beginnings of a development towards the European academic tradition.

At the outset of modern science, it was, as it may have been in antiquity, still possible to engage in direct conversation. The arenas of science and learning were like villages: face to face societies where every scholar was well acquainted with the other and their work. But, the villages of academia grew to become cities. Observers at the time commented that the transformation of the sciences, research and learning was happening at an industrial scale with the trend going towards large research and teaching institutions whose organisational structures were based on division of labour principles. Direct conversation and discussion would necessarily have to fall by the wayside in these structures. This development simultaneously and inevitably fostered the creation of disjointed communicative spheres, which barred society as a whole from participating.

Academic development itself pushed in this direction. Modern academic knowledge is synonymous with specialised knowledge. This specialised knowledge cannot be attained without the development of subject-specific jargon. Not only does this ultimately exclude the interested layperson from participating in academic discussion, it also makes communication across disciplinary borders increasingly difficult.

\footnotetext{
G. Ruppert ( $\square)$

University of Bamberg, Bamberg, Germany

e-mail: godehard.ruppert@uni-bamberg.de

(C) The Author(s) 2021 
During the past 20 years, we have witnessed a passionate discussion in many countries about higher education systems. The main reason for this is that the number of students has grown enormously in the recent decades, while the number of university faculty has not matched this growth, and apart from this, university finances are insufficient.

\section{II}

A common phrase used in discourses on higher education policy goes as follows: The modern university is founded on the heritage of Wilhelm von Humboldt. Surely, there were others as well - like Schleiermacher - who is, especially outside of Germany, seldom, if ever mentioned.

In the US, modern universities, i.e. those that combine research and teaching, have existed since the last quarter of the 19th century. Whereas today, it is often said that the Humboldtian University in Germany has ceased to exist, representatives of the leading universities in the USA refer to the heritage of Humboldt and attribute the success of the Western universities to his ideals. How can these different views be accounted for? What, in Humboldt's eyes, are the essential qualities of a university that would merit the foundation of a university? As a result of the French revolution, the universities in France were dissolved and reappeared only later following the reorganisation of the educational system, including the replacement of universities by schools for specific professions. The Prussian King Friedrich Wilhelm III also followed the widespread ideas of the Enlightenment. This meant that the universities, with their corporate autonomy, were considered relics of the so-called dark Middle Ages and were replaced by state-controlled university-schools for advanced studies. In 1801, Friedrich Wilhelm explicitly demanded that the Royal Academy for Construction, which was founded in Berlin, instruct "practical workers for construction and not professors".

Indeed, the traditional university of the Middle Ages prepared students only for the profession of a scholar or a teacher. The Baccalaurean had to learn to teach under the supervision of the Magister. Through promotion to Magister and Doctor, as expressed in the titles, he was recognised as an autonomous teacher and was granted the right to teach. But, ever since the founding of the first universities in the early 13th century, the combined concept of learning and teaching, that is, the method of searching for truth through reason, has proven to be an excellent training for the rational mastering of other public tasks as well. Under the influence of Humanism, theoretical efforts to gain scientific knowledge became secondary to training for public service. Schools for military and veterinary professions, as well as academies for construction and mining were founded in addition to universities.

Wilhelm von Humboldt was an opponent of this development. He convinced the king that the renewal of state and society could not be achieved by mere professional training in specialised higher education facilities, but that it depended on a revival of scientific training. For this purpose, the university was believed to be the best option. The special role Humboldt foresaw for the university was that it should concern itself with the sciences to solve problems with the help of research; professional schools, in 
contrast, dealt with accepted knowledge. In order to achieve its aims, the university required freedom. In terms of practical life, the students were to live closely together with their peers having similar ways of thinking, as well as in proximity to scholars and teachers devoted to their disciplines. This social-cultural aspect, and not the mere listening to lectures, was perceived as the foremost goal of the university. The state's role was to restrict itself to creating favourable conditions in support of such endeavours. Therefore, the newly founded universities were not only designed as teaching institutions but also as corporations equipped with essential rights. The most decisive right granted was freedom of research and teaching, which was added to the right of awarding academic degrees and the right to self-administration of academic affairs.

The university is both a consequence and driving force in the process of rationalisation and urbanisation. Up to the First World War, most of the German population, for example, had professions in agriculture, trade and industry. Only a few required a scientific education. However, in the modern information society, scientific knowledge is necessary for most professions. Today, we need an education system which gives large parts of the population access to scientific knowledge, not only for professional use but also for a better understanding of the world at large.

We should never forget: Universities have other tasks than guaranteeing everchanging and highly specialised instruction. Universities should never transform into something like vocational high schools; that would be non-profitable in economic terms and, moreover, nothing less than dangerous. The success and appeal of a higher education system do not depend on the quantifiable results of particular disciplines. The humanities face more difficulties in this regard than the natural or technical sciences.

The teaching of ready-made knowledge - as Humboldt was quite right to say - is typical of schools, while the classic university always "remains in a state of research". It is one of the fundamental tasks of the university to criticise established knowledge in order to confirm, correct, expand or replace it with new knowledge.

It is another fundamental task of the university to pose questions to society and discern and identify those developments that are truly conducive to healthy human relations and progress. Universities should shape ideas and concepts about education and culture; and this principle should never be sacrificed in favour of short-term profits and mono-dimensional utility.

\section{III}

Historical development, sociologically as well as politically speaking, cannot be reversed. Following the Second World War, this development aptly described as "Big Science" accelerated. The unparalleled growth of industrial-produced knowledge in many research institutions outside of the universities further marginalised the conventional village-like modes of academic communication... One talks less and publishes more.

In conclusion: the progress of opening universities to society was a tremendous advancement, and we must not begin to regress. However, this advancement has not 
come without a cost. The modes of communication at mass universities are quite different from those at traditional, smaller universities.

\section{IV}

What is to be done? There seem to be three options.

Option One: One can simply accept the circumstances as they are and isolate oneself in specialised jargon. In my opinion, this already happens far too often. This option, of course, is a winning strategy for those who are rewarded for knowing as much as possible about as little as possible. However, this type of specialisation comes with a price: they turn into silos of specialised knowledge and a lack of transversal skills. One who sets up a shop in a single room built of their own specialised competence is indeed familiar with every nook and cranny. But a constant perspectivation of who is in charge of what is the foundation of the worst kind of bureaucracy.

Many have noted that new knowledge emerges more between departments and faculties, rather than within them. This is especially important today for two reasons: The first one is obvious, economic and social problems have become so complex that even marginally satisfactory solutions cannot be found without cooperation and discussion between disciplines. The second reason is not as straightforward: More and more problems - and increasingly everyday life — cannot be resolved without the specialised knowledge that is generated within academic disciplines. If, however, the representatives of such specialised disciplines do not seek contact and engage in discussion with their peers, then they voluntarily, needlessly, and rather foolishly forfeit their academically entitled privilege to think beyond and across the borders of specified fields of knowledge.

Option two: To counter the inability to communicate and bridge a wide range of subjects is well-intentioned but is unfortunately often ineffective: pleas for cooperative discussions, working across borders and seeking communication are favoured as a means to counteract tendencies towards excessive specialisation and reciprocal compartmentalisation in academia. This kind of appeal has been a standard of academic policy rhetoric since at least the 1960s.

Are these appeals naive? Is it not also true that often individual scholars are faced with valid and undeniable challenges to engage in interdisciplinary dialogue? Some are even praised for leaving the ivory tower without ever having set foot inside it. One can, of course, also ask if an excess of interdisciplinarity would not represent a return to dilettantism.

Durable and effective action also always requires an institutional framework. This leaves us with the third option of dealing with the negative effects of specialisation and the lack of communication in academia. It is necessary to create an institutional framework under which representatives of different fields can and must come together. It is imperative that we precisely foster those institutions that place a focus on interdisciplinary discussion, as they are the gardens in which we might plant conversations like trees. 
With an ever-growing student population, we will have more and more institutions of higher education operating like small universities. What used to be different kinds of higher education institutions will soon lose their distinctive profiles. The dangerous outcome of this development is that we will be left with, on the one hand, research universities in which research-professors will not have enough time for teaching, and on the other hand teaching universities in which teaching-professors will not have enough time for research.

\section{V}

If one differentiates between forms of communication based on content, meaning comprehensiveness versus lacking content or the content of veiled communication, then the public areas in which communication often stands above academic insight become clear. By the way, this phenomenon is nothing new: even the Romans differentiated between "dicere" (speak, say) and "loqui" (talk, chat), whereby, concerning the often quoted ecclesiastic phrase "Roma locuta, causa finita", I often ask myself if its author didn't intentionally insert some bitter irony, as the phrase refers to Augustine's 131st Sermon, in which loqui is not used.

But, let us stick to our "academic" context. Academics and the university proudly trace this appellation back to Plato's academy, which, over the course of 700 years, laid the foundation for the western concept of academic endeavours, namely the search for knowledge based on systematic inquiry.

If one looks closely at the fundamental educational goal, one finds three core competencies that ought to characterise an academic's entire life and serve to allow him or her to recognise their societal responsibility:

- the ability to assess academically

- the ability to communicate academically

- an academic openness to new ideas.

These three core competencies have one thing in common: they require that one directly experiences the academic process. Only those who have experienced the ways that new knowledge is created, or "old" knowledge is challenged, can assess knowledge, communicate it to others, and revise their own position in the face of new knowledge. They characterise the academic who, not primarily as a titleholder but rather as a "citizen of the society of knowledge", is bound to reason and therefore consistently challenges "common sense".

With regards to academia, this means that knowledge as a process remains an object of our actions; a process in which development, assessment and communication are integrated. If this academic standard can be successfully communicated in such a way that academia is understood to be the driving force behind the development of a knowledge society, then we need not worry about the quality of the communication.

Perhaps, the word academia itself is laden with an old malediction, as Plato's Academy took its name from the Grove of Akademos, who betrayed Helen's hiding place to the Spartans, and in so doing saved Athens. If this is true, then we must 
search the depths of our vocabulary so that we might, as in Pandora's Box, find beneath so much calamity the real gift: hope. For 70 years now, the IAU has been immersed in bringing this hope to the fore on a global level. For, as Schleiermacher states, at its heart, every academic pursuit is communication, and strictly speaking, communication that keeps society alive. Indeed, we must plant conversations like trees.

Godehard Ruppert was President of the University of Bamberg from 2000 until 2020. He has been also the President of the Virtual University of Bavaria (since 2002). He has been Professor of Religious Education (Chair) at the University of Bamberg and Associate Professor of educational science at University of Hanover. He served for twenty-four years as a member of the University Board. As an experienced expert in Higher Education policy and leadership, he is a member of several national and international organizations and boards (i.a. IAU-Board).

Open Access This chapter is licensed under the terms of the Creative Commons Attribution 4.0 International License (http://creativecommons.org/licenses/by/4.0/), which permits use, sharing, adaptation, distribution and reproduction in any medium or format, as long as you give appropriate credit to the original author(s) and the source, provide a link to the Creative Commons license and indicate if changes were made.

The images or other third party material in this chapter are included in the chapter's Creative Commons license, unless indicated otherwise in a credit line to the material. If material is not included in the chapter's Creative Commons license and your intended use is not permitted by statutory regulation or exceeds the permitted use, you will need to obtain permission directly from the copyright holder.

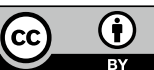




\title{
Unlocking the Potential of Higher Education by Serving the Common Good
}

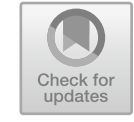

\author{
Patrick Blessinger, Enakshi Sengupta, and Mandla S. Makhanya
}

\section{Introduction}

The more pluralistic a society, the more diverse its educational system tends to be to address the diverse needs within society. No single institutional type and no single pedagogical approach can hope to address all the diverse educational and learning needs within society. In short, a one-size-fits-all approach to higher education is not well-suited to the modern age, which is increasingly characterized by diversity, complexity, uncertainty, risk, and hyper-connectivity. Furthermore, the democratic principles of inclusion, equity, justice, and rights require a more pluralistic structure to meet the diverse needs of society at all levels and in all segments. Therefore, a diverse higher education system is better able to promote the general well-being of society.

The argument and debate over higher education are often framed as a dichotomous question: Is the purpose of higher education to promote individual success or to promote the common good? But framing the question as an either/or question implies that the answer must be only one or the other. It further implies that higher education can only have one purpose or aim.

However, higher education has evolved over its nearly one-thousand-year history to perform three basic functions: teaching, research, and service. These three functions support its core purpose to produce learning (i.e., promote human development), and in so doing, it achieves its other aims such as forming more engaged citizens

P. Blessinger $(\varangle)$

St. John's University, New York, NY, USA

e-mail: patrickblessinger@gmail.com

P. Blessinger $\cdot$ E. Sengupta $\cdot$ M. S. Makhanya

International Higher Education Teaching and Learning Association, New York, NY, USA

e-mail: ekapur@gmail.com

M. S. Makhanya

University of South Africa, Pretoria, South Africa

e-mail:makhams@unisa.ac.za

(c) The Author(s) 2021 
(political/civic purpose), developing more productive workers (economic purpose), and creating more knowledgeable individuals (social/personal purpose) (Blessinger and Anchan 2015; Dorn 2017).

Furthermore, higher education has adapted to the changing political, economic, social, technological, and environmental landscapes over the past millennium. In an age where these landscapes are increasingly interconnected and interdependent, the sustainability of the planet is increasingly linked to and dependent upon how well humans promote the common good. By promoting common interests, humans are also promoting their individual interests and needs.

Evolution has allowed humans to become the dominant species on the planet. This has led to both positive and negative consequences. Not only does this give humans certain benefits and advantages over other species, but it also places on humans an ethical responsibility to be good stewards of the planet. Thus, the new realities of global warming, widespread destruction of ecosystems, pervasive loss of biodiversity, mass deforestation, rising sea levels, shrinking glaciers, increasingly erratic and unpredictable climate change, and increased social instability are likely linked to human-induced activities (Ford 2002, 2016).

Hence, while political, economic, social, and technological disruptions have generally yielded positive results in recent human history (for example, democratic revolution, industrial revolution, cultural revolution, and digital revolution, respectively), the concomitant environmental disruptions that have occurred over the past few hundred years have been largely negative and potentially irreversible. Thus, the next great challenge for higher education institutions is to prepare students and society to address these highly complex, intractable, and urgent questions (Blessinger 2018a,b).

\section{Development of Modern Higher Education}

\section{First wave: nineteenth century to 1945}

During the first wave of modern higher education, institutions began to adopt the Humboldtian model of higher education by integrating research and teaching. During this wave, higher education focused primarily on basic research to produce new knowledge to build out the academic disciplines with specialized knowledge bases. Since, during this time, human activity had relatively less impact on the global environment, applied research was largely a secondary focus. This wave also saw the initial growth of public universities (for example, community colleges and land grant universities in the USA) to bring higher learning to more people. Despite these efforts to bring higher learning to the masses, higher education was still, by and large, an elite higher education system. Martin Trow (1973) defined an elite higher 
education system as one that had up to a $15 \%$ participation rate of the relevant age group.

Second Wave: 1946-1980

After World War II, some countries experienced a huge increase in enrolment as nations shifted their focus from war-time activities to economy-building activities since these new economies required a more professionalized workforce (for example, scientists, engineers, architects, physicians, lawyers, managers, teachers). As such, the primary focus of colleges and universities shifted towards applied research by fostering such issues as democracy around the world, medical and technological inventions, social justice and human rights, and poverty and illiteracy reduction. It was also during this wave that the right to access education at all levels became established in various international laws and human rights documents such as the United Nations International Covenant on Economic, Social, and Cultural Rights (United Nations 1976). As a result, it was during this wave that higher education morphed from an elite system to a mass system of higher education (that is, a $16 \%$ to $50 \%$ participation rate).

\section{Third Wave: 1981-2015}

During the third wave, the world experienced major political, economic, social, and technological changes around the world. During this wave, new global technologies such as the internet spread rapidly and the number of countries that adopted democratic and capitalistic systems (in one form or another) increased significantly (Roser 2019). As a result, demand for higher learning surged as new business models, and delivery modes (e.g., online learning) became more prevalent. During this wave, participation rates in developed and developing countries continued to increase closer to universal rates (that is, over 50\% participation rate). Trow (1973) considered a participation rate of over $50 \%$ to be a system with open access.

\section{Fourth Wave: 2015 to present}

During the fourth wave, the United Nations created the Sustainable Development Goals, which outlined 17 goals that humanity needs to reach to create a more sustainable planet. These goals have become imperative because scientific research on climate change provides unequivocal evidence that human activity over the past few hundred years has severely degraded the planet. Thus, educating current and future generations on how to create a more sustainable planet for the common good is now necessary. As such, a new type of higher education system is needed and is slowly emerging, one that better serves the contemporary and future needs of humanity and the planet, one for the common good (Locatelli 2018, 2019). 


\section{Towards Education for the Common Good}

From an economic science perspective, a private good is a good that is both rivalrous and excludable, a public good is a good that is both non-rivalrous and non-excludable, and a common good is a good that is both rivalrous and non-excludable. Thus, common goods are those goods that are common resources (that is, freely available) but their supply is limited, and it is difficult to prevent people from consuming or hoarding as much as they want.

Examples of common goods include air, atmosphere, natural forests/minerals, wildlife, ecosystems, water, and rivers/lakes/oceans. In the absence of rules and collective action, individual self-interests often lead to abuse, exploitation, and depletion of common resources which, in turn, typically results in air, water, and land pollution, deforestation, severe depletion of natural resources, species/ecosystem extinction, climate change, and uncontrolled population growth (that is., the tragedy of the commons).

There are many different types and levels of education and learning (e.g., public, private, open, formal, non-formal). Thus, education, as well as learning and knowledge production and consumption, does not fit neatly and exclusively into a single box (category) based upon just a few narrow criteria (for example, rivalry and excludability). Furthermore, there are many ways, using different criteria, to classify goods and services.

Thus, to accommodate this situation and to take into account a broader set of criteria (for example, political, social, and environmental criteria) and to take a more holistic view of the education system, education is often classified as a merit good because of the huge positive externalities that it creates (for example, justice, economic growth, innovation, human capital, cultural capital, social capital). Regardless of the criteria used to define education, in a diverse society there exists many forms of education and learning to meet the diverse needs of the population.

Although the technical economic classification and definition of goods help us understand the concept, they are, nonetheless, insufficient. To better understand what is best for the common good (that is, the general well-being), a broader humanistic view of education is needed. From a broader humanistic view, the common good (that is, an ideal social outcome), as opposed to $a$ common good (that is, a specific type of good), can be considered as those shared benefits that are achieved by all members of society through shared values and collective action.

Thus, to achieve the most equitable and inclusive allocation of shared benefits for society, the democratic principles of rights and justice are instituted to promote and protect the common good. In addition, some self-interested behaviours such as rent-seeking behaviour (more aptly referred to as privilege-seeking behaviour) and free-riding behaviour can severely diminish the benefits of the common good. Therefore, reasonable rules and regulations are needed in order to promote and protect the common good. 
Furthermore, the narrow economic definition of goods has limitations from a humanistic perspective. Thus, an increasing number of scholars have advocated for a rights-based approach to higher education, such as Blessinger and Anchan (2015) and McGowan (2013). This rights-based approach lends itself to viewing education for the common good, which in turn, lends itself to promoting the idea of higher education for sustainable development. In 2015, in one of the greatest acts of global collective action, the world community developed the Sustainable Development Goals (United Nations 2015). It is now time for higher education institutions around the world to implement these goals into their missions, policies, and practices, including their teaching, research, and service functions.

Sustainable development is one of the most pressing issues of the current generation. Education at all levels should be recognized as a right whose remit serves the global common good (UNESCO 2015). As noted by Ford (2016, para. 14), “The only justification for an institution of higher education is that it serves the greatest needs of a particular civilization." Also, as Daviet (2016, p. 8) notes, "Finally, the concept of common good, encompassing ethical and political concerns, provides a principle to rethink the purpose of education." Finally, as noted by UNESCO (2015, p. 80), "Education and knowledge should be considered global common goods. The creation of knowledge, its control, acquisition, validation, and use, are common to all people as a collective social endeavour."

As noted by Blessinger (2018a, b), humanistic higher education is oriented around the principles of our shared humanity, such as equity, inclusion, justice, and rights. To that end, sustainable development becomes important because it serves the common good. Reorienting and reorganizing institutions of higher education to adopt the sustainable development goals should be one of the top priorities of our century. What is urgently needed, therefore, is a renewed vision of higher education and its role in the world.

\section{References}

Blessinger, P. \& Anchan, J. (2015). Democratizing higher education. Routledge Publishing.

Blessinger, P. (2018a). Higher education's key role in sustainable development. University World News. Retrieved from: https://www.universityworldnews.com/post.php? story $=20180905082834986(26.07 .2020)$

Blessinger, P. (2018b). A higher ideal for higher education, HERDSA CONNECT, Volume 40, Number 3, Spring 2018.

Daviet, B. (2016). Revisiting the principle of education as a public good. UNESCO. Retrieved from: https://unesdoc.unesco.org/ark:/48223/pf0000245306 (26.07.2020)

Dorn, C. (2017). For the common good: A new history of higher education in America. Cornell University Press.

Ford, M.P. (2002). Beyond the modern university: Toward a constructive postmodern university. Praeger Publishing. 
Ford, M.P. (2016). Education for the common good. AAUP. Retrieved from: https://www.aaup.org/ article/education-common-good\#.Xrgw_i-z3jA (26.07. 2020)

Locatelli, R. (2018). Education as a public and common good: reframing the governance of education in a changing context. UNESCO. Retrieved from: https://unesdoc.unesco.org/ark:/48223/ pf0000261614 (26.07.2020)

Locatelli, R. (2019). Reframing Education as a Public and Common Good: Enhancing Democratic Governance. Palgrave Macmillan.

McGowan, T. (2013). Education as a human right: Principles for a universal entitlement to learning. Bloomsbury Academic.

Roser, M. (2019). Number of democracies. Our World in Data. Retrieved from: https:// ourworldindata.org/democracy (26.07.2020)

Trow, M. (1973). Problems in the transition from elite to mass higher education. Carnegie Commission on Higher Education.

UNESCO (2015). Rethinking education: Towards a global common good. UNESCO Publishing. Retrieved from: https://unesdoc.unesco.org/ark:/48223/pf0000232555 (26.07.2020)

United Nations (1976). International Covenant on Economic, Social and Cultural Rights. Retrieved from: https://www.ohchr.org/Documents/ProfessionalInterest/cescr.pdf (26.07.2020)

United Nations (2015). Sustainable Development Goals. United Nations. Retrieved from: https:// sustainabledevelopment.un.org (26.07.2020)

Patrick Blessinger is an adjunct associate professor of education at St. John's University, an educator with the New York State Education Department, and chief research scientist of the International Higher Education Teaching and Learning Association (in consultative status with the United Nations). He is the editor and author of many books and articles, and he is an educational policy analyst and contributing writer with UNESCO's Inclusive Policy Lab, University World News, The Hechinger Report, The Guardian, and Higher Education Tomorrow, among others.

Enakshi Sengupta is director of the Center for Advanced Research in Education at HETL (International Higher Education Teaching \& Learning Association. She has been appointed as the Principal Strategic Advisor to HETL and will be responsible for reputation building and strategic alliances for HETL. She is also the Associate Series Editor of the book series, Innovations in Higher Education Teaching and Learning, Emerald Group Publishing. She is the Managing Editor of the Journal of Applied Research in Higher Education, Emerald Publishing, and serves as the Vice Chair of the Editorial Advisory Board of the Innovations in Higher Education Teaching and Learning, Emerald Publishing.

Mandla S. Makhanya is Principal and Vice-Chancellor of the University of South Africa and President of the Higher Education Teaching and Learning Association (HETL) - International Body. He is past President of the International Council for Distance Education (ICDE) and is also Treasurer of the African Council for Distance Education (ACDE). He is a Deputy Chairperson of the South African National Commission for UNESCO and Chairperson of the Culture Sector of the South African National Commission for UNESCO. 
Open Access This chapter is licensed under the terms of the Creative Commons Attribution 4.0 International License (http://creativecommons.org/licenses/by/4.0/), which permits use, sharing, adaptation, distribution and reproduction in any medium or format, as long as you give appropriate credit to the original author(s) and the source, provide a link to the Creative Commons license and indicate if changes were made.

The images or other third party material in this chapter are included in the chapter's Creative Commons license, unless indicated otherwise in a credit line to the material. If material is not included in the chapter's Creative Commons license and your intended use is not permitted by statutory regulation or exceeds the permitted use, you will need to obtain permission directly from the copyright holder. 


\title{
IAU: The Power to Foster Higher Education for Sustainable Development
}

\author{
Pornchai Mongkhonvanit, Chanita Rukspollmuang, and Yhing Sawheny
}

\section{A Paradigm Shift in Development: From Economic Growth to Sustainability}

Modernization theory, which believes that "development equates economic growth" and changes in social, political, and cultural structures are the pathways for societies to become modernized, has been the predominant paradigm for the development of nations for decades. However, the model was met with a lot of criticism, and there was a movement to rethink the real meaning of development and well-being. Alternatives for development were proposed, but the most widely accepted paradigm is "sustainability" or "sustainable development" which was defined by the World Commission on Environment and Development (WCED) in the 1987 Brundtland Report (also called "Our Common Future") as "development that meets the needs of the present without compromising the ability of future generations to meet their own needs." Under this development paradigm, programs, initiatives, and actions aim not only at the preservation of a particular resource but also at other distinct areas: economic, environmental, and social - known as the three pillars of sustainability. The Brundtland Report has had a worldwide impact. "Agenda 21", a comprehensive plan of action to build a global partnership for sustainable development to improve human lives and protect the environment, was adopted in the 1992 Earth Summit in Rio de Janeiro, followed by many other agendas, including the United Nations Millennium Development Goals (MDG) (2000-2015) and the present United Nations 2030 Agenda for Sustainable Development or the 17 SDGs. The 2030 Agenda is not

\footnotetext{
P. Mongkhonvanit $(\bowtie) \cdot C$. Rukspollmuang · Y. Sawheny

Siam University, Bangkok, Thailand

e-mail: pornchai@siam.edu

C. Rukspollmuang

e-mail: chanita@siam.edu

Y. Sawheny

e-mail: yhing@siam.edu 
only an urgent call for action by all countries - developed and developing - in a global partnership, it also provides clear guidelines and targets for all countries to adopt in accordance with their own development priorities and principle guidelines. For example, Thailand's practical approach toward sustainable development is guided by the Sufficiency Economy Philosophy (SEP) which was bestowed upon the Thai people by His Majesty the late King Bhumibol Adulyadej in 1974. He has repeatedly reminded us about the genuine meaning of development as well as the challenges and consequences of rapid modernization and proposed the idea of balanced and selfreliant development based on the belief in the middle path ${ }^{1}$ as the proper guideline to live sustainably. SEP contains 3 key components: moderation, reasonableness, and prudence, and based on knowledge and virtues. It underlines a balanced approach to the use of economic, social, environmental and cultural capital while underlining the importance of preparedness in dealing with changes in these four dimensions (see Fig. 1). Progress with balance promotes stability and, ultimately, provides a basis for sustainability. The Thai government has adopted SEP as the guiding principle of national development plans since the 1997 economic crisis. In recognition of his devoted work for sustainability of the country, in 2006, the King was awarded the first United Nations Human Development Lifetime Achievement Award. For decades, especially during the Covid-19 pandemic, the Thais have valued SEP as the true foundation of sustainable development and the main driving force for SDGs. Nowadays, SEP is not only practiced in Thailand but it was recognized as a gift to the world (Avery and Bergsteiner 2016). In other words, SEP has proven to be one of the major leaps towards a paradigm shift from "economic growth" to "balanced and sustainable development".

\section{Higher Education as a Prime Mover of SDGs}

Education has always been recognized as one of the most important key factors for the achievement of sustainable development (SD) as indicated in the UN Decade of Education for Sustainable Development (UN-DESD) (2005-2014). It emphasizes that learners at all levels are expected to acquire the skills, capacities, values and knowledge required to ensure sustainable development and become co-creators of a more sustainable future in terms of environmental integrity, economic viability and a just society for present and future generations. It is noteworthy that this Whole Institution Approaches for Education for Sustainable Development (WIA-ESD) has been fostered internationally, including by UNESCO and IAU. Furthermore, SD has also brought about the rethinking of the four pillars of education in the Delors' report to the UNESCO International Commission on Education for the Twenty-first Century

\footnotetext{
${ }^{1}$ The concept of "middle path" is not necessarily drawn from Buddhist thinking, the philosophy is not exclusively grounded in one religion, but has also found Muslim and Catholic proponents in the country. It has likewise gained appreciation as an approach in line with humanist economics that emphasize humanity and happiness above economic priorities.
} 


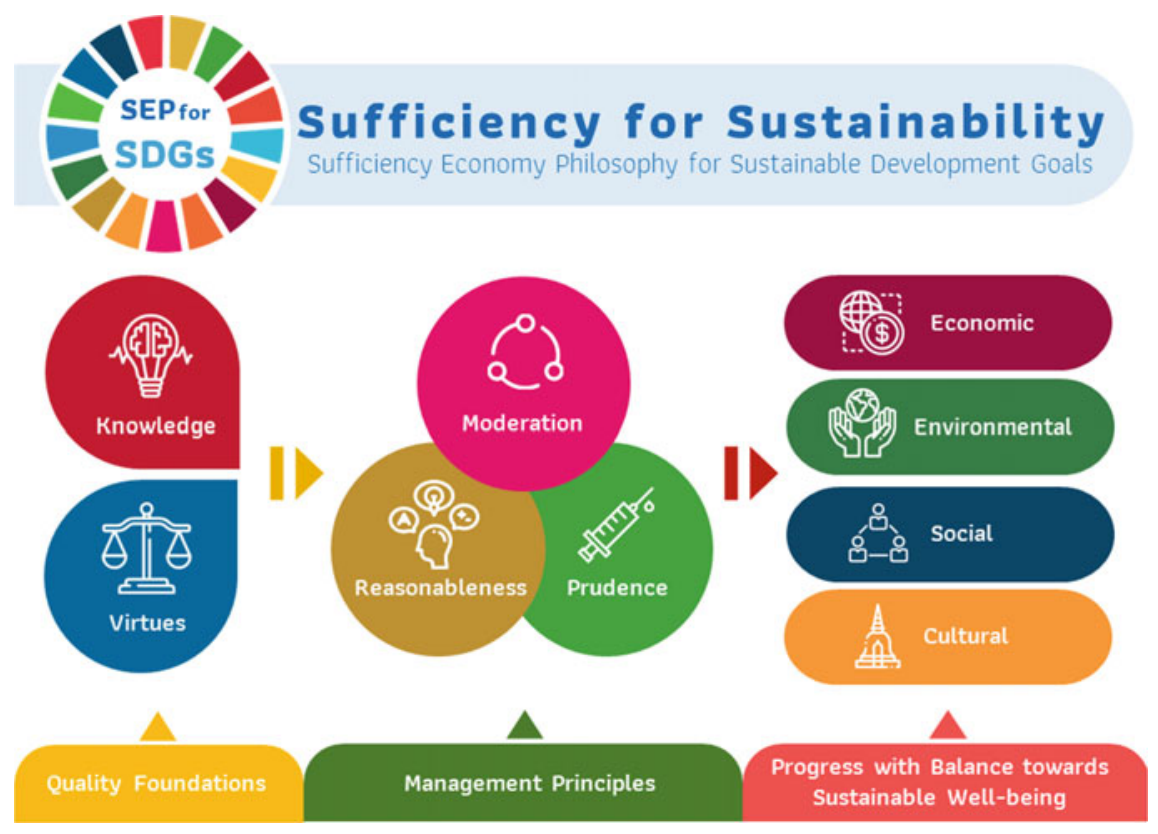

Fig. 1 Sufficiency economy philosophy for sustainable development goals of Thailand. Edited by Open Development Thailand (ODT), from TSDF (ODT 2018). Source: Thailand Sustainable Development Foundation, www.tsdf.or.th

(learning to BE, to KNOW, to DO, and to LIVE TOGETHER). In 2012, UNESCO'S Education for Sustainable Development Initiative presented a conceptual framework for lifelong learning and added the fifth pillar - Learning to TRANSFORM ONESELF and SOCIETY - it is the learning which individuals and groups gain knowledge, develop skills, and acquire new values as a result of learning, they are equipped with tools and mindsets for creating lasting change in organizations, communities, and societies.

As part of a global academic community, it is not only a duty to engage with global challenges - SD and SDGs - it is also the social responsibility of universities to promote and protect, to reflect on and to show the challenges and consequences of the paradigm shift from "economic growth" to "sustainability". Many higher education institutions are fully aware that it is our responsibility to take a leading role to accomplish the goal. For instance, University of Bergen 2020) has formed a working group to discuss SDG quality in higher education. Moreover, since all the 17 sustainable goals base their argument on knowledge, it is time to rethink new meaning of knowledge, the benefit of multidisciplinary collaboration as well as how to share knowledge and cooperation among local and international universities and how to put the fifth pillar of learning, learning to transform oneself and society, into action. In short, HEIs have to transform themselves in order to ensure that 
their members - administrators, faculty members, students, supporting personnel become sustainability change-makers and lead to a transformation of how we treat, preserve, and protect nature, how we produce and consume, how we distribute values and how we secure an inclusive, fair and equal society.

In 2018, the Southeast Asia ESD Teacher Educators Network (SEA-ESD Network), organized by UNESCO Bangkok and SEAMEO, convened to share experiences of member universities in the Asia-Pacific region about disseminating SDGs, with special emphasis on SDG4. The participants agreed that at the institutional level, all personnel and students should be motivated to participate in ESD/SDGs activities, both within the campus and local communities. The Indonesia University of Education presented how to integrate ESD/SDGs into the existing curricula and lessons to equip teacher and personnel with ESD knowledge and the use of project-based learning through collective and experiential learning to enhance the capabilities of students. The University of Indonesia became the leader of GreenMetric activities and has performed particularly well in research funds dedicated to sustainability research and the number of courses related to sustainability. Te Herenga Waka Victoria University of Wellington has shown effective ways to promote human rights, sustainability and social justice. In accordance with the Philippines "Target 2040", Cebu Normal University has clearly articulated its mission to protect nature as reflected in its ESD mandate "iGreenCNU” (Okayama University 2019 and UNESCO Bangkok 2019). As for Siam University in Thailand, "sustainability" has been one of the main pillars in the mission statement. The university has a policy in place to integrate SDGs in its academic activities: teaching, research, service and student engagement. The latest survey reported that 2,023 courses provided for both undergraduate and graduate students in the year of 2020 by 13 faculties and the general education program had integrated SDGs in terms of content and class activities (Siam University 2020).

\section{IAU as the Global Voice of He for Sdgs and the Well-Being of the People and the Planet}

Sustainable Development (SD) is one of the key priorities of the strategic plan of the International Association of Universities (IAU). We have fostered SD for a long time since the adoption of the 1992 Earth Summit in Rio de Janeiro and the 1993 IAU Kyoto Declaration on Sustainable Development. Besides being one of the key partners of the UNESCO Global Action Program on education for sustainable development (GAP-ESD), the Association now plays significant roles in the UNESCO ESD for 2030 program. The IAU leads the work on SDG 17 by fostering global HE partnerships and develops new richly diverse and intercultural projects engaging higher education into the UN Agenda 2030 process, by fostering attention and work specifically on the SDGs. We have regularly organized international conferences and worked with organizations and networks such as the Global University Network for Innovation (GUNI), Sustainable University Network Thailand (SUN), Asia 
Cooperation Dialogue University Network (ACD-UN) and the British Broadcasting Corporation (BBC) in promoting SDGs.

For more than three decades, IAU has been working on Higher Education and Research for Sustainable Development (HESD). In 2014, IAU adopted a second SDrelated statement: the Iquitos statement sets out to connect knowledge and research systems on sustainable development from around the world. This latest Statement was one of the many IAU contributions to the UN-DESD and our efforts to accomplish the 2030 Agenda for Sustainable Development (SD) and the 17 Sustainable Development Goals (SGDs). The IAU Global Cluster on Higher Education and Research for Sustainable Development (HESD) was then established. The cluster involves 16 lead universities, each engaging more specifically on one of the SDGs while connecting to the other SDGs as well. The lead universities, from all world regions, collaborate with 2 to 8 "satellite" institutions, engage with a particular SDG and initiate concrete projects, also across all goals. The cluster has two concrete objectives. Firstly, it serves as a resource and networking hub for collaboration and guidance on best practices to advance on the SDGs in local, national and international contexts. The cluster aims to be beneficial for those institutions already engaged with the SDGs and to engage new ones.

Secondly, the IAU Global Cluster serves as a global voice for higher education and sustainable development. Siam University as one of the leading institutions has supported the IAU advocates for HESD at the UN, in particular at the HighLevel-Political Forum, at IAU global Conferences, at Member workshops and other initiatives developed at the local and the regional level. The Association has been internationally recognized as a promoter of mutual learning processes through continuous exchange of ideas and experiences and global collaboration. Many publications with regards to SD and SDGs have been disseminated by IAU. In the context of the UNESCO GAP-ESD, IAU developed the 1st Global Survey on Higher Education and Research for Sustainable Development (HESD) in 2016 and the 2nd one in 2019. The survey (Mallow et al. 2020) indicated that there has been increasing commitment to sustainable development in the higher education sector worldwide, but not all SDGs were equally addressed. There are obstacles still to be resolved, and more needs to be done.

This report is one of the exemplary works of IAU as the "Global Platform and Global Voice for Sustainable Development". In the future, the Association and the IAU Global Cluster will surely continue to play this important role, especially after the Covid-19 pandemic since our world is at a point of change. New questions are being asked about the meaning and goals of "development" and "well-being" of people and society. The ecosystem of education is completely transformed. It is time to "Rethink SDGs and Refocus Higher Education" to keep up with this "transformative shift" (Maesincee 2020). IAU has a strong positioning to take an active part in rethinking, reinvestigating, and re-prioritizing the sustainable development goals and make this opportunity to act as the leader to refocus higher education to make universities a successful vehicle for the achievement of desirable SD and SDGs. In doing so, IAU can act as a think-tank, share and disseminate "best practices" of how to transform 
higher education institutions and how to Refocus Higher Education which can be summarized as follows:

1. Transforming universities to transform people and society. Universities should endorse sustainability as a priority in their mission statement. They should aim to transform themselves to be sustainable in all their actions - from policies to practices - to ensure the well-being of people, community, society, and our planet.

2. Developing university campuses as models of sustainability and sustainable living labs. Universities need to become a role model for sustainability. They should take responsibility for the use of knowledge and an ethical responsibility that follows from our accountability to the SDGs. At the same time, they provide research platforms and take action to leverage the campus as a testbed for innovation and the co-production of sustainability knowledge and practices.

3. Transforming academic programs and activities for sustainability. HEIs should transform from universities that provide specialized academic disciplines to universities that provide training and innovation for the well-being of people and society. It is imperative to prepare learners to deal with the complexity of the issues connected to sustainability by empowering them with a mindset and key competences for sustainability, especially the 21 st-century skills: systems thinking, anticipatory competency, normative competency, strategic competency, transdisciplinary collaboration, critical thinking, creativity, self-awareness, integrated problem-solving competency (UNESCO 2017). Universities should promote (1) programme development - creating undergraduate or graduate programmes of study in SDGs to produce leaders for sustainable development; (2) curriculum/course development -revising curriculum, courses (especially general education), textbooks so that all students will learn about SDGs and SDG-related issues, such as sustainable balanced and circular economy, Sufficiency Economy Philosophy (SEP), responsible consumption, climate action, duties and responsibilities of global citizens; (3) promoting transformative learning - active/experiential learning and activities should be encouraged; (4) redefining learning outcomes and evaluation - integrating key competencies for SDGs in learning outcomes and criteria for course evaluation; (5) training, retraining and reskilling academic staff - professionals with knowledge and understanding of the interconnection between the social, economic, environmental and natural worlds will be the most important change agents.

4. Supporting student-driven activities/student engagement. Universities have an obligation to put students on the right path towards creating a sustainable society. The universities should act as a role model for students and facilitate collaborations towards sustainable development. Student activities relating to SDGs should be promoted and make sure that the values of SD are reflected in actions.

5. Redefining “Quality Education” and Quality Assurance. SDGs have brought a new paradigm of education and learning. Quality of education and evaluation in the QA system, internal and external, need to recognize and reward initiatives in higher education both for, as, and about sustainable development. 
6. Promoting mutual collaboration and networking for sustainability. In order to make substantial progress towards the fulfilment of SDGs, universities must increase collaboration among HEIs and with all stakeholders, public/private sectors, policymakers, community leaders, and NGOs. In other words, "Sustainable Development for All” will not be successful without "All for Sustainable Development".

Since the early nineties, IAU has been committed to promoting the important role of higher education for sustainability. In 2005, a decade before the SDGs were published by the UN, former President of IAU (2000-2004), Hans van Ginkel, made the argument that sustainability without development or development without sustainability are both not possible, nor desirable. Therefore, sustainable development is the education required to build a better future for all (van Ginkel 2020).

In 2015, Goolam Mohamedbhai, former President of IAU from 2004-2008, underlined the role of university as role models for society. He stressed that HEIs have the responsibility, more than ever before, to integrate sustainable development into their teaching, research, community engagement and campus operations (Mohamedbhai 2015).

Dzulkifli Abdul Razak, former President of the IAU from 2012-2016, pointed out that university leadership has to understand that the SDGs are mandatory and no longer just an option. Sustainable development is part and parcel of education within universities and he invited all institutions to engage with the SDGs (Sharma 2015).

Pam Fredman, IAU President (2016-2021) argued that working closely with the community is essential (Fredman 2019). Individually, we cannot bring about the level of change required, it takes active international collaboration to bring about systemic change. By working as a collective, we become more active, less dependent, and more committed to what we believe in. We gain the ability to choose what is best for us and for others.

Finally, the International Association of Universities (IAU) with the active HESD Cluster and Platform is now uniquely positioned to be the catalyst and facilitator for universities across borders to be active and influential engines for sustainability. Through strong international partnership, the Association is committed to be the Driving Force for Higher Education sustainable development and to offer a much needed Global Platform for Sustainable Development to ensure that universities transform their own systems and structures toward reaching the SDGs - for the well-being of the people and the planet.

\section{References}

Avery, G.C., \& Bergsteiner H. (2016). Sufficiency Thinking: Thailand's gift to an unsustainable world. New York: Allen \& Unwin.

Fredman, P. (2019). The Local Mission of Higher Education: A Global View, in: S. Bergan, I. Harkavy and Ronaldo Munck, The Local Mission of Higher Education. Principles and Practice, Glasnevin Publishing, Dublin, pp. 114-121. 
Maesincee, S. (2020). The Seven Shifts How “WE" can thrive in the post-COVID-19 World. Bangkok, Thailand: Ministry of Higher Education, Science, Research and Innovation.

Mallow S., \& Toman, I. \& van't Land, H. (2020). Higher Education and the 2030 Agenda: Moving into the 'Decade of Action and Delivery for the SDGs'. IAU 2nd Global Survey Report on Higher Education and Research for Sustainable Development. Retrieved from: https://www.iau-aiu.net/ IMG/pdf/iau_hesd_survey_report_final_jan2020.pdf (26.07.2020)

Mohamedbhai, G. (2015). What role for higher education in sustainable development? University World News (09.01.2015), Retrieved from: https://www.universityworldnews.com/post.php? story $=20150108194231213(26.07 .2020)$

ODT (Open Development Thailand). (2018). "Sufficiency Economy Philosophy for Sustainable Development Goals of Thailand", in Sustainable Development Goals. Retrieved from: https:// thailand.opendevelopmentmekong.net/topics/sustainable-development-goals/ (26.07.2020)

Okayama University, ACCU \& INTEI. (2019). Guide for the Effective Dissemination of the AsiaPacific ESD Teacher Competency Framework, the second report of the Project "Teacher Education for ESD in the Asia-Pacific Region", 17-19 September, 2019, Bangkok, Thailand, organized by Okayama University in cooperation with ACCU (Asia Pacific Cultural Center for UNESCO) and INTEI with the financial support of the Japanese National commission for UNESCO and UNESCO Bangkok and technical support of UNESCO Bangkok.

Sharma, Y. (2015). Towards higher education for a single planet - IAU, University World News (23.11.2015), Retrieved from: https://www.universityworldnews.com/post.php? story $=20151021201137410(26.07 .2020)$

Siam University. (2020). Survey on the integration of the 17SDGs in the class activities. Report to the Office of the National Economic \& Social Development Board (NESDB).

UNESCO. (2017). Education for Sustainable Development Goals. Learning Objectives. Education 2030. Paris. UNESCO publ.

UNESCO Bangkok. (2019). Report of the Panel Discussion Education and Learning in and through Environmental Assessment: Experiences from Higher Education Institutions in Asia. The 10th World Environmental Education Congress, 3-7 November 2019, BITEC, Bangkok, Thailand, organized by UNESCO Bangkok, in cooperation with the United Nations University Institute for the Advanced Study of Sustainability (UNU-IAS).

University of Bergen. (2020). Report from working group. SDG Quality in higher education: Developing a platform for sharing of ideas and practices within the universities. Retrieved from: www.uib.no/sites/w3.uib.no/files/attachments/sdg_-_quality_in_higher_ education_-_report_feb_2020.pdf (26.07.2020)

van Ginkel, H. (2005). Report from Globalization and education for sustainable development: sustaining the future, Nagoya, Japan, Retrieved from: https://unesdoc.unesco.org/ark:/48223/ pf0000149295 (26.07.2020)

Pornchai Mongkhonvanit is President of Siam University and vice president of IAU. He is also serving as the Executive Director of Asia Cooperation Dialogue University Network (ACD-UN). He earned his undergraduate degree in Mechanical Engineering from Kasetsart University in Thailand and a post-graduate degree in finance from University of Wisconsin-Madison. He is also a member of IEM's 2000 of Harvard Graduate School of Education. Pornchai is recognized as an expert in Higher Education Strategy on University Industry partnership as evidenced by the award received by Siam University in 2012 as Thailand's best institution in Cooperative Education among all public and private universities.

Chanita Rukspollmuang Vice President and Dean of the Graduate School of Education, Siam University, is responsible for academic development and the Center of Sustainability. She was a former Dean of the Faculty of Education, Chulalongkorn University and served in many committees and national offices such as Office of the Education Council, Office for National Educa- 
tion Standards and Quality Assessment, and Ministry of Education. Internationally, she has served twice as elected President, Comparative Education Society of Asia (CESA).

Yhing Sawheny is Deputy Director for International Affairs and Lecturer of English and Marketing at Siam University, Thailand. Currently she is pursuing her Ph.D. in Management at AIT (Asian Institute of Technology). She is the member of the Editorial Board for ACADEME - the Academic Journal of Higher Education and Leadership and extensively published on higher education issues in several prestigious international journals, amongst which the International Association of Universities (IAU) Horizons.

Open Access This chapter is licensed under the terms of the Creative Commons Attribution 4.0 International License (http://creativecommons.org/licenses/by/4.0/), which permits use, sharing, adaptation, distribution and reproduction in any medium or format, as long as you give appropriate credit to the original author(s) and the source, provide a link to the Creative Commons license and indicate if changes were made.

The images or other third party material in this chapter are included in the chapter's Creative Commons license, unless indicated otherwise in a credit line to the material. If material is not included in the chapter's Creative Commons license and your intended use is not permitted by statutory regulation or exceeds the permitted use, you will need to obtain permission directly from the copyright holder. 


\title{
Aligning Higher Education's Promise of Well-Being with Sustainability as a Purpose of Education
}

\author{
Katrin Kohl and Charles Hopkins
}

\section{Introduction}

In a world of increasing complexity, there is a growing demand for access to higher education. People of all ages aim at academic degrees to qualify for decent career opportunities in the future, often in hope of a better life. Numbers in higher education are globally on the rise with today approximately $38 \%$ gross enrolment in tertiary education (UNESCO 2018).

While there is an unspoken assumption that an academic degree opens up opportunities, in many countries still only a comparatively small number of students have access and the means to attend an institution of higher education. These inequalities are a major concern for education systems worldwide.

Therefore, for the first time in the history of United Nations (UN), the Sustainable Development Goal 4 (SDG target 4.3) explicitly requires equal access for women and men to an affordable tertiary education as an aspect of the international education agenda. Embedded as one of 169 targets in the 17 SDGs of the 2030 Agenda, access to higher education is an element in the vision of the world's future, aiming at an educated public and workforce.

Beyond educating bigger portions of future generations, higher education serves further roles in the 2030 Agenda. Better understanding and learning to cope with the world that we are in and that we have co-created, research and science are needed to serve society to find solutions for the grand challenges of today and tomorrow. Higher education is crucial for the individual and for societies in the pursuit of well-being and sustainable development.

\footnotetext{
K. Kohl $(\varangle) \cdot$ C. Hopkins

York University, Toronto, Canada

e-mail:kkohl@edu.yorku.ca

C. Hopkins

e-mail: chopkins@edu.yorku.ca 


\section{The Role of Higher Education: Teaching and Learning for Life}

It is widely understood that higher education can play a pivotal role to equip graduates with the knowledge and skills to seek career opportunities and create livelihoods; but also to learn making informed decisions in fast-changing environments and understanding potential consequences of individual and collective actions.

Graduates of higher education represent today's and most likely tomorrow's majority of leaders. They do not only shape their local and regional business world and government policies, but their lifestyle decisions most likely have consequences for others in our interconnected world. Graduates often become important societal influencers and therefore, the combined insight and skills gained in higher education programmes have an impact on economy, the environment and society.

Receiving higher education is not limited to achieving a degree based on knowing and applying technical expertise attained in the programme, but it means understanding that knowledge and skills taught are based on science. Students learn facts, but they also acquire the competency of how to research (new) knowledge for an entire lifetime. This skill is essential as science and technology continuously develop. What was taught during years of education will potentially be challenged. And every student entering higher education is welcome to contribute knowledge and seek better ways of doing things during their programme and beyond.

Higher education includes the opportunity to attain a broader personal skill set. Indepth factual examinations of topics combined with developing the ability to discuss differing opinions with peers are fundamental aspects of academic programmes. Through these interactions, students are expected to recognize a responsibility of respecting diverse worldviews, clarifying personal values and attaining leadership.

In addition, a growing number of students are expected to study abroad or to move between countries throughout the course of their professional career. And while the consequences of the COVID-19 world-changing pandemic are yet unknown, we are already expecting up to 1 billion climate migrants to move within their countries or across borders by 2050 , escaping the negative impacts of climate change. Consequently, many of today's students might not only be educated in several education systems but might contribute to other workforces and societies than of the countries where they received education. The ability to find ways to adapt and to lead a reasonable and meaningful life to be experienced in changing economic, social and environmental settings is crucial for today's students.

\section{The Role of Higher Education: Research}

Continuously working to expand factual knowledge, being critical of what we know and what we do with our knowledge and constantly seeking new ways to improve our understanding of our world is the focus of higher education research. More research 
is needed and to be shared to secure humankind's survival in an era of Anthropocene and a pandemic shaking our world. The 2030 Agenda aligns the need for education with such a need for research aspiring for a better future for all. We need research and science to fight hunger (SDG 2) and climate change (SDG 13), to conserve life below water (SDG 14), to create healthy societies (SDG 3) with sufficient industrial infrastructure (SDG 9), to benefit from clean energy (SDG 7), and decent employment opportunities (SDG 8). Fostering international partnership towards the global goals, facilitating responsible competition and providing research-based knowledge are at the core of higher education research (SDG 17).

\section{The Role of Higher Education: Service to Society}

In their third mission, higher education today attempts to serve society's development towards a better future. In particular, universities and colleges connect to and serve the local community through the knowledge created in the academic environment and through building relationships to businesses, but also to governments and the not-for-profit sector.

\section{Our Common Vision}

How do we envision a 'better future' or a 'better world'? A highly aspirational common vision since the 1980s and now for 2030 has been the quest for sustainable development. It drives the world's actions to eradicate poverty and create peaceful societies as a progress for humanity ".that meets the needs of today without compromising future generations? abilities to meet their needs. ..” (United Nations 1987).

Adopted as Agenda 21 by the UN in 1992 and in a belief of global partnership of all countries, the world started pursuing sustainable development as a fundamental principle to guide action. At that time, it was unanimously acknowledged that education would be a crucial instrument to achieve sustainable development for all. Chapter 36 Promoting Education, Public Awareness and Training of Agenda 21, prepared in advance to the 1992 Earth Summit in Rio de Janeiro, defined the elements of Education for Sustainable Development (further 'ESD') as (1) reorienting education towards sustainable development; (2) increasing public awareness; and (3) promoting training. The need for (4) access and retention in a quality education was the fourth element named in Chapter 36 and also stated in Agenda 21's Chapter 25 Children and Youth in Sustainable Development.

Since Agenda 21, many programmes and initiatives have recognized the concept and improved the emphasis on ESD internationally. The United Nations Educational, Scientific and Cultural Organization (UNESCO) was tasked to lead the implementation of Chapter 36 with approaches to reach students and educators at all levels of education and to create public awareness. 
A United Nations Decade on Education for Sustainable Development (20052014) was set to integrate principles, values and practices of sustainable development into all aspects of education and learning. A UNESCO Global Action Programme on Education for Sustainable Development (2015-2019) aimed to scale-up ESD and to accelerate progress. Now, a new ESD for 2030 Framework (2020-2030) focuses on ESD's specific function as a vital means of a quality education (SDG 4/SDG 4.7) and as a key enabler of all of the SDGs. These efforts have led to ESD becoming a relevant and much discussed education concept and to reach public interest, especially since the necessity to fight climate change has reached a new level of visibility through youth leadership.

Today, ESD's transformative potential to “... empower learners to transform themselves and the society they live in by developing knowledge, skills, attitudes, competences and values required for addressing global citizenship and local contextual challenges of the present and the future..." (UNESCO 2014) is often emphasized. It is important that the original four thrusts of ESD are infused in this definition to preserve ESD's holistic concept.

Closely connected to the discussions around sustainable development is the concept of well-being. Rooted in psychology, it was first discussed as a goal for national economies reaching beyond linear economic growth for their citizens, achieving prosperity, health and happiness within certain environments and economic circumstances. Being well is more than satisfying Maslowian needs and staying physically healthy. It includes finding meaningfulness and balance in one's life. Indigenous worldviews of well-being extend the concept beyond the well-being of humans to address the well-being of all life forms, present and future.

Goals of sustainable development and well-being often align but can also be opposites (e.g. if seeking well-being requires the use of natural resources or shortterm choices for individual well-being endanger long-term well-being for all). In this case, the pursuit of individual well-being must take into account the consequences for the collective well-being and be limited by global capacities.

\section{Achieving Well-Being Within Sustainable Development}

How does the higher education promise of individual well-being align with sustainable development becoming a purpose of education? How can universities and colleges actively shape the future while adapting and transforming themselves as institutions?

Firstly, students might initially work for individual goals of decent employment and hope to be 'well-off' through achieving a certain economic and social status in life than consciously aiming towards sustainable lifestyles. But, universities and colleges can question or broaden worldviews and offer exposure to new ways of thinking. Higher education does not only impart the factual knowledge but actively adds soft skills to equip students with competencies needed to achieve the common goal of sustainable development. Also, if the recognition of qualifications in higher 
education is brought forward as commenced by UNESCO, graduates will reach a new geographic level of opportunity allowing movement without losing credentials and creating new networks of international cooperation.

As a result, the opportunity to graduate for each student might come with an assumed moral price: the individual accepts their social responsibility and at times, takes on an overt or subtle leading position in collectively helping to reduce the imbalance in the world. Not everyone might become a leader, but everyone should have the competencies to make conscious choices within a value set of sustainability.

In addition, universities and colleges can actively reach out to those who might not see themselves in higher education and raise numbers and diversity of student cohorts throughout all academic disciplines, broadening the spectrum of attendees in their programmes and who will qualify for future leadership. In face of the COVID19 pandemic, higher education has just shown its unique potential to transform itself in previously unimaginable ways. In 2020, we have seen the unleashing of the digital potential of universities in moving to online and distance teaching overnight. A safe and healthy return to campus is preferred for human connections and is important for programmes where experiments and practice require physical attendance. Recruiting a sufficient number of students with adequate fee schedules to assure financial survival is needed. If full online and distance programmes are expanded, universities and colleges are no longer limited to recruiting students from their local community and regions and a small selection of students from abroad. These opportunities for globalized education efforts bring the goal of equal access for women and men to affordable tertiary education (SDG target 4.3) much closer to reality.

Secondly, higher education must bring forward more research for a sustainable future and underline the importance of science-based knowledge, the value of independent research and the need for international science collaboration. Broader involvement of enrolled students in research and research design might hold opportunities for diverse youth perspectives.

Undisputedly, the necessity of academic freedom with the freedom of teaching and discussion, freedom in carrying out research and disseminating and publishing the results and also the freedom to express opinions (UNESCO 1997) remains central. Yet, the recognition of the global objectives of international peace, understanding, cooperation and sustainable development as fundamental principles for exercising academic freedom is an imperative for research.

While striving towards sustainable development as the current vision of the world we want, higher education must retain its role as a strategic and trusted partner. The higher education community has been recognized as an important stakeholder and honest broker of knowledge and truth for coping with great challenges and the serious problem of sustainability.

Furthermore, higher education in all of its disciplines must question the concept of sustainable development as a continuing vision for the future. Sustainable development, as described in the 1980s and shaped but not fundamentally changed to date, has its limitations, such as being too vague at times, too human-centred and an idealistic, unattainable concept. What will be the world's next vision of a functional yet desirable future and what kind of education will be needed to make it reality? 
With the 2030 Agenda, higher education with all three streams of teaching, research and service to their community can play an important role. It is now time to create a strong unified voice on the global level to advocate for the commitment to a sustainable future for all. Under the impression of the urgency of the climate crisis and exponentially growing inequalities in the world, a broader approach to higher education's third mission in aligning the three streams of the mandate towards an overall service to society can create even more relevance for the higher education community as a whole.

If graduates also commit to serving society during their careers and with personal choices, they can influence trends and public opinion. Conducting research to gather and share new knowledge and to develop innovation processes can help societies striving towards peace and sustainable development.

In working for global goals, international partnerships are crucial. They help to understand the various perspectives infused by knowledge, history and culture. They serve as learning circles, for peer-to-peer exchange and to generate new joint and collaborative ideas and ventures. The IAU Global Cluster on Higher Education and Research for Sustainable Development is one of the most relevant global initiatives to target the SDGs in higher education and contributing perspectives to the global discussion. IAU, associated with UNESCO, assists the higher education community to enhance their policies, develop appropriate responses and support institutions to achieve their goal set within the SDGs. The IAU Cluster encourages a holistic approach to the SDGs, focusing specifically on the various and multi-faceted aspects of universities in a whole-institution approach. While sustainable development itself or its succeeding vision are broader than the SDGs, the latter offers a current and accepted global framework to develop strategies in higher education institutions towards a sustainable future.

As SDG 4 is both a singular goal as well as interrelated with the other SDGs, it is of utmost importance to ensure its successful implementation. The IAU SDG 4 Subcluster particularly encourages universities and colleges to localize SDG-inspired action at the institutional level to improve social impact and expound upon social responsibility. It also aims at a better understanding of the potential of addressing the SDGs as a driver of transformation and promotes ESD as an element of a quality education in light of SDG 4.

ESD, embedded throughout all aspects of higher education, is the key to unlock the potential with providing educated future leaders, providing the science-based knowledge needed and localizing issues within the SDGs to identify and improve the particular sustainability issues in the community. If ESD is given priority and the means for further development and implementation, higher education alone and in partnerships within the community and beyond can significantly contribute to the well-being of all and greatly enhance the chances for a more sustainable future. 


\section{References}

UNESCO (1997). Recommendation concerning the Status of Higher-Education Teaching Personnel. Retrieved from: http://portal.unesco.org/en/ev.php-URL\$_\$ID=13144\&URL\$_\$DO=DO\$_ \$TOPIC\&URL\$_\$SECTION=201.html (16.05.2020)

UNESCO (2014). UNESCO World Conference on Education for Sustainable Development, AichiNagoya, Japan, 2014: Aichi-Nagoya Declaration on Education for Sustainable Development. Retrieved from: https://unesdoc.unesco.org/ark:/48223/pf0000231074. (16.05.2020)

UNESCO Institute for Statistics (2018). Sustainable Development Goal 4: 4.3.2 Gross enrolment ratio for tertiary education by sex (administrative data). Retrieved from: http://data.uis.unesco. org/ (16.05.2020)

United Nations (1987). United Nations General Assembly: Development and International Co-operation: Environment Report of the World Commission on Environment and Development. Annex. Report of the World Commission on Environment and Development. Our Common Future. Released by the Brundtland Commission. Retrieved from: https:// sustainabledevelopment.un.org/content/documents/5987our-common-future.pdf. (16.05.2020)

United Nations (1992). United Nations Conference on Environment and Development. Earth summit, Agenda 21. Retrieved from: http://www.un-documents.net/agenda21.htm (16.05.2020)

Katrin Kohl is Focal Point for SDG 4 (Quality Education) at the Higher Education and Research for Sustainable Development (HESD) Global Cluster, International Association of Universities (IAU). She is Executive Coordinator to the UNESCO Chair, York University (Canada), and responsible for overall strategy and global research. With a background in law and management, she served as Managing Director of the German Commission for UNESCO and as Strategic Advisor to the Vice-Chancellor at the University of Düsseldorf (Germany) in prior positions.

Charles Hopkins holds the UNESCO Chair in Reorienting Education towards Sustainability at York University (Canada) serving the Global Education 2030 Agenda with research and in coordinating two global networks: the International Network of Teacher Education Institutions (INTEI) and the \#IndigenousESD research network focusing on the education of Indigenous youth. Hopkins is also Advisor to the Global Network of Regional Centres of Expertise on ESD, and CoDirector of the Asia-Pacific Institute on ESD in Beijing (China).

Open Access This chapter is licensed under the terms of the Creative Commons Attribution 4.0 International License (http://creativecommons.org/licenses/by/4.0/), which permits use, sharing, adaptation, distribution and reproduction in any medium or format, as long as you give appropriate credit to the original author(s) and the source, provide a link to the Creative Commons license and indicate if changes were made.

The images or other third party material in this chapter are included in the chapter's Creative Commons license, unless indicated otherwise in a credit line to the material. If material is not included in the chapter's Creative Commons license and your intended use is not permitted by statutory regulation or exceeds the permitted use, you will need to obtain permission directly from the copyright holder.

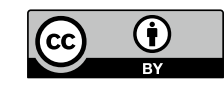




\title{
Accelerating the Future into the Present: Re-imagining Higher Education in the Caribbean
}

\author{
Hilary Beckles and Stacy Richards-Kennedy
}

Progressive societies invest in higher education institutions to help them meet their current and anticipated workforce needs, to find innovative solutions to their most pressing development problems, to think deeply and push the frontiers of knowledge and to help craft a better future. The response of universities globally to the current COVID-19 pandemic, by mobilizing scientific, psycho-social, macro-economic and virtual pedagogical expertise, has demonstrated how critical universities are to securing the present and future needs of society. This foundational mission of higher education has, undoubtedly, been the driving force of societal development. History has shown that universities are the lifeblood of societies, strengthening individual capacity to think critically and creatively and honing collective technical and social skills for global advancement. Today, however, as the world continues to fight a deadly virus that has brought some economies to a standstill, there are fundamental questions that the leadership of all universities, public and private, big and small, must confront: how do universities foresee higher education meeting the future needs of individuals and society? Will universities be agile enough to undertake the rapid organizational transformation necessary for their continued relevance and survival? Will there be a sustained commitment by governments to invest in the higher education sector as the bedrock of human enlightenment, justice, peace and progress?

H. Beckles $(\varangle) \cdot$ S. Richards-Kennedy

The University of the West Indies, Kingston, Jamaica

e-mail:vcoffice@uwimona.edu.jm

S. Richards-Kennedy

e-mail: stacy.kennedy@sta.uwi.edu

(C) The Author(s) 2021 


\section{Higher Education and the Caribbean in Context}

A first step to unpacking the discourse around the future of the university is understanding and reflecting on the context in which Caribbean universities operate. The Caribbean education system itself is a product of the region's history which has been shaped by exploitation, slavery and colonialism for centuries. Thus, the residual structural inequity in Caribbean society also manifests itself in the education system. With the lowest higher education enrolment in the hemisphere, the Caribbean's tertiary enrolment rate is less than $25 \%$ compared with the North American average of near $60 \%$ and the Latin America average of 52\% (The World Bank 2020). Disparities within the Caribbean sub-region are also quite concerning. Enrolment rates in Eastern Caribbean countries lag behind the rest of the Caribbean with only $15 \%$ of secondary school graduates going on to pursue tertiary education and less than $10 \%$ of adults having successfully undertaken programmes at the tertiary level (OECS Secretariat 2012). Gender disparities and a lack of opportunity for the most vulnerable add further complexities (OECS Secretariat 2012). This, in turn, hinders the potential of many workers who do not have the necessary skills, competencies and knowledge to function effectively and contribute to building the competitiveness of the sub-region.

The vestiges of slavery and indentureship are also visible in the health challenges that afflict Caribbean people. Chronic non-communicable diseases such as diabetes and hypertension disproportionately affect Caribbean people, and this is, in large part, owing to centuries of poor diet heavily concentrated in food with high sugar, oil and salt content. In 2016, more than $76 \%$ of total deaths in the non-Latin Caribbean (excluding Haiti) were due to non-communicable diseases, $58.8 \%$ of which were caused by cardiovascular diseases, cancer (17.2\%) and diabetes (10.8\%) (Caribbean Public Health Agency 2020).

The IPCC Special Report, Global Warming of $1.5^{\circ} \mathrm{C}$, highlighted the extent to which the Small Island Developing States (SIDS) of the Caribbean are disproportionately affected by climate change and suffer frequent and extreme weather events. Between 2017 and 2019, three mega-hurricanes, Irma, Maria and Dorian had a devastating impact on countries in the region. Damage caused by the 2017 hurricanes, Irma and Maria, was estimated at almost US $\$ 100$ billion (Ram 2019), with the Gross Domestic Product (GDP) of countries being decimated in several cases. Estimates of damage caused by these hurricanes was $225 \%$ of GDP in Dominica; more than $300 \%$ of GDP in British Virgin Islands; $10 \%$ of GDP in Antigua and Barbuda, with 95\% of buildings destroyed in Barbuda; and near 100\% of GDP in Anguilla (Smith 2018). Estimates of the total cost of the impacts and effects of Hurricane Dorian, which hit The Bahamas in 2019 was US\$3.4 billion, $25 \%$ of the country's GDP (Inter-American Development Bank 2019). Despite these acute vulnerabilities, the Caribbean region continues to have limited access to concessionary financing, and multilateral development banks continue to maintain GDP as the primary means of eligibility for official development assistance. 
The current COVID-19 pandemic has joined chronic diseases and climate change as the third deadly ' $\mathrm{C}$ ' to afflict the Caribbean. Keeping in mind the scientific evidence that global warming, changing weather patterns and human activity contribute to the spread of infectious diseases, the current pandemic exemplifies the crippling effect that infectious diseases can have on our highly interconnected, globalized world economy and the duty of universities to provide the scientific evidence needed for collective and coordinated action. Since March 2020, Caribbean universities have mobilized all resources at their disposal in an attempt to support governments' efforts at containing the spread of the virus and contributing to re-building more resilient societies. The University of the West Indies (The UWI), like over 50 sister higher education member institutions of the regional network, Universities Caribbean, worked closely with the public and private sector to facilitate a robust COVID-19 response.

As at end-May 2019, the English-speaking Caribbean has been recognized as having the lowest rates of COVID-19 related deaths in North America, Europe and Latin America. This is in part due to the work of The UWI's COVID-19 Task Force, formed prior to the first COVID-19 case entering the region. The UWI's Task Force provided data, public health modelling scenarios and policy guidance to regional decision-makers. Caribbean populations were also kept informed via our UWI-TV Global public education channel. The biggest lesson here for universities in the future is that, owing to the limited capacity of the Caribbean's healthcare system, Caribbean leaders recognized the importance of acting on the guidance of university scientists and other global experts and took swift action to protect lives, thereby demonstrating that where political will and science converge, the outcome will be in the best interest of the society.

The regional approach adopted by the Caribbean is rooted in the Caribbean's strategy to overcome challenges of size, geographical dispersion, and limited resources through regionalism. Organizations such as the Caribbean Community (CARICOM), Organization of Eastern Caribbean States (OECS), Caribbean Development Bank (CDB), Caribbean Regional Public Health Agency (CARPHA) and The UWI have been hallmarks of Caribbean society, built on a common history and motivated by a shared vision of a prosperous and sustainable future. The largest and most longstanding public higher education institution in the Caribbean, The UWI was founded in 1948 to serve Caribbean development, and it has evolved from a college at Mona, Jamaica with 33 medical students into a regional university with near 50,000 students across 5 Campuses serving 17 Caribbean nations and with eight global centres established in partnership with world-class universities across five continents. In many ways, the Caribbean's regional university has served to unlock the potential of Caribbean people and has contributed to shaping the identity, social fabric, and leadership of the region through education. 


\section{Re-imagining the Caribbean University}

Without a doubt, the current pandemic has accelerated the future of higher education into the present. Now forced to grapple with a volatile, uncertain, complex and ambiguous (VUCA) environment that warrants restructured workplaces, redefined roles and rapid learning, universities have had to quickly pivot and reposition themselves for enhanced relevance and competitiveness. In looking towards the future, universities are tasked with undertaking visioning exercises to deliver on the promise of higher education within an ongoing pandemic and post-pandemic paradigm and within a tighter fiscal space. Attempting to future-proof the university's academic and business operations, once a noteworthy goal of strategic planning, now seems like a futile exercise in an environment where the contraction of time is so rapid, the financial impact is so acute, and the urgency to respond to current stakeholder needs is so intense. This has implications for teaching modalities, enrolment rates, graduation rates, internationalization, mobility, student residential life, university academic, sporting and cultural events, institutional financing and so much more.

University leadership teams, therefore, face the difficult task of ensuring the survival of the university as an institution, in many instances rapidly adjusting its business model, cutting and re-training staff and rationalizing its teaching and research agenda, while at the same time preserving and enacting the university's societal mission as the engine of teaching, research, innovation and entrepreneurship for the societies it serves. In the Caribbean, a region whose commodity and tourism-dependent economies will suffer significant shocks as a result of the economic impact of the pandemic, the prospect for receiving traditional levels of government subvention in support of higher education institutions is quite bleak.

Against this regional landscape characterized by unprecedented macro-economic challenges, the search for more sustainable financial models for Caribbean universities must be deliberate and aggressive. The UWI, like many public universities in the region, is currently engaged in this process. With a laser-sharp focus on expenditure reduction and revenue generation, new financial strategies including innovative debt and equity instruments, debt for asset swaps as well as regional and international collaborations to underwrite entrepreneurial ventures, are being explored to supplement traditional financial contributions by governments and tuition fees from students. Diversification of product, price, pedagogy and partnerships will need to be pursued while maintaining our regional university's commitment to quality, its international ranking among the top $4 \%$ of universities globally and its brand promise as a university committed to integrity, excellence, gender justice, diversity and studentcentredness.

At the faculty level, greater attention will need to be placed on flexible teaching and learning modalities to provide online experiences that retain some of the richness of in-person interactions while benefiting from the advantages of distance education such as increased access, self-paced learning, quick re-skilling and re-tooling of adult learners as well as greater diversity and portability of certification through micro and digital credentialing. The immediate future will see Caribbean univer- 
sities upgrading their offering with new digital technologies, robust and integrated business enterprise systems, expanded online and blended teaching, complemented by targeted experiential learning. Universities will also invest in new pedagogical material and approaches that allow for smooth transitions to virtual delivery and online business continuity when necessary. These are all part of the Caribbean's journey towards increased resilience, as was envisioned by CARICOM's Pathway for Resilient Development. This new university model will thus take into account the new possibilities generated by artificial intelligence, blockchain technology and other evolutions of digital technologies, the rapidly changing world of work which requires more knowledge-intense skills than before and also the need to bridge the digital divide so that we leave no one behind.

As the future of global universities unfolds, Caribbean universities that were established primarily as developmental universities to contribute to strengthening democracy in the post-independent period shall remain true to their mission, carrying forward the ethos of Caribbean society. No doubt this will entail reinventing the academe as a more agile and effective institution to better serve the evolving needs of the workforce and wider society. It will also involve harnessing the university's collective disruptive thinking to produce a shift in regional and global development paradigms for a more just and sustainable future for all. Going beyond the concept of higher education in service of the higher purpose of education, Caribbean universities must continue to nurture the human and social capital upon which the future of Caribbean society rests.

During this UN-declared Decade of Action, we are summoned to unite behind science and work in concert towards shared global goals. The experience of the pandemic underscores the extent to which countries and regions are interconnected. The pathway to more sustainable futures will, therefore, require a fervent commitment to science diplomacy, multilateralism, and partnerships. Regional and international networks will be harnessed by universities now more than ever before, to build trust, advance knowledge exchange and foster deeper collaborations for greater societal impact. The celebration of the International Association of Universities' 70th anniversary through this publication could not be timelier. The IAU continues to be a beacon of reflection and action on common priorities that promote respect for diversity and social responsibility — an endeavour for which higher education institutions must increasingly use their voice as they work together to build new, more inclusive frameworks for cooperation and development.

\section{References}

Caribbean Public Health Agency. (2020). What we do: Overview. Retrieved from: https://carpha. org/What-We-Do/NCD/Overview (01.06.2020).

Inter-American Development Bank. (2019). Damages and other impacts on Bahamas by Hurricane Dorian estimated at \$3.4 billion: report. Retrieved from: https://www.iadb.org/en/damages-andother-impacts-bahamas-hurricane-dorian-estimated-34-billion-report (01.06.2020). 
Jamaica Information Service. (2020). Caribbean Focused on Building Resilience in Tourism. Retrieved from: https://jis.gov.jm/caribbean-focused-on-building-resilience-in-tourismminister-bartlett/ (25.05.2020).

McCowan, Tristan. (2019). Higher education for and beyond the Sustainable Development Goals. London: Palgrave Macmillan.

OECS Secretariat. (2012). OECS Education Sector Strategy 2012-2021. Retrieved from: https://www.oecs.org/en/our-work/r/research-and-publication/oecs-education-strategy/ viewdocument/520 (25.05.2020).

Ram, J. (2019). 2019 Annual News Conference. Speech. Caribbean Development Bank. Retrieved from: https://www.caribank.org/newsroom/news-and-events/speeches/2019-annualnews-conference-dr-justin-ram (01.06.2020).

Smith, W. (2018). 2018 Annual News Conference. Statement. Caribbean Development Bank. Retrieved from: https://www.caribank.org/sites/default/files/publication-resources/CDB_ President_Statement_CDBAnnualNewsConference_Feb72018.pdf (01.06.2020).

The World Bank. (2020). Second enrollment, tertiary (\& gross), Retrieved from: https://data. worldbank.org/indicator/SE.TER.ENRR?locations=ZJ

Hilary Beckles is the 8th Vice-Chancellor of The University of the West Indies (The UWI), a distinguished academic, international thought leader, United Nations committee official and global public activist in the field of social justice and minority empowerment. Before assuming office as Vice-Chancellor in 2015, he served the university as Professor of Economic History, Pro-ViceChancellor for Undergraduate Studies, and Principal of the UWI Cave Hill Campus in Barbados for thirteen years (2002-2015).

Stacy Richards-Kennedy heads the regional Office of Global Partnerships and Sustainable Futures at The University of the West Indies (UWI). Dr. Richards-Kennedy has over 20 years' experience in development management and development financing. Previous appointments include Assistant Resident Representative of the United Nations Development Programme (UNDP) for Trinidad and Tobago, Aruba, Curaçao and Sint Maarten, Chief Technical Advisor, Inter-American Development Bank (IDB)-Washington DC, Consultant, The World Bank-Washington DC and Programme Specialist, UNESCO-Paris.

Open Access This chapter is licensed under the terms of the Creative Commons Attribution 4.0 International License (http://creativecommons.org/licenses/by/4.0/), which permits use, sharing, adaptation, distribution and reproduction in any medium or format, as long as you give appropriate credit to the original author(s) and the source, provide a link to the Creative Commons license and indicate if changes were made.

The images or other third party material in this chapter are included in the chapter's Creative Commons license, unless indicated otherwise in a credit line to the material. If material is not included in the chapter's Creative Commons license and your intended use is not permitted by statutory regulation or exceeds the permitted use, you will need to obtain permission directly from the copyright holder.

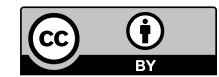




\title{
The Future of Higher Education: A New Paradigm Shift Addressing Students' Diversity
}

\author{
Khalid Arar and David Chen
}

\section{Introduction}

Recent higher education (HE) trends, including broader accessibility, privatization, increased demands for accountability, and technological implementation, have largely neglected consideration of human diversity, including the individual learner's nature and learning style. Two distinctive scientific perspectives pertain to these individual differences. In addition to the classical perspective of a bell-shaped normal distribution of mental abilities, a new perspective driven by behavioural genetics, neuroscience, learning science, and molecular biology reveals the immense complexity of the mind's architecture and functions in the population. Knowledge technologies might offer an innovative educational response to the immense diversity of students' and the complexity of the learning processes.

Technology should be defined as the human capacity to solve existential problems so that technology is first and foremost a cognitive trait, rather than a tool or machine. Today's educational policies seem to be dominated by an erroneous perception of man, aspiring to achieve uniform standards as if people were machines. We suggest that the biggest problem for present-day HE is the persistent overlooking of individual learner differences while its prevailing conceptualization is based on behaviourist principles. Ignoring human diversity and failing to address this fact is the main cause for educational ineffectiveness and inequality that prevails almost everywhere.

This essay suggests how major technologies might improve equity and efficacy through the recognition and resolution of the problem of individual differences and diversity in future HE institutions, noting the promise of "learning analytics" intended

\footnotetext{
K. Arar $(\varangle)$

Texas State University, San Marcos, USA

e-mail: khalidarr@gmail.com

D. Chen

Tel-Aviv University, Tel Aviv-Yafo, Israel

e-mail: chen@tauex.tau.ac.il 
mainly to introduce adaptive education and artificial intelligence usage in knowledge spaces and provide alternative curriculum choices to meet personal learning needs. Such developments should meet UNESCO's call to rethink and reshape higher education in line with increasing world complexity. The article concludes with several changes in the knowledge world and possible consequences for HE systems to enable them to address students' diversity and produce appropriate adaptive learning.

\section{Current Global Higher Education Policy}

Higher education institutions (HEI's) have undergone unending reforms designed to respond to the priorities of commercial markets and governments and to render universities more economic, efficient, and effective. However, by the 1990s, many national governments believed that the future lay in a 'global knowledge economy'. They implemented policies to repurpose HE to produce knowledge, skills and graduates that would generate intellectual capital and innovative products and make their countries more globally competitive. These reforms relied on neoliberal ideas aimed at turning universities into autonomous and entrepreneurial 'knowledge organizations' by prompting competition, and opening them up to private investors, to maximize individuals' skills in global labour markets (Shore and Wright 2017, p. 1). These policy narratives positioned universities as static entities within a market economy. An alternative narrative would see the university as a dynamic and fluid set of relations within a wider 'ecology' of diverse interests and organizations (Shore and Wright 2017).

Under pressure to produce 'excellence', foster social cohesion, improve social mobility, and challenge received wisdom (Brooks and Waters 2011), the boundaries of the HEI are being constantly negotiated while their core values and distinctive purpose change towards 'academic capitalism'. The following major trends influence HEIs today:

1 State withdrawal from investments in universities: state funding per student declines and cost-sharing shrinks.

2 New competitive regimes: Funding and assessment regimes are created to increase national and international productivity and competition between universities. Ranking is introduced, including ranking of institutions, disciplines, departments, and even individuals. Funds are then allocated to higher ranking HEIs, creating an 'audit culture'.

3 Administrative Bloat and Academic Decline, an extraordinary growth in the number and statuses of university administrators far beyond the growth in the number of faculty or even students is partially due to harvesting of data by the ranking industry and enormous rise in government regulations. Administrators become those who determine the university's core functions. Many universities have dropped the term 'academic support staff' in favor of terms like 'senior administrators' and 'pro- 
fessional staff', while faculty are managed as 'human capital' and a resource, and universities have become 'business corporations' (Levin and Greenwood 2016).

4 Privatization: faced with diminishing state funding and budget cuts, universities seek alternative funds, entailing fostering lucrative entrepreneurial partnerships with industry, conducting commission research for businesses and government, commercializing the university's intellectual property through patents and licenses, engaging proactively in city development. HEIs compete to recruit additional higher fee-paying international students, effectively generating the 'export of education'. Thus, HEI education has become a private, positional investment rather than a public good, while students' grants are replaced with loans. This has been coupled with a massive hike in student fees or what is called 'cost-sharing' by ministries and world bank experts (McGettigan 2013).

Global motilities, migration and internationalization lead to widening participation, diversity, equity and inclusion necessitating attempts to balance between expansion and quality assurance (Arar et al. 2019; Huisman 2009). In 2019, it was estimated that $3.5 \%$ of the total global population, or 272 million people, were on the move (IOM 2020). In 2016, there were 3.3 million international students (OECD 2017), most (58\%) moving from the east (China, India, Hong Kong, Singapore), mainly to Anglophonic states, including the USA, Australia, UK, Canada and New-Zealand which received $65 \%$ of these students (Arar et al. 2020).

5 Under globalization, a market-driven process, and knowledge-based production have become the distinguishing characteristic of globalized economies (Altbach et al. 2018). Technological developments have transformed the world economy's organization and the way that HE is provided. Thus, globalization of HE has shaped HEIs over three distinct, interrelated phases: (1) a surge in cross-border student flow, (2) the development of education hubs and branch campuses, and (3) most recently - program mobility, revolutionized by mass courses such as Massive Open Online Courses (MOOCs), enable more distance learning while shining new campuses espouse lifelong access to 24/7 education for all.

The knowledge society has altered the relationship between the public and individual knowledge stock. Theoretically, learning can take place without mediating agencies. Do these trends spell the end of the public university? Perhaps not, because autonomous or independent learning requires strong motivation, self-discipline and the ability for formal thinking; only a very small percentage of the population have these capabilities.

Actually, access to universities has increased massively, and technological innovations, including online learning provide responses to the challenges of privatization and marketization. Indeed, despite reduced public investment, citizens' expectations from the HEIs are even higher than in the past, believing that HEIs should educate students to be exemplary citizens for tomorrow's world, a world where they will need more sophisticated skills, responding to the interaction between research and socio-economic development, and providing continuous innovation and knowledge transfer to external stakeholders. 'Doing more with less' is now an imperative that 
characterizes the funding of HEIs' operations and institutions (De Witte and LópezTorres 2017).

\section{The Future of Higher Education}

Traditionally, HEIs partition knowledge into different disciplinary faculties: science, liberal arts, medicine, engineering etc. Teaching and learning follow a linear structure through three stages: undergraduate, graduate and Ph.D. Socially, HEIs are highly selective institutions allowing access by an average thirty percent of the population (Drucker 1993; Whitty and Furlong 2017). Selection begins at the undergraduate level and continues more fiercely to the third level with remarkable difference between the selection rate of Ivy League institutions and community colleges. Yet, the bell shape distribution of mental traits apparent in the PISA database indicates that only three percent of this population become the intellectual elite that establishes society's productive leadership. Thus, different goals should be set for each of the three HE stages in line with students' abilities.

(1) The knowledge society's nature has entirely changed from the Enlightenment focus on local national state, national culture and identity into an extended world perspective implying global problem solving, multiculturalism, English as a lingua franca, social networking, and wide cooperation rather than clash and conflict. The OECD (2018a) offers an international futuristic vision, suggesting an ecosystem approach that would change the static, predetermined curriculum to a flexible, dynamic curriculum to cope with the various socio-economic problems in a complex, uncertain new world. New skills to be developed would include critical thinking, creativity, self-efficacy, and regulation as well as self-regulation and autonomy.

(2) The PISA international comparative study provides perhaps the best big database to inform policies and practices, reflecting the realities of education, since it collects learning data from 79 countries and millions of learners (OECD 2018b). A critical evaluation of PISA 2018 by Schleicher Andreas (2019) provides essential guidance for any future design of a learning system as PISA results establish immense differences between and within countries, opposing the idealistic vision reflected in many policy papers.

\section{What Next: Suggestions for a New Paradigm Shift}

Given this global debate on how knowledge, education and learning need to be reimagined in a complex and uncertain world, it becomes clear that universities can play a crucial active role in shaping the future if they can conceive and implement appropriate institutional transformation. This section identifies future challenges for 


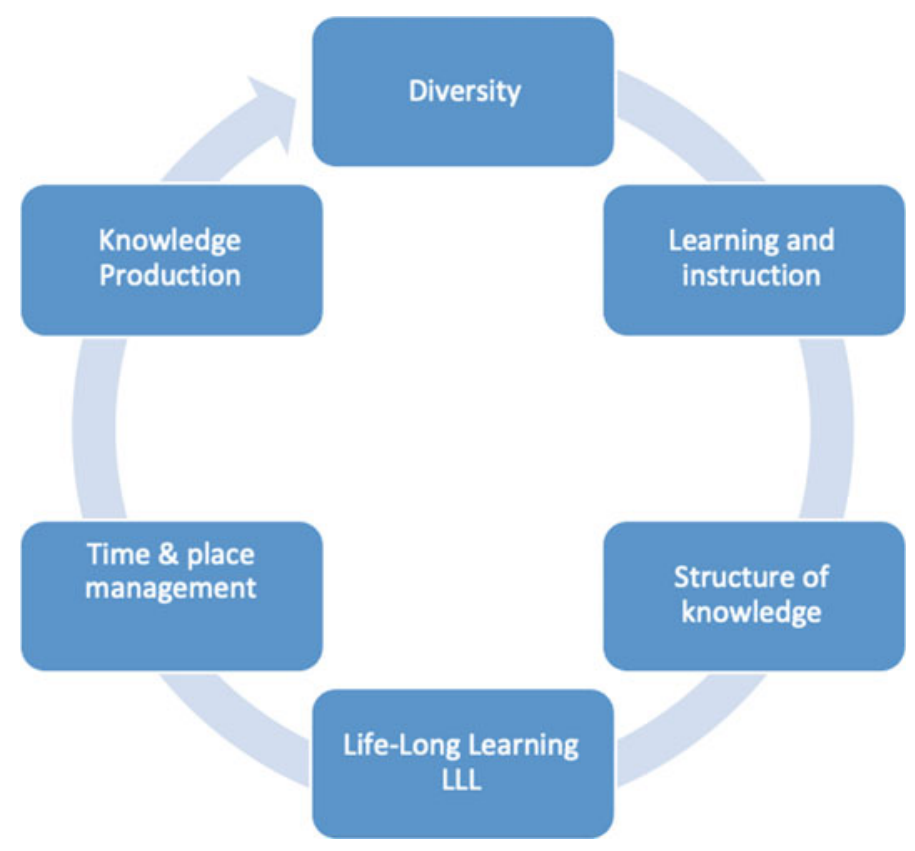

Fig. 1 Coping with diversity and individual differences in learner populations

the HEIs and sets the base for the next suggested paradigm shift, also addressing issues of diversity and inclusion, as presented in Fig. 1.

To retain their relevance to present-day life and to serve rapidly changing needs for the production and application of knowledge, HEIs must adapt to the following changes:

- The most significant aspect of the knowledge era is the exponential growth of knowledge; however, individual memory has remained practically static. An individual cannot make smart choices nor can a professional committee construct a reasonable curriculum without a clear knowledge technology, e.g. AI or Learning Analytics. These technologies are not yet mature enough for educational practice, but they are the only tools that can cope with the current complex quantities of the public knowledge stock.

- Learning and instruction need to consider growing understandings of the learning process and teaching strategies (neuroscience, cognitive psychology and education). It is important to recognize the distinction between declarative (symbolic) knowledge, the dominant knowledge delivered in universities transmitted in lectures and texts, and non-declarative knowledge without words (emotional knowledge, motoric knowledge, visual knowledge), which has been largely overlooked until recently. Stemming largely from learning through experience in tacit knowledge learned through experimentation (e.g. chemistry, engineering, physics). This knowledge is rarely given adequate coverage in educational institutions and should 
be recognized and employed in entrance exams and selection of candidates and over the academic programs. Teaching and learning will require collaborative, creative students who know how to learn well. To identify such applicants, universities will need to fulfil their responsibility to pre-collegiate education. Evaluation methods should correspondingly alter: from the testing of mastery of taught knowledge to assessments, which evaluate whether students are prepared for future learning. Students will be presented with new content they have not been taught in class - and evaluated by how well they assess and learn from that content.

- Diversity: The Personality Profile indicates that students' emotions are intertwined in learning, and universities should apply the concept of "adaptive education while aiming to meet learners' diversity." As science progressively reveals how different people learn and how to produce conditions that optimize learning, HIE pedagogies should be reconsidered to enable adaptation to meet students' diverse needs. New technologies can collect precise data on what is and is not helping students, enabling revision and continuous improvement of instruction and the underpinning scientific theories. Studies can be adapted to individual differences by relaxing choices, personalization of curricula, offering flexible time and place of learning and providing differential graduations. Adaptive education should replace the present rigid mechanical organization of learning. Open access universities that serve up to $30 \%$ of the student population, should adopt more flexible modular organization of knowledge beyond the present B.A, M.A, PhD pathway, creating smaller modules accumulated towards an academic degree, and professional learning during the working span to enable continuous learning.

- The reservoir of public knowledge grows exponentially, but human ability to absorb the knowledge remains static due to the inherent limitation of individual memory capacity. However, knowledge technologies can now extend human capacity to make choices in both chaotically organized and public stock knowledge.

- Pessimistic visions suggest that technology would replace HEIs' faculty, curriculum, and classrooms, because the individual understands how to interact directly with the stock of knowledge, without mediation agencies. This hypothesis does not stand up to the test of reality. Despite the success of the Open Universities, MOOCs and CORSERA, $90 \%$ of the students in the Open University and CORSERA reported that they preferred to learn in an organizational framework, indicating there is still a need for curricula, lecturers and educational institutions.

- Lifelong Learning (LLL), expands the HEIs' target population and the span of knowledge and relates to different age groups of students. While the present age is $18-30$, the future age span is expected to be $16-80$. This would cover both learning for an academic degree, and elective learning, addressing high school and other age groups and include learning in the community, learning for retirees (e.g. cultural and leisure studies), professional development for the industry (at work and in HEIs), second chance learners, special education, social projects (health, ecology, technology), and individual enrichment. College admission will no longer serve as the dreamy endpoint, rather just one chapter in a long life of learning.

- Managing time and place: Students should be able to study at any time and in any location, for example in a pandemic, attempts were made to facilitate dis- 
tance learning. Optimally, management of time and space would provide a hybrid framework, including classrooms, personal mentoring, experimental labs, workshops, independent learning and distant learning. Knowledge modules should be standardized, and there should be a global accreditation system. Such a shift facilitates inclusion of different types of students, e.g. migrants, displaced persons and international students or students in work etc.

- Production of knowledge needs to alter. In addition to the knowledge in HEIs there is now common wisdom, machine learning and business world knowledge. Universities' departmental fiefdoms need to be broken up or rearranged to support interdisciplinary efforts needed to create innovative solutions to major societal problems, and bureaucratic and cultural barriers to problem-focused research must be removed. However, the essential agent that can contribute well-based universal scientific knowledge remains the HEI.

Thus, despite the Knowledge Revolution, the long-awaited change is not a choice of one of two alternatives. Despite the current experience of online academic studies in the shadow of the epidemic or the Open University's attempts to lead international learning through radio, television, or the Internet, there is still an urgent need for oncampus learning, HEIs' research especially in science, agriculture and engineering, and academic mentoring, since most people are unable to learn autonomously and need mediation, and most prefer learning in groups. Universities should move to ecosystem planning, exposing knowledge to the community, delivering services, and sharing platforms for the public good. Seventy years ago, the IAU declared the principles it would promote: "the right to pursue knowledge for its own sake and to follow wherever the search for truth may lead; the tolerance of divergent opinion and freedom from political interference". In the spirit of this declaration, this innovative paradigm shift can be catalysed and led by the IAU, assisting universities to move to an ecosystems approach, exposing contemporary, relevant knowledge to the community, and sharing global platforms for the public good.

\section{References}

Altbach, P.G., Reisberg, L., Salmi, J., \& Froumin, I. (2018). Accelerated universities, ideas and money combine to build academic excellence. Global Perspectives on Higher Education, 40. Leiden; Boston: Brill.

Arar, K., Haj-Yehia, K., Ross, D.B., \& Kondakci, Y. (2019) Higher education challenges for migrants and refugee students in a global world. In K. Arar, K. Haj-Yehia, D.B. Ross \& Y. Kondakci (eds.) Higher education challenges for migrants and refugee students in a global world (pp. 1-23). New York: Peter Lang.

Arar, K., Kondakci, Y., \& Streitwieser, B. (2020). Higher education for forcibly displaced, migrants, refugees and asylum. Higher Education Policy, 33: 195-202.

Brooks, R., \& Waters, J. (2011) 'Student mobility, migration and the internalization of higher education', New York: Palgrave Macmillan.

De Witte, K., \& López-Torres, L. (2017). Efficiency in education: A review of literature and a way forward. Journal of the Operational Research Society, 68: 339-363. 
Drucker, Peter, F. (1993). Post-capitalist society. NY: Harper Collins.

Huisman, J. (2009). International perspectives on the governance of higher education, alternative frameworks for coordination. London: Routledge.

IOM [International Organization for Migration] (2020) 'World migration report 2020', Geneva, Switzerland: IOM.

Levin, L., \& Greenwood, D. J. (2016). Creating a new public university and reviving democracy: Action research in higher education. Oxford: Berghahn.

McGettigan, A. (2013). The university gamble: Money, markets and the future of higher education. London: Pluto.

OECD. (2017) International migration outlook 2017, Paris: OECD.

OECD (2018a). The future of education and skills: Education 2030. Paris: OECD. Retrieved from: https://www.oecd.org/education/2030/E2030\%20Position\%20Paper\%20(05. 04.2018).pdf (26.07.2020).

OECD (2018b). Pisa: Program for International Student Assessment. OECD. Retrieved from: https://www.oecd.org/pisa/ (26.07.2020).

Schleicher Andreas (2019). PISA 2018: Insights and interpretations. France: OECD. Retrieved from: https://www.oecd.org/pisa/PISA\%202018\%20Insights\%20and\%20Interpretations\%20FINAL \%20PDF.pdf(26.07.2020).

Shore, C., \& Wright, S. (2017). Privatizing the public university: Key trends, countertrends and alternatives, In S. Wright \& C. Shore (eds.), Death of the public university: Uncertain futures for higher education in the knowledge economy (pp. 2-27). New York: Berghahn.

Whitty, G., \& Furlong, J. (2017). Knowledge and the study of education- an international exploration. Oxford: Symposium Books.

Khalid Arar is Associate Professor of Educational Leadership and Policy at Texas State University and an Associate Editor of the International Journal of Leadership in Education. He was Dean of Research, at The Centre for Academic Studies and former President of Al-Qasemi Academic College of Education. For the past two decades, his research has focused on both K12 and higher education policies through the lens of equity and diversity.

David Chen is former Dean of the School of Education at Tel-Aviv University and visiting scholar in Harvard, Stanford, MIT and Oxford University. He recently initiated the School of the Future Project at Tel-Aviv University.

Open Access This chapter is licensed under the terms of the Creative Commons Attribution 4.0 International License (http://creativecommons.org/licenses/by/4.0/), which permits use, sharing, adaptation, distribution and reproduction in any medium or format, as long as you give appropriate credit to the original author(s) and the source, provide a link to the Creative Commons license and indicate if changes were made.

The images or other third party material in this chapter are included in the chapter's Creative Commons license, unless indicated otherwise in a credit line to the material. If material is not included in the chapter's Creative Commons license and your intended use is not permitted by statutory regulation or exceeds the permitted use, you will need to obtain permission directly from the copyright holder. 


\title{
Knowledge and Partnerships for Sustainability and Equality
}

\author{
Adam Habib
}

We live in interesting, but dangerous times; our world today is as unequal as it was before World War I and II. We are increasingly becoming as socially and politically polarized as we were then. Right-wing populist and nativist parties stalk all of our lands, deepening divides among our communities both nationally and internationally. Political and economic elites are paralyzed about what to do, or at least have not been able to marshal the will to undertake what needs to be done.

And yet, what needs to be done is known, or at least should be known. At the heart of the crisis today is the issue of social justice. Yes, we have taken millions out of poverty, but millions still remain mired in misery. As important, if not more threatening to our collective future, is inequality. So many have too little because so few have too much. This is the popular realization of our time, and it is why globalization has come under attack. It is why populist and nativist parties have been able to mobilize on the foundation of this popular resentment. But they, of course, have no answers as they propel us into a retreat to nativism and chauvinism of all kinds.

This deepening of human divides imperils humanity. Climate change, public health, renewable energy, inequality, and social and political polarization are transnational challenges that require the global community to cohere and act as one. Yet, this is not possible if the divides continue to deepen. Only if we build the bridges of human solidarity will we survive as a species. How to do this is one of the defining questions of our era and should be at the heart of how we reimagine universities in a post-pandemic world.

Universities are meant to assist in addressing the challenges of the historical moment. Inequality is perhaps the most significant of these because it politically and socially polarizes society and undermines our global and national capabilities to

\footnotetext{
A. Habib ( $\square)$

School of Oriental and African Studies (SOAS) - University of London, London, UK

e-mail: soasdirector@soas.ac.uk 
address the myriad of transnational challenges that we confront. But, addressing it requires universities to go beyond simply researching the challenges and proposing appropriate policies. Instead, it requires the university to transform its very essence: whom it brings to the university, how it teaches them, whom it employs, how it publicly expresses itself, and how it partners with other institutions around the world.

Essentially, if it is to address inequality, the university must undertake two distinct activities. First, it has to ensure that students from poor and marginalized communities are allowed in, provided with a quality education and graduate so as to enable the social mobility that addresses inequality within the society. But inequality is as much a feature of the global as it is of the local. This is why the university has to undertake a second activity; it has to partner with other similar institutions around the world to undertake the first activity on a global scale. The second activity also has to be undertaken so as to provide the human resource capacities and knowledge to address transnational challenges.

If this Covid-19 pandemic has demonstrated anything, it is that even though our challenges are global, local context and knowledge matter more than ever. Notice, for example, how the different parts of the globe battled with strategies for mitigating Covid-19, and how strategies such as a lockdown have had differential impacts across the globe. Thus, we require high quality institutions and human resource capacities across the world to address both global challenges and their local manifestations. Moreover, unless institutions in the global South are simultaneously able to innovate in their local context and also able to generate ideas and solutions to global problems from the perspective of their spatial and social specificity, we will not have reached effective and lasting solutions to our transnational challenges. We need more inventors, scientists, technologists, social actors, academics and students-in short innovators - to develop and adapt technologies for their circumstances. For this to happen, we need enabling environments. We need universities and vocational colleges that train, research and innovate; companies that are entrepreneurial; incubators that can nurture new technologies; and venture capital networks that can sponsor these initiatives. Essentially, as long as capable institutions and capacities do not exist across the world and in different contexts to contain global challenges like infectious diseases, the world will remain vulnerable to the next crisis.

The Sustainable Development Goals (SDGs) - those goals collectively recognized by the global community-recognize this. Goal 4-Quality Education-calls on us to: "Ensure inclusive and equitable quality education and promote lifelong learning opportunities for all". It proceeds by specifically calling for the expansion of scholarships in the STEM fields for developing countries.

By 2020, substantially expand globally the number of scholarships available to developing countries, in particular least developed countries, small island developing States and African countries, for enrolment in higher education, including vocational training and information and communications technology, technical, engineering and scientific programmes, in developed countries and other developing countries.

Goal 17 then states: "Strengthen the means of implementation and revitalize the global partnership for sustainable development". But, what if these two goals are in tension with each other. What if Goal 4 is undertaken in a manner that undermines 
Goal 17. Indeed, has this not been the case in the last few decades? In this era of globalization, we have had more global partnerships, more scholarships and more mobility across the world. Yet, this has also been the period in which brain drain has dramatically escalated, and institutions have weakened in some parts of the developing world.

This is definitely the case in African higher education. Of course, this dynamic is not the only causal factor in the weakening of African universities. They were irreparably damaged by structural adjustment to public policies in the 1980s, inspired by international development agencies that called for the prioritization of primary and secondary education, and the underfunding of universities. The idea was that tertiary education would be undertaken in the developed world. While this policy was partially reversed in the subsequent decades, the damage had been done. Moreover, our global partnership model has not fundamentally changed since the 1980s. Its methodology is to direct scholarships to talented individuals in the developing world and have them go to Europe and North America to acquire tertiary education. The assumption is, of course, that these students will return home. But, the evidence of the last few decades is that this is not the case. When these students go there, life happens. They fall in love, they have families, they get jobs and stay. At a recent conference on the diaspora at the African Union in Addis Ababa, it was demonstrated that more than $80 \%$ of students do not return. And this does not only speak to the African experience. Indeed, it is typical of much of the experiences of the developing world, including India and China, the latter having reversed the trend only recently.

The corollary of this in the developing world is that institutions have been weakened, human resource capacities are weakening or are not being developed, and inclusive development is being compromised. Of course, some among us speak of brain circulation rather than brain drain, and the importance of remittances to the developing world. But, if we are honest, we would recognize that these are weak countertrends that do not fundamentally change the negative institutional and structural dynamics that accompany the brain drain and compromise inclusive development.

It must be stressed that this is not only a problem for the developing world. It is as much a problem for the developed world. Herein lies the dilemma. As human resource capacities decline in the developing world, so does our ability to deal with the structural challenges of our era-which are also transnational. The most dramatic example of this is the coronavirus which has become a global pandemic. Imagine a pandemic caused by a pathogen that is equally infectious but even more deadly. The consequences would be devastating for the world. The only way we have a fighting chance to avoid this is for us to have the institutional infrastructure and human resources in both the developed and developing world to stem the challenge at its source, wherever it emerges. Yet, our global partnership methodologies undermine this, in practice if not in intent.

It should be noted that the argument here is not for some autarchic retreat into nationalism, nationhood and ethnicity. This is not possible; the human spirit has simultaneously an impulse to wander and explore-globalise-and identify and familiarize-localise if there is need for a term to describe this. These are not mutually exclusive agendas as populist and nativist parties tend to suggest. Instead, they 
can be complementary elements of human existence. Every one of us has families and communities whom we identify with and whom we love, but it need not dissuade us from caring about what happens to other members of the community elsewhere in the world. We can love our families and community networks and still practice human solidarity outside our familial networks. It is possible to be both local and global. Indeed, this is essential in this era if we are meant to survive as a human species.

What is being advocated is a new methodology of global partnership, one that is more rooted in institutions than individuals. In higher education, this would require joint teaching programs and split-site scholarships that would enable students to gain scientific knowledge, develop a global consciousness, have access to new equipment and funding networks, and yet be sufficiently rooted in institutions of the developing world to allow for this knowledge and skills to be deployed within their local contexts. Such a methodology would also allow students from the developed world to have the opportunity to visit the developing world, where institutional settings would exist that can host them, so that they too can understand the contextual circumstances of the developing world, and develop skills and knowledge that are more universally applicable.

This may go against the grain of the strategic plans of some universities in the developed world. Some of the more high-ranking of our institutions believe that their brands would be diluted by joint teaching agendas. They believe that they are here to train the scientists and knowledge brokers of our world. But they delude themselves. Whatever their scientific strengths, however recognized their academic cohort may be, however talented their students are, their contribution to our world is limited by the institutional arrogance that they matter more than others. In their legitimate desire to be competitive and their idiocy in believing that this needs to translate into a chauvinistic protection of an institutional brand, they undermine their own institutional mission. They have forgotten that great science needs to be accompanied by contextual understanding to have a dramatic impact.

The economic elites who sit in Davos or the researchers who sit behind their laptops in the coffee shops of the academic villages surrounding the great universities of the developed world cannot, on their own, solve the challenges of our era. They need an understanding of the context of the developing world, which is only possible through global teams of researchers and institutions coming together and deploying their collective knowledge, skill sets, and understanding to develop contextually relevant technologies and solutions to the challenges of our time. What we effectively need is an equitable global partnership of institutions that are rooted in the diversity of our community and deployed across all of our countries. This is a global agenda that is equitable, socially just, sustainable and universally relevant for this era.

What is being called for is an academy of commons. For centuries, we have pretended that science has no boundaries. Yet, every day we establish institutional and national boundaries that constrain science, knowledge and innovation. We need to seriously break down these boundaries, borrow and learn from each other in a collaborative and equal manner. Lessons learnt and innovations developed in each of our contexts could lead to changes in the rest of the world. We need a global academy 
of commons that understands the contextual nature of technological advances and how innovation can play a part in creating a more inclusive world.

Such a global academy could be a bridge of hope between an unequal and fractured past and present and an inclusive, collective future. But for it to become such a bridge of hope, we need to have the courage to ask the hard questions about our practices and improve them where we can. We have the intellectual resources across disciplines and institutions that can assist us in thinking through innovation more carefully to ensure that it is contextually grounded and inclusive. By doing so, we will genuinely address the inequalities and challenges of our time, creating a more socially inclusive and humane world.

Adam Habib is an academic, researcher, activist, administrator, and public intellectual. He is the Director of the School of Oriental and African Studies (SOAS) and has just completed his tenure as the Vice-Chancellor and Principal of the University of the Witwatersrand (Wits) in South Africa. He is the author of South Africa's Suspended Revolution: Hopes and Prospects, which investigates the country's transition to democracy, as well as Rebels and Rage: Reflecting on \#FeesMustFall, which provides an insight into the recent student uprisings.

Open Access This chapter is licensed under the terms of the Creative Commons Attribution 4.0 International License (http://creativecommons.org/licenses/by/4.0/), which permits use, sharing, adaptation, distribution and reproduction in any medium or format, as long as you give appropriate credit to the original author(s) and the source, provide a link to the Creative Commons license and indicate if changes were made.

The images or other third party material in this chapter are included in the chapter's Creative Commons license, unless indicated otherwise in a credit line to the material. If material is not included in the chapter's Creative Commons license and your intended use is not permitted by statutory regulation or exceeds the permitted use, you will need to obtain permission directly from the copyright holder. 


\title{
Post-COVID-19: A Time of Opportunity for Asian Universities
}

\author{
Eden Y. Woon
}

\section{Scene Setter-Global}

By the end of 2019, IAU member universities were already grappling with a variety of issues and knew that 2020 was going to be a challenging year. But many of them were still optimistic and looked forward to IAU's 70th Anniversary Year when universities would continue to push forward the frontiers of knowledge and play an increasing role of providing young people an understanding of the world beyond their hometown. And the key of this optimism was based on increased internationalization.

At that time, globally, there were 5.3 million international students. For top research universities in the USA, the percentage of international students was around $20 \%$, with Chinese and Indians being, by far, the most numerous, especially in postgraduate science and engineering departments. In the UK and Europe and Australia, there was increasing dependence on students from Asia. Universities' finances came to be very dependent on income from international students. For example, in the USA alone, one statistic calculated that every seven international students generated three jobs, providing US\$41 billion to the economy per year UNESCO (2019), NAFSA (2019).

Top universities were busy signing up student exchange partners, and international exchange experiences became something sought after by many students, although there was no doubt that the opportunities were limited to those who could afford the foreign travel and living expenses. And universities found dual degree programs and combination/unified programs to be excellent ways to contribute towards research cooperation.

Speaking of research, cross-border collaborations were numerous, and thousands of research publications had authors from different countries per year. Visiting scholars, both short term and long term, were going back and forth between countries

\footnotetext{
E. Y. Woon $(\bowtie)$

Asian Institute of Technology, Khlong Nueng, Thailand

e-mail: president@ait.asia 
and continents. But, this global outreach expanded both for academic and financial purposes. Seminars, workshops and conferences not only increased academic cooperation but allowed non-academic audiences from afar to be trained in a variety of subjects and skills.

\section{Scene Setter-Asia}

By the beginning of 2020, China, Japan, Korea, Hong Kong, and Singapore had universities ranked in the top 50 of the world in prestigious university rankings. Taiwan's universities have for decades sent top graduates in science and engineering to the US. Universities in Israel helped make the country into a "Starter Nation". India's technical institutes provided many top graduates to global technology institutions and companies, and Japan remained among the world's top producers of Nobel Prize laureates. Turkey, Iran, and Saudi Arabia were catching up fast in academics. Universities from other parts of Asia, like Thailand, Vietnam, Indonesia, Malaysia, and the Philippines, although they saw some of the better students from their home countries going to the West for undergraduate and graduate education, were themselves steadily improving their scholarly standing.

Top global universities continued to show an interest in Asia, both for the talent that could feed into their laboratories and for collaboration with increasingly substantive universities in Asia, although establishment of branch universities in Asia slowed in recent years.

Many Asian universities created regional alliances. They also reached out to the world and became active participants of significant international alliances such as the IAU. Collaboration in research and dual degrees between Asian universities and topranked global universities became more frequent, thereby lifting the standards for all. But, internationalization also still meant "westernization", since the top-ranked universities continued to be much more numerous in the West, whereas many top students came from Asia which provided much of the research and creative-and even management-talents that fuel the innovative industries of the West.

\section{Clouds on the Horizon}

But, for universities around the world, there were already clouds in the sky before 2020. First, the demographics were working against them. Young people of collegeage were diminishing in number in an aging society. Whether in China or Japan, the United States or the UK, this is worrisome for enrolment. Funding for all universities became tighter as taxpayers demanded more immediate "payback" for their money, and thus governments started to impose "Key Performance Indicators" to ensure more "accountability", something many universities were concerned with as it could 
encroach on academic freedom Quacquarelli (2019), Locke (2015:256-257), Hao (2015:121). Funding for fundamental research became harder and harder to obtain.

The fight for top students intensified between the top universities in Asia and the top universities of the West, with the latter increasingly dependent on international students from Asia for their research, education, and finances. And this competition began to tip in favour of Asian universities when many countries in the West tightened their visa rules on work-after-graduation — a big attraction for Asian students wanting to study in the West.

With growing populism and a general push-back against globalization, combined with geopolitics starting to interfere with the free flow of students and research talent, with universities' financial stability being shaky, the clouds were gathering, while we were in the "golden age of universities" at the end of 2019 and looking forward to celebrating IAU's 70th Birthday!

\section{COVID-19 Arrival}

In January 2020, the Covid-19 pandemic began to sweep the globe. Universities around the world scrambled to make sure their faculty, students, and staff were safe from the virus, and they closed down soon after, putting courses online. Internationalization efforts were halted, from student exchanges to research visits to international conferences. During the summer, universities were consumed with decisions on whether to open in the Fall, how to keep the campus safe, and how to manage education online. With the pandemic raging globally and travel, visa, and health restrictions proliferating, the result was a huge disruption to student lives, the recruitment "supply chain", and universities' finances. Research collaboration was badly affected, although academic exchanges and dialogue were actually able to continue through online forums and Zoom webinars.

In April 2020, the Asian Institute of Technology (AIT) came up with the Pipeline Partnership Program (PPP) which offered partner universities the opportunity to temporarily place some of their Asian students on AIT campus (for a semester or a year), whilst waiting for the virus situation to clear up in these partners' countries. After completing a residential period at AIT, these students can go to their destination universities when those countries' virus situation improves. This PPP can also morph into a $1+1$ dual master's degree or a $2+3$ master's/PhD degree for students to spend the initial period on the AIT campus and then go to other campuses later. Since then, due to the effect of the Coronavirus, several global universities have engaged in similar versions of PPP, with Cornell having the "Study Away" program with their students studying initially at partner universities around the world before coming to Ithaca, and NYU and Duke using their China branch campuses to accommodate their new Chinese intake for a while (Cornell Chronicle 2020; NYU Shanghai 2020; Duke University 2020).

With the Covid-19 pandemic raging even in the third quarter of 2020, there is an increasing realization that we are looking at a global environment which will be 
fundamentally different for several years, or even longer. The reference to a New Normal is now prevalent. Therefore, universities are not only scrambling to prepare for Fall semester 2020, they have begun to engage in sobering thinking about the future of their institutions. The big question is what is the value of a university education in the future? But, the sub-questions many will be asking themselves in the next three to five years range from recruitment to talent flow, internationalization, the value of residential universities, research collaboration, more use of technology in education, and the future business model.

As Asian universities address these questions, they will find that they can actually take advantage of the environment post-Covid-19, using technology, its geographic centrality, its growing economies, the abundance of bright students and scholars, and with more and more universities in this continent taking their place among the top in the world.

\section{How Asia Can Take Advantage}

1. Recruitment-Many students are now unable to go to the West for university education from heavily infected Asian countries. Now Asian universities can recruit more good quality students from their home country and neighboring countries. Universities in China, India, Taiwan and Singapore will especially benefit, at least in the short term. AIT has, in fact, doubled its Chinese student enrolment in Fall Semester 2020. And others can emulate the PPP to provide a regional partnership for top universities in the West. We expect dual degrees to flourish between Asian universities and Western universities. Student quality will definitely go up in many Asian universities in the next 3-5 years, allowing these universities to build up their academic reputation.

2. Talent Flow-We are likely to see a long-term change in talent flow and mobility coming from the West to Asia. Already, exacerbated by the geopolitical tension between the US and China, there is an effect on student recruitment. Furthermore, this sentiment extends to many successful research scientists originally from China currently in the US, who are starting to come home to lucrative opportunities in Chinese universities. Work-visa restrictions and a perceived lessthan-welcoming attitude towards Asians can discourage Asian talent from staying in the West. More will come home. This reverse brain drain will definitely help many Asian universities.

3. Internationalization-With technology providing many new internationalization experiences with wider access, more students in Asia, including the less well-todo, can benefit. Since there will be less travel for everyone, we need to maximize the "foreign exposure" of students through technology. We already mentioned above about accessing partner universities' classes via technology, and that can also extend to campus experience, with more virtual tours of campus facilities and local sights, more remote conversation with students across the globe, more participation in cross-border online activities, all to simulate a "presence" in 
a foreign land. These virtual exchanges can be more real than ever. Without traveling, using technology, ironically, accessing global universities is easier for more Asian students.

4. Education Collaboration-Asian universities can take advantage of technology to maintain dynamic global access. For example, AIT will be using Hybrid Instruction this Fall, with students both in the classroom and online. The latter, who are overseas initially, will have as good a residential classroom experience as possible. AIT plans to use Hybrid Instruction beyond Fall to integrate continuing education with academic programs, to provide flexibility for work-study students, and to allow international partnerships in lectures and classrooms with blended learning. The facility can provide scalability and flexibility to profoundly increase education across borders at a lower cost, making more inclusion possible. Modular delivery of programs can provide options and flexibility, with participation by overseas non-degree students. In short, there can be diversified and multiple options from different countries and universities, facilitating dual and joint degrees.

5. Research Collaboration-Since travel will be discouraged, the timeframe of exchanges of faculty members and researchers will be longer, allowing deeper collaboration between Asian universities and those in the West. Sharing of visiting faculty resources is essential as migration of faculty will be lessened in the future, either for health or geopolitical reasons. Longer visits by top faculty help to bolster the quality of Asian universities. For research, virtual laboratories and teaming up with students in laboratories across the globe and other simulation and artificial intelligence initiatives all can go a long way to complement in-presence research work. Zoom and other online platforms will become commonplace for academic discussions and collaborations across continents.

6. Complementary Collaboration-One particular method to foster collaboration is what can be called "complementary collaboration", where leading-edge technology in the West can be applied to sustainability issues - many of which are critical in Asia and being tackled by Asian scientists. AI as applied to climate change problems, or robotics applied to agriculture, come to mind. With problems involving nature, from Covid-19 to climate change seriously affecting humans globally, research on the Sustainable Development Goals will be emphasized more. These are fertile areas of complementary collaboration.

7. Regional Alliances - These will strengthen. With better students, better faculty, more certainty on public health, many Asian universities with a good academic base can already gain in this post-Covid-19 environment. And they can form more alliances and dialogue groups with each other, taking advantage of exchanges nearby. Universities in Asia will not only look to the West for collaboration but engage in more collaboration with universities within the region. They will need to be open-minded and look within the region for the acceptance of transfer credits and qualifications, including setting up regional funding schemes like an "Asian Erasmus", for example.

8. Asia's Importance-Universities in Asia can take advantage of Asia by playing a key role in working with not only local companies but also multinationals 
interested in the Asian market. They may not easily access Asian students in their HQ country but can draw on the students in Asia to help their companies in Asia. There will also be more opportunities to work with the private sector by providing continuing education to senior staff who may not travel as readily to multinationals' HQs, and we can use online modes of partnership or even "hybrid internship". In short, when travel is restricted, the unique position of Asia being a huge market and a rapidly developing region can foster closer ties of the private sector with increasingly respected Asian universities.

\section{Into the Future}

Universities in Asia, being younger, less established, increasingly respected, more dynamic, and eager, with a great geographic position and a large number of smart young populations eager to learn, with the embrace of more technology in education, can actually gain out of this crisis. Covid-19 may be a depressing chapter in the history of the human race, but its pervasive and lingering impact is moving, ever so slightly, the global centre of gravity of academic excellence towards Asia. Every crisis is an opportunity, and this is a time of opportunity for Asian universities.

\section{References}

Cornell Chronicle. (2020). 'Study Away option supports international students'. Retrieved from https://news.cornell.edu/stories/2020/07/study-away-option-supports-international-students.

Duke University. (2020). 'Message to Duke '24 International Students: DKU Option for Fall 2020'. Retrieved from https://dkurelations.duke.edu/students/duke-students-dku/messageduke-24-international-students-dku-option-fall-2020.

Hao, Zhidong. (2015). 'Commercialization and Corporatization Versus Professorial Roles and Academic Freedom in the United States and Greater China', Chinese Sociological Review, 47:2, p. 121.

Locke, Kirsten (2015). 'Performativity, Performance and Education', Educational Philosophy and Theory, 47:3.

NAFSA (2019). 'Despite Stagnant Enrolment, International Students Contribute Nearly \$41 Billion to the U.S. Economy'. Retrieved from: https://www.nafsa.org/about/about-nafsa/new-nafsadata-despite-stagnant-enrollment (26.08.2020).

NYU Shanghai. (2020). 'NYU Shanghai to Host Students from NYU and NYU Abu Dhabi in Shanghai This Fall'. Retrieved from https://shanghai.nyu.edu/news/nyu-shanghai-host-studentsnyu-and-nyu-abu-dhabi-shanghai-fall.

UNESCO: Institute for Statistics. (2019) 'Outbound internationally mobile students in 2017'. Retrieved from: http://data.uis.unesco.org/Index.aspx?queryid=172 (26.08.2020).

Quacquarelli Symonds (QS). (2019). 'How Aging Populations are Impacting the Higher Education Sector'. Retrieved from: https://www.qs.com/aging-populations-impacting-the-he-sector/ (26.08.2020). 
Eden Y. Woon became the President of Asian Institute of Technology (AIT) on September 1, 2018. He also serves as Special Advisor to the Shaw Foundation in Hong Kong. From 2010 until November 2017, Dr Woon was the Vice-President for Institutional Advancement of the globally highly-ranked Hong Kong University of Science and Technology (HKUST), responsible for international relations, China affairs, development, alumni, and public relations. Before HKUST, Dr Woon had a career in the military, government, business, and academia.

Open Access This chapter is licensed under the terms of the Creative Commons Attribution 4.0 International License (http://creativecommons.org/licenses/by/4.0/), which permits use, sharing, adaptation, distribution and reproduction in any medium or format, as long as you give appropriate credit to the original author(s) and the source, provide a link to the Creative Commons license and indicate if changes were made.

The images or other third party material in this chapter are included in the chapter's Creative Commons license, unless indicated otherwise in a credit line to the material. If material is not included in the chapter's Creative Commons license and your intended use is not permitted by statutory regulation or exceeds the permitted use, you will need to obtain permission directly from the copyright holder. 


$$
\begin{array}{r}
\text { Part VI } \\
\text { Opening up - The Future of Higher } \\
\text { Education }
\end{array}
$$




\title{
Envisioning Higher Education for the Future
}

\author{
Henning Jensen-Pennington
}

\section{Introduction-International Cooperation and the Significance of Integration}

In a constantly changing global society, higher education faces threats, challenges and opportunities that are not static, but are constantly evolving and transforming. Higher education institutions are prone to appreciate universal values, traditions and stability, which is specific and extremely relevant assets that help explain the profound roots they have put down across many cultures and highlight their enduring contribution to societal development in almost all dimensions, from material production and scientific innovation to artistic creativity and critical thinking about the surrounding world.

It is important to take note of the fact that these prominent, and unquestionably important, aspects of higher education also impair their capacity to anticipate and react critically — not adaptively in the sense of passive adjustment - to current and future challenges. In order to face dynamic new circumstances, higher education institutions, and their regional and international organizations, need to tenaciously rethink their contribution and position in a constantly changing world.

This is indeed a complex operation; for one, because the fabric of higher education is interwoven with multiple and diverse interests and expectations, both internal and external. Moreover, institutions are frequently pressured by political environments that are not necessarily attuned to education in general, and to science and knowledge in particular. It is essential for higher education to be fully aware of this complexity in order to discern how best to negotiate its way through the mesmerizing diversity of the present while remaining fully pertinent and relevant.

Universities play a fundamental role in the empowerment of individuals and societies. It is frequently argued that it is necessary to adhere to evaluation and accred-

\footnotetext{
H. Jensen-Pennington $(\varangle)$

Universidad de Costa Rica, San José, Costa Rica

e-mail: hjensenp@gmail.com 
itation processes to ensure quality and academic relevance. That is perhaps selfevident. But the emphasis placed on these processes in the last decades, including the proliferation of rankings, has led to a narrative that has undervalued-or at least disregarded - the importance of long-term planning, internal and international dialogue, and negotiation. More importantly, such a narrative pays insufficient heed to higher education's commitment to society. I do not refer to the latter in abstract terms, nor in the sense of vertical impacts, but as a process embedded in a reciprocal and intertwined learning experience that enriches both universities and societies.

In many countries of the world, universities are central and emblematic: much to the pride of nations, they play a central role in fostering the rule of law, in both social and democratic terms. In Latin America, for instance, public universities have been significant for the promotion of social mobility, a means for strengthening equality, combating poverty, and generating opportunities.

No country is immune to the erosion of its democratic institutional framework, and concessions to its academic freedom. Universities can mitigate these negative outcomes by participating in consensual alliances with similarly inspired civil society groups with national and regional agendas aimed at achieving prosperity and preserving the common good, which in turn are explicit values of the academic ethos.

\section{Promotion of Regional and International Integration Through Academic Mobility of Teachers, Students and Administrative Staff}

Universities, as institutions that cultivate science, technology, and culture, are part of a context of wide internationality, in which cross-transmission of knowledge and experiences predominates.

Knowledge - as we know-is currently more widely distributed in the world than ever before. Advanced universities are open to multidirectional mobility of faculty and students, carry out high-level shared projects, jointly address highly complex issues, and nurture cultural diversity via mutually-beneficial, respectful partnerships.

A comprehensive university must consolidate its position in such academic scenarios, now more extensively than ever, by forming academic alliances through broad and flexible networks. These will allow university groups to place themselves on the stage of science and technology, as well as of art and the humanities at regional and global scales. 


\section{Internationalization by Strengthening the Internal Capacity for International Cooperation}

Universities must meet the challenge of visualizing internationalization as an integral tool of organizational restructuring, of management models and should be part of the social responsibility of our institutions. This includes the design of effective policies in institutional terms, sponsoring greater participation for all sectors involved, such as academics, students, and administrative staff. But also with other external stakeholders or social forces with whom alliances can become fertile endeavours, not only to obtain resources or stimulating funding but to change mentalities, ways of perceiving and thinking, reactivating debate on the moral sense of internationalization.

The idea of structuring and applying an endogenous internationalization model bears many opportunities: it opens up possibilities to devise programmes focused on pragmatic, relevant or comprehensive internationalization, in line with priorities of institutional development projects, with demands coming from the receiving environments and interests of different stakeholders, in its literal meaning of this noun: an individual or groups of persons that are invested in - that is, endorse-the goals and values of higher education.

\section{Creation of an Ecosystem That Promotes Scientific and Technological Development}

The transfer of knowledge should contribute to the common good, foster social cohesion and production, promote the well-being of groups and communities, with a special focus on the most vulnerable.

The university must stimulate and take advantage of synergies and interactions with other national institutions and thus forge effective policies in the transfer of knowledge to society.

A more fertile and intense encounter between university and society can be achieved through stronger interlinkages of universities with their immediate social, political and economic environment and the needs of the population therein.

In these environments - and this may also apply to highly developed countriesthere are often issues such as health, food production and security, housing, energy, and water quality needs, among others. Many solutions require public intervention. But, solutions can often be facilitated with the help of advanced knowledge: universities can provide training and associated learning, carry out scientific and technological research, give advice to local governments.

We must not forget that the local dimension is very relevant to sustainable development strategies and plays a significant role in knowledge construction processes. This demands an integral vision of academic life so that interdisciplinary efforts and cross-fertilization between disciplines are facilitated with active student participation. 
Integration of the substantial activities of a university: teaching, research, and social responsibility and commitment, is a goal that is not easy to achieve. On the contrary, systematic efforts and coordinated programmes are required so that students receive updated knowledge, learn advanced research processes and, at the same time, together with faculty members, put that knowledge at the service of society. The proverbial wisdom that educators have to be educated is perhaps nowhere more appropriate than in this context: educate educators to generate, share, and implement knowledge, and its innovative iterations. No university purely dedicated to teaching can even begin to grasp the complexity of this, which becomes even bigger if we take into account the diversity of the social sectors involved and the speed with which knowledge evolves in all areas and disciplines.

That is why every university should place special emphasis on the quality of its teachers and students. To this end, the planning of generational replacement and the refinement of the processes and mechanisms of hiring academic personnel is essential. In addition, continuous training of administrative staff must be integrated into this mechanism in a complementary way. As part of this process, it is necessary to strengthen the institution's graduate programmes and direct academic policies towards a system of merit with competitive salaries within national and international frameworks.

Given the accelerated changes in knowledge, actions that contribute to greater flexibility and curricular versatility are required, with the creation of new programmes, integration of, amongst others, student mobility between different disciplines. In the case of those universities with regional representation, horizontal regionalization models must be promoted as they marry regional pertinence with national relevance. These models must be developed according to the needs of the country in general and of the regions in particular.

\section{Horizontal Creation of Programmes Which Include Student and Community Participation, and Recognition of the Dignity of Diversity (of Knowledge)}

By deepening horizontal processes, at all academic levels, a systemic, unitary, comprehensive and efficient institutional concept can be strengthened. The organic articulation of university development, which can be imagined as intertwined threads of academic initiatives, connected with and permeating the functioning of management, will contribute, without a doubt, to the social inclusion of wider sections of the population.

We live in exceptional circumstances and times, characterized by increasing epistemophobia and the predominance of a sort of logic of suspicion and disregard that undermines the legitimacy of systematic knowledge. Universities are, after all, cultural institutions - and the promoters of precise knowledge and critical appraisaland as such, must seek new alliances. These will inevitably embrace a new way of 
dealing with relevant public issues. But, the university that seeks those new alliances has to do so in a context of a new Enlightenment, a non-Eurocentric effort to include diverse knowledge systems and cultural practices.

Each member of the university community must experience how these institutions live up to their aspirations, grant them new points of view, and open opportunities and possibilities for development. Through something as obvious (yet often stifled) as the guarantee of fundamental rights in each institution, and through the expansion of services that have not been traditionally addressed, greater university cohesion can be created. Similarly, it is essential to generate more reflection on the type of services sought in public institutions, and that the State must warrant.

The knowledge generated in higher education should ideally impregnate the entire society, but that permeability must be bi-directional: the university must learn from the collective knowledge of all social agents.

\section{Contribution to the Achievement of the Sustainable Development Goals (SDGs)}

In the move towards sustainable development, scientific, technological and innovation, together with training, are undoubtedly fundamental. In many regions of the world, universities have extensive scientific and technological research capabilities, as well as human talent. Through its interactions with other social actors, transforming itself, and influencing public policies, higher education helps us to fight inequalities, improve the environment, and move forward towards development and remove barriers by resorting to knowledge, science, technology, and innovation.

Higher education institutions are aware of the demand for knowledge linked to the objectives of the 2030 Agenda, and of the important role they play in achieving them. The link between higher education and territorial development is one which promises to connect higher education to society and thus meet the demands of the SDGs.

The prevailing hegemonic development model is environmentally, economically, and socially unsustainable, and it is becoming increasingly clear that humanity needs to move towards a new model of development and a different concept of progress. Indeed, the bathe cry of the SDGs is to summon knowledge, education, science, technology and innovation to solve the problems addressed by the 2030 Agenda, and are precisely areas that higher education institutions directly address.

The Economic Commission for Latin America and the Caribbean (CEPAL, in Spanish) has defined a set of priorities that, fundamentally, connect the SDGs with core functions of higher education:

1. The centrality of equality. In addressing the issue from Latin America and the Caribbean, the most unequal region on the planet, CEPAL insists that equality is a key issue. The current production, dissemination, and use of knowledge are closely linked to inequality; 
2. Balanced integration of the three dimensions of development: economic, social and environmental;

3. A structural change that enables the incorporation of knowledge into production guarantees social inclusion and allows for progress on a low carbon-emission path through a large environmental impulse;

4. The advancement of technological innovation, the digital economy, and the information society;

5. Capacity building through quality education.

These challenges have emerged from the social capacities and weaknesses of Latin America, but they are not unique. Higher education institutions are called upon to actively engage in shaping global development plans; they must make sure that each contribution is made visible and addressed with the importance it deserves, and they must work toward successfully reaching the global development goals, ensuring equality among all inhabitants of the global village.

\section{Closing Remarks}

These are some of the challenges that the future poses. All of them must be seen in the context of complex and contradictory national, regional, and international realities. The leadership that universities worldwide have forged should be instrumental in promoting strong interaction with external social and political sectors, and this will benefit from a permanent process of dialogue and negotiation.

When facing new challenges, universities must not fall into complacency. On the contrary, they must be the living paradigm of scientific ethics and ethos regarding selfcriticism and demonstrate an openness to the contributions that come from beyond the campus. This dialogical attitude is elemental for social well-being and, as such, must become an integral part of the university.

Henning Jensen-Pennington is former Rector of Universidad de Costa Rica (2012-2020). Before that, he was Director of the Institute of Psychological Research, Dean of the School of Social Sciences, Director of Doctorate Studies of Society and Culture, and Research Vice-Rector at the same university. He has also been a consultant for the Pan American Health Organization and President of the Psychological Association of Costa Rica. From 2004 to 2011, he presided over the Foundation of the University of Costa Rica for Research. 
Open Access This chapter is licensed under the terms of the Creative Commons Attribution 4.0 International License (http://creativecommons.org/licenses/by/4.0/), which permits use, sharing, adaptation, distribution and reproduction in any medium or format, as long as you give appropriate credit to the original author(s) and the source, provide a link to the Creative Commons license and indicate if changes were made.

The images or other third party material in this chapter are included in the chapter's Creative Commons license, unless indicated otherwise in a credit line to the material. If material is not included in the chapter's Creative Commons license and your intended use is not permitted by statutory regulation or exceeds the permitted use, you will need to obtain permission directly from the copyright holder. 


\title{
From University to Multiversity to \\ Omniversity: HEIs as Hubs for Dynamic Development
}

\author{
Roberta Malee Bassett
}

Omni: in all ways or places; Omniverse: a universe that is spacio-temporally fourdimensional (Merriam-Webster).

When Clark Kerr coined the term 'multiversity', in 1963, he provided a dynamic proposition for the expanded purpose and value of higher education institutions (HEIs): "New knowledge is the most important factor in economic and social growth... What the railroads did for the second half of the last (19th) century, and the automobile for the first half of this (20th) century, may be done for the second half of this century by the knowledge industry: that is, to serve as the focal point for national growth." Kerr (1963) foretold the knowledge economy to come-that the real growth in economic development would not come through manufacturing or expanded industrialization, but instead from knowledge and information-and argued that universities would be the engines of that growth: the 'multiversity,' serving as a centre for teaching and learning, of course, but also for research and engagement beyond the classroom.

While utilizing James (1895) work on the multiverse, Kerr (1963) compared the multiversity to the university as like a federal republic versus a kingdom, where attention is paid to each part as separate and integrated versus seeing the entirety as all forms merged into one. Yet, this federated institution was still based on an identity tied specifically to location, mission, and the historic population of that campus (staff and students). An institution in three dimensions: teaching, research, and engagement with the community.

It is here where the omniversity diverges from its academic forebearers.

With its four-dimensional dynamic, the 21 st Century omniversity is a multiversity without borders or limits to its academic mission, taking the convening power of the university truly global. Creating hubs for teaching, research, innovation,

R. M. Bassett (凶)

The World Bank, Washington, DC, USA

e-mail: rbassett@worldbank.org 
entrepreneurship, and more than those previously anchored in local, regional, and national communities to create a span of impact and influence across the entire globe. The omniversity is a place where location - the institutions', students', and academic staff's-is almost irrelevant. Core functions are delivered in blended formats, engaging an institutional community not bound together via the physical plant of a campus but by a shared institutional mission. The omniversity is and will be one major piece in the dynamic puzzle that is the future of higher education.

First, then, is to define an omniversity and the emergence of such an institution from its origins of the university and multiversity. Since an exhaustive google search did not result in any previous use of the term, this is an opportunity to identify and define the omniversity as a major, transformational higher education institution of the present and future. In this rethinking of the constituent parts of a university, the omniversity is an institution that not only capitalizes on the concentration of talent, resources, reputation, and reach under its unified organizational umbrella to drive knowledge creation and dissemination as a broad-scale global enterprise, it also has the capacity and agility to innovate and expand its sphere of influence. The omniversity is a transcendent enterprise of global education reach and impact. As the definition of omni above attests - an omniversity is a university that is "in all ways or places." Indeed, such institutions most definitely exist today and are destined to expand in number and impact to drive global higher education in the future.

In looking at how an HEI would be "in all ways and places," we can first think about the "ways." The traditional universities first delivered teaching on a campus and encouraged its faculty to conduct research. The multiversity sought to expand the influence of the knowledge exchanged and developed on campus to external social and economic development but did not require broadscale definitional change to the modes of doing business. Teaching and research remained the anchors of multiversity engagements. What changed in the evolution of traditional universities to multiversities (again, as defined by Kerr and subsequent scholars of higher education) was an expanded notion of why HEIs operated as they did and the expected impacts of the enterprise-HEIs were widely accepted as social and economic engines. With the omniversity, social and economic development as an outcome of traditional teaching and research is far too limited.

Next, how the evolution of university-multiversity-omniversity was possible is very much a story of technology and globalization. The addition of this fourth, borderless, dimension to the core functions of the university, transforming the university to a onmiversity, was only possible with the massive growth in information and communication technology (ICT), the ease and affordability of international travel, and the global expansion of the knowledge economy. A HEI need not be local to deliver its curriculum to students, given the near ubiquity of ICT for education. Academic staff and students could (and will one day again) get on a plane and relocate for their work anywhere in the world. Government, industry, students, and staff all have grown to understand that the best outcomes from education are now in a knowledge-driven, global economy and society. All of this relies on advanced, borderless, high quality education-the omniversity. 
How does the omniversity differ from the university and multiversity in practical terms? Here are some emergent characteristics that pull the university of the past into the omniversity of the present and future:

- For students

- Multiple pathways to desired outcomes

- Traditional 3-4 year courses for a first degree

- Short course options (micro-credentials) to seek specific skill development of knowledge

- Stacked micro-credentials (from one or more HEIs) to achieve degrees

- Multiple modes of learning

- Traditional, campus-based instruction

- Blended learning, with time on and away from one or more physical campuses

- Fully remote participation, from anywhere, asynchronously.

- For academic staff

- Multiple career pathways

- Teaching only, with expertise especially in the pedagogy of remote learning, in multiple formats - in person, asynchronous online, short courses for skill development, traditional courses relying on longer-term relationship building, etc.

- Teaching and research, following a traditional model and with support from the teaching-specific staff

- Research only, building and innovating mechanisms for blended and remote research opportunities, to promote borderless communities of knowledge production and application

- For administrative staff

- Expanded role of ICT specialists into the core functions of the institution

- Expanded need for extra-academic support for its borderless and unbounded student populations, based in centres that span global time zones, for constant availability, with skills including:

- academic support staff and coaches with skills in global languages

- knowledge of student development theory (for traditional and non-traditional students)

- learning science expertise, to support academic staff and students in course development and delivery

- Expanded knowledge of quality assurance-both in support of crafting high quality, agile academic programs and in ensuring cross border programs achieve credential and degree recognition status in the countries where students are based 
- Expanded role of staff in building relationships with external stakeholders, including employers, investors, entrepreneurs, policymakers, and community leaders, to ensure relevance and adaptability of the education to the outcome potential of students and research.

Some of these are familiar today. Some are anathema to how universities operate in their national, traditional contexts. But, all of these are and will be core functions of the omniversity, which does, in fact, exist in some nascent form already.

Where are the omniversities of today? They are not yet the drivers of global higher education nor the beacons that attract policymakers, investors, academic staff, and students. They are, instead, making those institutions that dominate the global rankings and have captured the imagination of all those who aspire to world-class university status very nervous. Perhaps they will result from global mergers, where a central institution purchases, partners, or somehow pulls an array of institutions outside its existing borders under its own organizational umbrella. Institutions will perhaps choose to unite within a consortium, with some autonomy but shared delivery and global reach. Or, perhaps a strong leader emerges with a vision for a coalition of programs and staff unbound by location or tradition under this new HEI and has the charisma and influence to make it happen.

An institution that comes closest to this broad-scale definition of the omniversity is Arizona State University (USA), which has created an entire complementary institution to its traditional base to deliver global remote learning options on every continent while remaining anchored to its campus in Tempe, Arizona. Even ASU remains largely bound to its geographic location and language of instruction. Innovators in East Asia and the Middle East continue to seek avenues to push the boundaries of what higher education can be and whom it can serve. With the necessary resources, talent, and imagination, these education leaders may be the hubs of new, boundless, global omniversities.

It sounds almost like science-fiction that an institution can be a kind of education empire. It might also be seen as driving a form of education colonialism if unchecked and unfettered. If we learn anything from the changes being wrought by the COVID19 pandemic, we should learn this - the inevitable globalization of higher education will not necessarily come in one form, and higher education must continue to evolve to be more useful, adaptive, accessible, and meaningful. If the omniversity emerges that provides education to a borderless community of students and scholars in formats that span from the most applied short course to the most advanced doctoral program, with multiple modes of delivery and engagement and agile pathways for student achievement and research excellence, then the evolution of higher education in the 21 st century can surely be considered a success with obvious and unassailable relevance. For personal, social, and economic development, the omniversity can be an engine of transformative and sustainable good. 


\section{References}

James, W. (1895), "Is Life Worth Living?", Int. J. Ethics, 6(1), 1-24.

Kerr, C. (1963). The Uses of the University. Harvard University Press.

Roberta Malee Bassett is Global Lead for Tertiary Education and Senior Education Specialist at the World Bank, providing leadership and technical expertise for projects related to postsecondary education reform initiatives around the world. She currently serves on the Editorial Board of Higher Education Quarterly and the International Advisory Board of the International Network for Higher Education in Africa (INHEA) and teaches at the Harvard Graduate School of Education.

Open Access This chapter is licensed under the terms of the Creative Commons Attribution 4.0 International License (http://creativecommons.org/licenses/by/4.0/), which permits use, sharing, adaptation, distribution and reproduction in any medium or format, as long as you give appropriate credit to the original author(s) and the source, provide a link to the Creative Commons license and indicate if changes were made.

The images or other third party material in this chapter are included in the chapter's Creative Commons license, unless indicated otherwise in a credit line to the material. If material is not included in the chapter's Creative Commons license and your intended use is not permitted by statutory regulation or exceeds the permitted use, you will need to obtain permission directly from the copyright holder. 


\title{
The Disruptive Futures of \\ Education-Post-COVID-19 Pandemic
}

\author{
Dzulkifli Abdul Razak
}

\section{Introduction}

The year 2020 is mostly known to many as an inflection point. A metaphorical vision to look far ahead, with clarity, taking on the various "disruptions" that have been much touted, namely, the Fourth Industrial Revolution (4IR). Since its pronouncement, four years ago, during the 2016 World Economic Forum in Davos, the world of higher education has been inundated with demands to introduce the so-called 'Education 4.0'. It claimed that this is an attempt to maximise the impact of the latest "revolution" which allegedly, like the previous industrial (techno-centric, man-made) revolutions took the world by storm. Shaping new paradigms, while dismantling the old. We are familiar with their benefits, but not so when it comes to the reverse. Yet, the latter took greater toll in ecological and human terms since the first Industrial Revolution in the late $1700 \mathrm{~s}$. Many of the relationships between people and nature have suffered the worst over the last 300 years and still suffers today.

Now, we are standing on a new threshold called the Anthropocene era with the Sixth Mass Extinction already on the way according to some sources. It is as though people-nature relationships have been totally redefined whereby "anthropocentrism" got the upper hand. So much so, during the 2019 World Economic Forum, Sir David Attenborough declared that the "Garden of Eden is no more." The choice of metaphor is indeed apt, in terms of education, with reference to humans and the natural surroundings. Not surprisingly, the narrative of (higher) education followed very closely the same storyline where anthropocentrism rules. It is consequent to the emergence of a factory-like model to mass produce "workers" in the name of the "revolution," so to speak. It spewed out the language of the industrial age framed by the four Ms-Manpower, Mind and Machine, driven predominantly by the all-mighty Money! This continues into the current "revolution" where the terminologies are

D. A. Razak $(\bowtie)$

International Islamic University Malaysia, Kuala Lumpur, Malaysia

e-mail:dzulrazak@gmail.com 
rewritten but not the framing. Thus, instead of Manpower, it morphs to Human Capital; Mind becomes Invention; and the Machine turns into Technology. The human capital-invention-technology nexus is still very much the driver of education, where ecological and human dimensions remain on the backburner. In other words, the lingo is still economically biased which in turn, brought about an imbalance between the three aspects of Profit, Planet and People, otherwise dubbed as three Ps, distorting the true purpose of education as implied by Attenborough. This is increasingly well illustrated by the crises-susceptible world which has been the source of concern over at least three decades; even more so given the frequency and severity of the crises of late.

\section{Current Status of "Education"}

Simply put, the current status of "education" is fast becoming irrelevant for the future. Especially, with respect to the younger generation led by the likes of Greta Thunberg and millions of supporters globally. Their influence and articulation have reached far and wide onto global platforms that used to be dominated by mostly adult males as heads of states. This is now being challenged when Thunberg dared them to ensure that her generation has a sustainable future. Her statements are often direct and profound, centred on the question as to why should her generation even attend school when their future continues to be uncertain, if not bleak. This, no doubt, is a clear indictment as to the current state of education, mirrored socio-ecologically, in as far as the future generation is concerned. Such changing demand is presumably not much different from 70 years ago when UNESCO encouraged the foundation of IAU.

Fast forward. What is urgently at stake is a lasting solution within the framework of "Education for Sustainable Development" (ESD), aimed at bringing back the muchneeded balance between the three Ps - Profit, Planet and People-as mentioned above. Or as more recently understood, Education 2030 in the context of Sustainable Development Goals (SDGs) from 2016 until 2030. It encompasses 17 goals with overarching targets of five Ps, where the Partnership and Peace make up the additional two Ps. The platform for SDGs was launched in New York in September 2015, slightly earlier than that of 4IR in Davos. Not only SDGs act as a common global platform as endorsed by the United Nations General Assembly, but it is also a crucial bridge forward from the Millennium Development Goals (MDGs) for the period 20002015. During the period, it encapsulates the United Nations Decade on ESD from 2005 to 2014. Throughout the decade, IAU took an active role in partnering with many agencies, notably the United Nations University (UNU) in Tokyo. At one point during the decade, the Rector of UNU was also the President of IAU, indicating the seamless working relationships between the two committed entities in realising the three Ps, later five Ps, of SD through education (ESD). As far as IAU is concerned, MDGs, ESD and the later SDGs, featured strongly on its agenda during the 14th 
presidency (2012-2016) helmed by the author of this piece. Then, IAU adopted four vital inter-linking strategic areas to effectively become the global voice of higher education.

\section{IAU's Strategic Intent}

IAU, being mindful that the future well-being of humanity and the planet depends on successful resolution of the interconnected challenges of economic, socio-cultural, and environmental sustainability, has been advocating for higher education to actively participate in mainstreaming ESD since 1993. To date, it equivocally supports the 2030 Agenda for Sustainable Development in providing a "new" framework for universities to develop inter-institutional collaborations in pursuit of ESD. The overarching goal is to assist higher education leaders to embed SD concepts and principles in strategic planning, academic and organisational work. The main objectives include: to encourage peer-to-peer learning and share expertise on the SDGs, foster wholeinstitution approaches at the leadership level to integrate SD priorities, and provide capacity building and networking services. Towards this end, IAU has a developed a dedicated portal on Higher Education and Research for Sustainable Development (HERSD) at www.iau-hesd.net.

As it is well embedded in the use of technology, IAU regards this as an important dimension of higher education worldwide, bringing new opportunities to various parties involved. In reality, however, the impact to improve higher education is unevenly distributed and delivered. Thus, while it is important to pursue the potential of technology, bridging the divides in terms of access and success to knowledge and information is no less vital. IAU, therefore, acknowledges the high risk of exacerbating present or even future inequalities, rather than narrowing the existing gaps. As such, it is imperative that IAU aims to fully harness the potential use of technology as an affordable means to uplift the quality of higher education and to enhance access and success to relevant knowledge and education for all.

Overall, as an international organisation that acts as "The Global Voice of Higher Education," IAU put in place a deliberate strategy to improve the quality and relevance of higher education. It focuses on the academic rationales and the equitable and collaborative nature of the process. It aims to minimise the adverse effects of international interactions due to highly unequal and diverse contexts among higher education institutions (HEIs) with different resources, needs and interests.

In handling all these, leadership, at the core of quality higher education, is vital to respond to complex challenges and rapid socio-cultural change. Higher education leadership, in particular, must be supported by values and responsibility. It is essential that HEIs fully contribute to the development of sustainable and democratic societies. IAU targets strengthening the capacities of leaders and enhancing cooperation as well as collaboration among them as well as maximising their impact through engagement with communities. 
These interlinking aspects are in tandem with the 2015 World Education Forum held in Incheon, Republic of Korea, where IAU played an active role in support of the Incheon Declaration. It expresses agreement on "essential elements" of the Education 2030 Framework for Action, building on the UN-led Education for All framework and goals. The final version of the 2030 Framework was adopted and launched at a high-level meeting in November 2015 that took place alongside the 38th session of the UNESCO General Conference pointing to the SDGs. More specifically, SDG 4 is to ensure inclusive and equitable quality education and promote lifelong learning opportunities for all. It desires a more human-centric and humane dimension to fashion education of the future to balance out what the 4IR trajectory stands for in creating largely techno-centric (read, robotic) scenarios with its own (un)intended divides and complexities that IAU wants to minimise, if not eliminate.

\section{The Humanising, "Whole Person" Approach}

With this in mind, it could be argued that there is a need for a "novel" disruption to fundamentally reconstruct the four Ms model into a four Hs-together with their overarching drivers, in order to better embrace the challenges of the 21 st century. Essentially, this means a shift in emphasis from Manpower to Humanity; Mind to Heart; and Machine (Hi-Tech) to Hi-Touch. Whilst, the overarching driver morphs from Monetary (value) to a Humanising (values) framework. In doing so, the 4Hs model, which is more values-based, is set to replace the 4Ms mechanistic structure to a humanistic one. In this context, it is interesting to quote the current UNESCO Director-General, Audrey Azoulay, when speaking of UNESCO's leadership role in education, saying: "Our deeply humanist DNA cannot let us reduce education to a technical or technological issue, nor even to an economic one." Simply put, the Futures of Education is increasingly values-based in humanising education for the new century and beyond. It addresses the "whole person" as did one of the four pillars of education for the 21st as advocated by UNESCO in 1996 through the Delors Commission. Namely, Learning to Be which accommodates "the allround development of the whole person, to fulfil his/her highest potential, and be able to think, decide and act independently - the source of creativity, innovation and entrepreneurship. It involves activities that foster personal development (body, mind and spirit) and contribute to creativity, personal discovery and appreciation of the inherent value provided by these pursuits," involving the hand, head and heart. "The 21 st century will need a varied range of talents and personalities even more than exceptionally gifted individuals, who are equally essential in any society. In other words, children should be offered every opportunity for aesthetic, artistic, scientific, cultural and social discovery and experimentation."

Education, therefore, should cease to merely serve a utilitarian purpose (as it is currently) at the expense of cultural significance. Educating in developing imagination and creativity should also restore cultural values and knowledge drawn from indigenous wisdom and experiences in translating Learning to Be sustainably. 
The Delors Commission reasserted a fundamental principle in Learning to $\mathrm{Be}$ where the aim is the complete fulfilment of the person in all the richness of his/her personality. The Commission reportedly embraces one of the complexities of this form of expression and the various commitments - as an individual, member of a family and of a community, citizen, producer, inventor of techniques and creative dreamer. This holistic human development, which begins at birth and continues through a person's life, is a dialectic process which is based both on self-knowledge and on relationships with other people, as well as the natural surroundings.

\section{Learning to Become}

That said, more recently, UNESCO added yet another pillar of education to the existing four, that is, Learning to Become as part of the Futures of Education matrix closing the ESD loop, as it were. More specifically, Learning to Become Sustainable! And at once put a specific thrust to the three other pillars of Learning to Know, Learning to Do and Learning to Live Together so that they are better aligned to ESD. UNESCO, as the lead agency, is engaging "a global conversation as well as a report on the future of education, drawing on the diverse and fruitful ways of learning practised around the world, resolutely forward-looking, yet grounded in human rights at the service of the dignity of all." The latest (fifth) pillar can be construed as a "disruption" to the old model which would otherwise remain unsustainable and irrelevant to the future, if not altogether obsolete to ESD. This resonates closely with the $4 \mathrm{Hs}$ model discussed above.

Notwithstanding, the said disruption is starkly different from the more commonly understood techno-centric (man-made) types of disruptions as applied to education across the board. To fully appreciate the difference is to realise the (organic) impact of the disruption as manifested by the novel coronavirus, COVID-19. In a matter of months, a myriad of massive, rapid states of "biodisruption" overwhelmed the whole world, creating uncertain and unsustainable ecosystems worldwide. To begin with, being less predictable and left many unprepared, impacting on education at large, including suspending formal learning globally, and which affected millions for a lengthy period, causing varying (mental) anxieties. First and foremost is the question how to handle the biodisruption, that generally "disrupts" those very human emotions and relationships based on values, involving ethics, authenticity and integrity, all subsumed by Learning to Be and Learning to Become.

\section{Concluding Thought: The "Renewed" Normal}

Under the circumstances, this is how education needs to be transformed by learning from COVID-19, acting as the ultimate "equaliser"-a descriptor that once upon a time "education" was best known for. But not anymore, in fact the contrary is 
true. In many instances, "education" can be the source of social inequity, especially in the Global South due to the ever-widening gap. The unfolding protests symbolised by \#Black Lives Matter in many cities in the Global North markedly add to this unjust reality. Taking this tragedy into consideration, and looking through this lens, the takeaway lesson from the coronavirus outbreak is what I summarily called "COVID learning." It is framed within collaborative, open-accessed and openresourced dimensions, which are values-oriented, inclusive, yet diverse in content and delivery, all for the purpose of humanising education as represented by the $4 \mathrm{Hs}$ model. Indeed, it is about flattening the education curve aligned to what IAU is set to do, namely creating an equitable, accessible and quality of education post-COVID19. Evidently, it is not so much about fashioning a so-called "new" (ab)normal, as often suggested, but more about a "renewed" normal, one that rights the wrongs which were (un)intentionally carried out and in consequence "bio-disrupting" the humans. This, ultimately, demonstrates the failure in translating Learning to Become to narrowing, not just the existing gaps, but historical ones as well. Not just the extrinsic aspects but the intrinsic ones too. Summarily, Learning to Become could be an uphill battle to accomplish, should the "renewed" normal fail to become a reality for the futures of education.

To conclude, let us resort to the words of the Director-General of UNESCO during her investiture speech: "We are facing a moment of truth in which we become collectively liable at a time when the need for UNESCO is greater than ever. Together, we must take the right decisions to take it (sic) into the 21 st century and shape it [...], and we owe it to the young to maintain that ambition, with them and for them." Similarly, the same applies to IAU as well in regard to handling the bio-disruptions during and post-COVID pandemic towards humanising education for the 21 st century and beyond.

Dzulkifli Abdul Razak is Rector of International Islamic University Malaysia. From 2000 until 2011, he was the Vice-Chancellor of USM. He was the 14th President of IAU (2012-2016), and the 1st Deputy President of the Association (2008-2012). More recently, as Rector of IIUM, Dzul's dedication bears fruits when the University was recognised by UN University as the RCE on Education for Sustainable Development in April 2020. In July, IIUM was acknowledged as the Winner of Green Gown International Award as the Sustainability Institution of the Year 2020.

Open Access This chapter is licensed under the terms of the Creative Commons Attribution 4.0 International License (http://creativecommons.org/licenses/by/4.0/), which permits use, sharing, adaptation, distribution and reproduction in any medium or format, as long as you give appropriate credit to the original author(s) and the source, provide a link to the Creative Commons license and indicate if changes were made.

The images or other third party material in this chapter are included in the chapter's Creative Commons license, unless indicated otherwise in a credit line to the material. If material is not included in the chapter's Creative Commons license and your intended use is not permitted by statutory regulation or exceeds the permitted use, you will need to obtain permission directly from the copyright holder.

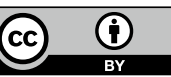




\title{
Universities Beyond 2020
}

\author{
Amr Salama
}

Universities play an important role as leaders in teaching and learning, in education, research and technology. Through their teaching activities, universities provide professional training for high-level jobs, as well as the education necessary for the development of the individual.

Universities are also important sources of many of the new ideas in science and technology that contribute to innovation.

Over the past few decades, tertiary education systems have experienced significant changes.

The great global upheavals shaping the world today are driving the fourth industrial revolution. Expansion of tertiary education, the growing demands of society for tertiary education, the increasing flow of students and the technological changes taking place due to the ICT revolution are today presenting universities with considerable challenges.

During the last two decades, the world has witnessed great changes that have been reflected in all sectors of society. These changes have also affected the concepts of power, work, progress and luxury, concepts which are linked to digital technology. The phenomena of information technology led to the emergence of a knowledge economy based on innovation and creativity if we consider that knowledge is the main source of wealth and the way to achieving a competitive advantage.

However, achieving this goal depends on the ability to invest in human resources (intellectual and knowledge capital), education and constant specialized training of the workforce, the effective use of information and communication technologies, using research and development as a motor of change and development for all sectors of society.

\footnotetext{
A. Salama (两)

Association of Arab Universities, Amman, Jordan

e-mail: aesalama@aaru.edu.jo 
At present, businesses and workers are facing challenges pushed by modern technology and digitalization. They have to be more innovative as they stand for progress and growth. Education and training are a precondition for innovation. The lack of relevant skills, rigid education systems and a reluctance to train and learn throughout one's professional life are obstacles to innovation in the world of work.

It is very important to empower individuals by giving them the relevant skills needed for the digital economy (critical and innovative thinking, communication skills, problem-solving skills, planning and organizational skills, etc.) to enable them to fully participate in the economic, social and cultural life of today and tomorrow.

The evolving nature of the digital economy requires individuals to rapidly adjust to the shifting demand for skills. Equipping individuals with strong foundation skills, high order thinking competencies as well as social and emotional skills would remove the greater levels of uncertainty for individuals. On top of this, digital literacy is essential in order to ensure inclusion in the digital economy and also society.

Today's reality has imposed new requirements for higher education to move to the knowledge economy, which is educational, human, technical, financial, social and cultural. This requires universities around the world to develop a strategy that takes into consideration the importance of the knowledge economy in the education system that it adopts.

This has prompted several international universities to develop their structures and systems to keep pace with the challenges of this era, strive to be smart and develop a digital global environment through steps such as training the staff and students, increasing ability to deal with the digital environment, developing the infrastructure for information technology, preparing research, expanding the scope of digital group management and working to provide the five elements that the smart university is based upon smart people, smart environment, smart management and governance, smart buildings and knowledge networks.

These universities that innovate will no doubt come out on the other side with stronger technology solutions and student support systems that will serve them for decades to come.

The study of the Humanities and Arts is as important as the study of natural and technical sciences. The Humanities encourage us to think creatively, to reason, ask the best questions, foster social justice and equality, teach us about various cultures, develop informed and critical citizens, enable us to understand the world around us; without the Humanities democracy would not flourish. Universities must continue to promote the Arts and Humanities within their disciplines. Establishing new branches of social sciences such as biological sociology, sociology of knowledge and sociology of technology makes the human being capable of adapting to all scientific research and the use of contemporary technology without bypassing systems of moral values, and without prejudicing the freedom of individuals or violating their dignity.

It is known that teaching, research, and community services are the three common functions of a university. Encouraging students to reflect on their moral beliefs and those of other people, fostering the values of responsible citizenship, peace, tolerance, harmony, pluralism, and co-existence. These aspects of the common good are not well represented at universities in its present form. 
To have education for a better society and the common good, I think universities should shift their focus to real-world problems and social transformation. That does not mean displacing job-specific education and research.

We should not lose sight of the Sustainable Development Goals. Making them a reality will require the participation of everyone, including governments, the private sector, civil society organizations, as well as the general population from around the world.

Some trends that will shape the future of higher education: Blended Learning will increase dramatically, and online education will be a strategic priority at every institution; lifelong learning will become more important than ever; students would undoubtedly be concerned that universities should continue their reforms to meet their needs and ensure good quality delivery; universities will also have to build further links and nurture long-term relationships with industry; universities will need to adjust their courses, curricula, and degree programmes to meet learners' needs, as well as the demands of new industries and an evolving workforce and the growing of the use of AI.

Since its foundation in 1950 under the aegis of UNESCO, the International Association of Universities (IAU) followed and is still following its mission to help its member institutions and organizations to achieve their common goals through international cooperation worldwide while keeping their cultural differences.

Among others, IAU contributes to the development of the long-term vision of the university's role and social responsibility; encouraging quality and design and implementing programmes for its Members, in partnership with other organizations working in the same field.

IAU fulfils its mission and contributes to global dialogue through conferences, webinars, workshops, experience-sharing, collaboration, networking, specialized portals, surveys, and analyses, as well as through its various reference and scholarly publications.

To the 70th Anniversary of IAU, I would like to say that we, at the Association of Arab Universities, are very pleased to work and cooperate with IAU to raise the international profile of the universities and achieve the SDGs for a better world.

Amr Salama is Secretary General of the Association of Arab Universities and Professor of Structural Engineering and former president of Helwan University, Egypt. He was the Counselor of The American University in Cairo and is the Former Minister of Higher Education, Scientific Research and Technology of Egypt. Dr. Amr Salama is also the Chairman of the Management Engineering Society, as well as the Chairman of the Council of Housing and Building of Academy of Scientific Research and Technology. 
Open Access This chapter is licensed under the terms of the Creative Commons Attribution 4.0 International License (http://creativecommons.org/licenses/by/4.0/), which permits use, sharing, adaptation, distribution and reproduction in any medium or format, as long as you give appropriate credit to the original author(s) and the source, provide a link to the Creative Commons license and indicate if changes were made.

The images or other third party material in this chapter are included in the chapter's Creative Commons license, unless indicated otherwise in a credit line to the material. If material is not included in the chapter's Creative Commons license and your intended use is not permitted by statutory regulation or exceeds the permitted use, you will need to obtain permission directly from the copyright holder. 


\title{
The Role of Digital Technologies in the New Present and Future of Higher Education
}

\author{
Carles Sigalés
}

Over the last two decades, digitization has transformed the world as we know it. It has changed our economies, industries, leisure, social practices, job markets, politics, and-of course - how we learn. Access to information has continuously been getting faster and more universal. A digital divide still exists but, if the political will is there, we are in a position to take major steps to overcome it.

From an educational point of view, the biggest change stems from the internet and the communication it enables. Digital networks allow content to be brought together, sent and displayed in multimedia formats and using virtual reality to reproduce real world scenes and phenomena, augmenting and enriching them when needed. What is particularly interesting for education is to explore the potential for communication and constant interaction thanks to interconnected devices.

Research consistently highlights the fact that education is a social process, an essential part of this being the interactions between teachers and students, or between the students themselves, as they work together towards collaborative achievements. Today these processes of interaction can take place in traditional classrooms, but they can also take place in digital environments, or sometimes in a combination of both. Face-to-face and online learning are both part of a continuum that offers a wide range of learning ecosystems: almost entirely on-site, blended to varying degrees, or almost entirely online. It is not a question of face-to-face versus online learning; instead, we need to determine which of the many ecosystems possible is best suited to the type of learning we want to provide and the type of students that it is aimed at. There can be more than one valid solution. The choice depends on the purpose.

Throughout history, technological progress has led to major changes in educational practices. As has often been noted, the printing press brought about a great leap forward in how people taught and studied, and undoubtedly represented a huge

C. Sigalés $(\bowtie)$

Universitat Oberta de Catalunya (Open University of Catalonia), UOC, Barcelona, Spain

e-mail: csigales@uoc.edu 
advance for the spread of knowledge. The potential of the technologies available today is enormous, and the changes we can bring about through their use are without precedent. Firstly, because they are of great help in our teaching innovation and improvement processes and in supporting our students' learning. Secondly, and perhaps more importantly, because they let us make education much more accessible to many more people. Nevertheless, teachers' relationships with digital technologies are complex. As some researchers have noted, we tend to approach new technology either with some trepidation or let ourselves be dazzled by it. We generally start by thinking about how this technology can help us improve or extend what we already do without it. And it is only when we get to know it better, and take ownership of it, that we start to think of new uses that had not occurred to us at first. New technologies can also be significant when they can help us achieve ambitious goals that were previously beyond our reach due to a lack of resources or elevated cost. Personalizing education on a large scale, for example, would be unthinkable without the help of digital technologies. The clarity of purpose in what is being taught is what ends up being most important. This does not mean that digital technologies are neutral, no technology is. They affect our lives and, to a certain extent, change them, not always for the better. The giant corporations of the digital era are becoming more powerful than governments and international institutions, selling our data and our privacy, while social media networks can create bubbles of intolerance or use chatbots to spread fake news. One of education's duties is to encourage critical thinking so we can protect ourselves against the misuse of such technology. Despite all this, digital technologies are essential for meeting the enormous challenges facing higher education in the coming decade.

The Universitat Oberta de Catalunya (UOC), the world's first entirely online university, is celebrating its 25th anniversary in 2020. Offering a wide range of bachelors, masters and doctoral degrees, as well as short learning programmes, it has over 70,000 students and many more alumni. Founded as a local online university, today it is a global university with students in more than 130 countries. Over these 25 years of its existence, we have had to be pioneers on many fronts to overcome prejudices favouring a traditional brick-and-mortar education and the stigma associated with distance learning, seen until very recently as a second-rate form of education for second-class citizens.

During this exciting adventure, that of building a new type of university, we have learned, through experience and research, the enormous potential of online learning for the future of higher education. This future has suddenly come much closer as a result of the health, social and economic crisis caused by the COVID-19 pandemic.

The abrupt suspension of face-to-face university lectures in many countries affected by the pandemic has driven an accelerated transition to emergency remote teaching. In this exceptional situation, universities have had to make many changes in a very short time, often without the necessary resources or preparation. The results to date have been very varied. However, given the uncertainty about how long the health crisis will last and its consequences for academic life, it is essential to develop more stable and long-lasting solutions. 
For many universities, the crisis may represent an opportunity to move digitization processes forward and transform their teaching methods for the longer term. But for future scenarios, the measures taken so far to alleviate the current emergency will not be sufficient. The digital transformation of universities has implications at many levels and demands wide-ranging cultural and organizational changes. It must have a real purpose, be shared, supervised and properly planned. If such a transformation is implemented superficially or too hastily, it may end up being frustrating for those carrying it out and counterproductive in terms of meeting its aims.

When considering purpose, we should think of the mission and vision of any given educational institution, its academic goals and the social impact it aims for, and, therefore, the choices it makes regarding its educational model. Higher education has expanded enormously in recent decades and is no longer the preserve of the intellectual and social elites. In some countries, up to $40 \%$ of young people aged between 18 and 25 receive higher education. Much of this growth is driven by new demand linked to the acquisition of high-level professional competencies, which are rooted in interdisciplinary learning.

Working on competencies calls into play information, understanding, skills, values and attitudes, requiring major changes to traditional teaching approaches. Studentfocused teaching and learning methodologies are better for activating knowledgebuilding mechanisms and are key to the development of competencies. The role of teachers remains fundamental in these methodologies but is more focused on guiding, mentoring and the continuous assessment of their students. The transmission of information has ceased to be teachers' main function; the information is now accessible via technology. Teachers can prepare, systematize and deliver it to students so that the time spent with them can be dedicated to more useful tasks: small-group seminars, tutorials, discussions on key subjects, problem-solving, case studies, answering questions, assessments, or other such activities.

The COVID-19 crisis has revealed the weaknesses of teaching methods in some universities. Teaching based on lecturing to large groups - with little interaction with students and limited use of digital media and resources - fell apart, as it did not work beyond the lecture halls. The universities that have adapted best to the closure of classrooms are, naturally, those which have the most developed digital platforms; but they are also those whose students were already more involved in their own learning processes, thanks to the use of more active and participative methods, with better systems of mentoring and assessment. This is the type of method that works best in the virtual environment of online learning. Other methodologies are also viable, but the more they try to imitate face-to-face teaching, the less effective and attractive they become.

Over 25 years, the UOC has experimented with the possibilities and the limits of online education. Today we can be confident in saying that anything that can be done in a traditional classroom can also be done in a virtual learning environment, in equivalent conditions. The vast majority of the services available on a university campus can be provided just as effectively online, so long as they can be digitized: libraries; certain types of laboratory; internships based on simulations or teleworking systems developed in partnership with other institutions and businesses; all the help 
and support services needed for teachers, researchers, students and the transfer of knowledge; spaces for the university community to socialize; guidance services, etc. For the moment, physical presence is still required for some experimental laboratories and internships outside of classrooms, for example, in schools, hospitals and other care facilities. However, constant developments in the use of virtual reality will soon make it possible to provide a significant proportion of these experiences online.

For this reason, the quality standards required of online universities must be as rigorous as those in place for brick-and-mortar universities. In quality assurance processes, some indicators need to be adapted, mainly because of the absence of physical spaces and because of the specific nature of online teaching methods. Nevertheless, the assessment of programme quality, learning outcomes, the effectiveness of learning support systems, and academic teams' teaching and research competencies using the same standards and the same evaluation bodies must be possible.

In recent years, many brick-and-mortar universities have begun to integrate digital technologies into their academic activities. The consequences of the pandemic have accelerated this process, and we can expect that universities will consolidate part of their teaching activities online, albeit conserving their physical campuses, where young people can socialize and experience other facets of university life besides attending classes. However, there are many people for whom the requirement to physically attend a certain number of classes represents an insuperable barrier which prevents them from going to university. These include adults who would have to juggle their studies with work commitments and family or personal responsibilities. For this population, online learning is ideal because of its flexibility and its adaptability to their needs. It is a segment that is increasing due to the growing need for lifelong training. It also includes people who live far from a university and whose circumstances make it impossible to travel or move to live there. Finally, people with disabilities find that online programmes and the use of technology provide them with the support and personalization that they need. Online learning is making a decisive contribution to the inclusion of segments of society which until recently have been underrepresented in university life, due to a lack of opportunities. Online universities now host a wide variety of students. Alongside people who were denied opportunities to study earlier in their lives, we find highly qualified professionals, social leaders, researchers and senior managers who need to regularly update their competencies for their careers to progress. In universities like ours, they find the quality, rigour and flexibility that they need. Technology has enabled us to overcome the limitations of the old distance learning system, putting it on a par with face-to-face teaching. Quality no longer depends on the learning format, but on the talent that the university attracts, how it adapts to meet students' needs and its ability to strive for excellence.

With sustainable development as one of the greatest challenges facing us in the coming decade, universities must also confront major challenges that the immediate future brings. The university must aspire to be a key institution in this new era, as the world's greatest generator of knowledge. Science and research, and the democratization of knowledge, as has been demonstrated during the present crisis, are fundamental to the progress of humanity. Universities must be active in claiming 
their central role in this. And the best way to do this is to understand and adapt to new demands and commit to meeting them.

In recent years, a new type of student has been enrolling in online universities: young people who have the time and resources to attend a brick-and-mortar university but who prefer the flexibility and richness of our methodology and the attractive approach of our programmes. Electronic devices and digital networks empower students, giving them ever greater agency year-on-year. More and more students are rejecting the strictures of traditional classes. Universities do not have a monopoly on knowledge, and they are not capable of meeting the wide variety of modern society's training needs. Students are increasingly accessing knowledge via the internet. They are even using it to listen to their own teachers. Soon it will no longer be possible for universities to maintain the rigid curricula we are used to. They will have to be much more responsive to students' demands and open to personalization. This would be a highly costly process without the support of technology and the advances in artificial intelligence, which is likely to become the teacher's greatest ally in the coming years.

The university will move towards becoming a node in a much wider network, together with other universities, research institutions, knowledge-intensive companies, and public or private institutions. Most of these nodes will be supported by regional and global digital networks. Online universities will be able to reach every corner of the planet where there are people who need to learn and who have an internet connection. Technology will make it possible to offer educational products on a much greater scale, much more sustainably. According to the UNESCO Institute for Statistics, it is estimated that by 2030 there will be 377.4 million students globally enrolled in higher education institutions. This demand, which will be mainly concentrated in emerging economies with rapidly growing populations, can only be met with the support of online learning. Expanding digital networks and providing education and mobile devices to the entire population appears to be more sustainable than growth based exclusively on the construction of new brick-and-mortar campuses, with all the infrastructure that they require. Digital technologies will be key to the goal of delivering universal access to knowledge.

Carles Sigalés is Associate Professor and Vice President for Teaching and Learning at the Open University of Catalonia (UOC). He has been teaching Educational Policies and is also a researcher in the field of online learning and the educational uses of the Internet. He has also been collaborating with the Ministry of Universities and the National Agency for Quality Assessment and Accreditation of Spain (ANECA) in order to promote quality assurance guidelines and criteria for online degrees and master's degrees accreditations. 
Open Access This chapter is licensed under the terms of the Creative Commons Attribution 4.0 International License (http://creativecommons.org/licenses/by/4.0/), which permits use, sharing, adaptation, distribution and reproduction in any medium or format, as long as you give appropriate credit to the original author(s) and the source, provide a link to the Creative Commons license and indicate if changes were made.

The images or other third party material in this chapter are included in the chapter's Creative Commons license, unless indicated otherwise in a credit line to the material. If material is not included in the chapter's Creative Commons license and your intended use is not permitted by statutory regulation or exceeds the permitted use, you will need to obtain permission directly from the copyright holder. 


\title{
Toward a Different Type of Education
}

\author{
David Fernández Dávalos
}

\section{The Diagnosis}

Like Ernesto Sabato said in his last book La Resistencia, we must urgently address the need to reinvent, to bolster, to develop a different type of education. It must be rooted in the conviction that only spiritual values can save us from the tremor that is threatening human existence. Indeed, we most certainly find ourselves facing the most serious crossroads in the history of humankind. Pope Francis has said as much in his encyclical Laudato Si': we cannot continue to move in the same direction as we have been. The humanism that has characterized Western thought since its inception has been undermined by overwhelming skepticism and has even been expelled by attacks from the economic productive rationality that is levelling everything in its path. Faith in human beings and in the forces that sustained us has been broken in the heart of humanity. "The first tragedy that must urgently be repaired," says the Argentine writer, "is the devaluation of oneself which man feels, and which adapts the previous steps to submission and massification. Today, man does not feel himself a sinner, he thinks he is a mechanism, which is tragically worse." (Sabato 2000:125126)

Human freedom is thus seriously threatened. And without freedom, human existence is worthless, because it is what has been given to us so that we can fulfil our mission in life.

Today, in this new century of integrated humanity, education has been taken over by the market. It is no longer, like in days gone by, the instrument to fight against submission and ignorance but is something to be acquired and possessed, with production costs and an exchange value.

There is then a tendency to look upon resources allotted by the state for education, not as an act of justice or compliance with a public duty, but rather as an expense,

D. Fernández Dávalos (凶)

Universidad Iberoamericana Mexico City, Mexico City, Mexico

e-mail: david.fernandez@ibero.mx

(C) The Author(s) 2021

H. van't Land et al. (eds.), The Promise of Higher Education,

https://doi.org/10.1007/978-3-030-67245-4_63 
an investment, or subsidy. The right to education has become a right to avail of education services, and this, in turn, has made students become clients at schools. The project of forming free, autonomous subjects has turned into the production of human resources, and the old evaluation criteria have become quality standards. Citizens have thus become the demand-side and clients of education services, just as they are the demand-side or clients of water or electricity services (Rodríguez 2000). In globalization, there are no more citizens; there are only consumers, potential clients who demand services.

Once education is conceived as a benefit, and when the justice of benefits is advocated for rather than the principles of justice, then free education becomes irrational and morally inadmissible. "In the logic of benefit," he writes, "the enemy to beat is not the right to education; its dark beast is its free nature." (Rodríguez 2000: 107-108)

I am convinced that the strengthening of our democracies depends greatly on actions taken to reduce inequality, particularly in the education system, and a turn toward the formation of fully democratic, solidary, participatory, and enlightened citizens.

\section{Jesuit Universities in Mexico's Moment}

The Jesuit university system right now is barely at the threshold of what I believe will be the key aspect of the new university model we strive for. I am referring specifically to a review of the curriculum.

To explain, I will closely follow in this section the notes systemized by Luna (2001). The main points to be covered in this process and which, in my opinion, every humanistic education should aspire for in this century are explained below.

(a) The preparation for a life in which a socially useful profession is practiced This goal goes far beyond the technical and disciplinary aspects of professional training in a strict sense. It can also be seen in the notion of "comprehensive formation", coherent with a vision of human beings that recognizes their many complex dimensions and dynamics and is committed to them based on this complexity.

Concretely, the formation we offer should cover work preparation, social formation, ethical training, expressive-cultural formation, collaborative training, preparation for uncertainty and change, preparation for permanent learning, ecological training, and formation for transcendence.

(b) The socio-professional target: Between the job market and the social project Of the series of learning aspects, preparing for work is what gives university programs their specific identity and sets the curriculum. This identity is built based on a socio-professional target. Defining a socio-professional target always compares job-market facts against the social project backed by the university. This contradiction needs to be reconciled. If what we seek is to contribute to building a more just, more humane society, we must bet on socio-professional targets 
where, even if only hypothetically, the university's contribution to this quest is visible. Therefore, we do not seek to separate the market from the university's values but rather to build a socially pertinent educational plan. To be pertinent, it must be based on the reality of the systematic analysis of professional market conditions, yet able to recognize this reality's diversity and impetus and be based on the possibilities of university action, like coherent options that seek to transform.

(c) The socio-professional target: Between specialization and general education Knowledge expansion has occurred hand-in-hand with growing specialization. Scientific and technological development has been responsible for the fragmentation of knowledge and the difficulty in recognizing how knowledge can be applied. To deal with this situation, our universities plan to include elements that precisely promote and address the criticism of knowledge, as well as the search for an articulated understanding of reality in its many facets-not a fragmented one. Furthermore, universities should also opt to work on the notion of professional families instead of the traditional idea of a profession as a definitive, excluding reality, and to provide students with the necessary know-how to face the changing work arena with flexibility.

Our work hypothesis is mainly one of recognition and formulation of this strategic know-how, meaning a better ability to sustain desirable professional achievements and to create educational options and specific learning objectives in classroom programs.

In any case, since professions and knowledge are now socially dynamic, the tension between general education and specialization can only be met by making "learning to learn" a key point of our university's teaching plan.

\section{(d) Learning focused on subjects and their processes}

Although we have emphasized the idea that learning must be focused on the student, we have yet to appreciate what that really entails. One way would be to assume the premise that students learn based on their own activity linked to learning targets and not based on what others do with them, be it the professor or the institution. It means knowing what the students really are. It means focusing on what actions are implicit to the learning process and how these actions lead to the desired learning.

From this perspective, professors are not the focus, or even better, the professors' role in teaching interactions is reshaped: they become assistants, mediators, helpers, facilitators.

Thus, teaching is no longer considered a one-way act from professor to student, carried out through the transmission of information and in the verification that this information is adequately returned, but is rather a question of learning environments or situations. Education is the intentional bringing together of different aspects - content, actions, spaces, times, resources — with an intent or purpose, using a teaching strategy. 
(e) The attributes of learning In our conception, we refer to three desirable learning criteria or attributes: learning that is significant, situated, and geared toward achieving competencies. Carlos Luna, from the ITESO, has recreated this proposal, breaking it down into six attributes that should be goals for the permanent construction of teaching processes. They are as follows:

- Significant learning: When subjects link the new information with their field of experience, their learning projects, and their lives.

- Reflexive learning: When subjects are able to realize what they have learned, and which actions and interactions led to that learning.

- Situated learning: Contextualizing historically the goal and content and pitting the learning processes against concrete questions or problems in a context of reality to give pertinent, consistent responses.

- Action-based learning: It can be seen in observable, evaluable results to concrete, situated problems. Subjects learn by doing and evaluating the results.

- Collaborative learning: It means learning with others, an interdisciplinary approach to problems, and teamwork, but especially respect for differences and diversity.

- Transferable learning: Allow subjects to apply the knowledge acquired to several situations and to enhance it permanently each time it is applied. It is based on "learning how to learn."

The goal of all these measures is to achieve a comprehensive outlook on learning.

(f) Beyond the classroom The language, as I have presented it, reaches far beyond the classroom, and takes on a kind of ubiquity in dealing with several situations both within the university and outside of it. It means reconsidering the role of the classroom in the learning process and a new outlook on a class subject as a unit of the curriculum.

It means going from the notion of a subject as packaged, transmittable knowledge to one of a comprehensive learning experience carried out through different activities and situations presented methodologically-including professor lectures when called for-based on a learning target and purpose.

Only from this perspective is it possible to face the complexity and wealth of learning and to incorporate the situations, formats, and times that this complexity requires: at times a lecture, a discussion seminar, individual study, workshops for production, lab practice, fieldwork, team projects, shared leisure time, the recovery of what has been learned, etc.

\section{First Conclusion}

As we can see, these are ambitious, perhaps radical, principles and ideas. Once again, I quote Ernesto Sábato. "There is something unfailing and it is the conviction that only spiritual values can save us from this earthquake that threatens the human condition." That is the huge task that we are facing as educators. 
As Pablo Latapí (2001:54-55) mentions in one of his final articles:

Education without compassion is poor; it is poor if, carried away by the cult of rationality, it sees human existence as entirely intelligible and ignores its contradictions. It is poor if it strives for a self-sufficient leadership separate from others. It is poor if it does not accept that we are beings-at-the limit, at times triumphant but often losers.

Is it possible to have a university that educates and teaches differently?

Here, I present some of the reflections that Ignacio Ellacuría made in several writings, which deal less so with educational processes and programs and more with the role the university should play in society.

We should clarify that this assumption is based on:

- A university should stand out for how it affects historical reality, something prominently political.

- Those who are oppressed and excluded are the objectives of the university's outreach activity.

- University activity finds its outlet in cultural aspects: cultivating the national reality, being critically and creatively aware.

- The goal of university action is to change the unjust, exclusionary reality.

Circumstances might seem to suggest that the education and university model we strive for is impossible to build. Let us take a closer look at what these hindrances are:

- Universities are economically dependent, whether on tuition, private capital, or government subsidies. If the university is coherent with what it says, if it insists on its autonomy, financial resources may dry up.

- There is social and political resistance to the university changing and being critical; people who hold the power in question are always a threat to the university.

- Students are also resistant; they do not want to be troubled but only to learn a profession.

- Likewise, professors show resistance, usually more passively than actively, but most of them usually resist change and are afraid of the consequences of institutional options.

- The authorities at the university are also resistant. It is much more difficult to run an engaged university, a more aware student body.

- More recently, rankings and accreditations act as obstacles to an autonomous, critically-minded university. They tend to follow market rules, which are often not in line with the university mission we have defined here.

What real possibilities are there to build a different type of university?

Let us reiterate some of the points:

1. The university, as an instrument for forming professionals, is necessary to society.

Higher education is needed. It will always exist, regardless of our role in it or our will. 
We are here to neutralize the damage it could do to society. We are here to attempt to use it to bring about social change.

2. Even if we cannot achieve the ideal we are proposing; the university can at least work toward the following:

- Legitimize and support ideologically those striving for change.

- Help to lessen personal and professional resistance to change.

- Limit power cores.

- Offer analysis and public-policy proposals in all areas of reality.

- Help to combat fear of change.

3. Furthermore, in universities, the first steps can be taken toward building new institutions aligned with what we are trying to do, such as:

- Define a different university model outside of the norms imposed. A truly autonomous university with no conditions.

- Develop its non-profit nature. The idea of a university education as a public good and a human right.

- Analyse the most pressing national issues to make rigorous, substantial contributions.

- Offer an independent voice, beyond the economic and political interests of the ruling classes and sectors.

- Offer honest professionals who support change. Educate for justice, empathy, solidarity, commitment, and transformative action.

- At times serve as a voice for the voiceless. Or, if preferred, open a space for those sectors that have been denied a voice. Open spaces for the poor and excluded to make their voices heard.

- Help marginalized sectors with projects covering several topics and areas, such as psychology, law, architecture, design, health, business, engineering, etc.

- Develop different perspectives: Prove that it is possible to create processes, practices, and actions that point in a new direction against the outlook of the mainstream. These options should create a life of abundance.

The Company of Jesus believes that a different type of university is possible. It believes that the university itself contributes to the mission of service to faith and the promotion of justice. It recognizes the university's multiple determinations, its complexity, and it strives to achieve full autonomy.

\section{References}

Latapí Sarre, P. (15.07.2001). "Los triunfadores”, Proceso No. 1289, pp 54-55.

Luna, C. (2001), Revisión curricular, Documento de trabajo, Dirección General Académica del ITESO, borrador, septiembre. 
Rodríguez, P. G. (2000). "Mirar el presente", Revista Latinoamericana de Estudios Educativos. México, Vol XXX, No. 2, pp. 85-113.

Sabato, E. (2000). La resistencia, Argentina: Seix Barral.

David Fernández Dávalos S. J. is the former Rector of Universidad Iberoamericana Ciudad de Mexico (IBERO) (2014-2020). From 1990 to 1994, he worked as founder and director of the Movement for Supporting Working and Street Children (MATRACA), and from 1994 to 1998 he was Director of the Miguel Agustín Pro Juárez Center for Human Rights, A.C. From July of 1998 to January of 2002 he has also served as rector of the Technological Institute and of Studies Superiors of the Occident (University ITESO) in Guadalajara; and from 2008 to 2013 he was rector of the Universidad Iberoamericana Puebla.

Open Access This chapter is licensed under the terms of the Creative Commons Attribution 4.0 International License (http://creativecommons.org/licenses/by/4.0/), which permits use, sharing, adaptation, distribution and reproduction in any medium or format, as long as you give appropriate credit to the original author(s) and the source, provide a link to the Creative Commons license and indicate if changes were made.

The images or other third party material in this chapter are included in the chapter's Creative Commons license, unless indicated otherwise in a credit line to the material. If material is not included in the chapter's Creative Commons license and your intended use is not permitted by statutory regulation or exceeds the permitted use, you will need to obtain permission directly from the copyright holder. 


\title{
Transforming Universities for a Sustainable Future
}

\author{
Dirk van Damme
}

\section{The Historical Record}

Universities have survived history. They survived numerous revolutions of different natures: scientific, economic, and political. Their millenarian history suggests that their core identity and values stand above time, and the expectation is that they will last many more centuries. Yet, universities, as we know them, face some very serious challenges. In a society where artificial intelligence will fundamentally transform the way we work, connect, participate, and enjoy life, several patterns of research, teaching, and learning which constitute the daily lives of universities will change. Consequently, some have predicted the death of the university as we know it, while others believe that the age of unlimited knowledge will herald the historical triumph of universities.

Universities withstood the test of time because they were flexible enough to adapt to changing circumstances. On top of the medieval and early-modern enlightenment, the scientific revolution of the 17 th century and the industrial revolution of the late 18 th century, the processes of nation-state formation in the 19th and 20th centuries and the massification of educational participation of the late 20th century shaped the modern university. Each subsequent historical stage transformed the modern university, without fundamentally breaking with the accumulated heritage of past phases. Some developments, in particular the massification of educational participation over the past 50 years, forced universities to a real stretch of their educational identity. But, they survived this test gloriously. Thus, they helped modern societies make the transition to an unprecedented level of educational attainment, with over $50 \%$ of the young age cohort (25-34 years-old) qualifying at the tertiary level. On the research front, the expansion of scientific research in the knowledge economy required universities to give up their monopoly and to redefine their value proposition in the

\footnotetext{
D. van Damme $(\bowtie)$

OECD, Paris, France

e-mail: dirk.vandamme@oecd.org

(C) The Author(s) 2021 
research and development chain. Today, universities are widely recognised for their unique role as places for fundamental and applied research and scholarship.

Will universities be able to demonstrate equal degrees of versatility in the $21 \mathrm{st}$ century, marked by disruptions caused by artificial intelligence and many other technological breakthroughs. Will they be capable of adapting to the needs of a lifelong learning society and the changing skill demands of the digital age? Will they be able to endure systemic shocks, such as the COVID19 pandemic? What can we say about the future-readiness of today's universities? How can we foster a sustainable future for the modern university? I will explore some of these questions by discussing two fundamental challenges of the modern university system.

\section{Tackling the Inequalities in the Global University System}

Few modern systems are as global in nature as higher education. From their earliest days, universities aspired to be places of research, scholarship, study, and debate, speaking to the learning community regardless of geographical boundaries. In early modern times, travelling scholars and students were a familiar phenomenon in Europe, but also in other places around the globe, such as the Arab world or China. Today, scientific research is one of the most globally connected and integrated systems of modern human society. Transnational research networks and international co-publishing are growing in scope and impact every year. Talented researchers and academics constitute a global market to which ambitious universities are tapping in order to increase their research output and status. Research is the most powerful driver of internationalisation of universities. However, the education side is following very rapidly. Today, over five million students are mobile and studying in another country worldwide. Still, the numbers are growing every year.

But the internationalisation of universities and academic globalisation are about much more. Despite the absence of any form of global governance, there are important trends and mechanisms of international convergence. International agreements, for example, with regard to recognition of degrees, mutual acceptance of accreditation arrangements, common qualification frameworks, and credit transfer systems, represent important regulatory frameworks for the global system. In certain regions, for example, within the European Union or the European Higher Education Area, they have become very powerful as a result of the Bologna Process. Other regions of the world, often in the context of international trade agreements, have seen similar arrangements put in place. On top of all this, global university rankings are classifying the complex reality of global higher education in an easily readable, but hierarchical and reductionist, list of status and reputation. Thereby falsely suggesting a global level playing field of academic merit. Through these processes of convergence, individual universities have been connected with each other. By this interconnectedness, they have established a truly global system.

Yet, the global higher education system is not without its limits, contradictions, and tensions. There are many signs that the glory days of unbridled internationalisation 
are over. In many countries - the US and the UK are visible examples, but there are many more-nationalist policies seem to take priority over international aspirations. This is not entirely new. Truly global universities constitute only a very small fringe of the system. Most universities define and identify themselves as belonging to specific national systems of history, culture, language, and politics. Universities are making every effort to integrate themselves more firmly in regional knowledge and innovation ecosystems. Political shifts are also important. Conservative opinion leaders in some countries have started to attack universities as 'globalist propaganda machines'. It is very likely that internationalisation and globalisation of higher education are turning into a politically contested reality.

The COVID-19 crisis is accelerating some of the ambiguous trends in global higher education. A first and almost immediate consequence of the pandemic is the sudden fall in the numbers of fee-paying international students. Many foreign students, especially those from Asian countries and China, in particular, left and went back home. For the next academic year, institutions will have to account for a significant income loss from fee-paying international students. For countries where universities have become dependent on this income stream, the situation looks very dire. In the UK, universities estimate the total financial loss of around 6.9-billion-pound sterling, and several university leaders have pressed the government to consider an institutional bail-out. Also, in Australia, another country with universities very much dependent on income from fee-paying international students, similar emergency calls have been heard. Even regardless of the financial consequences, the sudden drop and subsequent reorientation in international student mobility will have a deep impact on the global university landscape.

It is important to look beyond the surface at the more fundamental trends. Global higher education is itself one of the most unequal systems the world has seen. Processes of colonialism, asymmetrical trade, and economic inequalities have deeply influenced the expansion of academic institutions over past centuries. Centres of academic development have been concentrated on the economic and political hegemony of the global order. Since the middle of the 20th century, the global hierarchy of the academic system has been consolidated in these hegemonic countries. Only in recent decades, things have started to change when emerging economies have started to invest and expand their own higher education systems to meet the demand of aspiring and increasingly prosperous middle classes. China, followed by India, is taking the lead as an example to many other emerging economies. It is extremely difficult for ambitious universities in these countries to challenge the power mechanisms behind academic excellence, but China seems to become successful in slowly penetrating the upper ranks of the global system. This will be almost impossible for many other countries. The measurements, definitions, and data collections behind the assessment of academic reputation are not free of cultural bias, and the academic community has a hard time improving its definition of success.

The historical legacy of concentration of academic excellence is increasingly coming at odds with the reality of higher education development and demand. Participation and graduation rates in the countries of academic hegemony are reaching ceiling levels, while demand is exploding in many other parts of the world. From 
around 150 million tertiary graduates worldwide in 2015, we will advance to 300 million in 2030, doubling the numbers. The bulk of that historically unseen expansion of higher education delivery will be in emerging economies such as China, India, Brazil, Indonesia, and Arab states. The share of the United States and Europe in the global pool of graduates will shrink, for the United States from 14\% in 2015 to $8 \%$ in 2030 . Consequently, from a geographical point of view, there will be an enormous mismatch between the location of exploding demand and the location of perceived academic excellence. In itself, this mismatch is driving global student and staff mobility, because people who can afford it look for the best opportunities in the world. Rankings serve as search tools for aspiring students, and in doing so, their biased definition of academic excellence is reinforced.

One of the most important questions facing the global academic community is whether the sharp inequalities in the system are sustainable. In the 21 st century, is it still sustainable to maintain a system that is built on 19 and 20th century premises and is clearly at odds with meeting the needs of demand for knowledge, research, and education in other parts of the world? Is it sustainable to implicitly and explicitly support academic hegemony and power imbalances? And is it even possible to do so when knowledge travels the world at the speed of bits and bytes?

A community, for which freedom of research, the free flow of knowledge, and the power of scientific reason are essential cornerstones of the value system, would enormously benefit from a level playing field between all members, the closing down of historical privilege, and the elimination of power imbalances. This noble idea is getting political traction because of the unique opportunities provided by the United Nations' Sustainable Development Goals (SDGs), including SDG4 on education. These goals, adopted by the international community, are very important drivers for a more sustainable global higher education system. So far, universities have been largely absent in the international debate on SDG4. Recently, things have started to move, and international university associations are making strong arguments in favour of including universities as partners and actors in achieving progress towards the SDGs.

International associations of universities, such as the IAU, can play a very important role in fostering responsible and sustainable internationalisation. They manage the interconnectedness of universities, are the guardians of the shared value system of universities and generate mutual trust in the global system. They should not behave as the safeguards of current hierarchies and power differences in the system but should endeavour to create an inclusive and level playing field for all universities.

\section{Transforming the Universities' Educational Purpose}

Contemporary universities have been educating students for a rather stable professional environment for many decades. The skills needed by professions such as medical doctors, lawyers, psychologists, or even historians and philosophers define the 
framework of programmes. There are well-established scientific disciplines beyond professional fields, such as physics, biology, or political science, which provide the foundations for learning at universities. Academic attitudes and values, such as the search for truthfulness, critical thinking, and dealing with uncertainty permeate all of this.

The identity of the modern university in its teaching and learning function rests on the interplay between research-based professional training, disciplinary education, and academic values. In essence, it is a supply-side approach to education and learning which defines the identity of the university as a learning environment.

However, this approach is coming under pressure in recent years. Universities are increasingly criticised by employers (among other stakeholders) for not listening carefully enough to the skill needs of workplaces in contemporary economies. Critical disputes and tensions between educational institutions and employers on what kind of knowledge and skills graduates bring to the labour market are not new and mostly lead to a productive dialogue. Currently, there are signs indicating that these tensions have accumulated and become explosive, with the risk of short circuits between both sides. An example is the public announcement of the global consultancy firm Ernst \& Young in 2015, stating that it would no longer look at university qualifications when recruiting talent because there was "no evidence that success at university correlates with achievement later in life" (Sherriff 2019).

One of the main reasons for the growing tension between supply-side approaches dominant in universities and calls by employers and other stakeholders to become more demand-sensitive is the profound changes in skill demand, both quantitatively and qualitatively. Universities are doing reasonably well in translating changes in scientific knowledge into course contents but do not identify similarly important changes in skill demand in the external world and transform their education programmes accordingly.

Think, for example, of the consequences of task digitalisation that universityeducated professionals will have to do by 2040. Much more important than which jobs will disappear or how many alternative jobs will emerge as a result of digitalisation, such as robotisation and artificial intelligence, is the question of the changes in the tasks of professionals. Routine tasks, procedural labour and other 'predictable activities', even at a rather high level of cognitive demand, will gradually be taken over by smart machines. Imagine what this will do to legal professions, where large parts of what such professionals do today will be automated. Digitalisation will not only affect low-skilled markets but will have a profound impact on university-educated professionals as well.

The complex and rather unpredictable shifts in skill demand will increase the importance of skills, such as higher-order cognitive skills, complex communication skills, and emotional skills. Higher-order cognitive skills are aligned with the research and analytical skills that universities already develop in many programmes. However, universities see these skills mainly as part of advanced programmes leading to research masters or doctoral degrees. Understanding that such skills should no longer be preserved for students aspiring to research and academic careers, but rather be part of any university education, is a mind shift that most universities still have to 
make. Complex communication skills have slowly become part of the curriculum in various programmes, but a lot is still to be done in this area as well.

Finally, emotional skills are mostly seen as something to be developed in previous stages of a person's educational trajectory. They are also part of the explicit or implicit selection process through which students are admitted to university education. Yet, the evidence clearly shows that emotional skills are part of the 'hidden curriculum' of university education. Universities can transform people into well-rounded individuals also in their personality traits, with clear progress on, for example, conscientiousness and openness. This explains why, even after controlling for variables such as income or employment, university-educated individuals are healthier and have higher levels of interpersonal trust than their lower-educated peers. Addressing changing skill demand will require universities to explicitly look at these 'soft' skills as much as they are looking into higher-level cognitive skills.

In general, universities have been willing to update their curricula and innovate to better meet external demands. In Europe, the implementation of the legislation following the Bologna Process has been an excellent opportunity to critically examine and revise curricula. Universities have prepared to listen more carefully to employerdriven demands and have, for example, included entrepreneurship education in some of their programmes. But, the question is: will this be sufficient? More ambitious and forward-looking answers will be necessary.

In multiple variations on 'the death of the university'-thesis, some experts have argued that universities are something of the past and will no longer be capable of addressing the skill development needs of highly volatile and uncertain economies and societies. These experts believe that radical demand-driven approaches to education and skills will favour a de-institutionalisation of learning and the development of user-driven technology-based learning modes.

Universities will be asked to demonstrate the added value of an institutional and supply-side approach to skills development. This is no easy task. But, the value system of universities, driving inquiry, critical thinking, and scientific attitudes, will prevail in the end. Atomised, user-driven learning, such as we see in many MOOCs or professional training, will never be able to compete with universities for the development of such higher-order skills. That is no reason for complacency, but an argument for more ambitiously developing approaches to teaching and learning that prove to be effective, relevant, and responsible. The really important question thus is what intrinsically defines the educational experience at the university and what makes it so worthwhile. Even if massification has fundamentally modified the dream of the medieval encounter between the master and the pupil or the Humboldtian ideal of research-based Bildung, many students and graduates would still see the personal exchange with researchers and professors and the small-group collaboration with students in laboratories and seminars as the most valuable learning experiences. The COVID-19 crisis and its aftermath might force universities and students to shift their frame of reference of high-quality teaching and learning, but to develop new modes of delivery which are equally motivating and effective, while remaining competitive against alternative modes of provision and certification. This, however, will require an awful lot of imagination, creativity, and ingenuity. Universities need to rethink 
their value for money proposition and examine whether it is not the time to make the necessary investments to make the transition happen.

\section{Conclusion}

In the early decades of the 21 st century, when economies are in deep transformation, the world order is changing, and societies are struck by disruption, universities find themselves in the centre of humanity's hope for sustainable social progress and justice. From climate change to artificial intelligence, pandemics to social cohesion, humanity's hope for survival rests with the knowledge, skills, and wisdom which universities cultivate and transmit. Fulfilling the promise of a sustainable future for humanity requires a successful resolution of some critically important challenges within the university system itself. In this short paper, I briefly discussed two fundamental ones, knowing that there are many more.

Many have predicted the end of the university as we know it today. In contrast, this paper argues that universities will be able to adapt to radically changing circumstances. However, adaptation is not what will characterise universities in the future. We should expect them to also construct the future. That is the meaning of sustainability.

\section{Reference}

Sherriff, L. 2019 (2015) (7 August 2019), Ernst \& Young Removes University Degree Classification From Entry Criteria As There's 'No Evidence' It Equals Success, in HuffPost, Retrieved from: https://www.huffingtonpost.co.uk/2016/01/07/ernst-and-young-removesdegree-classification-entry-criteria_n_7932590.html?guccounter=1 (24.04.2020)

Dirk van Damme is Senior Counsellor in the Directorate for Education and Skills at the OECD in Paris and is also serving as Head of the Centre for Educational Research and Innovation. Between 2017 and 2019 he was also Head of the OECD work on skills. Before joining the OECD, he was professor at Ghent University, General Director of the Flemish Rectors' Conference VLIR (2000-2003) and chief of staff of Flemish education minister Frank Vandenbroucke (2004-2008). He worked extensively with international organisations such as UNESCO, IAUP, EUA, ENQA, INQAAHE and others. 
Open Access This chapter is licensed under the terms of the Creative Commons Attribution 4.0 International License (http://creativecommons.org/licenses/by/4.0/), which permits use, sharing, adaptation, distribution and reproduction in any medium or format, as long as you give appropriate credit to the original author(s) and the source, provide a link to the Creative Commons license and indicate if changes were made.

The images or other third party material in this chapter are included in the chapter's Creative Commons license, unless indicated otherwise in a credit line to the material. If material is not included in the chapter's Creative Commons license and your intended use is not permitted by statutory regulation or exceeds the permitted use, you will need to obtain permission directly from the copyright holder. 


\title{
Education: We Must Keep Our Promise
}

\author{
Sjur Bergan
}

Describing the promise of Education for the future could be done very summarily: without education, no future - or at least not one worth waiting for. While true, this summary description is nevertheless unsatisfactory. It does not say why education is crucial, and what the role of higher education should be.

Promises are made to be fulfilled, and to do so, we must spell out what the promise of education is. As I see it, the promise is composed of four parts, which correspond to the purposes of higher education:

- Preparation for sustainable employment;

- Preparation for life as active citizens in democratic societies;

- Personal development;

- The development and maintenance of a broad, advanced knowledge base (Bergan 2005; Council of Europe 2007).

It is encouraging to see that the unilateral focus on educating for the labour market that was often seen in the early 2000s is giving way to a broader view of the societal importance of education. In Europe, this is reflected in the priorities and ministerial communiqués of the Bologna Process starting with the 2007 London Communiqué and culminating in the Yerevan and Paris Communiqués Bologna Process 2007, 2015, 2018. In the United States, this development is reflected in the work of the International Consortium for Higher Education, Civic Responsibility and Democracy (n.d.) and the Anchor Institutions Task Force (n.d.). Globally, the IAU plays a vital role through its commitment to education and research for sustainable development, its commitment to values-based higher education, its work to enhance capacities and commitment to the broader mission of higher education on all continents, and now also by bringing a global perspective to the work the Council of Europe and the

\footnotetext{
S. Bergan $(\bowtie)$

Council of Europe, Strasbourg, France

e-mail: sjur.bergan@coe.int 
International Consortium are doing on the democratic mission of higher education (Council of Europe, n.d.).

One and the same competence can be relevant to several purposes of education. Analytical abilities, critical thinking skills, and language competences all strengthen our possibilities on the labour market. They also make us better suited to helping develop our societies and contribute to our personal development, and we cannot do serious research without them.

That many of the jobs today's students will compete for in a decade do not yet exist, is a truism, but this should not lead to the conclusion that higher education institutions cannot prepare their students for them. Higher education should not aim to prepare for very specific jobs but rather provide subject-specific and generic competences that prepare for a whole range of jobs and that encourage students to continue learning after graduation. Perhaps more importantly, higher education should not see the labour market as something that evolves and that they just have to adapt to. Higher education should influence the labour market by developing new knowledge and understanding that can be put to innovative use in creating new jobs. Information technology would not have been omnipresent if higher education had not played its part.

What is true for the development of the labour market is even more true for the development of society. Higher education must help shape our society, not just sit back and observe it develop (Harkavy et al. 2020). This is an issue of knowledge and understanding but also of ethics and values. Knowing and being able to do something without considering the consequences should not be what higher education teaches and students learn. Therefore, the traditional definition of learning outcomes as what the learner knows, understands, and is able to do is inadequate. The definition must comprise not only what learners are able to do but also what they are willing to do, and by implication what they are willing to abstain from doing for ethical reasons. Being able to alter plants or animals genetically may be a matter of technical competence, but decision on whether we should do so draws on our ethical competence. Subjectspecific and generic competences must be developed together.

History shows that the forms of democracy are insufficient. Parliaments, constitutions, and elections cannot be democratic unless they build on a culture of democracy: a set of attitudes and behaviours that accept, inter alia, that while majorities decide, minorities have inalienable rights, that conflicts need to be resolved peacefully through dialogue, and that diversity is a strength rather than a threat. A culture of democracy requires competences for democratic culture (Council of Europe 2018a, b, c), and higher education must help develop them.

The technical complexity of modern societies makes advanced competences more important for more people than ever before. Here, higher education has largely done its job: it has trained more highly qualified subject specialists than at any other time in our history. I am less convinced, though, that higher education has fulfilled another part of its mission: educating intellectuals, by which I mean graduates who are able and willing to put their advanced subject-specific competences in a broader context, ask the difficult questions we face as societies, and find ethically sound answers to those questions. 
To fulfil its promise, higher education must fulfil all its major purposes. It must educate students that are technically competent, intellectually curious, and endowed with a sense of ethical and societal responsibility. Its research must be guided by concern for our societies. To fulfil its promise, higher education must not wait for the future to arrive-it must shape the future and help develop societies worth living in. To fulfil its promise, higher education must deliver knowledge and understanding. It must also deliver the ethical compass we need to navigate the future.

To fulfil its promise, the IAU must continue to develop a sustainable and responsible higher education on a global scale. The IAU must persuade higher education to be brave, independent, and committed. It must help defend higher education against governments that see critical analysis, academic freedom, and institutional autonomy as a threat.

If the first seven decades of the IAU can be used as an indicator, there is every reason to be hopeful that the IAU will continue to be a guide on the way to democratic sustainable societies built on knowledge and understanding, ethics, and societal responsibility in the decades and even centuries to come.

\section{References}

Anchor Institutions Task Force (AITF) (n.d.), Strategic Plan 2020-2023, Retrieved from: https:// www.margainc.com/aitf/ (24.04.2020)

Bergan, S. (2005). "Higher Education as a "Public Good and a Public Responsibility": What Does it Mean?". In L. Weber \& S. Bergan (Eds.), The Public Responsibility for Higher Education and Research Strasbourg: Council of Europe Publishing -Council of Europe Higher Education Series No. 2: $13-28$

Bologna Process (2007): "European Higher Education in a Global Setting. A Strategy for the External Dimension of the Bologna Process", Retrieved from: http://www.ehea.info/media.ehea. info/file/2007_London/35/4/2007_London_Strategy-for-EHEA-in-global-setting_581354.pdf (24.04.2020)

Bologna Process (2015): "Yerevan Communiqué", Retrieved from: http://www.ehea.info/media. ehea.info/file/2015_Yerevan/70/7/YerevanCommuniqueFinal_613707.pdf (24.04.2020)

Bologna Process (2018): "Paris Communiqué. Paris, 25th May 2018, Retrieved from: http://www. ehea.info/Upload/document/ministerial_declarations/EHEAParis2018_Communique_final_ 952771.pdf (24.04.2020)

Council of Europe (n.d.). The Democratic Mission of Higher Education, Retrieved from: https://www.coe.int/en/web/higher-education-and-research/democratic-mission-of-highereducation (24.04.2020)

Council of Europe (2007): Recommendation Rec (2007) 6 of the Committee of Ministers to member states on the Public Responsibility for Higher Education and Research, Retrieved from: https:// search.coe.int/cm/Pages/result_details.aspx?ObjectId=09000016805d5dae (24.04.2020).

Council of Europe (2018a): Reference Framework of Competences for Democratic Culture, Volume 1, Context, concepts and model, Retrieved from: https://www.coe.int/en/web/referenceframework-of-competences-for-democratic-culture/context-concepts-and-model (24.04.2020)

Council of Europe (2018b): Reference Framework of Competences for Democratic Culture, Volume 2, Descriptors, Retrieved from: https://www.coe.int/en/web/reference-framework-ofcompetences-for-democratic-culture/descriptors-of-competences (24.04.2020) 
Council of Europe (2018c): Reference Framework of Competences for Democratic Culture, Volume 3, Guidance documents, Retrieved from: https://www.coe.int/en/web/reference-framework-ofcompetences-for-democratic-culture/guidance-for-implementation (24.04.2020)

Harkavy, Ira; Sjur Bergan; Tony Gallagher; Hilligje van't Land (2020): “Universities must help shape the post-COVID-19 world", in University World News April 19, 2020, Retrieved from: https://www.universityworldnews.com/post.php?story=20200413152542750 (24.04.2020)

International Consortium for Higher Education, Civic Responsibility and Democracy (n.d.), Introduction, Retrieved from: http://www.internationalconsortium.org/, (24.04.2020)

Sjur Bergan is Head of the Education Department of the Council of Europe and leads its projects on Competences for Democratic Culture and the European Qualifications Passport for Refugees. $\mathrm{He}$ has represented the Council of Europe in the Bologna Follow Up Group and Board since 2000 and chaired three successive working groups on structural reforms 2007-15. Sjur is the editor of the Council of Europe Higher Education Series and was a main author of the Lisbon Recognition Convention.

Open Access This chapter is licensed under the terms of the Creative Commons Attribution 4.0 International License (http://creativecommons.org/licenses/by/4.0/), which permits use, sharing, adaptation, distribution and reproduction in any medium or format, as long as you give appropriate credit to the original author(s) and the source, provide a link to the Creative Commons license and indicate if changes were made.

The images or other third party material in this chapter are included in the chapter's Creative Commons license, unless indicated otherwise in a credit line to the material. If material is not included in the chapter's Creative Commons license and your intended use is not permitted by statutory regulation or exceeds the permitted use, you will need to obtain permission directly from the copyright holder.

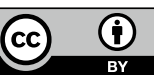

